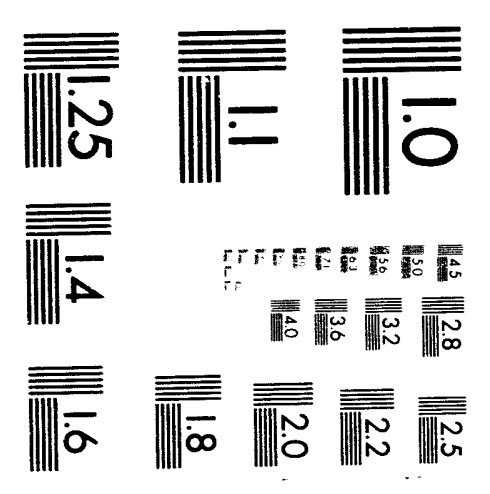



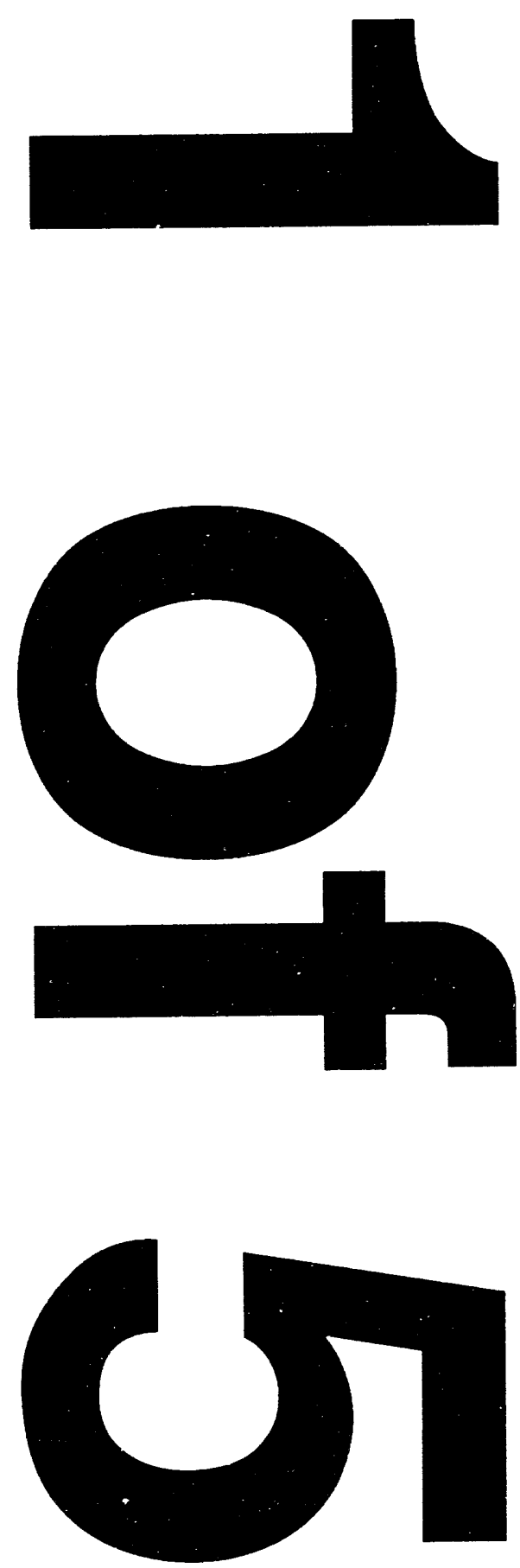


\section{SHEREM \\ STANDARD DESIGN}

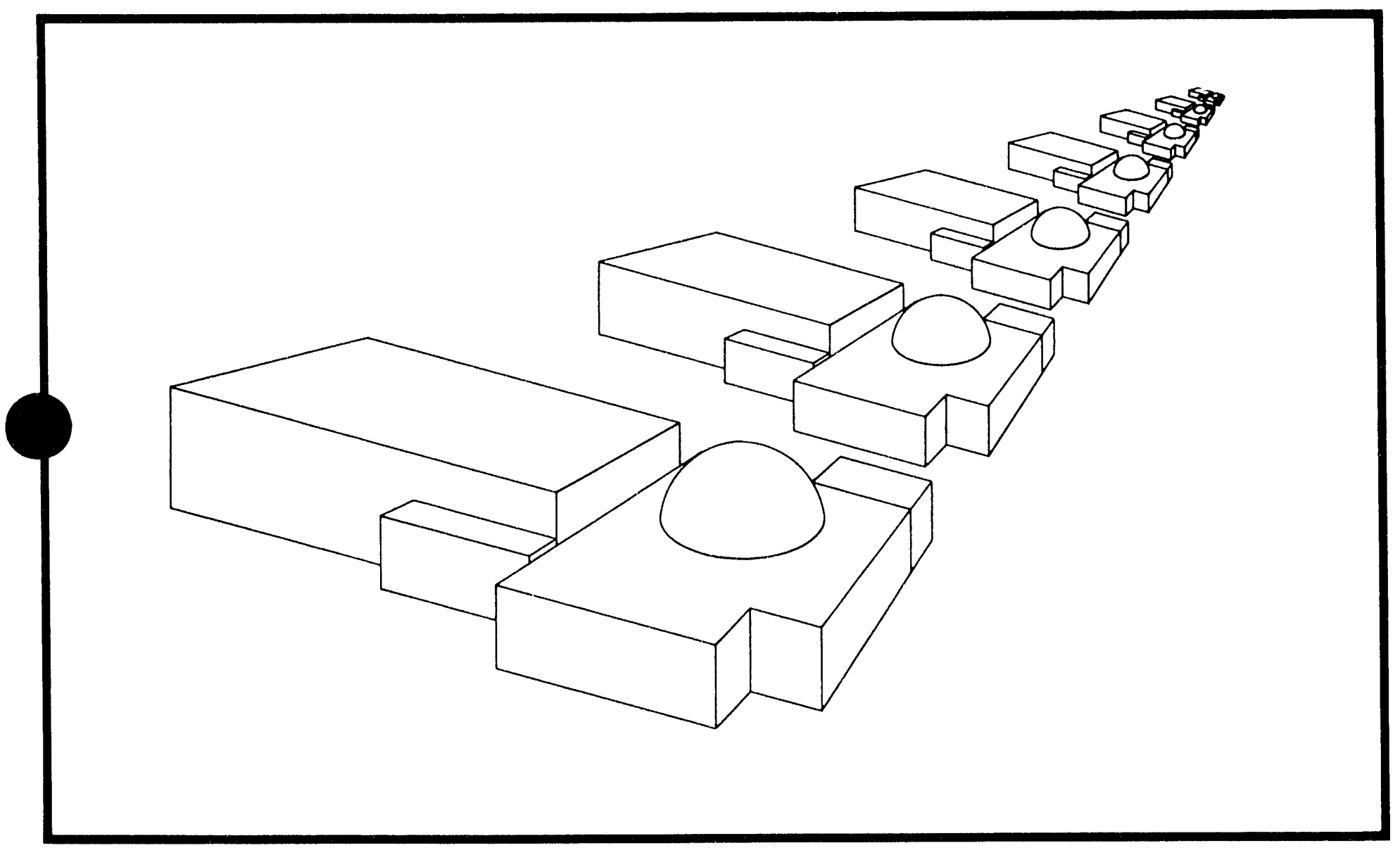

\section{CESSAR DESIGN certification}

meris

DISTRIBUTION OF THIS DOCUMENT IS UNLIMITED $y^{2}$ 


\section{DISCLAIMER}

This report was prepared as an account of work sponsored by an agency of the United States Government. Neither the United States Government nor any agency thereof, nor any of their employees, makes any warranty, express or implied, or assumes any legal liability or responsibility for the accuracy, completeness, or usefulness of any information, apparatus, product, or process disclosed, or represents that its use would not infringe privately owned rights. Reference herein to any specific commercial product, process, or service by trade name, trademark, manufacturer, or otherwise does not necessarily constitute or imply its endorsement, recommendation, or favoring by the United States Government or any agency thereof. The views and opinions of authors expressed herein do not necessarily state or reflect those of the United States Government or any agency thereof. 


\section{EFFECTIVE PAGE LISTING}

\section{CHAPTER 7}

\section{Table of Contents}

\section{Page}

$i$

ii

iii

iv

v

vi

vii

viii

ix

$x$

$x i$

xii

xiii

xiv

$x V$

$x v i$

xvii

xviii

$x i x$

$x \mathrm{x}$

$x \times i$

xxii

xxiii

xxiv

$\mathrm{xxV}$

$x x v i$

xxvii

xxviii

$x$ xix

Text

\section{Page}

7. 1-1

7. $1-2$

7. 1-3

7. $1-4$

7. 1-5

7. $1-6$

7. 1-7

7. $1-8$

7. 1-9

7. $1-10$

\section{Amendment}

D

D

D

E

E

I

E

E

I

D

D

D

D

D

I

D

D

E

E

I

E

E

I

I

D

I

I

I

Amendment

I

I

I

I

I

I

I

D

D

D

Amendment I

December 21, 1990 


\section{EFFECTIVE PAGE LISTING (Cont'd)}

\section{CHAPTER 7}

\section{Text (Cont'd)}

\section{Page}

$7.1-11$

7. $1-12$

$7 \cdot 1-13$

7. $1-14$

7. $1-15$

7. $1-16$

7. $1-17$

7. $1-18$

7. $1-19$

$7.1-20$

$7.1-21$

7. $1-22$

$7.1-23$

7. $1-24$

7. $1-25$

7. $1-26$

7. $1-27$

$7 \cdot 1-28$

7. $2-1$

$7 \cdot 2-2$

$7 \cdot 2-3$

$7.2-4$

$7 \cdot 2-5$

$7 \cdot 2-6$

7. $2-7$

$7.2-8$

$7.2-9$

$7 \cdot 2-10$

7. 2-11

$7.2-12$

$7 \cdot 2-13$

$7 \cdot 2-14$

$7 \cdot 2-15$

7. $2-16$

7. $2-17$

7. $2-18$

7. 2-19

$7.2-20$

$7.2-21$

$7 \cdot 2-22$

$7.2-23$

7. 2-24

\section{Amendment}

I

I

I

I

D

D

D

D

E

I

I

D

D

D

D

D

D

D

I

E

I

E

E

I

I

I

I

I

I

I

E

E

E

E

I

I

$\mathrm{E}$

I

E 


\section{EFFECTIVE PAGE LISTING (Cont'd)}

\section{CHAPTER 7}

Text (Cont'd)

Page

$7.2-25$

$7.2-26$

$7.2-27$

$7.2-28$

$7.2-29$

$7.2-30$

$7 \cdot 2-31$

$7 \cdot 2-32$

$7.2-33$

$7.2-34$

$7.2-35$

$7.2-36$

$7.2-37$

7. $2-38$

$7.2-39$

$7.2-40$

$7.2-41$

$7.2-42$

$7.2-43$

$7.2-44$

$7.2-45$

$7.2-46$

$7.2-47$

$7 \cdot 2-48$

$7.2-49$

7. $2-50$

7. $2-51$

7. 2-52

$7.2-53$

$7.2-54$

$7.2-55$

7. $2-56$

7. 3-1

$7 \cdot 3-2$

$7 \cdot 3-3$

$7 \cdot 3-4$

$7 \cdot 3-5$

7. $3-6$

7. 3-7

7. 3-8

7. $3-9$

7. $3-10$

\section{Amendment}

I

E

E

I

E

E

E

E

I

E

I

E

I

E

I

E

I

I

E'

E

I

I

I

$\mathrm{E}$

$\mathrm{E}$

E

I

I

E

E

I

I

E

I

I

$\mathrm{E}$

I

I

I

Amendment I

December 21, 1990 


\section{EFFECTIVE PAGE LISTING (Cont'd)}

\section{CHAPTER 7}

\section{Text (Cont'd)}

\section{Page}

$$
\begin{aligned}
& 7 \cdot 3-11 \\
& 7 \cdot 3-12 \\
& 7 \cdot 3-13 \\
& 7 \cdot 3-14 \\
& 7 \cdot 3-15 \\
& 7 \cdot 3-16 \\
& 7 \cdot 3-16 a \\
& 7 \cdot 3-17 \\
& 7 \cdot 3-18 \\
& 7 \cdot 3-19 \\
& 7 \cdot 3-20 \\
& 7 \cdot 3-21 \\
& 7 \cdot 3-22 \\
& 7 \cdot 3-23 \\
& 7 \cdot 3-24 \\
& 7 \cdot 3-25 \\
& 7 \cdot 3-26 \\
& 7 \cdot 3-27 \\
& 7 \cdot 3-28 \\
& 7 \cdot 3-29 \\
& 7 \cdot 3-30 \\
& 7 \cdot 3-31 \\
& 7 \cdot 3-32 \\
& 7 \cdot 3-33 \\
& 7 \cdot 3-34 \\
& 7 \cdot 3-35 \\
& 7 \cdot 3-36 \\
& 7 \cdot 3-37 \\
& 7 \cdot 3-38 \\
& 7 \cdot 3-39 \\
& 7 \cdot 3-40 \\
& 7 \cdot 3-41 \\
& 7 \cdot 3-42 \\
& 7 \cdot 4-1 \\
& 7 \cdot 4-2 \\
& 7 \cdot 4-3 \\
& 7 \cdot 4-4 \\
& 7 \cdot 4-5 \\
& 7 \cdot 4-6 \\
& 7 \cdot 4-7 \\
& 7
\end{aligned}
$$

Amendment

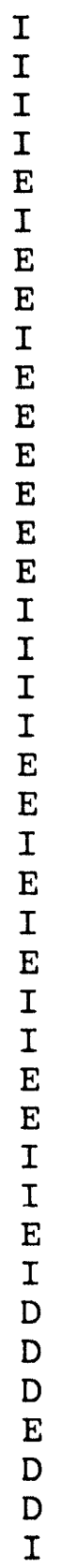




\section{EFFECTIVE PAGE LISTING (Cont'd)}

\section{CHAPTER 7}

Text (Cont'd)

\section{Page}

Amendment

$$
\begin{aligned}
& \text { 7. 4-8 } \\
& \text { 7. 4-9 } \\
& \text { 7. } 4-10 \\
& \text { 7. } 4-11 \\
& \text { 7. } 4-12 \\
& \text { 7. } 4-13 \\
& \text { 7. 5-1 } \\
& 7 \cdot 5-2 \\
& \text { 7. 5-3 } \\
& \text { 7. 5-4 } \\
& 7 \cdot 5-5 \\
& \text { 7. 5-6 } \\
& \text { 7. 5-7 } \\
& \text { 7. 5-8 } \\
& \text { 7. 5-9 } \\
& \text { 7. 5-10 } \\
& \text { 7. 5-11 } \\
& \text { 7. 5-12 } \\
& \text { 7. } 5-13 \\
& \text { 7. 5-14 } \\
& \text { 7. 5-15 } \\
& \text { 7. 5-16 } \\
& \text { 7. } 5-17 \\
& \text { 7. } 5-18 \\
& \text { 7. } 5-19 \\
& \text { 7. 5-20 } \\
& \text { 7. 5-21 } \\
& 7.5-22 \\
& \text { 7. 5-23 } \\
& \text { 7. 5-24 } \\
& \text { 7. } 5-25 \\
& \text { 7. 5-26 } \\
& \text { 7. } 5-27 \\
& 7.5-28 \\
& \text { 7. 5-29 } \\
& \text { 7. 6-1 } \\
& 7.6-2 \\
& \text { 7. 6-3 } \\
& \text { 7. 6-4 }
\end{aligned}
$$

D

D

D

I

D

D

D

D

D

D

I

D

D

D

D

D

I

E

D

D

D

D

D

D

D

I

D

D

D

D

D

D

D

D

D

E

D

I

Amendment I

December 21, 1990 


\section{EFFECTIVE PAGE LISTING (Cont'd)}

\section{CHAPTER 7}

\section{Text (Cont'd)}

\section{Page}

$7.6-5$

$7.6-6$

$7.6-7$

$7.6-8$

$7 \cdot 6-9$

$7 \cdot 6-10$

7. 6-11

7. $6-12$

$7 \cdot 6-13$

$7 \cdot 7-1$

$7.7-2$

$7 \cdot 7-3$

$7 \cdot 7-4$

$7.7-5$

$7.7-6$

$7 \cdot 7-7$

$7.7-8$

$7.7-9$

7. $7-10$

$7 \cdot 7-11$

$7 \cdot 7-12$

$7 \cdot 7-13$

$7 \cdot 7-14$

$7 \cdot 7-15$

$7.7-16$

$7.7-16 a$

$7.7-17$

$7 \cdot 7-18$

7. 7-19

$7.7-19 a$

$7.7-19 \mathrm{~b}$

$7.7-20$

7. 7-21

$7.7-22$

$7.7-23$

7. 7-24

$7.7-25$

$7.7-26$

$7.7-27$

$7.7-28$

$7.7-29$

$7.7-30$

7. 7-30a

\section{Amendment}

E

I

D

D

D

I

D

D

I

D

D

D

I

D

I

D

I

I.

D

I

I

D

D

I

I

D

D

D

D

I

I

D

D

D

I

D

D

I

D

I

I

I

D 


\section{EFFECTIVE PAGE LISTING (Cont'd)}

\section{CHAPTER 7}

Text (Cont'd)

Page

$7 \cdot 7-31$

$7.7-32$

$7 \cdot 7-33$

$7 \cdot 7-34$

$7 \cdot 7-35$

7. 7-36

$7 \cdot 7-37$

$7 \cdot 7-38$

7. $7-39$

7. 7-40

$7 \cdot 7-41$

$7 \cdot 7-42$

$7 \cdot 7-43$

$7 \cdot 7-44$

$7 \cdot 7-45$

$7 \cdot 7-46$

$7 \cdot 7-47$

$7 \cdot 7-48$

7. $7-49$

$7.7-50$

7. 7-51

$7 \cdot 7-52$

$7.7-53$

$7.7-54$

$7 \cdot 7-55$

$7.7-56$

$7.7-57$

$7.7-58$

Tables

7. 1-1

7.2-1 (Sheet 1)

7.2-1 (Sheet 2)

$7.2-2$

7. 2-3

7.2-4 (Sheet 1)

7.2-4 (Sheet 2)

7.2-4 (Sheet 3)

7.2-5 (Sheet 1)

7.2-5 (Sheet 2)

7.2-5 (Sheet 3)

7.2-5 (Sheet 4)

\section{Amendment}

I

D

D

D

D

D

D

D

D

D

D

E

D

D

D

D

D

D

D

D

D

D

D

I

D

D

D

E

Amendment

I
$I$
$I$
$I$
$E$
$I$
$I$
$I$
$E$
$E$
$E$
$E$

Amendment I

December 21, 1990 


\section{EFFECTIVE PAGE LISTING (Cont'd)}

\section{CHAPTER 7}

Tables (Cont'd)

Amendment

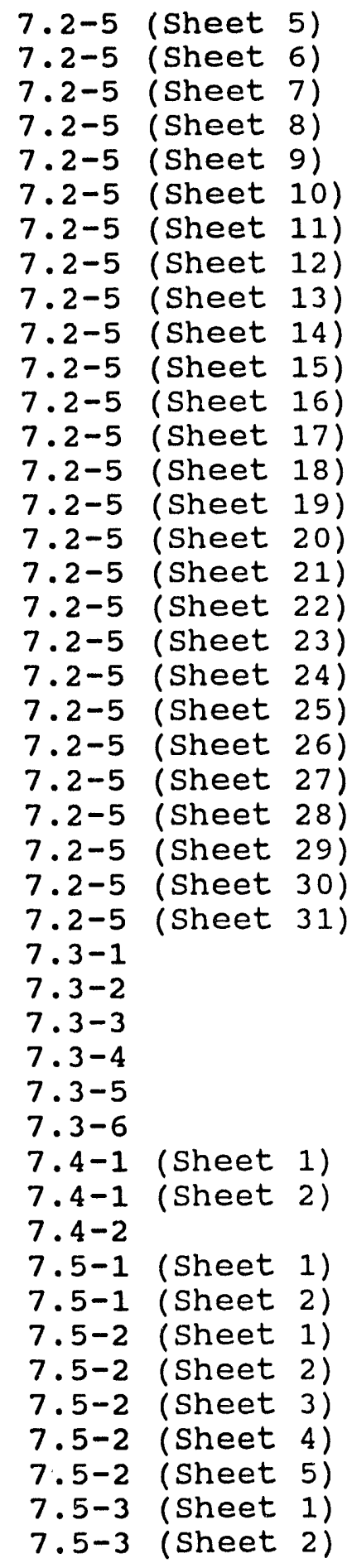

E

E

E

E

E

E

E

E

E

I

I

I

E

E

E

E

E

E

I

I

I

I

I

I

I

I

I

E

I

E

E

I

I

D

I

E

I

I

I

I

I

I

I

I

I 


\section{EFFECTIVE PAGE LISTING (Cont'd)}

\section{CHAPTER 7}

\section{Tables (Cont'd)}

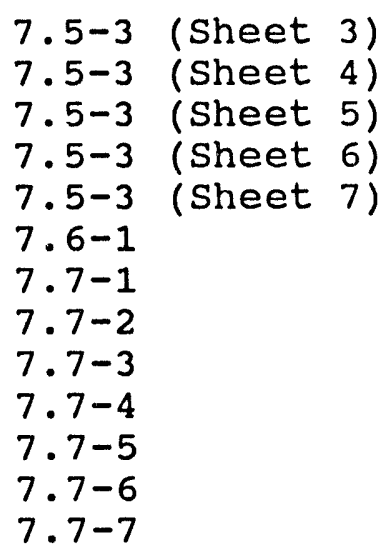

$\underline{\text { Figures }}$

$$
\begin{aligned}
& 7.2-1 \\
& 7.2-2 \\
& 7.2-3 \\
& 7.2-4 \\
& 7.2-5 \\
& 7.2-6 \\
& 7.2-7 \\
& 7.2-8 \\
& 7.2-9 \\
& 7.2-10 \\
& 7.2-11 \\
& 7.2-12 \\
& 7.2-13 \\
& 7.2-14 \\
& 7.2-15 \\
& 7.2-16 \\
& 7.2-17 \\
& 7.2-18 \\
& 7.2-19 \\
& 7.2-20 \\
& 7.2-21 \mathrm{a} \\
& 7.2-21 \mathrm{~b} \\
& 7.2-22 \mathrm{a} \\
& 7.2-22 \mathrm{~b} \\
& 7.2-23 \mathrm{a} \\
& 7.2-23 \mathrm{~b} \\
& 7.2-24 \\
& 7.2-25
\end{aligned}
$$

\section{Amendment}

$$
\begin{aligned}
& \text { I } \\
& \text { I } \\
& \text { I } \\
& \text { I } \\
& \text { I } \\
& \text { I } \\
& \text { I } \\
& \text { D } \\
& \text { I } \\
& \text { I } \\
& \text { D } \\
& \text { I } \\
& \text { I }
\end{aligned}
$$

Amendment

I
$I$
$E$
$E$
$I$
$E$
$I$
$E$
$E$
$I$
$E$
$I$
$E$
$I$
$E$
$E$
$E$
$I$
$I$
$I$
$I$
$I$
$I$
$I$
$E$
$I$
$I$
$I$

Amendment I

December 21, 1990 


\section{EFFECTIVE PAGE LISTING (Cont'd)}

\section{CHAPTER 7}

\section{Figures (Cont'd)}

\section{Amendment}

$7.2-26$

I

$7.2-27 a$

E

$7.2-27 b$

$7.2-28 a$

$7.2-28 \mathrm{~b}$

$7.2-29 a$

$7.2-2.9 \mathrm{~b}$

$7.2-30$

$7.3-1 \mathrm{a}$

$7 \cdot 3-1 \mathrm{~b}$

$7 \cdot 3-1 c$

$7 \cdot 3-1 d$

7. 3-2

7. $3-3$

$7 \cdot 3-4$

$7 \cdot 3-5$

$7 \cdot 3-6$

$7 \cdot 3-7$

7. $3-8 a$

$7.3-8 \mathrm{~b}$

$7.3-9 a$

$7.3-9 b$

7.3-10a

7. $3-10 b$

7. 3-11

$7.3-12$

$7.3-13 a$

$7.3-13 b$

$7.3-14 \mathrm{a}$

$7.3-14 \mathrm{~b}$

$7.3-15 a$

$7.3-15 b$

7. $3-16$

7. $3-17$

7. $3-18$

7. $3-19$

7. 3-20a

$7.3-20 \mathrm{~b}$

7. 3-20c

7. $3-20 d$

7. 3-21

$7 \cdot 3-22$

$7 \cdot 3-23$

$7 \cdot 3-24$

$7.5-1$

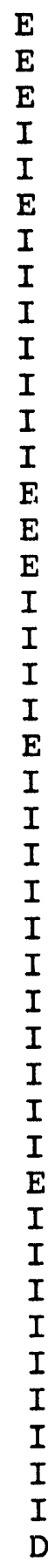

Amendment I December 21, 1990 


\section{EFFECTIVE PAGE LISTING (Cont'd)}

\section{CHAPTER 7}

\section{Figures (Cont'd)}

\section{Amendment}

$7 \cdot 5-2$

$7 \cdot 5-3$

$7 \cdot 5-4$

$7 \cdot 5-5$

$7 \cdot 5-6$

$7 \cdot 5-7$

$7 \cdot 5-8$

$7 \cdot 6-1 \mathrm{a}$

$7 \cdot 6-1 b$

$7 \cdot 6-1 c$

$7.6-2$

$7 \cdot 6-3$

$7 \cdot 7-1$

$7 \cdot 7-2$

7. $7-3$

7. $7-4$

7. $7-5$

7. 7-6

$7 \cdot 7-7$

7. 7-8

$7 \cdot 7-9$

7. 7-10

7. 7-11

$7 \cdot 7-12$

7. 7-13

$7 \cdot 7-14$

7. 7-15

$7 \cdot 7-16$

$7 \cdot 7-17$

7. 7-18

7. 7-19

7. 7-20

$7 \cdot 7-21$

$7 \cdot 7-22$

$7.7-23$

7. 7-24

$7.7-25 a$

$7.7-25 b$

$7.7-26 a$

$7.7-26 \mathrm{~b}$

$7.7-27$

$7.7-28$

7. 7-29

$$
\begin{aligned}
& \text { D } \\
& \text { D } \\
& \text { D } \\
& \text { I } \\
& \text { D } \\
& \text { D } \\
& \text { I } \\
& \text { I } \\
& \text { I } \\
& \text { I } \\
& \text { I } \\
& \text { D } \\
& \text { I } \\
& \text { I } \\
& \text { E } \\
& \text { I } \\
& \text { D } \\
& \text { I } \\
& \text { E } \\
& \text { E } \\
& \text { I } \\
& \text { D } \\
& \text { D } \\
& \text { E } \\
& \text { I } \\
& \text { I } \\
& \text { D } \\
& \text { D } \\
& \text { I } \\
& \text { I } \\
& \text { D } \\
& \text { D } \\
& \text { D } \\
& \text { I } \\
& \text { D } \\
& \text { E } \\
& \text { E } \\
& \text { E } \\
& \text { I } \\
& \text { I } \\
& \text { I } \\
& \text { I }
\end{aligned}
$$

Amendment I

December 21, 1990 


\section{TABLE OF CONTENTS}

CAAPTER 7

Section

7.0

7.1

7.1 .1

$7 \cdot 1 \cdot 1 \cdot 1$

7.1 .1 .1 .1

$7 \cdot 1 \cdot 1.2$

$7 \cdot 1 \cdot 1 \cdot 3$

7.1 .1 .4

$7.1 \cdot 1.5$

7.1 .1 .6

7.1 .1 .7

7.1 .1 .8

7.1 .1 .9

7.1 .2

7.1 .2 .1

$7 \cdot 1 \cdot 2 \cdot 1 \cdot 1$

$7.1 .2 \cdot 1.2$

$7.1 .2 \cdot 1 \cdot 3$

$7.1 .2 \cdot 1.4$
Subject

INSTRUMENTATION AND CONTROLS

INTRODUCTION

IDENTIFICATION OF SAFETY-RELATED SYSTEMS

Plant Protection System (PPS)

Alternate Protection

system (APS)

Reactor Trip System (RTS)

Engineered Safety Feature

Systems (ESF systems)

Systems Required for Safe

Shutdown

Safety-Related Display

Instrumentation

All other systems Required

for safety

Design Comparison

System Drawings

System Diversity

IDENTIFICATION OF SAFETY CRITERIA

Design Bases

Systems Required for Plant Protection

Systems Required for Safe Shutdown

Safety-Related Display

Instrumentation

All other systems Required

for Safety
$7 \cdot 1-4$

$7 \cdot 1-5$

$7.1-5$

$7.1-5$

$7 \cdot 1-5$

Page No.

$7 \cdot 1-1$

$7 \cdot 1-1$

$7 \cdot 1-1$

$7 \cdot 1-1$

$7.1-2 \mid D$

$7 \cdot 1-2$

$7 \cdot 1-2$

$7 \cdot 1-2$

$7 \cdot 1-4$

$7.1-4$

$7 \cdot 1-6$

$7.1-6$

$7.1-6$

$7.1-6$ 


\section{TABLE OF CONTENTS (Cont'd)}

CHAPTER 7

\section{Section}

$7 \cdot 1 \cdot 2 \cdot 2$

$7 \cdot 1 \cdot 2 \cdot 3$

$7 \cdot 1 \cdot 2 \cdot 4$

$7,1 \cdot 2 \cdot 5$

7.1 .2 .6

7.1 .2 .7

7.1 .2 .8

7.1 .2 .9

7.1 .2 .10

$7.1 .2 \cdot 11$

7.1 .2 .12

$7.1 .2 \cdot 13$

$7.1 .2 \cdot 14$

\section{Subject}

Conformance to IEEE 279-1971

Conformance to IEEE $308-1980$

Conformance to IEEE 317-1983

Conformance to IEEE 323-1983, as Augmented by Regulatory Guide 1.89

Conformance to IEEE 336-1985, as Augmented by Regulatory Guide 1.30

Conformance to IEEE 338-1977, as Augmented by Regulatory Guide 1.118

Conformance to IEEE 344-1987, as Augmented by Regulatory Guide 1.100

Conformance to IEEE $379-1977$, as Augmented by Regulatory Guide 1.53

Conformance to IEEE 384-1981, as Augmented by Regulatory Guide 1.75

Conformance to IEEE 387-1984

Conformance to IEEE $450-1980$

Conformance to IEEE 603-1980, as Augmented by Regulatory

Guide 1.153

Comparison of Design with Regulatory Guide 1.6
Page No.

$7.1-7$

$7.1-7$

$7 \cdot 1-7$

$7 \cdot 1-7$

$7 \cdot 1-7$

$7.1-7$

$7 \cdot 1-8$

$7.1-8$

$7.1-9$

$7 \cdot 1-10$

7. $1-10$

$7 \cdot 1-10$

7. 1-10 
TABLE OF CONTENTS (Cont'd)

CHAPTER 7

Section

7.1 .2 .15

7.1 .2 .16

7.1 .2 .17

7.1 .2 .18

7.1 .2 .19

7.1 .2 .20

7.1 .2 .21

7.1 .2 .21 .1

7.1 .2 .21 .2

7.1 .2 .21 .3

7.1 .2 .22

7.1 .2 .23

7.1 .2 .24

7.1 .2 .25

7.1 .2 .26

7.1 .2 .27

7.1 .2 .28

7.1 .2 .29

$7 \cdot 1 \cdot 2 \cdot 30$

$7 \cdot 1 \cdot 2 \cdot 31$

7.1 .2 .32

7.1 .2 .33

$7.1 .2 \cdot 34$
Subject

Conformance to Regulatory Guide 1.11

Conformance to Regulatory Guide 1.17

Conformance to Regulatory Guide 1.22

Conformance to Regulatory Guide 1.29

Conformance to Regulatory Guide 1.40

Conformance to Regulatory Guide 1.45

Conformance to Regulatory Guide 1.47

Operating Bypasses

Trip Channel Bypasses

ESF Components Inoperable

Conformance to Regulatory Guide 1.62

Conformance to Regulatory Guide 1.63

Conformance to Regulatory Guide 1.68

Conformance to Regulatory Guide 1.73

Conformance to Regulatory Guide 1.97

Conformance to Regulatory Guide 1.105

Conformance to Regulatory Guide 1.106

Conformance to Regulatory Guide 1.120

as Augmented by BTP CMEB 9.5-1

Conformance to Regulatory Guide

to 1.133

Conformance to Regulatory Guide 1.151

Conformance to Regulatory Guide 1.152

Conformance to Regulatory Guide 1.156

Conformance to Regulatory Guide 8.12
Page No

$7.1-10$

7. 1-11

$7 \cdot 1-12$

$7 \cdot 1-13$

$7 \cdot 1-13$

$7 \cdot 1-14$

$7 \cdot 1-14$

$7 \cdot 1-15$

$7 \cdot 1-15$

$7 \cdot 1-15$

$7.1-16$ D

$7 \cdot 1-16$

$7 \cdot 1-17$

7. 1-17

$7.1-17$

$7 \cdot 1-18$

$7.1-18$

7. 1-19

7. 1-19

$7 \cdot 1-19$

$7 \cdot 1-20$

$7 \cdot 1-20$

$7 \cdot 1-20$ 


\section{TABLE OF CONTENTS (Cont'd)}

\section{CHAPTER 7}

\section{Section}

$7 \cdot 1 \cdot 3$

7.2

7.2 .1

$7 \cdot 2 \cdot 1 \cdot 1$

$7 \cdot 2 \cdot 1 \cdot 1.1$

$7 \cdot 2 \cdot 1 \cdot 1 \cdot 1 \cdot 1$

$7.2 \cdot 1 \cdot 1 \cdot 1 \cdot 2$

$7 \cdot 2 \cdot 1 \cdot 1 \cdot 1 \cdot 3$

$7 \cdot 2 \cdot 1 \cdot 1 \cdot 1 \cdot 4$

$7 \cdot 2 \cdot 1 \cdot 1 \cdot 1 \cdot 5$

$7 \cdot 2 \cdot 1 \cdot 1 \cdot 1 \cdot 6$

$7 \cdot 2 \cdot 1 \cdot 1 \cdot 1 \cdot 7$

$7 \cdot 2 \cdot 1 \cdot 1 \cdot 1 \cdot 8$

$7 \cdot 2 \cdot 1 \cdot 1 \cdot 1 \cdot 9$

$7.2 .1 \cdot 1.1 .10$

$7 \cdot 2 \cdot 1 \cdot 1 \cdot 1 \cdot 11$

$7 \cdot 2 \cdot 1 \cdot 1 \cdot 1 \cdot 12$

$7 \cdot 2 \cdot 1 \cdot 1.2$

$7 \cdot 2 \cdot 1 \cdot 1 \cdot 2 \cdot 1$

$7.2 \cdot 1 \cdot 1 \cdot 2 \cdot 2$

$7 \cdot 2 \cdot 1 \cdot 1 \cdot 2 \cdot 2 \cdot 1$

$7 \cdot 2 \cdot 1 \cdot 1 \cdot 2 \cdot 2 \cdot 2$
Subject

INTERFACE REQUIREMENTS

REACTOR PROTECTIVE SYSTEM

DESCRIPTION

Systems Description

Trips

Variable overpower

High Logarithmic Power

Level

High Local Power Density

Low Departure From Nucleate

Boiling Ratio

High Pressurizer Pressure

Low Pressurizer Pressure

Low Steam Generator water

Level

Low Steam Generator Pressure

High Containment Pressure

High Steam Generator Water Level

Manual Trip

Low Reactor coolant Flow

Initiating circuits

Process Measurements

CEA Position Measurements

CEA Position Monitoring by the RPS

Control and Protective Actions for CEA

Misalignments
Page No.

$7 \cdot 1-21$

$7 \cdot 2-1$

$7 \cdot 2-1$

$7.2-1$

$7.2-2$

$7.2-2$

$7.2-2$

$7 \cdot 2-3$

$7 \cdot 2-3$

$7 \cdot 2-3$

$7.2-4$

$7 \cdot 2-4$

$7 \cdot 2-4$

$7.2-5$

$7 \cdot 2-5$

$7.2-5$

7. 2-6 $\mid \mathrm{E}$

$7.2-6$

$7.2-6$

$7 \cdot 2-6$

\begin{tabular}{c|}
$7.2-7$ \\
$7.2-8$
\end{tabular} \mid $\mathrm{E}$ 


\section{TABLE OF CONTENTS (Cont'd)}

\section{CHAPTER 7}

Section

$7.2 \cdot 1 \cdot 1.2 \cdot 3$

$7 \cdot 2 \cdot 1 \cdot 1 \cdot 2 \cdot 4$

$7 \cdot 2 \cdot 1 \cdot 1 \cdot 2 \cdot 5$

7.2 .1 .1 .2 .6

$7 \cdot 2 \cdot 1 \cdot 1 \cdot 3$

$7 \cdot 2 \cdot 1 \cdot 1 \cdot 4$

$7 \cdot 2 \cdot 1 \cdot 1 \cdot 5$

7.2 .1 .1 .6

$7.2 \cdot 1 \cdot 1.7$

7.2 .1 .1 .8

7.2 .1 .1 .9

$7 \cdot 2 \cdot 1 \cdot 1 \cdot 9 \cdot 1$

$7 \cdot 2 \cdot 1 \cdot 1 \cdot 9 \cdot 2$

$7 \cdot 2 \cdot 1 \cdot 1 \cdot 9 \cdot 3$

$7 \cdot 2 \cdot 1 \cdot 1 \cdot 9 \cdot 4$

$7 \cdot 2 \cdot 1 \cdot 1 \cdot 9 \cdot 5$

$7 \cdot 2 \cdot 1 \cdot 1 \cdot 9 \cdot 6$

$7 \cdot 2 \cdot 1 \cdot 1 \cdot 9 \cdot 7$

$7.2 \cdot 1 \cdot 1 \cdot 9 \cdot 8$

$7 \cdot 2 \cdot 1 \cdot 1 \cdot 10$

$7 \cdot 2 \cdot 1 \cdot 1 \cdot 11$

$7 \cdot 2 \cdot 1 \cdot 2$

$7 \cdot 2 \cdot 1 \cdot 3$

7.2 .2

$7 \cdot 2 \cdot 2 \cdot 1$

$7 \cdot 2 \cdot 2 \cdot 1 \cdot 1$

$7 \cdot 2 \cdot 2 \cdot 1.2$

\section{Subject}

Ex-core Neutron Flux

Measurements

Reactor Coolant Flow

Measurements

Core Protection Calculators

Bistable Trip Generation

Logic

Actuated Devices

Bypasses

Interlocks

Redundancy

Diversity

Testing

Sensor Check

Trip Bistable Tests

Core Protection Calculator

Tests

Local Coincidence Logic

Testing

RPS Initiation Logic Testing

Manual Trip Test

Bypass Testing

Response Time Tests

Vital Instrument Power

Supply

System Arrangement

Design Bases

System Drawings

ANALYSIS

Introduction

Anticipated operational

occurrences

Accidents
Page No

$7 \cdot 2-10$

$7 \cdot 2-10$

$7.2-11$

$7.2-14$

$7.2-16$

$7 \cdot 2-18$

$7 \cdot 2-18$

$7.2-21$

$7.2-22$

$7.2-22$

$7.2-24$

$7 \cdot 2-25$

$7.2-25$

$7.2-28$

$7.2-29$

$7.2-29$

$7.2-30$

$7.2-30$

$7.2-30$

$7.2-32$

$7.2-32 \mid \mathrm{E}$

$7 \cdot 2-32$

$7 \cdot 2-35$

$7.2-35$

$7 \cdot 2-35$

$7.2-37$

$7 \cdot 2-39$ 
TABLE OF CONTENTS (Cont'd)

\section{CHAPTER 7}

\section{Section}

7.2 .2 .2

7.2 .2 .2 .1

$7.2 \cdot 2 \cdot 2 \cdot 2$

$7.2 \cdot 2 \cdot 2 \cdot 3$

$7 \cdot 2 \cdot 2 \cdot 2 \cdot 4$

$7 \cdot 2 \cdot 2 \cdot 2 \cdot 5$

7.2 .2 .2 .6

7.2 .2 .2 .7

7.2 .2 .2 .8

$7.2 \cdot 2 \cdot 2 \cdot 9$

$7.2 \cdot 2 \cdot 2 \cdot 10$

$7 \cdot 2 \cdot 2 \cdot 2 \cdot 11$

7.2 .2 .2 .12

$7 \cdot 2 \cdot 2 \cdot 3$

$7 \cdot 2 \cdot 2 \cdot 3 \cdot 1$

$7 \cdot 2 \cdot 2 \cdot 3 \cdot 2$

$7.2 \cdot 2 \cdot 3 \cdot 3$

7.2 .2 .4

7.2 .3

7.2 .4

7.3

$7 \cdot 3 \cdot 1$

$7 \cdot 3 \cdot 1 \cdot 1$

$7 \cdot 3 \cdot 1 \cdot 1 \cdot 1$

$7.3 \cdot 1.1 .2$

$7 \cdot 3 \cdot 1 \cdot 1 \cdot 2 \cdot 1$

$7 \cdot 3 \cdot 1 \cdot 1 \cdot 2 \cdot 2$
Subject

Trip Bases

Variable Overpower Trip

High Logarithmic Power Level Trip

High Local Power Density Trip

LOW DNBR Trip

High Pressurizer Pressure Trip

Low Pressurizer Pressure Trip

Low steam Generator water

Level Trips

Low Steam Generator Pressure Trips

High Containment Pressure Trip

High Steam Generator Water

Level Trips

Low Reactor Coolant Flow

Manual Reactor Trip

Design

General Design Criteria

Equipment Design Criteria

Testing Criteria

Failure Modes and Effects

Analysis (FMEA)

REACTOR PROTECTIVE SYSTEM INTERFACES

ALTERNATE PROTECTION SYSTEM

ENGINEERED SAFETY FEATURES ACTUATION

SYSTEM

DESCRIPTION

System Description

ESFAS Measurement Channels Logic

ESFAS Bistable and Coincidence Logic Actuation Logic
Page No.

$7.2-40$

$7.2-40$

$7.2-40$

$7 \cdot 2-41$

$7.2-41$

$7.2-42$

$7.2-42$

$7 \cdot 2-42$

$7 \cdot 2-43$

$7 \cdot 2-43$

$7.2-43$

$7.2-43$

$7.2-44$

$7.2-44$

$7 \cdot 2-44$

$7 \cdot 2-46$

$7,2-52$

$7 \cdot 2-53$

7. $2-53$

$7.2-55$

$7 \cdot 3-1$

$7 \cdot 3-1$

$7.3-2 \mid \mathrm{E}$

$7.3-5$

7. $3-6$

$7 \cdot 3-6$

$7 \cdot 3-6$

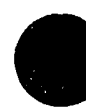




\section{TABLE OF CONTENTS (Cont'd)}

\section{CHAPTER 7}

Section

$7 \cdot 3 \cdot 1 \cdot 1 \cdot 2 \cdot 2 \cdot 1$

$7 \cdot 3 \cdot 1 \cdot 1 \cdot 2 \cdot 2 \cdot 1 \cdot 1$

$7 \cdot 3 \cdot 1 \cdot 1 \cdot 2 \cdot 2 \cdot 1 \cdot 1 \cdot 1$

$7 \cdot 3 \cdot 1 \cdot 1 \cdot 2 \cdot 2 \cdot 1 \cdot 1 \cdot 2$

$7 \cdot 3 \cdot 1 \cdot 1 \cdot 2 \cdot 2 \cdot 1 \cdot 2$

$7 \cdot 3 \cdot 1 \cdot 1 \cdot 2 \cdot 2 \cdot 1 \cdot 2 \cdot 1$

$7.3 \cdot 1.1 .2 \cdot 2 \cdot 1 \cdot 2 \cdot 2$

$7 \cdot 3 \cdot 1 \cdot 1 \cdot 2 \cdot 2 \cdot 1 \cdot 2 \cdot 3$

$7 \cdot 3 \cdot 1 \cdot 1 \cdot 2 \cdot 2 \cdot 1 \cdot 3$

$7 \cdot 3 \cdot 1 \cdot 1 \cdot 2 \cdot 2 \cdot 1 \cdot 4$

$7 \cdot 3 \cdot 1 \cdot 1 \cdot 2 \cdot 2 \cdot 1 \cdot 5$

$7 \cdot 3 \cdot 1 \cdot 1 \cdot 2 \cdot 2 \cdot 2$

$7 \cdot 3 \cdot 1 \cdot 1 \cdot 2 \cdot 3$

$7 \cdot 3 \cdot 1 \cdot 1 \cdot 3$

$7 \cdot 3 \cdot 1 \cdot 1 \cdot 3 \cdot 1$

$7 \cdot 3 \cdot 1 \cdot 1 \cdot 3 \cdot 2$

$7 \cdot 3 \cdot 1 \cdot 1 \cdot 3 \cdot 3$

$7 \cdot 3 \cdot 1 \cdot 1 \cdot 4$

$7 \cdot 3 \cdot 1 \cdot 1 \cdot 5$

$7.3 \cdot 1 \cdot 1.6$

$7.3 \cdot 1 \cdot 1.7$

$7.3 \cdot 1 \cdot 1.8$
Subject

Component Control Logic

Page No.

$7 \cdot 3-7$

Solenoid-operated Valves

$7 \cdot 3-7$

Two-state Solenoid Valve

$7 \cdot 3-7$

Control

Modulating Valves with

Solenoid operators

Motor-operated Valves

$7 \cdot 3-8$

$7 \cdot 3-9$

Interface Signals

Throttling and Full

Throw Designs

Thermal Overload

Monitoring

$7 \cdot 3-9$

$7 \cdot 3-10$

$7 \cdot 3-10$

Contactor-operated

Components

Circuit Breaker-

Operated Components

Modulating Components

Group Actuation

CSS-Diesel Loading Sequencer

Bypasses

Bistable Trip Channel Bypass

operating Bypass

Bypasses and Inoperable status

Interlocks

Redundancy

Diversity

Sequencing

Testing
$7 \cdot 3-12$

$7 \cdot 3-13$

$7 \cdot 3-13$

$7 \cdot 3-15$

$7 \cdot 3-10$

$7 \cdot 3-11$

$7 \cdot 3-15 \mid \mathrm{E}$

$7 \cdot 3-15$

7. 3-16|E

$7 \cdot 3-16$

$7.3-16 \mathrm{a}$

$7 \cdot 3-17$

$7 \cdot 3-17$

$7 \cdot 3-17$ 


\section{TABLE OF CONTENTS (Cont'd)}

\section{CHAPTER 7}

\section{Section}

$7 \cdot 3 \cdot 1 \cdot 1 \cdot 8 \cdot 1$

$7.3 \cdot 1 \cdot 1 \cdot 8 \cdot 2$

$7 \cdot 3 \cdot 1 \cdot 1 \cdot 8 \cdot 3$

7.3 .1 .1 .8 .4

$7.3 \cdot 1 \cdot 1.8 \cdot 5$

7.3 .1 .1 .8 .6

7.3 .1 .1 .8 .7

$7 \cdot 3 \cdot 1 \cdot 1 \cdot 8 \cdot 8$

$7 \cdot 3 \cdot 1 \cdot 1 \cdot 8 \cdot 9$

7.3 .1 .1 .9

$7.3 \cdot 1 \cdot 1.10$

$7 \cdot 3 \cdot 1 \cdot 1 \cdot 10 \cdot 1$

7.3.1.1.10.2

7.3.1.1.10.3

7.3.1.1.10.4

7.3 .1 .1 .10 .5

7.3 .1 .2

$7 \cdot 3 \cdot 1 \cdot 3$

$7 \cdot 3 \cdot 1.4$

7.3 .2

$7.3 \cdot 2 \cdot 1$

$7 \cdot 3 \cdot 2 \cdot 1 \cdot 1$

$7 \cdot 3 \cdot 2 \cdot 2$

$7 \cdot 3 \cdot 2 \cdot 2 \cdot 1$

7.3 .2 .2 .2

$7 \cdot 3 \cdot 2 \cdot 2 \cdot 3$

$7 \cdot 3 \cdot 2 \cdot 2 \cdot 4$

$7.3 \cdot 2.2 .5$
Subject

Sensor Checks

Trip Bistable Test

Local Coincidence Logic Tests

Initiation Logic Tests

Actuating Logic Test

Selective Group Test

Bypass Tests

Response Time Tests

Diesel Load Sequencer Tests

Vital Instrument Power Supply

Actuated Systems

Containment Isolation

System

Containment spray system

Main steam Isolation System

Safety Injection system

Emergency Feedwater system

Design Bases

System Drawings

ESFAS Supporting systems

ANALYSIS

Introduction

Design Basis Events (DBE)

Actuation Bases

Safety Injection Actuation

Signal (SIAS)

Containment Spray Actuation

Signal (CSAS)

Containment Isolation

Actuation Signal (CIAS)

Main Steam Isolation Signal (MSIS)

Emergency Feedwater Actuation

signal (EFAS)
Page No.

$7 \cdot 3-18$

$7 \cdot 3-18$

$7 \cdot 3-18$

$7 \cdot 3-18$

$7 \cdot 3-19$

$7.3-20$

$7 \cdot 3-21$

$7 \cdot 3-21$

$7.3-\left.22\right|_{\mathrm{E}}$

$7 \cdot 3-23$

$7.3-23$

$7 \cdot 3-23$

$7.3-24$

$7 \cdot 3-24$

$7.3-25$

$7 \cdot 3-25$

$7 \cdot 3-26$

$7 \cdot 3-27$

$7 \cdot 3-27$

$7 \cdot 3-27$

$7 \cdot 3-27$

$7 \cdot 3-28$

7. 3-29

7. $3-29$

$7.3-30 \mid \mathrm{E}$

$7 \cdot 3-30$

7. $3-30$

7. $3-30$ 


\section{TABLE OF CONTENTS (Cont'd)}

CHAPTER 7

Section

$7 \cdot 3 \cdot 2 \cdot 3$

$7 \cdot 3 \cdot 2 \cdot 3 \cdot 1$

$7.3 \cdot 2 \cdot 3 \cdot 2$

$7 \cdot 3 \cdot 2 \cdot 3 \cdot 3$

$7 \cdot 3 \cdot 2 \cdot 4$

$7 \cdot 3 \cdot 2 \cdot 5$

$7 \cdot 3 \cdot 2 \cdot 6$

$7 \cdot 3 \cdot 2 \cdot 7$

$7 \cdot 3 \cdot 3$

7.4

7.4 .1

7.4 .1 .1

$7 \cdot 4 \cdot 1 \cdot 1 \cdot 1$

7.4 .1 .1 .2

$7 \cdot 4 \cdot 1 \cdot 1 \cdot 3$

7.4 .1 .1 .4

$7.4 \cdot 1 \cdot 1.5$

7.4 .1 .1 .6

$7 \cdot 4 \cdot 1 \cdot 1 \cdot 7$

$7.4 \cdot 1.1 .8$

$7 \cdot 4 \cdot 1 \cdot 1.8 \cdot 1$

$7 \cdot 4 \cdot 1 \cdot 1 \cdot 8 \cdot 2$

$7 \cdot 4 \cdot 1 \cdot 1 \cdot 8 \cdot 3$

7.4 .1 .1 .8 .4

$7.4 \cdot 1.1 .9$
Subject

Design

General Design Criteria Equipment Design Criteria Testing Criteria

Failure Modes and Effects Analysis (FMEA)

Setpoint Methodology

ESF Valve Operability

Containment Hydrogen Recombiner System (CHRS)

ENGINEERED SAFETY FEATURES ACTUATION

SYSTEM INTERFACE REQUIREMENTS

SYSTEMS REQUIRED FOR SAFE SHUTDOWN

DESCRIPTION

Systems Required for Safe Shutdown

Plant Diesel Generators

Plant Diesel Generator Fuel Oil

Storage and Transfer System

Class $1 \mathrm{E}$ Power Distribution system

Station Service Water system

Component cooling Water system

Emergency Feedwater system

Atmospheric Dump System (ADS)

Shutdown cooling system (SCS)

Initiating circuits and

Logic

Interlocks, Sequencing and

Bypasses

Redundancy and Diversity

Supporting systems

Safety Injection system (SIS)
Page No

$7 \cdot 3-31$

$7 \cdot 3-31$

$7 \cdot 3-32$

$7 \cdot 3-38$

$7 \cdot 3-39$

\begin{tabular}{r|r|}
$7.3-39$ & $\mathrm{E}$ \\
$7.3-39$ & $\mathrm{I}$
\end{tabular}

$7 \cdot 3-40$

7. 4-1

$7.4-2$

$7 \cdot 4-2$

$7.4-3$

$7.4-3$

$7.4-3$

$7.4-3$

$7.4-4$

$7.4-4$

$7.4-4$

$7 \cdot 4-4$

$7.4-4$

$7 \cdot 4-5$

$7 \cdot 4-5$

$7 \cdot 4-5$

$7.4-\left.5 \quad\right|_{D}$ 


\section{TABLE OF CONTENTS (Cont'd)}

CHAPTER 7

\section{Section}

$$
\begin{aligned}
& 7.4 .1 .1 .9 .1 \\
& 7.4 .1 .1 .9 .2 \\
& 7.4 \cdot 1.1 .9 .3 \\
& 7.4 .1 .1 .9 .4 \\
& 7.4 .1 .1 .10 \\
& 7.4 \cdot 1.1 .10 .1 \\
& 7.4 \cdot 1.1 .10 .2 \\
& 7.4 .1 .1 .11
\end{aligned}
$$$$
7.4 .1 .2
$$$$
7.4 .2
$$$$
7.4 .2 .1
$$$$
7 \cdot 4 \cdot 2 \cdot 2
$$$$
7 \cdot 4 \cdot 2 \cdot 3
$$$$
7 \cdot 4 \cdot 2 \cdot 4
$$$$
7 \cdot 4 \cdot 2 \cdot 4 \cdot 1
$$$$
7.4 .2 .4 .2
$$$$
7 \cdot 4 \cdot 2 \cdot 4 \cdot 3
$$

\section{Subject}

Initiating circuits and Logic

Interlocks, sequencing and Bypasses Redundancy and Diversity supporting systems

Emergency shutdown from Outside the Control Room

$$
\begin{aligned}
& \text { Hot standby } \\
& \text { cold Shutdown }
\end{aligned}
$$

Safety Depressurization System (SDS)

System Drawings
ANALYSIS
Conformance to IEEE $279-1971$
Conformance to IEEE $308-1980$
Conformance to General Design
Criterion 19
Consideration of Selected
Plant Contingencies
Loss of Instrument Air System
Loss of Cooling Water to Vital
Equipment
Plant Load Rejection, Turbine
Trip, and Loss of offsite Power

Page No.

$7.4-6$

$7.4-6$

$7.4-6$

$7.4-6$

$7.4-6$

7. 4-7

$7.4-7$

$7.4-8 \mid \mathrm{D}$

$7.4-8$

$7.4-8$

$7.4-8$

$7 \cdot 4-\left.12\right|_{D}$

7. $4-12$

$7.4-12$

$7.4-12$

$7.4-12$

$7 \cdot 4-12$ 


\section{TABI,E OF CONTENTS (Cont'd)}

\section{CHAPTER 7}

\section{Section}

$7 \cdot 4 \cdot 2 \cdot 5$

$7.4 \cdot 2 \cdot 5 \cdot 1$

$7.4 \cdot 2 \cdot 5 \cdot 2$

7.5

7.5 .1

7.5 .1 .1

$7 \cdot 5 \cdot 1 \cdot 1.1$

$7.5 \cdot 1 \cdot 1.2$

7.5 .1 .1 .3

$7 \cdot 5 \cdot 1 \cdot 1.4$

7.5 .1 .1 .5

7.5 .1 .1 .6

$7.5 \cdot 1.1 .7$

$7.5 \cdot 1.1 .7 .1$

$7 \cdot 5 \cdot 1 \cdot 1 \cdot 7 \cdot 1.1$

$7.5 \cdot 1 \cdot 1 \cdot 7 \cdot 1.2$

$7.5 \cdot 1 \cdot 1 \cdot 7 \cdot 1.3$

$7.5 \cdot 1 \cdot 1 \cdot 7.2$

7.5 .1 .1 .7 .2 .1

$7 \cdot 5 \cdot 1 \cdot 1 \cdot 7 \cdot 2 \cdot 2$
Subject

Emergency Shutdown From Outside

the control Room

Design Capability for Prompt

Hot standby and to Maintain

Hot Standby

cold Shutdown

SAFETY RELATED DISPLAY INSTRUMENTATION

DESCRIPTION

System Description

Safety-Related Plant Process

Display Instrumentation

Reactor Trip System Monitoring

Engineered Safety Features

Monitoring

CEA Position Indication

Post-Accident Monitoring

Automatic Bypass Indication on

a System Level

Inadequate core cooling

Monitoring Instrumentation

Sensor Design

Saturation Margin

Sensors

Heated Junction Thermo-

couple (HJTC) Probe

Assembly

Core Exit Thermocouple

(CET)

Description of ICC Sensor

Signal Processing

Heated Junction Thermocouple

Core Exit Thermocouple
Page No.

$7.4-13$

$7.4-13$

$7 \cdot 4-13$

$7 \cdot 5-1$

$7 \cdot 5-1$

$7 \cdot 5-3$

$7 \cdot 5-3$

$7 \cdot 5-3$

$7 \cdot 5-4$

$7 \cdot 5-4$

$7 \cdot 5-6$

$7 \cdot 5-6$

$7.5-6$

$7 \cdot 5-7$

$7.5-8$

$7 \cdot 5-8$

$7.5-9$

$7 \cdot 5-9$

$7 \cdot 5-10$

$7 \cdot 5-10$ 


\section{TABLE OF CONTENTS (Cont'd)}

CHAPTER 7

Section

$7 \cdot 5 \cdot 1 \cdot 1 \cdot 7 \cdot 3$

$7 \cdot 5 \cdot 1 \cdot 1 \cdot 7 \cdot 3 \cdot 1$

$7 \cdot 5 \cdot 1 \cdot 1 \cdot 7 \cdot 3 \cdot 2$

$7 \cdot 5 \cdot 1 \cdot 1 \cdot 7 \cdot 3 \cdot 3$

7.5 .2

$7 \cdot 5 \cdot 2 \cdot 1$

$7 \cdot 5 \cdot 2 \cdot 2$

$7 \cdot 5 \cdot 2 \cdot 3$

7.5 .2 .4

7.5 .2 .5

$7 \cdot 5 \cdot 2 \cdot 5 \cdot 1$

$7.5 .2 \cdot 5.2$

$7 \cdot 5 \cdot 2 \cdot 5 \cdot 3$

$7.5 .2 \cdot 5.4$

$7 \cdot 5 \cdot 2 \cdot 5 \cdot 5$

7.5 .2 .5 .6

$7 \cdot 5 \cdot 2 \cdot 5 \cdot 7$

$7.5 .2 \cdot 5.8$

$7.5 .2 \cdot 5.9$

$7.5 \cdot 2 \cdot 5 \cdot 10$

$7.5 \cdot 2 \cdot 5.11$

$7.5 \cdot 2 \cdot 5 \cdot 12$

7.5 .2 .6

7.5 .2 .7
Subject

\author{
ICC Information Displays \\ DIAS Channel P \\ DIAS Channel $\mathrm{N}$ \\ DPS ICC Displays
}

ANALYSIS

Analysis of Safety-Related Plant Process Display Instrumentation

Analysis of Reactor Trip system? Monitoring

Analysis of Engineered Safety

Features Monitoring

Analysis of CEA Position

Indication

$7 \cdot 5-16$

Analysis of Post-Accident

Monitoring Instrumentation

$7 \cdot 5-16$

Equipment Qualification

Redundancy

Power Source

Channel Availability

Quality Assurance

Display and Recording

Page No.

$7 \cdot 5-11$

$7 \cdot 5-11$

$7 \cdot 5-11$

$7 \cdot 5-12$

$7 \cdot 5-14$

$7 \cdot 5-14$

$7 \cdot 5-15$

$7 \cdot 5-15$

Range

Equipment Identification

Interfaces

Servicing, Testing and Calibration

Human Factors

Direct Measurement

$7.5-17$

$7 \cdot 5-18$

$7.5-19$

$7.5-20$

$7 \cdot 5-21$

$7.5-21$

$7 \cdot 5-22$

$7.5-22$

$7.5-23$

$7 \cdot 5-24$

$7 \cdot 5-24$

$7.5-25$

Analysis of Automatic Bypass Indication

$7 \cdot 5-25$

$7.5-26$

Analysis of Inadequate Core Cooling Monitors 


\section{TABLE OF CONTENTS (Cont'd)}

CHAPTER 7

\section{Section}

$7 \cdot 5 \cdot 2 \cdot 7 \cdot 1$

$7 \cdot 5 \cdot 2 \cdot 7 \cdot 1 \cdot 1$

$7 \cdot 5 \cdot 2 \cdot 7 \cdot 1 \cdot 2$

$7 \cdot 5 \cdot 2 \cdot 7.2$

7.6

7.6 .1

$7 \cdot 6 \cdot 1.1$

$7.6 \cdot 1.1 .1$

$7.6 \cdot 1.1 .2$

$7 \cdot 6 \cdot 1 \cdot 1 \cdot 3$

$7 \cdot 6 \cdot 1 \cdot 1 \cdot 3 \cdot 1$

$7 \cdot 6 \cdot 1 \cdot 1 \cdot 3 \cdot 2$

$7 \cdot 6 \cdot 1 \cdot 1.4$

7.6 .1 .2

$7 \cdot 6 \cdot 1 \cdot 2 \cdot 1$

7.6 .1 .2 .2

$7 \cdot 6 \cdot 1 \cdot 3$

7.6 .2

7.6 .2 .1

\section{Subject}

Description of ICC Progression

(Coolant states Related to ICC)

Approach to ICC

Recovery from ICC

Instrument Range

ALL OTHER INSTRUMENTATION SYSTEMS

REQUIRED FOR SAFETY

INTRODUCTION

System Descriptions

Shutdown cooling system suction I ine Valve Interlocks

Safety Injection Tank Isolation Valve Interlocks

DIAS Channel $\mathrm{N}$ and DPS Alarms

Reactor Coolant Pump Cooling Water Supply Monitoring Safety Injection Tank Pressure Monitoring

Fire Protection Instrumentation and Detection system

Design Bases

Shutdown cooling system suction Line Valve Interlocks

Safety Injection Tank Isolation

Valve Interlocks

System Drawings

ANALYSIS

Design Criteria
Page No.

$7 \cdot 5-26$

$7 \cdot 5-27$

$7 \cdot 5-28$

$7 \cdot 5-28$

$7 \cdot 6-1$

$7 \cdot 6-1$

$7 \cdot 6-1$

7. 6-1

$7 \cdot 6-2$

$7.6-3$

$7 \cdot 6-3$

$7 \cdot 6-3$

$7 \cdot 6-4$

$7 \cdot 6-4$

$7.6-4$

$7.6-5$

$7 \cdot 6-5$

$7 \cdot 6-5$

$7.6-5$ 
TABLE OF CONTENTS (Cont'd)

CHAPTER 7

\section{Section}

7.6 .2 .1 .1

$7 \cdot 6.2 .1 .2$

$7 \cdot 6 \cdot 2 \cdot 1 \cdot 3$

$7 \cdot 6 \cdot 2 \cdot 1 \cdot 3.1$

$7 \cdot 6 \cdot 2 \cdot 1 \cdot 3 \cdot 2$

7.6 .2 .2

$7 \cdot 6 \cdot 2 \cdot 2 \cdot 1$

7.6 .2 .2 .2

$7 \cdot 6 \cdot 2 \cdot 3$

7.7

7.7 .1

7.7 .1 .1

7.7 .1 .1 .1

7.7 .1 .1 .2

7.7 .1 .1 .2 .1

7.7 .1 .1 .2 .2

$7 \cdot 7 \cdot 1 \cdot 1 \cdot 3$

7.7 .1 .1 .4

7.7 .1 .1 .5

7.7 .1 .1 .6

7.7 .1 .1 .7

7.7 .1 .1 .8

7.7 .1 .1 .9

\section{Subject}

Shutdown cooling system suction Line Valve Interlocks Safety Injection Tank Isolation Valve Interlocks

DIAS Channel $\mathrm{N}$ and DPS Alarms

Reactor Coolant Pump Cooling Supply Monitoring Safety Injection Tank Pressure Monitoring

Equipment Design Criteria

Shutdown cooling system suction Line Valve Interlocks Safety Injection Tank Isolation Valve Interlocks

Fire Protection Instrumentation and Detection system

CONTROL SYSTEMS NOT REQUIRED FOR

\section{SAFETY}

DESCRIPTION

Control systems

Reactivity Control systems

Pressurizer Pressure and Level

Control Systems

Pressurizer Pressure Control System Pressurizer Level Control System

Megawatt Demand Setter Feedwater Control System Steam Bypass Control system Reactor Power Cutback System Boron Control system In-Core Instrumentation system Ex-Core Neutron Flux Monitoring System
Page No.

$7.6-5$

$7 \cdot 6-6$

$7 \cdot 6-6$

$7.6-6$

$7.6-7$

$7 \cdot 6-7$

$7.6-7$

7. $6-10$

$7 \cdot 6-13$

7. 7-1

$7 \cdot 7-1$

$7 \cdot 7-1$

$7 \cdot 7-1$

$7.7-4$

$7 \cdot 7-4$

$7 \cdot 7-5$

$7.7-5$

$7 \cdot 7-8$

$7.7-9$

7. $7-10$

$7 \cdot 7-12$

7. $7-13$

$7 \cdot 7-13$

$$
\text { xiv } \begin{aligned}
& \text { Amendment D } \\
& \text { September } 30,1988
\end{aligned}
$$




\section{TABLE OF CONTENTS (Cont'd)}

\section{CHAPTER 7}

Section

$7 \cdot 7 \cdot 1 \cdot 1 \cdot 10$

7.7 .1 .1 .11

7.7 .1 .1 .12

7.7 .1 .1 .13

$7 \cdot 7 \cdot 1 \cdot 2$

$7 \cdot 7 \cdot 1 \cdot 2 \cdot 1$

7.7 .1 .2 .2

$7.7 .1 .2 \cdot 3$

$7 \cdot 7 \cdot 1 \cdot 2 \cdot 4$

$7 \cdot 7 \cdot 1 \cdot 2 \cdot 5$

$7 \cdot 7 \cdot 1 \cdot 2 \cdot 6$

$7 \cdot 7 \cdot 1 \cdot 2 \cdot 7$

$7 \cdot 7 \cdot 1.2 .8$

7.7 .1 .2 .9

$7 \cdot 7 \cdot 1 \cdot 2 \cdot 10$

$7 \cdot 7 \cdot 1 \cdot 2 \cdot 11$

7.7 .1 .2 .12

$7 \cdot 7.1 .1 .13$

$7 \cdot 7 \cdot 1 \cdot 1 \cdot 14$

$7 \cdot 7 \cdot 1 \cdot 3$

$7 \cdot 7 \cdot 1 \cdot 3 \cdot 1$

$7.7 \cdot 1 \cdot 3 \cdot 2$

7.7 .1 .4

$7 \cdot 7 \cdot 1 \cdot 4 \cdot 1$

$7.7 \cdot 1 \cdot 4 \cdot 2$

$7 \cdot 7 \cdot 1 \cdot 4 \cdot 3$

$7.7 .1 \cdot 4 \cdot 4$

$7.7 \cdot 1.4 .5$

$7.7 \cdot 1 \cdot 5$
Subject

Boron Dilution Alarm System Alternate Protection system Process Component Control System Control and Monitoring Systems Sensed Parameters

Design Comparison

Reactivity Control Systems Pressurizer Pressure and Level Control Systems

Megawatt Demand setter

Feedwater Control system

Steam Bypass Control System

Reactor Power Cutback System

Boron Control System

In-Core Instrumentation system

Ex-Core Neutron Flux Monitoring System

Boron Dilution Alarm System

Alternate Protection system

Process Component Control system

Control and Monitoring Systems

Sensed Parameters

Severe Accident Systems

Advanced Control Complex

$7 \cdot 7-23$

Main Control Room and Panels Technical Support Center and Emergency operations Facility Interfaces

Discrete Indication and Alarm system (DIAS)

DIAS System Architecture

Discrete Indicators

Alarm Tiles and Message Windows

DIAS Environmental Qualification

DIAS Quality Classification

$7.7-24$

$7.7-26$

$7 \cdot 7-21$

$7.7-21$

$7 \cdot 7-21$

$7 \cdot 7-21$

$7 \cdot 7-21$

$7 \cdot 7-21$

$7.7-22$

$7.7-22$

$7.7-22$

$7.7-22$

Integrated Process status Overview (IPSO) 


\section{TABLE OF CONTENTS (Cont'd)}

\section{CHAPTER 7}

\section{Section}

$7 \cdot 7 \cdot 1 \cdot 5 \cdot 1$

7.7 .1 .5 .2

$7 \cdot 7 \cdot 1 \cdot 5 \cdot 3$

7.7 .1 .6

$7 \cdot 7 \cdot 1 \cdot 6 \cdot 1$

$7 \cdot 7 \cdot 1 \cdot 6 \cdot 2$

$7 \cdot 7 \cdot 1 \cdot 6 \cdot 3$

7.7 .1 .7

$7 \cdot 7 \cdot 1 \cdot 7 \cdot 1$

7.7 .1 .7 .2

7.7 .1 .7 .3

7.7 .1 .7 .4

7.7 .1 .8

$7.7 .1 .8 \cdot 1$

$7.7 \cdot 1.8 \cdot 1.1$

$7.7 .1 .8 \cdot 1.2$

$7.7 .1 .8 \cdot 1.3$

$7 \cdot 7 \cdot 1 \cdot 8 \cdot 1 \cdot 3 \cdot 1$

$7.7 .1 .8 \cdot 1.3 .2$

$7 \cdot 7 \cdot 1.8 \cdot 1 \cdot 3 \cdot 3$

$7 \cdot 7 \cdot 1 \cdot 8 \cdot 1 \cdot 3 \cdot 4$

$7 \cdot 7 \cdot 1 \cdot 8 \cdot 1 \cdot 3 \cdot 5$
Subject

IPSO Configuration
IPSO Big Board Panel
DPS IPSO Display

NSSS Integrity Monitoring system

Internals Vibration Monitoring System (IVMS)

Acoustic Leak Monitoring system (ALMS)

Loose Parts Monitoring system (LPMS)

Data Processing system (DPS)

DPS Functions

DPS Configuration

DPS Environmental Qualification

DPS Verification and Validation Requirements

DPS NSSS Applications Programs

Core operating Limit Supervisory system (COLSS)

General

System Description Description of COLSS Algorithms

Reactor Coolant Volumetric Flow Rate Core power Calculation CoLsS Determination of Power Distribution Core Power operating Limit Based on Peak Linear Heat Rate Core Power operating Limit Based on Margin to DNB
Page No.

$7 \cdot 7-33$

$7.7-33$

$7 \cdot 7-34$

$7 \cdot 7-34$

$7 \cdot 7-34$

$7 \cdot 7-35$

$7 \cdot 7-37$

$7 \cdot 7-37$

$7 \cdot 7-38$

$7 \cdot 7-40$

$7 \cdot 7-42$

$7 \cdot 7-42$

$7 \cdot 7-42$

$7 \cdot 7-42$

$7 \cdot 7-42$

$7 \cdot 7-44$

$7 \cdot 7-46$

$7.7-46$

$7 \cdot 7-46$

$7 \cdot 7-47$

$7 \cdot 7-49$

$7.7-49$ 


\section{TABLE OF CONTENTS (Cont'd)}

CHAPTER 7

Section

$7 \cdot 7 \cdot 1 \cdot 8 \cdot 1 \cdot 4$

$7.7 \cdot 1 \cdot 8 \cdot 2$

$7 \cdot 7 \cdot 1.8 \cdot 3$

7.7 .1 .9

7.7 .1 .10

7.7 .2
Subject

Calculation and Measurement Uncertainties

NSSS Monitoring Programs

NSSS Interactive Programs

Balance of Plant Application Programs

DPS Critical Functions Monitoring Program

ANALYSIS
Page No.

$7 \cdot 7-49$

$7 \cdot 7-50$

$7 \cdot 7-54$

$7 \cdot 7-54$

$7 \cdot 7-55$

$7 \cdot 7-56$ 


\section{LIST OF TABLES}

\section{CHAPTER 7}

\section{Table}

7. 1-1

$7 \cdot 2-1$

$7 \cdot 2-2$

$7 \cdot 2-3$

$7 \cdot 2-4$

$7 \cdot 2-5$

$7 \cdot 3-1$

$7 \cdot 3-2$

$7 \cdot 3-3$

$7 \cdot 3-4$

$7 \cdot 3-5$

$7 \cdot 3-6$

7. 4-1

$7 \cdot 4-2$

$7 \cdot 5-1$

$7 \cdot 5-2$

$7 \cdot 5-3$
Subject

Auxiliary and Supporting system Descriptions

Reactor Protective System Bypasses

Reactor Protective System Monitored Plant Variable Ranges

Reactor Protective System Sensors

Reactor Protective System Design Inputs

Plant Protection System Failure Modes and Effects Analysis

ESFAS Bypasses

Design Basis Events Requiring ESF System Action

Monitored Variables Required for ESFAS protective Signals

Engineered Safety Features Actuation System Sensors

Engineered Safety Features Actuation System Setpoints and Margins to Actuation

Engineered Safety Features Actuation system Plant Variable Ranges

Remote Shutdown Panel Instrumentation and Controls for Hot Standby

Remote Shutdown controlled Functions for cold Shutdown

Safety-Related Instrumentation

Plant Process Display

Engineered Safety Feature system Monitoring

Post-Accident Monitoring Instrumentation 


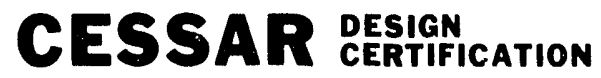

\section{LIST OF TABLES (Cont'd) \\ CHAPTER 7}

\section{Table}

7. 6-1

7. 7-1

$7 \cdot 7-2$

$7 \cdot 7-3$

$7 \cdot 7-4$

$7 \cdot 7-5$

$7 \cdot 7-6$

$7 \cdot 7-7$

\section{Subject}

Shutdown cooling system and safety Injection Tank Interlocks

Alternate Protection System Sensed Parameters

DIAS segments

Sensor Locatjons for Acoustic Leak Monitoring System

Location of Loose Parts Monitoring System Accelerometers

DPS Nuclear steam Supply system Application Programs

CoLss Monitored Plant Variables

Balance of Plant Application Programs

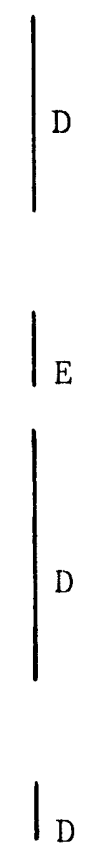




\section{LIST OF FIGURES}

CHAPTER 7

\section{Figure}

7. 2-1

$7 \cdot 2-2$

$7 \cdot 2-3$

$7 \cdot 2-4$

$7 \cdot 2-5$

$7.2-6$

$7 \cdot 2-7$

$7 \cdot 2-8$

$7 \cdot 2-9$

$7 \cdot 2-10$

$7 \cdot 2-11$

$7.2-12$

$7 \cdot 2-13$

$7 \cdot 2-14$

$7 \cdot 2-15$

$7 \cdot 2-16$

$7.2-17$

\section{Subject}

PPS Basic Block Diagram

PPS Functional Interface and Testing Diagram

Typical PPS Low Reactor coolant Flow Trip Setpoint operation

Typical PPS Measurement Channel Functional

Diagram (Pressurizex Pressure Wide Range)

Reed Switch Position Transmitter Assembly Schematic

Reed Switch Position Transmitter Cable Assemblies Core Protection Calculator

Ex-Core Neutron Flux Monitoring System

Reactor Coolant Pump speed Sensors Typical

for Each Reactor Coolant Pump

Trip Logic Calculator Functional Block Diagram PPS Bistable Trip Logic Functional Block Diagram PPS Reactor Trip System Simplified Functional Logic Diagram

Typical PPS Channel Funciional Bistable Trip Channel Bypass

Typical PPS Channel Functional RPS Initiation Logic

Typical PPS Variable setpoint operation (Manual Reset)

PPS Testing Overlap

PPS Manual Bistable Trip Test Functional Block Diagram 


\section{LIST OF FIGURES (Cont'd)}

CHAPTER 7

Figure

7. $2-18$

$7 \cdot 2-19$

$7 \cdot 2-20 a$

$7 \cdot 2-20 b$

$7.2-20 \mathrm{C}$

$7 \cdot 2-21 a$

$7 \cdot 2-21 b$

$7 \cdot 2-22 a$

$7.2-22 b$

$7 \cdot 2-23 a$

$7 \cdot 2-23 b$

$7 \cdot 2-24$

$7 \cdot 2-25$

$7 \cdot 2-26$

$7 \cdot 2-27 a$

$7.2-27 b$

$7.2-28 a$

$7.2-28 b$

$7 \cdot 2-29 a$

$7.2-29 b$

$7 \cdot 2-30$
Subject

Typical PPS Channel Contact Bistable Interface Diagram

Plant Protection System Interface Logic Diagram MCBD Symbols, Notes and Abbreviations MCBD Symbols, Notes and Abbreviations MCBD Symbols, Notes and Abbreviations RCS Loop 1 Temperatures (Narrow) MCBD RCS Loop 2 Temperatures (Narrow) MCBD RCS Loop 1 Temperatures (Wide) MCBD RCS Loop 2 Temperatures (Wide) MCBD Reactor Coolant Pump Pressure MCBD Reactor Coolant Pump speed MCBD

Pressurizer Pressure MCBD

Nuclear Instrumentation MCBD

Containment Pressure MCBD

Steam Generator-1 Level (Wide) MCBD

Steam Generator-2 Level (Wide) MCBD

Steam Generator-1 Pressure MCBD

Steam Generator-2 Pressure MCBD

Steam Generator-1 Level (Narrow) MCBD

Steam Generator-2 Level (Narrow) MCBD

Steam Generator Primary D/P MCBD 


\section{LIST OF FIGURES (Cont'd) \\ CHAPTER 7}

Figure

$7 \cdot 3-1 a$

$7 \cdot 3-1 b$

$7 \cdot 3-1 \mathrm{c}$

$7 \cdot 3-1 d$

$7 \cdot 3-2$

$7 \cdot 3-3$

$7 \cdot 3-4$

$7 \cdot 3-5$

$7 \cdot 3-6$

$7 \cdot 3-7$

$7 \cdot 3-8 a$

$7 \cdot 3-8 b$

$7 \cdot 3-9 a$

$7 \cdot 3-9 b$

$7 \cdot 3-10 a$

$7 \cdot 3-10 b$

$7 \cdot 3-11$

\section{Subject}

ESFAS Functional Logic (SIAS)

ESFAS Functional Logic (CSAS, CIAS)

ESFAS Functional Logic (MSIS)

ESFAS Functional Logic (EFAS 1, EFAS 2)

ESF-CCS Simplified Logic Diagram for Typical Selective 2 out of 4 Actuation

Functional Diagram of Engineered Safety FeaturesComponent control system (ESF-CCS)

Typical Electrical Interface for Panel-Mounted Switches and status Indicators

Diesel Load Sequencer-Simplified Logic Diagram

Diesel Load Sequencer-Simplified Test Logic Diagram

ESF-CCS Test Logic-Simplified Logic Diagram

Typical FCLD for a Solenoid-operated Valve

Typical Electrical Interface for a Solenoidoperated Valve

Typical FCLD for a Modulating Valve with Solenoid-operator

Typical Electrical Interface for a Modulating Valve with Solenoid operator

Typical Mov Functional Interface Design

Typical Electrical Interface for a MotorOperated Valve

Typical FCLD for a Full Throw Motor-operated Valve 


\section{LIST OF FIGURES (Cont'd) CHAPTER 7}

\section{Figure}

7. 3-12

$7 \cdot 3-13 a$

$7 \cdot 3-13 b$

$7 \cdot 3-14 a$

$7.3-14 b$

$7 \cdot 3-15 a$

$7 \cdot 3-15 b$

$7.3-16$

$7 \cdot 3-17$

$7 \cdot 3-18$

$7.3-19$

7. 3-20a

$7.3-20 b$

$7.3-20 \mathrm{C}$

$7.3-20 d$

$7.3-21$

$7.3-22$

$7.3-23$

\section{Subject}

Typical FCLD for a Throttling Motor-operated Valve

Typical FCLD for a Contactor-operated Component

Typical Electrical Interface for a contactoroperated Component

Typical FCLD for a circuit Breaker-operated Component

Typical Electrical Interface for a circuit Breaker-Operated Component

Typical FCLD for a Modulating Component

Typical Electrical Interface for a Modulating Component

Typical ESF Initiation to Actuation Logic Functional Diagram

Simplified Schematics for Thermal Overload Monitoring

In-containment Refueling water storage Tank MCBD

Emergency Feedwater MCBD

Safety Injection Tank 1 MCBD

Safety Injection Tank 2 MCBD

Safety Injection Tank 3 MCBD

Safety Injection Tank 4 MCBD

Containment spray MCBD

Shutdown cooling MCBD

Safety Injection MCBD 


\section{LIST OF FIGURES (Cont'd) CHAPTER 7}

\section{Figure}

$7 \cdot 3-24$

7. 5-1

$7 \cdot 5-2$

$7.5-3$

$7.5-4$

$7 \cdot 5-5$

$7.5-6$

$7 \cdot 5-7$

$7 \cdot 5-8$

$7 \cdot 6-1 a$

$7 \cdot 6-1 b$

$7.6 .1 \mathrm{C}$

$7 \cdot 6-2$

$7 \cdot 6-3$

7. 7-1

7. 7-2

$7 \cdot 7-3$

$7 \cdot 7-4$

\section{Subject}

Safety Depressurization MCBD

Post-Accident Monitoring

HJTC Sensor-HJTC/Splash Shield

Heated Junction Thermocouple Probe Assembly

HJTC Sensor and Separator Tube

In-core Instrumentation Locations

Electrical Diagram of HJTC

HJTC System Processing Configuration (One Channel Shown)

Pressurizer Level MCBD

Functional Control Logic, Shutdown cooling system

Functional Control Logic, Shutdown cooling system

Functional control Logic, Shutdown cooling system

Functional Control Logic, safety Injection system Safety-Related Interlock Test Method

Reactor Regulating System Block Diagram

PCS (CEDMCS) - RPS Interface Block Diagram

Pressurizer Pressure Control System Block Diagram Pressurizer Level Control System Block Diagram 


\section{LIST OF FIGURES (Cont'd) \\ CHAPTER 7}

Figure

7. 7-5

$7 \cdot 7-6$

7. 7-7

$7 \cdot 7-8$

7. 7-9

7. 7-10

7. 7-11

$7 \cdot 7-12$

$7 \cdot 7-13$

$7 \cdot 7-14$

$7 \cdot 7-15$

$7 \cdot 7-16$

$7.7-17$

$7 \cdot 7-18$

$7 \cdot 7-19$

$7 \cdot 7-20$

$7 \cdot 7-21$

$7 \cdot 7-22$

$7 \cdot 7-23$

\section{Subject}

Megawatt Demand Setter Block Diagram

Simplified MDS Block Diagram, Automatic Dispatch Mode

Feedwater Control System Block Diagram

Steam Bypass Control system Block Diagram

Reactor Power Cutback system Simplified Block Diagram

Boronometer Block Diagram

Boron Dilution Alarm System Simplified Block Diagram

Alternate Protection System Block Diagram

Process-Component Control system Simplified Block Diagram

Nuplex $80+$ Control Room

ACC Information Processing Block Diagram

DIAS-P Segment Architecture

DIAS-N Segment Block Diagram

Discrete Indicator (Pressurizer Pressure and Level)

IPSO/DIAS/DPS Data Communications

Block Diagram of the Data Processing System

overview of Hierarchical Display structure

Data Processing System Configuration

Functional Diagram of the Core operating Limit supervisory system 


\section{LIST OF FIGURES (Cont'd) CHAPTER 7}

\section{$\underline{\text { Figure }}$}

$7 \cdot 7-24$

$7 \cdot 7-25 a$

$7.7-25 b$

$7 \cdot 7-26 a$

$7.7-26 b$

$7 \cdot 7-27$

$7 \cdot 7-28$

$7.7-29$

\section{Subject}

Alternate Protection system (ARTS) MCBD

Alternate Protection system (AFAS-1) MCBD

Alternate Protection system (AFAS-2) MCBD

Acoustic Leak Monitoring system (ALMS) MCBD

Loose Parts Monitoring system (LPMS) MCBD

IRWST/Reactor Cavity Flooding system MCBD

Holdup Volume/Reactor Vessel Cavity flooding System MCBD

Reactor Vessel Cavity flooding system MCBD 


\section{LIST OF ABBREVIATIONS}

\section{CHAPTER 7}

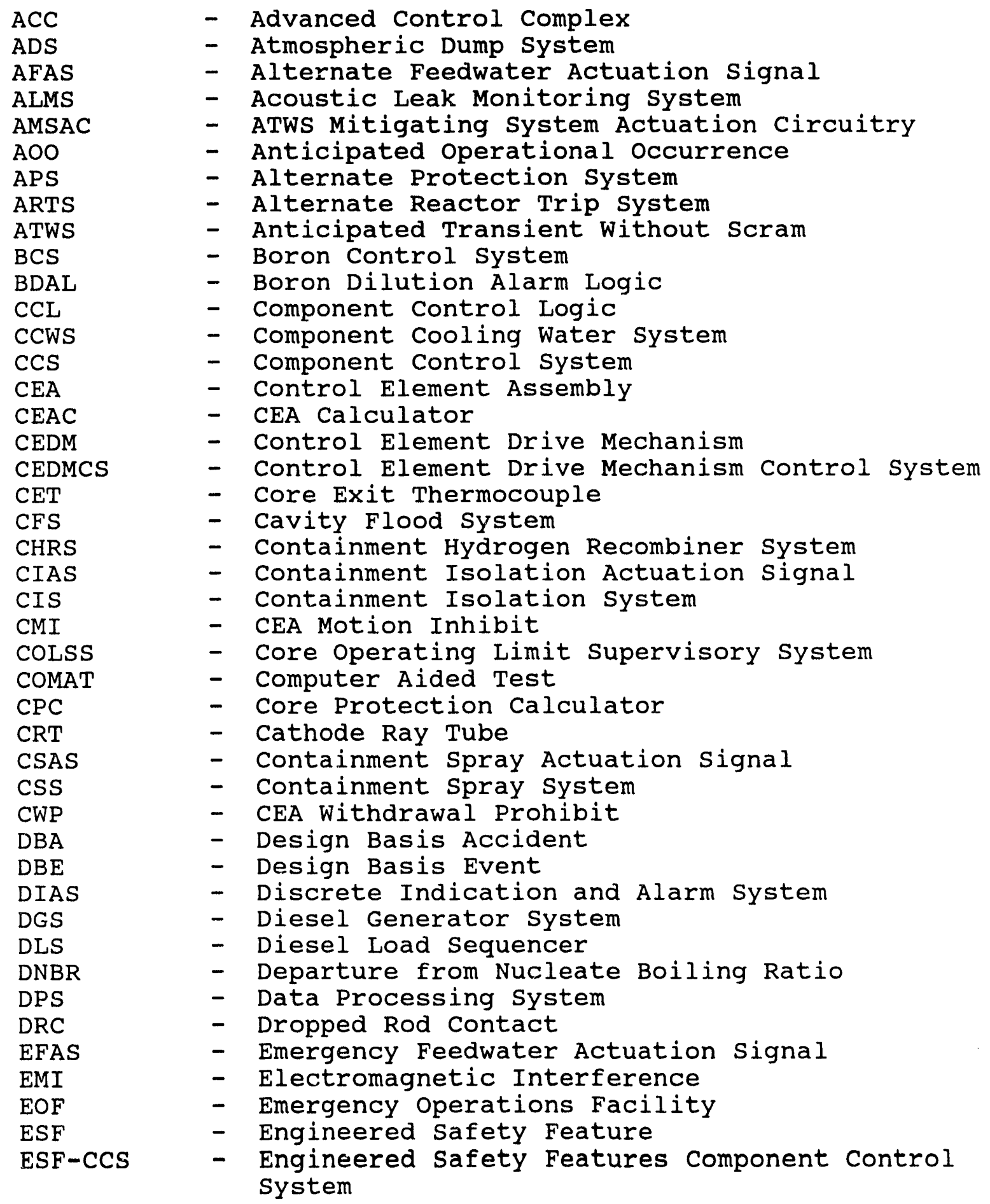




\section{LIST OF ABBREVIATIONS (Cont'd)}

\section{CHAPTER 7}

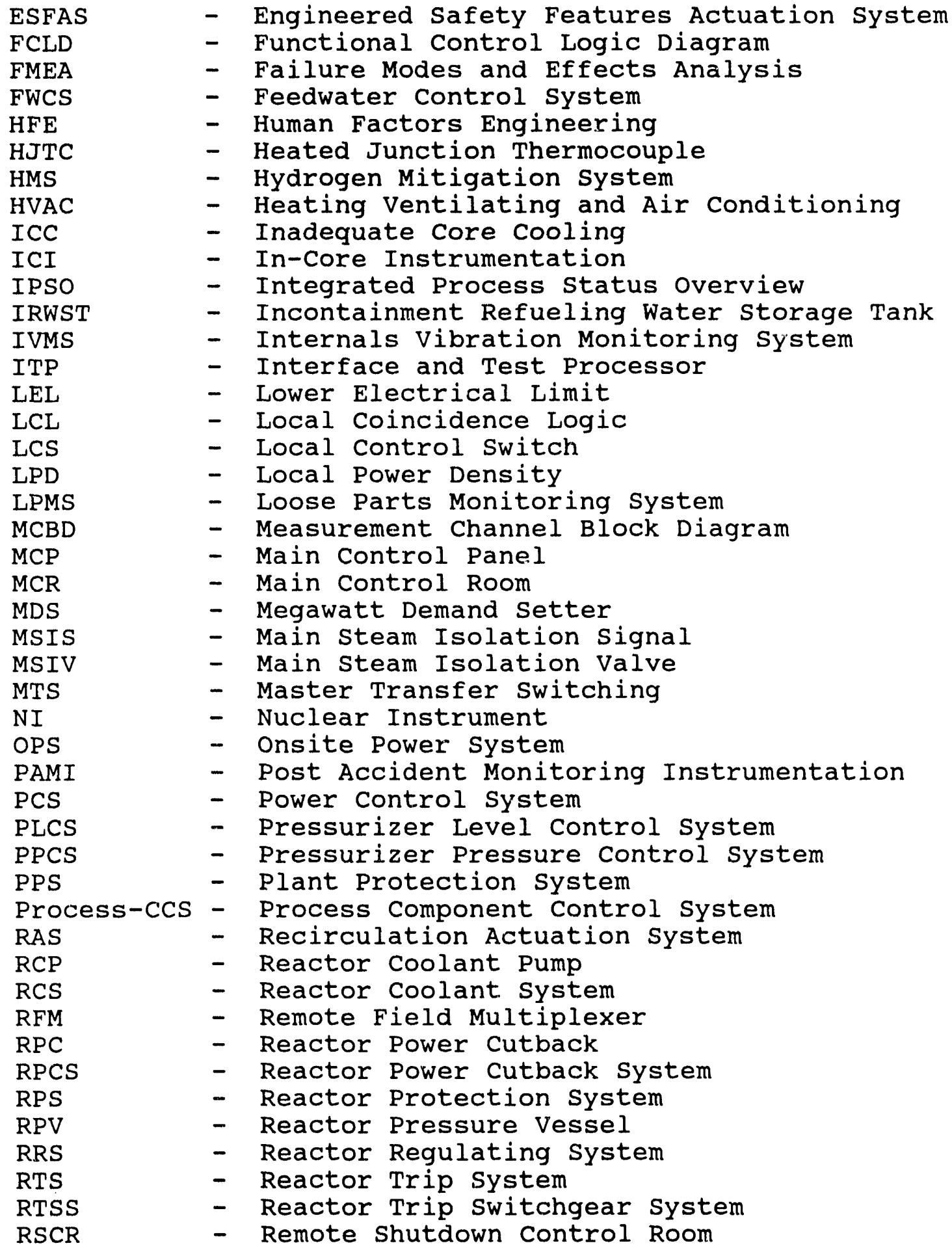

ESFAS

FCLD

FMEA

FWCS

HFE

HJTC

HMS

HVAC

ICC

ICI

IPSO

IRWST

IVMS

ITP

LEL

LCL

LCS

LPD

LPMS

MCBD

MCP

MCR

MDS

MSIS

MSIV

MTS

NI

OPS

PAMI

PCS

PLCS

PPCS

PPS

Process-CCS

RAS

RCP

RCS

RFM

RPC

RPCS

RPS

RPV

RRS

RTS

RTSS

RSCR

- Engineered Safety Features Actuation System

- Functional Control Logic Diagram

- Failure Modes and Effects Analysis

- Feedwater Control system

- Human Factors Engineering

- Heated Junction Thermocouple

- Hydrogen Mitigation system

- Heating Ventilating and Air Conditioning

- Inadequate core cooling

- In-Core Instrumentation

- Integrated Process status overview

- Incontainment Refueling Water storage Tank

- Internals Vibration Monitoring System

- Interface and Test Processor

- Lower Electrical Limit

- Local Coincidence Logic

- Local control Switch

- Local Power Density

- Loose Parts Monitoring system

- Measurement Channel Block Diagram

- Main Control Panel

- Main Control Room

- Megawatt Demand Setter

- Main steam Isolation Signal

- Main Steam Isolation Valve

- Master Transfer Switching

- Nuclear Instrument

- Onsite Power system

- Post Accident Monitoring Instrumentation

- Power Control system

- Pressurizer Level Control system

- Pressurizer Pressure Control system

- Plant Protection system

- Process Component Control system

- Recirculation Actuation System

- Reactor Coolant Pump

- Reactor Coolant System

- Remote Field Multiplexer

- Reactor Power Cutback

- Reactor Power Cutback System

- Reactor protection system

- Reactor Pressure Vessel

- Reactor Regulating system

- Reactor Trip system

- Reactor Trip Switchgear system

- Remote Shutdown Control Room 


\section{LIST OF ABBREVIATIONS (Cont'd)}

\section{CHAPTER 7}

$\begin{array}{ll}\text { RSP } & \text { - Remote Shutdown Panel } \\ \text { RTSG } & \text { - Reactor Trip Switchgear } \\ \text { SBCS } & \text { - Steam Bypass Control System } \\ \text { SCL } & \text { - Subgroup Control Logic } \\ \text { SCS } & \text { - Shutdown Cooling System } \\ \text { SDS } & \text { - Selective Group Test Logic } \\ \text { SGT } & \text { - Safety Injection Actuation Signal } \\ \text { SIAS } & \text { - Safety Injection System } \\ \text { SIS } & \text { - Safety Injection Tank } \\ \text { SIT } & \text { - Saturation Margin Monitoring } \\ \text { SMM } & - \text { Safety Parameter Display System } \\ \text { SPDS } & - \text { Supplementary Protection System } \\ \text { SPS } & - \text { Station Service Water System } \\ \text { SSWS } & - \text { Turbine Control System } \\ \text { TCS } & - \text { Technical Support Center } \\ \text { TSC } & - \text { Upper Electrical Limit } \\ \text { UEL } & \end{array}$




\subsection{INSTRUMENTATION AND CONTROLS}

\subsection{INTRODUCTION}

The System $80^{\mathrm{m}}$ Standard Design includes the Nuplex $80+^{\mathrm{m}}$ Advanced Control Complex $(A C C)$. The design integrates the instrumentation and controls for an essentially complete plant into the ACC design.

The ACC design consists of the following major interdependent systems: Main Control Panels (MCP), Remote Shutdown Panel (RSP), Discrete Indication and Alarm System (DIAS), Data Processing System (DPS), ESF and Process Component Control systems (CCS), Plant protection system (PPS) and Power Control system (PCS) which includes the Megawatt Demand Setter (MDS).

The Nuplex $80+$ design takes advantage of modern digital processing equipment to implement the safety, control and information display systems. These systems are implemented in accordance with the Human Factors Engineering design criteria and process as described in Chapter 18.

\subsubsection{IDENTIFICATION OF SAFETY-REILATED SYSTEMS}

The safety-related instrumentation and controls, including supporting systems, are identified below.

\subsubsection{Plant Protection System (PPS)}

The PPS includes the electrical and mechanical devices and circuitry required to perform the protective functions defined below.

\section{A. Reactor Protective System (RPS)}

The RPS is the portion of the PPS that acts to trip the reactor when required. The RPS is described in section 7.2.

B. Engineered Safety Features Actuation System (ESFAS)

The ESFAS is the portion of the PPS which activates the Engineered Safety Feature systems listed in section 7.1.1.3 and described in section 7.3.

\subsection{Alternate Protection System (APS)}

The Alternate protection system (APS) augments reactor protection and emergency feedwater actuation by utilizing non-1E trip logic which is separate and diverse from the Plant protection system. Refer to section 7.7.1.1.11 for a description of these ATWS prevention and mitigation systems. 
7.1.1.2

Reactor Trip System (RTS)

The RTS includes the RPS portion of the PPS, Reactor Trip Switchgear system (RTSS) and the arrangement of components that perform a reactor trip after receiving a signal from the RPS either automatically or manually by the operator. The RTS initiates a reactor trip based on the signals from the sensors which monitor various NSSS parameters and the containment pressure.

\subsubsection{Engineered Safety Feature Systems (ESF Systems)}

The ESF Systems include the ESF Actuation system (ESFAS) and the arrangement of components that perform protective actions after receiving a signal from the ESFAS or the operator.

The ESF Systems are:

A. Containment Isolation system

B. Main steam Isolation system

C. Safety Injection system

D. Emergency Feedwater system

E. Containment spray system

F. Safety Depressurization system

G. Supporting systems

The instrumentation and controls for ESF systems are described in Section 7.3 .

\subsubsection{Systems Reguired for Safe Shutdown}

Systems required for safe shutdown are defined as those essential for pressure and reactivity control, coolant inventory makeup, and removal of residual heat once the reactor has been brought to a subcritical condition. These systems are categorized according to the following shutdown modes:

A. Hot shutdown

Systems required for maintenance of the primary system at, or near, operating temperature and pressure. 
B. Cold Shutdown

Systems required to cool down and maintain the primary system at, or near, ambient conditions.

C. Safe shutdown

The systems required for safe shutdown are listed below and described in section 7.4.

The safe shutdown systems required to place the reactor in hot shutdown include:
A. Emergency Diesel Generator
B. Emergency Diesel Generator Fuel storage and Transfer System
C. Emergency Power storage system
D. Emergency on-site Power Distribution System
E. Safety Injection system
F. Emergency Feedwater system
G. Atmospheric Steam Dump system
H. Safety Depressurization system
I. Station Service Water system
J. Component cooling water system
K. Heating, Ventilating and Air Conditioning systems

In addition, Remote shutdown Panel (RSP) equipment and systems are provided to allow emergency shutdown from outside the control room.

The safe shutdown systems or portions of systems required to place the reactor in cold shutdown include those in $A$. through $K$. above, plus the following:

L. Shutdown cooling system 


\subsubsection{Safety-Related Display Instrumentation}

The safety-related display instrumentation provides information to the operator to allow him to adequately monitor plant operating conditions and to perform any required manual safety functions. Safety-related display instrumentation is described in Section 7.5 .

Safety-related displays are provided for:

A. Safety-Related Plant Process

Display Instrumentation

B. Reactor Trip system Monitoring

C. Engineered Safety Features Actuation System Monitoring

D. CEA Position Indication

E. Post-Accident Monitoring Indication

F. ESF Systems Performance and Availability Indication

G. Critical Functions Monitoring Indication

\subsubsection{All other Systems Required for Safety}

other systems required for safety include the interlocks required to prevent overpressurization of the shutdown cooling system and to ensure safety injection availability. These are provided as listed below and described in section 7.6 .

A. Shutdown cooling system suction Line Isolation Valve Interlocks

B. Safety Injection Tank Isolation Valve Interlocks

\subsubsection{Design Comparison}

The RPS will be functionally identical to the system provided for the Palo Verde Nuclear Generating station (PVNGS, NRC Docket No. 50-528) with the following exception:

The Supplementary Protection System (SPS) is replaced by the Alternate Protection system (APS), as described in section 7.7.1.1.11. The APS is specifically designed to increase the reliability of reactor trip initiation and address ATWS 
Mitigating systems Actuation Circuitry (AMSAC) requirements by incorporating an alternate emergency feedwater actuation signal.

The logic of each ESF initiation system, including testing features, is similar to the logic for the RPS and is contained in the same physical enclosures. The actuation logic and devices are contained in the ESF component control system (CCS). The design of this system is described in section 7.3. The following ESFAS changes from the PVNGS design have been made:

A. Recirculation Actuation Signal (RAS) has been deleted due to the addition of the In-Containment Refueling water storage Tank.

B. EFAS initiation logic is simplified by deleting the D requirement for automatic identification and isolation of a ruptured steam generator.

\subsubsection{System Drawings}

I \& C system Measurement Channel Block Diagrams (MCBDs) appear at the end of each section of Chapter 7 .

All other I \& C drawings for the auxiliary support systems are located within the applicable system section of CESSAR-DC.

\subsubsection{System Diversity}

The design of Nuplex $80+$ systems maintains diversity in key areas to provide a defense-in-depth approach against the effects of common mode failures.

Nuplex $80+$ employs diversity in the system designs as follows:

\begin{tabular}{ll}
\multicolumn{1}{c}{ Function } & \multicolumn{1}{c}{$\begin{array}{c}\text { System } \\
\text { Design Type 1 }\end{array}$} \\
Reactor Trip & $\begin{array}{l}\text { Plant Protection } \\
\text { System }\end{array}$ \\
Fluid System & $\begin{array}{l}\text { Emergency Success } \\
\text { Paths (e.g. } \\
\text { Emergency Feed- } \\
\text { water) via ESF-CCS }\end{array}$ \\
Reactivity & Emergency Boration \\
Controls & via ESF-CCS
\end{tabular}

System Design Type 2

Alternate Reactor Trip Within Process-cCS

Normal Success Paths (e.g., Main Feedwater) via Process-CCS

Normal CEA Control via Power Control System 
Function

Alarm and Indication
System

Design Type 1

Alarm Tiles and

Discrete Indicators via DIAS

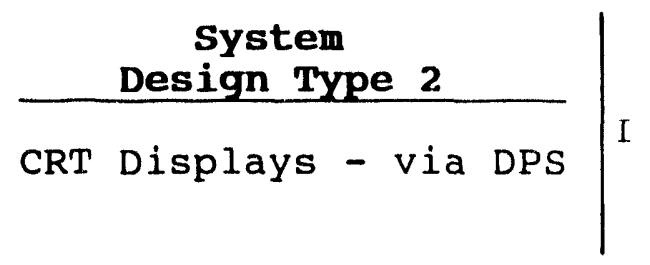

\section{1 .2}

\section{IDENTIFICATION OF SAFETY CRITERIA}

Comparison of the design with applicable Regulatory Guide recommendations and the degree of compliance with the appropriate design bases, General Design criteria, standards, and other documents used in the design of the systems listed in section 7.1 .1 are described in sections 7.1.2.2 through 7.1.2.34, and in each of the sections describing the system. (Refer to sections 7.2 through 7.6. )

\subsubsection{Design Bases}

The design bases for the safety-related instrumentation and control of each safety-related system are presented in the section of this chapter that discusses the system to which the information applies.

Consideration has been given to instrument error in the selection of all safety system setpoints. Where setpoints are listed in Chapter 7, it is understood that these are nominal values. The actual setpoint may vary within prescribed accuracies which have been considered in selection of the values.

\subsection{Systems Required for Plant Protection}

The instrumentation and controls for the Reactor Trip system and Engineered Safety Feature systems conform to the following:

A. The systems conform to IEEE Standards 279-1971 and 603-1980. Detailed discussion of conformance for these and other safety-related system instrumentation and controls is provided in the applicable section of this chapter. Conformance to these and other IEEE standards is discussed in sections 7.1.2.2 through 7.1.2.13.

B. Comparison with Regulatory Guide recommendations for Water-Cooled Nuclear Power Plants, Division of Reactor Standards, Nuclear Regulatory Commission, is discussed in Sections 7.1 .2 .5 through 7.1 .2 .10 , and 7.1 .2 .13 through 7.1 .2 .34 . 
C. The quality assurance program is described in Chapter 17 .

D. General Design Criteria for Nuclear Power Plants, Appendix A
to 10 CFR 50 as described in Section 3.1. 7.1.2.1.2 Systems Required for Safe Shutdown

The design bases for the systems required for safe shutdown are described in section 7.4.

7.1.2.1.3 Safety-Related Display Instrumentation

The design bases for safety-related display instrumentation are described in section 7.5 .

\section{$7 \cdot 1 \cdot 2 \cdot 1 \cdot 4$ \\ Al1 Other Systems Required for Safety}

The design bases for all other systems required for safety are described in section 7.6.

Auxiliary and support systems necessary to the proper functioning of safety systems are identified in the CESSAR section for the safety system requiring the support system. Descriptions of these systems are included in the appropriate cESSAR section as identified in Table 7.1-1.

\subsubsection{Conformance to IEEE 279-1971}

Extent of conformance to IEEE standard 279-1971 is discussed in Sections $7.2,7.3$ and 7.6 .

\subsubsection{Conformance to IEEE 308-1980}

Descriptions of electrical components, equipment and systems which are vital to safe operation are described in chapter 8 . Conformance to IEEE 308-1980, "IEEE Standard Criteria for Class $1 \mathrm{E}$ Power systems for Nuclear Power Generating Stations," as criteria in the design of these systems is also discussed in Chapter 8 .

\subsubsection{Conformance to IEEE 317-1983}

Electrical penetrations and their conformance to IEEE 317-1983, "Electrical Penetration Assemblies in Containment structures for Nuclear Power Generating Stations," is discussed in Chapter 8 . 
7.1 .2 .5

Conformance to IREE 323-1983, as Augmented by Regulatory Guide 1.89

Compliance with IEEE 323-1983, "IEEE standard for Qualifying Class 1E Equipment for Nuclear Power Generating stations," for instrumentation is discussed in Combustion Engineering Topical Report CENPD-255-A, "Qualification of Combustion Engineering Class 1E Instrumentation" (Reference 2). The basic qualification requirements are discussed in section 3.11 .

7.1 .2 .6

Conformance to IEEE $336-1985$, as Augmented by Regulatory Guide 1.30

Conformance with IEEE 336-1985, "Installation, Inspection, and Tes ing Requirements for Instrumentation and Electric Equipment Dur.. 19 the Construction of Nuclear Power Generating stations," are iscussed in section 1.8 .

7.1.2.7 Conformance to IEEE 338-1977, as Augmented by Regulatory Guide 1.118

The PPS and ESF-CCS, as well as the RTSS, are designed so that they can be periodically tested in accordance with the criteria of IEEE 338-1977, "Periodic Testing of Nuclear Power Generating station class $1 \mathrm{E}$ Power and Protection systems." Combustion Engineering supplies the response times of instrumentation and control components as a result of factory tests to the site operator. It is the site operator's responsibility to test the integrated response time of each protection system after installation. Testing criteria are specified in sections 7.2.2.3.3 and 7.3.2.3.3. Minimum testing frequency requirements are provided in the Technical specifications (Chapter 16).

Since operation of the ESF systems is not expected, the systems are periodically tested to verify operability. complete channels, in the ESFAS, can be individually tested without initiating protective action and without inhibiting the operation of the system.

The system can be checked from the sensor signal through the actuation devices. The functional modules in the sensor system can be tested during reactor operation. The sensors can be checked by comparison with similar channels. 
Those actuated devices, which are not tested during reactor operation, will be tested during scheduled reactor shutdown to show that they are capable of performing the necessary functions.

\subsubsection{Conformance to IEEE 344-1987, as Augmented by Regulatory Guide 1.100}

Compliance with IEEE 344-1987, "IEEE Recommended Practices for Seismic Qualification of class $1 \mathrm{E}$ Equipment for Nuclear Power Generating stations," is discussed in Combustion Engineering Topical Report CENPD-182, "Seismic Qualification of Instrumentation Equipment," (Reference 3). The basic seismic qualification requirements are discussed in section 3.10 .

The adequacy of the design of Class $1 \mathrm{E}$ Equipment is verified by a combination of testing and/or analysis for the performance of its functions during and after the equipment is subjected to the forces resulting from one SSE preceded by a number of DBES. Also, the similarity between the tested equipment and the installed equipment is proven (e.g., design, orientation, foundation, performance). The seismic tests take into consideration the operability of the equipment during seismic events.

7.1 .2 .9

Conformance to IEEE 379-1977, as Augmented by Regulatory Guide 1.53

Instrumentation for the PPS and ESF CCS, and the RTSS conform to the requirements of IEEE 379-1977, "IEEE Standard Application of the Single Failure Criterion to Nuclear Power Generating station Class 1E Systems," as augmented by Regulatory Guide 1.53, "Application of the single Failure Criterion to Nuclear Power Plant Protection Systems." A discussion of the application of the single failure criterion is provided in sections 7.2.2.3.2 and 7.3 .2 .3 .2 for these systems.

\subsubsection{Conformance to IEEE 384-1981, as Augmented by Regulatory Guide 1.75}

The instrumentation for the safety-related electric systems conforms to the requirements of IEEE 384-1981, "IEEE standard Criteria for Independence of Class $1 \mathrm{E}$ Equipment and Circuits," as augmented by Regulatory Guide 1.75, "Physical Independence of Electric systems." A discussion of the physical independence is provided below which describes the compliance with section 4.6 of IEEE 279-1971 and General Design Criteria 3 and 21.

The PPS is divided into four assemblies which are physically located in different geographic fire zones within the control complex. Each assembly contains one of the four redundant 
channels of the RPS and ESFAS. This provides the separation and independence necessary to meet the requirements of section 4.6 of IEEE 279-1971.

The independence and separation of redundant class $1 \mathrm{E}$ circuits within and between the PPS assemblies or ESF-CCS assemblies is accomplished primarily through the use of fiber-optic technology and, as necessary, by 6-inch separation, barriers or conduits. The optical technology ensures that no single credible electrical fault in a PPS channel can prevent the circuitry in any other redundant channel from performing its safety function.

The ESF Component Control system cabinets provide separation and independence for the selective two-out-of-four actuation and component control logic of the redundant ESF systems trains. Each train's component control logic is contained in a separate cabinet. The redundant cabinets are physically separated from each other by locating them in separate zones. Redundant train remote I/O multiplexers are located to maintain physical separation.

The RTSS consists of a set of four Reactor Trip Switchgears (RTSG). Each RTSG and its associated switches, contacts and relays is contained in a separate cabinet. Each cabinet is physically separate from the other cabinets. This method of construction ensures that a single credible failure in one RTSG cannot cause malfunction or failure in another cabinet.

The separation and independence of the power supplies for each of the above systems is discussed further in Chapter 8.

Protection system analog and digital signals sent to non-Class $1 \mathrm{E}$ systems for status monitoring, alarm and display (e.g., DPS, DIAS, CEDMCS) are isolated from the protection system. Fiber-optic isolation and other techniques are used to ensure no credible failures on the non-1E side of the isolation device will affect the PPS side and that independence of the PPS is not jeopardized.

\subsubsection{Conformance to IEEE 387-1984}

Conformance to IEEE 387-1984, "IEEE Standard Criteria for Diesel-Generator Units Applied as Standby Power Supplies for Nuclear Power Generating stations," as criteria in the design of these systems is discussed in sections 8.3.1, and 9.5.4 through 9.5 .8 . 


\section{1 .2 .12 Conformance to IEEE 450-1980}

Conformance to IEEE 450-1980, "IEEE Recommended Practice for Large Lead storage Batteries for Generating stations and Substations," as criteria in the design of these systems is discussed in chapter 8 .

\subsubsection{Conformance to IEEE 603-1980, as Augmented by Regulatory Guide 1.153}

The safety systems such as PPS, ESF-CCS and RTSS conform to the requirements of IEEE 603-1980, "standard Criteria for Safety Systems for Nuclear Power Generating stations," as augmented by Regulatory Guide 1.153, "Criteria for Power, Instrumentation, and Control portion of Safety systems." For descriptions of conformances, refer to sections $7.1 .2 .2,7.1 .2 .3,7.1 .2 .5$, $7.1 .2 .7,7.1 .2 .9$ and 7.1 .2 .10 .

\subsubsection{Comparison of Design with Regulatory Guide 1.6}

See Chapter 8 .

\subsubsection{Conformance to Regulatory Guide 1.11}

Guidelines for instrumert lines which penetrate primary reactor containment, and which are part of the reactor coolant pressure boundary or are connected directly to the containment atmosphere do not apply, since there are no lines which fall directly into this category. Containment pressure is monitored by four redundant pressure transmitters located outside of containment which monitor containment atmosphere. The lines both inside and outside containment are kept as short as possible. No other instrument lines penetrate reactor containment.

\subsubsection{Conformance to Regulatory Guide 1.17}

The following design features address the requirements of Regulatory Guide 1.17, "Protection of Nuclear Power Plants Against Industrial Sabotage":

A. Separate Geographic Locations for Equipment

1. Redundant channels of safety-related instrumentation and control cabinets are designed to be located in separate plant locations. These equipment locations car. be designed by the site operator to meet NUREG-0908, "Acceptance Criteria for the Evaluation of Nuclear Power Reactor security Plans." 
B. Limited Ability to Change system Hardware and software Configurations

1. Portions of systems are designed to limit the ability of operating and maintenance personnel to change basic system functions (e.g., setpoints can be changed, but the trip function calculation cannot be altered).

2. The transfer of control between the Main control Room and Remote Shutdown Panel is under key lock administrative control with built-in alarms.

3. The PPS design does not permit bypassing either the RPS or ESFAS signals at the system level. Bypasses can be initiated in only one of the four redundant protection channels at a time. Attempts to bypass additional channels will be rejected and be annunciated, as discussed in sections 7.2.1 and 7.3.1.

4. Vital instrumentation cabinet doors are locked and equipped with "door open" alarms.

C. Fail-Safe Design Philosophy

1. Systems are generally designed to fail safely upon de-energization, removal of printed circuit boards and disconnection of cables and data links.

2. Test modes are designed such that they do not prevent system actuation.

D. Safety system status Monitoring

1. Critical safety system setpoints can be determined manualiy and/or are automatically monitored via the Plant Protection system (PPS) Interface and Test Processor (ITP), and the plant Data Processing system.

2. Reactor trip and ESFAS initiation trip channel bypass alarms are provided.

3. Component level bypasses in the ESF systems result in system level inoperable alarms for the affected systems, as described in section 7.1.2.21.

E. Diverse Manual vs Automatic Reactor Trip and ESFAS Initiation

1. Reactor Trip and ESFAS are automatically initiated by the PPS. These same functions can be manually 
initiated by the operator. The RTSS and ESF-CCS manual initiation trips do not rely on any PPS components for actuation. Therefore, these functions can be manually initiated with a complete failure of the PPS automatic initiation logic.

The above features are designed to impede sabotage. See chapter 13 and the site-specific SAR for a more comprehensive discussion on protection against sabotage.

\subsubsection{Conformance to Regulatory Guide 1.22}

The PPS, ESF-CCS, and the RTSS, as described in section 7.1.1, D conform to the guidance of Regulatory Guide 1.22, "Periodic Testing of Protection system Actuation Functions." This conformance is described below.

A. Provisions are made to permit periodic testing of the complete PPS, ESF-CCS, and RTSS with the reactor operating at power or when shutdown. These tests cover the trip action from sensor input to actuated devices. Those ESF actuated devices which could affect operations are not tested while the reactor is operating but, instead, are tested while the reactor is shutdown.

B. The provisions of this position are incorporated in the testing of the PPS, from sensor to actuation device, I
including the ESFAS and ESF-CCS and the RTSS.

C. No provisions are made in the design of the PPS, ESF-CCS, ID and RTSS at the systems level to intentionally bypass an actuation signal that may be required during power operation. All bypasses are on a channel level to prevent an operator from inadvertently bypassing a trip function.

D. The manual testing circuitry for an RPS channel is interlocked to prevent testing in more than one redundant channel simultaneously. When a channel is bypassed for manual testing, the bypass is automatically indicated in the main control room.

E. When an ESFAS is bypassed for manual testing, the bypass is automatically indicated in the main control room.

F. Actuated devices which cannot be tested during reactor operation will be tested by the ESFAS circuitry when the reactor is shut down. 
A further description of the PPS, RTSS and ESF-CCS test features is provided in sections 7.2 and 7.3 .

\subsubsection{Conformance to Regulatory Guide 1.29}

The PPS and ESF-CCS and other instrumentation and controls necessary for safety conform to the guidance of Regulatory Guide 1.29, "Seismic Design Classification." This conformance is described below.

The systems designated as seismic Category I are items listed in C.1.k, C.1.1, C.1.n and C.1.q. The seismic classification and qualification methods are discussed in Combustion Engineering's Topical Report CENPD-182 (Reference 3), Chapter 18 and Section 3.10 .

Those portions of structures, systems, or components whose continued function is not required, are designated as seismic Category II and designed so that the SSE will not cause a failure which will reduce the functioning of any plant safety feature to an unacceptable level, including incapacitating injury to the occupants of the control room.

\subsubsection{Conformance to Regulatory Guide 1.40}

Continuous duty motors and their conformance to Regulatory Guide 1.40, "Qualification Tests of Continuous-Duty Motors Installed Inside the Containment of Water-Cooled Nuclear Power Plants," are discussed in the site-specific SAR.

\subsubsection{Conformance to Regulatory Guide 1.45}

The Acoustic Leak Monitoring System, as described in the NSSS Integrity Monitoring system, section 7.7.1.6, is employed as one of the three methods of detecting RCS leaks in accordance with Regulatory Guide 1.45, "Reactor Coolant Pressure Boundary Leakage Detection systems." Refer to Section 5.2.5 for a more comprehensive discussion on RCS leak detection methods.

\subsubsection{Conformance to Regulatory Guide 1.47}

The design of the RPS and the ESFAS as indicated in sections 7.2 and 7.3 , is consistent with the recommendations of Regulatory Guide 1.47, "Bypassed and Inoperable status Indication for Nuclear Power Plant Safety systems." Conformance is described below. 
A. Annunciator outputs are provided to indicate, at the system level, the bypassing or deliberate inducing of inoperability of a protection system. The system level alarms are actuated when a component actuated by a protection system is bypassed or deliberately rendered inoperable.

B. Those auxiliary and support systems within the CESSAR licensing scope provide automatic annunciator activation to indicate, on a system level, the bypassed or deliberately induced inoperability of an auxiliary or support system that effectively bypasses or renders inoperable a protection system and the systems actuated or controlled by a protection system.

c. Annunciation is provided in the control room, at the system level, for each bypassed or deliberately induced inoperable status in a protection system.

1. These are supplied for those systems discussed in $A$. and B. above.

2. All of these bypasses are expected to be used at least once a year.

3. All of these bypasses are expected to be usable when the annunciated system is expected to be operable.

D. The operator is able to activate each system level bypass indicator manually in the control room.

Bypasses and inoperable status conditions can be classified into the following groups:

1) operating bypasses,

2) trip channel bypasses, and

3) ESF components inoperable.

There are no system level bypasses for the RPS or ESFAS.

\subsection{Operating Bypasses}

The operating bypass is used during routine startup and shutdown. These bypasses must be manually inserted. They utilize permissive logic generated from the parameter(s) being bypassed to ensure the bypass is removed if plant conditions deviate to the point where the bypass is no longer safe. (Example: If the coolant system pressure rises above a predetermined setpoint, the RPS/ESFAS pressurizer pressure bypass is automatically removed.) once a bypass is automatically removed, the manual normal (unbypassed) position must be actuated and then the bypass position reactuated in order to reinsert the bypass. 
This prevents cycling the bypass with the permissive contact status. Bypass status indication is provided on the PPS remote operator's modules for each channel. The bypass and bypass permissive status are provided to the plant Data Processing system. operating bypasses include the RPS/ESFAS pressurizer pressure bypass, the high log power bypass and the CPC DNBR/LPD trip bypass.

\subsection{Trip Channel Bypasses}

These bypasses are used to individually bypass channel trip inputs to the protection system logic for maintenance or testing. The trip logic is converted from a two-out-of-four to a two-out-of-three logic for the parameters being bypassed, while maintaining a coincidence of two for actuation. Only one channel for any one parameter may be bypassed at any one time. These bypasses must be manually initiated and removed. Individual bypass indication is provided locally at the PPS and at the PPS remote operator's modules located in the control room. In addition, the status of each bypass is provided to the plant Data Processing system.

\subsection{ESF Components Inoperable}

The bypassed and/or inoperable condition of ESF components is monitored by the ESF-CCS, as described in section 7.3. ESF-CCS status outputs are provided to the Data Processing system (DPS) which processes logic to indicate at the system level, the bypassing, inoperability or deliberate inducing of inoperability of an ESF system. The DPS also provides status information at the component level. The operator has the ability to activate each ESF system level bypass indicator manually in the control room. Inoperable indication is shown on the DPS CRTs, Integrated Process Status overview (IPSO) panel and Discrete Indication and Alarm system (DIAS) alarm tiles as further described in sections 7.7 .1 .4 and 7.7 .1 .5 .

\subsubsection{Conformance to Regulatory Guide 1.62}

Manual initiation of the RPS is described in sections 7.2.1.1.1.11 and 7.2.2.3.2. Manual initiation of the ESFAS is described in Section 7.3.2.3.2. Conformance to Regulatory Guide 1.62, "Manual Initiation of Protective Actions," is as follows:

A. Each of the above systems can be manually actuated.

B. Manual initiation of a protective action causes the same actions to be performed by the protection system as would be performed if the protection system had been initiated by automatic action. 
C. Manual switches are located in the control room, ESF CCS and at the RTSS for use by the operators. Some ESF functions also have manual actuation at the Remote Shutdown Panel.

D. The amount of equipment common to the manual and automatic initiation paths is kept to a minimum, usually just the actuation devices. No single credible failure in the manual, automatic, or common portions of the protective system will prevent initiation of a protective action by manual or automatic means.

E. Manual initiation requires a minimum of equipment consistent with the needs of $A, B, C$, and $D$ above.

F. Once initiated, manual protective action will go to completion.

\subsubsection{Conformance to Regulatory Guide 1.63}

Electrical penetrations and their conformance to Regulatory Guide 1.63, "Electric Penetration Assemblies in Containment structures for Water-Cooled Nuclear Power Plants," are discussed in section 3.8 .2 and the site-specific SAR.

\subsubsection{Conformance to Regulatory Guide $\mathbf{1 . 6 8}$}

Conformance with Regulatory Guide 1.68, "Preoperational and Initial start-Up Test Program for Water-Cooled Power Reactors," is discussed in Chapter 14.

\subsubsection{Conformance to Regulatory Guide 1.73}

The Nuclear Power Module licensing scope electric valve operators intended to be installed inside the containment are qualified in compliance with Regulatory Guide 1.73, "Qualification Tests of Electric Valve operators Installed Inside the containment of Nuclear Power Plants," (see Section 3.11). The class 1 electric valve operators inside the containment are qualified according to the requirements of section II of Appendix B to $10 \mathrm{CFR} 50$. The qualification tests of the electric valve operators follow the applicable requirements of IEEE 382-1980, 344-1987 and 323-1983. The qualification tests demonstrate the design adequacy of the operators for service inside containment. These tests simulate those conditions that would be imposed during and after a Design Basis Event (e.g., LOCA) and those occurring during normal operating conditions. The qualification tests verify the adequacy of design for service under DBE conditions subject to the following: 
A. Subcomponents (e.g., limit switches) are not integrated with the valve operator mechanism but are, instead, part of the installed operator assembly.

B. The test sequence described in IEEE 382-1980 or the actual service sequence is used during operator qualification tests whichever has the most severe operating conditions.

C. The valve operator is tested under the severest environmental conditions ( $T, P, R H$, Radiation) that simulate the conditions to which the valve operator is expected to be exposed during and following a DBA.

D. The radiological source term for qualification tests is based on the same source term used in Regulatory Guide 1.7 taking into consideration the containment size, beta and gamma radiation.

\subsubsection{Conformance to Regulatory Guide 1.97}

The design of the post-accident monitoring instrumentation and information display via the DPS and DIAS is described in Sections 3.1 and 7.5. The design conforms to Regulatory Guide 1.97, "Instrumentation for Light-Water-Cooled Nuclear Power Plants To Assess Plant and Environs Conditions During and Following an Accident."

\subsubsection{Conformance to Regulatory Guide 1.105}

The generation of safety system setpoints conforms to ISA-S67.04-1987, "Setpoints for Nuclear Safety Related Instrumentation Used in Nuclear Power Plants."

The setpoint methodology is similar to that explained in CEN-278(V), "Selection of Trip setpoint values for the plant Protection system," submitted on the Palo Verde Nuclear Generating station Unit 1 Docket, STN-50-528. The environment considered when determining errors is the most detrimental realistic environment calculated or postulated to exist up to the longest time of the required Reactor Trip or Engineered Safety Feature Actuation. This environment may be different for different events analyzed. For the setpoint calculation, the accident environment error calculation for process equipment uses the environmental conditions up to the longest required time of trip or actuation that results in the largest errors, thus providing additional conservatism to the resulting setpoints. 
The reference leg heating component uncertainties for steam generator level also take into account pressure and temperature variation within the steam generator.

For all temperature and pressure setpoints, the trip will be initiated at a point that is not at saturation for the equipment. For level setpoints, no analysis setpoint is within $5 \%$ of the ends of the level span.

\subsubsection{Conformance to Regulatory Guide 1.106}

Conformance to Regulatory Guide 1.106, "Thermal overload Protection for Electric Motors on Motor-operated Valves," is accomplished as follows. Thermal overload protection devices are not used in safety-related motor-operated valve control circuits. Thermal overload signals are used only for status annunciation.

The ESF-CCS, as described in section 7.3, has the design capability to provide MOV thermal overload status which is available via the DIAS and DFS described in section 7.7.1.4 and 7.7 .1 .7 .

\subsubsection{Conformance to Regulatory Guide 1.120, as} Augmented by BTP CMEB 9.5-1

The following design features address the guidelines contained in Regulatory Guide 1.120, "Fire protection Guidelines For Nuclear Power Plants":

A. Redundant channels and divisions of safety-related instrumentation and control cabinets are designed to be located in separate geographic plant fire zones.

B. The Control complex is designed to allow a safe plant shutdown with a major fire in the main control room. The design utilizes fiber-optics and other signal isolation technologies in conjunction with the ability to manually transfer control to the Remote shutdown Panel(s).

c. The minimization of combustible materials is considered in the design and fabrication of the instrumentation and controls.

D. The control room design includes provisions to locate fire protection system audible and visual alarm panels within the control room or, alternately, to integrate the alarms into the DIAS and DPS. 
E. Control room and computer room equipment, panels and consoles that are safety related, contain fire detection D devices with local and remote alarm annunciators.

The above features and design considerations form only a part of the defense in depth fire protection philosophy. See section 9.5 for a more comprehensive discussion of the plant's fire protection program.

\section{$7 \cdot 1 \cdot 2 \cdot 30$ \\ Conformance to Regulatory Guide 1.133}

The design of the Loose Parts Monitoring system conforms to Regulatory Guide 1.133, "Loose-Part Detection Program for the Primary System of Light-Water-Cooled Reactors," and is described in detail in section 7.7.1.6.3.

\section{$7 \cdot 1 \cdot 2 \cdot 31$ \\ Conformance to Regrulatory Guide 1.151}

All protection and control sensing methods meet the independence requirements of Regulatory Guide 1.151, "Instrument sensing Lines" as described in sections 3.1.20, and 7.7.1.1.13.

\section{$7 \cdot 1 \cdot 2 \cdot 32$ \\ Conformance to Regulatory Guide 1.1 'D2}

Regulatory Guide 1.152, "Criteria for Programmable Digital Computer system software in safety-Related systems of Nuclear Power Plants," states that the requirements set forth in ANSI/IEEE-ANS-7-4.3.2-1982 provide a method acceptable to the NRC staff for designing software, verifying software, implementing software, and validating computer systems in safety-related systems of nuclear power plants.

A. The Core protection Calculator system (CPCS) described in Section 7.2 .1 .1 .2 .5 is a digital computer system that generates reactor trip signals for low DNBR and high Local Power Density. The CPCS software is developed and tested in accordance with Regulatory Guide 1.152 as described by CEN-39(A)-P, "CPC Protection Algorithm Software Change Procedure," (Reference 4).

B. The Plant protection system (PPS) described in section 7.2 is a multiple microprocessor based system that generates RPS and ESF initiation signals. The PPS software is developed and tested in accordance with Regulatory Guide 1.152 .

C. The ESF Component Control system (CCS) described in section 7.3 is a multiple microprocessor based system that controls and actuates ESF fluid system components. The ESF-CCS software is developed and tested in accordance with Regulatory Guide 1.152. 
D. The Discrete Indication and Alarm system (DIAS) described in Section 7.7 .1 .4 is a microprocessor based system that includes PAMI. The DIAS software is developed and tested in accordance with Regulatory Guide 1.152 .

\subsubsection{Conformance to Regulatory Guide 1.156}

Conformance to Regulatory Guide 1.156, "Environmental Qualification of Connection Assemblies for Nuclear Power Plants", is as described in sections 7.1.2.5, 7.1.2.8 and 7.1.2.18.

\subsubsection{Conformance to Regulatory Guide 8.12}

Conformance to Regulatory Guide 8.12, "Criticality Accident Alarm Systems," for the reactor is accommodated via the Boron Dilution Alarm Logic described in section 7.7.1.1.10. In addition, the Ex-Core Neutron Flux Monitoring System Start-up Channels provide an audible count rate via speakers located in the main control room and containment building.

Both the DIAS and DPS are designed to present this alarm information, as well as any other plant specific criticality accident alarms, to trie control room operator.

\subsubsection{INTERFACE REQUIREMENTS}

General instrumentation and control interface requirements and the specific interface requirements are discussed in the principal section for the safety-related systems. Table 7.1-1 identifies the applicable section where standardized functional descriptions for the interfacing auxiliary and supporting systems are provided.

\section{A. Operational Controls}

All control modules supplied by the site operator for installation in the Main Control Panels and/or the Remote Shutdown Panels shall be designed to be compatible with the HFE design assumptions, criteria and task analyses identified in Chapter 18. 


\section{REFERENCES FOR SECTION 7.1}

1. "Qualification of Combustion Engineering class $1 \mathrm{E}$ CENPD-255-A-1983, Revision 03, October 1985.

2. "Seismic Qualification of Instrumentation Equipment," Combustion Engineering, Inc., CENPD-182, May 1977.

3. "CPC Protection Algorithm Software Change Procedure," Combustion Engineering, Inc., CEN-39(A)-P, Revision 03, D
November 1986. 4. NUREG-0908, August, 1982, "Acceptance Criteria for the |
Evaluation of Nuclear Power Reactor Security Plans." 
TABLE 7.1-1

AUXILIARY AND SUPPORTING SYSTEM

DESCRIPTIONS

\section{Description}

Control Room

Emergency operations Facility

Technical support Center

Electric Power Distribution System

Fire Protection system

Diesel Generator system

station Service water system

Component cooling water system

Instrument Air system

Automatic Dispatch system

Environmental support systems (HVAC)

Alternate AC Source
Applicable CESSAR-DC Section

18.4

18.4

18.4

$8 \cdot 3$

9.5

8.3 and 9.5

9.2

9.2

9.3

10.2

9.4

8.3 
7.2

7.2 .1

7.2 .1 .1

REACTOR PROTECTIVE SYSTEM

\section{DESCRIPTION}

\section{System Description}

The Reactor Protective system (RPS) portion of the plant Protection system (PPS) (as shown on Figure 7.2-1) consists of sensors, calculators, logic, and other equipment necessary to monitor selected plant conditions and to effect reliable and rapid reactor shutdown (reactor trip) if monitored conditions approach specified safety system settings. The system's functions are to protect the core fuel design limits and Reactor coolant system (RCS) pressure boundary for Anticipated operational Occurrences, and also to provide assistance in mitigating the consequences of accidents. Four measurement channels with electrical and physical separation are provided for each parameter used in the direct generation of trip signals, with the exception of Control Element Assembly (CEA) position which is a two channel measurement.

The Reactor Protection system (RPS) portion of the PPS includes the following functions: bistable trip, local coincidence logic, reactor trip initiation logic and automatic testing of PPS logic. The bistable trip processors generate trips based on the measurement channel digitized value exceeding a digital setpoint. The bistable trip processors provide their trip signals to the coincidence processors located in the four redundant PPS channels. The coincidence processors evaluate the local coincidence logic based on the state of the four like trip signals and their respective bypasses. The coincidence signals are used in the generation of the Reactor Trip Switchgear system (RTSS) or Engineered Safety Features-component Control system (ESF-CCS) initiation. Software is developed and tested for the above processors, as stated in section 7.1. A coincidence of two-out-of-four like trip signals is required to generate a reactor trip signal. The fourth channel is provided as a spare and allows bypassing of one channel while maintaining a two-out-of-three system.

The reactor trip signal deenergizes the Control Element Drive Mechanism (CEDM) coils, allowing all CEAs to drop into the core.

PPS interfaces (RPS and ESFAS) for functions, such as operator interaction, alarm annunciation and testing (manual and
automatic), are shown on Figure $7.2-2$. 
The local and main control room PPS operator's module (one per channel) provides for entering trip channel bypasses, operating bypasses, and variable setpoint resets. These modules also provide indication of status of bypasses, operating bypasses, bistable trip and pre-trip. The local operator module provides the man-machine interface during manual testing of bistable trip functions not tested automaticaliy.

The main control room (MCR) panels provide means to manually initiate engineered safeguards.

The Remote Shutdown Panel provides selected functions needed for safe shutdown and cooldown, as described in section 7.4.

Each PPS channel cabinet contains a manual transfer switch that enables the RSP or MCR for PPS channel functions that are common to both.

The Interface and Testing Processor (ITP), one per channel, communicates with the bistable trip processors, coincidence processors, operator's modules, ESF-CCS, RTSS and ITP's in the other three channels to monitor, test and control the operational state of the PPS. It also provides selected PPS channel status and test results information to the Data Processing system (DPS), and Discrete Indication and Alarm System (DIAS).

\subsection{Trips}

\subsection{Variable Overpower}

The variable overpower trip is provided to trip the reactor when indicated neutron flux power either increases at a great enough rate, or reaches a preset value. The flux signal used is the average of the three linear subchannel flux signals originating in each nuclear instrument safety channel. The nominal trip setpoints are provided in Table $7.2-4$.

Pre-trip alarms are initiated below the trip value to provide audible and visible indication of approach to a trip condition.

\subsection{High Logarithmic Power Level}

The high logarithmic power level trip is provided to trip the reactor when indicated neutron flux power reaches a preset value. The flux signal used is the logarithmic power signal originating in each nuclear instrument safety channel. The nominal setpoint is provided in Table 7.2-4. The trip may be manually bypassed by the operator. This bypass point is provided in Table $7.2-1$. 
Pre-trip alarms are initiated below the trip value to provide audible and visible indication of approach to a trip condition. The trip bypass also bypasses the pre-trip alarms.

\subsection{High Local Power Density}

The high local power density trip is provided to trip the reactor when calculated core peak local power density reaches a preset value. The preset value is less than that value which would cause fuel centerline melting. The calculation of the peak local power density is performed by the Trip Logic Calculators (TLC) in I I the core protection Calculators (CPCs), which compensate the calculated peak local power density to account for the thermal capacity of the fuel. The calculation considers axial distribution, average power, and radial peaking factors (based on target CEA position) and CEAC penalty factors to calculate the current value of compensated peak local power density. A trip results if the compensated peak local power density reaches the preset value. The calculated trip assures a core peak local power density below the safety limit for peak linear heat rate $(\mathrm{kW} / \mathrm{ft})$. The nominal trip setpoint is given in Table 7.2-4. The effects of core burnup are considered in the determination of the local power density trip.

Pre-trip alarms are initiated below the trip value to provide audible and visible indication of approach to a trip condition.

\subsection{Low Departure from Nucleate Boiling Ratio}

The low Departure from Nucleate Boiling Ratio (DNBR) trip is provided to trip the reactor when the calculated DNBR approaches a preset value. The calculation of DNBR is performed by the TLCs based on core average power, reactor coolant pressure, I I reactor inlet temperature, reactor coolant flow, and the core power distribution. The calculations include allowances for I I sensor and processing time delays and inaccuracies such that a trip is generated within the TLCs before violation of the DNBR safety limit in the limiting coolant channel in the core occurs during Anticipated operational occurrences. The nominal trip setpoint is given in Table 7.2-4.

The low DNBR trip incorporates a low pressurizer pressure floor, with the value given in Table 7.2-4. At this pressure, a low DNBR trip will automatically occur.

Pre-trip alarms are initiated above the trip value to provide audible and visible indication of approach to a trip condition. 


\subsection{High Pressurizer Pressure}

The high pressurizer pressure trip is provided to trip the reactor when measured pressurizer pressure reaches a high preset value. The nominal trip setpoint is provided in Table 7.2-4.

Pre-trip alarms are initiated below the trip setpoint to provide audible and visible indication of approach to a trip condition.

\subsection{Low Pressurizer Pressure}

The low pressurizer pressure trip is provided to trip the reactor when the measured pressurizer pressure falls to a low preset value. The nominal trip setpoint for normal operation is provided in Table 7.2-4. At pressures below the normal operating range, this setpoint can be manually decreased to a fixed increment below the existing pressurizer pressure down to a mirimum value. The incremental and minimum values are given in Table 7.2-4. This ensures the capability of a trip when required during plant cooldown.

The trip may be manually bypassed by the operator. This bypass point is provided in Table 7.2-1. The bypass is automatically removed as pressure is increased above a fixed value and the low pressure setpoint automatically increases, maintaining the fixed increment between the plant pressure and the setpoint. These values are shown in Table $7.2-4$.

Pre-trip alarms are initiated above the trip setpoint to provide audible and visible indication of approach to a trip condition.

\subsection{Low Steam Generator Water Level}

A variable low steam generator water level trip is provided to trip the reactor when measured steam generator water level falls to a low calculated value. The low level setpoint is programmed such that as reactor power decreases, the level setpoint is decreased from the normal full power value down to a minimum preset low power value. Separate trips are provided from each steam generator. The nominal trip setpoint is provided in Table $7.2-4$.

Pre-trip alarms are initiated above the trip setpoint to provide audible and visible indication of approach to a trip condition.

\subsection{Low Steam Generator Pressure}

The low steam generator pressure trip is provided to trip the reactor when the measured steam generator pressure falls to a low preset value. Separate trips are provided from each steam 
generator. The nominal trip setpoint during normal operation is provided in Table 7.2-4. At steam generator pressures below normal, the operator has the ability to manually decrease the setpoint to a fixed increment below existing system pressure. This is used during plant cooldown. During startup, this setpoint is automatically increased and remains at the fixed increment below generator pressure. This fixed increment is provided in Table 7.2-4.

Pre-trip alarms are initiated to provide audible and visible indication of approach to a trip condition.

\subsection{High Containment Pressure}

The high containment pressure trip is provided to trip the reactor when measured containment pressure reaches a high preset value. The nominal trip setpoint is provided in Table 7.2-4. The trip is provided as additional design conservatism (i.e., additional means of providing a reactor trip). The high containment pressure trip setpoint is selected in conjunction with the high-high containment pressure setpoint to prevent exceeding the containment design pressure during a design basis LOCA or main steam line break accident.

Pre-trip alarms are initiated to provide audible and visible indication of approach to a trip condition.

\subsection{High Steam Generator Water Level}

A high steam generator water level trip is provided to trip the reactor when measured steam generator water level rises to a high preset value. Separate trips are provided from each steam generator. The nominal trip setpoint is provided in Table 7.2-4.

Pre-trip alarms are initiated to provide audible and visible indication of approach to a trip condition.

\subsection{Manual Trip}

A manual reactor trip is provided to permit the operator to trip the reactor. Actuation of two adjacent switches in the main control room will cause interruption of the $A C$ power to the CEDMs. Two independent sets of trip pushbuttons are provided, either one of which will cause a reactor trip. There are also manual reactor trip switches at the reactor trip switchgear.

The remote manual initiation portion of the Reactor Trip system is designed as an input to the RTSS. This design is consistent with the recommendations of NRC Regulatory Guide 1.62. The amount of equipment common to both automatic and manual 
initiation is kept to a minimum. Once initiated, the manual trip will go to completion as required in section 4.16 of IEEE standard 279-1971.

\subsection{Low Reactor Coolant Flow}

The low reactor coolant flow trip is provided to trip the reactor when the pressure differential across the primary side of either steam generator decreases below a rate limited variable setpoint, as shown in Figure 7.2-3. A separate trip is provided for each steam generator. This function is used to provide a reactor trip for a reactor coolant pump sheared shaft event.

Pre-trip alarms are provided.

$7.2 \cdot 1 \cdot 1 \cdot 2$

7.2 .1 .1 .2 .1

\section{Initiating circuits}

\section{Process Measurements}

Various pressures, levels, and temperatures are continuously monitored to provide signals to the RPS trip bistable processors. These process protective parameters are measured with four independent process instrument channels. A derailed listing of the parameters measured is contained in Table 7.2-3.

A typical protective channel, as shown in Figure 7.2-4, consists of a sensor/transmitter, loop power supply, current loop resistors, and fiber-optic transmitter outputs to the process control systems. Main control room and RSP displays are provided from Data Processing system (DPS), and Discrete Indication and Alarm system (DIAS) via the PPS.

The piping, wiring, and components of each channel are physically separated from that of other like protective channels to provide independence. The output of each transmitter is an ungrounded current loop. Exceptions are:

A. Nuclear instruments.

B. Reactor coolant pump speed sensors which provide a pulsed voltage signal.

Signal isolation is provided for DIAS, DPS, and process control system inputs via fiber-optic cables. Each redundant channel is powered from a separate vital AC bus.

$7.2 \cdot 1 \cdot 1 \cdot 2 \cdot 2$

CEA Position Measurements

CEA positions are monitored by monitoring is used for display of

two diverse means. This CEA position to the operator 
and to initiate alarms and control actions to prevent CEA
misalignments. CEA misalignments are factored into the TLC I calculation of DNBR and LPD to reduce the margins to trip.

\subsection{1 CEA Position Monitoring by the RPS}

The position of each CEA is an input to the RPS. These positions are measured by means of two reed switch assemblies on each CEA.

Each reed switch assembly consists of a series of magnetically actuated reed switches spaced at intervals along the CEA housing and wired with precision resistors in a voltage divider network (see Figure 7.2-5). A magnet attached to the CEA extension shaft actuates the adjacent reed switches, causing voltages proportional to position to be transmitted for each assembly. The two assemblies and wiring are physically and electrically separated from each other (see Figure 7.2-6).

The CEAs are arranged into control groups that are controlled as subgroups of CEAs. The subgroups are symmetric about the core center. The subgroups are required to move together as a control group and should always indicate the same CEA group position. Each TLC channel monitors the position of one "target" CEA in each subgroup via the reed switch position signal. "The "target" CEA represents a measure of subgroup CEA position. To make each TLC channel aware of position deviations of CEAs within a subgroup, all CEA positions are monitored by the CEA Calculators. one set of the redundant reed switch signals for all CEAs is monitored by one CEA Calculator, and the other set of signals by the redundant CEA Calculator. Each CEA Calculator monitors the position of all CEAs within each control subgroup. Should a CEA deviate from its subgroup position, the CEA Calculators will monitor the event, activate alarms via DPS and DIAS, and transmit appropriate "penalty" factors to the CPCs. Within the CPCs the penalty factors result in the initiation of control actions to mitigate the event and, if still needed, a reduction in margins-to-trip for low DNBR and high local power density. This assures conservative operation of the RPS. The control and protection actions for single CEA deviation events are described in more detail below.

The CEA Calculators provide the position of each regulating, shutdown and part-strength CEA via the CPC operator's module, and DPS displays in the main control room. Optical isolation is utilized at each CEA Calculator for these outputs. The detailed signal paths of CEA position information within the RPS are shown in Figure 7.2-7. 
To avert unwarranted reactor trips due to single CEA deviation events, the control and protection systems have design features to minimize the probability of these events occurring. In addition, the RPS will initiate protective actions for those events that cannot be precluded and which have not been successfully terminated by the control systems.

A. CEDMCS

The Control Element Drive Mechanism Control system (CEDMCS) monitors the mechanical actions of the Control Element Drive Mechanism for each CEA to provide continuous closed loop control of the drive mechanism. If, during control group motion, a mechanism fails to move its CEA, the CEDMCS will block further movement of the remainder of the control group to prevent CEA deviations from occurring.

In addition, the CEDMCS continuously determines CEA position based on counting the number of inward and outward mechanical. actions of the CEDM latch mechanism. If $a$ position deviation is detected among CEAs in a control group, a CEA Motion Inhibit (CMI) is generated.

The CEDMCS also monitors the dropped rod contact (DRC) of the reed switch position transmitter (RSPT). If a rod drop occurs for a 12-finger CEA, the CEDMCS will initiate a reactor power cutback. The reduced power is sufficient to avert a condition requiring protective action. This is further explained below.

The CEDMCS CEA Withdrawal Prohibit (CWP) two-out-of-four logic utilizes three signals from each CPC to generate a CEA withdrawal prohibit signal. The CPC signals are $\mathrm{Hi}$ Pressurizer Pressure CWP, DNBR CWP and LPD CWP generated at pre-trip conditions of $\mathrm{Hi}$ Pressurizer Pressure, DNBR and LPD respectively.

B. Reactor Protection System

Due to the differences in required control and protective actions for insertion and withdrawal deviations, each event is explained separately below.

\section{Insertion Deviations}

The TLCs use the most conservative insertion deviation penalty factors from the two CEACs to initially generate a CEA Motion Inhibit. This CMI initiation is 
effectively a one-out-of-two logic function performed in each TLC channel. All four TLC channels generate a CMI signal which is interfaced to the CEDMCS to block rod motion and thereby prevent further CEA deviations. The CEDMCS executes the rod block on coincidence of two-out-of-four CMI signals from the TLCs.

While the CMI logic is being executed, the TLCs also apply the most conservative insertion penalty factor to the DNBR and LPD calculations. If the calculations result in a pre-trip condition, each TLC will generate a Reactor Power Cutback (RPC) signal. The RPC demand signals are sent to the CEDMCS which actuates gravity insertion of CEAs (i.e., Reactor Power cutback) using a two-out-of-four actuation logic.

The reduction in reactor power will be sufficient to prevent a DNBR or LPD trip. However, regardless of this control action, the TLCs continue to use the most conservative insertion penalty factor in the DNBR and LPD trip algorithms. If the Reactor Power cutback is not successfully executed or does not result in sufficient thermal margin, a DNBR and/or LPD trip will be generated.

If a CEAC is out of service, the TLCs will use the available CEAC penalty factors to generate the CMI, RPC and reactor trip signals. To relax technical specification limitations during this mode of operation, the CEDMCS also initiates CMI and Reactor Power Cutback signals. This was described in Paragraph A above.

2. Withdrawal Deviations

A CMI is generated by the integrated actions of the CEACS, TLCs and CEDMCS for withdrawal deviations in the same manner as for insertion deviations described in paragraph 1 above. The CEDMCS also prevents withdrawal deviations through its own CEA position monitoring, group motion interlocks and self-generated CMI, as described in $A$ above. These four levels of single CEA deviation prevention, coupled with the inherent low probability of the event (i.e., these events are rare in C-E plants) and analysis that shows acceptable effects of the event (see Chapter 15), have resulted in the reclassification of single $C E A$ withdrawals from Anticipated Operational occurrences to Accidents. Therefore, there is no need for the TLCs to initiate protective action for single CEA withdrawal deviation 
events. It is noted that this reclassification also encompasses a group insertion with a single stuck CEA.

\subsection{Ex-core Neutron Flux Measurements}

The ex-core nuclear instrumentation includes neutron detectors located around the reactor core, and signal conditioning equipment located within the containment and the auxiliary building. Neutron flux is monitored from source levels through full power operation, and signal outputs are provided for reactor protection, control and information display. There are 4 channels of safety instrumentation (see Figure 7.2-8).

The four safety channels provide neutron flux information from near startup neutron flux levels to $200 \%$ of rated power covering a single range of approximately $1 \times 10^{-7}$ to $200 \%$ power ( 9 decades). Each safety channel consists of three fission chambers, a preamplifier and a signal conditioning drawer containing power supplies, a logarithmic amplifier (including combination counting and mean square variation techniques), linear amplifiers, test circuitry, and a rate-of-change of power circuit. These channels provide the RPS information for rate-of-change of power display, DNBR, local power density, and overpower protection.

The detector assembly provided for each safety channel consists of three identical fission chambers stacked vertically alony the length of the reactor core. The use of multiple subchannel detectors in this arrangement permits the determination of axial power shape during power operation.

The fission chambers are mounted in holder assemblies, which in turn are located in four dry instrument wells (thimbles) at or in the primary shield. The wells are spaced around the reactor vessel to provide optimum neutron flux information.

Four safety channel preamplifier/filter assemblies for the fission chambers are mounted outside the reactor containment building in the cable chase of the subsphere. Physical and electrical separation of the preamplifiers and cabling between redundant channels is provided.

\subsection{Reactor Coolant Flow Measurements}

The speed of each reactor coolant pump motor is measured to provide a basis for calculation of reactor coolant flow through each pump. The measurement of reactor coolant pump speed is accurate to within $0.43 \%$ of the actual pump speed. Two metal discs, each with 44 uniformly spaced slots about its periphery are scanned by proximity devices. The metal discs are attached 
to the pump motor shaft, one to the upper portion and one to the lower portion (see Figure 7.2-9). Each scanning device produces a voltage pulse signal. The pulse train that is input to the CPCs to calculate flow rate is based upon a variable number of pulses from the scanning device. The frequency of this pulse train is proportional to pump speed. Adequate separation between proximity devices is provided.

The mass flow rate is obtained using the pump speed inputs from the four reactor coolant pumps, the cold leg temperatures, and the hot leg temperatures. The volumetric flow rate through each reactor coolant pump is dependent upon the rotational speed of the pump and the pump head. This relationship is typically shown in pump characteristic curves. Flow changes resulting from changes in the loop flow resistances occur slowly (i.e., core crud buildup and increase in steam generator resistance). Calibration of the calculated mass flow rate will be performed periodically using instrumentation which is not part of the Reactor Coolant Pump speed Sensing system.

Flow reductions associated with pump speed reductions are more rapid than those produced from loop flow resistance changes. Mass flow rate is calculated for each pump from the pump speed, the density of cold leg coolant and a correction term based on the hot leg temperature.

The mass flow rates calculated for each pump are summed to give a core mass flow rate. This flow rate is then used in the CPC DNBR and $\Delta T$ power algorithms.

The RCP speed is also transmitted from each CPC channel over isolated fiber-optic data links to the DPS where signal cross-channel validation is performed prior to use for display and use in colss.

The reactor coolant pump speed measurement system is designed, manufactured, tested, and installed to the identical design, quality assurance, and testing criteria as the remainder of the signal generation and processing equipment for signals utilized by the RPS.

\subsection{Core Protection Calculators}

Four independent Trip Logic Calculators (TLCS) are provided, one in each core Protection Calculator (CPC) channel. Calculation of DNBR and local power density is performed in each TLC, utilizing the input signals described below. The DNBR and local power density so calculated are compared with trip setpoints for initiation of a low DNBR trip (Section 7.2.1.1.1.4) and the high local power density trip (Section 7.2.1.1.1.3). 
Two independent CEA Calculators are provided as part of the CPC to calculate individual CEA deviations from the position of the other CEAs in their subgroup. The TLCs and CEA calculations are described in detail in References 1 and 2 .

As shown in Figure 7.2-10, each TLC receives the following inputs:

A. Core inlet and outlet temperature.

B. Pressurizer pressure.

C. Reactor coolant pump speed.

D. Ex-core nuclear instrumentation flux power (each subchannel from the safety channel).

E. Selected CEA position.

F. Penalty factors for CEA deviations within a subgroup from the CEA Calculators.

Input signals are conditioned and processed. The following calculations are performed in the TLC or the CEA Calculators:

A. CEA deviations.

B. Correction factor for excore flux power for shape annealing and CEA shadowing.

C. Reactor coolant flowrate from reactor coolant pump speeds and temperatures and DNBR penalty for pump speeds less than a setpoint.

D. $\Delta \mathrm{T}$ power from reactor coolant temperatures, pressure, and flow information.

E. Ex-core flux power:

Ex-core flux power signals are summed and corrected for CEA shadowing, shape annealing, and cold leg temperature shadowing. This corrected flux power is periodically calibrated to the actual core power measured independently of the Reactor Protection system. This calibration does not modify the inherent fast time response of the ex-core signals to power transients. 
F. Axial power distribution from the corrected ex-core flux power signals.

G. Fuel rod and coolant channel planar radial peaking factors, selection of predetermined coefficients based on CEA positions.

H. DNBR.

I. Comparison of DNBR with a fixed trip setpoint.

J. Local power density.

K. Comparison of local power density with a fixed trip setpoint.

L. CEA deviation alarm.

M. Calculation of cold leg temperature difference for
asymmetric steam generator transient trip determination. Outputs of each TLC are:

A. DNBR trip and pre-trip.

B. DNBR margin (to DIAS and DPS for control board indication).

C. Local power density trip and pre-trip.

D. Local power density margin (to DIAS and DPS for control board indication).

E. Calibrated neutron flux power (to DIAS and DPS for control board indication).

F. High pressurizer pressure pre-trip to CEDM Control system CWP logic.

G. CEA inward deviation cutback demand to Reactor Power Cutback system.

H. CEA deviation motion inhibit to CEDM Control system. I. RCP speeds and other TLC measurement channel parameters to
Data Processing system. 
J. RPC Demand Signal to RPCS logic.

K. CMI signal to CEDM Control system CMI logic.

Each calculator is mounted in cabinets located in separate channelized equipment rooms with an operator's display and control module located in the main control room. From the four modules an operator can monitor all calculators, including specific inputs or calculated functions. Changes to CPC constants by the operator are controlled by administrative procedures.

\section{2 .1 .1 .2 .6 \\ Bistable Trip Generation}

Except for the TLCs, signals from process measurement loops are sent to bistable comparators where the input signals are compared to either fixed or variable setpoints. Refer to Table 7.2-4 for identification of trip parameters vs. type setpoints. When the input parameter reaches the setpoint the bistable produces trip signals. In the case of the TLC outputs, the TLC provides trip status inputs to the bistable logic. See Figure 7.2-18. The trip outputs of the bistable logics are sent to the local coincidence logics. (Each bistable logic in each channel provides a trip signal to each of the four protective channels Figure 7.2-11). A pre-trip output is also provided as part of the bistable logic.

In addition to the trip and pre-trip functions, the bistables logic contain test logic. The test logic allows testing of the following bistable information:

1. Analog input

2. Trip setpoint

3. Pre-trip setpoint

4. Status information (pre-trip, trip, operating bypass).

A. Bistable with Fixed setpoint

For those bistables whose setpoint is fixed, (i.e., digital), the setpoint can be changed at the PPS. Access to change the setpoint is controlled by administrative procedures. All of the fixed setpoints are monitored by the automatic test network.

B. Bistable with Variable setpoint

Variable setpoints are provided for some bistables to permit safe and orderly plant startup and shutdown. Three types of variable setpoints are utilized, they are: 
1. Variable setpoint with manual reset.

2. Variable setpoint with automatic rate limiting.

3. Variable setpoint with diverse trip parameter.

B.1 Variable setpoint with manual reset

This type of variable setpoint is a function of the input signal to the bistable. The design permits manually initiated automatic decrementing of the setpoint. Decrementing of the setpoint may be initiated at the PPS operator's modules or remote shutdown panel. When decremented, the setpoint resets itself to a fixed value below the actual input signal which exists at that time. By continuing to reset each time the pre-trip setpoint is reached the plant can be shutdown without causing any unnecessary protective actions. If the input signal rises above the point at which it was last reset, the variable setpoint logic will cause the setpoint to automatically rise to maintain a fixed value between the input signal and setpoint. If the input parameter falls, the setpoint will hold and the operator must again reset the setpoint to permit tracking. Figure 7.2-15 illustrates typical operation of a variable setpoint. Each variable setpoint contains a timer which allows a reset to be initiated only after some predetermined time interval has elapsed since the last reset. The design also includes the capability of fixed upper and lower limits.

The design also provides a pre-trip variable setpoint which is always related to the trip setpoint by a fixed value.

The actual value of the setpoint is available and may be displayed at the PPS cabinet or remotely via the DPS and operator's module in the control room.

Separate reset pushbuttons are provided for each protection channel.

\section{B.2 Variable Setpoint with Automatic Rate Limiting}

This type of variable setpoint permits automatic incrementing and decrementing of the setpoint sused upon the action of the bistable input variable. (See Figure 7.2-3.) The design attempts to maintain a fixed differential between the bistable input and the setpoint. The design includes the ability to adjust the rate at which the setpoint is allowed to change. If the input signal is changing at a 
rate greater than the rate at which the setpoint can change, the differential between the two values eventually becomes zero, creating a condition such that the bistable trips. When the bistable trip occurs, it prevents the setpoint from changing until the bistable trip clears. The design includes the capability of having fixed upper and lower limits.

Two forms of the rate limited setpoint are utilized in the system. The first form provides a setpoint which is higher than the input signal, as such it provides protection for signals that should not increase at too rapid a rate. The second form provides a setpoint which is lower than the input signal, as such it provides protection for signals that should not decrease at too rapid a rate. Figure 7.2-3 illustrates typical operation of this type of variable setpoint.

The design also provides a variable pre-trip setpoint which is always related to the trip setpoint by a fixed value.

The actual value of the setpoint is available and may be displayed at the PPS cabinet or remotely in the control room via the DPS and PPS operator's module.

B.3 Variable Setpoint with Diverse Trip Parameter

This type of variable setpoint is a function of a parameter that is different than the bistable trip input. The variable setpoint is preprogrammed as a function of the different parameter. The design includes the capability of having fixed upper and lower limits.

The design also provides a variable pre-trip setpoint which is always related to the trip setpoint by a fixed value.

The actual value of the setpoint is available and may be displayed at the PPS cabinet or remotely in the control room via the DPS and PPS operator's module.

\subsection{Logic}

A. Local Coincidence Logic

There is one Local Coincidence Logic (LCL) associated with each trip bistable logic of each channel. Each local coincidence logic receives four trip signals, one from its 
associated bistable logic in the channel and one from each of the equivalent bistable logic located in the other three channels (Figure 7.2-12). The local coincidence logic also receives the trip channel bypass status associated with each of the above mentioned bistables (Figure 7.2-13 illustrates distribution of a typical bypass). The function of the local coincidence logic is to generate a coincidence signal whenever two or more like bistables are in a tripped condition. The LCL takes into consideration the trip bypass input state when determining the coincidence logics state. Designating the protective channels as A, B, C, D, with no trip bypass present, the local coincidence logic will produce a coincidence signal for any of the following trip inputs: $A B, A C, A D, B C, B D, C D, A B C, A B D, A C D, B C D, A B C D$. These represent all possible two- or more out-of-four trip combinations of the four protective channels. Should a trip bypass be present, the logic will provide a coincidence signal when two or more of the three unbypassed bistables are in a tripped condition.

on a system basis, a coincidence signal is generated in all four protective channels whenever a coincidence of two or more like bistables of the four channels are in a tripped state.

In addition to a coinciden signal, each LCL also provides bypass status outputs. verify that a bypass $h$. logic either locally or $r$ jypass status is provided to ually been entered into the ely via the operator's module. The bypass status is available for display at the local and remote operators modules and DPS.

B. Initiation circuit

There is an initiation circuit in each channel for each PPS protective function (i.e., RPS, CIAS). For the Reactor Protective system, the initiation logic consists of an "OR" circuit (e.g., a coincidence of high log power or low pressurizer pressure or etc., will result in an initiation signal). For ESFAS's the initiation logic also consist of "OR" circuits.

The inputs to the initiation logic are the LCL outputs from the appropriate local coincidence logics. The initiation circuits also contain a time delay (TD). The TD functions as a noise and/or transient filter. It accomplishes this filter action by monitoring the continuous presence of an input for a minimum period of time. If the signal is present for the required time, the signal is transmitted to the initiation relay. Test capability is also provided. 
Figure 7.2-14 illustrates the initiation logic applied to the RPS function. There are separate "OR" circuits for undervoltage and shunt trip initiation.

\subsection{Actuated Devices}

The final actuation logic for the Reactor Protection system is in the power path to the Control Element Drive Mechanisms Control System and is called the Reactor Trip Switchgear system (RTSS) . As illustrated in Figure 7.2-12, the initiation relays interface with the shunt trip and undervoltage devices to trip the circuit breakers that make up the Reactor Trip Switchgear system. To completely remove power from the output circuits requires a minimum of two initiation relays (in opposite legs of the circuit) opening their associated circuit breakers.

Power input to the RTSS comes from two full-capacity motorgenerator sets, so that the loss of either set does not cause a release of the CEAs. Each line passes through two trip circuit breakers (each actuated by a separate initiation circuit) in series so that, although both sides of the branch lines must be deenergized to release the CEAs, there are two separate means of interrupting each side of the line. Upon removal of power to the CEDM power supplies, the CEAs fall into the reactor core by gravity.

Two sets of manual trip switches are provided to opey the trip circuit breakers, if desired. The manual trip completely bypasses the trip logic. As can be seen in Figure 7.2-12, both manual trip switches in a set must be actuated to initiate a $\left.\right|_{E}$ reactor trip.

The trip switchgear is housed in separate cabinets from the RPS. In addition to the trip circuit breakers, the cabinet also contains current monitoring devices for testing purposes and pushbuttons on each trip switchgear which allow for manual opening the circuit breaker.

\subsection{Bypasses}

The design provides for two types of bypasses: operating bypasses and bistable trip channel bypasses as listed in Table 7.2-1. The status of any bypass is indicated at the PPS channel cabinet and PPS Remote operators Module in the main control room. In addition, all operating bypasses and a summary of the bistable bypasses in each channel are made available for control room indication via the DIAS and DPS. 
A. Operating Bypasses

operating bypasses are provided to permit orderly startup and shutdown of the plant and to allow low power testing. The following operating bypasses are provided:

1. DNBR/LPD Trip Bypass

The DNBR and local power density bypass, which bypasses the low DNBR and high local power density trips from the TLC, is provided to allow system tests at low power when pressurizer pressure may be low or reactor coolant pumps may be off. The bypass may be manually initiated if power is below the bypass setpoint and is automatically removed when the power level increases above the bypass setpoint.

2. Low Pressurizer Pressure Bypass

The RPS/ESFAS pressurizer pressure bypass is provided for two conditions:

a. System tests at low pressure.

b. Heatup and cooldown with shutdown CEAs withdrawn.

The bypass may be manually initiated if pressurizer pressure is below the bypass setpoint.

3. High Logarithmic Power Level Bypass

The high logarithmic power level bypass is provided to allow the reactor to be brought to the power range during a reactor startup. The bypass may be manually initiated above the bypass setpoint and is automatically removed when power decreases below the bypass setpoint.

4. TLC DNBR CWP and LPD CWP Bypass

For each channel, an automatic bypass is provided for the DNBR CWP and LPD CWP signals to the CWP logic if the power level is less than 1 percent full power. The high pressurizer pressure pre-trip to the CWP logic is unaffected by this bypass. Local indication of the nuclear instrument bistable used to generate the one percent full power signal is provided on the safety channel nuclear instrument drawer. 
5. TLC RPC Demand Bypass

For each channel, an automatic bypass is provided for the TLC RPC Demand signal if the power level is less than one percent full power. Local indication of the nuclear instrument bistable used to generate the one percent full power signal is provided on the safety channel nuclear instrument drawer.

6. TLC CMI Bypass

For each channel, an automatic bypass is provided for the TLC CMI signal if the power level is less than one percent full power. Local indication of the nuclear instrument bistable used to generate the one percent full power signal is provided on the safety channel nuclear instrument drawer.

B. Bistable Trip Channel Bypass

A bistable trip channel bypass prevents a bistable trip from contributing to the initiation of protective action. The bistable bypass converts the local coincidence logic to a two-out-of-three coincidence. (See section 7.2.1.1.3.)

There are two methods of initiating a bistable bypass:

1. Individual bistable bypasses located on each local and main control room PPS operators module for each bistable trip.

This method is used when removing a trip channel input from service for maintenance or manual testing. The trip bypass signal is distributed to the appropriate LCL's in the four redundant channels via its interface and test processor.

2. Four individual bistable bypasses (one for each channel) located on each local and main control room PPS operator's module, for each bistable trip.

This method is used when a complete channel becomes disabled (such as loss of vital bus) resulting in trips and no bypasses being sent to the LCL's in the remaining three channels. Each remaining channel's LCLs can be returned to a two-out-of-three condition for coincidence by the operator inserting trip bypasses, for the disabled channel trips from its own panel. Administrative procedures ensure the trip bypassing in the three remaining channels is consistent. 


\subsection{Interlocks}

The following interlocks are provided:

A. Bistable Trip Channel Bypass Interlock

The LCL trip channel bypass logic allows only one (first entered) of the four trip bypass inputs possible to affect coincidence generations. The coincidence logic becomes two-out-of-three for the remaining unbypassed bistable trips. Bypassing of a bistable, associated with a particular parameter (e.g., high pressurizer pressure), does not place any restrictions on the bypassing of other bistables (e.g. low pressurizer pressure) or other bistables associated with other parameters.

B. Manual Bistable Test Interlock

The manual bistable test function in the four redundant PPS cabinets are interlocked via the four trip channel bypasses, so that only one of the four may be selected for manual bistable testing at any one time.

C. Initiation Circuit Test Interlock

Testing of the initiation circuit is restricted to one redundant PPS cabinet at a time to prevent spurious safeguard actuation. This restriction is accomplished by an interlock which prevents test signals from being generated in more than one PPS cabinet at a time.

D. Nuclear Instrumentation Test

Placement of the linear calibration switch on the Nuclear Instrument (NI) drawer to other than "operate" will cause a channel variable overpower trip. Placement of the logarithmic calibration switch to other than "operate" will cause a channel high logarithmic power trip. In addition to these two trips, placing either of these calibration switches, or any other calibration switch on the NI drawer to other than "operate" will cause a Power Trip Test interlock to generate a low DNBR, high LPD and steam generator low water level RPS bistable trips in that channel.

E. Trip Logic Calculator Test

The low DNBR and high local power density channel trips are interlocked such that they both must be bypassed to test a TLC channel. 


\subsection{Redundancy}

Redundant features of the RPS include:

A. Four independent channels, from process sensor through and including channel trip bistables. The CEA position input is from two independent channels.

Four redundant sets of local coincidence logics, each set
performs a full two-out-of-four trip function.

c. Four initiation circuits, including four control logic paths and four sets of two initiation relays (shunt trip and undervoltage).

D. Two sets of manual trip pushbuttons with either set being sufficient to cause a reactor trip.

E. AC power for the system from four separate vital instrument buses. DC power for the trip switchgear circuit breakers control logic is provided from four separate battery systems, as described in Chapter 8.

The result of the redundant features is a system that meets the single failure criterion, can be tested during reactor operation, and can be indefinitely shifted to two-out-of-three coincidence $\operatorname{logic}$.

The benefit of a system that includes four independent and redundant channels is that the system can be operated, if need be, with up to two channels out of service (one bypassed and another tripped) and still meet the single failure criterion. The only operating restriction while in this condition (effectively one-out-of-two logic) is that no provision is made to bypass another channel for periodic testing or maintenance. The system logic must be restored to at least a three operating channel condition prior to removing another channel for maintenance. (See Section 16.3/4.3.1 Technical Specifications on the RPS.)

\subsection{Diversity}

The system is designed to eliminate credible multiple channel failures originating from a common cause. The failure modes of redundant channels and the conditions of operation that are common to them have been considered in the design to assure that a predictable common failure mode does not exist. The design provides reasonable assurance that: 
A. The monitored variables provide adequate information during design basis events (design basis events are listed in Sections 7.2 .2 .1 .1 and 7.2 .2 .1 .2$)$.

B. The equipment can perform as required.

c. The interactions of protective actions, control actions and the environmental changes that cause, or are caused by the design basis events do not prevent the mitigation of the consequences of the event.

D. The system will not be made inoperable by the inadvertent actions of operating and maintenance personnel.

E. There are alternate bistable trips available to provide the reactor trip function, should the initial trip function used in the safety analysis be disabled. This is accomplished by distributing the systems protective functions between two processors within each of the redundant PPS cabinets, such that a degree of functional diversity is achieved. As depicted on Figure 7.2-12 bistable trip and local coincidence logic functions are not implemented together in the same processors.

In addition, the bistable trip functions are further distributed between the bistable processors within a redundant PPS cabinet. The distribution assignment is based on a review of the safety analysis transients, such that when multiple trips are available to mitigate the transient, they are assigned between two separate bistable trip logic processors. This diversity improves the availability of the system to handle a transient.

F. Plant protection is augmented through the use of a separate and diverse Alternate protection System as described in
Section 7.7.1.1.11.

G. Both the RPS and Process-CCS which includes the Alternate Protection system utilize two different design types, thereby eliminating those hardware and software design common causes which may make them both inoperable.

H. Miscalibration of redundant instrument channels and trip E logic is minimized by not using a single unit to test all four redundant channels. Additionally, appropriate maintenance and test procedures are implemented by the site operator. 
I. Incorrect operator action which directly affect the ability of the RPS to function are precluded by designing the man machine interface such that two or more operator actions are required. For example, see the interlock logics and bypasses described in sections 7.2 .1 .1 .6 and 7.2.1.1.5.

J. Each RTSS circuit breakers has diverse methods of being automatically opened via the shunt trip and undervoltage trip devices.

In addition, the design is not encumbered with additional components or channels without reasonable assurance that such additions are beneficial.

\subsection{Testing}

Provisions are made to permit periodic testing of the complete RPS with the reactor operating at power or when shutdown. These tests cover the trip actions from sensor input through the protective system and the trip circuit breakers. The system test does not interfere with the protective function of the system. The testing system meets the criteria of IEEE Std. 338-1977, "IEEE Standard Criteria for the Periodic Testing of Nuclear Power Generating station Class $1 \mathrm{E}$ Power and Protection systems," and is consistent with the recommendations of NRC Regulatory Guide 1.22, "Periodic Testing of Protection System Actuator Functions."

Periodic testing consists of automatic testing and manual testing. The two methods compliment each other and provide for complete testing of the protection system. There are areas of overlap between the two methods so that the entire RPS can be tested. The overlap test methods also permit either system to, in part, verify proper functioning of the other. See Figure $7.2-16$.

Major portions of the Reactor Protection system are monitored and/or tested by the automatic test network. Those portions of the system which are not amenable to automatic testing because they involve actuation of electromechanical devices, or involve devices which are not within the PPS cabinets, can be tested manually. The automatic test network is capable of performing tests during reactor operation. The automatic testing does not degrade the ability of the RPS to perform its intended function. The automatic test network consists of channelized Interface and Test processors (ITPs), their associated protection system interface circuits, test voltage generation circuits, and test prohibit circuits (the latter prevents malfunctions of the test system from interfering with the normal operation of the safety system). Overlap exists between the individual tests performed 
by the automatic test network. The automatic test network can test the protection system continuously. Operation of the automatic test network may be verified locally at the PPS cabinet by requesting test results data. The status and a summary of the automatic testing results are available to the operator via the DIAS and DPS. The monitoring and testing performed by the automatic test network are described below.

The monitoring tasks performed by the automatic test network are passive in nature; that is, no active test signals are applied to the protection system. The monitoring consists of reading into the ITPs all of the protection system data that is accessible to the test task. This data is then analyzed to determine if the protection system is operating properly. The analysis consists of :

A. Channel to channel comparison of input signals to detect any channel to channel signal discrepancies (e.g., variance between channels exceeds a predetermined limit). Similar checks are done in the DPS. This monitors sensor and transmitter operation and $A / D$ conversion accuracy.

B. Setpoint checks to verify proper setpoint settings.

c. Status consistency checks (i.e., determining that a $E$ operating bypass, if initiated, is entered into all of the proper logic elements).

The individual tests are described briefly below. overlap between individual tests exists so that the entire RPS can be tested. Frequency of accomplishing these tests is listed in Technical Specification $16.6 / 3.3 .1$.

\subsection{Sensor Check}

During reactor operation, the measurement channels providing an input to the RPS are checked by comparing the outputs of similar channels and cross-checking with related measurements. The ITP provides sensor data to the DPS where a similar check is done.

During extended shutdown periods or refueling, these measurement channels (where possible) are checked and calibrated against known standards.

\subsection{Trip Bistable Tests}

A. Automatic Bistable Testing

The automatic test network performs several tests to insure $E$ that the bistable logic is operating properly. First, a status check is performed. The test task reads the input 
signal after it has been converted into digital form by the analog input circuit, and also reads the setpoints (trip and pre-trip). From these readings the test task makes a determination of what the status should be and compares it to the actual status of the bistable logic.

If a discrepancy exists, the test task annunciates a test failure and provides a message that describes the failure in more detail. If the bistable logic is not in a tripped state, testing is continued. By applying known test input signals, the test task can determine if the pre-trip and trip functions of the bistable logic are operating properly. To ensure that the test signal will not interfere with a valid trip signal which may be present, the bistable logic is designed to accept the signal which is closest to the trip setpoint in the trip direction. Thus, the bistable logic function can never be forced to the untripped state by the test task. Additionally, testing of the bistable logic will not produce a system initiation because:

1. The test task removes the test signal before the initiation circuit time delay can respond.

2. Any test input signal not removed by the automatic test network will be removed by the timing logic built into the bistable trip logic. The actual measurement channel signal is not affected by this function; its input into the bistable is thus assured at all times.

Bistable logic function accuracy tests are performed by applying a known test signal into the analog input circuit of the bistable and sampling its converted digitized value. Proper response of the analog to digital converter to these test signals insures that the bistables logic will trip and pre-trip within an acceptable tolerance of their setpoints.

\section{B. Manual Bistable Testing}

Manual testing of the bistable logic functions can be performed to verify proper bistable logic functions not tested automatically.

The testing is accomplished by varying the input signal up to or down to the trip setpoint level on one bistable logic function at a time.

Using a bistable selection switch, and the built in digital voltmeter, it is possible to read the bistable input signal. 
Varying the input signal is accomplished by means of a trip test circuit consisting of a digital voltmeter, a test circuit, and trip test switch. The test circuit is interlocked so that it can be used in only one channel at a time, as shown in F-gure 7.2-17. A switch is provided to select the measurement channel, and a test switch is provided to apply the test signal. The digital voltmeter indicates the value of the test signal. Each bistable's trip status is provided to verify its proper response.

The interlock assures the manual bistable testing can only be used in one channel at a time. The interlock is satisfied when trip channel bypasses from the 4 protective channels for the selected bistable are true. This places the selected bistables LCLs in a two-out-of-three coincidence. Because a test signal can be less conservative than the process input applied during manual bistable testing, the bistable trip output is forced into a tripped state while the momentary trip test switch is active. Deactivating the switch or changing the trip channel bypass status will remove the test input voltage and forced trip.

c. Manual Testing of Variable setpoint with Automatic Rate Limiting

Manual testing of bistables that utilize this type of setpoint verifies that:

1. The setpoint tracks the input signal both for increasing and decreasing signals.

2. For fixed input the setpoint is fixed and within the prescribed tolerance.

3. Maximum and minimum setpoint values if applicable are within the prescribed tolerances.

4. The setpoint no longer tracks once a bistable trip occurs but remains fixed until the signal returns to untripped levels.

D. Manual Testing of Variable setpoint with Manual Reset

Testing of bistables using this variable setpoint circuitry is accomplished by use of both automatic and manual tests. Automatic testing is limited to a passive check. This check consists of determining if the setpoint is appropriate for a 
given input signal level (e.g., considering a bistable logic function that trips on a falling signal, the setpoint should not be more than a predetermined increment below the input signal level).

The ability of the variable setpoint circuitry to track the input signal can be verified by means of the manual test panel. From the test panel the bistable input signal may be moved in any direction (i.e., toward the trip value or away from the trip value, whereas the automatic test system can only move the input signal level in the direction of a trip). Using this manual capability it is also possible to verify that a specific time interval must elapse between resets to the circuit. To test this, the setpoint is reset; the input is then manually changed. It is then verified that the manual reset has no effect upon the setpoint until the appropriate time interval has elapsed.

E. Manual Testing of Variable setpoint with Diverse Trip Parameter

Testing of bistables using a aiverse trip process for setpoint generation will be manually tested in two parts. The first part is done when the bistable is selected and tested for normal trip process input variations. Since the variable setpoint is not controlled during the first part, the second part will test the variable setpoint function when the trip process used for setpoint generation is varied. Bypassing of the bistable is required during both parts of the testing.

\subsection{Core Protection Calculator Tests}

The operation and calculations of the Trip Logic Calculators (TLCS) in the Core Protection Calculators (CPCs) are tested at three overlapping levels. The first level makes use of operator's modules to make redundant channel comparisons. This testing verifies the proper operation of the sensors and data acquisition portion of the TLC. The second level is performed with the TLC off line. An interlock is provided to ensure that this testing is done on only one channel at a time. See section 7.2.1.1.6E. Testing consists of loading test data from a disk into the TLC to test the program/calculations. During the period that the TLC is off line, trip signals are sent from the TLC to the PPS. The third level of testing takes place with the TLC on line. With the TLC on line and bistable bypasses present for high LPD and low DNBR, nuclear power is increased at the ruclear instrument until trip signals are generated by the calculator. Presence of the trip signals are verified at the PPS. 
Testing of the local coincidence logic is done by the automatic test network. One of the tests performed by the automatic test network is a status check. It does so by reading the status of the inputs to the logic (trips and bypasses). Based upon those inputs, the test task determines what the outputs (coincidence signal and bypass status) should be. If there is a discrepancy between the actual outputs and the determined outputs, the test task annunciates a test failure and provides a message that describes the failure in more detail. If there is no discrepancy and conditions are such that the local coincidence logic is not generating a coincidence signal, testing of the logic continues.

The additional testing that is done is dependent upon the status of those inputs over which the test task has no control (bistable bypasses, operating bypasses, and bistable trips due to the signal inputs). Based upon the known inputs, the test system will generate all bistable trip combinations that are within its control, recalling that a tripped bistable cannot be forced to the untripped condition by the test task. The outputs of the local coincidence logic are then monitored for correctness. All possible combinations of bistable trips are generated.

\section{$7 \cdot 2 \cdot 1 \cdot 1 \cdot 9 \cdot 5$}

\section{RPS Initiation Logic Testing}

The initiatior logic, which consists of an "OR" logic is tested at the same time the local coincidence logic is tested. (see Figure 7.2-14) Each time a coincidence signal is generated, the automatic test task verifies that the signal is propagated through the "OR" logic. Failure of the coincidence signal to propagate through the "OR" logic will result in the annunciation of a test failure and a message that describes the failure in more detail.

A. Testing of RPS Time Delay and Reactor Trip Circuit Breakers

The RPS time delay and circuit breaker test is a manually initiated test. The test is manually initiated because the test philosophy requires operator involvement in the testing and reclosing of these important reactor trip devices. The operator can obtain status information from the undervoltage, shunt trip and current monitors depicted in Figure 7.2-12 and thus determine the success or failure of the test for both of the diverse methods of tripping the breaker. 
The manual trip feature is tested by depressing one of the four manual trip pushbuttons, observing a trip of a trip breaker, and resetting the breaker prior to depressing the next manual trip pushbutton. Closing of the circuit breaker can be initiated from the PPS operator's module locally or at the main control room.

The manual initiation switch is a 3-position rotary return to center with a momentary pushbutton. The three positions are: (1) Undervoltage Coil, (2) Shunt Trip Coil and (3) Both. The center position is Both.

\section{$7 \cdot 2 \cdot 1 \cdot 1 \cdot 9 \cdot 7$ \\ Bypass Testing}

A. Operating Bypass Testing

The operating Bypasses are automatically tested. Testing is both passive and active. The fassive check consists of verifying the appropriateness of the bypass, i.e., is the input parameter in the range of values over which the bypass is allowed. The active test, as a part of the bistable logic testing, verifies that the bistable can have an output consister.t with the operating bypass status, i.e., if an operating bypass is not present, the bistable can be tripped; with an operating bypass present, the bistable cannot be tripped.

The permissive bistable logic from which the operating bypass logic receives the auto-removal signal is also verified. This is accomplished by actively testing the permissive bistable logic in the same manner that the trip bistable logic functions are tested. When testing the permissive bistable it can be verified that when the auto-removal condition is present, the operating bypass is removed.

B. Bistable Trip Channel Bypass Testing

A description of testing bistable trip channel bypasses is included as part of the local coincidence logic testing described in section 7.2.1.1.9.4.

$7 \cdot 2 \cdot 1 \cdot 1 \cdot 9 \cdot 8$

Response Time Tests

Response time testing of the complete Reactor Protective system, is accomplished by the combined use of portable field installed test equipment and test features provided as part of the PPS automatic test network. 


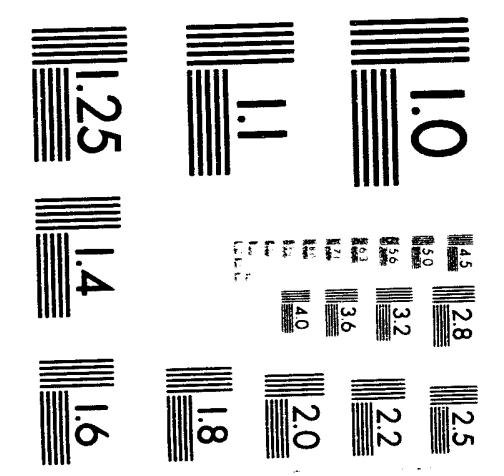



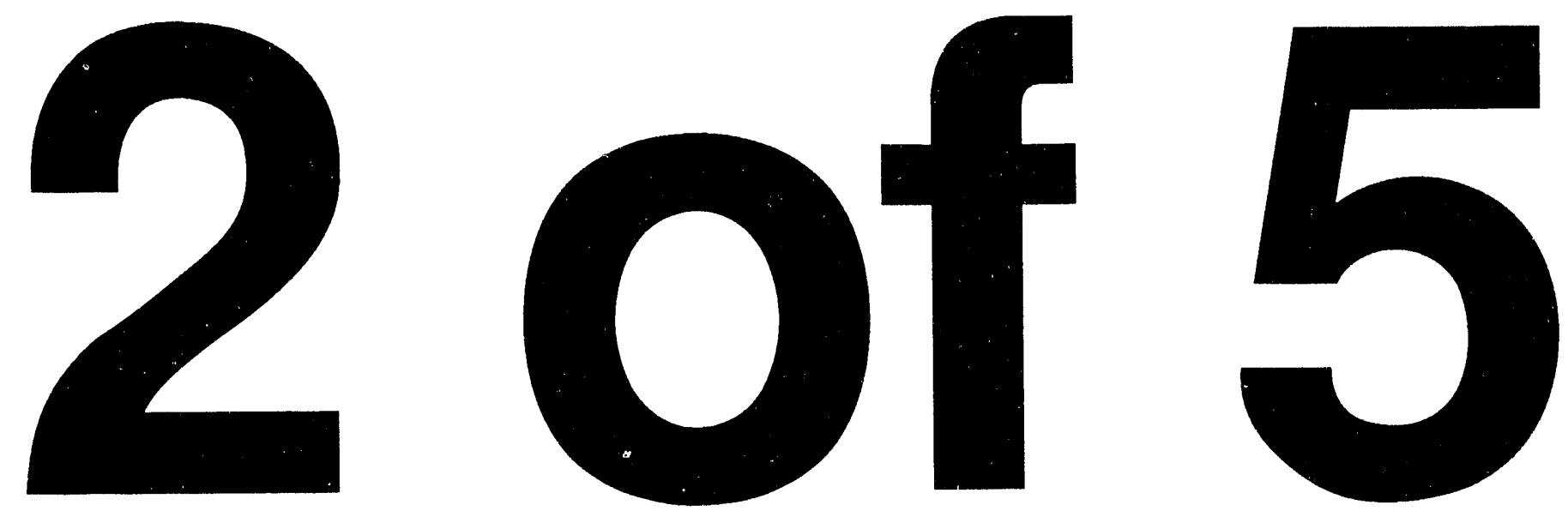
Measurement Channel Response Time Tests, which include portions of the system (such as cables and sensors) may be conducted on a $E$ system basis or an overlapping subsystem basis.

Methods which are used to conduct these tests include:

A. Perturbation and monitoring of plant parameters - either during operation or while shutdown. This method is $/ E$ applicable to RTDs (monitored following a plant trip), reactor coolant pump speed sensors (monitored following turn-off of pump), and CEA position reed switches (monitored during CEA motion).

B. On-line power spectral density analysis. This method would be applicable to analog sensors.

c. Off-line injection of step or ramp changes for RPS inputs. $E$ This method would be applicable to sensors (via special pressure test rigs, hot oil baths or hot sand boxes) or electronics and logic (via special electrical test boxes).

D. The automatic test network in the course of its normal testing implicitly verifies that the response time of the PPS is less than a known upper limit. The upper limit is bounded by the bistable logic processor execution time (fixed) plus the coincidence processor execution time (fixed) plus the worst case skew time due to the asychronous operation of the processor. An independent timer monitors the fixed execution time and provides overruns status. The automatic test network reads this status and will annunciate a failure.

E. Operation and monitoring of actuated devices. This method would be applicable to the CEDMs, including their control logic and switchgear.

F. System test - from sensor to actuated device - utilizing a combination of the above techniques. This method might incorporate, for example, a step input from a test rig to a sensor, measuring total time until CEDMs drop.

G. Factory or laboratory tests of removed components. This method would be applicable to all components.

The trip delay times used in the chapter 15 safety Analysis for various trips are verified by using the above methods. E specifically, the methods applicable to each trip are: 
(1) High Logarithmic and Variable overpower Levels use method B, $C, D, F$ or $G$.

(2) Low DNBR and High Local Power Density use method A, B, C, D, $E, F$ or $G$.

(3) High Pressurizer Pressure, Low Pressurizer Pressure, Low Steam Generator Water Level, Low steam Generator Pressure and High Steam Generator Water Level use method B, C, D, E, $F$ or $G$.

The design of the Reactor protective system is such that connections may conveniently be made for the appropriate test equipment. The hardware design includes test connections on the instrument lines going to pressure and differential pressure transmitters, and test points wired out to convenient connectors or terminal strips. C-E supplies to the site operator the data obtained during factory or laboratory testing so that this may be correlated with this field data.

\section{$7 \cdot 2 \cdot 1 \cdot 1 \cdot 10$ \\ Vital Instrument Power supply}

The vital instrument power supply requirements are discussed in Chapter 8 .

$7 \cdot 2 \cdot 1 \cdot 1 \cdot 11$

System Arrangement

RPS components are arranged so as to conform to the separation, independence, and other criteria specified in this chapter. The safety-related components are located to provide access for maintenance, testing and operation as required.

The redundant channels and divisions of the PPS, RPS and RTSS instrumentation and control cabinets are designed to be located in separate plant control complex locations. These locations conform to Regulatory Guides 1.17 and 1.120 for safety system security and fire protection as described in sections 7.1.2.16 and 7.1 .2 .29 .

The control complex and RPS arrangements are designed to maintain independence between the Main control Room and Remote shutdown Panel such that transfer of control can be achieved as described in sections 7.4.1.1.10 and 7.7.1.3.

\subsubsection{Design Bases}

The RPS is designed to assure adequate protection of the fuel, fuel cladding, and RCS boundary during Anticipated operational occurrences. In addition, the system is designed to assist the 
ESF systems in mitigating the consequences of accidents. To ensure that these design bases are achieved, the reactor must be maintained within the limiting conditions of operation, as defined in Technical specification $16.6 / 3.3$ and the limiting safety system settings implemented consistent with section $16.2 / 2.0$.

The system is designed on the following bases to assure adequate performance of its protective function:

A. The system is designed in compliance with the applicable criteria of the "General Design Criteria for Nuclear Power Plants," Appendix A of 10 CFR 50.

B. Instrumentation, function, and operation of the system conforms to the requirements of IEEE standard 279-1971, "Criteria for Protective systems for Nuclear Power Generating stations."

C. System testing conforms to the requirements of IEEE standard 338-1977, "Standard Criteria for Periodic Testing of Nuclear Power Generating station Protection systems."

D. The system is designed in consistence with the recommendations of Regulatory Guide 1.53, "Application of the Single-Failure Criterion to Nuclear Power Plant Protective Systems," and Regulatory Guide 1.22, "Periodic Testing of Protection System Actuation Functions."

E. The system is designed to determine the following generating station conditions in order to provide adequate protection during Anticipated operational occurrences:

1. Core power (neutron flux).

2. Reactor coolant system pressure.

3. DNBR in the limiting coolant channel in the core.

4. Peak local power density in the limiting fuel pin in the core.

5. Steam generator water level.

6. Reactor coolant flow. 
F. The system is designed to determine the following generating station conditions in order to provide mitigation assistance to the ESF during accidents :

1. Core power.

2. RCS pressure.

3. Steam generator pressure.

4. Containment pressure.

5. Reactor coolant flow.

6. Steam Generator Water Level.

7. DNBR in the limiting coolant channel in the core.

G. The system is designed to monitor all generating station variables that are needed to assure adequate determination of the conditions given in listings $E$ and $F$ above, over the entire range of normal operation and transient conditions. The full power nominal values and the maximum and minimum values that can be sensed for each monitored plant variable are given in Table 7.2-2. The type, number, and location of the sensors provided to monitor these variables are given in Table $7.2-3$.

H. The system is designed to alert the operator when any monitored plant condition is approaching a condition that would initiate protective action.

I. The system is designed so that protective action will not be initiated due to normal operation of the generating station.

Nominal full power values of monitored conditions and their corresponding protective action (trip) setpoints are given in Table $7.2-4$.

The selection of these trip setpoints is such that adequate protection is provided when all sensor and processing time delays and inaccuracies are taken into account. Reactor trip delay times and analysis setpoints are given in the chapter 15 safety analyses.

The reactor protective system sensor response times, reactor trip delay times, and analysis setpoints used in chapter 15 are representative of the manner in which the RPS and associated instrumentation will operate. These quantities

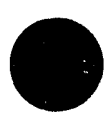


are used in the transient analysis documented in Chapter 15. Note that the reactor trip delay times shown in Chapter 15 do not include the sensor response times. Actual RPS equipment uncertainties, response times and reactor trip delay times are obtained from calculations and tests performed on the RPS and associated instrumentation. The verified system uncertainties are factored into all RPS settings and/or setpoints to assure that the system adequately performs its intended function when the errors and uncertainties combine in an adverse manner.

J. All system components are qualified for environmental and seismic conditions in accordance with IEEE standard 323-1983, and IEEE Standard 344-1987. Compliance is addressed in sections 3.10 and 3.11 , respectively. In addition, the system is capable of performing its intended function under the most degraded conditions of the energy supply, as addressed in section 8.3 .

K. System components with known susceptibility to electromagnetic interference (EMI) are subjerted to EMI qualification in accordance with applicable requirements of MIL-STD-461C, 1986, "Electromagnetic Emission and Susceptibility Requirements for the control of Electromagnetic Interference." Radiated and conducted EMI envelopes are established for qualification. A site-specific EMI survey is then performed to ensure that system exposure to EMI is within qualification envelope limits.

\subsubsection{System Drawings}

The RPS MCBDs, signal logics, block diagrams, and test circuit block diagrams are shown in Figures 7.2-1 through 7.2-30.

7.2 .2

7.2 .2 .1

\section{ANALYSIS}

\section{Introduction}

The RPS is designed to provide the following protective functions :

A. Initiate automatic protective action to assure that acceptable RCS and fuel design limits are not exceeded during specified Anticipated Operational Occurrences.

B. Initiate automatic protective action during accidents to aid the ESF systems in limiting the consequences of the accidents. 
A description of the reactor trips provided in the RPS is given in section 7.2.1.1.1. Section 7.2.2.2 provides the bases for all the RPS trips and Table 7.2-4 gives the applicable nominal trip setpoints.

Some of the trips in the RPS are single parameter trips (i.e., a trip signal is generated by comparing a single measured variable with a fixed setpoint). The RPS trips that do not fall into this category are as follows:

A. Low Pressurizer Pressure Trip

This trip employs a setpoint that is determined as a function of the measured pressurizer pressure or that is varied by the operator.

B. Low Steam Generator Pressure Trip

This trip employs a setpoint that is determined as a function of the measured steam generator pressure or that is varied by the operator.

C. Low Steam Generator Water Level Trip

This trip employs a variable setpoint that is a function of reactor power. The setpoint will track automatically in an increasing or decreasing direction. A fixed minimum low setpoint is also incorporated.

D. High Local Power Density Trip

This trip is calculated as a function of several measured variables.

E. LOW DNBR Trip

This trip is calculated as a function of several measured variables.

F. Variable overpower

This trip employs a variable setpoint that will track automatically in an increasing or decreasing direction. Rate of change of an increasing neutron flux power input is limited by a predetermined input to setpoint margin and setpoint tracking rate. A fixed high setpoint is also incorporated. 
G. Low Reactor coolant Flow Trip

This trip employs a variable setpoint that will track automatically in an increasing or decreasing direction. A decreasing rate of change of the differential pressure across the primary side of the steam generator input signal is limited by a predetermined input to setpoint margin and setpoint tracking rate. A fixed low setpoint is also incorporated.

The low DNBR and high local power density trips are provided in the TLCS. All RPS trips are provided with a pre-trip alarm in addition to the trip alarm. pre-trip alarms are provided to alert the operator to an approach to a trip condition and play no part in the safety evaluation of the plant.

Each RPS setpoint is chosen to be consistent with the function of the respective trip. The adequacy of all RPS trip setpoints, with the exception of the low DNBR and high local power density trips, is verified through an analysis of the pertinent system transients reported in chapter 16. These analyses utilize an Analysis setpoint (assumed trip initiation point) and system delay times associated with the respective trip functions. The analysis setpoint along with instrument uncertainties provides the basis for the calculation of the final equipment setpoints to be reported in the Technical specifications. Limiting trip delay times are given in chapter 15. The manner by which these delay times and uncertainties will be verified is discussed in section 7.2 .1 .2 .

The adequacy of the low DNBR and high local power density trips was certified by a combination of static and dynamic analyses. These arialyses provide assurance that the low DNBR and high local power density trips function as required and provide the justification for the TLC time response assumed in chapter 15 safety analyses. This is accomplished by certifying that algorithms used in these two trips predict results that are conservative with respect to the results obtained from standard design methods, models, and computer codes used in evaluating plant performance. This verification also takes into account all errors and uncertainties associated with these two trips, in addition to trip delay times, and will assure that the consequences of any Anticipated operational Occurrences do not include violation of specified acceptable fuel design limits. Examples of the computer codes that will be used in this verification are given in chapter 15.

\subsection{Anticipated Operational Occurrences}

Anticipated Operational occurrences that are accommodated by the system are those conditions that may occur one or more times 
during the life of the plant. In particular, the occurrences considered include single component or control system failures resulting in transients which may require protective action.

The fuel design and RCPB limits used in the RPS design for Anticipated Operational Occurrence are:

A. The DNBR, in the limiting coolant channel in the core, shall not be less than the DNBR safety limit.

B. The peak local power density in the limiting fuel pin in the core shall not be greater than the peak linear heat rate safety limit.

C. The RCS pressure shall not exceed established pressure boundary limits.

The Anticipated Operational Occurrence that were used to determine the system design requirements are:

A. Insertion or withdrawal of CEA groups, including:

1. Uncontrolled sequential withdrawal of CEA groups.

2. Out of sequence insertion or withdrawal of CEA groups.

3. Excessive sequential insertion of CEA groups.

B. Insertion or withdrawal of CEA subgroups, including:

1. Uncontrolled insertion or withdrawal of a CEA subgroup.

2. Dropping of one CEA subgroup.

3. Misalignment of CEA subgroups comprising a designated CEA group.

C. Insertion of a single CEA, including:

1. Uncontrolled insertion of a single CEA.

2. A dropped full- or part-length CEA.

3. A statically misaligned CEA.

D. Uncontrolled boron dilution.

E. Excess heat removal due to secondary system malfunctions.

F. Change of forced reactor coolant flow resulting from a loss of electrical power to reactor coolant pumps. 
G. Inadvertent pressurization or depressurization of RCS resulting from anticipated single control system malfunctions.

H. Change of normal heat transfer capability between steam and reactor coolant systems resulting from improper feedwater flow, a loss of external load and/or turbine trip, or a loss of condenser vacuum.

I. Complete loss of AC power to the station auxiliaries.

J. Asymmetric steam generator transients due to instantaneous closure of one MSIV.

K. Uncontrolled axial Xenon oscillations.

L. Depressurization due to the inadvertent actuation of primary or secondary safety valves.

The implementation of TLC initiated CEA motion inhibit and cutback demand functions has resulted in the reclassification of selected CEA malfunction events to be classed as Accidents. These events are included in section 7.2.2.1.2 as unplanned events for which the RPS will take action.

\subsection{Accidents}

The accidents for which the system will take action are those unplanned events under any conditions that may occur once during the life of several stations and certain combinations of unplanned events and degraded systems that are never expected to occur. The consequences of most of these limiting faults will be limited by the ESF Systems; the RPS will provide action to assist in limiting these conditions for these accidents. The accidents for which the RPS will provide protective action assistance are:

A. RCS pipe rupture.

B. CEA events, including:

1. Ejection of any single CEA.

2. Uncontrolled witharawal of single CEA.

3. A single CEA sticking, with the remainder of the CEAs in that group moving.

C. Steam system pipe rupture. 
D. Feedwater system pipe rupture.

E. Reactor coolant pump shaft seizure.

F. Break in a line from the reactor coolant pressure boundary that penetrates containment.

G. A reactor coolant pump sheared shaft.

H. Steam generator tube rupture.

$7 \cdot 2 \cdot 2 \cdot 2$

Trip Bases

The RPS consists of fifteen trips in each of the four RPS/E channels that will initiate the required automatic protective action utilizing a coincidence of two like trip signals.

A brief description of the inputs and purpose of each trip is presented in sections 7.2.2.2.1 through 7.2.2.2.11.

\subsection{Variable Overpower Trip}

A. Input

Neutron flux power from the excore neutron flux monitoring system.

B. Purpose

To provide a reactor trip to assist the ESF systems in the event of an ejected CEA Accidents.

7.2.2.2.2 High Logarithmic Power Level Trip

A. Input

Neutron flux power from the excore neutron flux monitoring system.

B. Purpose

To assure the integrity of the fuel cladding and RCS boundary in the event of unplanned criticality from a shutdown condition, resulting from either dilution of the soluble boron concentration or uncontrolled withdrawal of CEAs. In the event that CEAs are in the withdrawn position, automatic trip action will be initiated. If all CEAs are inserted, an alarm is provided to alert the operator to take appropriate action in the event of an unplanned criticality. 
7.2 .2 .2 .3

High Local Power Density Trip

A. Inputs

1. Neutron flux power and axial power distribution from the excore neutron flux monitoring system.

2. Radial peaking factors from CEA position measurement system (reed switch assemblies).

3. Thermal power from coolant temperatures, pressure and flow measurements.

4. Penalty factors from CEFCs for CEA deviation within a subgroup.

5. Penalty factors generated within the TLC for subgroup | I
deviation and groups out-of-sequence.

B. Purpose

To prevent the linear heat rate $(\mathrm{kW} / \mathrm{ft})$ in the limiting fuel pin in the core from exceeding fuel design limits in the event of defined Anticipated Operational Occurrences.

\subsection{LOW DNBR Trip}

A. Inputs

1. Neutron flux power and axial power distribution from the excore neutron flux monitoring system.

2. RCS pressure from pressurizer pressure measurement.

3. Thermal power from coolant temperatures, pressure and flow measurements.

4. Radial peaking factors from CEA position measurement (reed switch assemblies).

5. Reactor coolant mass flow from reactor coolant pump speeds and temperatures.

6. Core inlet temperature from reactor coolant cold leg temperature measurements.

7. Penalty factors from CEACs for CEA deviation within a subgroup. 
8. Penalty factors generated within the TLC for subgroup deviation and groups out-of-sequence.

B. Purpose

To prevent the DNB ratio in the limiting coolant channel in the core from exceeding the fuel design limit in the event of defined Anticipated Operational Occurrences. In addition, this trip will provide a reactor trip to assist the ESF systems in limiting the consequences of the steam line break inside and outside containment, steam generator tube rupture and reactor coolant pump shaft seizure accidents.

7.2.2.2.5 High Pressurizer Pressure Trip

A. Input

Reactor coolant pressure from narrow range (1500-2500 psia) pressurizer pressure measurement.

B. Purpose

To help assure the integrity of the RCS boundary for any defined Anticipated operational occurrence that could lead to an overpressurization of the RCS.

7.2.2.2.6 Low Pressurizer Pressure Trip

A. Input

Reactor coolant pressure from combined high and low range pressurizer pressure measurements.

B. Purpose

To provide a reactor trip in the event of reduction in system pressure, in addition to the DNBR trip, and to provide a reactor trip to assist the ESF systems in the event of a LOCA.

\subsection{Low St:aam Generator Water Level Trips}

A. Input

Level of water in each steam generator downcomer region from wide range differential pressure measurements. Neutron flux power from the ex-core neutron flux monitors for determination of the variable water level setpoint. 


\section{B. Purpose}

To provide a reactor trip to assist the ESF systems to assure that there is sufficient time for actuating the emergency feedwater pumps to remove decay heat from the reactor in the event of a reduction of steam generator water inventory.

\subsection{Low Steam Generator Pressure Trips}

\section{A. Input}

steam pressure in each steam generator.

B. Purpose

To provide a reactor trip to assist the ESF systems in the event of a steam line break accident.

\subsection{High Containment Pressure Trip}

A. Input

Pressure inside reactor containment.

B. Purpose

To assist the ESF Systems by tripping the reactor coincident with the initiation of safety injection caused by excess pressure in containment.

\section{2 .2 .2 .10 \\ High Steam Generator Water Level Trips}

A. Input

Level of water in each steam generator downcomer region from narrow range differential pressure measurements.

B. Purpose

To assist the ESF systems by tripping the reactor coincident with initiation of Main steam Isolation caused by a high steam generator water level.

\subsection{Low Reactor Coolant Flow}

\section{A. Input}

Pressure differential measured across the steam generator primary side. 
B. Purpose

To provide a reactor trip in the event of a reactor coolant pump sheared shaft.

7.2.2.2.12 Manual Reactor Trip

A. Input

Two independent sets of trip pushbuttons.

B. Purpose

A Manual Reactor Trip is provided to permit the operator to trip the reactor.

\subsubsection{Design}

7.2.2.3.1 General Design Criteria

Appendix A of 10 CFR 50, "General Design Criteria for Nuclear Power Plants," establishes minimum requirements for the principle design criteria for water-cooled nuclear power plants. This section describes how the requirements that are applicable to the RPS are satisfied.

Criterion 1 - Quality standards and Records:

Refer to section 3.1 .1 for compliance.

Criterion 2 - Design Bases for Protection Against Natural Phenomenon:

Refer to section 3.1 .2 for compliance.

Criterion 3 - Fire Protection:

Refer to section 3.1 .3 for compliance.

Criterion 4 - Environmental and Missile Design Bases:

Refer to section 3.1.4 for compliance.

Criterion 5 - Sharing of structures, systems, and Components:

Refer to section 3.1 .5 for compliance. 
Criterion 10 - Reactor Design:

Refer to section 3.1 .6 for compliance. Typical margins between the normal operating value and the trip setpoint are given on Table 7.2-4.

Criterion 12 - Suppression of Reactor Power Oscillations:

Refer to section 3.1 .8 for compliance. The axial power distribution is continuously monitored by the RPS and factored into the low DNBR and high LPD trips. This assures that acceptable fuel design limits are not exceeded in the event of axial power oscillations. Allowances are made in the trip setpoints for azimuthal power tilts.

criterion 13 - Instrumentation and Control:

Refer to section 3.1 .9 for compliance.

Criterion 15 - Reactor Coolant System Design:

Refer to section 3.1 .11 for compliance.

Criterion 16 - Containment Design:

Refer to Section 3.1 .12 for compliance.

Criterion 19 - control Room:

Refer to Section 3.1.15 for compliance. RPS status monitoring and controls necessary for safe operation of the unit are provided in the main control room via the DIAS, DPS, CPC Remote Operators Modules and the PPS Remote operators Modules.

Criterion 20 - Protection system Functions: Refer to section 3.1 .16 and 7.2 .2 .1 for $\mid E$
compliance. $\begin{array}{llll}\text { Criterion } 21- & \text { Protection } & \text { Testability: } & \text { Tystem and }\end{array}$ Refer to section 3.1 .17 and 7.2 .2 .3 .3 for $\mid E$
compliance. 
Criterion 22 - Protection System Independence:

Refer to sections 3.1 .18 and $7.2 .2 .3 .2 . \mathrm{F}$ for compliance.

Criterion 23 - Protection System Failure Modes:

Refer to sections 3.1 .19 and 7.2 .2 .4 for compliance.

Criterion 24 - Separation of Protection and Control systems:

Refer to sections $3.1 .20,7.2 .2 .3 .2 . \mathrm{G}$ and 7.7.1.1.13 for compliance.

Criterion 25 - Protection System Requirements for Reactivity Control Malfunctions:

Refer to section 3.1 .21 for compliance.

Criterion 29 - Protection Against Anticipated Operational occurrences:

Refer to section 3.1 .25 for compliance.

\subsection{Equipment Design Criteria}

IEEE Std. 279-1971 "Criteria for Protection systems for Nuclear Power Generating stations," establishes minimum requirements for safety-related functional performance and reliability of the RPS. This section describes how the requirements of Section 4 of IEEE std. 279-1971 are satisfied. The parenthesized data, following headings, correspond to the section numbers of IEEE Std. 279-1971.

A. General Functional Requirement (Section 4.1):

The RPS is designed to limit reactor fuel, fuel cladding, and coolant conditions to levels within plant and fuel design limits. Instrument performance characteristics, response times, and accuracy are selected for compatibility with and adequacy for the particular function. Trip setpoints are established by analysis of the system parameters. Factors such as instrument inaccuracies, bistable trip times, CEA travel times, and circuit breaker trip times are considered in the design of the system.

B. Single Failure criterion (Section 4.2):

The RPS is designed so that any single failure within the system shall not prevent proper protective action at the 
system level. No single failure will defeat more than one of the four protective channels associated with any one trip function. The wiring in the system is grouped so that no single fault or failure, including either an open or shorted circuit, will negate protective system operation. Signals routed between redundant PPS cabinets utilizes fiber-optic cables. Signal conductors and power leads coming into or going out of each cabinet are protected and routed separately for each channel of each system to minimize possible interaction. Single failures considered in the design of the RPS are described in the Failure Modes and Effects Analysis (FMEA) shown on Table 7.2-5.

C. Quality Control of Components and Modules (Section 4.3):

The systems which function to provide protective action are designed in accordance with the Quality Assurance program described in chapter 17.

D. Equipment Qualification (Section 4.4):

The RPS meets the equipment requirements described in Sections 3.10, 3.11, 7.1.2.5 and 7.1.2.8. Safety-related RPS equipment is located so as not to violate qualification I limits.

E. Channel Integrity (Section 4.5):

Type testing of components, separation of sensors and channels, and qualification of the cabling by the site operator, are utilized to ensure that the channels will maintain their functional capability required under applicable extremes of environment, power supplied, malfunction and fault conditions. Loss of or damage to any one channel will not prevent the protective action of the RPS. Sensors are connected so that blockage or failure of any one connection does not prevent protective system action. The process transducers located in the containment building are specified and rated for the intended service. Components which must operate during or after an accident are qualified for the most limiting environment for the period of time for which they must maintain their functional capability. Results of type tests are used to verify this.

F. Channel Independence (Section 4.6):

The routing of $1 \mathrm{E}$ and associated cabling and sensing 1 ines from sensors meets the requirements of Regulatory Guides 1.75 and 1.151. They are arranged to minimize the possibility of common mode failure. This requires that the 
cabling for the four safety channels be routed separately; however, the cables of different safety functions within one channel may be routed together. Low energy signal cables are generally routed separately from all power cables. safety-related sensors are separated. The separation of safety-related cables requires that the cables be routed in separate cable trays. Associated circuit cabling from redundant channels is handled the same as $1 \mathrm{E}$ cabling.

Cabling associated with redundant channels of safety-related circuits is installed such that a single credible event cannot cause multiple channel malfunctions or interactions between channels.

Non-Class $1 \mathrm{E}$ instrumentation circuits and cables (low level) which may be in proximity to Class $1 \mathrm{E}$ or associated circuits and cables, are treated as associated circuits unless analyses or tests demonstrate that credible failures therein cannot adversely affect Class $1 \mathrm{E}$ circuits.

Each redundant channel is independent of the other redundant channels. The sensors are separated, cabling is routed separately and each redundant channel is located in a separate cabinet, geographically located in different fire zones. This minimizes the possibility of a single event causing more than one channel's failure. The outputs from these redundant channels are isolated from each other so that a single failure does not cause impairment of the system function. The Reed Switch Position Transmitter signals are sent to separate CEA Calculators. To provide the required input to the CEAC, the signals utilized as inputs are sent through optical isolators (see Figure $7.2-7)$.

Outputs from the redundant channels to non-safety related areas are isolated utilizing fiber-optic cable so that a failure in the non-safety related area does not cause loss of the safety system function. Outputs from the components of the RPS to the control boards are isolated. The signals originating in the RPS which feed the DIAS, DPS and control systems are isolated utilizing fiber optic cable to maintain their channel independence.

The compliance of the RPS with the requirements of IEEE 384-1981, "IEEE Standard Criteria for Independence of Class $1 \mathrm{E}$ Equipment and Circuits," and Regulatory Guide 1.75, "Physical Independence of Electric systems," is discussed in section 7.1 .2 .10 . 
G. Control and Protection system Interaction (Section 4.7):

1. Classification of Equipment (Section 4.7.1):

Protective system functions and control systems that have identical sensor requirements may utilize the same sensors (see the MCBDs for the specific sensors which are shared). The control systems use sensor signal validation logic, as described in section 7.7.1.1.13, to avoid control protection system interactions.

The RPS' DNBR, LPD, and high pressurizer pressure pre-trips provide a CEA Withdrawal Prohibit (CWP) to the CEDMCS.

The TLCs provide CEA Motion Inhibit (CMI) and Reactor Power Cutback Demand signals to the CEDMCS.

The MDS monitors margin-to-trip conditions for RPS parameters to establish limiting conditions of operation for load following maneuvers.

Portions of the protective channels used for both protection and control are classified as part of the protection system up to and including the isolation device used to interface with the control system.

2. Isolation Devices (Section 4.7.2):

Control signals from the RPS are isolated using fiber optic cable such that a failure will not affect the protective action of the RPS.

3. Single Random Failure (Section 4.7.3):

This criterion is not applicable. Due to signal validation, the signals which are sent to the control systems cannot cause a control action which could require a protective action.

4. Multiple Failures Resulting from a credible single Event (Section 4.7.4):

This cannot exist since failures within the protective system can not propagate to the control systems due to isolation devices. 
H. Derivation of System Input (Section 4.8):

Insofar as is practicable, system inputs are derived from signals that are direct measures of the desired variables. Variables that are measured directly include neutron flux, temperatures, and pressures. Level information is derived from appropriate differential pressure measurements. Flow information is derived from steam generator primary side differential pressure measurements, reactor coolant pump speed measurement and coolant temperature.

I. Capability for Sensor Checks (Section 4.9):

RPS sensors are checked by cross-channel comparison. Each channel has a known relationship with the other channels of the same parameter.

J. Capability for Test and Calibration (Section 4.10):

The RPS design complies with IEEE std. 338-1977, "Periodic Testing of Nuclear Power Generating station Class $1 \mathrm{E}$ Power and Protection Systems," and the intent of Regulatory Guide 1.22, "Periodic Testing of Protection system Actuator Functions," as discussed in section 7.2.2.3.3.

K. Channel Bypass or Removal From Operation (Section 4.11):

Any one of the four protection channels in the RPS may be tested, calibrated, or repaired without impairing the systems' protective action capability. In the RPS, individual trip channels may be bypassed to create a two-out-of-three logic on the remaining channels which maintains the coincidence of two required for trip. The single failure criterion is met during this condition. Testing of each of the two CEA position indication channels can be accomplished in a very brief time. The probability of failure of the other position indication system is acceptably low during such testing periods.

L. Operating Bypasses (Section 4.12):

Operating bypasses are provided as shown on Table 7.2-1. The operating bypasses are automatically removed when the permissive conditions are not met. The circuitry and devices which function to remove these inhibits are designed in accordance with IEEE std. 279-1971. 
M. Indication of Bypasses (Section 4.13):

Indication of test or bypass conditions, or removal of any channel from service is given via remote operator's modules and DPS. Operating bypasses that are automatically removed at fixed setpoints are alarmed and indicated via remote operator's modules and DPS.

N. Access to Means for Bypassing (Section 4.14):

Trip channel Lypasses from the PPS cabinets are controlled since the equipment rooms have access controlled by means of key locked doors. Trip channel bypasses from the main control room PPS operator's modules are under the control room operator's cognizance. When the first parameter is bypassed there is an alarm to indicate which channel is being bypassed. The specific parameter or parameters which are being bypassed are indicated at the PPS cabinet and its remote operator's module.

The operating bypasses have audible and visible alarms. The operating bypasses have automatic features which provide a permissive range at which they can be actuated. Should the permissive range be exceeded, the bypass will be automatically removed.

O. Multiple setpoints (Section 4.15):

Manual reduction of the setpoints for low pressurizer pressure and low steam generator pressure trips are used for the controlled reduction of pressurizer pressure and steam generator pressure as discussed in sections 7.2.1.1.1.6 and 7.2.1.1.1.8. The setpoint reductions are initiated by main control board pushbuttons for each channel, one pushbutton for the pressurizer pressure and one pushbutton for both steam generator pressures within the one channel. This method of setpoint reduction provides positive assurance that the setpoint is never decreased below the existing pressure by more than a predetermined amount.

The variable low water level setpoint for each steam generator automatically tracks reactor power from a minimum low power value to a maximum full power value and vice versa. The variable setpoint is designed with maximum ceiling and minimum floor values such that sufficient water inventory is available to prevent unwarranted actuation of emergency feedwater following a reactor trip. 
The variable overpower trip setpoint tracks the actual reactor power from a minimum value to a high value or vice versa, if the power changes slowly enough. The variable overpower trip setpoint is designed with a maximum rate of decrease or increase. Should the actual power increase at too rapid a rate, it will catch up with the more slowly increasing setpoint and cause a trip.

The low reactor coolant flow trip setpoint automatically tracks below the input variables by a fixed margin for all decreasing inputs with a rate less than the rate limit. The setpoint decreases at a fixed rate for all decreasing input variable changes greater than the rate limit. Should the input variable decrease at too rapid a rate, it will catch up with the more slowly decreasing setpoint and cause a trip. The setpoint automatically increases as the input variable increases independent of rate.

P. Completion of Protective Action once it is Initiated (Section 4.16):

The system is designed to ensure that protective action (reactor trip) will go to completion once initiated. operator action is required to clear the trip and return to operation. Protective action is initiated when the reactor trip circuit breakers open. Protective action is completed when the CEAs arrive at their full-in position.

Q. Manual Initiation (Section 4.17):

A manual trip is effected by depressing either of two sets of trip pushbuttons in the main control room for remotely tripping the RTSS or using the local pushbuttons on the RTSS. No single failure will prevent a manual trip.

R. Access to Setpoint Adjustments, Calibration and Test points (Section 4.18 ):

Keys or built-in features are provided to control setpoints, changes to CPC constants, calibration, and test point adjustments. Access is indicated to the operator. The site operator controls access via key locks, administrative procedures, and other means to limit access.

S. Identification of Protective Action (Section 4.19):

Indications are provided for all protective actions, including identification of channel trips. The breaker status and current indication are available to the operator. 
T. Information Readout (Section 4.20):

Means are provided to allow the operator to monitor all trip system inputs, outputs and calculations. The specific displays that are provided for RPS status monitoring are described in section 7.5. The RPS alarms and the remote PPS and CPC Operator's Modules are located in the main control room.

U. System Repair (Section 4.21):

Identification of a defective input channel will be accomplished by observation of system status lights or by testing as described in section 7.2.1.1.9. Replacement or repair of components is accomplished with the affected input channel bypassed. The affected trip function then operates in a two-out-of-three trip logic while maintaining the coincidence of two required for trip.

V. Identification (Section 4.22 ):

All equipment, including panels, modules, and cables, associated with the trip system will be marked in order to facilitate identification.

Physical identification is provided to enable plant personnel to recognize that PPS cabinets, RTSS, and their cabling are safety-related. The cabinets are identified by nameplates. A color coding scheme is used to identify the physically separated channel cabling from sensor to the PPS. The same color code is used for interbay or intercabinet identification.

Cabling or wiring within a bay at the cabinet which is in the channel of its circuit classification is not color coded. The cabinet nameplates and cabling between cabinets is color coded as follows:

\section{Protective \\ Channel \\ ESF Train Divisions}

Channel A: Red

Channel B: Green

Channel C: Yellow

Channel D: Blue

A: $\quad$ Red

B: Green
Channel K: White/Green Stripe Channel L: White/Yellow Stripe Channel M: White/Blue Stripe

\section{Associated Channel}

Channel J: White/Red Stripe 


\section{$7.2 \cdot 2 \cdot 3 \cdot 3$}

Conformance to Guide 1.22 are intervals and Specifications tested without system operability. overlap in the RPS scheme is discussed in detail in 7.2.1.1.9, "Testing".

Since operation of the RPS will be infrequent, the system is periodically and routinely tested to verify its operability. A complete channel can be individually tested without initiating a reactor trip, without violating the single failure criterion, and without inhibiting the operation of the system. The system can be checked from the sensor signal through the circuit breakers of the RTSS. The RPS can be tested during reactor operation. The sensors can be checked by comparison with similar channels or channels that invoive related information. Minimum frequencies for checks, calibration, and testing of the RPS instrumentation are given in technical specifications. Overlap in the checking and testing is provided to assure that the entire channel is functional. The use of ground detection at the supply bus, assures that grounds will be detected.

\subsubsection{Failure Modes and Effects Analyis (FMEA)}

A FMEA for the RPS and ESFAS is provided in Table 7.2-5. The FMEA is for protection systems' sensors, and coincidence and actuating logics. The FMEA was prepared assuming that one set of the redundant channels is bypassed for maintenance. The logic interface for the protection systems is shown on Figure 7.2-19.

\subsubsection{REACTOR PROTECTIVE SYSTEM INTERFACES}

Refer to section 7.1 .3 for interface requirements.

\section{2 .4 ALTERNATE PROTECTION SYSTEM}

The Alternate Protection system (APS) augments reactor protection by utilizing a separate and diverse trip logic from the Reactor Protective system (RPS) for initiation of reactor trip. The addition of the APS provides a simple, reliable, yet diverse mechanism which is designed to increase the reliability of initiating reactor trip, as described in section 7.7 .
IEEE std. 338-1977 and the intent of Regulatory their bases are included in the Technical $\mathrm{E}$ 


\section{REFERENCES FOR SECTION 7.2}

1. "Functional Design Requirement for CPC," Combustion Engineering, Inc., CEN-305-P, Revision 2-P, May 1988 .

2. "Functional Design Requirement for CEAC," Combustion E Engineering, Inc., CEN-304-P, Revision 2-P, May 1988.

3. "Assessment of the Accuracy of PWR Safety system Actuation as Performed by the Core Protection calculator (CPC)," Combustion Engineering, Inc., CENPD-170, July 1975, and Supplement 1, November 1975. 


\section{TABLE 7.2-1}

(Sheet 1 of 2)

\section{REACTOR PROTECTIVE SYSTEM BYPASSES}

\begin{tabular}{|c|c|c|}
\hline Title & Function & Initiated By \\
\hline $\begin{array}{l}\text { DNBR and local } \\
\text { power density } \\
\text { bypass }\end{array}$ & $\begin{array}{l}\text { Disable low DNBR and } \\
\text { high local power } \\
\text { density trips }\end{array}$ & $\begin{array}{l}\text { Manual switch } \\
\text { (1 per channel) }\end{array}$ \\
\hline $\begin{array}{l}\text { Pressurizer } \\
\text { pressure } \\
\text { bypass }\end{array}$ & $\begin{array}{l}\text { Disables low pressur- } \\
\text { izer pressure trip, } \\
\text { SIAS, and CIAS }\end{array}$ & $\begin{array}{l}\text { Manual switch } \\
\text { ( } 1 \text { per channel) } \\
\text { if pressure is } \\
<400 \text { psia }\end{array}$ \\
\hline $\begin{array}{l}\text { High log power } \\
\text { level bypass }\end{array}$ & $\begin{array}{l}\text { Disables high logarith- } \\
\text { mic power level trip }\end{array}$ & $\begin{array}{l}\text { Manual switch } \\
\text { ( } 1 \text { per channel) if } \\
\text { power is }>10^{-3} \%\end{array}$ \\
\hline $\begin{array}{l}\text { Trip channel } \\
\text { bypass }\end{array}$ & $\begin{array}{l}\text { Disables any given } \\
\text { trip channel }\end{array}$ & $\begin{array}{l}\text { Manually by } \\
\text { controlled access } \\
\text { switch }\end{array}$ \\
\hline
\end{tabular}

Removed By

Automatic if

power is $\geq 10^{-4} \%$

Automatic if pressure is $>500$ psia

Automatic if
power is
$<10^{-3} \%$
Same switch

Notes
Allows Tow power testing

Bypassed during
reactor startup

Interlocks allow only one channel for any one type trip to be bypassed at one time 


\section{TABLE 7.2-1 (Cont'd)}

\section{(Sheet 2 of 2)}

\section{REACTOR PROTECTIVE SYSTEM BYPASSES}

\section{Title}

CPC DNBR CWP

\& LPD CWP

Bypass

CPC CMI

Bypass

CPC RPC Demand

Bypass
Disables DNBR CWP

and LPD CWP signals

to CWP logic

Disables CPC CMI

signal

Disables CPC RPC

demand signal
Initiated By

Automatic when

power is $<10^{-4} \%$

Automatic when

power is $<10^{-4} \%$

Automatic when

power is $<10^{-4} \%$
Removed By

Notes

Automatic if Allows low power

power is $\geq 10^{-4} \%$ testing.

$\mid \mathrm{I}$

Automatic if

power is $\geq 10^{-4} \%$

$I_{I}$

Automatic if

power is $\geq 10^{-4} \%$ 
TABLE 7.2-2

\section{REACTOR PROTECTIVE SYSTEM MONITORED PLANT VARIABLE RANGES}

\begin{tabular}{|c|c|c|c|}
\hline Monitored Variable & Minimum & $\begin{array}{r}\text { Nowinal (d) } \\
\text { (full power) }\end{array}$ & Maximum \\
\hline $\begin{array}{l}\text { Neutron flux power, \% } \\
\text { of full power }\end{array}$ & $1 \times 10^{-7}$ & 100 & 200 \\
\hline Cold leg temperature, ${ }^{\circ} \mathrm{F}$ & 465 & 558 & 615 \\
\hline Hot leg temperature, ${ }^{\circ} \mathrm{F}$ & 525 & 615 & 675 \\
\hline $\begin{array}{l}\text { Pressurizer Pressure } \\
\text { (high range), psia }\end{array}$ & 1,500 & 2,250 & 2,500 \\
\hline $\begin{array}{l}\text { Pressurizer pressure } \\
\text { (low range), psia }\end{array}$ & 0 & (c) & 1,600 \\
\hline CEA positions & full in & NA & full out \\
\hline $\begin{array}{l}\text { Reactor coolant pump } \\
\text { speed, rpm }\end{array}$ & 100 & 1,190 & 1,200 \\
\hline $\begin{array}{l}\text { Steam generator water } \\
\text { level (wide range), } \%(a)\end{array}$ & 0 & 76.8 & 100 \\
\hline $\begin{array}{l}\text { Steam generator water } \\
\text { level (narrow range), } \%(b)\end{array}$ & 0 & 59.1 & 100 \\
\hline $\begin{array}{l}\text { Steam generator pressure, } \\
\text { psia }\end{array}$ & 0 & 1,000 & 1,524 \\
\hline Containment pressure, psig & -5 & 0 & 60 \\
\hline $\begin{array}{l}\text { Steam generator primary } \\
\text { pressure differential, psid }\end{array}$ & 0 & 43 & 47 \\
\hline
\end{tabular}

NOTES: a. $\%$ of the distance between the wide range level instrument nozzles (above the lower nozzle).

b. $\%$ of the distance between the narrow range instrument nozzles (above the lower nozzle).

c. The high and low pressurizer pressure sensor ranges are combined electronically within the PPS bistable for wide range applications.

d. Nominal values given are typical. These values may be adjusted during the final design process. 
TABLE 7.2-3

REACTOR PROTECTIVE SYSTEM SENSORS

\begin{tabular}{|c|c|c|c|}
\hline Monitored Variable & Type & $\begin{array}{c}\text { Number of } \\
\text { Sensors }\end{array}$ & Location \\
\hline Neutron flux power & Fission chamber & $12^{(b)}$ & Biological shield \\
\hline Cold leg temperature & Precision RTD & $8^{(b)}$ & Cold leg piping \\
\hline Hot leg temperature & Precision RTD & $8^{(b)}$ & Hot leg piping \\
\hline $\begin{array}{l}\text { Pressurizer pressure } \\
\text { (high range) }\end{array}$ & Pressure transducer & $4^{(a)(b)}$ & Pressurizer \\
\hline $\begin{array}{l}\text { Pressurizer pressure } \\
\text { (1ow range) }\end{array}$ & Pressure transducer & $4^{(b)}$ & Pressurizer \\
\hline CEA positions & Reed switch assemblies & $2 /$ CEA $^{(b)}$ & $\begin{array}{l}\text { Control Element Drive } \\
\text { Mechanism }\end{array}$ \\
\hline $\begin{array}{l}\text { Reactor coolant } \\
\text { pump speed }\end{array}$ & Proximity device & $4 /$ pump (b) & Reactor coolant $p$ \\
\hline $\begin{array}{l}\text { Steam generator } \\
\text { level }\end{array}$ & $\begin{array}{l}\text { Differential pressure } \\
\text { transducer }\end{array}$ & $\begin{array}{l}\text { 8/steam }(a)(c) \\
\text { generator }\end{array}$ & Steam generators \\
\hline $\begin{array}{l}\text { Steam generator } \\
\text { pressure }\end{array}$ & Pressure transducer & $\begin{array}{l}4 / \text { steam } \\
\text { generator }(a)(b)\end{array}$ & Steam generators \\
\hline Containment pressure & Pressure transducer & $4^{(a)}$ & Containment structure \\
\hline $\begin{array}{l}\text { Steam generator } \\
\text { primary differential } \\
\text { pressure }\end{array}$ & $\begin{array}{l}\text { Differential pressure } \\
\text { transducer }\end{array}$ & $\begin{array}{l}4 / \text { steam } \\
\text { generator }\end{array}$ & Steam generators \\
\hline
\end{tabular}

NOTES: a. Common with Engineered Safety Feature Actuation System.

b. Common with control systems.

c. Only narrow range common with control systems. 


\section{TABLE 7.2-4}

(Sheet 1 of 3)

REACTOR PROTECTIVE SYSTEM DESIGR INPUTS

\begin{tabular}{|c|c|c|c|c|}
\hline Type & $\begin{array}{l}\text { Nominal }(j) \\
\text { Value } \\
\text { full power } \\
\end{array}$ & $\begin{array}{c}\text { Nominal }(j) \\
\text { Irip Setpoint } \\
\end{array}$ & Type(i) & $\begin{array}{l}\text { Mominal }(j) \\
\text { Margin } \\
\text { to Trip }\end{array}$ \\
\hline High logarithmic power level & NA & $1 \%$ power & $\mathrm{F}$ & NA \\
\hline Variable Overpower (Ex-core) & $\begin{array}{l}100 \% \text { power } \\
0 \% / \text { min } \\
\text { NA }\end{array}$ & $\begin{array}{l}112.7 \% \text { power } \\
13.5 \% / \mathrm{min} \\
12.5 \% \text { band }^{(f)}\end{array}$ & $\begin{array}{l}\text { RLVSP } \\
\text { RLVSP } \\
\text { RLVSP }\end{array}$ & $\begin{array}{l}12.7 \% \text { power } \\
13.5 \% / \mathrm{min} \\
\text { NA }\end{array}$ \\
\hline $\begin{array}{l}\text { Low DNBR } \\
\text { (Low Pressure floor, psia) }\end{array}$ & $\begin{array}{l}2.1^{(a)} \\
(2,250)\end{array}$ & $\begin{array}{l}\geq 1.24 \\
(1,750)\end{array}$ & $F$ & $\begin{array}{l}\leq 0.86 \\
(500)\end{array}$ \\
\hline $\begin{array}{l}\text { High local power density, } \\
\mathrm{kW} / \mathrm{ft}\end{array}$ & $\leq 5.42$ (peak) & 21 & $\mathrm{~F}$ & $\geq 15.58$ \\
\hline $\begin{array}{l}\text { High pressurizer pressure, } \\
\text { psia }\end{array}$ & 2,250 & 2370 & $\mathrm{~F}$ & 120 \\
\hline Low pressurizer pressure, psia & 2,250 & $1825(\mathrm{c})(\mathrm{e})$ & VSP & 425 \\
\hline $\begin{array}{l}\text { Low steam generator water } \\
\text { level, } \%(b)\end{array}$ & $76.8 \% W R$ & $44.2^{(n)}$ & RLVSPD & 32.6 \\
\hline $\begin{array}{l}\text { Low steam generator } \\
\text { pressure, psia }\end{array}$ & 1000 & $843^{(c)}$ & VSP & 157 \\
\hline $\begin{array}{l}\text { High containment pressure, } \\
\text { psig }\end{array}$ & 0 & 2.7 & $\mathrm{~F}$ & 2.7 \\
\hline $\begin{array}{l}\text { High steam generator water } \\
\text { level, } \% \text { (d) }\end{array}$ & $59.1 \% \mathrm{NR}$ & 90.8 & $\mathrm{~F}$ & 31.7 \\
\hline Low reactor coolant flow, \% & 100 & $(\mathrm{~g})$ & RLVSP & $(\mathrm{g})$ \\
\hline $\begin{array}{l}\text { Alternate Protection System, } \\
\text { High Pressurizer Pressure, } \\
\text { psia }\end{array}$ & 2250 & 2420 & $\mathrm{~F}$ & 170 \\
\hline
\end{tabular}


TABLE 7.2-4 (Cont'd)

(Sheet 2 of 3 )

REACTOR PROTECTIVE SYSTEM DESIGN INPUTS

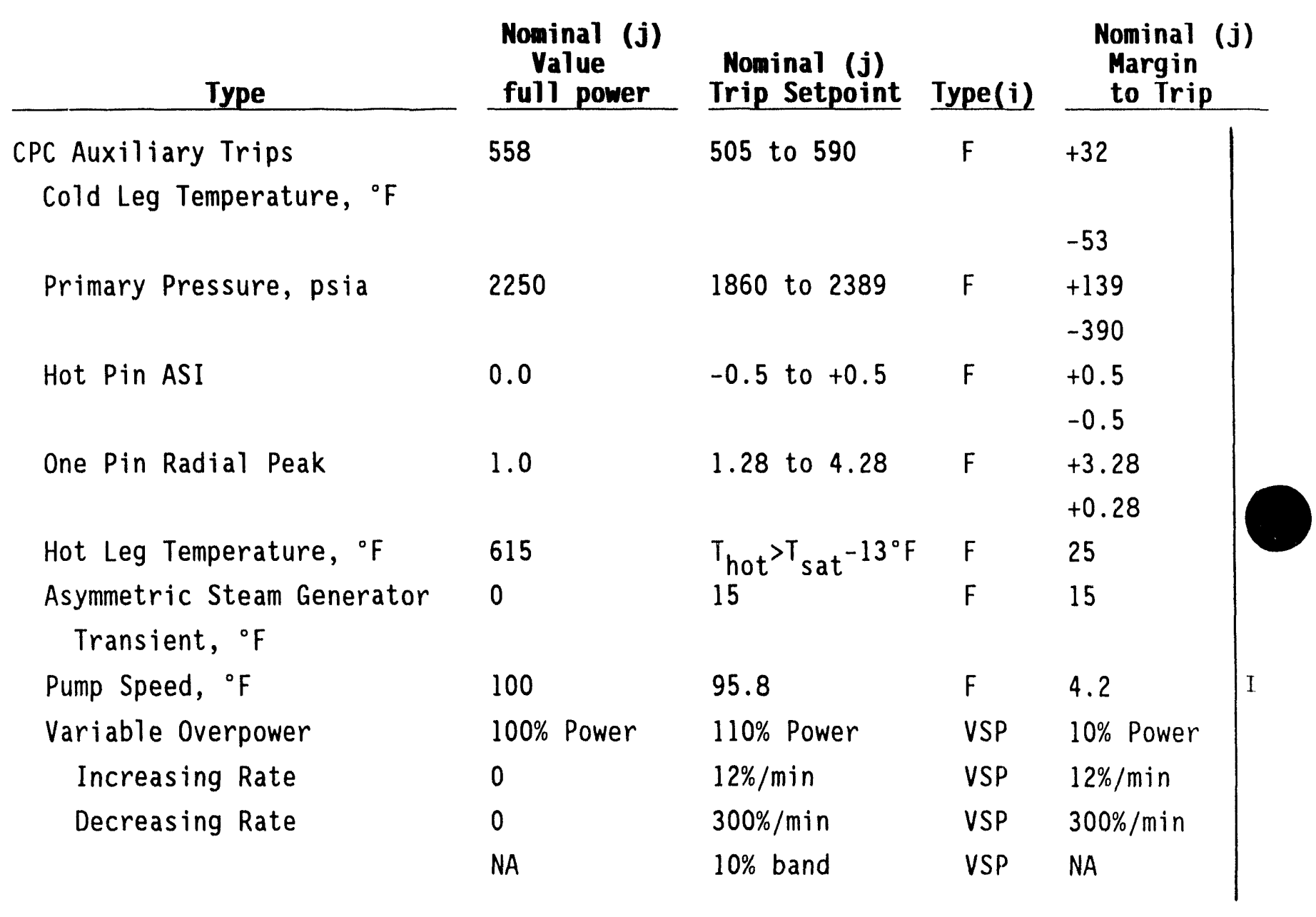




\section{TABLE 7.2-4 (Cont'd)}

(Sheet 3 of 3)

\section{REACTOR PROTECTIVE SYSTEM DESIGN INPUTS}

Nominal (j)

Value

Type full power
Nominal (j)

Trip Setpoint Type(i)
Nominal (j)

Margin to Trip

\section{NOTES:}

a. Calculated value of DNBR assures trip conservatively considering all sensor and processing time delays and inaccuracies. Calculated DNBR will be less than or equal to actual core DNBR.

b. \% of the distance between the wide range level instrument nozzles above the lower nozzle.

c. Setpoint can be manually decreased to a fixed increment below existing pressure as pressure is reduced during controlled plant cooldown and is automatically increased as pressure is increased maintaining a fixed increment. This fixed increment is 400 psia for pressurizer pressure and 200 psia for steam generator pressure.

d. \% of the distance between the narrow range level instrument nozzles above the lower nozzle.

e. Trip setpoint has a minimum value of 300 psia.

f. $\%$ band is percent above measured excore power level.

g. Actual differential pressure values are field determined, during calibration, using fractional setpoints that include all required uncertainty components.

h. The nominal setpoint is a variable setpoint programmed as a function of reactor power. The trip setpoint has a minimum value.

i. Type of setpoint generation; $F=f i x e d, V S P=$ variable based on trip process with reset; RLVSP=rate limited variable based on trip process; RLVSPD=rate limited variable based on process diverse from trip.

j. Values given are typical. Actual values are site dependent based on the equipment procured. Therefore, the site specific SAR shall make appropriate adjustments as necessary. 
IABLE $7.2-5$

(Sheet 1 of 31)

PLANT PROTECTION SYSTEM FAILURE MODES AND EFFECTS AMALYSIS

(Figure 7.2-19)

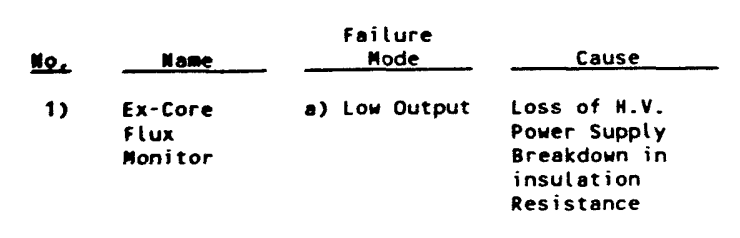

b) High Detector shorts,

2)

\section{Symptoms and Local Effluents}

Loss of data, erroneous data. Failure to detect $\mathrm{KI}$ flux levels.

Erroneous data. Possible channel trip for HI LINEAR
PUR, LO DNBR, HI LOG PWR. HI PWR DENSITY or LO Stea Generator Level.

Reduces delta-T power indication. Channel will not trip on a valid $h$ temp. condition. bridge netwo failure

Reactor Trip Logic for 10 DNBR and HI PWR DENS is coincidence.

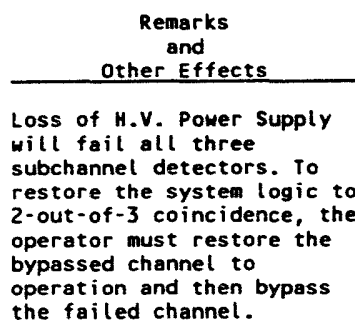

To restore the system logic to 2-out-of-3 coincidence, the operator must restore the bypassed channel to operation and then bypass

Calculated values of DMBR calibrated nuclear power and local power density restore the system logic to restore the system logic to
2 -out-of-3 coincidence, the operator must restore the bypassed channel to operation and then bypass

To restore the system logic to 2-out-of-3 coincidence, the operator must restore the bypassed channel to operation and then bypass 
IABLE $7.2-5$ (COnt'd)

(sheet 2 of 3 i) EAILURE MODES AND EFFECTS ANALYSIS (Figure 7.2-19)

No. Name failure

Core inlet 'cold

spurious

lou

b) One

spurious

high

4) Reactor Coclant Pump
Speed Sensor

a) One spurious irans.

Power supply or tailure, mect. mech. camage to sensor

Loss of data.
trip possioie.

Low ONSR channel

Symptoms and Local Effects Including oependent failures Increases delta-t power indication. POssible

Decrease in celta-t power icold goes low.

Method

$\frac{\begin{array}{c}\text { Mf } \\ \text { Detection }\end{array}}{\text { Annunciating, automatic }}$

DIAS and DPS senso

3-channel comparison.

Periodic test.

Annunciating, automatic

DIAS and DPS sensor

3-channel comparison.

b) High signal
rate

c) Low signal
raie raie

HI REP speed input to CPC indicating $h$ i Res flow, or notmal flow when fiow actually hom. Calculared cass mill be vatid low RCS flow.

Low RCP speed input to CPC High resistance
in tines, losso in lines, loss of hindicating !o kes $\begin{array}{ll}\text { Annunciating, automatic } & 3 \text {-channel redundancy } \\ \text { DIAS and DPS sensor } & \text { trip bypass (4th CPC }\end{array}$ siatus indication. bypass) See Note ( 1 DIAS and DPS sensor validity 3-channe! test.

Pre-trip/trip alarms. Annunciating, automatic DIAS and DPS sensor

comparison, periodic test.

-channel redundancy (4th CPC channel trips (i) 3- channel redundancy
ith $C P C$ channel trips in bypass) See kote (1)
Annunciating, aut omatic intermitient channel. Possible lo OKBr trip in (4th channet bypass)

Inherent Compensating
provision

3-channet redundancy (4th channel bypass)
See Note ( 1 )

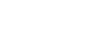

Effect Upon PPS

Reactor trip logic for 10 converted to 1 - out-of - 2 coincidence.

Reactor trip logic for 10 RMBR and HI PUR DENS is
converted to 2 -out-of-2 coincidence. DNBR is converted to 1-out-of-2 coincidence.

RPS trip logi for 10 ONBR becomes 2 -out -of

RPS trip logic for 10 DNBR would become Other Effects To restore the system logic 2-out-of-3 coincidence, the operassed channel to operation and then bypass the failed.

io restore the system logic to 2-out-of-3 coincidence, the operator must

restore the bypassed channel to operation and then bypass the failed

Sensor transmits pulses. Pulse rate related to flow. ro restore the system logic Theut-of-3 coincidence. the operator must restore
the bypassed channel to operation and then bypass the failed channel.

To restore the system logic 2-out-of-3 coincidence. the bypassed channel to operation and then bypass the failed channel.

To restore the system logic 2-out-of-3 coincidence, the bypassed channel to operation and then bypass the failed channet. 


\begin{tabular}{|c|c|c|c|c|c|c|c|c|}
\hline \multirow{2}{*}{ No. } & \multirow{3}{*}{$\begin{array}{l}\text { Name } \\
\text { Non-Target } \\
\text { CEA } \\
\text { Position }\end{array}$} & \multirow{2}{*}{$\begin{array}{c}\text { Failure } \\
\text { Mode }\end{array}$} & \multirow[b]{2}{*}{ Cause } & \multirow[b]{2}{*}{$\begin{array}{r}\text { Symptoms and Local Effects } \\
\text { Including Dependent Failures } \\
\end{array}$} & $\begin{array}{l}\text { LE } 7.2-5 \text { (CONT'd) } \\
\text { (Sheet } 3 \text { of } 31) \\
\text { I PROTECTION SYSTEM } \\
\text { DES AND EFFCTS ANALYSIS } \\
\text { (Figure } 7.2^{-19} \text {-19) }\end{array}$ & \multirow[b]{2}{*}{$\begin{array}{l}\text { Inherent } \\
\text { Compensating } \\
\text { provision }\end{array}$} & \multirow[b]{2}{*}{$\begin{array}{c}\text { Effect Upon } \\
\text { PPS }\end{array}$} & \multirow[b]{2}{*}{ 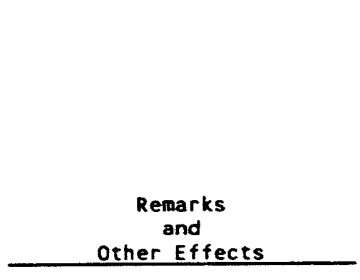 } \\
\hline & & & & & $\begin{array}{c}\text { Method } \\
\text { of } \\
\text { Detection } \\
\end{array}$ & & & \\
\hline 5) & & a) Low & $\begin{array}{l}\text { Shorted resistor. } \\
\text { power supply mal: } \\
\text { function }\end{array}$ & $\begin{array}{l}\text { Erroneous data input to one CEA } \\
\text { calculator. Possible CMI and } \\
\text { RPCS demand from CPC Channels. }\end{array}$ & $\begin{array}{l}\text { Annunciation, aut omatic } \\
\text { OPS sensor validity } \\
\text { test, CER deviation. } \\
\text { CMI and RPS activated. }\end{array}$ & $\begin{array}{l}\text { A pena! ty factor. See } \\
\text { Note (1) }\end{array}$ & $\begin{array}{l}\text { Penalty factors are } \\
\text { initiated in the core } \\
\text { protection calculators } \\
\text { DNBR and LPD operating } \\
\text { margins reduced). }\end{array}$ & $\begin{array}{l}\text { One CEA calculator will } \\
\text { shour CEA deviation to a all } \\
\text { cPC catculation Possible } \\
\text { reactor trip will occur if } \\
\text { RPCs not available. }\end{array}$ \\
\hline & & b) $\mathrm{High}$ & $\begin{array}{l}\text { Shorted resistor: } \\
\text { power supply mal: } \\
\text { function }\end{array}$ & $\begin{array}{l}\text { Erroneous data input to one CEA } \\
\text { calculator. possible CMI and } \\
\text { RPCS demand from CPC channeis. }\end{array}$ & $\begin{array}{l}\text { Annunciation, automatic } \\
\text { DPS sensor vatidity } \\
\text { test, CEA deviation. } \\
\text { CMI and RPCS activated. }\end{array}$ & $\begin{array}{l}\text { A penalty factor. See } \\
\text { Note (1) }\end{array}$ & $\begin{array}{l}\text { Penalty factors are } \\
\text { initiated in the core } \\
\text { protection calculators } \\
\text { DNBR and LPD operating } \\
\text { margins reduced). }\end{array}$ & $\begin{array}{l}\text { One CEA calculator will } \\
\text { show CEA deviation to a all } \\
\text { cPC catculation possibte } \\
\text { reactor trip will occur if } \\
\text { RPCS not available. }\end{array}$ \\
\hline & & $\begin{array}{l}\text { c) Other than } \\
\text { actuat } \\
\text { position }\end{array}$ & $\begin{array}{l}\text { Shorted resistor. } \\
\text { shorted reed } \\
\text { switches, power } \\
\text { supply } \\
\text { malfunction }\end{array}$ & $\begin{array}{l}\text { Erroneous data input to one } C E A \\
\text { calculator. possible CMI and } \\
\text { RPCS demand from CPC Channels. }\end{array}$ & $\begin{array}{l}\text { Annunciation, OPS } \\
\text { automatic sensor } \\
\text { validity test. CEA } \\
\text { deviation. CMI and RPC } \\
\text { activated. }\end{array}$ & $\begin{array}{l}\text { Penalty factors. See } \\
\text { Note (1) }\end{array}$ & $\begin{array}{l}\text { Penalty factors are } \\
\text { initiated in the core } \\
\text { protection calculators } \\
\text { DNBR \& LPD margins } \\
\text { reduced). }\end{array}$ & $\begin{array}{l}\text { One CEA calculator will } \\
\text { show CEA deviation to all } \\
\text { cPC calculation Possible } \\
\text { reactor trip will occur if } \\
\text { RPCS not available. }\end{array}$ \\
\hline & & d) Off scale & $\begin{array}{l}\text { Broken wire, open } \\
\text { resistor, } \\
\text { electrical short: } \\
\text { power supply mal: } \\
\text { function }\end{array}$ & Loss of data or invalid data. & $\begin{array}{l}\text { Annunciation, DPS } \\
\text { automatic sensor } \\
\text { validity test. CEA } \\
\text { deviation. CMI and RPC } \\
\text { activated. }\end{array}$ & $\begin{array}{l}\text { Penalty factors. See } \\
\text { Note (1) }\end{array}$ & $\begin{array}{l}\text { Penalty factors are } \\
\text { initiated in the core } \\
\text { protection calculators } \\
\text { (DNBR \& LPD margins } \\
\text { reduced). }\end{array}$ & $\begin{array}{l}\text { One CEA calculator will } \\
\text { shou CEA deviation to all } \\
\text { cPC CElculation possible } \\
\text { reactor trip will oceur if } \\
\text { RPCS not available. }\end{array}$ \\
\hline \multirow[t]{2}{*}{ 6) } & $\begin{array}{l}\text { Target CEA } \\
\text { Position }\end{array}$ & a) Low & $\begin{array}{l}\text { Shorted resistor, } \\
\text { power supply mal- } \\
\text { function }\end{array}$ & $\begin{array}{l}\text { Erroneous data input affects } \\
\text { DNBR and LD calculation and one } \\
\text { CEA calculator. }\end{array}$ & $\begin{array}{l}\text { Annunciation, oPS } \\
\text { automatic sensor } \\
\text { validity test. } 3 . \\
\text { channel comparison. }\end{array}$ & $\begin{array}{l}\text { 3- channel redundancy } \\
\text { (4th channel in } \\
\text { bypass) See Note (1) }\end{array}$ & $\begin{array}{l}\text { Makes reactor trip logic } \\
\text { tor } 10 \text { ONBR and HI power } \\
\text { density } 1 \text {-out }-0 f-2 \\
\text { coincidence. }\end{array}$ & $\begin{array}{l}\text { In addition to the effects } \\
\text { identified in (5) above for } \\
\text { non-target CEA position, } \\
\text { possible trip in one safety } \\
\text { channel. Trip effected } \\
\text { will show CEA deviation. }\end{array}$ \\
\hline & & b) High & $\begin{array}{l}\text { Shorted resistor, } \\
\text { power supply mal: } \\
\text { function }\end{array}$ & $\begin{array}{l}\text { Erroneous data input to CPC } \\
\text { calculator and (one) CEA } \\
\text { calculator. }\end{array}$ & $\begin{array}{l}\text { Annunciation, DPS } \\
\text { automatic sensor } \\
\text { validity test. CEA } \\
\text { deviation. CMI and RPC } \\
\text { activated. }\end{array}$ & $\begin{array}{l}\text { 3- channel redundancy } \\
\text { (4th channel in } \\
\text { bypass) See Note (1) }\end{array}$ & $\begin{array}{l}\text { Makes reactor trip logic } \\
\text { for } 10 \text { onsR and HI power } \\
\text { density } 1 \text { - out }- \text { of }-2 \\
\text { coincidence. }\end{array}$ & $\begin{array}{l}\text { In addition to the effects } \\
\text { identified in (5) above for } \\
\text { non-target CEA position } \\
\text { possible trip in one safety } \\
\text { channel. Trip effected } \\
\text { will show CEA deviation. }\end{array}$ \\
\hline
\end{tabular}




\section{PLANTLRE PROTECTION SYSTEM
$\frac{\text { MODES AND EFFECTS ANALSIS }}{\text { (FigUre } 7.2-19)}$}

Method

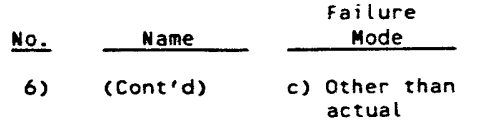
actual cause

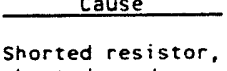
shorted reed switches, power supply
mal function

Erroneous data input to Core

resistor,
electrical short.

malfunction

Sensor failure,
component failu

on (High

pressure

signal

pressure
signal

$\begin{array}{ll}\text { High Range } & \text { a) On (High } \\ \text { PZR } & \text { pressure } \\ \text { Pressure } & \text { signal } \\ \text { Signal } & \text { tevel) }\end{array}$
b) One fails off (Low pressure (evel) tevel)

Sensor failure; d/c power supply
fail; open circuit

Sensor failure.

Sensor failure,
component failure logic state and
channet trip.
Symptoms and Local Effects Including Dependent Failures Protection calculator and (one)

Method

$\frac{\text { of }}{\text { Detection }}$

Annunciation, DPS automatic sensor deviation. CMI and RPC activated.

Annunciation DIAS, and OPS automatic sensor deviation.

\begin{tabular}{|c|c|}
\hline $\begin{array}{l}\text { Inherent } \\
\text { Compensating } \\
\text { Provision }\end{array}$ & $\begin{array}{l}\text { Effect Upon } \\
\text { PPS }\end{array}$ \\
\hline $\begin{array}{l}\text { 3-channel redundancy } \\
\text { (4th channel in } \\
\text { bypass) See Note (1) }\end{array}$ & $\begin{array}{l}\text { Makes reactor trip logic } \\
\text { for LO DWBR and HI POWER } \\
\text { DENS } 1 \text {-out-of }-2 \\
\text { coincidence. }\end{array}$ \\
\hline
\end{tabular}

3-channel redundancy (4th channel in

3-channel redundancy (4th channel in bypass)

Annunciation. Dias and validity check.

channel comparison. Press B/S. LO PZR pressu does not

Annunciating, DIAS and DPS automatic sensor validity check. Pretrip

and trip ress $B / S$. Bistable changes 3-channel redundancy
Trip Channel Bypass

High PZR press signal to HI PZR Annunciating, DIAS and RESSS $B / S$ and core protection catculator. HI PZR PRESS $8 / S$ will change logic state and DPS automatic sensor (4th channel bypass) validity check. Pretrip See Note (1)

and trip alarms in $H I$
PZR channel.
Makes reactor trip logic for LO DNBR and HI POWER crincidence.

Reactor Trip logic for LP PZR Press is converted to CSAS, SIAS logic LO PZR press 2 -out-of- 2 coincidence.

Reactor Trip logic for to PZR Press is converted to
1 -out-of-2 coincidence and 1-out-of-2 coincidence and
CSAS, SIAS logic CSAS. SIAS logic

Reactor IRIP logic for 10 DNBR is converted to 2 out-of -2 coincidence and for H! PZR PRESS is converted to
coincidence.

\section{Remarks other Effects \\ In addition to the effects dentified in (5) above for possible trip in one safety channel. Trip effected
will show CEA deviation.}

In addition to the effects identified in (5) above for possible trip in one safety channel. Irip effected will show CEA deviation.

ack-up for SIAS is the ontainment pressure

To restore the system logic to 2-out-of-3 coincidence, the operator must restore the bypassed channel to operation and then bypa
the failed channel.

To restore the system logi to 2-out-of-3 coincidence. the operator must restore the bypassed chst operation and then bypg
the failed channel.

To restore the system logic to 2-out-of-3 coincidence. the operator must restore the bypassed channel co the failed channel. Cup becomes 1 -out-of-2 coincidence for HI PZR in CEDMCS. 


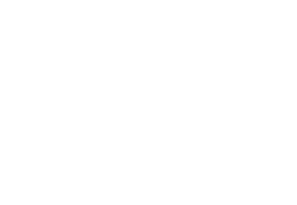

№. $\frac{\text { Name }}{\text { (Cont'd) }}$

\begin{tabular}{c} 
Failure \\
Mode \\
\hline b) Off (Low \\
Pressure \\
signal \\
level)
\end{tabular}

(evel) faii open circuit

Symptoms and Local Effects Including Dependent failures LO PZR PRESS Mill decrease DNBR channel trip. HI PZR PRESS $B$, will not trip for bonafide condition. May cause LO PZ

TABLE 7.2-5 (Cont'd)

(sheet 5 of 31 )

PLANT PROTECTION SYSTEM

(Figure $7.2-19$ )

\section{Method}

Annunciating, DIAS and DPS automatic sensor validity check. Pretrip and trip alarns
ONBR channel. PRESS B/S channel trip.

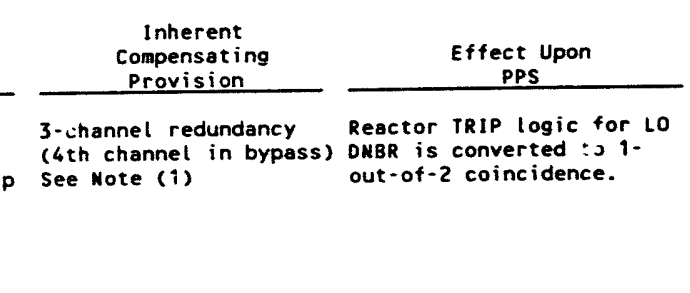

channet redundancy Annunciation, DIAS and DPS aut omatic sensor
validity check. Pretrip and trip alarm on low steam generator water level. signal to channel bistables. level bistables (B/S) change affected steam generator.

Reactor TRIP and EFAS logic for affected steam $\begin{array}{ll}\text { Level } & \text { signal } \\ \text { Signal: } & \text { level }\end{array}$ fail; open

Level Signal
(Wide Range)

\section{b) On (High Signa}

Sensor failure,
component failure

High steam generator water level level to channel bistables.

steam generator will not trip on

o level.

Annunciation on high S/G 3-channel redundancy level. Aut omatic DIAS and DPS sensor validity test, 3 -channet

(4th channel in bypass)

Reactor TRIP and EFAS logic for low steam converted to 2 -out-of -2 coincidence for affected steam gerierator. System will still operate on non-

10) Narrow Range Level
Sensor, SG Sensor,
No. 1; Narrow Range Level Sensor, a) off (Low Sensor failure, Signal Level d.c. power supply failure, open

Lo Level signal to one High SG level bistable for the affected steam generator. Bistable will steam generator.
Annunciated automatic 3-channel redundancy Reactor Trip Logic for HI (4th channel in bypass) steam generator level and validity test, 3-channel See Note (1) the MSIS actuation Logic comparison. the MSIS actuation Logic Level will be changed to

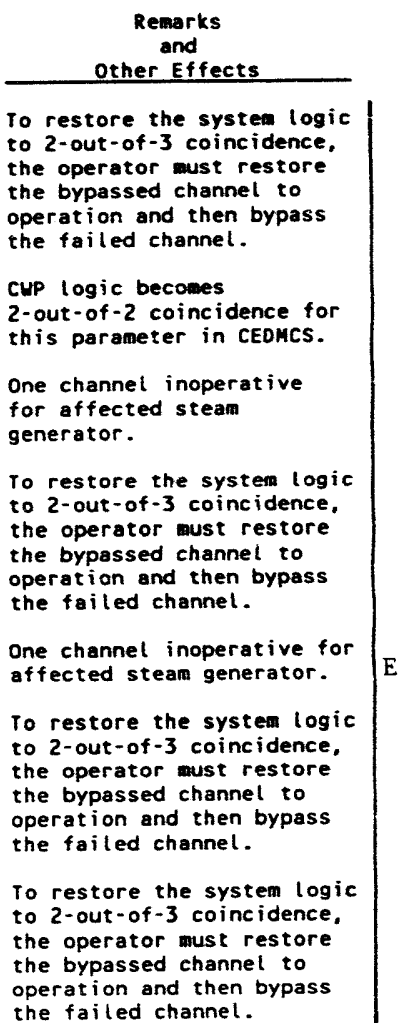


IABLE $7.2-5$ (Cont'd)

(Sheet 6 of 31 )

\section{$\frac{\text { PLANT PROTECTION SYSTEM }}{\text { FAILURE MODES AND EFFECTS AMALYSIS }}$}

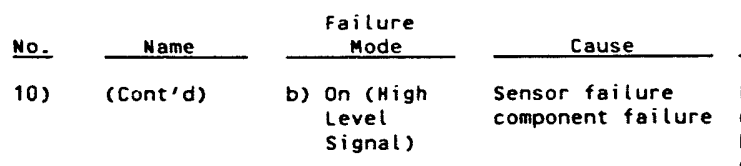

11) S/G Signal
No. 2;

S/G
Pressure Pressure
signal
No. 1

Pres.

$5 G 2$ Diff.

signa

$\begin{array}{ll}\text { b) One fails } & \text { Sensor failure, } \\ \text { off (Lo } & \text { d.c. power } \\ \text { signal } & \text { failure, open } \\ \text { level) } & \text { circuit }\end{array}$
$\begin{array}{ll}\text { a) One } & \text { Sensor failure, } \\ \text { spurious } & \text { d.c. power fail; } \\ \text { off. (low } & \text { open circuit }\end{array}$ signal

b) One
spurious
on, (High on, (High
signal
level)

a) One fails on (High signal

level)

Sensor fails
Symptoms and Local Effects
Including Dependent failure

ne steam generator HI Level Bistable for affected steam generator. Bistable will channel.

Method
of

Detection

DIAS and DPS sensor

pre-trip and trip

alarms.

Low steam generator pressure signal to SG Low Pressure (LO ERES histable (B/S) in RPS their logic state and initiates channel trip in SG LO PRESS for reactor IRIP, and MSIS actuation. signal to SG LO PRESS. Press Bistables. SG LO Press Channe for affected SG will not trip
for valid Lo Press condition.

Annunciating automatic DIAS and DPS sensor

and trip alarm on low steam generator pressure.

Annunciating automatic DIAS and DPS sensor

3-channel redundancy

validity test. Periodic See Note (1)

Inherent Compensating
Provision Effect Upon
PPS

3-channet redundancy 3-channet redundancy Reactor Trip Logic and
(4th channel in bypass) MSIS actuation logic for HI steam generator logic generator will be changed
to 1 -out-of- 2 coincidence.

3-channel redundancy Reactor TRIP logic for steam generator steam pressure is converted to
1 -out-of- 2 coincidence.

Reactor Trip and MSIS Reactor Trip and MSIS Press changes to
2 -out-of -2 coincidence. comparison.

Reactor trip logic for acs

HI or normal differential pres. Annunciating automatic signal received by one RCS 10 generator. One channel will ste trip on valid Lo flow condition
in affected steam generator. in affected steam generator.

LO Differential pres. signal received by one RCS LO Flow generator. Bistable will ch state, initiating a channel
trip. 2IAS and DPS sensor
validity test. Periodic test. 3-channel comparison.

Annunciating automatic DIAS and DPS sensor validity test. 3-channel comparison. 3-channel redundancy Reactor Irip Logic for RCS
(4th channel in bypass) Lo primary flow in affected SG changes to
2 -out-of-2. 3-channel redundancy
(4th channel in bypass)

Reactor Trip Logic for RCS Lo primary Flow in i-out-of-2.

\begin{tabular}{l} 
Remorks \\
Other Effects \\
\hline Same as 10a) above. \\
\\
To restore the system logic \\
to 2 -out-of -3 coincidence, \\
the operator must restore \\
the bypassed channel to \\
operation and then bypass \\
the failed channel. \\
To restore the system logic \\
to 2 -out-of-3 coincidence, \\
the operator must restore \\
the bypassed channel to \\
operation and then bypass \\
the failed channel. \\
To restore the system logic \\
to 2 -out-of-3 coincidence, \\
the operator must restore \\
the bypassed channel to \\
operation and then bypass \\
the faited channel. \\
Same as 12 a) above. \\
\end{tabular}


IABLE $7.2-5$ (Cont'd)

(sheet 7 of 31)

\section{PLANT PROTECTION SYSTEM
$\frac{\text { FAILURE MODES AND EFFECTS ANALYSIS }}{\text { (FigUre } 7.2-19)}$

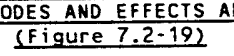

No.

13)

14) Wide Range a) ON (HI Signal
Level) Pres.

15) Control

Element Assembly

b) off signal
(evel)

a) No data
output

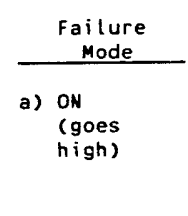
(goes low)

Component supply failure. supply failure,
open circuit

\section{Symptoms and Local Effects} Including Dependent failures

High CONT PRESS signal to: channel and in ESFS channel.
$\mathrm{B} / \mathrm{S}$ change logic state, and initiates channel trip for high TRIP, SIAS, CIAS, and MSIS

LOW CONT PRESS signal to: HI CONT PRESS B/S in RPS channe and ESFS channel. $B / S$ in logic state and trip for bonafide high containment condition.

Sensor failure other componen

HI Cont. Pres. Signal received by one HI-HI cont. pres.

bistable changes state,
initiating channel trip for CSAS actuation.

b) Off (LO

\section{Sensor d.c. power} supply failure.

One HI.HI Cont. Pres. Distable constantly receives a 10 or normal containment pres. signal. state for a valid HI-HI cont. pres. condition.

Loss of AC power; LOSS of CEA position display. input/out put Loss of CEAC operator's module

failure; Dat CONT PRESS bistable in RPS

\begin{tabular}{|c|}
\hline $\begin{array}{l}\text { Method } \\
\text { of } \\
\text { Detection }\end{array}$ \\
\hline $\begin{array}{l}\text { Annunciating automatic } \\
\text { DIAS and DPS sensor } \\
\text { validity test. Pretrip, } \\
\text { and alarm on high } \\
\text { containment pressure ESF } \\
\text { channel indication. }\end{array}$ \\
\hline
\end{tabular}

Annunciating automatic DIAS and DPS sensor val idity test.
test 3 -channei comparison.

\section{Annunciating automatic} DIAS and DPS sensor
validity test.

3-channel redundancy (4th channel in bypass)

Annunciating automatic 3-channel redundancy DIAS and DPS sensor ( 4 th channel in

validity test.
test 3 -channe

comparison.

Annunciating alarm on 2-channel redundancy 2-channel redur
See Note (1) Inherent
Compensating -channel redundancy th channel in

-channel redundancy channel in (bypas)

AnC link failure
Arithmetic,

logic or memory

failure

\section{Reactor Trip Logic converted to 1 -out-of -2 coincidence and CIAS, SIAS and MSIS logic for $\mathrm{HI}$ containment pressure
1 -out-of- 2 coincidence.}

Reactor Trip logic for HI containment pressure is coincidence, and CIAS. SIAS, and SMIS logic for HI containment pressure

Actuation logic for CSAS.

Actuation logic for CSAS Acturation logic for CSAS

To restore the system logic 2-out-of-3 coincidence, the operator must restore operation and then bypas

Same as 12a) above.

Same as 12a) above.

CPC uses data from the other CEAC and annunc failure. Restricted Operation with one or two
CEACS out of service. 


\begin{tabular}{|c|c|c|c|c|c|c|c|c|}
\hline \multirow{2}{*}{ No. } & \multirow[b]{2}{*}{ Name } & \multirow[b]{2}{*}{$\begin{array}{c}\text { Failure } \\
\text { Mode }\end{array}$} & \multirow[b]{2}{*}{ Caus } & \multicolumn{2}{|c|}{$\begin{array}{l}\frac{\text { TABLE } 7.2-5}{\text { (Cont'd) }} \\
\text { (Sheet } 8 \text { of } 31 \text { ) } \\
\frac{\text { PLANT PROTECTION SYSTEM }}{\text { RE MODES AND EFFECTS ANALYSIS }} \\
\text { (Figure } 7.2-19 \text { ) }\end{array}$} & \multirow[b]{2}{*}{$\begin{array}{c}\text { Inherent } \\
\text { Compensating } \\
\text { Provision }\end{array}$} & \multirow[b]{2}{*}{$\begin{array}{c}\text { Effect Upon } \\
\text { PPS }\end{array}$} & \multirow[b]{2}{*}{ 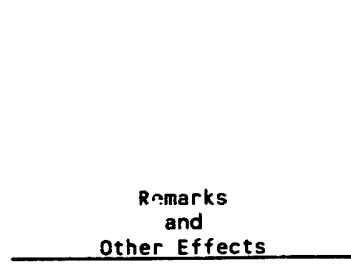 } \\
\hline & & & & $\begin{array}{l}\text { Symptoms and Local Effects } \\
\text { Including Dependent failures }\end{array}$ & $\begin{array}{c}\text { Method } \\
\text { of } \\
\text { Detection }\end{array}$ & & & \\
\hline 15) & (Cont'd) & $\begin{array}{l}\text { b) Errone- } \\
\text { ous data } \\
\text { output }\end{array}$ & $\begin{array}{l}\text { CEA position } \\
\text { sensor failure } \\
\text { input/output } \\
\text { failure; data } \\
\text { link failure } \\
\text { arithmetic, logic } \\
\text { or memory failure }\end{array}$ & $\begin{array}{l}\text { Erroneous calculated values. } \\
\text { Possible DNBR or LPD trip. }\end{array}$ & $\begin{array}{l}\text { Annunciating alarm on } \\
\text { CPC operator's module. } \\
\text { Comparison of CEA } \\
\text { position displays, } \\
\text { comparison of like } \\
\text { parameters on operator's } \\
\text { modules. }\end{array}$ & $\begin{array}{l}\text { 2-channel redundancy } \\
\text { See Note (1) }\end{array}$ & Possible DNBR or LPD trip. & $\begin{array}{l}\text { CPC compares data from the } \\
\text { two CEACs and annunciates } \\
\text { any significant } \\
\text { differences. Restricted } \\
\text { operation with one or two } \\
\text { CEACs out of service. }\end{array}$ \\
\hline \multirow[t]{2}{*}{ 16) } & $\begin{array}{l}\text { Core } \\
\text { Protection } \\
\text { Calculator }\end{array}$ & a) Tripped & $\begin{array}{l}\text { Loss of AC power } \\
\text { input/ output } \\
\text { faliure } \\
\text { arithmetic, } \\
\text { logic or mem- } \\
\text { ory failure } \\
\text { sensor failure }\end{array}$ & $\begin{array}{l}\text { Signal validation alarm for } \\
\text { control board displays. } \\
\text { Erroneous calculated results. }\end{array}$ & $\begin{array}{l}\text { Annunciating pPS alarm } \\
\text { on channel trips. } \\
3 \text {-channel comparisons } \\
\text { annunciating watchdog } \\
\text { timer. }\end{array}$ & $\begin{array}{l}\text { 3-channel redundancy } \\
4 \text { th channel in bypass) } \\
\text { See Note (1) }\end{array}$ & $\begin{array}{l}\text { Reactor trip logic for } \\
\text { DNBR and LPD is converted } \\
\text { to } 1 \text {-out-of-2 coincidence. }\end{array}$ & $\begin{array}{l}\text { Computer shuts down in } \\
\text { orderly sequence upon loss } \\
\text { of AC power and resumes } \\
\text { normat operation when power } \\
\text { is restored. } \\
\text { RPC demand, CHP logics in } \\
\text { CEDCS are converted to } \\
1 \text {-out-of-2 coincidence. } \\
\text { To restore the system logic } \\
5 \text { to } 2 \text {-out-of }-3 \\
\text { coincidence, the operator } \\
\text { must restore the bypassed } \\
\text { channel to operation and } \\
\text { then bypass the failed } \\
\text { channel. }\end{array}$ \\
\hline & & $\begin{array}{l}\text { b) Stays } \\
\text { in } \\
\text { untripped } \\
\text { state }\end{array}$ & $\begin{array}{l}\text { Input/output } \\
\text { failure } \\
\text { arithmetic, logic } \\
\text { or memory failure } \\
\text { sensor failure }\end{array}$ & Erroneous calculated results. & $\begin{array}{l}\text { 3-channel comparisons. } \\
\text { Annunciating watchdog } \\
\text { timer. }\end{array}$ & $\begin{array}{l}\text { 3-channel redundancy } \\
\text { (4th channel in } \\
\text { bypass) See Note (1)2 }\end{array}$ & $\begin{array}{l}\text { Reactor trip Logic for } \\
\text { DNBR and LPD is on } \\
\text { coincidence of } 2 \text {-out-of }-2 \\
\text { remaining channels. }\end{array}$ & $\begin{array}{l}\text { Computer shuts down in } \\
\text { orderly sequence upon loss } \\
\text { of AC power and resumes } \\
\text { normal operation when power } \\
\text { is restored. } \\
\text { RPC Demand, CMI and CUP } \\
\text { logics in CEDMCS are } \\
\text { converted to } 2 \text {-out-of-2 } \\
\text { remaining channels. } \\
\text { lo restore the systen logic } \\
\text { to } 2 \text {-out-of-3 coincidence, } \\
\text { the operator must restore } \\
\text { the bypassed channel to } \\
\text { operation and then bypass } \\
\text { the failed channel. }\end{array}$ \\
\hline
\end{tabular}

Amendment E
December 30, 1988 
TABLE 7.2-5 (cont'd)

(Sheet 9 of 31)

\section{PLANT PROTECTION SYSTEM
FAILURE MODES AND EFECTS AHALSIS}

(Figure 7.2-19)

\begin{tabular}{|c|c|c|c|c|}
\hline Vee. & Mease & & $\begin{array}{l}\text { Foilure } \\
\text { Mode } \\
\end{array}$ & Cause \\
\hline \multirow[t]{4}{*}{ 17) } & $\begin{array}{l}\text { Sofety } \\
\text { Channel } \\
\text { Muclear } \\
\text { Instrument } \\
\text { (Ch. A } \\
\text { Typical) }\end{array}$ & a) & $\begin{array}{l}\text { Trouble } \\
\text { onnune. } \\
\text { bistable } \\
\text { fails off }\end{array}$ & $\begin{array}{l}\text { Loss of } \\
\text { power supply, } \\
\text { open circuit, } \\
\text { component } \\
\text { failure }\end{array}$ \\
\hline & & b) & $\begin{array}{l}\text { Trouble } \\
\text { annunc. } \\
\text { bistable } \\
\text { fails on }\end{array}$ & $\begin{array}{l}\text { Component } \\
\text { failure. } \\
\text { short } \\
\text { circuit }\end{array}$ \\
\hline & & c) & $\begin{array}{l}\text { Trouble } \\
\text { bistable } \\
\text { relay } \\
\text { contacts } \\
\text { in annunc. } \\
\text { circuit } \\
\text { fail } \\
\text { closed. }\end{array}$ & $\begin{array}{l}\text { Contact arc } \\
\text { and weld }\end{array}$ \\
\hline & & d) & $\begin{array}{l}\text { Trouble } \\
\text { bistable } \\
\text { relay con- } \\
\text { tacts in } \\
\text { annunc. } \\
\text { circuit } \\
\text { fail open. }\end{array}$ & $\begin{array}{l}\text { Open circuit, } \\
\text { mech. failure }\end{array}$ \\
\hline
\end{tabular}
rouble indication and spurious de-energize during NI test or
Symptoms and Local Effects Including Dependent failures Trouble annunc. relays $O$ SG level, LPD and DNBR ch.

Trouble annunc. relays not when there is trouble in the $N$. drawer: Loss of trouble annunc. Dr level, LPO and DNBR

evel. LPD and DNBR bistables may not trip during $\mathrm{NI}$ test due to erroneous data.

NI test or trouble in MI not

Periodic test. lack of annunc.
during $N 1$ test.

None Method
of $\frac{\text { Detection }}{\text { Annunciating via DIAS }}$ and DPS.

Periodic test, lack of annunc.
during WI test.

\section{Inherent Compensat in 3-channel redundancy for $L 0$ SG level, LP and DNBR; None for trouble annun. (4th}

\begin{tabular}{l} 
Effect Upon \\
PPS \\
\hline RPS trip logic for LO SG \\
level. LPD and DNBR goes \\
to 1 -out-of-2.
\end{tabular}
to 1 -out-of-2.

3-channel redundancy (4th channel in bypass)

RPS trip logic for 10 SO evel, LPD and DNB

Spurious N1 trouble alarms. Annunciating via
DIAS and DPS.

None
RPS trip logic not affected.
RPS trip logic not

\section{and \\ To restore the system
logic to 2 -out-of -3 logic to 2-out-of-3 must restore the bypessed channel to operation and then bypass the failed channel.}

Same as 17a).

.




\begin{tabular}{|c|c|c|c|c|c|c|c|c|c|}
\hline & \multirow{2}{*}{ Name } & \multirow{2}{*}{\multicolumn{2}{|c|}{$\begin{array}{c}\text { Failure } \\
\text { Mode }\end{array}$}} & \multirow[b]{2}{*}{ Cause } & \multicolumn{2}{|c|}{$\begin{array}{l}\frac{\text { TABLE } 7.2-5}{\text { (Cont'd) }} \\
\text { (Sheet } 10 \text { of } 31) \\
\text { PLANT PROTECTION SYSTEM } \\
\frac{\text { RODES AND EFECTS ANALYSIS }}{\text { (Figure } 7.2-19)}\end{array}$} & \multirow[b]{2}{*}{$\begin{array}{l}\text { Inherent } \\
\text { Compensating } \\
\text { Provision }\end{array}$} & \multirow[b]{2}{*}{$\begin{array}{c}\text { Effect Upon } \\
\text { ppS }\end{array}$} & \multirow[b]{2}{*}{$\begin{array}{c}\text { Remarks } \\
\text { and } \\
\text { Other Effects }\end{array}$} \\
\hline & & & & & $\begin{array}{l}\text { Symptoms and Local Effects } \\
\text { Including Dependent failures } \\
\end{array}$ & $\begin{array}{c}\text { Method } \\
\text { of } \\
\text { Detection } \\
\end{array}$ & & & \\
\hline 17) & (Cont'd) & e) & $\begin{array}{l}\text { Trouble } \\
\text { bistable } \\
\text { relay con- } \\
\text { tacts in } \\
\text { power trip } \\
\text { test } \\
\text { interlock } \\
\text { fail } \\
\text { closed }\end{array}$ & $\begin{array}{l}\text { Contact arc and } \\
\text { weld }\end{array}$ & $\begin{array}{l}\text { LO SG level, LPD and DNBR } \\
\text { bistables in affected ch. will } \\
\text { not be tripped during NI ch. } \\
\text { test or when there is trouble } \\
\text { in the NI drawer. LO SG level, } \\
\text { LPD and DNBR bistables may not } \\
\text { trip due to erroneous data. }\end{array}$ & $\begin{array}{l}\text { Annunciating via } \\
\text { DIAS and DPS. }\end{array}$ & $\begin{array}{l}\text { 3-channel } \\
\text { redundancy } \\
\text { (4th channel } \\
\text { in bypass) }\end{array}$ & $\begin{array}{l}\text { RPS trip logic for LPD and } \\
\text { DNBR goes to } 1 \text {-out-of }-2 \text {. }\end{array}$ & Same as $17 \mathrm{a})$. \\
\hline & & f) & $\begin{array}{l}\text { Trouble } \\
\text { bistable } \\
\text { relay con- } \\
\text { tacts in } \\
\text { power trip } \\
\text { test } \\
\text { interlock } \\
\text { fail open }\end{array}$ & $\begin{array}{l}\text { Open circuit, } \\
\text { mech. failure }\end{array}$ & $\begin{array}{l}\text { Spurious ch. trips for } L O S G \\
\text { Level, LPD and DNBR if trip } \\
\text { channel bypasses not engaged. }\end{array}$ & $\begin{array}{l}\text { Annunciating via } \\
\text { DIAS and DPS. }\end{array}$ & $\begin{array}{l}\text { 3-channel } \\
\text { redundancy } \\
\text { (4th channel } \\
\text { in bypass) }\end{array}$ & $\begin{array}{l}\text { RPS trip logic for LO SG } \\
\text { level, LPD and DNBR goes to } \\
1 \text {-out-of-2. }\end{array}$ & Same as $17 a)$. \\
\hline & & g) & $\begin{array}{l}10^{-4} x \\
\text { log power } \\
\text { bistable } \\
\text { fails off }\end{array}$ & Same as 17a) & $\begin{array}{l}\text { Bistable will not energize } \\
\text { when power exceeds } 10 \% \% \text {. } \\
\text { One HI log power trip ch. } \\
\text { cannot be bypassed. Probable } \\
\text { ch. trip for high log power. } \\
\text { by DPS. }\end{array}$ & $\begin{array}{l}\text { Periodic test, } \\
\text { annunc. ch. trip } \\
\text { H1 log power bypass } \\
\text { permissive not } \\
\text { ind icated at power. }\end{array}$ & $\begin{array}{l}\text { 3-channel } \\
\text { redundancy } \\
\text { (4th channel } \\
\text { in bypass) }\end{array}$ & $\begin{array}{l}\text { One ch. of HI Log power } \\
\text { tripped at power. Other } 3 \\
\text { channels can still be } \\
\text { bypassed for operation. }\end{array}$ & Same as $17 \mathrm{a}$. \\
\hline & & h) & $\begin{array}{l}10^{-4} \% \\
\text { log power } \\
\text { bistable } \\
\text { fails on }\end{array}$ & Same as $17 b$ ) & $\begin{array}{l}\text { Bistable will be energized at } \\
\text { all power levels. Operator } \\
\text { can bypass HI log power } \\
\text { bistable at less than } 10^{-4} \%\end{array}$ & $\begin{array}{l}\text { 3-channel compari- } \\
\text { son by DPS and } \\
\text { DIAS annunciated, } \\
\text { periodic test. }\end{array}$ & $\begin{array}{l}\text { 3-channel } \\
\text { redundancy } \\
\text { (4th channel } \\
\text { in bypass) }\end{array}$ & $\begin{array}{l}\text { RPS trip logic for high } \\
\text { log power becomes } \\
\text { 2-out-of-2 if ch. is } \\
\text { bypassed. }\end{array}$ & Same as $17 \mathrm{a}$ ). \\
\hline & & i) & $\begin{array}{l}1 \% \log \\
\text { power bi- } \\
\text { stable } \\
\text { fails off }\end{array}$ & Same as $17 a$ ) & $\begin{array}{l}\text { Bistable relay will not be } \\
\text { energized below } 1 \% \text { power. } \\
\text { CWP will not be bypassed and } \\
\text { CPC cannot be bypassed. } \\
\text { Spurious LPD and DNBR ch. trips } \\
\text { at Lo power plus spurious CMI, } \\
\text { CWP's at LO power. }\end{array}$ & $\begin{array}{l}\text { Periodic test, } \\
\text { 3-channel compari- } \\
\text { son by DPS and } \\
\text { DIAS annunciated. }\end{array}$ & $\begin{array}{l}\text { 3- channel } \\
\text { redundancy } \\
\text { (4th channel } \\
\text { in bypass) }\end{array}$ & $\begin{array}{l}\text { One ch. for CMI, LPD, DNBR } \\
\text { and CWP tripped at Lo } \\
\text { power. Other } 2 \text { channels } \\
\text { can still be bypassed. }\end{array}$ & Same as $17 a)$ \\
\hline
\end{tabular}




\section{$\frac{\text { PLANT PROTECTION SYSTEM }}{\text { FAILURE MODES AMD EFFECSS AMALYSIS }}$}

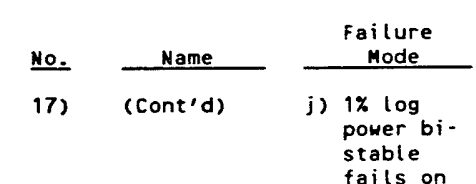
fails on
k) $1 \% \log$ stable contacts in $C P C$

1) $1 \% \log$ power bi stable contacts in cPC fail Rate of power bistable

n) Rate of change of power bistable

o) $\log$ power
level summers fail

Cause

Mech. failure,

open circuit

Contact orc and weld

Same as 17b)

comp. failure
Symptoms and Local Effects ncluding Dependent failures

Bistable relay will remain energized above $1 x$ power. One CPC will remain bypassed and ch. for $\mathrm{CMI}$.
bypassed. CPC bypass permissive for one
channel not enabled below $1 \%$ annunc. for ch. CPC. POssible to bypass one trip ch. trips at low power.

CPC bypass will not be autoCPC will be bypassed.

CPC bypass indic.

Detection

CPC bypass permis sive indication.

Periodic test.

Loss of annunc. at $\mathrm{HI}$ rate of change of power for one channel.

Periodic test. Spurious HI rate of change of power al arms.

Annunciating via
DIAS and DPS.

Validation alarm for log power level indic. at main control board or remote shutdown area. log power channel trif if less

Annunciating 3-channet comparison by DIAS and $D$.

\section{Inherent
Compensating
Proyision 3-channel redundancy RPS trip logic for LPD or} logic as other CPCs can ill be bypassed. 3-channel redundancy RPS trip logic for LPD and
(4th channel in bypass) DNBR becomes 2 -out-of-2.

Same as 17a). CHP, CMI and PC demand logic in CEDMCS Other Effects Same as 17a. CMI and CUP logic in cEDHCS becomes

Same as 17 a).
No impact on RPS trip

3-channel redundancy

HI rate of change of power annunc. logic goes to
2 -out-of- 3 in DIAS and 2-O

No impact on RPS trip logic.

3-channel redundancy No impact on RPS trip (4th channel in bypass) logic above $10^{-4} \%$ power.
Less than $10^{-4} \%$, RPS trip Less than $10 \%$, RPS trip
logic becomes 1 -out-of-2 


\begin{tabular}{|c|c|c|c|c|c|c|c|c|c|}
\hline \multirow{2}{*}{ No. } & \multirow[b]{2}{*}{ Name } & \multirow{2}{*}{\multicolumn{2}{|c|}{$\begin{array}{c}\text { Failure } \\
\text { Mode }\end{array}$}} & \multirow[b]{2}{*}{ Cause } & \multirow[b]{2}{*}{$\begin{array}{l}\text { Symptoms and Local Effects } \\
\text { Including Dependent Failures } \\
\end{array}$} & $\begin{array}{l}\text { E } 7.2-5 \text { (Cont'd) } \\
\text { heet } 12 \text { of } 31) \\
\text { PROTECTION SYSIEM } \\
\text { ES AND EFFECTS AHALYSIS } \\
\text { Figure } 7.2 \cdot 19)\end{array}$ & & \multirow[b]{2}{*}{$\begin{array}{c}\text { Effect Upon } \\
\text { pps }\end{array}$} & \multirow[b]{2}{*}{$\begin{array}{c}\text { Remarks } \\
\text { and } \\
\text { Other Effects } \\
\end{array}$} \\
\hline & & & & & & $\begin{array}{c}\text { Method } \\
\text { of } \\
\text { Detection } \\
\end{array}$ & $\begin{array}{c}\text { Inherent } \\
\text { Compensat ing } \\
\text { Provision }\end{array}$ & & \\
\hline \multirow[t]{5}{*}{ 17) } & (Cont'd) & p) & $\begin{array}{l}\text { Log } \\
\text { power } \\
\text { level } \\
\text { summers } \\
\text { fail off }\end{array}$ & $\begin{array}{l}\text { Comp. failure, } \\
\text { open circuit }\end{array}$ & $\begin{array}{l}\text { Validation alarm for log power } \\
\text { level indic. at main control } \\
\text { board or remote shutdown area. }\end{array}$ & $\begin{array}{l}\text { Annunciating } 3 \text {-channel } \\
\text { comparison by DiAS and } \\
\text { DPS. Periodic test. }\end{array}$ & $\begin{array}{l}\text { 3-channet redundancy } \\
\text { (4th channel in bypass) }\end{array}$ & $\begin{array}{l}\text { No impact on RPS trip } \\
\text { logic above } 10^{-4} \chi \text { power. } \\
\text { Less than } 10^{-4} \chi \text {, RPS trip } \\
\text { logic becomes } 2 \text {-out-of }-2 \\
\text { coincidence. }\end{array}$ & \\
\hline & & a) & $\begin{array}{l}\text { Cali- } \\
\text { brated } \\
\text { linear } \\
\text { power } \\
\text { level } \\
\text { summers } \\
\text { fail HI }\end{array}$ & Comp. failure & $\begin{array}{l}\text { Validation alarm for linear } \\
\text { power indic. at main control } \\
\text { board. Rate limited VOPT } \\
\text { bistable ch. trip. }\end{array}$ & $\begin{array}{l}\text { Annunciating } 3 \text {-channel } \\
\text { comparison by DIAS and } \\
\text { DPS. Periodic test. }\end{array}$ & $\begin{array}{l}\text { 3-channel redundancy } \\
\text { (4th channel in bypass) }\end{array}$ & $\begin{array}{l}\text { RPS VOPT trip logic } \\
\text { becomes } 1-\text { out-of-2 } \\
\text { coincidence. }\end{array}$ & See Note (1). \\
\hline & & г) & $\begin{array}{l}\text { Cali- } \\
\text { brated } \\
\text { linear } \\
\text { power } \\
\text { level } \\
\text { summers } \\
\text { fails off }\end{array}$ & $\begin{array}{l}\text { Comp. failure, } \\
\text { open circuit }\end{array}$ & $\begin{array}{l}\text { Validation alarm for linear } \\
\text { power indic. on main control } \\
\text { board. }\end{array}$ & $\begin{array}{l}\text { Annunciating } 3 \text {-channel } \\
\text { comparison by DIAS and } \\
\text { DPS. Periodic test. }\end{array}$ & $\begin{array}{l}\text { 3-channel redundancy } \\
\text { (4th channel in bypass) }\end{array}$ & $\begin{array}{l}\text { RPS VOPT trip logic } \\
\text { becomes } 2 \text {-out-of- } 2 \\
\text { coincidence. }\end{array}$ & See Note (1). \\
\hline & & s) & $\begin{array}{l}\text { Rate of } \\
\text { change of } \\
\text { power sum- } \\
\text { mers fails } \\
\text { H1. }\end{array}$ & Comp. failure & $\begin{array}{l}\text { Validation alarm for power } \\
\text { change rate indic. at main } \\
\text { control board. } \\
\text { and DPS. }\end{array}$ & $\begin{array}{l}\text { Annunciating } 3 \text {-channel } \\
\text { comparison by DIAS and } \\
\text { DPS. Periodic test. }\end{array}$ & $\begin{array}{l}\text { 3-channel redundancy } \\
\text { ( } 4 \text { th in bypass) }\end{array}$ & $\begin{array}{l}\text { No impact on RPS trip } \\
\text { logic. }\end{array}$ & \\
\hline & & t) & $\begin{array}{l}\text { Rate of } \\
\text { change of } \\
\text { power sum- } \\
\text { mers fails } \\
\text { off. }\end{array}$ & $\begin{array}{l}\text { Comp. failure, } \\
\text { open circuit }\end{array}$ & $\begin{array}{l}\text { Validation alarm for rate of } \\
\text { change of power indic. for one } \\
\text { channel. }\end{array}$ & $\begin{array}{l}\text { Operator, periodic test. } \\
\text { Annunciating } 3 \text {-channel } \\
\text { comparison by DIAS and } \\
\text { DPS. }\end{array}$ & $\begin{array}{l}\text { 3- channel redundancy } \\
\text { (4th channel in bypass) }\end{array}$ & $\begin{array}{l}\text { No impact on RPS trip } \\
\text { logic. }\end{array}$ & \\
\hline
\end{tabular}


TABLE 7.2-5 (Cont'd)

(Sheet 13 of 31 )

PLANT PROTECIION SYSTER
FAILURE MODES AND EFFECTS AMALYSIS

(Figure $7.2 \cdot 19)$

\section{-}

Method

Symptoms and Local Effects

Loss of power to initiating relay, signal "A" sIAs initiation relay open

circuit, relay

contact or wiring

open circuit

Relays
SSIAS

Channel A
Typical)

19) Remote Manual ESF
Initiation (SIAS Channel A
Typical)

Initiating relay Channel "A" SIAS initiation DPS. b) on signal not transmitted or welded closed; redundant ESF-CCS train for bona Initiating wiring fide SIAS trip signal. or PPS logic

initiating relay

initiating
energized

a) off

Remote manual

De-energizes SIAS Channel "A"

Switeh contact or initiation relay outputs to all circuit; fiber

circult; fiber

devices fail to

"off" state or

loss of power or

electroni

b) on
Remote manual suitch contact or wiring fails

Unable to de-energize the SIAS shorted; Fiber optic isolation devices fail to elec. component elec. compo
failure using the remote manual Including Dependent Failures

\section{$\frac{\begin{array}{c}\text { Interent } \\ \text { Compensating } \\ \text { Provision }\end{array}}{\text { Redundent chennel suAs ESF - ces ectuetion logic }}$}

Annunciating automatic from PPS interface/test processor via DIAS and DPS. Visual indication at PPS Local and control

Redundant channel SIAS ESF - CCS actuation logic

initiation relays and for sias changed from
logic not effected.

selective $2-$ of -4
selective $1-$ of -3

selective $1 \cdot 0 f-3$
coincidence.

Annunciat ing automatic

PPS interface/test
Psor via DIAS and

Redundant channel SIAS ESF - CCS actuation logic initiation relays and for slas changed from $\begin{array}{ll}\text { logic not affected. } & \text { selective } 2-\text { of-4 to } \\ \text { selective } 2-0 \text { of-3 logic. }\end{array}$

Same as 26a).

Annunciating automatic from PPS interface/test processor via DIAS and at PPS local and control room operators' modules.

Periodic manual testing. Same as 26b). Redundant manua available.

Remote manual actuation coincidence.

\section{Same as $26 a$.} logic changed from
selective 2 -of -4 to 2 -of signals unaffected.
Automatic SIAS initiation

\begin{tabular}{l}
$\substack{\text { Remerks } \\
\text { Ond } \\
\text { QSher Effects }}$ \\
\hline Automatic SIAS initiation \\
signals unaffected.
\end{tabular}




\section{TABLE 7.2-5 (cont'd) \\ (Sheet 14 of 31 ) \\ PLANT PROTECTION SYSTEM
FAILURE MODES AND EFFETS ANALYSIS \\ (Eigure $7.2-12$ )}

No. $\frac{\text { Name }}{\text { 20) }} \frac{\begin{array}{l}\text { Bistable } \\ \text { Trip } \\ \text { Processors } \\ \text { (A1, A2, } \\ \text { Typicali }\end{array}}{\text { Mode }}$

b) on

21) cross

Channel

Remote
I/O Droos

(AB, $A C$.

AD iypical)

a) off

\begin{tabular}{l}
\multicolumn{1}{c}{ Cause } \\
\hline Loss of power \\
supply or \\
failures in \\
input/output \\
multiplexers; \\
Failures \\
(hardware or \\
sof tware) of CPU \\
or data \\
communications \\
links; \\
Erroneous trip \\
setpoints
\end{tabular}

Symptoms and Local Effects Including Dependent Failures Bistable trip outputs generated and to redundant channel $\mathrm{LCL}$ processors via remote channel l/o drops. Pre-trip and trip

Input or output Bistable output devices will not change state

bistable trip

logic demands
CPU failures

CPU failures
(hardware or

(hardware or
software) stop

execution;

Erroneous trip

setpoints

Loss of power Failure to communicate over

in input/output cross channel data links is

multiplexer, data LCL processors, which then

communications initiate bistable channel trip

links, or optical

isolators; Open logics.

circuited

bistable trip

to remote $1 / 0$

drop

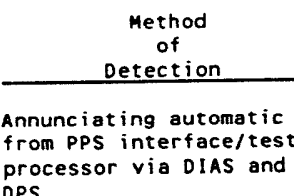

Annunciating automatic rom PPS interface tes

3-channel redundancy

RPS and ESFAS LCL coincidence.

\begin{tabular}{|c|c|}
\hline $\begin{array}{l}\text { Inherent } \\
\text { Compensating } \\
\text { Provision }\end{array}$ & $\begin{array}{c}\text { Effect Upon } \\
\text { PPS }\end{array}$ \\
\hline $\begin{array}{l}\text { 3-channel redundancy } \\
\text { (4th channel in bypass) } \\
\text { Processor defaults } \\
\text { outputs to trip state }\end{array}$ & $\begin{array}{l}\text { RPS and ESFAS LCLS } \\
\text { conver:ed to } 1 \text {-out-of-2 } \\
\text { coincidence. }\end{array}$ \\
\hline
\end{tabular}

to restore the system logic the operator must restore the bypassed channels to operation and then bypass the failed bistable trip processor parameters. Loss parameters and status to channels.

Same as 20a).

Annunciating automatic 3-channel redundancy RPS and ESF LCLS coincidence. DPS.

To restore the system logic the -out-of-3 coincidence, the operator must restore operation and then bypass the failed bistable trip processor parameters. 
TABLE 7.2-5 (Cont'd)

(Sheet 15 of 31 )

PLANT PROTECTION SYSTEM
FAILURE MODES AND EFFECTS ANALYSIS

\begin{tabular}{|c|c|c|c|}
\hline $\begin{array}{c}\text { Method } \\
\text { of } \\
\text { Detection }\end{array}$ & $\begin{array}{c}\text { Inherent } \\
\text { Compensating } \\
\text { Provision }\end{array}$ & $\begin{array}{c}\text { Effect Upon } \\
\text { PPS }\end{array}$ & $\begin{array}{c}\text { Remarks } \\
\text { and } \\
\text { Other Effects } \\
\end{array}$ \\
\hline $\begin{array}{l}\text { Annunciat ing automatic } \\
\text { from PPS interface/test } \\
\text { processor via DIAS and } \\
\text { DPS. }\end{array}$ & $\begin{array}{l}\text { 3-channel redundancy } \\
\text { (4th channel in } \\
\text { bypass) }\end{array}$ & $\begin{array}{l}\text { RPS and ESF LCLS } \\
\text { converted to } 2 \text {-out-of-2 } \\
\text { coincidence. }\end{array}$ & Same as 21a). \\
\hline $\begin{array}{l}\text { Annunciating automatic } \\
\text { from PPS interface/test } \\
\text { processor via DIAS and } \\
\text { DPS. }\end{array}$ & $\begin{array}{l}\text { A minimum of two RPS or } \\
\text { ESFAS initiation } \\
\text { channels must be } \\
\text { generated to cause } \\
\text { reactor trip or ESF } \\
\text { system actuation. }\end{array}$ & $\begin{array}{l}\text { RPS and ESFAS LCLs remain } \\
\text { in } 2 \text {-out-of }-3 \text { in the other } \\
\text { redundant LCL processors } \\
\text { ( } 4 \text { th channel bypassed at } \\
\text { bistables). }\end{array}$ & $\begin{array}{l}\text { RTSS and ESF-CCS actuation } \\
\text { logic is converted to } \\
\text { selective } 1 \text {-out-of }-3 \\
\text { coincidence. }\end{array}$ \\
\hline
\end{tabular}

22) Local
Coincidence
Logic (LCL)
Processors

(A1, A2,

a) of $f$
Cause

channel LCL processors.

inputs.

input/output

multiplexor

stops execution
or fails to

or fails to
refresh outpu

data

communication

buffer; Shorting

of bistable trip

output wiring to

Loss of power

supply or

failures in

input/output

Failures

(hardware or

sof tware) in CPU

or data

communication
links: Open

links: Open

bistable trip

output wiring

to LCL processor

列

\section{Symptoms and Local Effect}

Ona-fide bistable trip signals
RPS and ESF initiation signals are generated in the affected breaker will open. hannels must be reactor trip or ESF 2-out-of-3 in the other

ESF-CCS actuation 


\begin{tabular}{|c|c|c|c|c|c|c|c|c|}
\hline \multirow[b]{2}{*}{ No. } & \multirow[b]{2}{*}{ Name } & \multirow[b]{2}{*}{$\begin{array}{c}\text { Failure } \\
\text { Mode }\end{array}$} & \multirow[b]{2}{*}{ Cause } & \multicolumn{2}{|c|}{$\begin{array}{l}\frac{\text { TABLE } 7.2-5}{\text { (CONT'd) }} \\
\text { (Sheet } 16 \text { of } 31 \text { ) } \\
\frac{\text { PLANT PROTECTION SYSTEM }}{\text { E MODES AND EFFECTS AMALYSIS }} \\
\text { (Figure } 7.2-12 \text { ) }\end{array}$} & \multirow[b]{2}{*}{$\begin{array}{c}\text { Intherent } \\
\text { Compensating } \\
\text { Provision }\end{array}$} & \multirow[b]{2}{*}{$\begin{array}{c}\text { Effect Upon } \\
\text { pps }\end{array}$} & \multirow[b]{2}{*}{$\begin{array}{c}\text { Remarks } \\
\text { and } \\
\text { Other Effects } \\
\end{array}$} \\
\hline & & & & $\begin{array}{l}\text { Symptoms and Local Effects } \\
\text { Including Dependent failures } \\
\end{array}$ & $\begin{array}{c}\text { Method } \\
\text { of } \\
\text { Detection } \\
\end{array}$ & & & \\
\hline \multirow[t]{2}{*}{ 22) } & (Cont'd) & b) on & $\begin{array}{l}\text { Failure of LCL } \\
\text { input modules to } \\
\text { detect change of } \\
\text { state of bistable } \\
\text { processor trip } \\
\text { outputs: } \\
\text { Failures } \\
\text { (hardware or } \\
\text { software) stop } \\
\text { CPU or fail to } \\
\text { refresh LCL } \\
\text { outputs }\end{array}$ & $\begin{array}{l}\text { Affected LCL processor will not } \\
\text { respond to bona-fide bistable } \\
\text { trip conditions. RPS and ESF } \\
\text { initiation signals will not be } \\
\text { generated by the failed LCL } \\
\text { processor in the affected } \\
\text { channel. }\end{array}$ & $\begin{array}{l}\text { Annunciating automatic } \\
\text { from PPS interface/test } \\
\text { processor via DIAS and } \\
\text { DPS. }\end{array}$ & $\begin{array}{l}\text { Two redundant sets of } \\
\text { LCL processors in } \\
\text { other channels. } \\
\text { Unaffected LCL } \\
\text { processor in same } \\
\text { channel is available } \\
\text { to initiate RPS and } \\
\text { ESF functions. Manual } \\
\text { actuation not } \\
\text { affected. }\end{array}$ & $\begin{array}{l}\text { RPS and ESFAS LCLs remain } \\
2 \text {-out-of-3 in other } \\
\text { redundant LCL processors } \\
\text { (4th channel bypassed at } \\
\text { bistables). }\end{array}$ & $\begin{array}{l}\text { RISS and ESF-CCS actuation } \\
\text { logic is converted to } \\
\text { selective } 2 \text {-out-of-3 } \\
\text { coincidence. }\end{array}$ \\
\hline & & $\begin{array}{l}\text { c) More than } \\
\text { one } \\
\text { bistable } \\
\text { bypass } \\
\text { present on } \\
\text { LCL input }\end{array}$ & $\begin{array}{l}\text { Failure of LCL } \\
\text { processor input } \\
\text { module or wiring }\end{array}$ & Bypass error annunciator. & $\begin{array}{l}\text { Annunciating automatic } \\
\text { from PPS interface/test } \\
\text { processor via DIAS and } \\
\text { OPS. }\end{array}$ & $\begin{array}{l}\text { LCL designed to reject } \\
\text { more than one trip } \\
\text { channel bypass. Four } \\
\text { channet LCL redundancy. }\end{array}$ & $\begin{array}{l}\text { None, RPS and ESFAS LCLS } \\
\text { remain in } 2 \text {-out-of - } 3 \text { ( } 4 \text { th } \\
\text { channet in bypass). }\end{array}$ & \\
\hline
\end{tabular}


IABLE 7.2-5 (cont'd)

\section{$\frac{\text { PLANT PROTECTION SYSTEM }}{\text { FAILURE RODES AND EFFECTS AMALYSIS }}$}

\section{No.}

23)

\begin{tabular}{|c|c|c|}
\hline Name & $\begin{array}{l}\text { Failure } \\
\text { Mode }\end{array}$ & Cause \\
\hline $\begin{array}{l}\text { Interface/ } \\
\text { Test } \\
\text { Processor } \\
\text { (Channel A } \\
\text { Typical) }\end{array}$ & a) off & $\begin{array}{l}\text { Loss of power } \\
\text { supply, falures } \\
\text { in input/output } \\
\text { multiplexors. CPU } \\
\text { or data } \\
\text { communications } \\
\text { links; Failures } \\
\text { of PPS local or } \\
\text { MCR remote } \\
\text { operators } \\
\text { modules }\end{array}$ \\
\hline
\end{tabular}

b) on

Symptoms and Local Effects
Including Dependent Failures
Loss of affected channels'
status and controls located on
local, remote shut down panel
and control room pPS operators
modules (e.g., bypasses,
variable setpoint resets).
Automatic testing Hithin
affected channel disabled.

Affected channeis' dat

Same as 23a) above.
Method
of Detection

Periodic surveillance and testing by operato Automatic failure detection by redundant processors.

$\frac{\begin{array}{c}\text { Inherent } \\ \text { Compensating } \\ \text { Provision }\end{array}}{\text { four redundant }}$

Four redundant

interface/test

processors.
Unaffected processors

still available to

perform necessary PPS
functions and 1 imited

testing.

DIAS and DPS annunciates four channel loss of data
communication.

redundancy.

Same as 23a) above.

Same as 23a) above. Same as 23a) above

Mone

RPS and ESF coincidence emains in 2-out-of-3

bypass).
Remarks

and

Automeric testing of Automatic testing of
remaining PPS channels can cont inue except for initiation logic, due to lack of test feedback and

test permissives from
affected channet.

DIAS and DPS perform signal val idation based on remain ing redundant channel

Same as 23a) bov: multi communications links fail to respond to CPU: PPS local and MCR remo modules fail or CPU stops execution 


\begin{tabular}{|c|c|c|c|c|c|c|c|c|c|}
\hline \multirow{2}{*}{ o. } & \multirow[b]{2}{*}{ Mave } & \multirow{2}{*}{\multicolumn{2}{|c|}{$\begin{array}{l}\text { Foilure } \\
\text { Mode }\end{array}$}} & \multirow[b]{2}{*}{ cause } & \multicolumn{2}{|c|}{$\begin{array}{l}\frac{\text { TABLE } 7.2-5}{\text { (CONT'd) }} \\
\text { (Sheet } 18 \text { of } 31) \\
\frac{\text { PLAMT PROTECTION SYSTEM }}{\text { RE MOOES AMD EFFECTS AMALYSIS }} \\
\frac{\text { (Figure } 7.2-12)}{}\end{array}$} & \multirow[b]{2}{*}{$\begin{array}{c}\text { Intherent } \\
\text { Compensating } \\
\text { Provision }\end{array}$} & \multirow[b]{2}{*}{$\begin{array}{c}\text { Effect Upon } \\
\text { PPS }\end{array}$} & \multirow[b]{2}{*}{$\begin{array}{c}\text { Remarks } \\
\text { ond } \\
\text { Other Effects } \\
\end{array}$} \\
\hline & & & & & $\begin{array}{l}\text { Symptoons and Local Effects } \\
\text { Including Dependent Failures }\end{array}$ & $\begin{array}{c}\text { Method } \\
\text { of } \\
\text { Detectic } \\
\end{array}$ & & & \\
\hline \multirow[t]{4}{*}{ 26) } & $\begin{array}{l}\text { RPS } \\
\text { Initiation } \\
\text { Circuits } \\
\text { (Channel A } \\
\text { Typical) }\end{array}$ & & $\begin{array}{l}\text { Under- } \\
\text { voltage } \\
\text { initiation } \\
\text { relay(s) } \\
\text { fails } \\
\text { "off" }\end{array}$ & $\begin{array}{l}\text { Loss of power } \\
\text { supply. relay } \\
\text { open circuit. } \\
\text { relay contact } \\
\text { or wiring open } \\
\text { circuit }\end{array}$ & $\begin{array}{l}\text { RTSS TCB-1 under voltage trip } \\
\text { circuit de-energized and TCB } \\
\text { will open. }\end{array}$ & $\begin{array}{l}\text { Annunciating automatic } \\
\text { from PPS interface/test } \\
\text { system via DIAS and DPS. } \\
\text { Visual indication at PPS } \\
\text { local and control room } \\
\text { operators modules. }\end{array}$ & $\begin{array}{l}\text { Redundant remaining uv } \\
\text { initiation relays and } \\
\text { logic not affected. }\end{array}$ & $\begin{array}{l}\text { RISS actuation logic } \\
\text { changes from selective } \\
2-\text { of }-4 \text { to selective } 1-\text { of }-3 \\
\text { coincidence. }\end{array}$ & All CEDMs remain energized. \\
\hline & & b) & $\begin{array}{l}\text { Under- } \\
\text { voltage } \\
\text { initiation } \\
\text { relay(s) } \\
\text { fails "on" }\end{array}$ & $\begin{array}{l}\text { Initiation relay } \\
\text { contact shorted } \\
\text { or welded closed; } \\
\text { Wiring or PPS } \\
\text { logic fault } \\
\text { keeps relay } \\
\text { energized: } \\
\text { Initiation } \\
\text { time delay } \\
\text { fails to time } \\
\text { out or } \\
\text { de-energize }\end{array}$ & $\begin{array}{l}\text { RISS TCB-1 under voltage trip } \\
\text { remains energized and TCB will } \\
\text { not open for bona-fide RPS UV } \\
\text { trip signal. }\end{array}$ & $\begin{array}{l}\text { Annunciating automatic } \\
\text { from PPS interface/test } \\
\text { system via DIAS and DPS. }\end{array}$ & $\begin{array}{l}\text { Redundant remaining UV } \\
\text { initiation relays in } \\
\text { same channel affected. } \\
\text { shunt trip initiation } \\
\text { relays not affected. } \\
\text { UV initiation relays } \\
\text { in redundant PPS } \\
\text { channels not affected. }\end{array}$ & $\begin{array}{l}\text { RTSS actuation becomes } \\
\text { selective } 2-\text { of }-3 \\
\text { coincidence for affected } \\
\text { LCL UV trip. RTSS } \\
\text { actuation remains } \\
\text { selective } 2-\text { of }-4 \text { for shunt } \\
\text { trip and unaffected uV } \\
\text { initiation relays. }\end{array}$ & $\begin{array}{l}\text { Manual reactor trip } \\
\text { capabil ity unaffected. All } \\
\text { CEDMs remain energized. }\end{array}$ \\
\hline & & c) & $\begin{array}{l}\text { Shunt } \\
\text { trip } \\
\text { initiation } \\
\text { relay } \\
\text { fails "on" }\end{array}$ & $\begin{array}{l}\text { Initiation } \\
\text { relay contact } \\
\text { stays open } \\
\text { upon de-energi- } \\
\text { zation; pPS logic } \\
\text { fault keeps relay } \\
\text { energized; or } \\
\text { open circuited } \\
\text { output to RisS }\end{array}$ & $\begin{array}{l}\text { RTSS TCB-1 shunt trip remains } \\
\text { de-energized and ICB will not } \\
\text { open for bona-tide RPS shunt } \\
\text { trip signal. }\end{array}$ & $\begin{array}{l}\text { Annunciating automatic } \\
\text { from PPS interface/test } \\
\text { processor via DIAS and } \\
\text { DPS. }\end{array}$ & $\begin{array}{l}\text { Redundant remaining } \\
\text { S.T. initiation relays } \\
\text { in same channel not } \\
\text { aftected. UV } \\
\text { initiation relays not } \\
\text { affected. }\end{array}$ & $\begin{array}{l}\text { RISS actuation becomes } \\
\text { selective } 2-\text { of }-3 \\
\text { Coincidence for affected } \\
\text { LCL shunt trip initiation } \\
\text { relay. RISS actuation } \\
\text { remains selective } 2 \text {-of- } 4 \\
\text { for uv trip and unaffected } \\
\text { S.T. initiation relays. }\end{array}$ & $\begin{array}{l}\text { Manual reactor trip } \\
\text { capabil lity unaffected. All } \\
\text { CEDHs reaain energized. }\end{array}$ \\
\hline & & d) & $\begin{array}{l}\text { Shunt } \\
\text { trip } \\
\text { initiation } \\
\text { relay } \\
\text { fails } \\
\text { "off" }\end{array}$ & $\begin{array}{l}\text { Loss of power } \\
\text { supply, relay } \\
\text { open circuit } \\
\text { or contact } \\
\text { shorted or } \\
\text { wiring short }\end{array}$ & $\begin{array}{l}\text { RISS ICB- } 1 \text { shunt trip energized } \\
\text { and TCB will open. }\end{array}$ & $\begin{array}{l}\text { Annunciating automatic } \\
\text { from PPS interface/test } \\
\text { processor via DiAs and } \\
\text { OPS. Visual indication } \\
\text { at pPS local and control } \\
\text { room operator modules. }\end{array}$ & $\begin{array}{l}\text { Redundant remaining } 3 \\
\text { PPS channels of } S \text {. T. } \\
\text { initiation relays and } \\
\text { logic not affected. } \\
\text { UV initiat ion relays not } \\
\text { affected. }\end{array}$ & $\begin{array}{l}\text { RTSS actuation becomes } \\
\text { selective } 1 \text {-of }-3 \\
\text { coincidence. }\end{array}$ & $\begin{array}{l}\text { All CEDM's remain } \\
\text { energized. }\end{array}$ \\
\hline
\end{tabular}


TABLE 7.2-5 (Cont'd)

(Sheet 19 of $3 i$ )

$\frac{\text { PLLANT PROTECTION SYSTEM }}{\text { FAILURE MODES AND EFFECTS AMALYSIS }}$

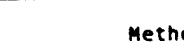

4). Mame $\frac{\text { Failure }}{\text { Mode }}$

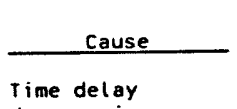

Symptoms and Local Effects Including Dependent failures Time delay de-energizes or

out: Open circui

coil or contact

or loss of power

supply

$\begin{array}{ll}\text { f) Uv time } & \text { Time delay does } \\ \text { delay } & \text { not de-energize } \\ \text { fails "on" } & \text { or fails to time }\end{array}$

out or shorted

sontact output

g) Shunt time delay does
trip time not energize or

fails to time

$\begin{array}{ll}\text { fails } & \text { out; Open circuit } \\ \text { "off" } & \text { coil or contact }\end{array}$

h) Shunt trip delay
fails "on"

Time delay energizes or
prematurely

times out or

shorted contact

Same as $24 a$ ).

Same as $24 a$ )

Same as $26 b$ ).

Same as $24 f$ ).

Same as $24 d$ ).

Same as $24 d$ ).
Method

of
Detection

ion
Inherent PPS channels of UV
$t$ ime delays not
affected. Redundant remaining 3 Same as $24 a$ ).

Periodic maintenance and Redundant remaining 3
PPS channels of UV

time delays not

affected. Shunt trip

circuits remain

coincidence.

Redundant 3 PPS

channels of S.T. $t$ ime

delays not affected.

remain functional

2-of-4 coincidence.

Same as $24 \mathrm{~g}$ ).

Same as 24d).

Same as 24d).

Remarks ather Effects

Same as 24a).

Same as $24 b$ ).

bec actuation logic coincidence for uv trips.

RTSS actuation logic becomes selective 2-0f-3

Same as 24b).
Same as $24 d$. 


\begin{tabular}{|c|c|c|c|c|c|c|c|c|}
\hline \multirow{2}{*}{ No. } & \multirow[b]{2}{*}{ Mame } & \multirow[b]{2}{*}{$\begin{array}{c}\text { Failure } \\
\text { Mode }\end{array}$} & \multirow[b]{2}{*}{ Cause } & \multicolumn{2}{|c|}{$\begin{array}{c}\frac{\text { TABLE } 7.2-5 \text { (Cont'd) }}{\text { (Sheet } 20 \text { of } 31 \text { ) }} \\
\frac{\text { PLILUNT PROTECTION SYSTEM }}{\text { FODES AKD EFFECTS AMALYSIS }} \\
\text { (Figure } 7.2-12)\end{array}$} & \multirow[b]{2}{*}{$\begin{array}{l}\text { Inherent } \\
\text { Compensating } \\
\text { Provision }\end{array}$} & \multirow[b]{2}{*}{$\begin{array}{c}\text { Effect Upon } \\
\text { PPS }\end{array}$} & \multirow[b]{2}{*}{$\begin{array}{c}\begin{array}{c}\text { Remarks } \\
\text { and } \\
\text { Other Effects }\end{array} \\
\end{array}$} \\
\hline & & & & $\begin{array}{l}\text { Symptoms and Local Effects } \\
\text { Including Dependent Failures }\end{array}$ & $\begin{array}{c}\text { Method } \\
\text { of } \\
\text { Detection } \\
\end{array}$ & & & \\
\hline \multirow[t]{2}{*}{ 25) } & $\begin{array}{l}\text { Riss } \\
\text { Trip } \\
\text { Circuit } \\
\text { Breaker } \\
\text { Actuation } \\
\text { (TCB-1 } \\
\text { Typical) }\end{array}$ & a) Open & $\begin{array}{l}\text { Loss of } 125 \mathrm{Vdc} \\
\text { Bus } 1 \text { control } \\
\text { power; Spurious } \\
\text { actuation of S.T. } \\
\text { or UV coils; TCB } \\
\text { mechanical } \\
\text { failure }\end{array}$ & TCB -1 opens. & $\begin{array}{l}\text { Annunciating automatic } \\
\text { from PPS interface/test } \\
\text { processor via DIAS and } \\
\text { DPS. Visual indication } \\
\text { PPS local and control } \\
\text { room operator modules. }\end{array}$ & $\begin{array}{l}\text { Other } 3 \text { ICBs not } \\
\text { affected. }\end{array}$ & $\begin{array}{l}\text { RTSS actuation logic } \\
\text { changes from selective } \\
2-\text { of }-4 \text { to selective } 1-\text { of }-3 \\
\text { coincidence. }\end{array}$ & All CEDMs remain energized. \\
\hline & & b) closed & $\begin{array}{l}\text { TCB mechanical } \\
\text { failure; Failure } \\
\text { of S.T. or UV } \\
\text { coils to trip } \\
\text { breaker; Shorting } \\
\text { of TCB main } \\
\text { contactors }\end{array}$ & TCB-2 will not open. & Manual periodic test. & $\begin{array}{l}\text { other } 3 \text { TCBS not } \\
\text { affected. }\end{array}$ & $\begin{array}{l}\text { RTSS actuation logic } \\
\text { changes to selective } \\
2-\text { of }-3 \text { coincidence for } 3 \\
\text { other unaffected iCB's. }\end{array}$ & \\
\hline \multirow[t]{2}{*}{ 26) } & $\begin{array}{l}\text { Manual } \\
\text { Trip Switch } \\
\text { (rcB-1 } \\
\text { Typical) }\end{array}$ & a) off & $\begin{array}{l}\text { Mechanical switch } \\
\text { failure of "Uw" } \\
\text { "shunt" or "Uv" } \\
\text { or "both" trip } \\
\text { switch position } \\
\text { contacts. UV } \\
\text { shorted or ST } \\
\text { open circuit. }\end{array}$ & TCB-1 will not open. & Manual periodic test. & $\begin{array}{l}\text { other } 3 \text { manual trip } \\
\text { suitches not af fected } \\
\text { for other TCBs } \\
\text { Automatic RPS trips } \\
\text { not affected. }\end{array}$ & $\begin{array}{l}\text { Manual trip actuation } \\
\text { logic changes to selective } \\
2-\text { of }-3 \text { roincidence. }\end{array}$ & \\
\hline & & b) on & $\begin{array}{l}\text { Mechanical switch } \\
\text { failure of } \\
\text { "shunt" or } \\
\text { "uv" or "both" } \\
\text { trip switch } \\
\text { position } \\
\text { contacts. uv } \\
\text { open or si } \\
\text { short circuit. }\end{array}$ & TCB-1 opens. & $\begin{array}{l}\text { Annunciating automatic } \\
\text { from PPS interface/test } \\
\text { processor via DIAS and } \\
\text { DPS. Visual indication } \\
\text { at pPs local and control } \\
\text { room operator modules. }\end{array}$ & Mone. & $\begin{array}{l}\text { Manual trip actuation } \\
\text { logic becomes selective } \\
1-\text { of }-3 \text { coincidence. }\end{array}$ & \\
\hline
\end{tabular}


IABLE 7.2-5 (Cont'd)

(Sheet 21 of 31 )

PLANT PROTECTION SYSTEM
EAILURE MODES AND EFFECTS ANALYSIS

\begin{tabular}{|c|c|c|c|}
\hline $\begin{array}{c}\text { Method } \\
\text { of } \\
\text { Detection }\end{array}$ & $\begin{array}{c}\text { Inherent } \\
\text { Compensating } \\
\text { Provision }\end{array}$ & $\begin{array}{c}\text { Effect Upon } \\
\text { PPS }\end{array}$ & 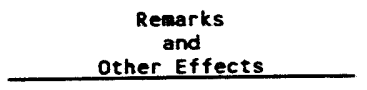 \\
\hline $\begin{array}{l}\text { Visual indication from } \\
\text { pPS local and remote } \\
\text { operator modules. } \\
\text { visual indication from } \\
\text { olas and DPS via PPS } \\
\text { interface/test } \\
\text { processor. }\end{array}$ & $\begin{array}{l}\text { other } 3 \text { TCBs are not } \\
\text { affected. }\end{array}$ & $\begin{array}{l}\text { RTSS actuation becomes } \\
\text { selective } 1-\text { of }-3 \\
\text { coincidence if affected } \\
\text { ICB is open. }\end{array}$ & $\begin{array}{l}\text { No impact on RPS initiation } \\
\text { or RTSS actuation. }\end{array}$ \\
\hline Manual periodic test. & $\begin{array}{l}\text { TCB will still open on } \\
\text { trip signal. other } 3 \\
\text { TCBs not affected. }\end{array}$ & $\begin{array}{l}\text { RTSS actuation logic } \\
\text { remains } 2-\text { of }-4 \\
\text { coincidence. }\end{array}$ & $\begin{array}{l}\text { No impact on RPS initiation } \\
\text { or RTSS actuation. }\end{array}$ \\
\hline $\begin{array}{l}\text { Periodic maintenance and } \\
\text { testigd during } \\
\text { refceling. }\end{array}$ & $\begin{array}{l}\text { PPS sensors and RPS } \\
\text { togic independent, } \\
\text { diverse and separate } \\
\text { from APS. }\end{array}$ & Wo effect on RPS or RTSS. & $\begin{array}{l}\text { M-G output contactor can be } \\
\text { manually opened. }\end{array}$ \\
\hline $\begin{array}{l}\text { Annunciation sutomatic } \\
\text { from Process-CCS via } \\
\text { DIAS and DPS. }\end{array}$ & $\begin{array}{l}\text { Redundant M-G set } \\
\text { unaritieted and sized to } \\
\text { carry full CEDM load. }\end{array}$ & No effect on RPS or RTSS. & \\
\hline $\begin{array}{l}\text { Bus current indication } \\
\text { via oPS and PPS } \\
\text { operators modules. }\end{array}$ & $\begin{array}{l}\text { Redundant bus to other } \\
\text { MG set. }\end{array}$ & None. & \\
\hline
\end{tabular}

Symptoms and Local Effects
Including Dependent failures
Unable to energize TCB closing
circuit to close TCB after
manual test or automatic trip.

closing coil will remain energized and oppose the shunt trip circuit. PPS operators module failure processor output relay closes contact; Shorted

Aps trip signal not generated due to sensor failure
or Process-ccs or Process-CCS

b) off

APs trip signat generated by sensor failure Process-ccs
failure

Short, mech.

M-G(1) output load contactor no opened by APS. Protection
System Trip Signal

(Channel $x$
Typical)

generated by
sensor failure
Process-ccs

$M-G(1)$
opens.

Loss of one of two redundant
$V$ AC supplies to the CEDMs. 


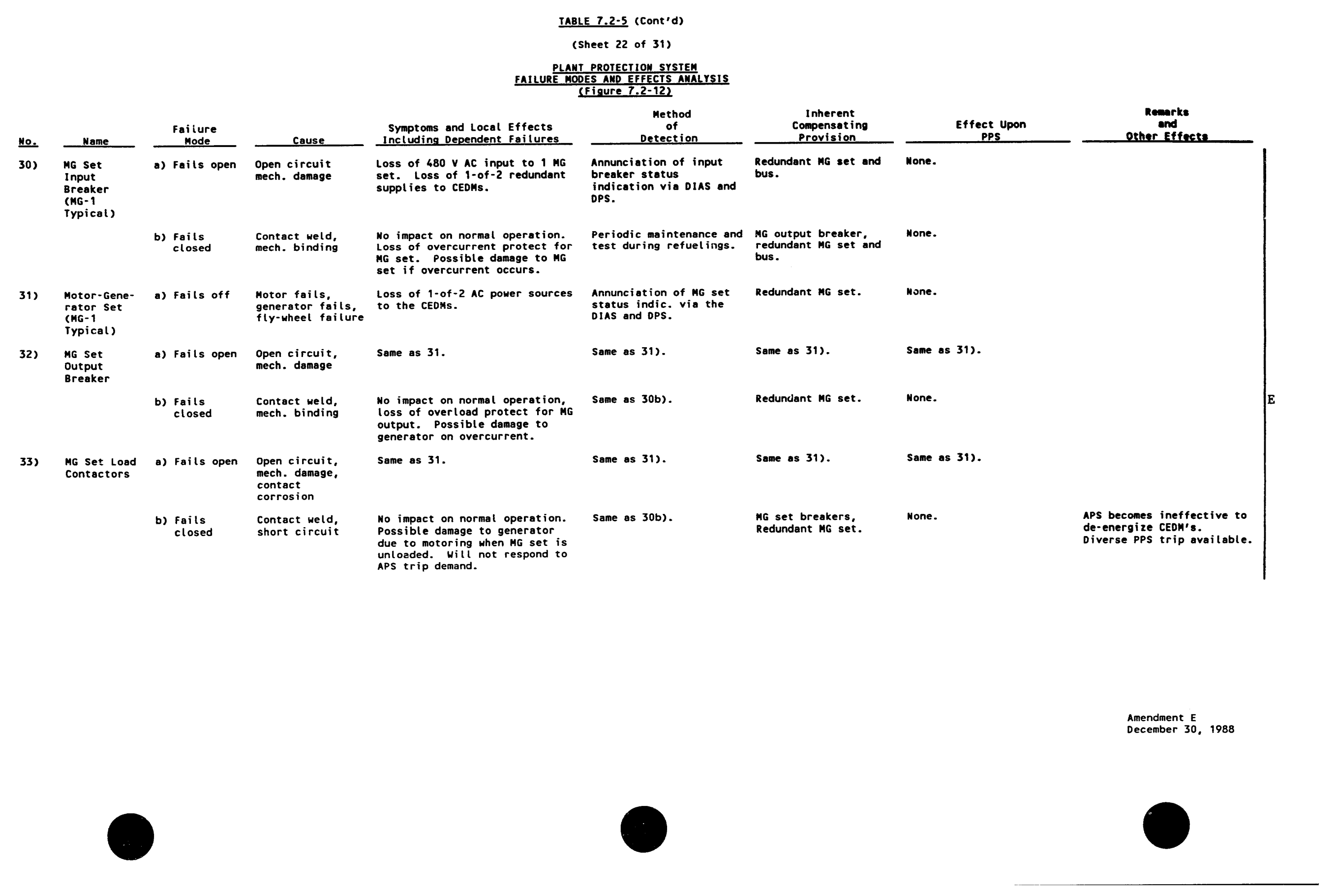




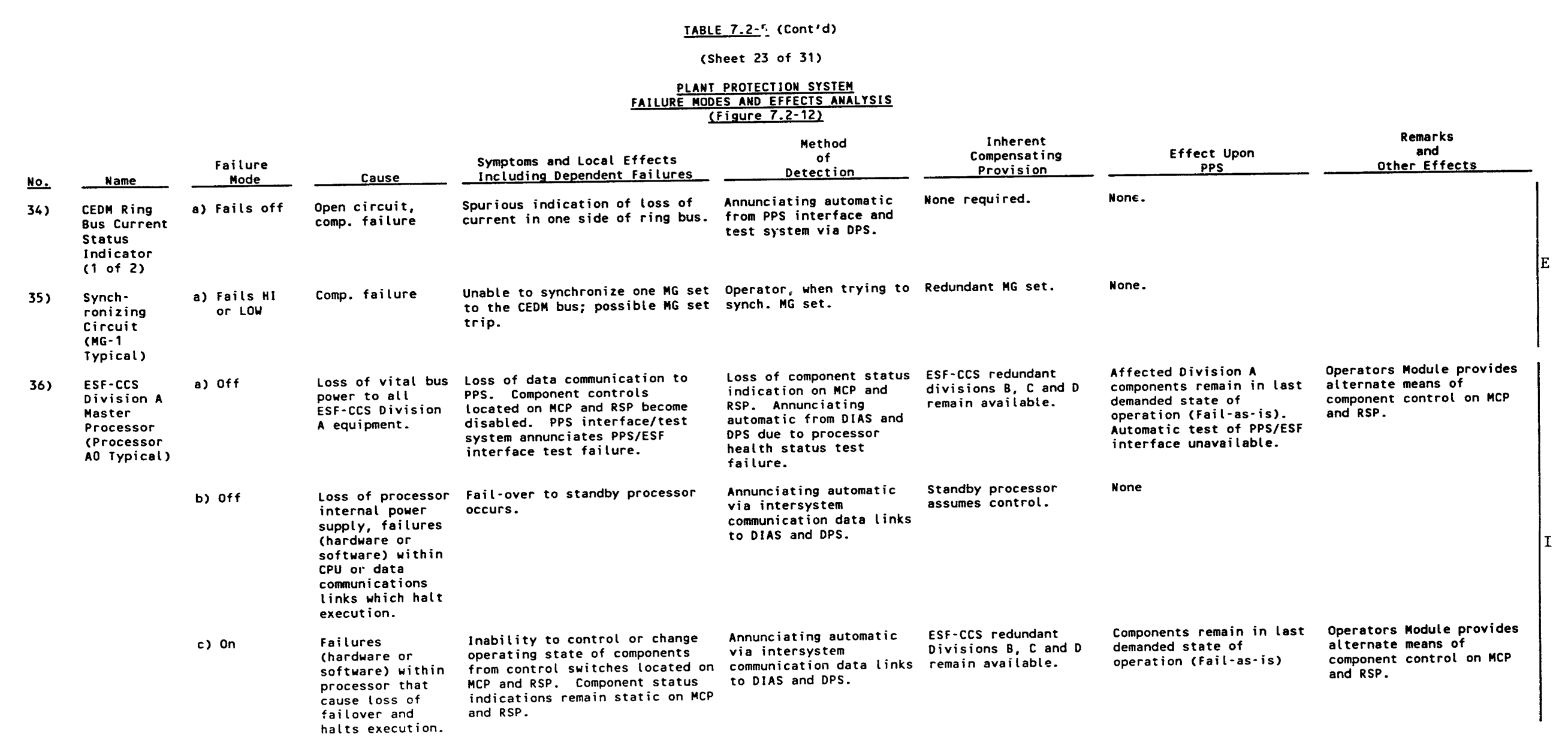


TABLE $7.2-5$ (Cont'd)

(Sheet 24 of 31 )

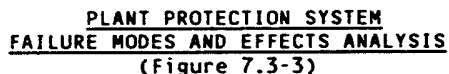

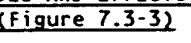

\begin{tabular}{|c|c|c|c|}
\hline №. & Name & $\begin{array}{c}\text { Fai i ure } \\
\text { Mode } \\
\end{array}$ & Cause \\
\hline 37) & $\begin{array}{l}\text { ESF-CCS MCP } \\
\text { Controls } \\
\text { and } \\
\text { Indication } \\
\text { I/O } \\
\text { Multiplexor } \\
\text { (MUX A0-1 } \\
\text { (Typical) }\end{array}$ & a) off & $\begin{array}{l}\text { Loss of } \\
\text { Multiplexor power } \\
\text { supply \& } \\
\text { electronics } \\
\text { failures } \\
\text { within } \\
\text { Multiplexor; } \\
\text { open circuit } \\
\text { wiring to } \\
\text { switches and } \\
\text { status } \\
\text { indication or } \\
\text { loss of } \\
\text { Hultiplexor } \\
\text { data } \\
\text { communications }\end{array}$ \\
\hline
\end{tabular}

faitures

Multiplexor,

wiring to

status

indication

Symptoms and Local Effects
Including Dependent failures
Loss of status indication and
control of components assigned
to multiptexor on RCP.

Erroneous status indication and actuation of components assigned to multiplexor on ACP.
Method Annunciating automatic ESF-CCS redundant via DPS and DIAS LoSS Divisions B C and of status indication remain available. observed by operator. Operator can take Periodic test and control of affected
maintenance. ESF-CCS "A" operators
module on MCP.

Erroneous status indication and/or component activation

Same as $37 a$ ).

\begin{tabular}{|c|c|}
\hline $\begin{array}{c}\text { Effect Upon } \\
\text { PPS }\end{array}$ & $\begin{array}{c}\text { Remarks } \\
\text { and } \\
\text { Other Effects } \\
\end{array}$ \\
\hline $\begin{array}{l}\text { Components remain in } \\
\text { last demanded state of } \\
\text { operation (Fail-as-is). }\end{array}$ & $\begin{array}{l}\text { Automatic or manual ESF } \\
\text { actuation via PPS not } \\
\text { affected. }\end{array}$ \\
\hline $\begin{array}{l}\text { Affected ESF components } \\
\text { actuated. }\end{array}$ & $\begin{array}{l}\text { Same es } 37 a) \text {. Plant power } \\
\text { production process may be } \\
\text { perturbed. }\end{array}$ \\
\hline
\end{tabular}


№.

38)

\begin{tabular}{l} 
Name \\
\hline ESF-CCS RSP \\
Controls \\
and \\
Indication \\
$1 / 0$ \\
Multiplexor \\
(MUX or \\
AO-2 \\
typical)
\end{tabular}

39) b) on

Same as $37 b$ ).

a) off

Same as 36 a).

Division A
Master

Processor

(A)

\begin{tabular}{|c|c|c|}
\hline $\begin{array}{l}\text { Failure } \\
\text { Mode }\end{array}$ & Cause & $\begin{array}{l}\text { Symptoms and Local Effects } \\
\text { Including Dependent Failures } \\
\end{array}$ \\
\hline a) Off & Same as 37a). & $\begin{array}{l}\text { Loss of status indication and } \\
\text { control of components assigned } \\
\text { to multiplexor if control is } \\
\text { transferred to RSP. }\end{array}$ \\
\hline
\end{tabular}
to multiplexor if control is to RSP.

Indication on RSP erroneous or components within train.

Loss of data communication to DPS. Loss of indications and
control from Operators Module indication on operators control Method
of of
Detection

Loss of component status indication and controls inserved by operator. by CCS processors self
diagnostics via DIAS and DPS.

Same as 37b).

Loss of ESF-CCS status module on MCP. from DIAS due to
processor health status test failure.

b) off

c) on Same as 366).

Same as 39a)

Data remains static on DPS displays. Loss of control
operators module on MCP. (hardware or processor that processor that
halt execution.
Same as 39a).

Annunciating automatic from DIAS due to processor health status test failure.

\begin{tabular}{|c|c|c|}
\hline $\begin{array}{c}\text { Inherent } \\
\text { Compensating } \\
\text { Provision }\end{array}$ & $\begin{array}{c}\text { Effect Upon } \\
\text { PPS }\end{array}$ & 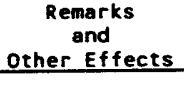 \\
\hline $\begin{array}{l}\text { Operator can take } \\
\text { control of af fected } \\
\text { components using } \\
\text { ESF-CS "A" operators } \\
\text { module on RSP. }\end{array}$ & Same as $37 \mathrm{a}$ ). & \\
\hline Same as $38 \mathrm{a}$ ) & Same as $38 \mathrm{a}$ ). & \\
\hline $\begin{array}{l}\text { Operator retains } \\
\text { component control from } \\
\text { control switches on } \\
\text { MCP. DIAS provides } \\
\text { indication and } \\
\text { annunciating. }\end{array}$ & None & \\
\hline Same as $39 a$ ). & None & \\
\hline Same as $39 a$ ). & None & \\
\hline
\end{tabular}




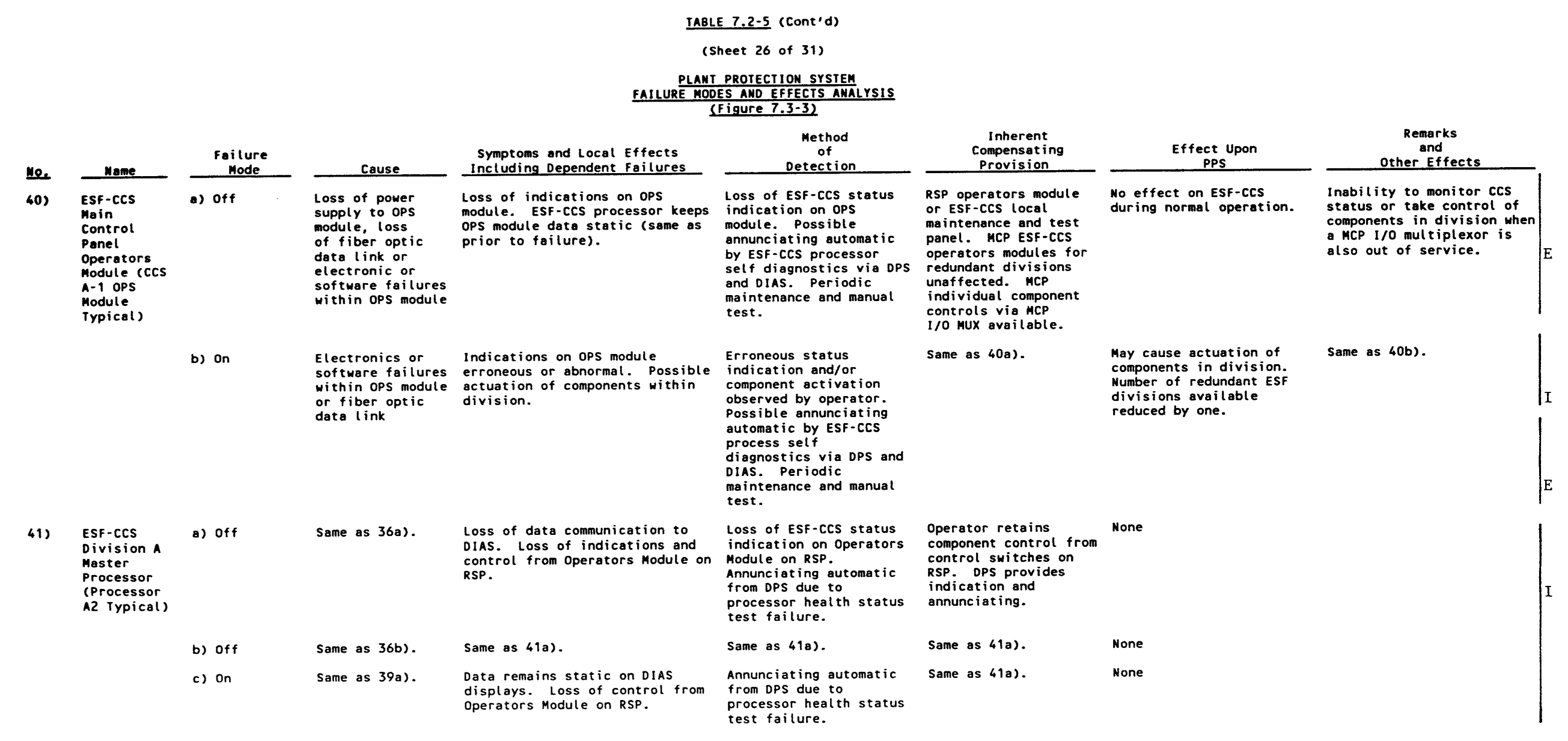




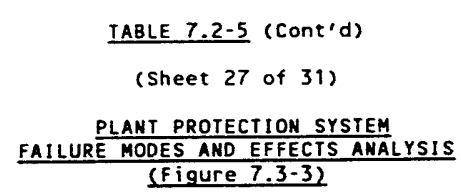

(Figure 7.3-3)

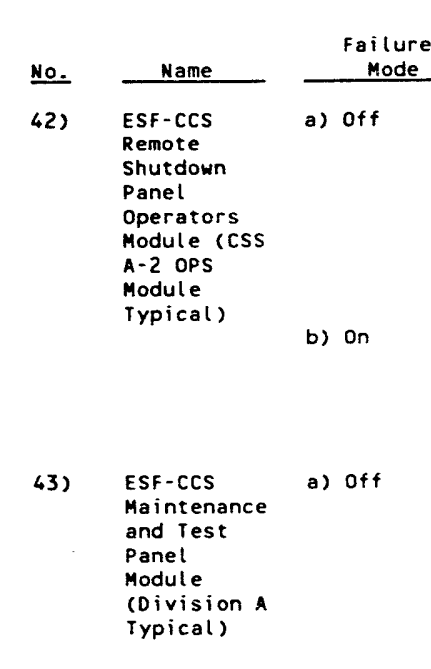

b) on
Same as $40 \mathrm{~b})$.

Loss of power supply, loss data link or electronics sof tware failure
within module.

Same as $40 \mathrm{~b}$ ), if control is

Same as 40b).

Loss of local indications on

of local indications on Loss of status module data static (same as maintenance and test capability. tintenance Doally at ESF-CCS. Possible annunciation automatic by ESF-CCS processor self diagnostics via DPS and mas. Periodic
maintenance and test.

Same as 40b)

Erroneous or abnormal indications on module. Possible Electronics
hardware or software failures conts within division.

\begin{tabular}{|c|c|c|}
\hline $\begin{array}{c}\text { Inherent } \\
\text { Compensating } \\
\text { Provision }\end{array}$ & $\begin{array}{c}\text { Effect Upon } \\
\text { PPS }\end{array}$ & $\begin{array}{c}\text { Remarks } \\
\text { and } \\
\text { Other Effects } \\
\end{array}$ \\
\hline $\begin{array}{l}\text { ESF-CCS local } \\
\text { maintenance and test } \\
\text { panel. }\end{array}$ & $\begin{array}{l}\text { No effect on ESF-CCS } \\
\text { during normal operation. } \\
\text { If control transferred to } \\
\text { RSP, loss of control and } \\
\text { status indication of } \\
\text { affected ESF system } \\
\text { through operators module } \\
\text { in one division. }\end{array}$ & \\
\hline Same as $42 a$ ) & $\begin{array}{l}\text { No effect on ESF-CCS } \\
\text { during normal operation. } \\
\text { if control transferred to } \\
\text { RSP, may cause activation } \\
\text { of components in division. }\end{array}$ & \\
\hline $\begin{array}{l}\text { Ability to use either } \\
\text { MCP or RSP ESF-CCS } \\
\text { operators module for } \\
\text { component status and } \\
\text { control, dependent upon } \\
\text { which was last selected } \\
\text { for control. }\end{array}$ & $\begin{array}{l}\text { No effect on ESF-CCS } \\
\text { during normal operation. } \\
\text { Inability to transfer } \\
\text { control from MCR to RSP or } \\
\text { vice versa in one division. }\end{array}$ & $\begin{array}{l}\text { Automatic ESFAS actuation } \\
\text { by PPS not affected. }\end{array}$ \\
\hline $\begin{array}{l}\text { Redundant division } \\
\text { ESF-CCS maintenance } \\
\text { and test paneis } \\
\text { unaffected. }\end{array}$ & & \\
\hline Same as $43 a$ ). & $\begin{array}{l}\text { Possible actuations of } \\
\text { components within } \\
\text { division. Inability to } \\
\text { transfer control from MCR } \\
\text { to RSP or vice versa in } \\
\text { one division. }\end{array}$ & $\begin{array}{l}\text { Automatic ESFAS actuation } \\
\text { by PPS in one division mayl } \\
\text { be affected. Plant power } \\
\text { production process may be } \\
\text { perturbed. }\end{array}$ \\
\hline
\end{tabular}




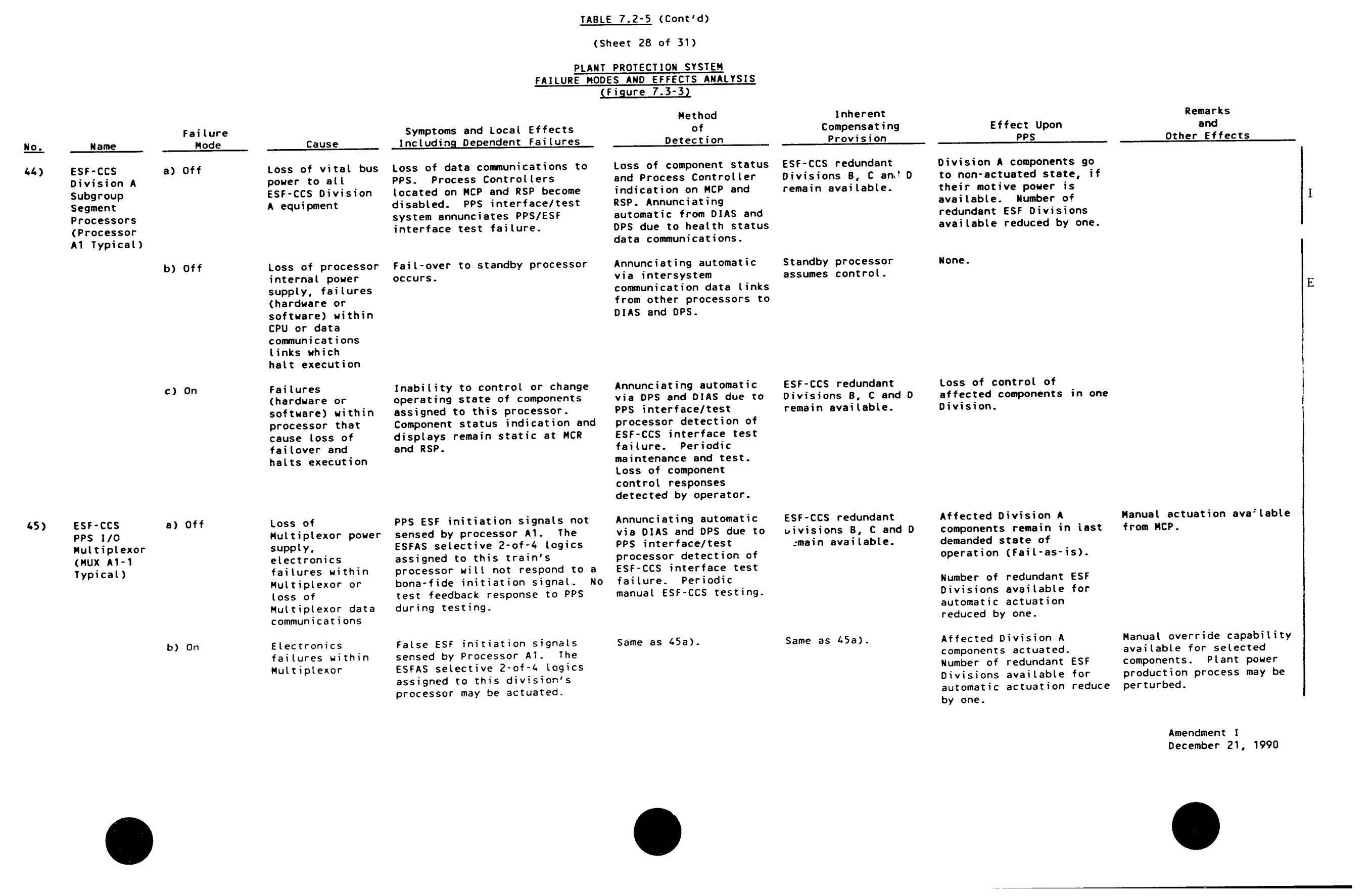


TABLE $7.2-5$ (Cont'd)

(Sheet 29 of 31 )

PLANT PROTECIION SYSTEM
FAILURE MODES AND EFFECTS AMALYSIS

(Figure 7.3-3)

\begin{tabular}{|c|c|c|c|c|}
\hline №. & Name & $\begin{array}{l}\text { Failure } \\
\text { Mode }\end{array}$ & - Cause & $\begin{array}{l}\text { Symptoms and Local Effects } \\
\text { Including Dependent failures }\end{array}$ \\
\hline \multirow[t]{2}{*}{ 46) } & $\begin{array}{l}\text { Fiber optic } \\
\text { interfaces } \\
\text { between } \\
\text { ESF-cCS and } \\
\text { PPS (MUX } \\
\text { A1-1 } \\
\text { Typical) }\end{array}$ & a) off & $\begin{array}{l}\text { Loss of power } \\
\text { supply or } \\
\text { electronics } \\
\text { failure in } \\
\text { fiber optic } \\
\text { transmitter or } \\
\text { receiver; } \\
\text { Severing of fiber } \\
\text { optic cable(s) in } \\
\text { one redundant PPS } \\
\text { channel }\end{array}$ & $\begin{array}{l}\text { Loss of PPS signals sensed as } \\
\text { channel initiation trip signal } \\
\text { into ESF-CCS processor selective } \\
\text { 2-of- }-4 \text { coincidence logic. }\end{array}$ \\
\hline & & b) on & $\begin{array}{l}\text { Electronics } \\
\text { failure causes } \\
\text { fiber optic } \\
\text { transmitter or } \\
\text { receiver to } \\
\text { stay on from } \\
\text { one redundant } \\
\text { PPS channel }\end{array}$ & $\begin{array}{l}\text { PPS ESF initiation signals not } \\
\text { sensed by ESF-CCS processor } \\
\text { selective } 2-\text { of }-4 \text { coincidence } \\
\text { logic. }\end{array}$ \\
\hline \multirow[t]{2}{*}{ 47) } & $\begin{array}{l}\text { ESF-cCS } \\
\text { Component } \\
\text { I/O } \\
\text { Multiplexor } \\
\text { (MUX A1-2 } \\
\text { Typical) }\end{array}$ & a) off & $\begin{array}{l}\text { Loss of } \\
\text { multiplexor power } \\
\text { supply. } \\
\text { electronics } \\
\text { failure within } \\
\text { multiplexor or } \\
\text { data } \\
\text { communication } \\
\text { network causes } \\
\text { outputs to } \\
\text { assume default } \\
\text { state }\end{array}$ & $\begin{array}{l}\text { Components assigned to } \\
\text { multiplexor revert to } \\
\text { non-actuated state. Process } \\
\text { instrumentation or component } \\
\text { status inputs to affected } \\
\text { ESf-cCs processor not refreshed } \\
\text { for affected ESF system. }\end{array}$ \\
\hline & & b) on & $\begin{array}{l}\text { Failure in } \\
\text { electronics or } \\
\text { multiplexor } \\
\text { data } \\
\text { communications } \\
\text { causes } \\
\text { multiplexor } \\
\text { outputs to } \\
\text { assume their }\end{array}$ & $\begin{array}{l}\text { Components assigned to } \\
\text { multiplexor go to the ESF } \\
\text { actuated state. }\end{array}$ \\
\hline
\end{tabular}

\begin{tabular}{|c|c|c|c|}
\hline $\begin{array}{c}\text { Method } \\
\text { of } \\
\text { Detection }\end{array}$ & $\begin{array}{c}\text { Inherent } \\
\text { Compensating } \\
\text { Provision } \\
\end{array}$ & $\begin{array}{c}\text { Effect Upon } \\
\text { PPS }\end{array}$ & $\begin{array}{c}\text { Remarks } \\
\text { and } \\
\text { other Effects } \\
\end{array}$ \\
\hline Same as $45 a$ ). & Same as $45 a$ ). & $\begin{array}{l}\text { ESF-CCS actuation logic } \\
\text { becomes selective } 1-0 f-3 \\
\text { coincidence. }\end{array}$ & Same as $45 b$ ). \\
\hline Same as $45 a)$. & Same as $45 a)$ & $\begin{array}{l}\text { ESF-CCS actuation logic } \\
\text { becomes selective } 2-\text { of }-3 \\
\text { coincidence. }\end{array}$ & Same as $45 a$ ). \\
\hline $\begin{array}{l}\text { Periodic maintenance and } \\
\text { test. Loss of component } \\
\text { controls response } \\
\text { detected by operator. } \\
\text { Annunciating automatic } \\
\text { by processor self } \\
\text { diagnostics via DPS and } \\
\text { DIAS. }\end{array}$ & $\begin{array}{l}\text { ESF-CCS redundant } \\
\text { Divisions } B \text {, C and } D \\
\text { remain available. }\end{array}$ & $\begin{array}{l}\text { Loss of control and status } \\
\text { indication of affected ESF } \\
\text { system in one division. } \\
\text { Mumber of redundant ESF } \\
\text { divisions ovailable } \\
\text { reduced by one. }\end{array}$ & \\
\hline $\begin{array}{l}\text { Erroneous status } \\
\text { indication and component } \\
\text { activation observed by } \\
\text { operator. Periodic } \\
\text { maintenance and testing. }\end{array}$ & $\begin{array}{l}\text { ESF-CCS redundant } \\
\text { Divisions } B \text {, C and D } \\
\text { remain unaffected. } \\
\text { Components assigned to } \\
\text { different mult tiplexors } \\
\text { for pump and valves in } \\
\text { same division such } \\
\text { that full fluid system } \\
\text { not actuated for EFH } \\
\text { and sis. }\end{array}$ & $\begin{array}{l}\text { Affected Division A } \\
\text { components actuated. } \\
\text { Number of redundant ESF } \\
\text { divisions available } \\
\text { reduced by one. }\end{array}$ & $\begin{array}{l}\text { Plant power production } \\
\text { process may be perturbed. }\end{array}$ \\
\hline
\end{tabular}




\begin{tabular}{|c|c|c|c|c|c|c|c|c|}
\hline \multirow[b]{2}{*}{ №. } & \multirow[b]{2}{*}{ Name } & \multirow[b]{2}{*}{$\begin{array}{l}\text { Failure } \\
\text { Mode }\end{array}$} & \multirow[b]{2}{*}{ Cause } & \multicolumn{2}{|c|}{$\begin{array}{l}\text { (Sheet } 30 \text { of 31) } \\
\frac{\text { PLANT PROTECTION SYSTEM }}{\text { FAILURE MODES AHD EFFECTS AMALYSIS }} \\
\text { (Figure } 7.3 .3 \text { ) }\end{array}$} & \multirow[b]{2}{*}{$\begin{array}{c}\text { Inherent } \\
\text { Compensating } \\
\text { Provision }\end{array}$} & \multirow[b]{2}{*}{$\begin{array}{c}\text { Effect Upon } \\
\text { PPS }\end{array}$} & \multirow[b]{2}{*}{$\begin{array}{c}\text { Remarks } \\
\text { and } \\
\text { Other Effects } \\
\end{array}$} \\
\hline & & & & $\begin{array}{l}\text { Symptoms and Local Effects } \\
\text { Including Dependent Failures } \\
\end{array}$ & $\begin{array}{c}\begin{array}{c}\text { Method } \\
\text { of } \\
\text { Detection }\end{array} \\
\end{array}$ & & & \\
\hline \multirow[t]{2}{*}{ 48) } & $\begin{array}{l}\text { ESF-ccs } \\
\text { Multidrop } \\
\text { Networks } \\
\text { (Channel A1 } \\
\text { Typical) }\end{array}$ & a) off & $\begin{array}{l}\text { Open, short, } \\
\text { ground or } \\
\text { application of } \\
480 \text { v AC to } \\
\text { one network in } \\
\text { division. }\end{array}$ & $\begin{array}{l}\text { Possible damage to } \\
\text { communications module. ESF-CCS } \\
\text { processor self diagnostics } \\
\text { detects loss of data } \\
\text { communications; shifts to } \\
\text { redundant network and } \\
\text { annunciates via DPS and DIAS. }\end{array}$ & $\begin{array}{l}\text { Annunciating automatic } \\
\text { by associated ESF-CCS } \\
\text { processor self } \\
\text { diagnostics via DPS and } \\
\text { DIAS. Periodic } \\
\text { maintenance and test. }\end{array}$ & $\begin{array}{l}\text { Redundant multidrop } \\
\text { network available. }\end{array}$ & Mone. & \\
\hline & & b) off & $\begin{array}{l}\text { Open, short, } \\
\text { ground or } \\
\text { application of } \\
480 \text { VAC to } \\
\text { both networks } \\
\text { in division }\end{array}$ & Same as $38 a), 40 a), 42 a), 47 a)$ & Same as $38 a$ ). & Same as $38 a$ ). & Same as $38 a$ ) and $(2 a)$ & Same as $40 a$ ) and $(2 a)$. \\
\hline \multirow[t]{2}{*}{ 49) } & $\begin{array}{l}\text { ESF-CCS } \\
\text { Intra-divi- } \\
\text { sion } \\
\text { Communica- }\end{array}$ & a) off & Same as $48 a$ ). & Same as $48 a$ ). & Same as $48 a$ ). & $\begin{array}{l}\text { Redundant } \\
\text { Intra-division } \\
\text { communications network } \\
\text { available. }\end{array}$ & Mone & \\
\hline & & b) of? & Same as $48 b)$ & $\begin{array}{l}\text { Loss of data communications } \\
\text { between processors in same } \\
\text { ESF-CCS division. Possible loss } \\
\text { of data refresh to DiAS and/or } \\
\text { DPS dependent upon failure } \\
\text { location. }\end{array}$ & $\begin{array}{l}\text { Periodic maintenance and } \\
\text { test. Possible } \\
\text { annunciation by ESF-cCS } \\
\text { processor self } \\
\text { diagnostics via DPS and } \\
\text { DIAS. }\end{array}$ & Same as $47 \mathrm{a})$. & $\begin{array}{l}\text { May loose some } \\
\text { interlocking signs.s } \\
\text { between processors yínin } \\
\text { same ESF-CCS division. } \\
\text { Manual component controls } \\
\text { not affected. }\end{array}$ & \\
\hline \multirow[t]{2}{*}{ 50) } & $\begin{array}{l}\text { ESF-CCS } \\
\text { Intersystem } \\
\text { Comunica- } \\
\text { tions Data } \\
\text { Link to } \\
\text { DPS. }\end{array}$ & a) off & Same as $48 a$ ). & $\begin{array}{l}\text { Possible damage to data } \\
\text { communication module. Loss of } \\
\text { data to ops, until manual shift } \\
\text { to backup processor or redundant } \\
\text { data link. }\end{array}$ & $\begin{array}{l}\text { Annunciating by DPS or } \\
\text { DIAS. Periodic } \\
\text { maintenance and test. }\end{array}$ & $\begin{array}{l}\text { Fiber optic cable pre- } \\
\text { vents faults originat- } \\
\text { ing in oPS from } \\
\text { affecting ESF-CCS }\end{array}$ & None & $\begin{array}{l}\text { Data sent to DiAs not } \\
\text { affected. }\end{array}$ \\
\hline & & b) off & Same as $48 b$ ). & $\begin{array}{l}\text { Possible damage to both data } \\
\text { communications modules. Loss of } \\
\text { data to DPS. }\end{array}$ & Same as $50 a$ ). & Same as $50 a$ ). & None & Same as 50a). \\
\hline
\end{tabular}


IABLE 7.2-5 (cont'd)

(sheet 31 of 31 )

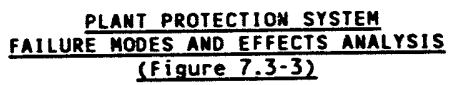

(Figure $7.3 \cdot 3$ )

No.

51)

52) ESF-CCS

ESF-CCS
Process

Controller

b) on

a) off

Communica-

tions Dat

DIAS

(Division

b) off

a) off
Controller

Symptoms and Local Effects Symptoms and Local Effects
Including Dependent Failures

Possible damage to data

Method

Failure
Mode

Same as $48 b$ ) data to Dias until manual shift data link.

Same as $50 \mathrm{a}$ ).

Inherent
compensating
Provision

Effect Upon
PPS

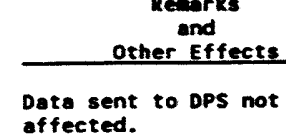

affected. supply to process applicable subgroup segment controller, libs components. controller. ESF-CCS annunciating automatic electronic or process controller data static softuare failures (same as prior to failure). within process
controller. by subgroup segment

self-diagnostics via DPS

and DIAS. Periodic

maintenance and manual

Erroneous status

Same as 40b).

Electronics or Indications on Process

within Process abnormal possible erroneous component activation

Controller or modulation or activation of

fiber optic data

link.

comperved by operator.

possible annunciating

aut omatic by subgroup
Same as 50a). None

Same as 51a). maintenance and test

self-diagnostics via DPS

and DIAS. Periodic

test.

MCP Operacors Module

panel.

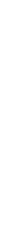


ONE TRIP BISTABLE PER PARAMETER SET POINT I $\mathrm{CPC} / \mathrm{CH}$.

2 BIST. PROC. $/ \mathrm{CH}$.

CHANNEL TO CHANNEL TRIP SIGNAL ISOLATION

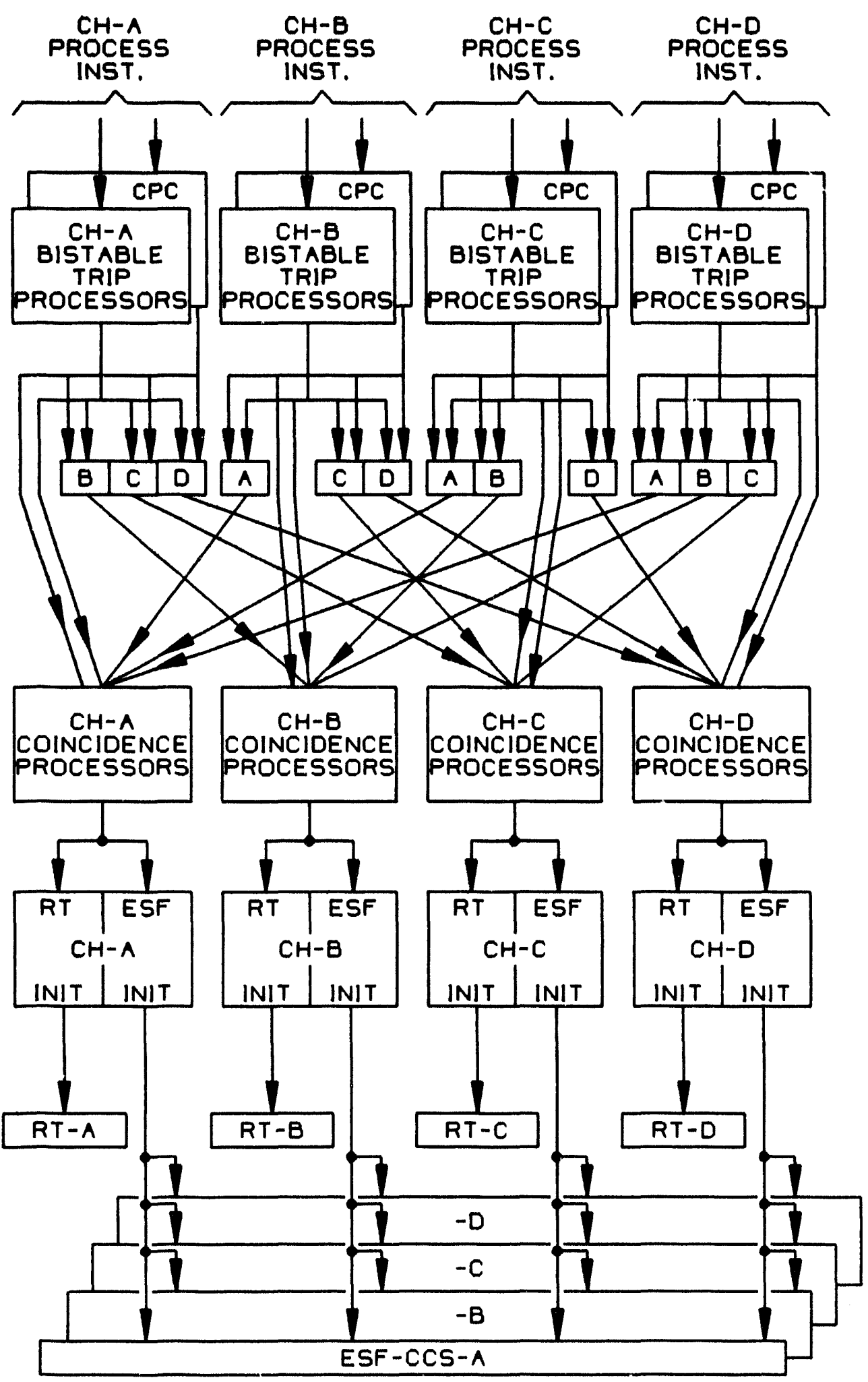

ESF FUNCTIONS

INITIATION LOGIC ONE INITIATION LOGIC, EACH RT FUNCTION, EACH ESF FUNCTION. PER CHANNEL

REACTOR TRIP FUNCTIONS 


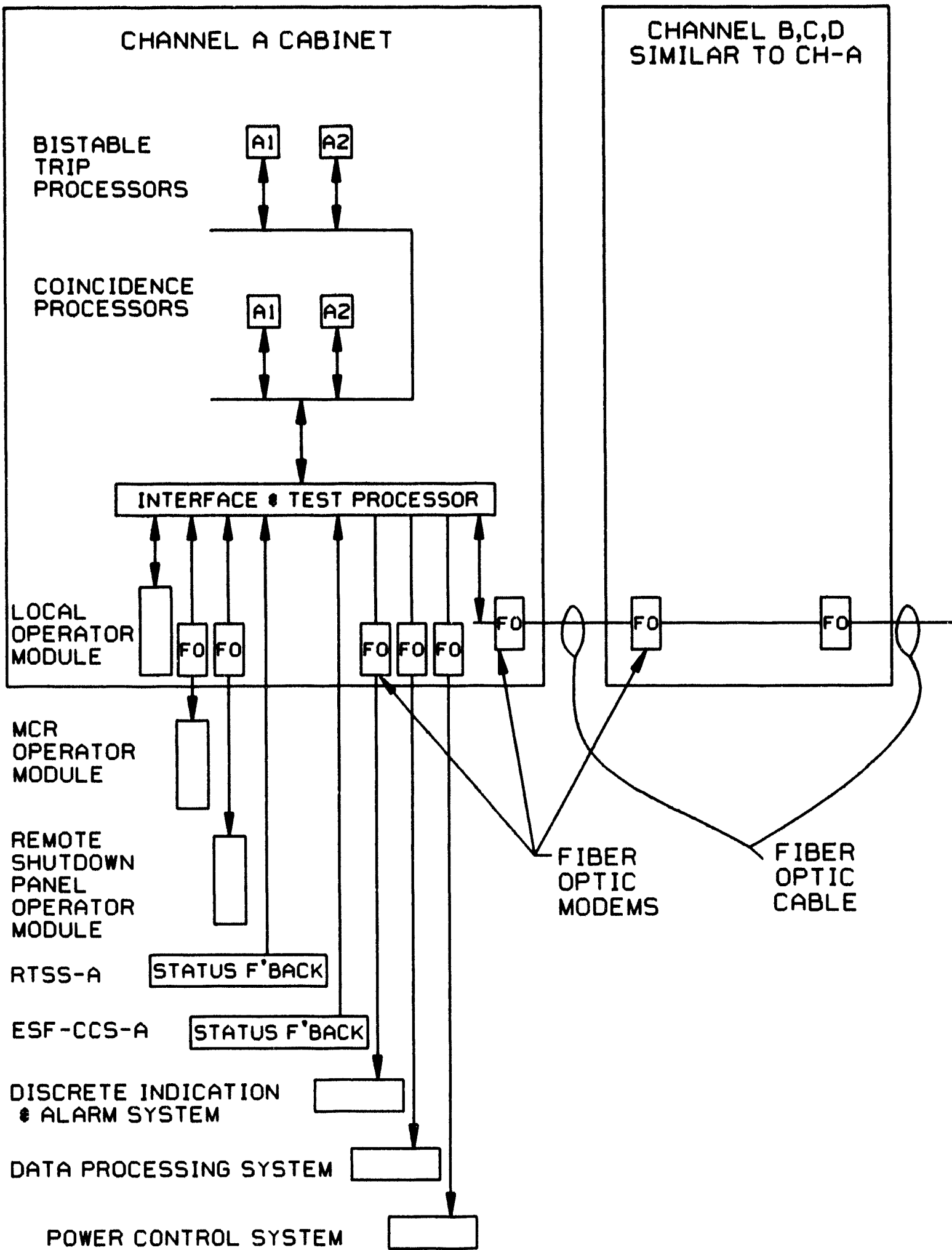

Amendment I

December 21, 199 


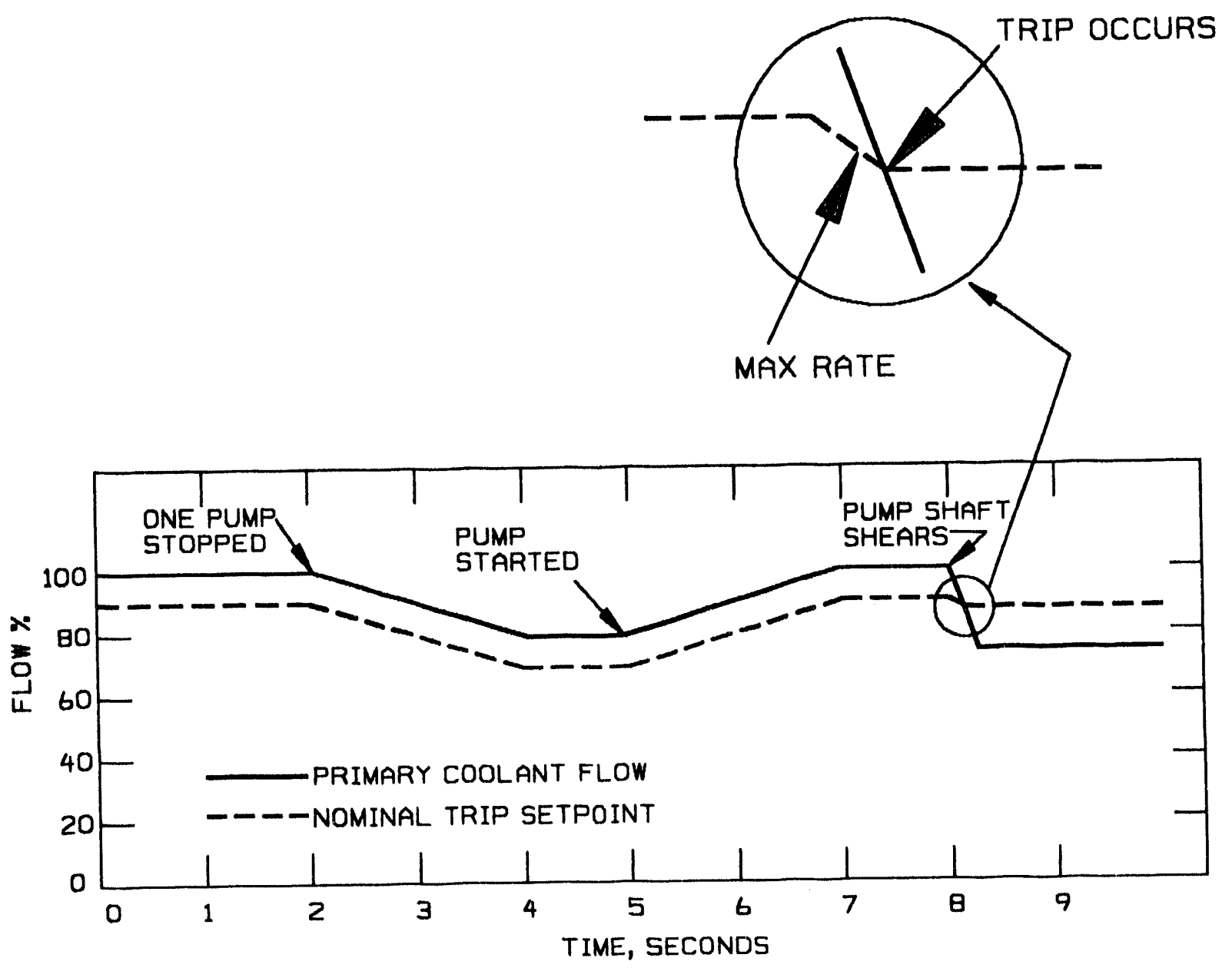

CALMA FILE:

I.CLGONYNORJSYS8OFIG 720 
PLANT PROTECTION SYSTEM

CHANNEL " $A$ " $(B, C, D$ SIMILAR $)$

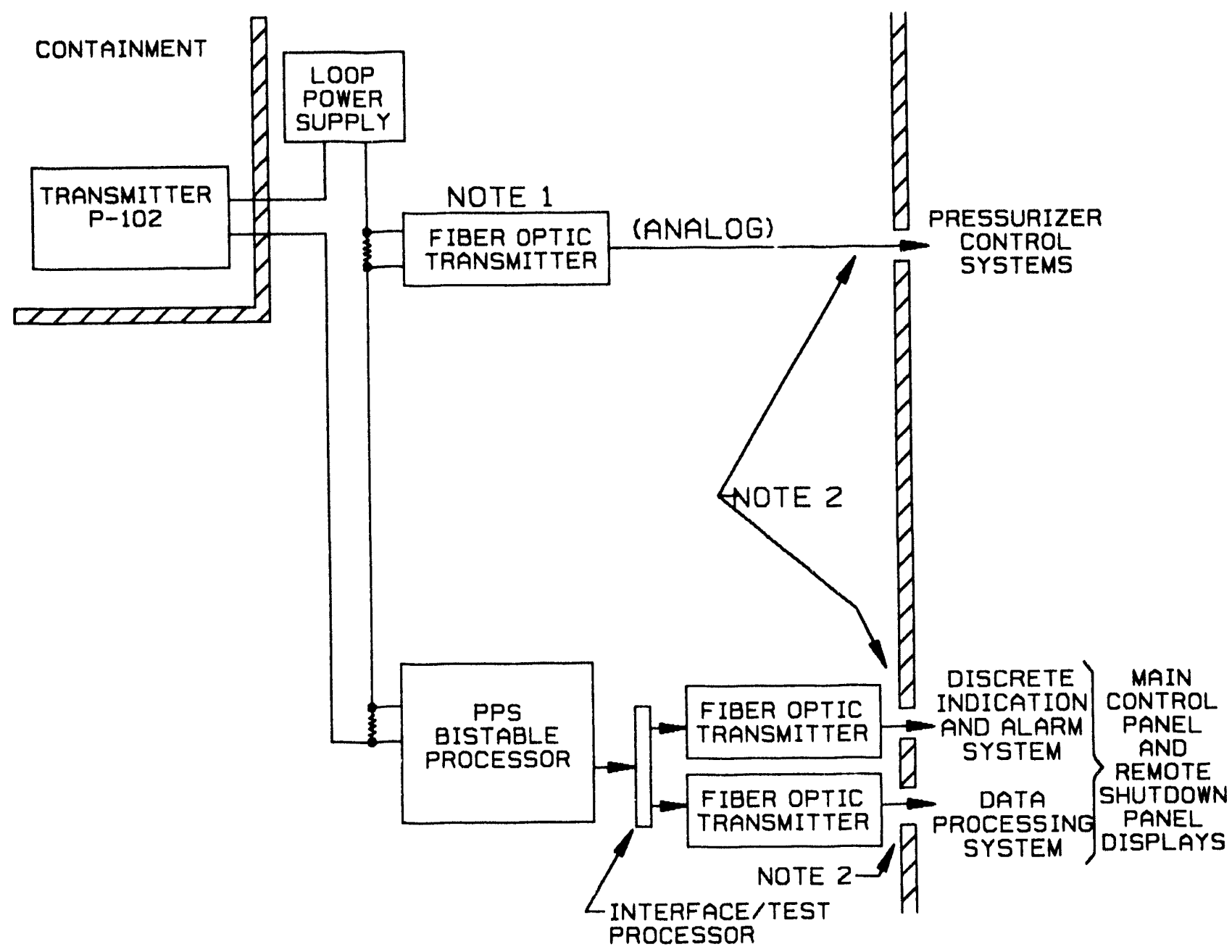

NOTES:

1-INCLUDED ONLY WHERE PROTECTIVE CHANNEL IS ALSO USED

FOR CONTROL (SEE SECTION 7.2.2.3.2.G)

2-FIBER OPTIC CABLE

CALMA FILE:

[.CLGONYNORISYS8OFIG721

Amendment $\mathrm{E}$

December 30, 1988 


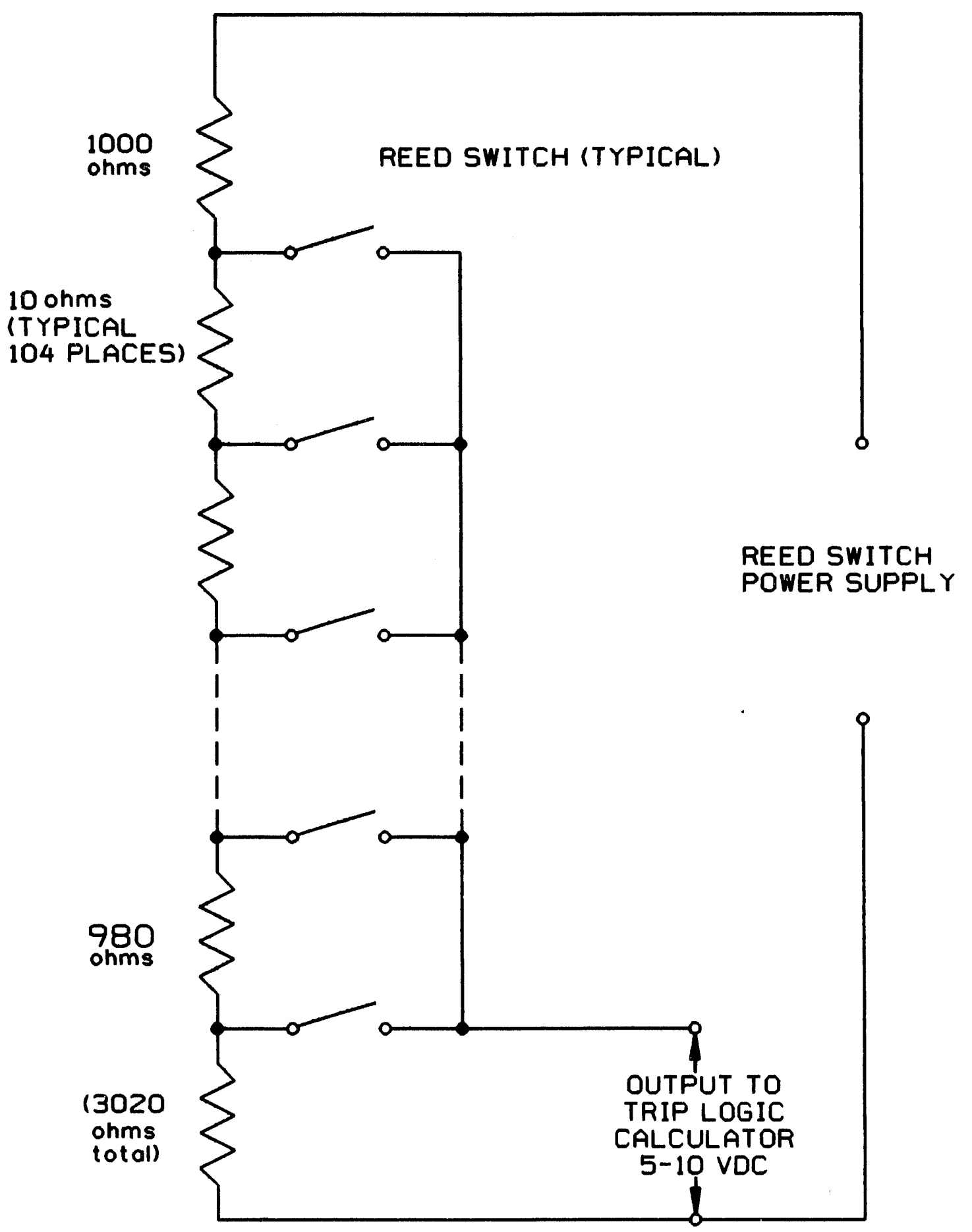




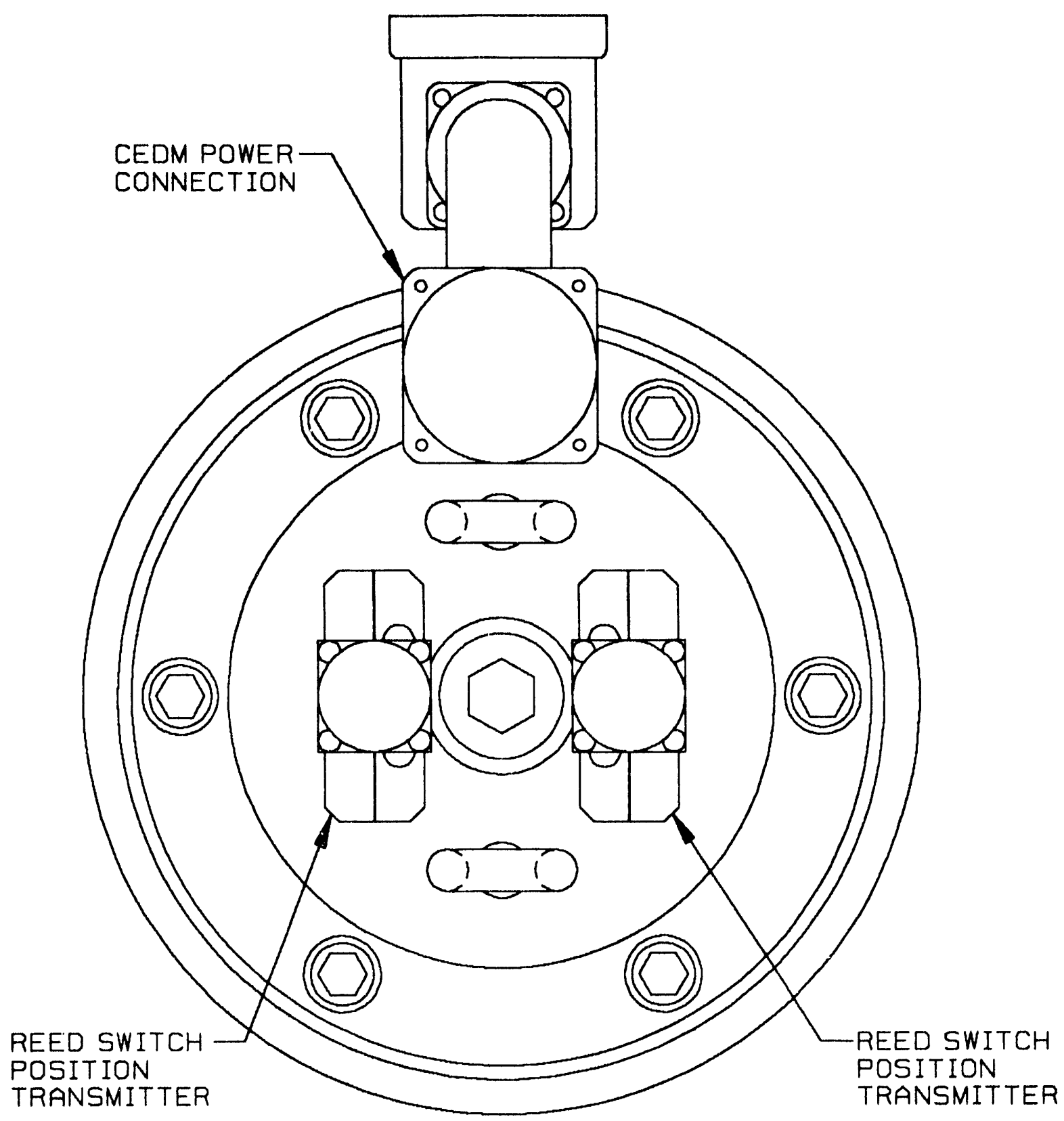

CALMA FILE:

[.CLGONYNOR]SYS8OFIG 716

Amendment $\mathrm{E}$

December 30, 1988 


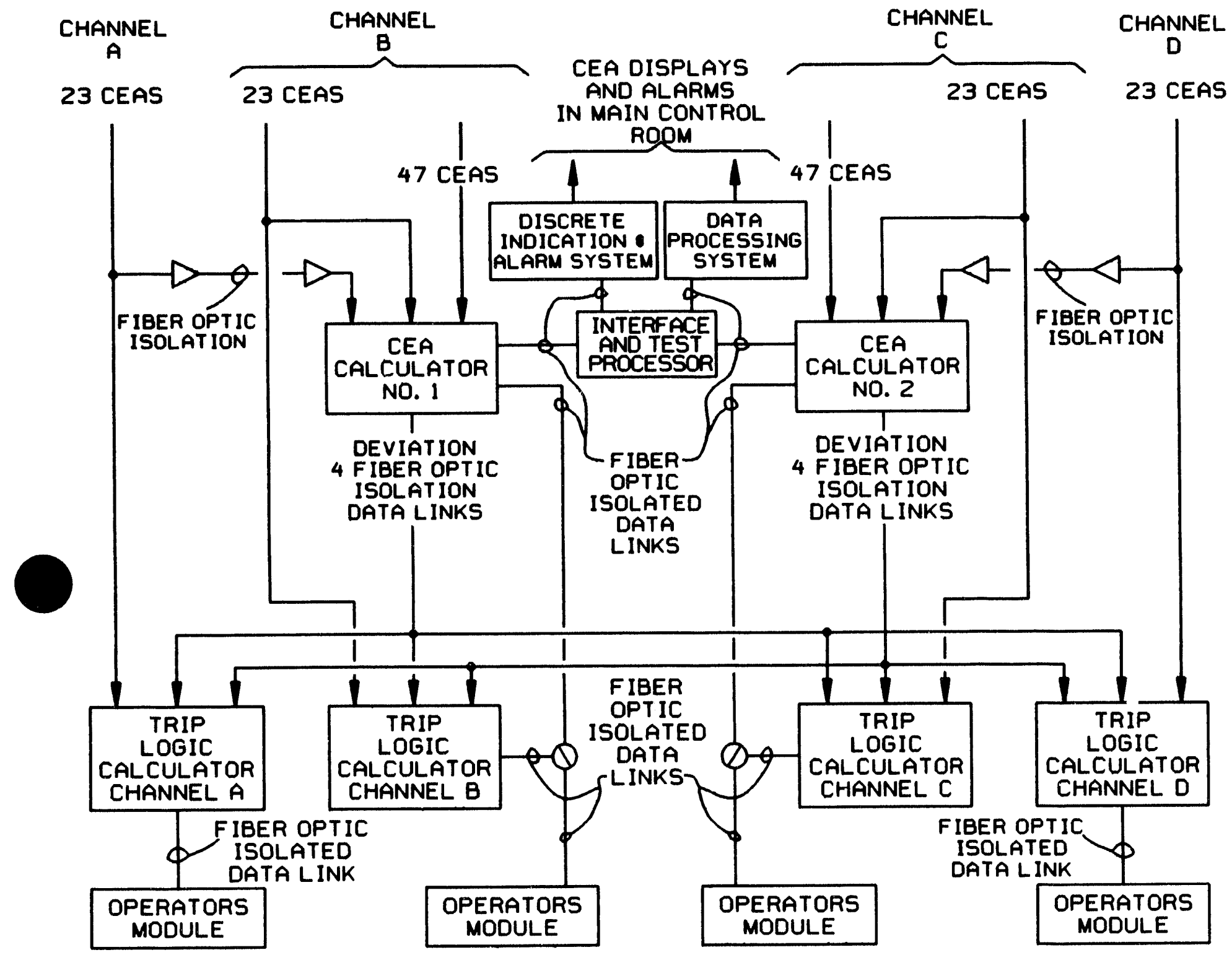

Amendment I

December 21, 1990

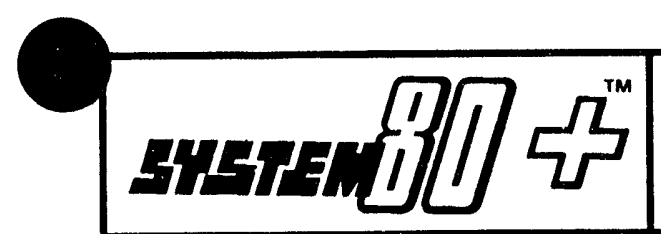




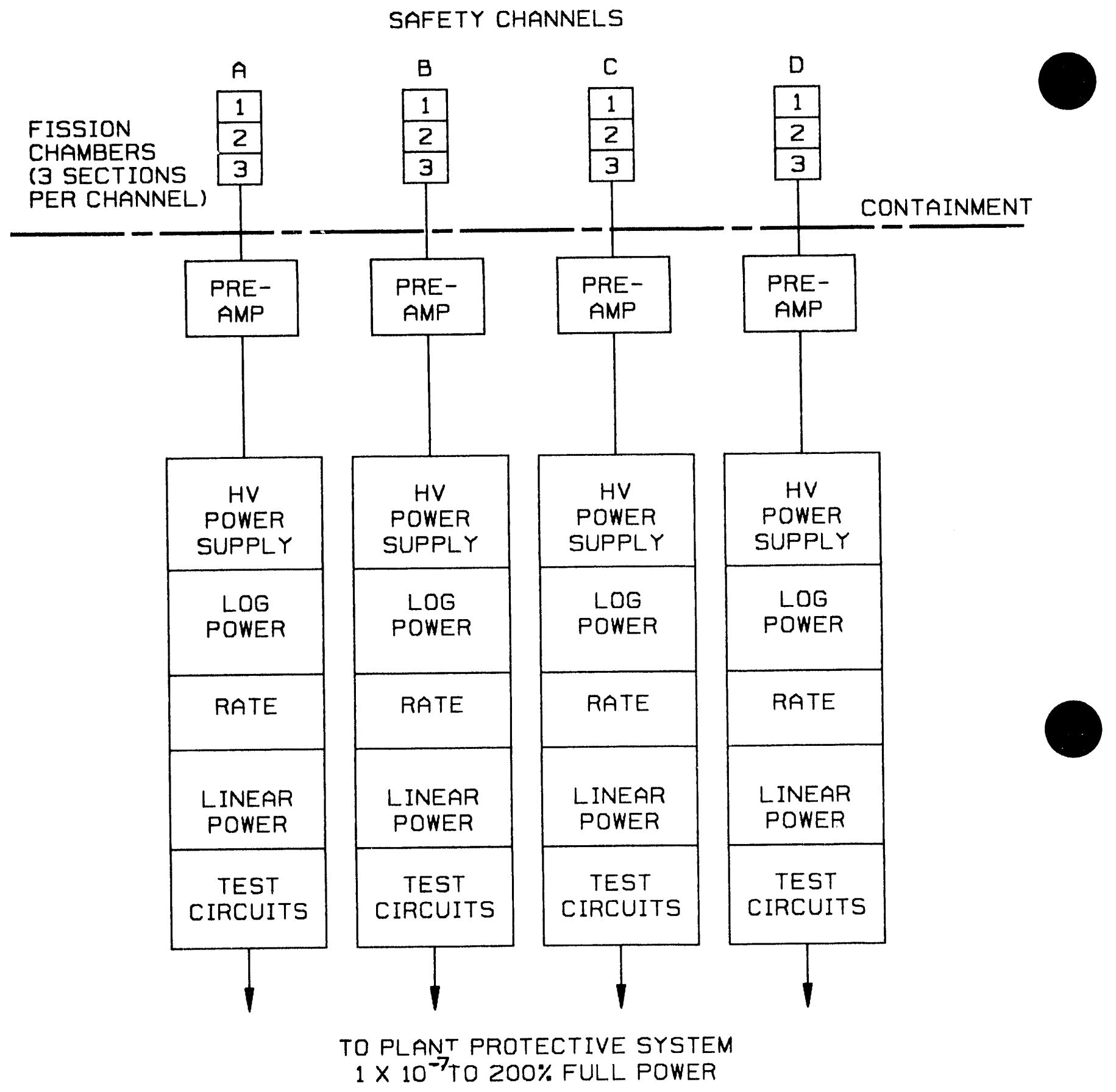

CALMA FILE:

[.CLGONYNOR]SYSBOFIG 725

Amendment $\mathrm{E}$

December 30, 1988 
TERMINAL BOX

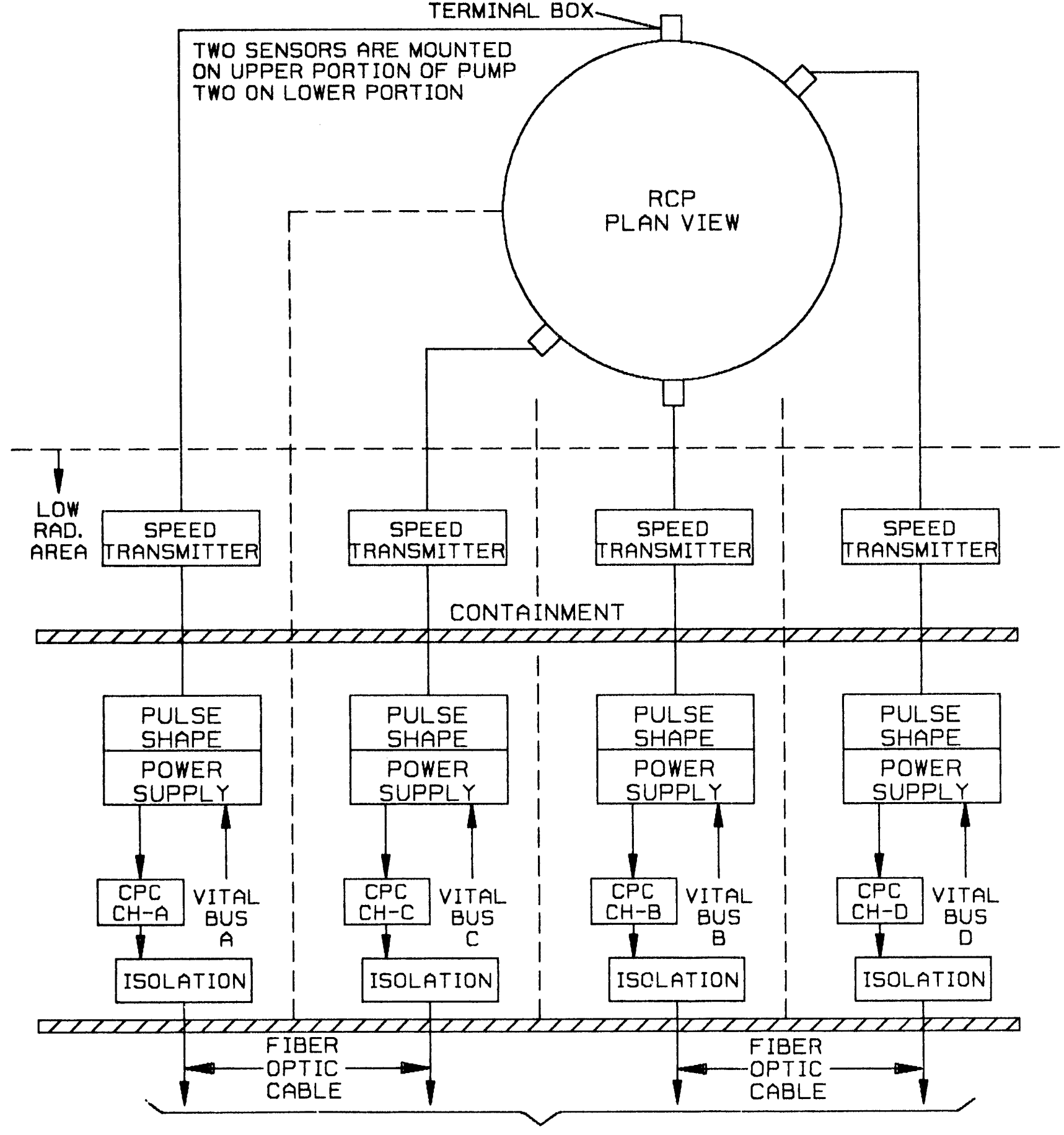

TO DATA PROCESSING SYSTEM FOR COLSS

CALMA FILE:

[.CLGONYNOR]SYS8OFIG 726

Amendment $\mathrm{E}$

December 30, 1988 


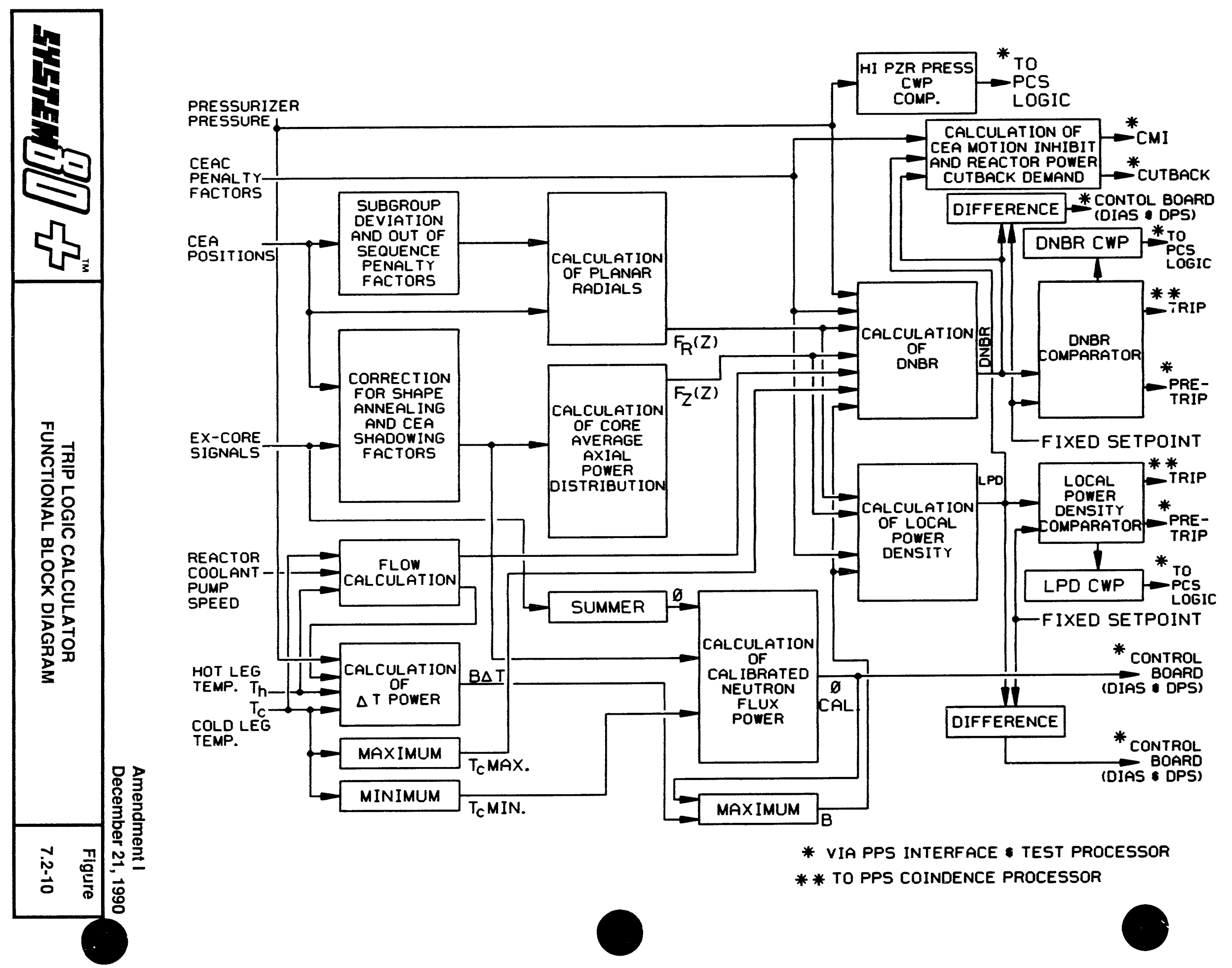




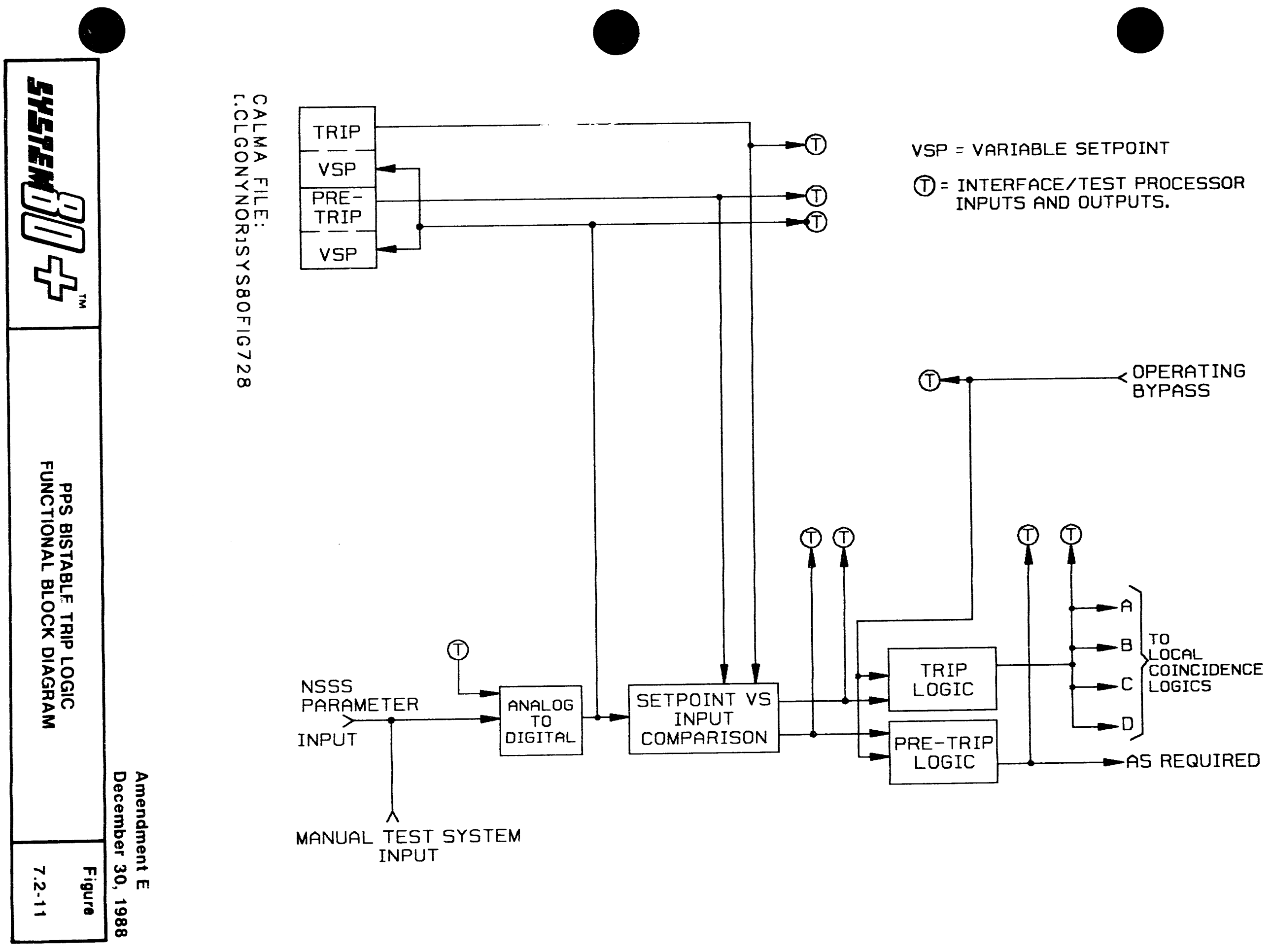




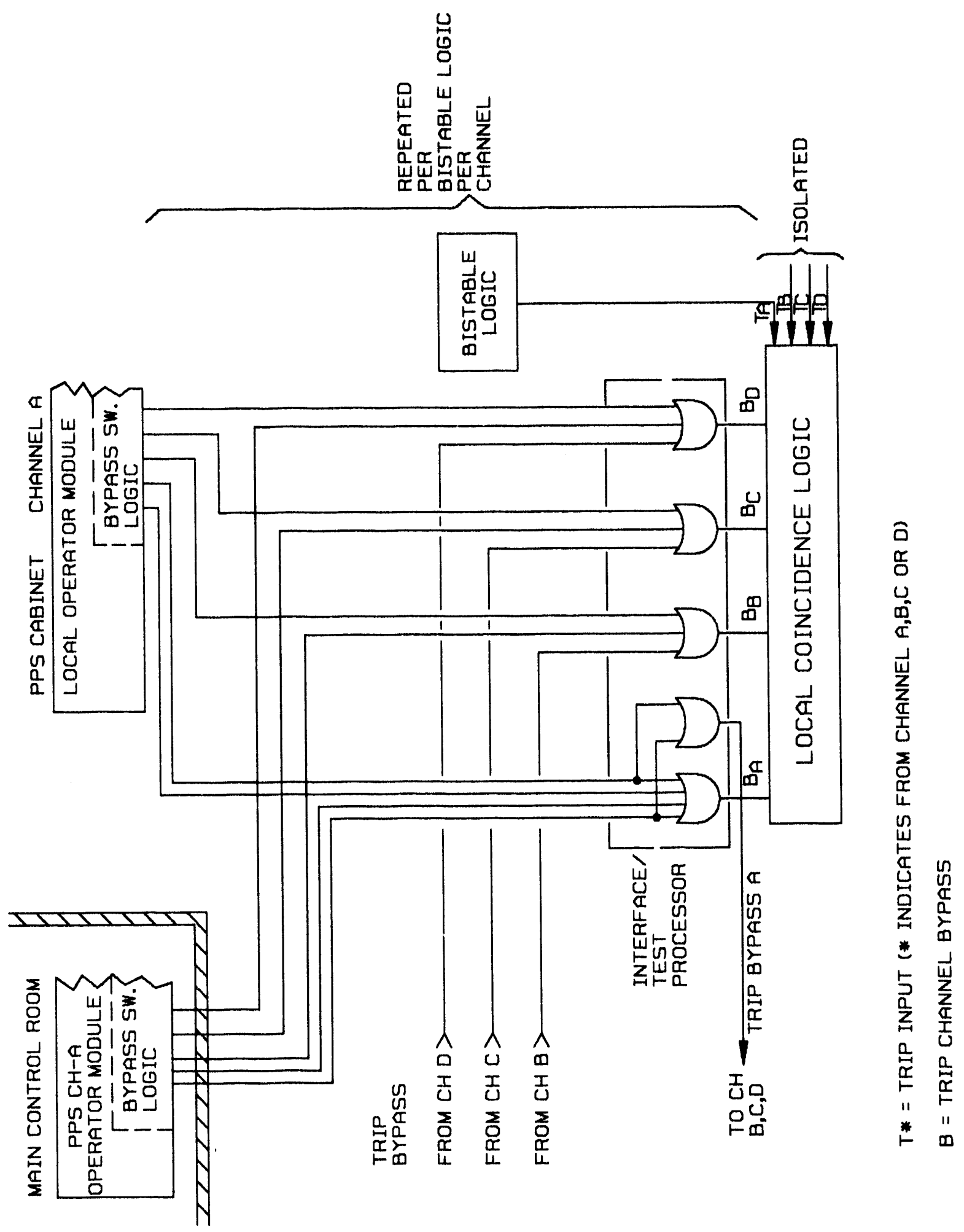

Amendment $\mathrm{E}$ December 30, 1988 

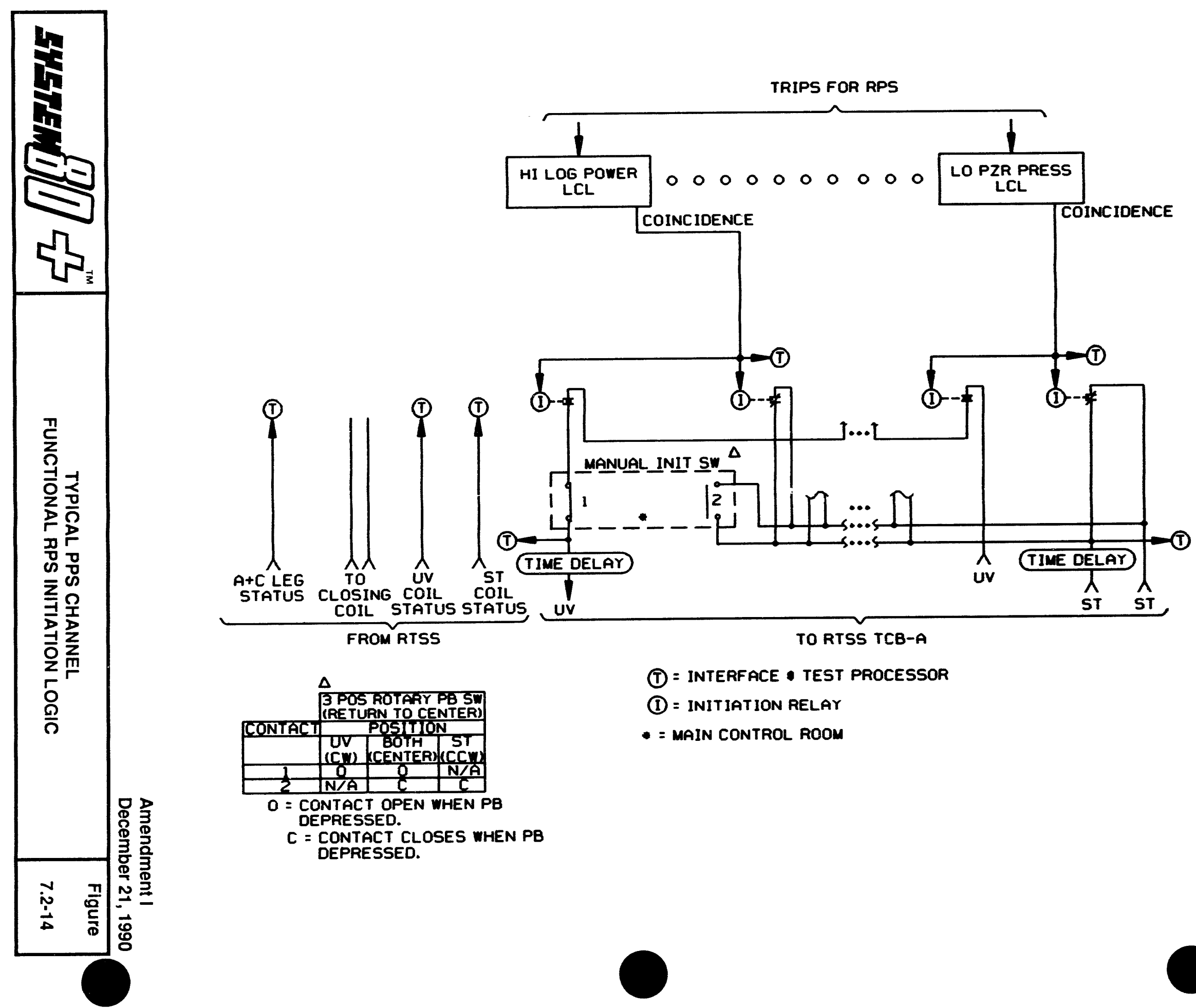

FROM RTSS

TO RTSS TCB-A

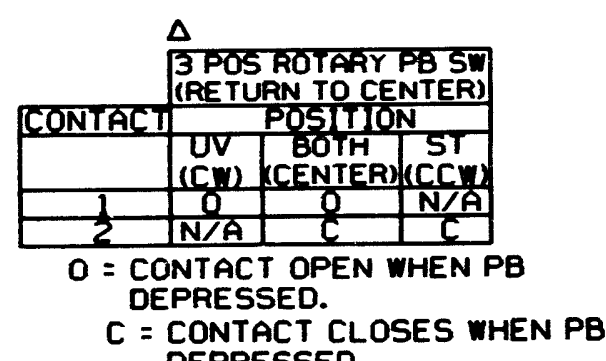

(T) = INTERFACE \& TEST PROCESSOR

(I) = INITIATION RELAY

- = MAIN CONTROL ROOM

DEPRESSED. 


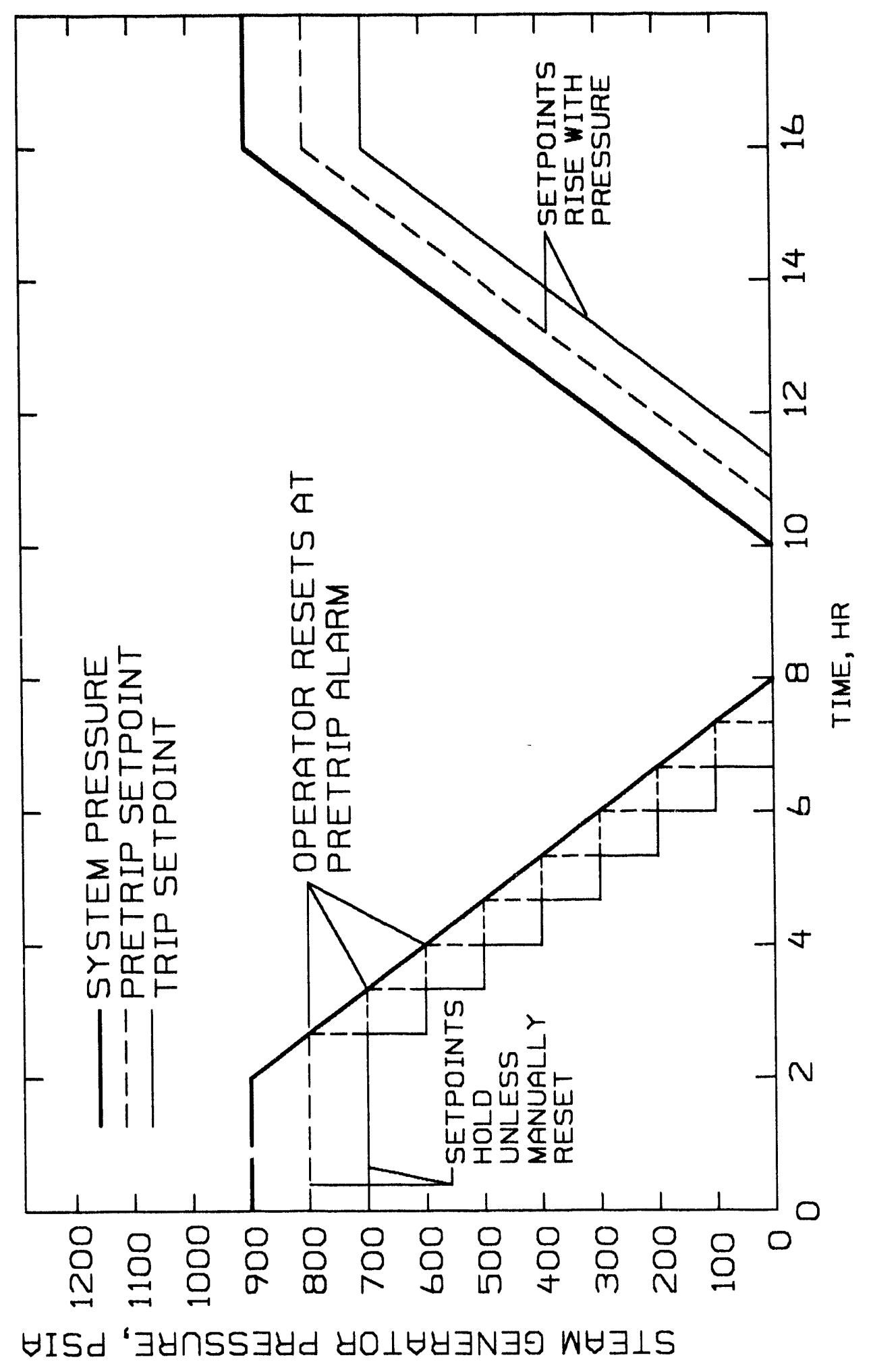

CALMA FILE:

I.CLGONYNORISYS8OFIG715

Amendment $\mathrm{E}$

December 30, 1988 

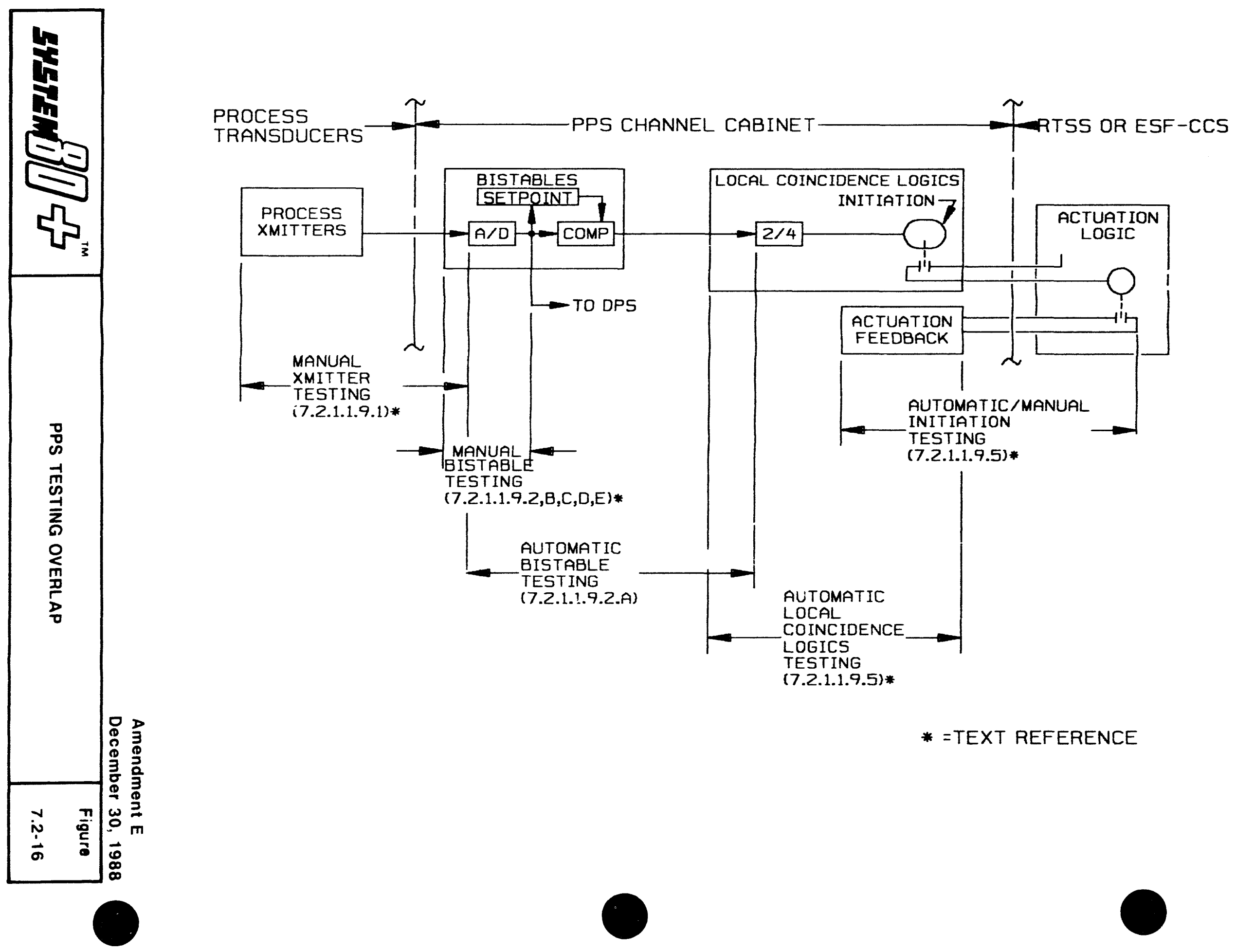

* =TEXT REFERENCE 


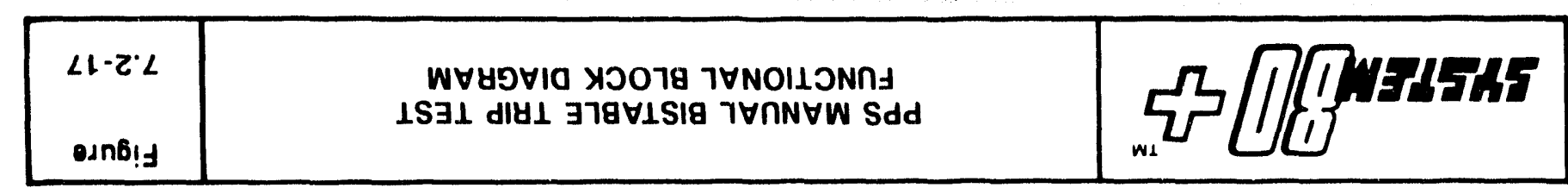

8861 ' $0 \varepsilon$ dəquəoə0

$\exists$ luәшрนәш $\forall$
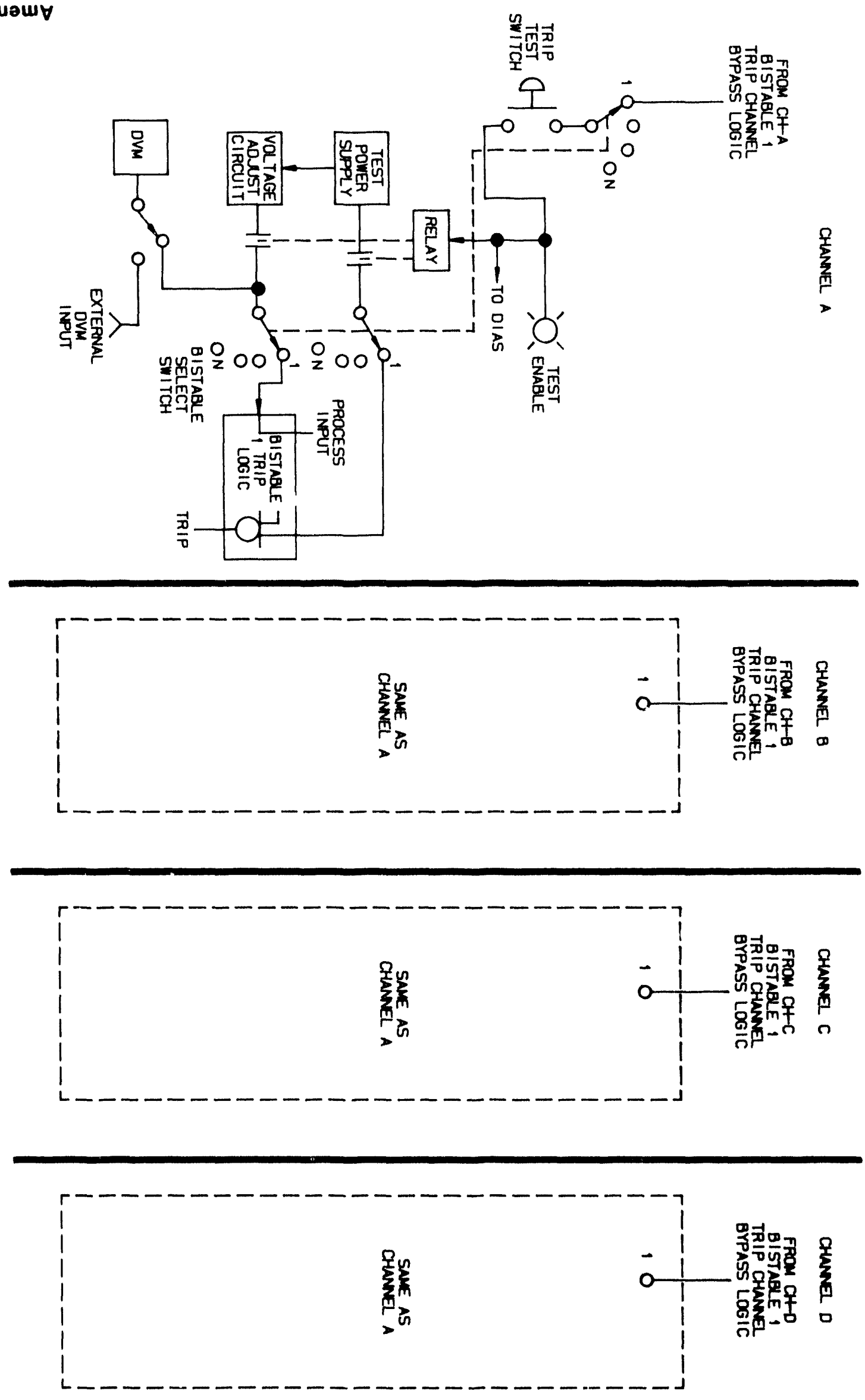


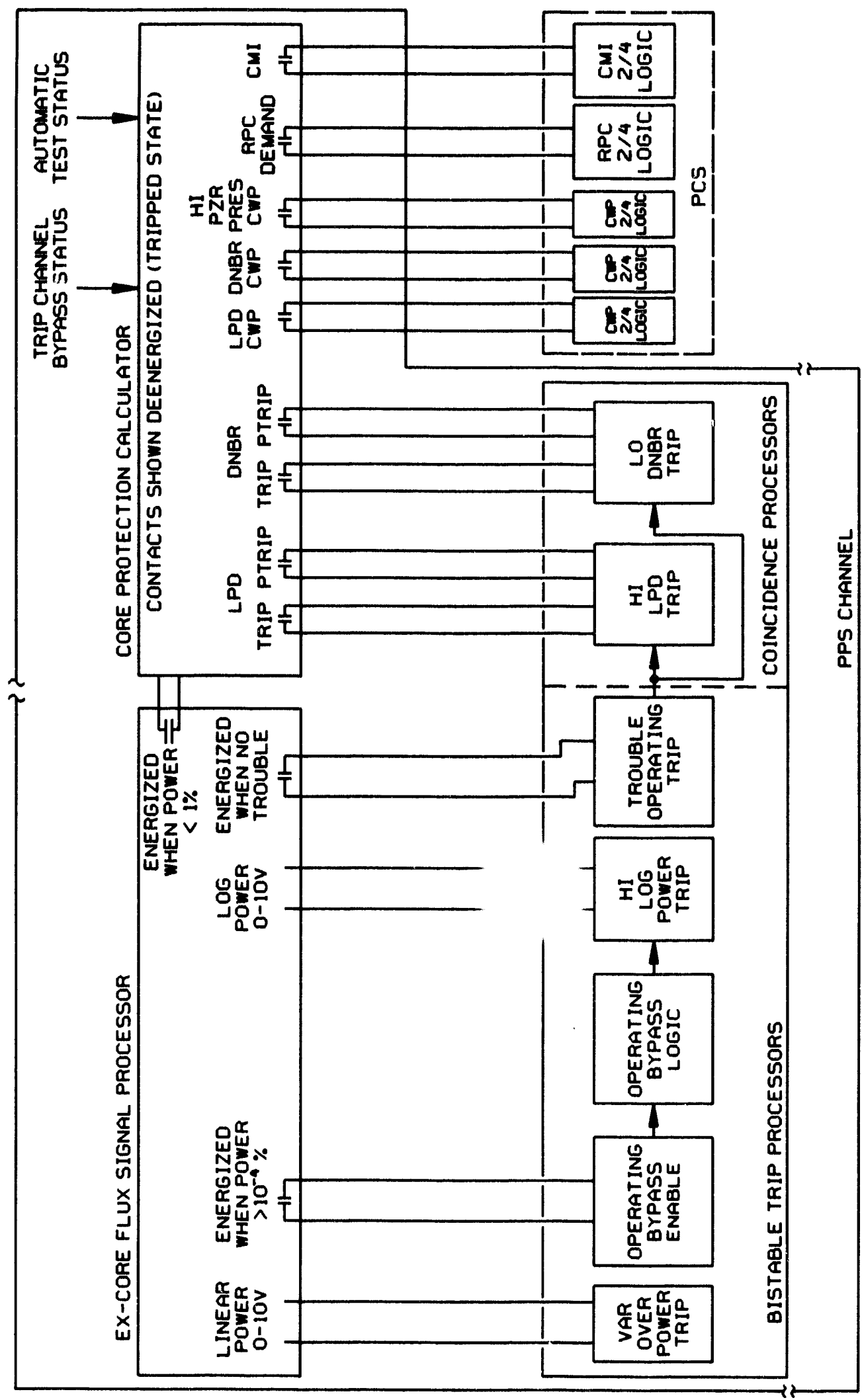

Amendment I

December 21, 199 


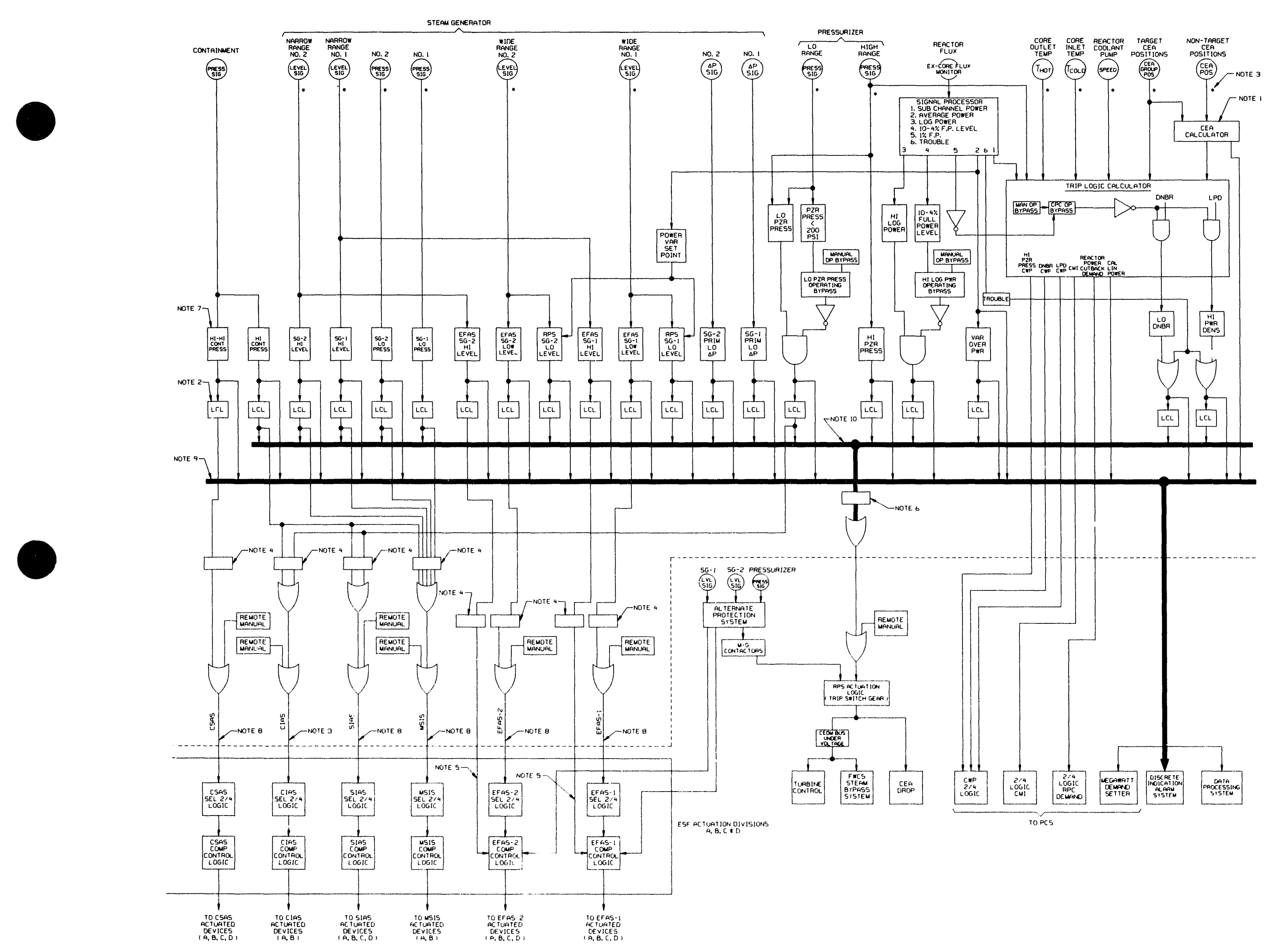

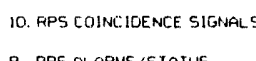

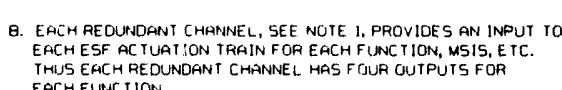

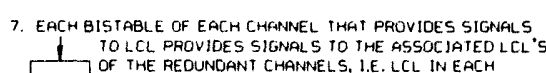

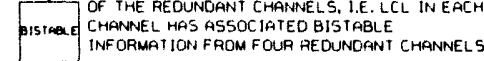

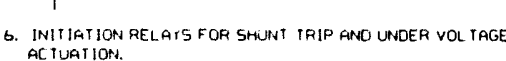
5. CL OSES FEE D VuUES ON HISH LEVEL.

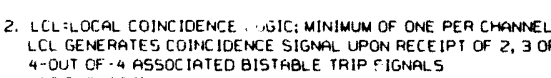

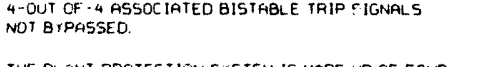

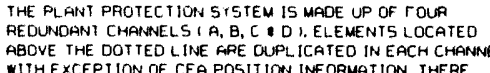

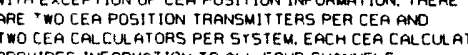

Amendment 1

\begin{tabular}{|c|c|c|}
\hline 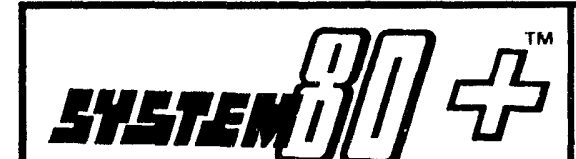 & $\begin{array}{l}\text { PLANT PROTECTION SYSTEM } \\
\text { INTERFACE LOGIC DIAGRAM }\end{array}$ & $\begin{array}{r}\text { Figure } \\
7.2-19\end{array}$ \\
\hline
\end{tabular}




\begin{tabular}{|c|c|}
\hline ABBREVIATION & EXPLANATION \\
\hline ALMS & ACOSTIC LEAK MONITORING SYSTEM \\
\hline AMI & AUTO MOTION INHIBIT \\
\hline APC & AUXILIARY PROTECTIVE CABINET \\
\hline AWP & AUTOMATIC WITHDRAWAL PROHIBIT \\
\hline $\mathrm{BA}$ & $B O R I C \quad A C I D$ \\
\hline $\operatorname{ccs}$ & COMPONENT CONTROL SYSTEM \\
\hline CEA & CONTROL ELEMENT ASSEMBLY \\
\hline CEDMCS & CEDM CONTROL SYSTEM \\
\hline CIAS & CONTAINMENT ISOLATION ACTUATION SIGNAL \\
\hline $\mathrm{CPC}$ & CORE PROTECTION CALCULATOR \\
\hline CSAS & CONTAINMENT SPRAY ACTUATION SIGNAL \\
\hline CSP & CONTAINMENT SPRAY PUMP \\
\hline C5S & CONTAINMENT SPRAY SYSTEM \\
\hline CVCS & CHEMICAL \& VOLUME CONTROL SYSTEM \\
\hline $\mathrm{CVH}$ & CONTAINMENT VENT HEADER \\
\hline DIAS & DISCRETE INDICATION \& ALARM SYSTEM \\
\hline DNBR & DEPARTURE FROM NUCLEAR BOILING RATIO \\
\hline DPS & DATA PROCESSING SYSTEM \\
\hline EDT & EQUIPMENT DRAIN TANK \\
\hline EFAS & EMERGENCY FEED ACTUATION SIGNAL \\
\hline$F W$ & FEEDWATER \\
\hline FWCS & FEEDWATER CONTROL SYSTEM \\
\hline $\mathrm{HX}$ & HEAT EXCHANGER \\
\hline IRST & INCONTAINMENT REFUELING WATER STORAGE TANK \\
\hline $1 \times$ & ION EXCHANGER \\
\hline MCBD & MEASUREMENT CHANNEL BLOCK DIAGRAM \\
\hline MCR & MAIN CONTROL ROOM \\
\hline MDS & MEGAWATT DEMAND SETTER SYSTEM \\
\hline MSIS & MAIN STEAM ISOLATION SIGNAL \\
\hline $\mathrm{NI}$ & NUCLEAR INSTRUMENTATION \\
\hline NIMS & NUCLEAR INTEGRITY MONITORING SYSTEM \\
\hline PAMI & POST ACCIDENT MONITORING INSTRUMENT \\
\hline PCS & POWER CONTROL SYSTEM \\
\hline PLCS & PZR LEVEL CONTROL SYSTEM \\
\hline PPS & PLANT PROTECTION SYSTEM \\
\hline$P Z R$ & PRESSURIZER \\
\hline RCP & REACTOR COOLANT PUMP \\
\hline RCS & REACTOR COOLANT SYSTEM \\
\hline $\mathrm{RD}$ & REACTOR ORAIN \\
\hline RDT & REACTOR DRAIN TANK \\
\hline RMW & REACTOR MAKEUP WATER \\
\hline RPCS & REACTOR POWER CUTBACK SYSTEM \\
\hline RRS & REACTOR REGULATING SYSTEM \\
\hline
\end{tabular}

\begin{tabular}{|c|l|}
\hline ABBREVIATION & EXPLANATION \\
\hline SBCS & STEAM BYPASS CONTROL SYSTEM \\
\hline SCS & SHUTDOWN COOLING SYSTEM \\
\hline SCST & SPRAY CHEMICAL STORAGE TANK \\
\hline SG & STEAM GENERATOR \\
\hline SIAS & SAFETY INJECTION ACTUATION SIGNAL \\
\hline SIS & SAFETY IN JECTION SYSTEM \\
\hline VCT & VOLUME CONTROL TANK \\
\hline
\end{tabular}

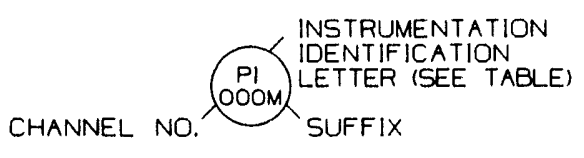

TABLE I

\begin{tabular}{|c|c|}
\hline \multicolumn{2}{|c|}{ TABLE I } \\
\hline \multicolumn{2}{|c|}{ INSTRUMENTATION IDENTIFICATION LETTERS } \\
\hline FIRST LETTER & SUCCEEDING LETTER \\
\hline MEASURED OR INITIATING VARIABLE & READ OUT OR FUNCTION \\
\hline A ANALYSIS & ALARM \\
\hline \multicolumn{2}{|l|}{$B$} \\
\hline CONDUCTIVITY & CONTROL \\
\hline D DENSITY OF SPECIAL GRAVITY & DIFFERENTIAL \\
\hline \multirow{2}{*}{$\begin{array}{ll}E & \text { VOLTAGE (EMF) } \\
\text { F } & \text { FLOW RATE OR FLOW } \\
\end{array}$} & ELEMENT \\
\hline & \\
\hline G GAGING (DIMENSIONAL) & GLASS \\
\hline \multicolumn{2}{|l|}{ H HAND INITIATED (MANUALLY) } \\
\hline CURRENT & INDICATOR \\
\hline \multicolumn{2}{|l|}{$J$ POWER } \\
\hline K TIME OR TIME SCHEDULE & RATE OR CHANGE \\
\hline L LEVEL & LIGHT \\
\hline \multicolumn{2}{|c|}{ M MOISTURE OR HUMIDITY } \\
\hline \multicolumn{2}{|l|}{$\bar{N}$ VIBRATION } \\
\hline \multicolumn{2}{|c|}{\begin{tabular}{l|l} 
O ROTATION & ORIFICE (RESTRICTION) \\
\end{tabular}} \\
\hline \multicolumn{2}{|c|}{ P PRESSURE OR VACUUM } \\
\hline O $\quad$ OUALITY OR EVENT & INTEGRATE OR TOTALIZER \\
\hline \multirow{2}{*}{$\begin{array}{ll}R & \text { RADIOACTIVITY } \\
S & \text { SPEED OR FREOUENCY }\end{array}$} & RECORDER \\
\hline & SWITCH \\
\hline T TEMPERATURE & TRANSMITTER \\
\hline \multicolumn{2}{|l|}{$\mathrm{U}$} \\
\hline $\mathrm{V}$ & VALVE \\
\hline W WEIGHT & WELL \\
\hline $\bar{x}$ & TEST POINT \\
\hline \multirow[b]{2}{*}{ VALVE POSITION } & SIGNAL PROCESSING DEVICE \\
\hline & \\
\hline
\end{tabular}

Amendment I

December 21, 1990

\begin{tabular}{|c|c|c|c|} 
& \multicolumn{2}{c}{$\begin{array}{c}\text { Amendment I } \\
\text { December 21, 1990 }\end{array}$} \\
\hline
\end{tabular}



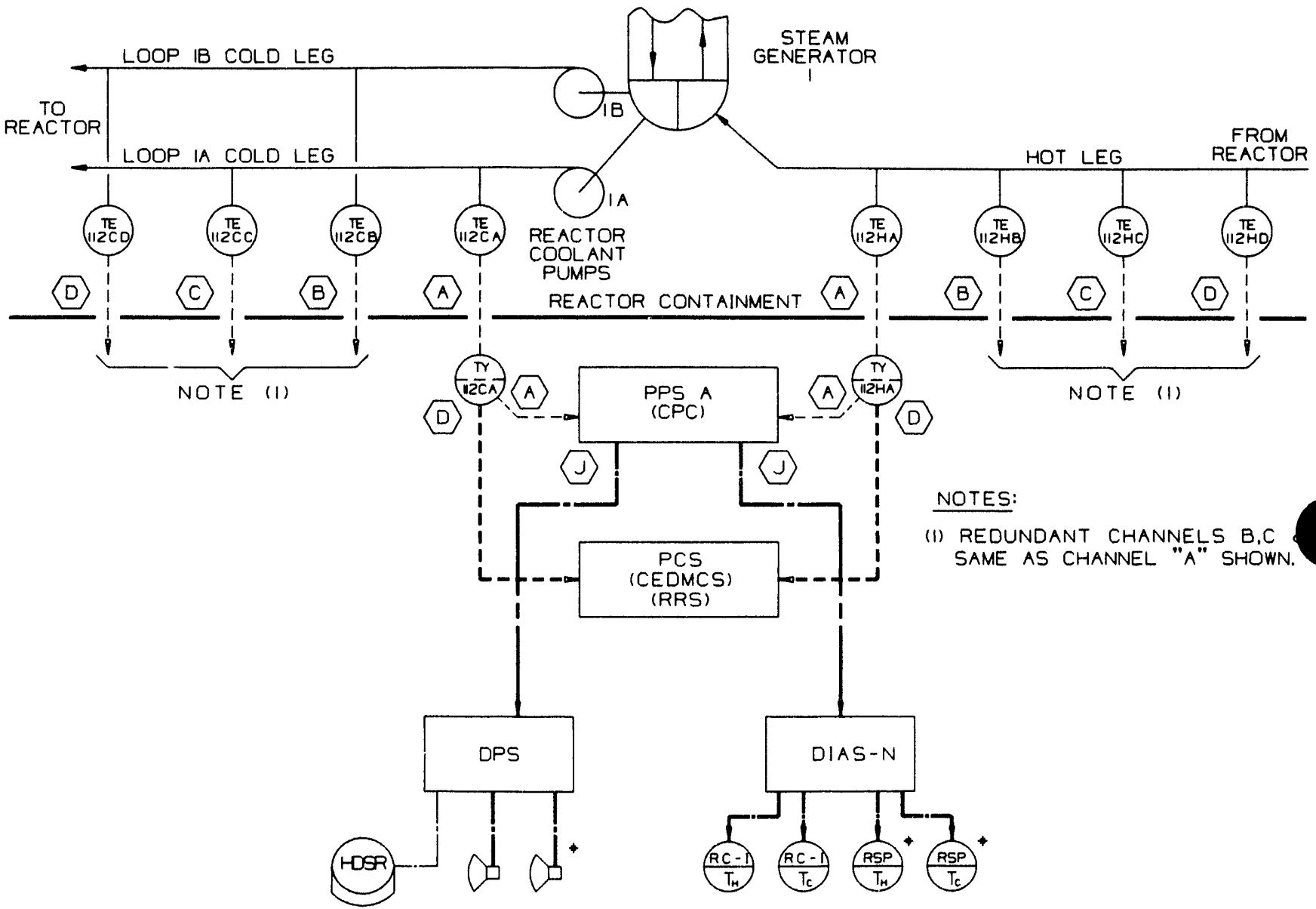

Amendment I

December 21, 1990 


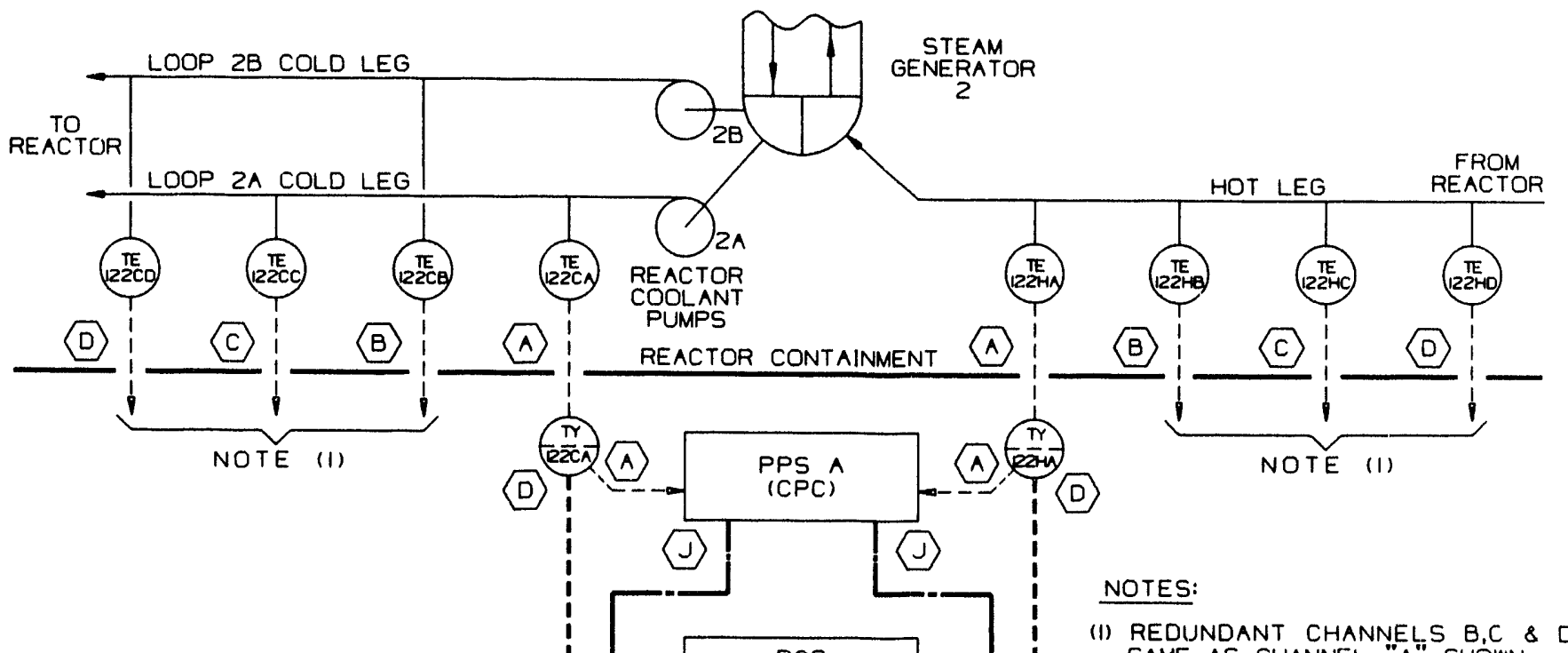
SAME AS CHANNEL "A" SHOWN.

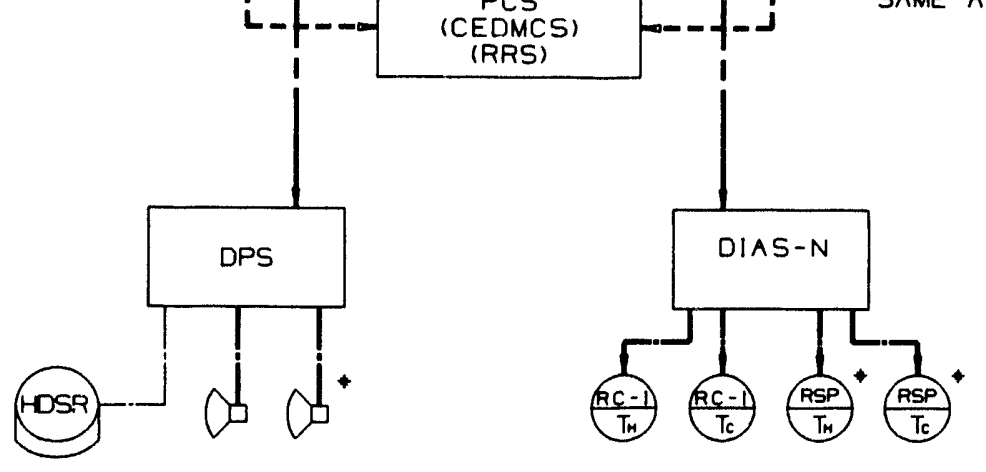



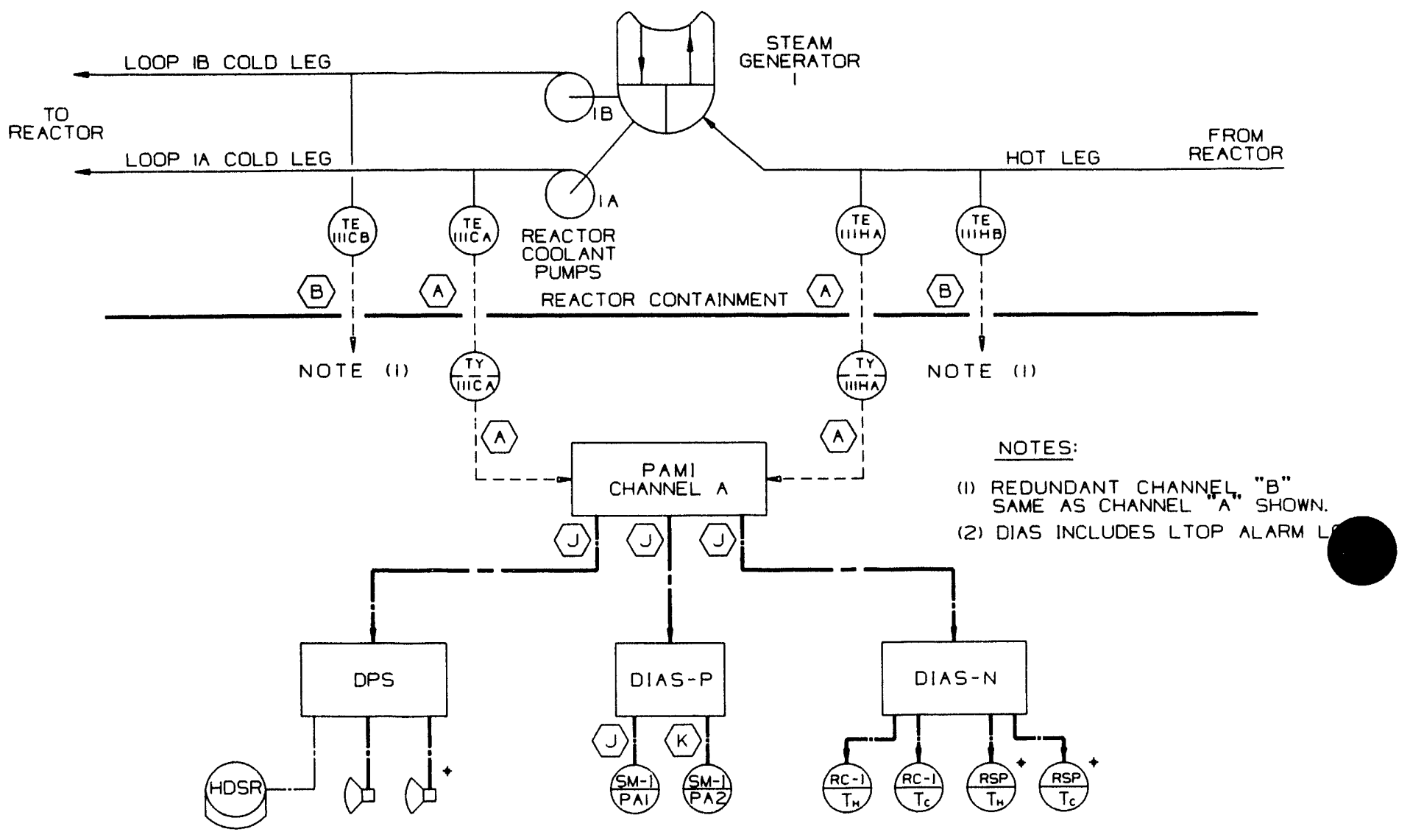

Amendment I

December 21, 1990 


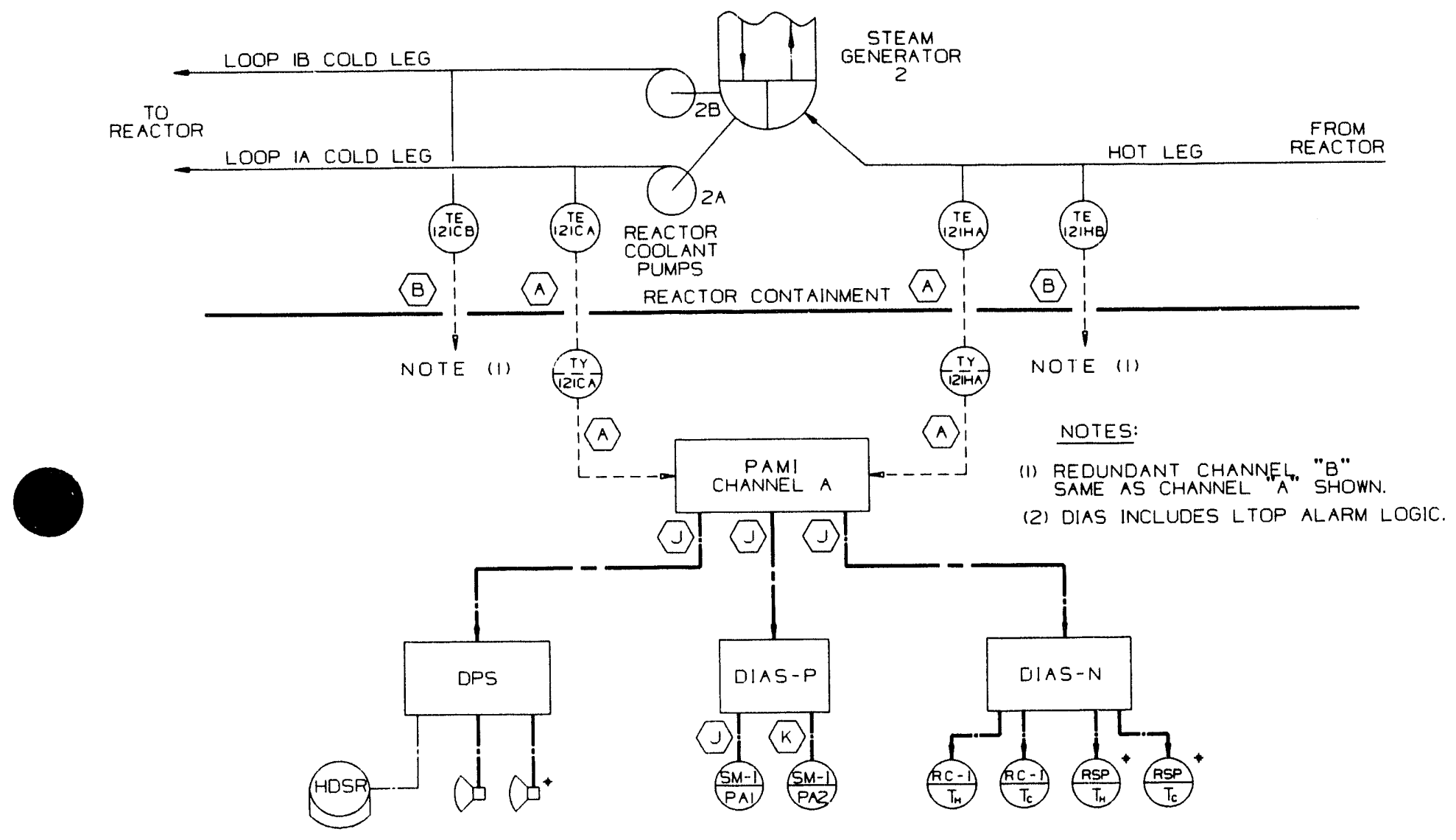

Amendment I

December 21, 1990 


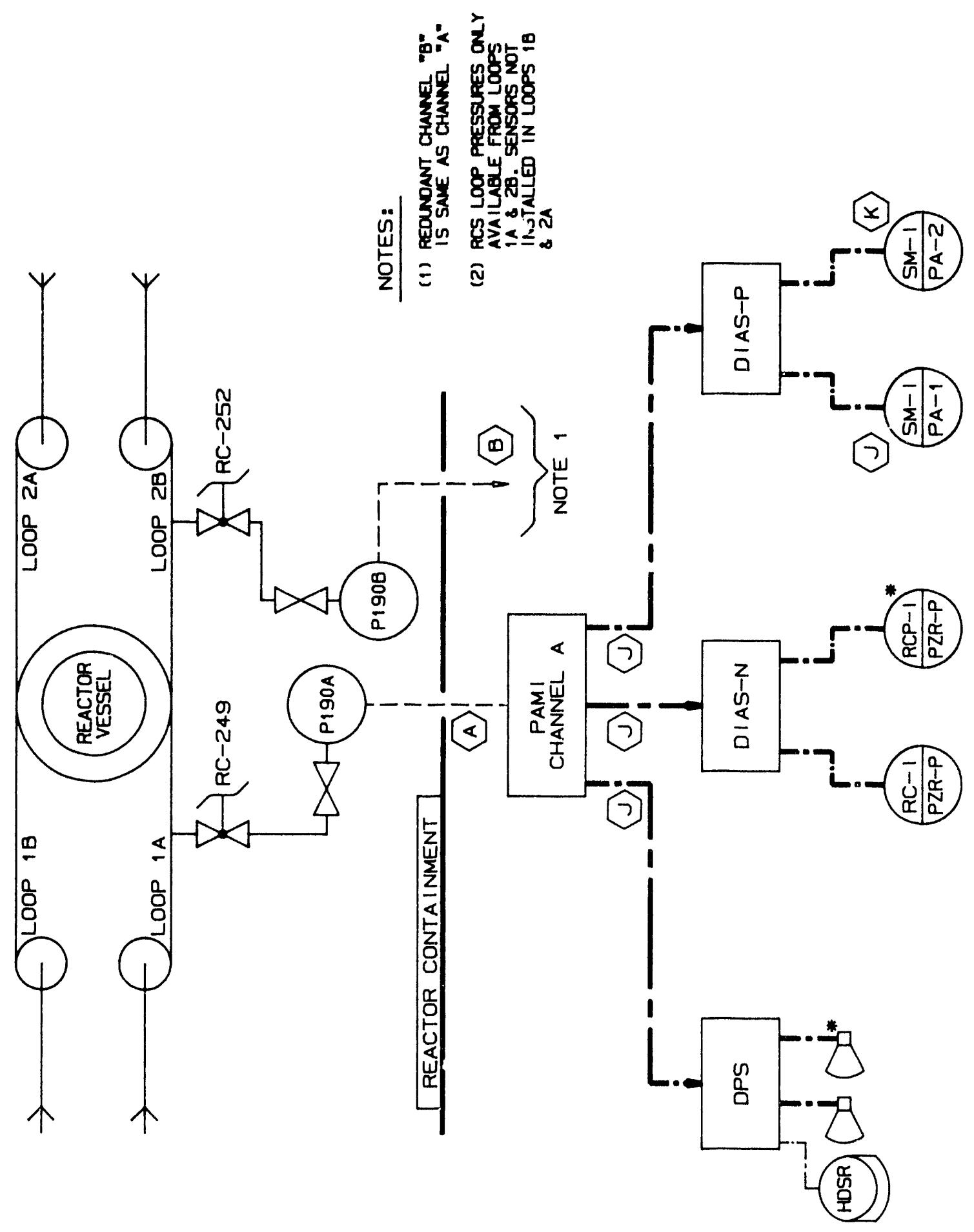

Amendment $E$

December 30, 1988 

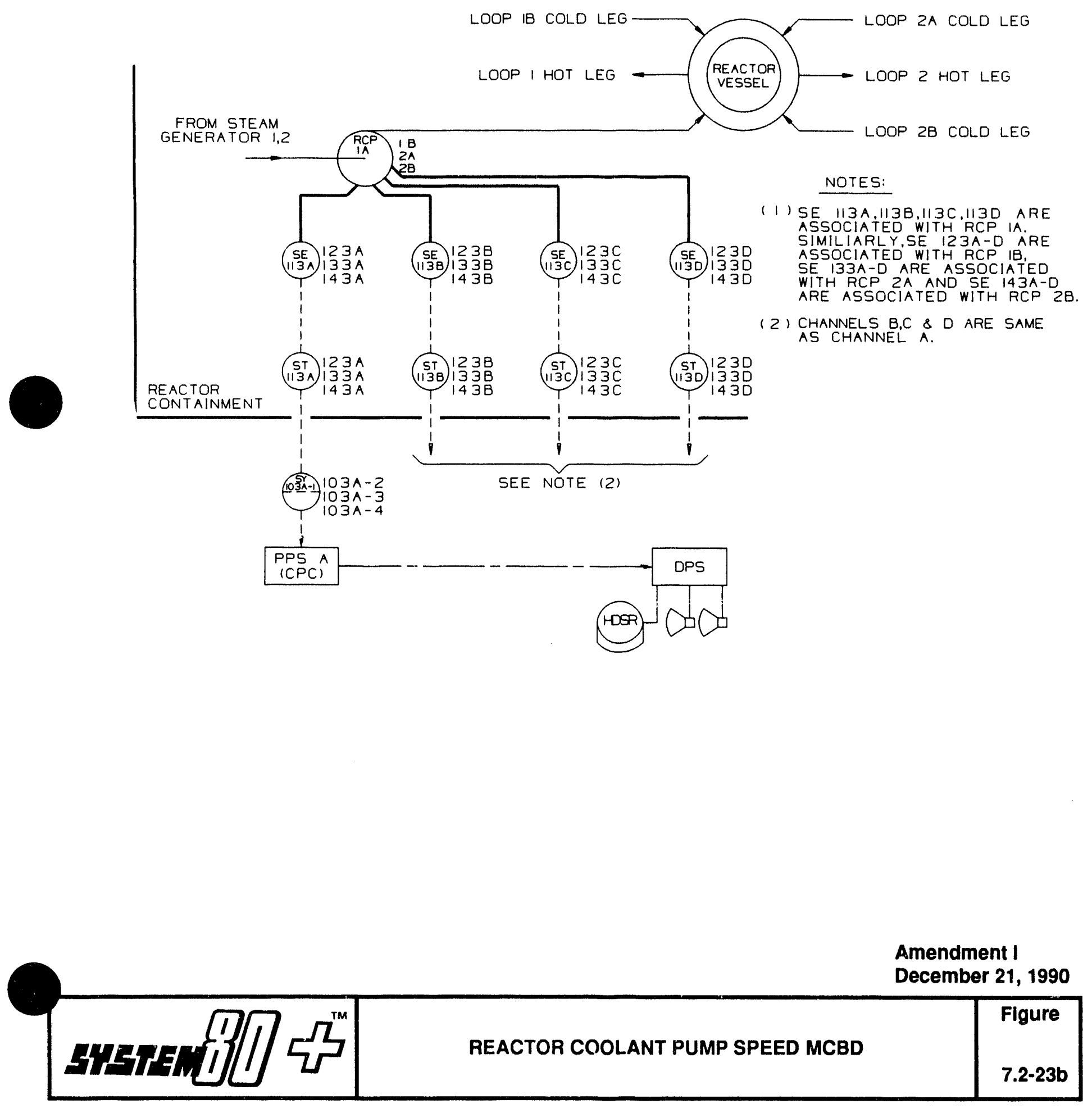


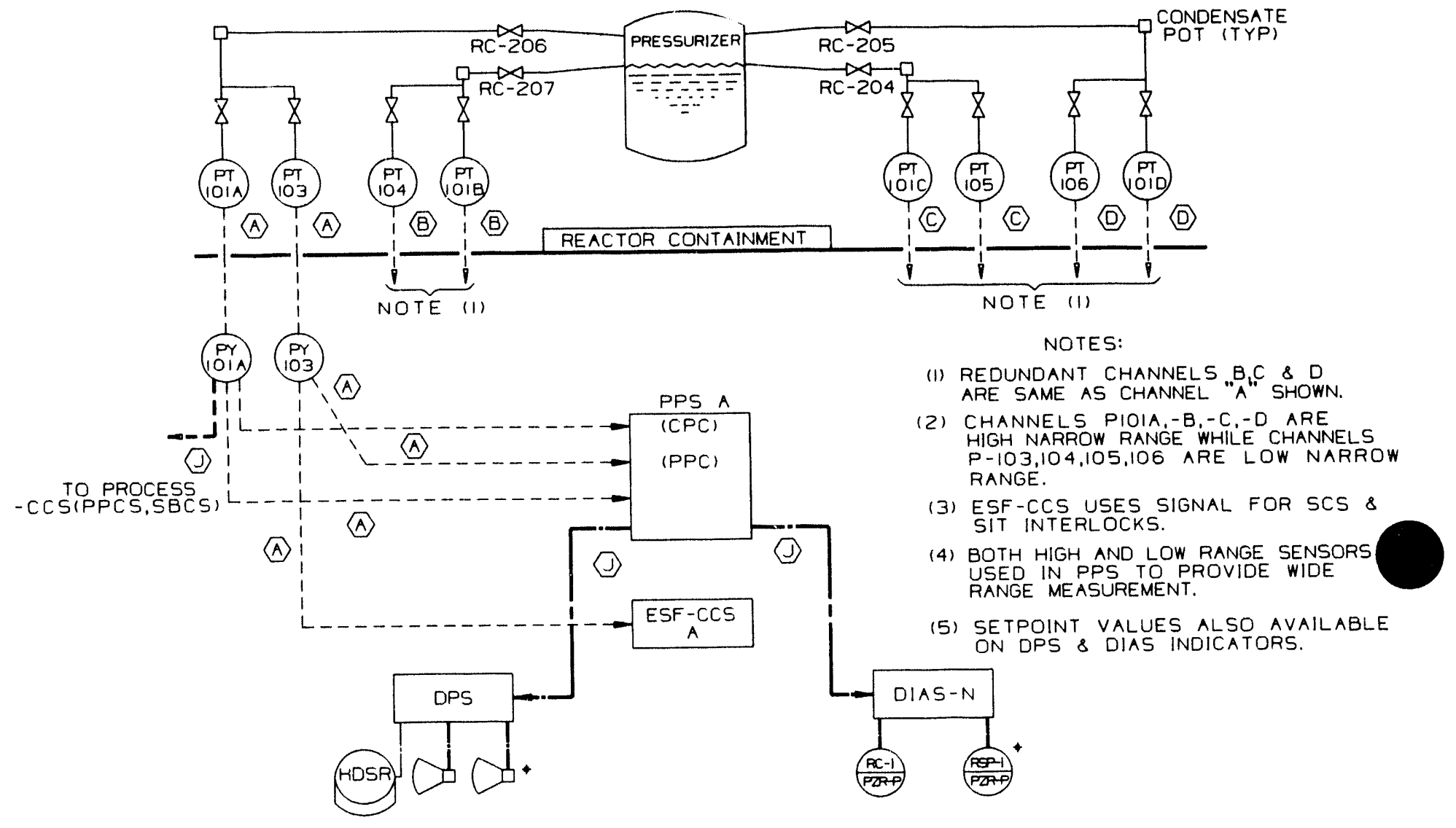

Amendment I 


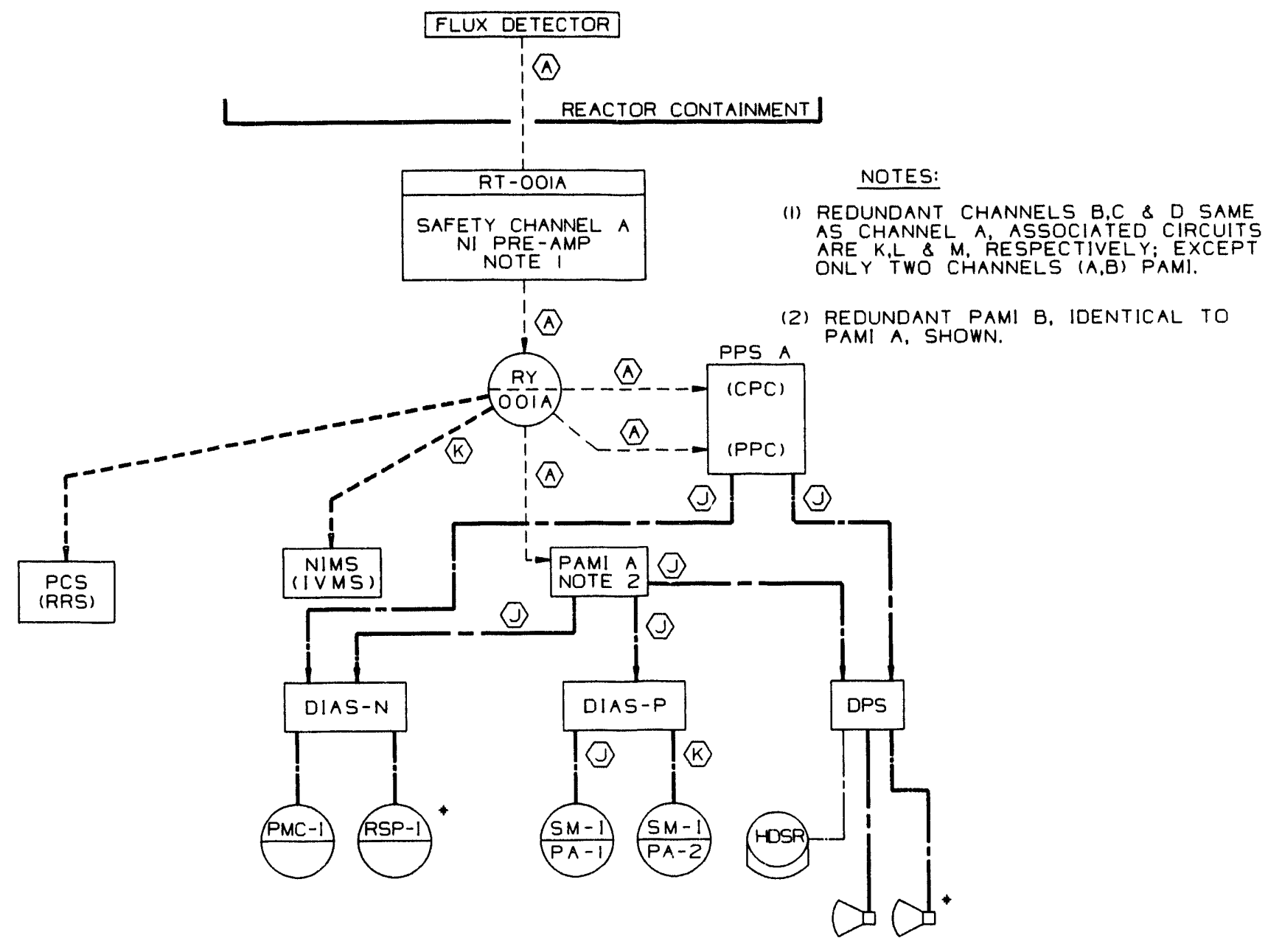




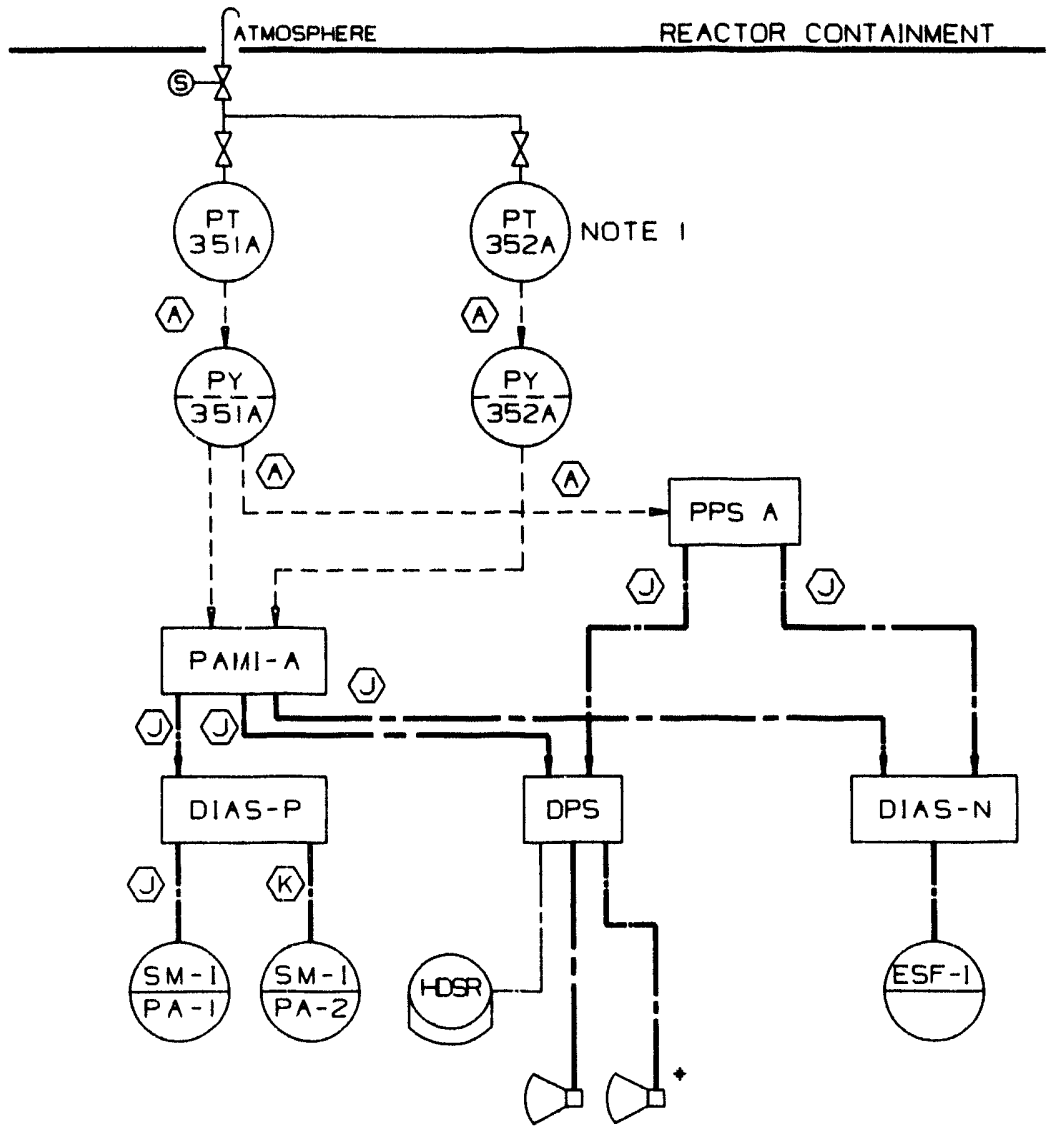

\section{NOTES:}

(1) REDUNDANT CHANNELS B,C \& D SAME AS CHANNEL $A$, ASSOCIATED CIRCUITS ARE K,L \& $M$, RESPECTIVELY; EXCEPT ONLY TWO CHANNELS $(A, B)$ OF PAMI

(2) PT-352A 15 WIDE RANGE.

(3) PT-35IA IS NARROW RANGE.

Amendment I

December 21, 1990 


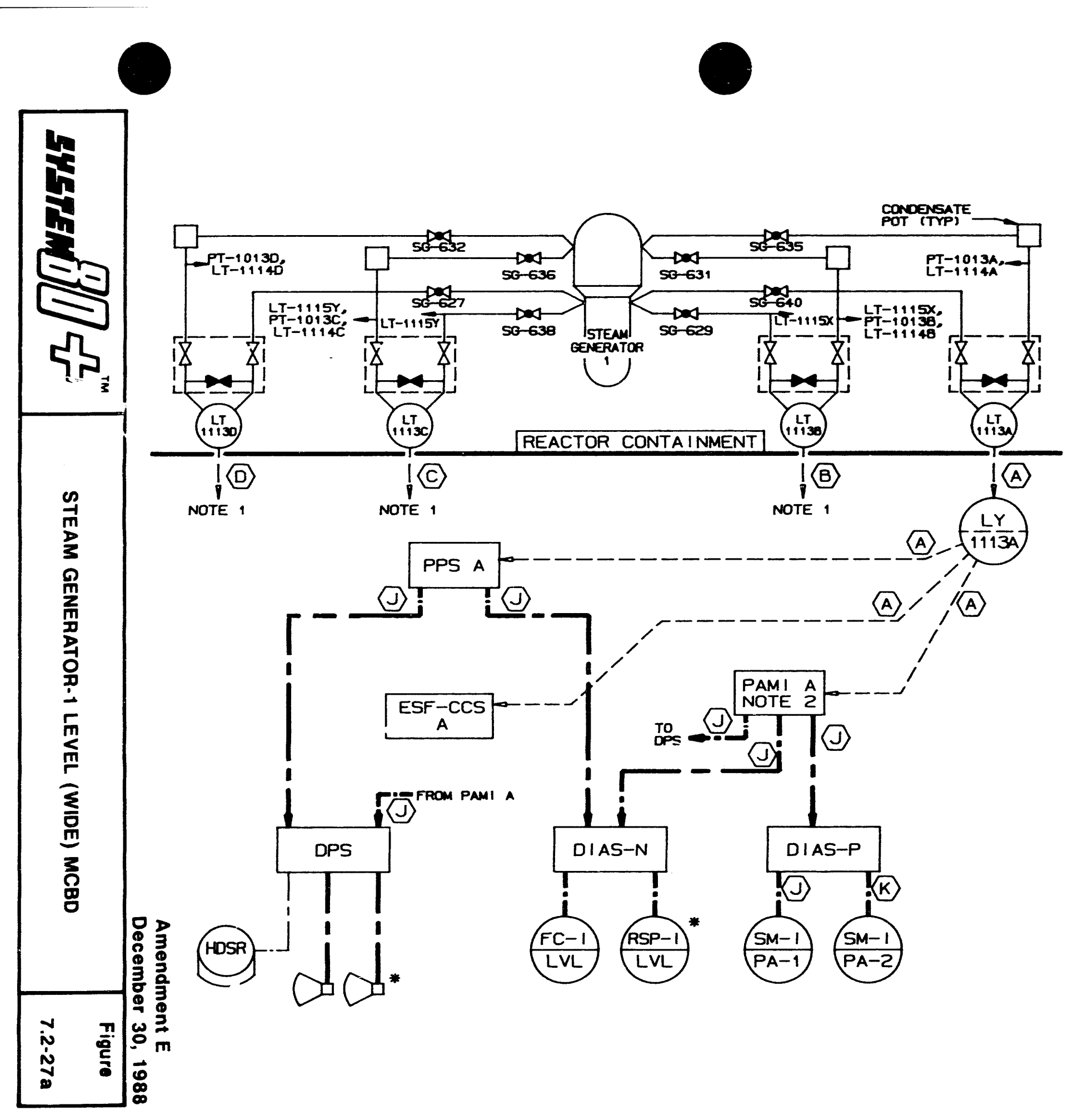

NOTES:

1. REDUNDANT CHANNELS B, $\&$ \& SAME AS CHANNEL A, ASSOCIATED RESPECTIVELY; ÉXCEPT' ONLY TWO C:IANNELS $(A, B)$ PAMI.

2. REDUNDANT PAMI 8, IDENTICAL TO PAMI A, SHOWN. 


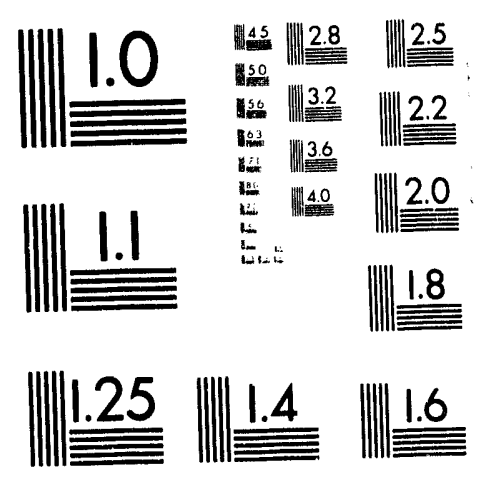



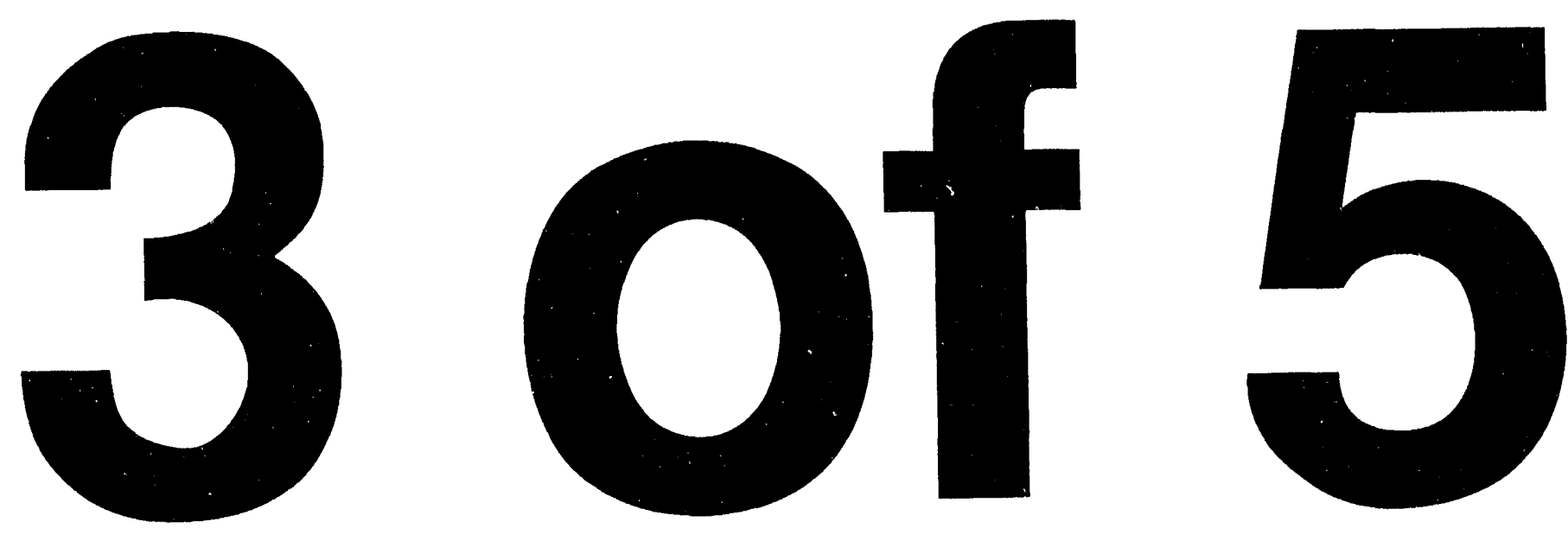

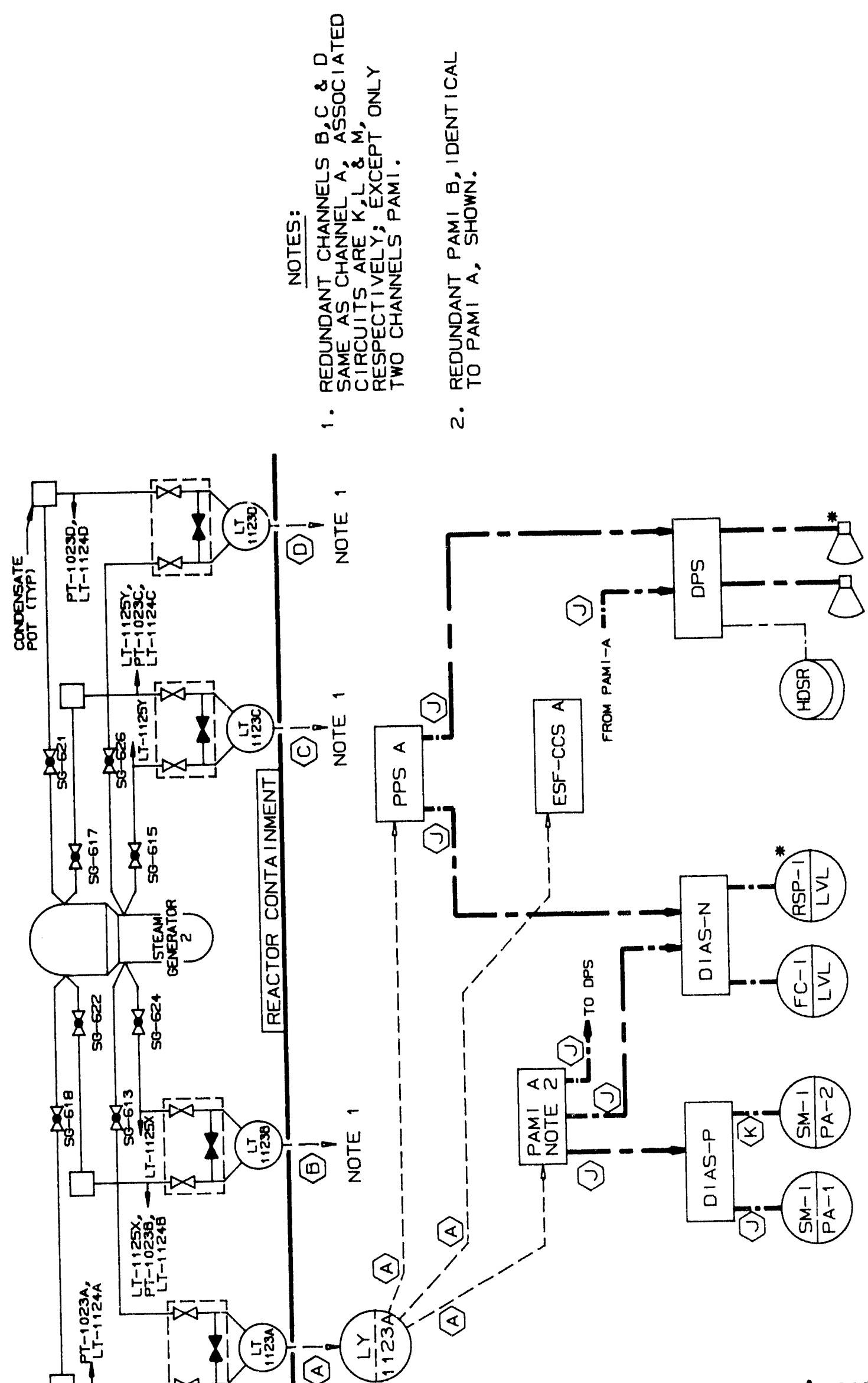

Amendment $E$

December 30,1988 

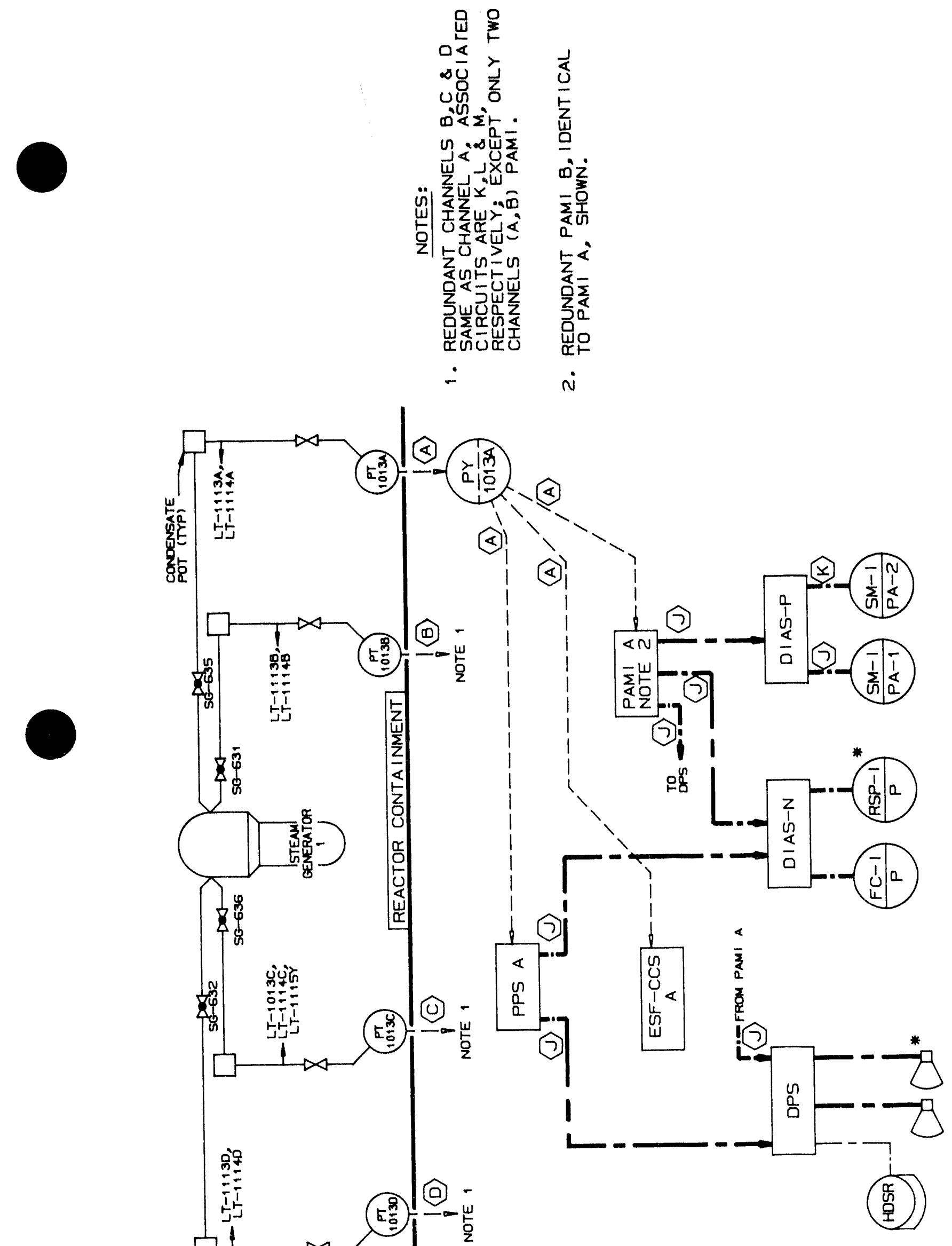

Amendment $\mathrm{E}$ December 30, 1988 

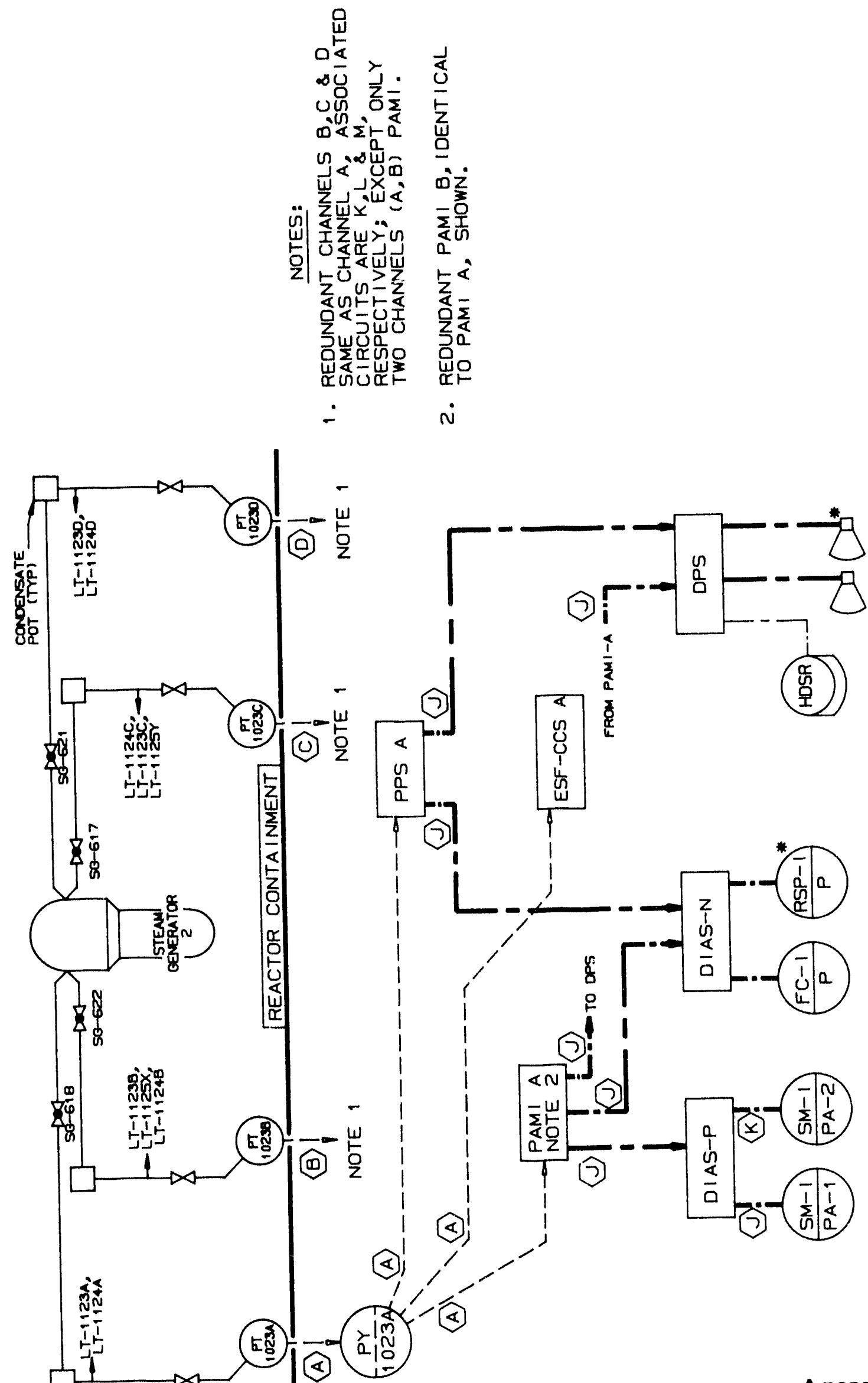

Amendment $\mathrm{E}$

December 30, 1988 


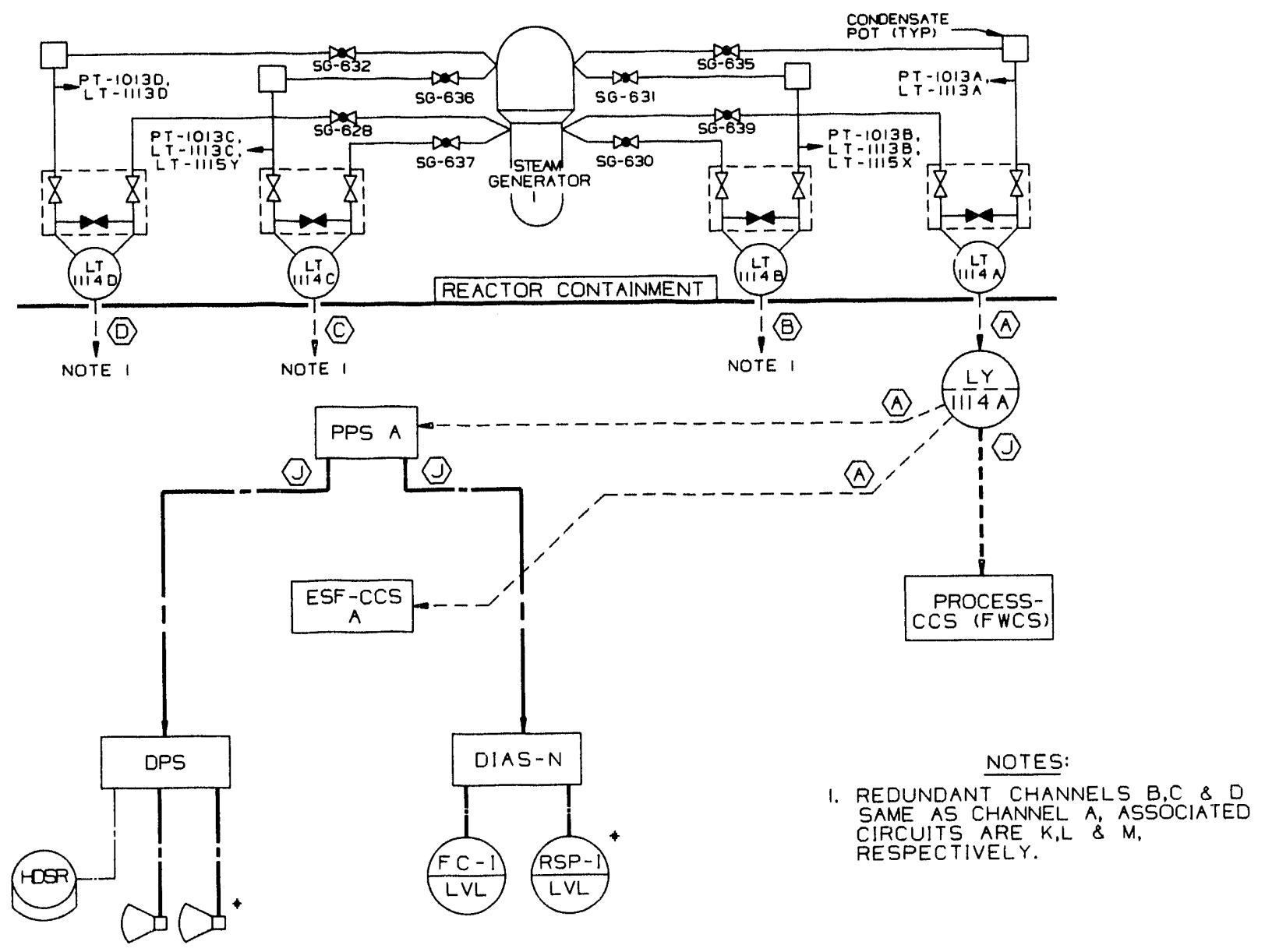



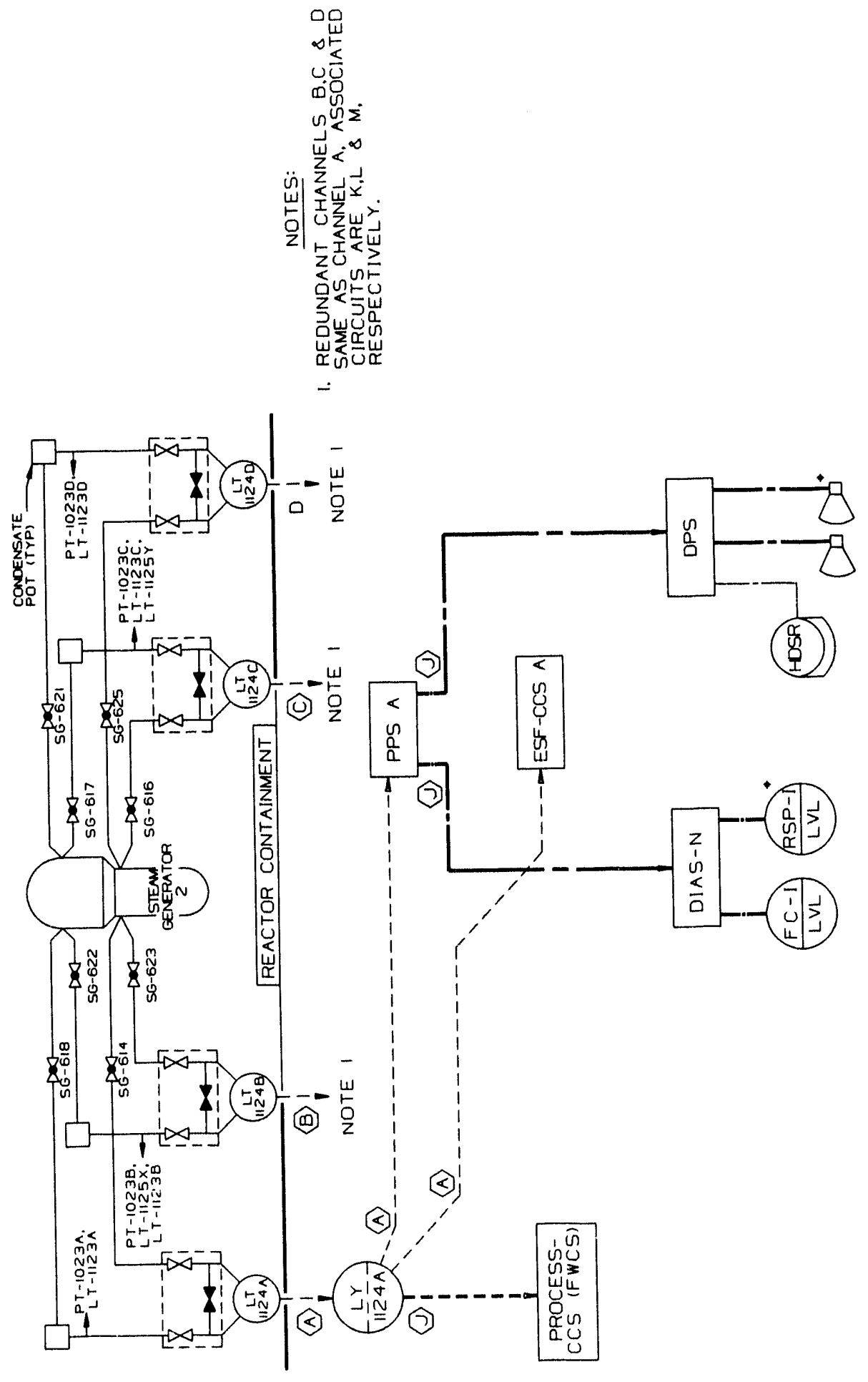

Amendment I

December 21, 1990 


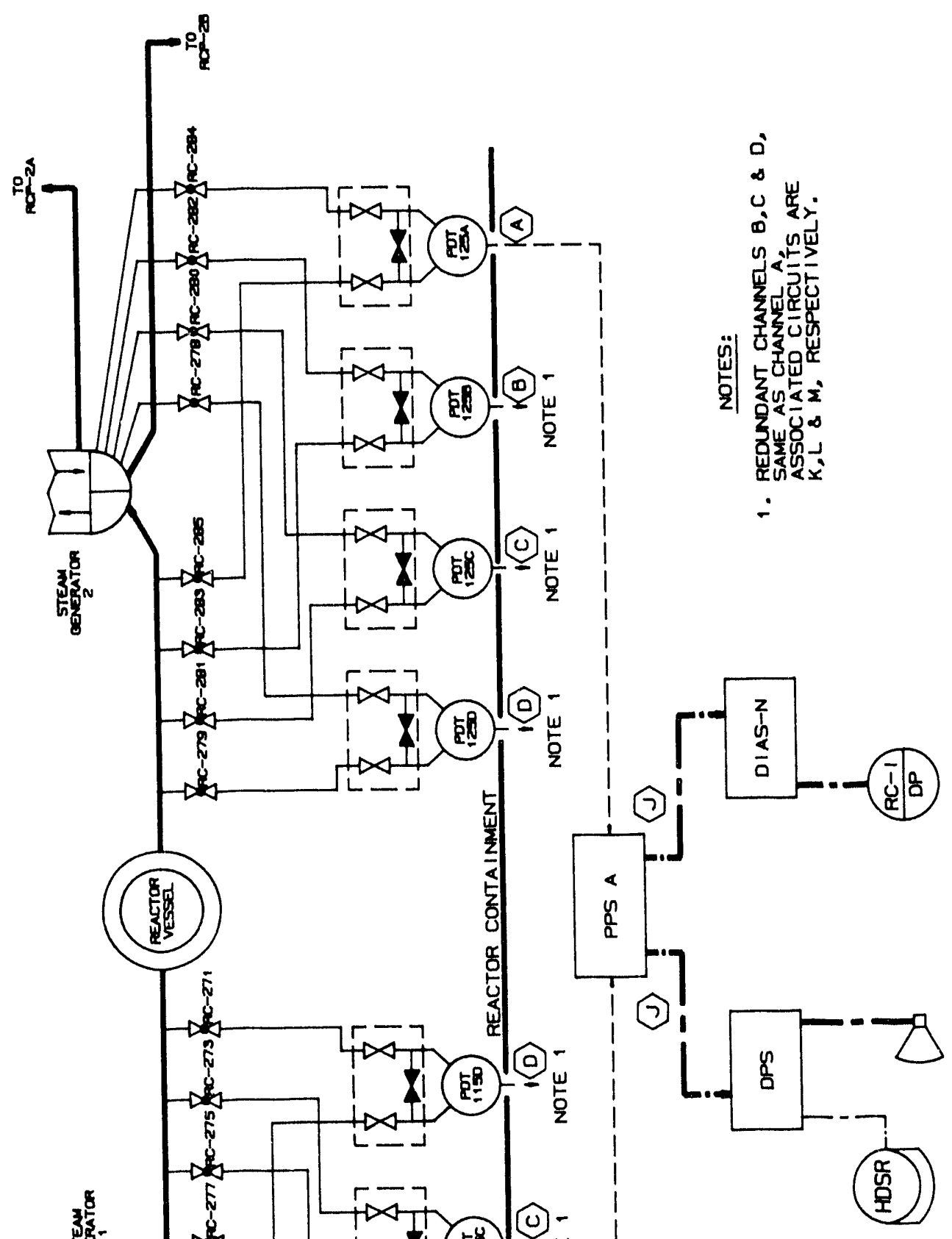

Amendment $\mathrm{E}$

December 30, 1988 
7.3 .1

\section{DESCRIPTION}

The safety-related instrumentation and controls of the Engineered Safety Feature Systems (ESF Systems) are those of the Engineered Safety Features Actuation system (ESFAS). The safety-related instrumentation and controls consist of the electrical and mechanical devices and circuitry, from sensors to actuation device input terminals, involved in generating those signals that actuate the required ESF Systems.

The ESF systems sense and command function is referred to as the ESFAS. The ESFAS utilizes bistable trip functions and coincidence logic in the plant protection system (PPS) and component control logic in the Engineered Safety Feature-Component Control System (ESF-CCS) to generate actuation signals. Actuation signals are provided as input signals to ESF system execute features. The following actuation signals are generated by the ESFAS when the monitored variable reaches the levels that are indicative of conditions which require protective action:
A. Containment Isolation Actuation Signal (CIAS)
B. Containment Spray Actuation Signal (CSAS)
C. Main steam Isolation Signal (MSIS)
D. Safety Injection Actuation Signai (SIAS)
E. Emergency Feedwater Actuation Signal (EFAS)

The ESFAS signals actuate the ESF systems equipment. The control I circuitry for the components provides sequencing necessary to provide proper ESF systems operation.

The ESF-CCS provides control of safety-related plant components, as well as control and actuation of Engineered safety Feature systems. It is the central controlling system for safety-related plant components. Such components include breaker and relay operated components (e.g., pumps, fans, heaters and motor operated valves), and solenoid operated components (e.g., pneumatic, electro-pneumatic and direct operated valves).

The ESF System components are manually controlled through the ESF-CCS during normal plant operation, and automatically actuated upon receipt of ESFAS initiation signals from the PPS. 


\subsubsection{System Description}

The actuation system consists of the sensors, logic, and actuation circuits which monitor selected plant parameters and provide an actuating signal to each actuated component in the ESF system required to be actuated, if the selected plant parameters reach predetermined setpoints. ESF system functions are distributed among various actuation systems. Each actuation system is identical except that specific inputs and logic (and blocks, where provided) vary from system to system and the actuated devices are different. The overall logic is shown in Figures 7.3-1a through 7.3-1d.

Within the PPS, the Local Coincidence Logic (LCL) is like that shown on Figure 7.2-1. The LCL provides the full two-out-of-four coincidence. Each Local Coincidence Logic operates Initiation Logic which controls the initiation relays. The outputs of the initiation relays are directed to the selective two-out-of-four logic in the ESF-CCS where they are logically combined for the given function as shown on Figure 7.3-2.

A. ESF-CCS Configuration

Each cabinet contains the logic for ESF-CCS division A, B, $C$, and $D$ equipment (refer to Figure 7.3-3). Each ESF-CCS division is similar, therefore only ESF-CCS division $A$ is described.

The ESF-CCS division includes a Division Master segment and multiple subgroup segments (A1 through $A n$ ). Each segment contains processors, local and remote multiplexers, and communications interfaces. The Division Master segment supports component control switch and operators module interfaces, Intersystem Communication datalinks, and a Maintenance and Test Panel. Each subgroup segment supports component and data acquisition interfaces and related Process controllers. Several levels of redundancy are provided in each segment to enhance reliability. Primary and standby processors function such that the primary unit actively performs the control functions while the standby unit passively follows (tracks) the actions of the primary unit. Primary and standby processor performance is continuously monitored by a redundancy controller. Control tasks are automatically transferred to the standby unit upon detection of a primary unit failure and confirmation of standby unit operability.

Local and remote multiplexing is incorporated in the ESF-CCS to reduce and simplify plant wiring. Remote multiplexers are physically located in the main control panels (MCP), the remote shutdown panel (RSP) and ESF-CCS remote multiplexer 
cabinets which are located near plant component and instrumentation interface locations. Fiber-optic cable provides electrical isolation where required to meet channel independence provisions of IEEE std. 279-1971. Multidrop Networks utilize active redundant cabling to maintain multiplexer operability under single cable fault conditions.

Exchange of data between each segment within an ESF-CCS division is provided by an Intradivision communication Network. This network utilizes active redundant cables to maintain communication between segments under single cable fault conditions.

Control hardware failures are annunciated, and modularity is utilized to minimize mean-time-to-repair (MTTR).

Hardware reliability is enhanced by the use of redundancy, modularity, local and remote multiplexing and prudent distribution of power within each ESF-CCS division.

These functional distribution practices and ESF-CCS segment equipment redundancy provides a "defense-in-depth" approach resulting in a high degree of ESF-CCS reliability.

The ESF-CCS is a multiple microprocessor based system. The ESF-CCS software is developed and tested in accordance with Regulatory Guide 1.152 as described in Section 7.1.2.

B. ESF-CCS Logic

In addition to the system level selective two-out-of-four logic for ESF actuation, the ESF-CCS also provides Subgroup Control Logic (SCL), Component control Logic (CCL), Selective Group Test Logic (SGT), and Diesel Loading Sequencer (DLS) Logic. DLS logic is described in section 7.3.1.1.2.3 and SGT logic is described in section 7.3 .1 .1 .8 .6 .

SCL performs supervisory control of subgroups of components. The CCS also provides Master Transfer Switching (MTS) to disable all Main Control Room controls and enable Remote Shutdown Panel controls. Upon MTS, components are preprogrammed to remain as-is or to go to a predetermined state (e.g., safe shutdown lineup).

CCL is the component level logic that monitors the various digital inputs, such as manual on-off demands, interlocks, and automatic subgroup control signals from the MCL, and 
produces digital output signals to control the component (i.e., START/STOP, ON/OFF) through power level interface devices. This logic also generates digital outputs for status indication.

\section{ESF-CCS Operator Interfaces}

operator control functions are performed from the Main Control Panels (MCP) or Remote Shutdown Panel (RSP).

Automatic and manual component control and status indication is provided in the MCR by backlighted momentary pushbutton switches. A description of switch operation and component status indication is provided in section 18.7.1.6, and the typical electrical interface for these devices is shown in Figure 7.3-4. These devices interface with the ESF-CCS through remote multiplexers located in the MCPs. A remote ESF-CCS operators module is also provided in the main control room for backup in the event of switch or multiplexer failure. This panel provides component control through menu selection using a qualified video display unit.

Backlighted momentary pushbutton switches are also provided for the RSP controls identified in Table 7.4-1 to permit control of components required to achieve hot standby conditions when the main control room is uninhabitable. These devices also interface to the ESF-CCS through remote multiplexers located in the RSP. A remote ESF-CCS operators module is provided at the RSP for backup of control switch or multiplexer failure. This remote operators module also provides for control of all CCS components including components necessary to achieve cold shutdown as identified in Table 7.4-2. Transfer of control from the main control room to the RSP is performed by Master Transfer Switches (MTS) located on the ESF-CCS equipment cabinet. Fiber-optic cable is used to prevent fault propagation to the ESF-CCS from the main control room or the RSP.

As a "defense-in-depth" measure, Local control Switches (LCS) are provided independent from the ESF-CCS for components essential to hot shutdown. only manual control (i.e., ON/OFF, START/STOP, OPEN/CLOSE) is provided through LCS. LCS are field-wired for direct control of components or motor control center component actuators and are field located near actuated components in locations such as the motor control centers. The LCS may also be used for test and maintenance.

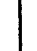


Process controllers are supported where required from ESF-CCS subgroup segments to facilitate operator manipulation of continuous process control functions (e.g., valve modulation control, auto/manual mode selection, etc.). A description of process controller operation is provided in Section $18.7 \cdot 1.7$.

A maintenance and test panel is included in the ESF-CCS equipment cabinet. This operator interface provides indications for ESF-CCS equipment status and is used for ESF-CCS maintenance, test and diagnostics. The panel includes the MTS for RSP transfer.

ESF functions are assigned to individual subgroup segments within each ESF-CCS division (refer to Figure 7.3-3). (For example: Consider the Safety Injection system (SIS), Containment Spray System (CSS), Emergency Feedwater System 1 $(E F W-1)$ and Emergency Feedwater system $2(E F W-2)$ related to steam generators 1 and 2 , respectively. SIS and EFW-1 are assigned to ESF-CCS Subgroup segment 1 . CSS and EFW-2 are assigned to subgroup segment 2 , and so forth). This functional assignment approach limits the effect of a single segment failure to selected ESF functions in a given division.

Additional segmentation of functional assignment is applied within each ESF-CCS subgroup segment. (For example: SIS and EFW-1 components and instrumentation are assigned to separate multiplexers and initiation signals (SIAS and EFAS-1) are assigned to separate input modules within a multiplexer). These practices limit the effect of single multiplexer or module failure to selected ESF functions in the division. ESF system interfaces are also confined within subgroup segments to minimize reliance on the Intradivision Communication Network for ESF operability. (For example: SIAS initiation signals and SIS component and instrumentation interfaces are confined to subgroup segment 1.) Failure of the Intradivision Communication Network, therefore, will not effect SIS operation.

$7.3 \cdot 1.1 .1$

ESFAS Measurement Channels

Process measurement channels, similar to those described in Section 7.2.1.1.2.1 are utilized to perform continuous monitoring of each selected generating station variable, provide indication of operational availability of each sensor to the operator, and transmit analog signals to bistables within the ESFAS initiating logic. All protective parameters are measured with four independent process instrument channels. 
A typical measurement channel is shown in Figure 7.2-4. It consists of a sensor/transmitter, current loop resistors, loop/power supply, fiber-optic isolated outputs for the process control systems, DPS and DIAS. The DPS and DIAS receive digitized information over data links which are not part of the process measurement loop.

Each measurement channel is separated from other like measurement channels to provide physical and electrical separation of the signals to the ESFAS coincidence logic. Cabling is separated within the cabinets and signals to non-1E systems are isolated. Each chanrel is supplied from a separate 120 volt vital AC distribution bus.

7.3.1.1.2 Logic

\subsection{ESFAS Bistable and Coincidence Logic}

The ESFAS Bistable Logic compares the analog signal from the sensors with predetermined fixed or variable setpoints (see Figure 7.2-12). If the input signal exceeds the setpoint the bistable produces trip signals which are transmitted to the Local Coincidence Logics (LCLs).

The setpoint values are controlled administratively and automatically monitored continuously. The fixed setpoints are adjusted at the PPS cabinet. Access for setpoint adjustment is limited by keylock with access annunciated by DIAS. The bistable setpoints are capable of being displayed at the PPs cabinet and DPS CRT displays in the main control room. Some setpoints are externally variable to avoid inadvertent initiation during normal operations such as startup, shutdown, cooldown, and evolutions such as low power testing. The steam generator and pressurizer pressure setpoints can be manually decreased by the operator and will automatically increase as pressure increases.

The bistable trip signals are directed to the LCLs (refer to Figure 7.3-16) in all channels such that full two-out-of-four coincidence is provided for each channel. The outputs of the LCLs control the initiation relays which send signals to the Actuation Logic in each ESF-CCS division cabinet.

Besides the automatic actuation of the initiation logic by the LCL, the initiation relays can be tripped by remote manual switches. All ESF actuation signals can be manually initiated by the operator from the control room in accordance with procedures. Following initiation, each engineered safety system, including latchea portions of EFAS, must be manually reset to restore the initiation logic to the non-actuated state. 


\subsection{Actuation Logic}

The ESFAS actuation and component control logics are physically located in four independent and geographically separate ESF-CCS cabinets.

The four initiation circuits in the PPS actuate a selective two-out-of-four logic in the ESF-CCS. In the actuation logic (refer to Figure 7.3-2), each signal also sets a latch when the selective two-out-of-four logic actuates to assure that the signal is not automatically reset once it has been initiated.

Receipt of two selective engineered safety system initiation channel signals will generate the actuation channel signals. This is done independently in each ESF-CCS cabinet, generating division division $A$ and division $B$ and where required, division $C$, and division D signals. The group component control logic is used to actuate the individual ESF components which are actuated to mitigate the consequences of the occurrence that caused the actuation.

\subsection{1 Component Control Logic}

This section describes the control logic designs for the five basic types of components to be controlled by the ESF-CCS.
A. Solenoid-operated Valves
B. Motor-operated Valves
C. Contactor-operated Components
D. Circuit Breaker-operated Components
E. Modulating Components

\section{$7.3 \cdot 1 \cdot 1 \cdot 2 \cdot 2 \cdot 1 \cdot 1$ \\ Solenoid-Operated Valves}

\subsection{1.1.1 Two-State Solenoid Valve Control}

The ESF-CCS executes the control logic necessary to energize the II solenoid, as a function of the open/closed state to which the energized solenoid corresponds (i.e., energize to open valve or energize to close valve). In general, there is one solenoid for direct operating electro-hydraulic or electro-pneumatic valve types. Figure 7.3-8a is a typical Functional control. Logic Diagram (FCLD) that depicts the control design for a solenoidoperated valve. Figure 7.3-8b depicts the generic electrical interface design for a solenoid-operated valve. For valves that have multiple solenoids with various energize/deenergize 
sequencing requirements that apply to different operating or test modes, the generic control logic design and electrical interface design is modified appropriately.

The following signals are utilized in the control logic:

A. Position status

The control logic utilizes "not full open" (NFO) and "not full closed" (NFC) position signals. These signals are from direct indicating limit switches on the process control valve. These signals are used primarily for status indication and interlocking with other components.

B. Control Signal

The control logic utilizes the state of the output relay and the continuity monitoring circuit associated with the output. A digital output module in the RFM provides the relay output interface to energize the solenoid.

The position signals, control output status and continuity monitoring status are logically combined to provide component status indication (OPEN/CLOSE), component discrepancy indication (component not in the required position), and component inoperable indication (loss of control power or circuit continuity).

The component inoperable signal is used to reset component control logic following a loss of motive or control power and is delayed momentarily to prevent normal switching transients or momentary losses of power from unnecessarily resetting component logic.

\section{$7 \cdot 3 \cdot 1 \cdot 1 \cdot 2 \cdot 2 \cdot 1 \cdot 1 \cdot 2$ \\ Modulating Valves with Solenoid Operators}

These are solenoid-operated valves that have electro-pneumatic modulators to allow continuous valve positioning. Figure 7.3-9a is a typical FCLD depicting the generic control design for a modulating valve with a solenoid operator. Figure 7.3-9b depicts the generic electrical interface design.

The following signals are utilized in the control logic:

A. Solenoid Energized

This signal is used for status to indicate the energized state of the solenoid. This signal is derived from limit switches on the solenoid itself. Where this is not available, the signal is derived from a logic element that is representative of solenoid energization. 
B. Analog Position

Continuous valve position indication is provided for valves where it is required for human factors engineering reasons. An analog input is received from a position transducer on the valve and interfaced with an analog input module in the Remote Field Multiplexer (RFM).

c. Control Signal

The continuous process signal for positioning the modulated valve is provided to the electro-pneumatic (E/P) or electro-hydraulic $(\mathrm{E} / \mathrm{H})$ positioner from an interface with an analog output module in the RFM.

The control design for modulating valves and other modulated components without discrete state operators are discussed in Section 7.3 .1 .1 .2 .2 .1 .5 .

\subsection{1.2 Motor-Operated Valves}

This section describes the control logic for motor-operated valves (MOVs) that use reversing motor contactors. The CCS executes the control logic necessary to energize the open and close contactors.

\subsection{1.2.1 Interface Signals}

Interlocking of the open/close contactors, electrical fault and/or thermal overload protection, and interlocking with limit and torque switches are wired external to the CCS control logic. These are not shown on the FCLDs. Figure 7.3-10a depicts a typical MOV functional interface design. Figure 7.3-10b shows the generic electrical interface design for a motor-operated valve. These figures show the signals that the ESF-CCS uses in the control logic. The interface signals are described as follows:

A. Position status

These signals are the same as those for solenoid valves (see section 7.3.1.1.2.2.1.1.1). All MOVs have discrete state position indicators. Throttling MOVs also have continuous position indication if required for human factors engineering reasons.

B. Control Signal

The control logic utilizes the state of the output relays and the continuity monitoring circuit associated with each output. A digital output module in the RFM provides the relay output interface to energize the contactor. 
C. Contactor Deenergized

The control logic utilizes one signal to determine when the opening coil and closing coil are deenergized. This signal is generated from a combination of opening and closing coil contacts which axe wired together in the motor starter. The signal interfaces with a digital input module in the RFM. This design allows the valve motor to be stopped by torque or limit switches without ESF-CCS intervention. The contactor deenergized signal results in the ESF-CCS opening its control contacts thereby allowing utilization of local controls.

The position signals, contactor deenergized signal, control output status and continuity monitoring status are logically combined to provide component status indication (OPEN/CLOSE), component discrepancy indication (component not in the requested position), component inoperable indication (loss of control power or circuit continuity), and high torque conditions (torque switch open). The component inoperable signal prevents resetting latches in the control logic and is used to provide indication to the operator that the component is inoperable.

\subsection{1.2.2 Throttling and Full Throw Designs}

The ESF-CCS provides full throw or throttling (or jogging) valve control. Full throw valves are actuated by signals that are latched in the control circuit such that valve travel will continue even if the initiating control signal is removed. All full throw MOVs can be reversed in mid-travel by removal of the initiating control signal and application of a control signal for travel in the opposite direction. Figure 7.3-11 is a typical FCLD depicting the generic design of a full throw motor-operated valve.

Throttling MOVs stop traveling when the operator initiated control signal is removed. As such they can be positioned by the operator anywhere from 0-100\%. Where throttling MoVs are also controlled by automatic ESF actuation signals, the control response to the automatic signal is always full-throw. Figure 7.3-12 is a typical FCLD depicting the generic design of a throttling motor-operated valve.

\subsection{1.2.3 Thermal Overload Monitoring}

The application of thermal overload protection devices in class $1 \mathrm{E}$ motor-operated valve circuits is in compliance with Regulatory Guide 1.106. Thermal overload protection devices are not used in safety-related motor-operated valve circuit. Thermal overload devices are used to provide alarm functions. Figure 7.3-17 provides a simplified schematic of this design.

Amendment I 


\subsection{1.3 Contactor-Operated Components}

A typical FCLD depicting the generic control design for a contactor-operated component is depicted in Figure 7.3-13a. The generic electrical interface design is shown in Figure 7.3-13b. The ESF-CCS provides the control logic necessary to energize the contactor. Designs for electrical fault and/or thermal overload protection are wired external to the ESF-CCS. The interface signals are described as follows:

\section{A. Position status}

The control logic utilizes "a" auxiliary contacts from the contractor for the status signal. This signal interfaces with a digital input module in the RFM.

\section{B. Control Signal}

The control logic utilizes the state of the output relay and continuity monitoring circuit associated with the output. A digital output module in the RFM provides the relay output interface to energize the contactor.

The position status signal, control signal, output status and continuity monitoring are logically combined to provide contactor status indication (ON/OFF), contactor discrepancy indication (contactor not in requested condition) and component inoperable (loss of control power or circuit continuity). The component inoperable signal prevents resetting latches in control logic and is used to provide indication to the operator that the component is inoperable.

\subsection{1.4 Circuit Breaker-Operated Components}

Circuit breakers are used to control most loads requiring voltage greater than $480 \mathrm{~V}$ AC. Figure $7.3-14 \mathrm{a}$ is a typical FCLD depicting the generic control logic necessary to energize the breaker's closing circuit and energize the breaker's trip circuit. The generic design of the electrical interfaces to the closing and trip circuits is shown in Figure 7.3-14b. Electrical fault protection interfaces and rack-out or test position interlocks are wired external to the ESF-CCS. The following status signals are used in the electrical portion of the design:

\section{A. Position status}

The control logic utilizes an breaker auxiliary switch for This signal interfaces with a digital input module in the RFM. "a" contact from the circuit position status indication. 
B. Control Signal

The control logic utilizes the state of the output relays and the continuity monitoring circuits associated with each output. A digital output module in the RFM provides the relay output interface to the circuit breaker opening and closing circuits.

C. Fault Trip

The control logic utilizes a signal from the overcurrent relay to provide fault indication. This signal interfaces with a digital input module in the RFM.

\section{Control Power}

The control logic receives a signal derived from control power monitoring contacts for closing and trip circuits (74-1 and 74-2). This signal is logically combined with control output status and coil continuity status to derive a control power status signal.

The position status signal, fault trip status signal, control power status signal, control output status signal and continuity monitoring signals are logically combined to provide circuit breaker status indication (OPEN/CLOSE, ON/OFF), discrepancy indication (circuit breaker is not in requested condition) and component inoperable (loss of control power or circuit continuity.)

The component inoperable signal prevents resetting latches in the control logic and is used to provide indication to the operator that the component is inoperable.

\subsection{1.5 Modulating Components}

A typical FCLD showing the generic design for a modulating component is depicted on Figure 7.3-15a. The generic electrical design is shown in Figure 7.3-15b. These types of devices include electro-pneumatic (E/P) and electro-hydraulic (E/H) actuated components (pumps or valves) that require only analog signal inputs for continuous control (i.e., no discrete state controls from pilot solenoids). 
The following signals are interfaced to the ESF-CCS from the component:

A. Status

1. Valve Position

a. "NOT FULL OPEN" and "NOT FULL CLOSED" position signals from indicating limit switches interface with a digital input module in the RFM.

b. Analog valve position is used, where required, based on human factors engineering considerations. The position signal is from a position transducer and interfaces with an analog input module in the RFM.

2. Pumps

a. "ON" and "OFF" signals are from contactor or circuit breaker auxiliary switch "a" contacts which interface with digital input modules in the RFM.

b. Turbine speed are analog input and output signals that interface with analog input and output modules in the RFM.

B. Component Inoperable

Component Inoperable indication may be provided where loss of control or motive power signals are available from the component (i.e. circuit breaker or contactor).

\subsection{2 Gioup Actuation}

Actuation signals, generated by the selective two-out-of-four logic in the ESF-CCS, are directed to actuate groups of ESF system components required by the ESFAS function. These components generally consist of solenoid-operated valves, motoroperated valves or motors of pumps. Figures 7.3-8a, 7.3-11 and 7.3-14a show typical ESFAS interlocks in the functional control logic for override of each of these components. Valves and pumps, related to a specific engineered safeguard function, are grouped within an ESF-CCS division, as shown in Figure 7.3-7, such that the required component groups are actuated by the appropriate logic. The actual ESFAS interface exists in the component control logic for each component. 


\subsection{CCS - Diesel Loading Sequencer}

Diesel generators as described in section 8.3.1.1.4 are utilized in the System $80+$ design as a source of backup electrical power to ensure availability of the plant's safety systems. Due to the large power requirements imposed on the diesel generators, there exists a need to sequentially load them. The system $80+$ plant equipment is arranged into several load groups. Load groups are energized one at a time by the CCS Diesel Loading sequencer, thus avoiding instantaneous overloading of the diesel generator. Equipment is energized as quickly as possible to minimize the overall plant disturbance.

The Diesel Loading Sequencer is designed assuming plant accidents occur prior to, concurrent with, or any time after the initial LOOP or blackout has occurred. The ESF equipment required in the event of a design basis accident is energized within a pre-determined time after the accident has occurred to maintain the plant within its design limits. The equipment required depends on the specific accident. Several load groups of equipment may be needed if multiple ESF systems are needed to accommodate the accident.

To minimize diesel generator size and eliminate unnecessary equipment cycling, but still meet concerns of plant safety, the CCS Diesel Load sequencer design ensures one group at a time loading but has the intelligence to vary the loading sequence in response to changing plant conditions (i.e., initiation of ESF systems). If an ESF system is actuated, the non-accident load sequence is interrupted to load the appropriate ESF system(s). If an accident does not occur, energizing of non-accident equipment is not delayed unnecessarily, since the sequence does not progress through the steps for the unused accident equipment. The sequencer is fully testable during on-line plant operation.

Figures 7.3-5 and 7.3-6 are simplified diagrams of the CCS Diesel Loading Sequencer (DLS). Figure 7.3-5 depicts the sequencer operation. The DLS consist of the following sections:

A. Sequence Initiation Logic

The Initiation Logic monitors various plant electrical busses to determine when abnormal power conditions exist. When the right combinations of bus abnormalities are present, a Loss of Power signal sets all sequencer output Latches (eleven, typical), generating Load shed (Trip) signals to the necessary plant equipment. A DG Auto start signal is also transmitted to the diesel generator upon Loss of Power, SIAS, CSAS or EFAS. When the diesel is ready to 
accept the first load group (Diesel Ready signal) a DG Circuit Breaker close signal is transmitted to connect the diesel generator to the plant bus. After the circuit breaker is closed successfully, (Breaker Closed signal) the equipment loading sequence begins.

B. Loading Sequence Logic

The basis of the Loading Sequence Logic is a sjmple eight step counter (additional steps are added, as necessary which provides the sequencing control for all non-accident equipment). When the diesel generator breaker is closed the counter advances, one step at a time, with a constant time base interva: between each step. The time base interval is determined by a clock pulse which is adjustable in distinct digital increments. At each step of the counter, one Sequencer output Latch is reset, removing the Load shed signal from that load group and re-energizing the required plant equipment. During non-accident plant conditions the counter will advance, uninterrupted, to reset eight output latches, re-energizing eight non-accident load groups.

c. Priority Interrupt Logic

Three priority load groups are designated to handle plant ESF equipment (additional load groups are added, as necessary). The Priority Interrupt Logic continuously monitors ESF actuation signals from the Plant Protection system. If an ESF actuation occurs, the clock pulse from the Load Sequence Logic (above) is re-directed from the step counter, to reset the sequencer output Latch for the appropriate priority load group. Hence, the non-accident loading sequence is interrupted and the required ESF load group is re-energized instead. The time base interval (between each sequence step) is always maintained by the common clock pulse.

The non-accident loading sequence may be interrupted two or three times in the event that multiple ESF Actuations occur at different times. A priority between ESF load groups is established such that if two or three ESF actuations occur during any one time base interval, the ESF load groups will be sequenced in two or three successive steps and in the established priority order. After the ESF load groups have been energized the non-accident sequence will resume (always maintaining the same time base interval). 
The DLS provides the following features:

A. Since all load groups are always energized one at a time, diesel generator size can be minimized.

B. Accident loads are always energized in the sequence step immediately following the accident occurrence. Thus, achieving the best availability possible, for accident equipment.

c. Since sequence steps are not pre-assigned to accident equipment (which may or may not be needed) no sequence step is wasted. All equipment is energized in the fastest time possible.

D. Equipment is load shed one time only. Once a class $1 E$ Division load group is energized, that group is unaffected by the occurrence of an accident. See 8.3.1.1.4.6 for additional sequencing of permanent non-safety loads when the Alternate AC Source is not available.

E. The DLS testing features, defined in section 7.3.1.1.8.9, allow complete system check-out while the plant remains on-line.

F. When offsite power is lost at some time after the diesel generators are up to rated voltage and speed, and after the required ESF equipment is running following one or more ESF actuations, the following response time requirements are met:

1. Interrupted SIS flow to the core can be fully
reestablished within 20 seconds.

2. Interrupted emergency feedwater flow to the steam generator(s) can be fully reestablished within 20 seconds.

G. In the event that offsite power is unavailable and the diesel generators are not yet up to rated voltage and speed at the time that an ESFAS is generated, there can be a delay of up to 20 seconds before the diesel generator output breakers close and power is supplied to the ESF buses. After the generators are supplying the ESF buses, the ESF loads which are appropriate in the particular ESFAS shall be automatically sequenced on. See Section 8.3, Table 8.3.1-4. 
$7 \cdot 3 \cdot 1 \cdot 1 \cdot 3$

$7 \cdot 3 \cdot 1 \cdot 1 \cdot 3 \cdot 1$
Bypasses

\section{Bistable Trip Channel Bypass}

Bypasses are provided, in the PPS, as shown in Table 7.3-1. The trip channel bypass is identical to the RPS trip channel bypass (Section 7.2.1.1.5) and is employed for maintenance and testing of a channel.

\subsection{Operating Bypass}

The low pressurizer pressure bypass as shown in Figure 7.3-1a, is provided to allow plant depressurization without initiating protective actions when not desired. The bypass may be initiated manually in each protective channel. However, the bypass canrot be initiated if pressurizer pressure is greater than that shown in Table 7.3-1. Once the bypass is initiated, it is automatically removed when pressurizer pressure increases above the value shown in the table.

\subsection{Bypasses and Inoperable Status}

Auxiliary and supporting systems for the safety-related instrumentation and controls are designed to cause a system level bypass indication when they are bypassed or deliberately made inoperable. The bypass indication is provided for the safety-related system which is affected by the bypassing or deliberate inoperability of the auxiliary or supporting system.

\section{$7.3 .1 .1 .4 \quad$ Interlocks}

The Bistable Trip Channel Bypass Interlocks for ESFAS, located in the PPS, prevent the operator from bypassing more than one trip channel of a trip parameter at a time. Different trip parameters may be bypassed simultanenusly, either in the same channel or in different channels. This function is shown in Figure 7.2-3.

During PPS testing, additional interlocks are provided as described in section 7.2.1.1.6 to prevent disabling more than one redundant protection function at a time or to prevent maintenance personnel from inadvertently causing unwarranted ESFAS signals. ESF-CCS component control interlocks are shown on the applicable component FCLDs.

\subsection{Redundancy}

There are many redundant features within the ESFAS. There are four independent channels for each parameter from process sensor through and including the initiation circuits located in four PPS channels. 
There are four redundant ESF-CCS divisions used to operate four (or two) totally redundant ESF trains. Where redundancy exists at the engineered safety system level, component assignments to redundant ESF-CCS divisions are made to maintain that level of design redundancy.

Redundant flow paths are provided, such as the Safety Injection system, to ensure flow under single failure conditions. In this instance, components from each flow path are assigned to independent ESF-CCS divisions to maintain flow path availability upon single failure within an ESF-CCS division (i.e., division A and $B)$. In addition, a redundant flow path may contain two valves in series, such as the Emergency Feedwater system or the Containment spray System, to preclude spurious flow path initiation upon single failures. In this instance, each valve is assigned to independent ESF-CCS divisions such that a single failure within an ESF-CCS division will not cause spurious flow path initiation. Preventing spurious flow path initiation is accomplished while maintaining independence of redundant ESF flow paths. To achieve this, selected components in ESF system trains $A$ and $B$ are assigned to ESF-CCS divisions $C$ and $D$, respectively. Refer to mechanical systems sections for component to train assignments.

Each ESFAS division; $A, B, C$ and $D$ receives vital AC power from separate I\&C buses $A, B, C$ and $D$, respectively.

The result is a system which meets the single failure criterion and can be tested during operation. The PPJ ESFAS can be shifted to two-out-of-three logic, when a channel is removed for testing $\mid E$ or maintenance without affecting system availability.

The ESF-CCS utilizes redundant selective two-out-of-four coincidence logic to actuate ESF components.

\title{
7.3.1.1.6 Diversity
}

The system is designed to eliminate credible multiple channel failures originating from a common cause. The failure modes of redundant channels and the conditions of operation that are common to them are analyzed to assure that a predictable common failure mode does not exist. The process-cCs is constructed from equipment which is diverse from the plant Protection system and the ESF-CCS.

The design provides assurance that the protective system cannot be made inoperable by the inadvertent actions of operating or

\author{
$7.3-18$


maintenance personnel. The design is not encumbered with additional channels or components without reasonable assurance that such additions are beneficial.

\subsection{Sequencing}

Component sequencing methods are discussed in section 7.3 .1 .1 .2 .3 . Component sequencing requirements are provided in
chapter 8.

\subsection{Testing}

Provisions are made to permit periodic testing of the complete ESFAS. These tests cover the trip actions from sensor input through the protection system and actuation devices. The system test does not interfere with the protective function of the system. Overlap between individual tests exists so that the entire ESFAS can be tested.

The testing system meets the criteria of IEEE Std. 338-1977, "IEEE Standard Criteria for the Periodic Testing of Nuclear Power Generating station Class $1 \mathrm{E}$ Power and Protection systems," and the intent of Regulatory Guide 1.22, "Periodic Testing of Protection System Actuator Functions."

The frequency of testing is given in Technical specifications Section $16.6 / 3.3 .11$.

\subsection{Sensor Checks}

During reactor operation, the measurement channels providing an input to the ESFAS are checked by the methods described in Section 7.2 .1 .1 .9 .1 .

\subsection{Trip Bistable Test}

Testing of the ESFAS trip bistables, located in the PPS, is accomplished as described in section 7.2.1.1.9.2.

Testing of ESF-CCS bistable functions used for process control setpoints and interlocks is provided as follows.

The DPS continuously monitors setpoints and provides alarms upon excessive setpoint deviations between channels. ESF-CCS bistable trip accuracy and interlock performance is also periodically verified during performance of the selective group testing described in section 7.3.1.1.8.6. This is accomplished through manual perturbation of the digitized interlocking parameter from the operators module in the main control room. Analog to digital conversion accuracy is also periodically verified at the operators module during sensor testing. The overlap of testing 
defined above results in complete verification of ESF-CCS bistable trip accuracy and interlock performance.

\subsection{Local Coincidence Logic Test}

Testing of the ESFAS local coincidence logic, located in the PPS, is accomplished as described in section 7.2.1.1.9.4.

\subsection{Initiation Logic Tests}

The initiation logic for each engineered safety system is automatically tested by the PPS test function to determine its ability to generate an initiation signal. Testing begins by interrogation of status of the input signals to the logic and the state of the output. The test function determines what the cutput of the logic should be, based upon the input signals. Should there be a discrepancy between the actual output and the output determined by the test function, the test function will annunciate the discrepancy and provide a message to identify the error. If there is no discrepancy, testing of the logic continues. The additional testing that will be done is dependent upon the status of those inputs to the logic over which the test function has no control (e.g., genuine coincidence signals). Based upon the known inputs, the test function will generate all combinations of input signals and monitor the output of the logic for currectness. A genuine coincidence signal or other genuine signal cannot be changed by the test function.

Testing of these functions is limited to one channel at a time to avoid the possibility of actuating any equipment during test. This testing is done in conjunction with the ESFAS initiation relay testing described below.

The ESF-CCS actuation logic is a selective two-out-of-four circuit controlled by the outputs of the initiation relays from the four PPS channels. Since the initiation relays are within the control of the PPS, it is possible to test them automatically. Before the automatic test function applies any signals to the system, it determines the status of the initiation circuit outputs. It then makes a determination of what the status of the actuation logic feedback signals should be. The actuation logic feedback signals, obtained from the actuation trains (refer to Figure 7.3-16), represent the state of the initiation relay outputs. If there is a difference between the actual output and the output that should exist, the condition is both annunciated and a message is provided on demand. If conditions are correct, the test system generates an initiation signal which propagates through to the ESF actuation trains. The test function monitors the ESF-CCS actuation logic circuit feedback signals to determine proper operation. If a fault is detected it is annunciated and a message is provided on demand. 
The initiation relay test is only performed in one PPS channel at a time. An interlock among the PPS channels ensures that only one channel at a time can be tested. Additionally the interlock verifies that the opposite leg of the actuation circuit is not already enabled. This interlock provides assurance that testing cannot result in inadvertent actuation.

\subsection{Actuating Logic Test}

The ESF-CCS actuation logic receives short duration initiation signals (test signals) from the PPS. These signals are processed in the ESF-CCS and returned to the PPS for detection of initiation signal failure or the loss of an actuation signal to a subgroup (refer to Figures $7 \cdot 3-7$ and 7.3-16). Sequentially, the PPS transmits short duration initiation signals, $A A, C A, B A$ and $D A$, for each ESFAS signal. (Note, that for initiation signal designations, first character represents PPS originating channel, and second character represents ESF-CCS destination division.)

The PPS processes the returned test signal for both the presence of an actuation signal when there should be one, and the absence of an actuation signal when there should not be one. The absence of a desired actuation signal or the presence of an unwanted actuation signal is detected at the time an abnormal or failed condition occurs. When an actuation channel is manually actuated at the ESF-CCS (e.g. for latch testing), a discrepancy between the PPS initiation signals and the state of the actuation channel is automatically detected.

\subsection{Selective Group Test}

ESFAS selective group testing is performed by an operator in the main control room. This testing, as shown in Figure 7.3-7, overlaps the PPS automatic testing of the ESF-CCS selective two-out-of-four coincidence logic and includes complete testing of the ESFAS through to the actuation of the components. The components for each ESFAS are grouped. Testing is conducted one group at a time, thus preventing the complete undesired actuation of an ESF system during testing. Since this testing causes components to actuate, an ESFAS signal from the PPS will not be impeded and the ESF system will proceed to full actuation.

The operator, using a written procedure, performs the following actions when making a selective group test.

A. Determines if the group test can be performed based on the plant conditions and lineup.

B. Selects the component group to be tested. 
C. Depresses a test pushbutton, latching the test group selection and initiating a "stop-and-Think" time delay.

D. Places the test group components and other related components in a test lineup (via component control switches).

E. A "Test Enabled" light will illuminate after the "stop-and-Think" time delay. The operator then initiates the actuation of the group components to their ESFAS required state.

F. Confirms that the group components have actuated to the ESFAS required state for the group being tested (via component control switch indicators).

G. Places components back to their initial lineup via component control switches).

The stop-and-Think interlock is provided in the ESF-CCS. This feature enables the test actuation logic (Step $\mathrm{E}$ above) for a fixed period after the group to be tested is latched (step $c$ above). Each time a new group is selected the time delay is reset preventing further testing. The operator must re-initiate the delay for subsequent testing.

The DPS CRT Displays can be used as an operational aid during the Selective Group Testing described above.

The operator may use the DPS to:

A. Store the initial state (position) of each component in the test group prior to placing the components in a test lineup.

B. Confirm that the operator has placed the components in the correct test lineup.

C. Confirm that the group components have actuated to the ESFAS required state for the group being tested.

D. Confirm that the components have been returned to the initial state (position) after the test has been completed.

This DPS application program is referred to as Computer Aided Testing (COMAT). The COMAT signals from the ESF-CCS are transmitted to the DPS via fiber-optic data link (refer to Figure 7.3-3. The DPS is used to aid the operator in monitoring the manual selective group testing. No interlock or control signals are transmitted from the DPS to the ESF-CCS. Selective group 
testing may be performed without COMAT therefore DPS availability is not required for performance of selective group testing.

\section{$7 \cdot 3 \cdot 1 \cdot 1 \cdot 8 \cdot 7$}

Bypass Tests

System bypasses in the PPS, as itemized in Table 7.3-1, are tested on a channel basis as described in section 7.2.1.1.9.7.

\subsection{Response Time Tests}

Required Response Time Tests for the ESFAS are identified in Technical Specifications Section 16.6/3.3.

The design of the ESFAS is such that connections may be made for any of a variety of methods as described in section 7.2.1.1.9.8 that may be used by the site operator. The hardware design includes test connections on instrument lines for pressure and differential pressure transmitters, and conveniently available test points.

\section{$7 \cdot 3 \cdot 1 \cdot 1 \cdot 8 \cdot 9$ \\ Diesel Load Sequencer Tests}

The DLS incorporates design features, shown in Figure 7.3-6, which allow complete on-line testing. During normal operation all output control signals are disabled, allowing all logic functions to be tested without disturbing plant equipment. The outputs become enabled automatically, anytime a valid Initiation Logic input signal is received. In this manner, testing may be conducted without impeding proper sequencer operation in the event of an actual black-out condition. Three distinct test phases are employed to assure maximum system reliability.

\section{A. Phase 1 - Automatic Testing}

The Automatic Test Phase provides continuous cycling of the Loading Sequence Logic which consists of the sequence counter, time base interval and all output latches. The latches are sequentially set and reset by the counter at a rate controlled by the time base interval. A failure of a latch to operate in the correct sequence or within the correct time is automatically detected at the time the failure occurs. Alarm output signals and front panel indicators are provided to diagnose the failure.

\section{B. Phase 2 - Input Testing}

All DLS external inputs are checked independent of Logic Testing. During this test actual Initiation logic input signals are generated from the sensors. Front panel 
indicators allow verification that all signals are being communicated properly to the Initiation Logic. Since these signals are considered (by the DLS) to be valid inputs, the automatic output enabling logic, described above, is blocked during this testing. After completion of the test the block is removed.

With the control outputs remaining blocked, the second phase of testing verifies power operation of the Loading sequence Logic and the priority Interrupt Logic. Front panel controls allow simulating all required inputs to initiate the non-accident sequence. other controls permit introduction of simulated accident signals at any point in the non-accident sequence. Any accident scenario may be simulated to verify that the correct loading sequence occurs. Front panel indicators display all Load Shed output signals.

C. Phase 3 - Load Shed Testing

The final test phase involves actual load shedding and re-energizing plant loads. Each load group is further sub-divided into test groups which may contain from one to all components in the Load Group. Load Shed signals are simulated separately for each test group in conjunction with the CCS - Selective Group Testing. As for ESF Actuation testing, described in section 7.3.1.1.8.6, the Computer Aided Test program (COMAT) in the DPS is used as an operator aid. The equipment is actually tripped and re-energized, but since one group is tested at a time, the overall plant disturbance is minimal.

\subsection{Vital Instrument Power Supply}

The vital instrument power supply requirements are discussed in section 7.1.3, and in chapter 8 .

\section{$7.3 \cdot 1 \cdot 1.10$}

\section{Actuated Systems}

The ESF systems are maintained in a standby mode during normal operations. Actuating signals, generated by the ESFAS are provided to assure that the ESF Systems provide the required protective actions. The following descriptions of the instrumentation and controls of the ESF systems is applicable to each ESF System. Table 7.3-2 presents the Design Basis Events (DBE) which require specific ESF system action. Table 7.3-3 presents the monitored variables required for ESF system actuation. The variables and their ranges are shown on Table $7.3-6$. 


\subsection{Containment Isolation System}

Section 6.2.4 contains a description of the containment Isolation system (CIS). The actuation system is composed of redundant trains $A$ and $B$. The instrumentation and controls of the two trains are physically and electrically separate and independent as discussed above such that the loss of one train will not impair the safety function.

The Containment Isolation system instrumentation and controls are designed for operation during all phases of plant operation. However, the system is removed from service prior to containment leak checking at refueling intervals in order to prevent undesired system actuation. The removal from service is accomplished in accordance with procedures prepared by the site operator.

The Containment Isolation system is automatically actuated by a CIAS from the ESFAS.

\subsection{Containment Spray System}

Refer to section 6.5, "Containment spray system," for a $\mid \mathrm{E}$ description of the containment spray system (CSS). The CSS is actuated by a CSAS. Containment spray pumps are actuated by an SIAS.

The actuation system is composed of redundant trains $A$ and $B$. The instrumentation and controls of each train are physically and electrically separate and independent. Each train is a $100 \%$ capacity system, therefore, the cSS can sustain the loss of an entire train and still provide its required protective action. The CSS instrumentation and controls are designed to operate under all plant conditions.

The CSAS is removed from service prior to the containment leak test at refueling intervals in order to prevent undesired system actuation. The removal from service is accomplished in accordance with procedures prepared by the site operator.

\subsection{Main Steam Isolation System}

Refer to Section 10.3, "Main Steam Supply System," for a description of the Main steam Isolation system. Refer to section 10.4.7, "Condensate and Feedwater System," for a description of the Main Feedwater Isolation system. Refer to section 10.4.8, "Steam Generator Blowdown system," for a description of the Blowdown Isolation System. Interface requirements for the Main steam Isolation system are provided in section 5.1.4. 
The actuation system is composed of redundant trains $A$ and $B$. The instrumentation and controls of the valves in train $A$ are physically and electrically separate and independent of the instrumentation and control of the valves of train $B$. The separation and independence are such that a failure of one train will not impair the protective action.

The Main steam Isolation Valves (MSIVs), MSIV Bypass Valves, Main IE Feedwater Isolation Valves (MFIV) and the isolation valves for the blowdown lines are actuated by an MSIS.

These valves effectively isolate the steam generators from the rest of the main steam and feed systems.

A variable steam generator pressure setpoint is implemented to allow controlled pressure reductions, such as shutdown depressurization, without initiating an MSIS. The pressure setpoint will track the pressure up until it reaches its normal setpoint value.

\subsection{Safety Injection System}

Refer to section 6.3, "Safety Injection system," for a description of the safety Injection system (SIS). The SIS is actuated by an SIAS. Interface requirements for the safety Injection system are provided in Section 6.3.13.

The actuation system is composed of redundant trains $A, B, C \mid \mathrm{E}$ and $D$. The instrumentation and controls of each train are physically and electrically separate and independent. The SIS can sustain the loss of an entire train and still provide its required protective action. The SIS instrumentation and controls are designed to operate under all plant conditions.

The low pressurizer pressure setpoint can be decreased as described in section 7.2.1.1.1.6 to avoid inadvertent operation during startup and shutdown. As pressurizer pressure increases, the setpoint will follow up to its normal value. The SIAS is removed from service during containment leak checking at refueling intervals to prevent undesired system operation. The removal from service is accomplished in accordance with procedures prepared by the site operator.

\subsection{Emergency Feedwater System}

Refer to Section 10.4.9, "Emergency Feedwater system," for a description of the Emergency Feedwater System (EFWS). The EFWS is actuated by an EFAS-1 for steam Generator 1 and an EFAS-2 for steam Generator 2. The EFWS is also actuated by the Alternate 
Protection system (APS), described in section 7.7. Interface requirements for the Emergency Feedwater system are provided in Section 10.4.9.

The actuation system is composed of redundant trains A, B, C, and D. The instrumentation and controls of each train are physically and electrically separate and independent. The EFWS can sustain the loss of an entire train and still provide its required protective action. The EFWS instrumentation and controls are designed to operate under all plant conditions.

On a low steam generator level, the EFAS signal starts the FFW pumps and opens the EFW isolation valves and flow control valves causing full flow system actuation. The actuation signal which opens the valves will clear automatically when normal steam generator level is restored. Upon clearing of the actuation signal, the valves will remain in their open position, however the plant operator can manually control (i.e., reduce flow) as defined in section 10.4.9, otherwise, maximum flow will continue. If steam generator water level again falls below the low steam generator water level setpoint after the actuation signal clears, the EFAS signal will reactuate again causing full flow system actuation.

To prevent steam generator overfill, a high steam generator level interlock is provided by the ESF-CCS to automatically close the isolation valves. This interlock is active only when EFAS actuation is not active. This interlock also protects against steam generator overfill due to erroneous operation of the EFW system by the operator or the APS.

\subsubsection{Design Bases}

The design bases of the ESF systems are discussed in chapter 6 . The ESFAS is designed to provide initiating signals for ESF components which require automatic actuation following the design bases events shown on Table 7.3-2.

The systems are designed in compliance with the applicable criteria of the NRC, "General Design Criteria for Nuclear Power Plants," Appendix A, 10 CFR 50. System testing conforms to the requirements of IEEE Std. 338-1977, "standard Criteria for Periodic Testing of Nuclear Power Generating station Protection Systems," and the intent of Regulatory Guide 1.22, "Periodic Testing of Protection system Actuation Functions."

Specific design criteria for the ESFAS are detailed in IEEE Std. 279-1971, "Criteria for Protection Systems for Nuclear Power Generating stations," Section 3. The following is a discussion of the specific items in IEEE std. 279-1971 and their implementation. 
The generating station conditions requiring actuation of the ESFAS are listed on Table 7.3-2, which also shows which system will actuate for each event. The monitored variables required for ESF System protective action are listed on Table 7.3-3, which also shows which signals are generated by the variable. The number and location of the sensors required to monitor the variables are listed in Table 7.3-4. The normal operating ranges, actuation setpoints, the nominal full power value, and the margin between the last two are listed on Table 7.3-5. The ranges of the ESFAS variables are listed on Table 7.3-6.

The ESFAS is designed with consideration given to unusual events which could degrade system performance. System components are qualified for the environmental conditions discussed in section 3.11 and the seismic conditions discussed in section 3.10. system components with known susceptibility to electromagnetic interference (EMI) are qualified by methods defined in section 7.2.1.2.K. A single failure within the system will not prevent proper protective action at the system level. The single failure criterion is discussed in section 7.3.2.3.2.

The ESFAS minimum response times are specified in the Technical specifications. The accuracies of the ESFAS measurement channels are given as ALLOWED VARIATION in the Technical specifications. The total ranges of ESFAS variables are provided in Table 7.3-6.

\subsubsection{System Drawings}

The typical MCBDs, functional logics and typical control circuits are shown in the figures following this section.

\subsubsection{ESFAS Supporting Systems}

The systems required to support the ESFAS are discussed in Section 7.4. The electrical power distribution is discussed in Section 8.3 .

\subsubsection{ANALYSIS}

7.3 .2 .1

\section{Introduction}

The ESFAS is designed to provide protection against the Design Basis Events listed on Table 7.3-2. The ESF Systems that are actuated are discussed in chapter 6 , along with their design bases and evaluations. The ESFAS is addressed in the chapter 15 Safety Analysis.

The sensor signals which will cause each ESF actuation signal are listed on Table 7.3-3. The bases are discussed in section 7.3.1.2. The trip setpoints are given on Table 7.3-5. Most ESF actuation signals are based on fixed setpoint trips. The trip setpoints that do not fall into this category are: 
A. Low pressurizer pressure - can be decreased to 200 psi below the existing pressurizer pressure by the operator.

B. Low steam generator pressure - can be decreased to 200 psi below the existing steam generator pressure by the operator.

These resets are controlled by administrative procedures provided by the site operator.

Additionally, several ESF actuation signals can be actuated by more than one parameter. That is, different parameters can cause the same ESF actuation signal. The ESF signals which fall into this category are:

A. SIAS by either low pressurizer pressure or high containment pressure.

B. CIAS by receiving the SIAS for that channel so that it actuates on low pressurizer pressure or high containment pressure.

c. MSIS by high steam generator water level in either steam generator, low steam generator pressure in either steam generator, or high containment pressure.

Each trip setpoint is selected to be consistent with the function of the respective ESF system requirements. The setpoints are selected to provide ESF actuation in sufficient time to provide the necessary actions to mitigate the consequences of the Design Basis Events which caused the ESFAS.

The adequacy of all ESF trip setpoints is verified through an analysis of the pertinent system transients reported in chapter 15. These analyses utilize an Analysis setpoint (assumed trip initiation point) and system delay times associated with the respective trip functions. The Analysis setpoint along with instrument uncertainties provides the basis for the calculation of the final equipment setpoints to be reported in the Technical Specifications. Limiting trip delay times are given in chapter 15. The manner by which these delay times and uncertainties will be verified is discussed in section 7.2.1.2.

\subsection{Design Bases Events (DBE)}

The DBE conditions for which the system will take action are those unplanned events under conditions that may occur once during the life of several nuclear generating stations, and certain combinations of unplanned events and degraded systems that are never expected to occur during the life of all nuclear power plants. The consequences of these events should be limited by the ESF systems. The ESF systems have a major responsibility 
to mitigate the consequences of the events listed below. This includes minimizing fuel damage and subsequent release of fission products or other related effects. The accidents for which the ESFAS actuates are:

A. RCS pipe rupture, including a double ended rupture.

B. Steam system pipe rupture.

c. Feedwater system pipe rupture.

D. Steam generator tube rupture.

E. Break in a line from the reactor pressure coolant boundary that penetrates containment.

F. Single CEA Ejection.

The ESFAS will also act to mitigate the consequences of Anticipated Operational Occurrences as follows:

A. Excess heat removal due to secondary system malfunctions.

B. Inadvertent pressurization or depressurization of the RCS.

c. Change in normal heat transfer capability between steam and reactor coolant systems, including:

1. Improper main feedwater flow

2. Loss of external load

D. Complete loss of AC power to the station auxiliaries.

E. Depressurization due to the inadvertent opening of a pressurizer safety or relief valve.

7.3 .2 .2

Actuation Bases

The ESFAS consists of five signals based on five parameters. Each ESF actuation signal has manual actuation switches on the main control panels. MSIS also has manual actuation switches at the remote shutdown panel.

\section{3 .2 .2 .1 \\ Safety Injection Actuation Signal (SIAS)}

A. Input

Pressurizer pressure, containment pressure, or manual pushbuttons. The pressure signals are shared with the RPS. 
B. Function

The SIAS actuates the components necessary to inject borated water into the reactor coolant system and actuates components for emergency cooling. SIAS also actuates containment spray pumps. SIAS is also initiated by a loss of power to two channels.

\subsection{Containment Spray Actuation Signal (CSAS)}

A. Input

Containment pressure signals or manual pushbuttons.

B. Function

The CSAS actuates the containment spray system. CSAS is also initiated by a loss of power to two channels.

$7 \cdot 3 \cdot 2 \cdot 2 \cdot 3$

Containment Isolation Actuation Signal (CIAS)

A. Input

Pressurizer pressure, containment pressure, or manual pushbuttons. The pressurizer and containment pressure signals are provided via the SIAS.

B. Function

The CIAS actuates the isolation of lines penetrating the containment. CIAS is also initiated by a loss of power to two channels.

\subsection{Main Steam Isolation Signal (MSIS)}

A. Input

Pressure from each steam generator, containment pressure, level from each steam generator, or manual pushbuttons.

B. Function

The MSIS is provided to actuate the isolation of each steam generator. MSIS is also initiated by a loss of power to two channels.

$7.3 \cdot 2 \cdot 2 \cdot 5$

Emergency Feedwater Actuation Signal (EFAS)

A. Input

Level from each steam generator or manual switches. 
B. Function

The EFAS actuates emergency feedwater on low water level to the steam generator(s). EFAS is also initiated by a loss of power to two channels.

Actuation function EFAS-1 pertains to steam Generator 1 and EFAS-2 actuation function pertains to steam Generator 2 .

$7 \cdot 3 \cdot 2 \cdot 3$

Design

$7 \cdot 3 \cdot 2 \cdot 3 \cdot 1$

General Design Criteria

Appendix A, 10 CFR 50, "General Design Criteria for Nuclear Power plants," established minimum requirements for the principle design criteria for water cooled nuclear power plants. This section describes the requirements that are applicable to the ESFAS. Most references will be to section 3.1 where the criteria are first addressed. Section 7.2 .2 .3 .1 will be referenced if other comments from the RPS are applicable.

Criterion 1 - Quality standards and Records:

Refer to section 3.1 .1 for compliance.

Criterion 2 - Design Bases for Protection Against Natural Phenomena:

Refer to section 3.1 .2 for compliance.

Criterion 3 - Fire Protection:

Refer to Section 3.1 .3 for compliance.

Criterion 5 - Environmental and Missile Design Bases:

Refer to Section 3.1 .4 for compliance.

Criterion 13 - Instrumentation and Control:

Refer to section 3.1.9 for compliance. Variables monitored are those which affect ESF Systems.

Criterion 16 - Containment Design:

Refer to Section 3.1 .12 for compliance. 


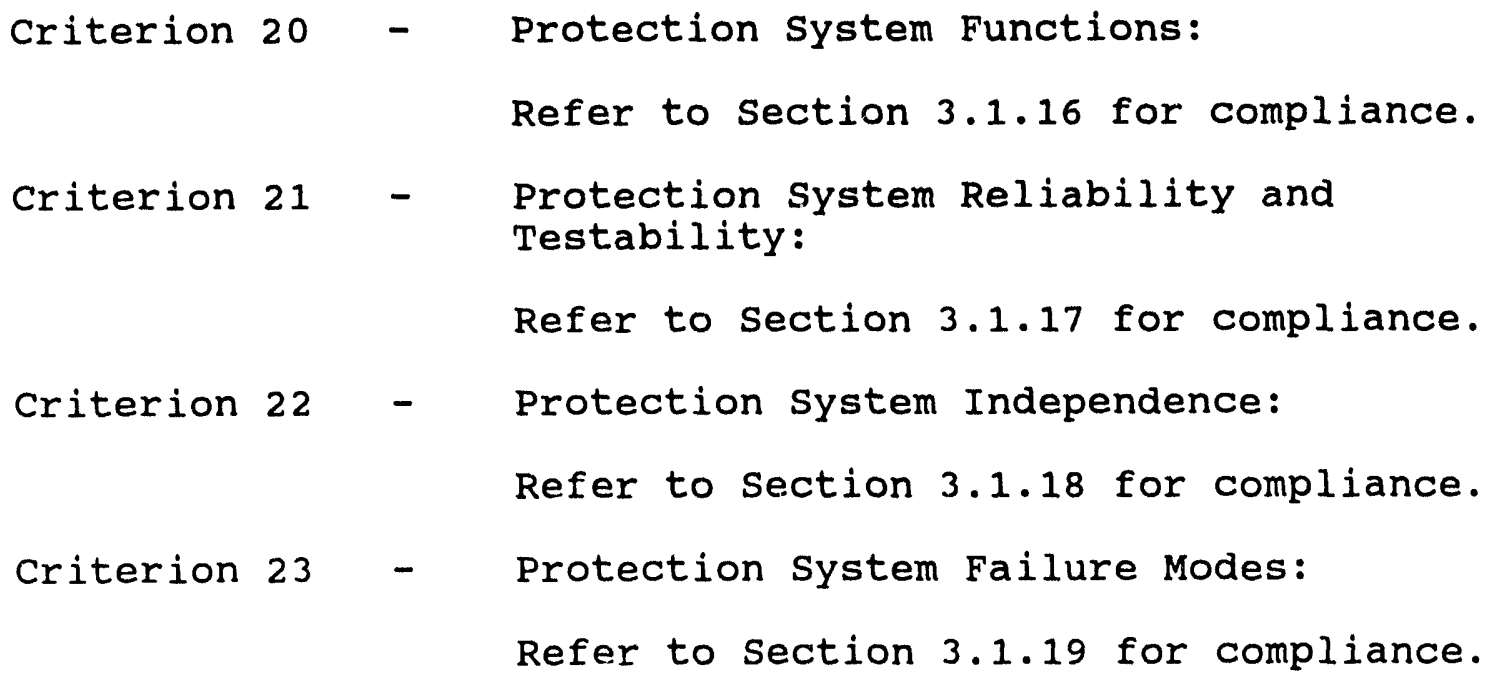

From the PPS cabinet the signals are sent to four ESF-CCS IE division cabinets. In each cabinet is the selective actuation $/$ I
logic for each division.

Criterion 24 - Separation of Protection and Control systems: Refer to section 3.1 .20 for compliance.

Criteria $34,35,37,38,40,41,43,44$ and 46:

Refer to sections $3.1 .30,31,33,34,36,37$, 39,40 and 42 for compliance.

The ESFAS provides the actuation which meets the requirements of IEEE std. 279-1971 and IEEE Std. 338-1977. The single failure criterion is met for all ESFAS. The ESFAS is fully testable. Those components which cannot be tested during power operations are tested when the plant is shutdown.

\subsection{Equipment Design Criteria}

Many of the design criteria for protection systems are discussed in Section 7.1.2. IEEE std. 279-1971, "Criteria for Protection systems for Nuclear Power Generating stations," establishes minimum requirements for safety-related functional performance and reliability of the ESFAS. This section describes how the requirements of section 4 of IEEE std. 279-1971 are satisfied. The following heading numbers correspond to the section numbers of IEEE Std. 279-1971. 
A. General Functional Requirements (Section 4.1):

The ESFAS is designed to actuate the appropriate ES Systems, when required, to mitigate the consequences of the specified Design Basis Events. Instrument performance characteristics, response times, and accuracies are selected for compatibility with, and adequacy for, the particular function. Actuation setpoints are established by analysis of the RCS parameters, steam generator parameters and containment pressure. Factors such as instrument inaccuracies, bistable trip delay times, valve travel times and pump starting times, are considered in establishing the margin between the actuation setpoints and the safety limits. In addition, the possible loss of $A C$ power and the time required to start standby power and to sequence loads must also be considered. The final determination of all of these times is the site operator's responsibility. The time response of the sensors or protection systems are evaluated for abnormal conditions. Since all uncertainty factors are considered as cumulative for the derivation of these times, the actual response time may be more rapid. However, even at the maximum times, the system provides conservative protection.

B. Single Failure criterion (Section 4.2):

The ESFAS is designed so that any single failure within the system will not prevent proper protective action at the system level. No single failure will defeat more than one of the four protective channels associated with any one trip function.

The effects of single faults in the RPS are discussed in Section 7.2.2.3.2. A similar analysis is applicable to that portion of the ESFAS located in the PPS cabinet. The initiating signal from the PPS goes to four separate ESF-CCS division cabinets. Each cabinet contains the actuation circuitry for each train, therefore, a failure in one cabinet cannot affect the circuitry and actuated equipment of the other divisions.

Single faults of initiation or actuation buses have no effect, as a selective two-out-of-four logic is required for actuation.

single faults of the actuation (or control) circuitry will cause, at worst, only a failure of a component, group of components, or actuation of a system within one of the 
redundant actuation trains; actuation of the remaining / $\mathrm{E}$ redundant train components is sufficient for the protective action.

C. Quality Control of Components and Modules (Section 4.3):

The system is designed in accordance with the Quality
Assurance Program described in section 17.0 .

D. Equipment Qualification (Section 4.4):

The ESFAS equipment is qualified in accordance with the methodology discussed in sections 3.10 and 3.11 . Safety-related ESFAS equipment is located so as not to violate qualification limits.

E. Channel Integrity (Section 4.5):

Type testing of components, separation of sensors and channels, and qualification of cabling are utilized to ensure that the channels will maintain their functional capability required under applicable extremes of environment, power supplied, malfunction, and DBE conditions. Loss or damage of any one path will not prevent the protective action of the ESFAS. Sensors are piped using materials of comparable quality to the systems to which they are attached so that, in the unlikely event of blockage or failure of any one connection, protective action is not prevented. The process sensors located in the containment building are specified and rated for the intended service. Components which must operate during or after DBEs are rated for the expected post-event environment. Results of type tests are used to verify these ratings.

F. Channel Independence (Section 4.6):

The routing of $1 \mathrm{E}$ and associated cabling and sensing lines from sensors meets the requirements of Regulatory Guides 1.75 and 1.151. They are arranged to minimize the possibility of common mode failure. This requires that the cabling for the four safety channels be routed separately; however, the cables of different safety functions within one channel may be routed together. Low energy signal cables are generally routed separately from all power cables. Safety-related sensors are separated. The separation of safety-related cables requires that the cables be routed in separate cable trays. Associated circuit cabling from redundant channels is handled the same as $1 \mathrm{E}$ cabling. 
Cabling associated with redundant channels of safety-related circuits is installed such that a single credible event cannot cause multiple channel malfunctions or interactions between channels.

Non-Class $1 \mathrm{E}$ instrumentation circuits and cables (low level) which may be in proximity to class $1 \mathrm{E}$ or associated circuits and cables are treated as associated circuits unless analyses or tests demonstrate that credible failures therein cannot adversely affect class $1 \mathrm{E}$ circuits.

The location of the sensors, for the ESFAS, and the points at which the sensing lines are connected to the process loop have been selected to provide physical separation of the channels within the system, thereby precluding a situation in which a single event could remove or negate a protective action. The routing of cables from protection system transmitters is arranged so that the cables are separated from each other, and from power cabling, to minimize the likelihood of common event failures. This includes separation of the containment penetration areas. The initiation paths are located in four PPS cabinets and the actuation devices are fed from the four ESF-CCS division cabinets. Geographical separation and electrical isolation between these cabinets minimize the possibility of a common mode failure.

The output from these redundant channels are isolated from each other so that loss of a channel does not cause loss of the system. The signals from the ESF-CCS which supply the II DPS and DIAS are isolated via fiber-optic cable.

The criteria for separation and physical independence of channels are based on the need for decoupling the effects of DBE consequences and power supply transients, and for reducing the likelihood of channel interaction during testing or in the event of a channel malfunction.

G. Control and Protection system Interaction (Section 4.7):

1. Classification of Equipment:

No portion of the ESFAS is used for both protective and control functions except sensor input signals as described in section 7.7.

2. Isolation Devices:

Signals sent from the ESFAS to the DPS and DIAS are isolated via fiber-optic cable such that a failure in these areas will not affect the protective action of the ESFAS. 
3. Single Random Failure:

This criterion is not applicable since there are no channels used for both control and protection except sensor input signals as described in section 7.7. Therefore a single random failure can only occur in either a control or a protection channel.

4. Multiple Failures Resulting from a Credible single Event:

This cannot exist, recause control and protection channels have nothing in common, except the use of protection sensors. Protection sensors provide fiber-optic isolated signals to the control systems for signal validation and control. Protection sensor failure effects are discussed in section 7.7.

H. Derivation of Signal Inputs (Section 4.8):

Insofar as possible, inputs are derived from signals that are direct measurements of the desired variable. Directly measured variables include pressurizer, containment, and steam generator pressures. The steam generator levels are derived from differential pressure signals.

I. Capability for Sensor Checks (Section 4.9):

ESFAS sensors are checked by methods described in section 7.7 including cross-channel comparison. Each channel has a known relationship with the other channels of the same parameter.

J. Capability for Test and Calibration (Section 4.10):

The ESFAS design comp?ies with IEEE Std. 338-1977, "Standard Criteria for the Periodic Testing of Nuclear Power Generating station Protection System Actuation Functions," as discussed in section 7.3.2.3.3.

K. Channel Bypass or Removal from Operation (Section 4.11):

Any one of the four protection channels in the ESFAS may be tested, calibrated or repaired without detrimental effect on the system. Individual actuation channels (i.e., pressurizer pressure, containment pressure, steam generator level) may be bypassed to create a two-out-of-three logic while maintaining the coincidence of two on the remaining channels. The single failure criterion is met during this condition. 
L. Operating Bypasses (Section 4.12):

Operating bypass is provided as shown on Table 7.3-1. The operating bypass is automatically removed when the permissive condition is not met. The circuitry and devices which function to remove this inhibit are designed in accordance with IEEE std. 279-1971.

M. Indication of Bypasses (Section 4.12):

Indication of test or bypass conditions, or removal of any channel from service is given by the DIAS and DPS. The $\left.\right|_{E}$ operating bypass that is automatically removed at a fixed setpoint, is alarmed and indicated.

N. Access to Means for Bypassing (Section 4.13):

Trip channel bypasses have controlled access. When the first parameter is bypassed there is an audible and visible alarm to indicate the bypass. The specific parameter or parameters which are being bypassed are indicated in the respective channel by lights at the PPS cabinet and its remote operators' module.

The operating bypasses also have audible and visible alarms. The operating bypasses have automatic features which provide a permissive level at which they can be actuated and a second level at which they are automatically removed.

o. Multiple setpoints (Section 4.15):

Manual reduction of the setpoints for low pressurizer and low steam generator pressures are used for the controlled reduction of pressures as discussed in sections 7.3.1.1.10.3 and 7.3 .1 .1 .10 .4 . The setpoint reductions are initiated by main control board controls for each channel, one for the pressurizer pressure and one for both steam generator pressures within the one channel. Operation of the controls will reduce the pressure actuation setpoint a selected increment below the existing system pressure. As the pressurizer or steam generator pressure increases the actuation setpoint will increase automatically with the pressure, maintaining a fixed increment, until the setpoint reaches its normal actuation setpoint value.

P. Completion of Protective Action once It is Initiated (Section 4.16):

The ESFAS is designed to ensure that protective action will go to completion once initiated. Actuation of an ESF can 
only be cleared by the operator after the trip condition clears by manualiy resetting the ESF at the ESF-CCS operators module. An ESF component actuation can only be overridden by the operator after protective action completion. A protective action is initiated when the selective two-out-of-four logic reaches the proper coincidence of two state. A protective action is completed when all of the appropriate ESF actuated components have assumed the proper state for their ESF function. The EFAS valves are not locked into its actuation but the pumps are locked in. EFAs is designed to cycle based on the steam generator level signal.

Q. Manual Initiation (Section 4.17):

A manual initiation is effected by operating manual switches at the main control panel or at the remote shutdown panel. $1 \mathrm{E}$ These are arranged in a selective two-out-of-four logic. No single failure will prevent a manual actuation at the system level.

R. Access to setpoint Adjustments, Calibration and Test points (Section 4.18$)$ :

Access to setpoint adjustments, calibration and test points is restricted. Access is also annunciated. Setpoints are continuously monitored by the DPS and PPS automatic test controller.

S. Identification of Protective Action (Section 4.19):

Indication lights are provided for all protective actions, including identification of the channel trips.

T. Information Readout (Section 4.20):

Means are provided to allow the operator to monitor all actuation system inputs, outputs, and calculations. The specific displays that are provided for continuous display are described in section 7.5. The ESFAS alarms and ESF-CCS operator's Modules are located in the main control room.

U. System Repair (Section 4.21):

Identification of a defective channel is accomplished by observation of system status lights, or by testing as described in section 7.3.1.1.8. Replacement or repair of components is accomplished with the affected channel bypassed. The affected function is then in a two-out-of-three logic, but still maintaining a coincidence of two for actuation. 
V. Identification (Section 4.22):

All equipment associated with the actuation system, including panels, modules, and cables, is marked in order to facilitate identification. Physical identification is provided to enable plant personnel to recognize that ESF-CCS Cabinets and their cabling are safety-related. The cabinets are identified by nameplates. A color coding scheme is used to identify the physically separated channel cabling from sensor to the ESF-CCS. The same color code is used for interbay or intercabinet identification.

Cabling or wiring within a bay at the cabinet which is in the channel of its circuit classification is not color coded. The cabinet nameplates and cabling between cabinets are codes as follows:

\begin{tabular}{cl}
$\begin{array}{c}\text { Protective } \\
\text { Channel }\end{array}$ & $\begin{array}{l}\text { ESF-CCS } \\
\text { Divisions }\end{array}$ \\
\hline
\end{tabular}

Channel A: Red

Channel B: Green B: Green

Channel C: Yellow C: Yellow

Channel D: Blue
A: $\quad$ Red

D: Blue

\section{Associated Channel}

Channel J: White/Red Stripe Channel K: White/Green Stripe Channel L: White/Yellow Stripe Channel M: White/Blue stripe

\subsection{Testing Criteria}

Conformance of the ESFAS to the requirements of IEEE std. 338-1977 and the intent of Regulatory Guide 1.22 is discussed in /E Sections 7.1 .2 .7 and 7.1.2.15. Test intervals and their bases are included in the Technical specifications section 16.4.3.2.

The periodic testing of the ESFAS is the site operator's responsibility. Because the ESFAS is required to operate infrequently, the system is continuously tested automatically and periodically and routinely tested manually to verify its operability. A complete channel is tested without causing a system actuation and without affecting system operability and availability. Overlap in the testing of the channels is provided to assure that the entire channel is functional. The testing scheme is discussed in detail in section 7.3.1.1.8. 
Each portion of the testing of the ESFAS, as discussed in section 7.3 .1 .1 .8 , causes a portion of the system to act as it would if a real actuation setpoint had been reached. The difference, while testing the local coincidence logic, is that only one channel is actuated and it can be bypassed for testing. If a genuine input signal is received during test, the signal will propagate through the remaining channels to cause actuation.

If the initiation or actuation circuit is being tested and a genuine input signal is received, the signal will propagate through.

It can be seen from section 7.3.1.1.8 and the above discussion that the testing of the ESFAs does not affect the system integrity or availability. When any one channel in the PPS portion is in test the remaining three channels can still provide a coincidence of two to effect actuation via the ESF-CCS.

The response time from an input signal to protective action, through the opening of the actuation relays is verified by measurement during plant startup testing. Sensor responses are measured during factory or laboratory testing and provided to the site operator for his use in his test program.

\section{3 .2 .4 \\ Failure Modes and Effects Analysis (FMEA)}

The FMEA for the ESFAS appears on Table 7.2-5.

\subsubsection{Setpoint Methodology}

Refer to Section 7.2 .2 .3 .2 .

\subsubsection{ESF Valve Operability}

The valves of the ESF systems are designed and tested as required by NUREG-0737, Section II.K.1.5, to ensure proper operation in the event of an accident. This is accomplished in several ways.

A. The valves of the ESF systems are interlocked to automatically provide the sequence of operations required after an actuation of the ESF.

B. Actuator-operated valves are status controlled using a combination of administrative controls and "stop and think" interlocks, where considered necessary, to prevent unintentional misalignment of valves during power operation. Additionally, the DPS includes Critical Function Monitoring and Success Path Monitoring displays to permit verification of proper valve alignments during post-accident conditions (refer to section 7.7 and Chapter 18). 
C. All manual valves that are not required to operate on initiation of safety injection, in the injection flow path, are locked in the post accident position. Administrative controls ensure that the valves are locked in the correct position.

D. Periodic pump and valve group tests and inspections are performed, as defined in section 7.3.1.1.8, to verify proper operation of each active component of the safety injection system.

\subsubsection{Containment Hydrogen Recombiner System (CHRS)}

The Containment Hydrogen Recombiner system (CHRS) prevents the concentration of hydrogen in containment from reaching flammability limits following a design basis loss-of-coolant accident (LOCA). The CHRS is an Engineered Safety Features (ESF) system designed to be manually initiated. CHRS controls and instrumentation are discussed in section 6.2.5.

\section{3 .3 \\ ENGINEERED SAFETY FEATURES ACTUATION SYSTEM INTERFACE REQUIREMENTS}

Refer to section 7.1 .3 for interface requirements. 
TABLE 7.3-1

\section{ESFAS BYPASSES}

\begin{tabular}{|c|c|c|c|c|}
\hline Title & Function & Initiated By & Removed By & Notes \\
\hline $\begin{array}{l}\text { Trip Channel } \\
\text { Bypass }\end{array}$ & $\begin{array}{l}\text { Disables any } \\
\text { given trip } \\
\text { channel }\end{array}$ & $\begin{array}{l}\text { Manually by } \\
\text { controlled } \\
\text { access switch }\end{array}$ & Same switch & $\begin{array}{l}\text { Interlocks } \\
\text { allow one } \\
\text { channel for } \\
\text { any type } \\
\text { trip to be } \\
\text { bypassed } \\
\text { at one time. }\end{array}$ \\
\hline $\begin{array}{l}\text { Pressurizer } \\
\text { Pressure } \\
\text { Operating } \\
\text { Bypass }\end{array}$ & $\begin{array}{l}\text { Disables low } \\
\text { pressurizer } \\
\text { pressure } \\
\text { portion of } \\
\text { SIAS/CIAS* }\end{array}$ & $\begin{array}{l}\text { Manual switch } \\
\text { (1 per channel) } \\
\text { if pressure } \\
<400 \text { psia }\end{array}$ & $\begin{array}{l}\text { Automatic if } \\
\text { pressurizer } \\
\text { pressure is } \\
>500 \text { psia }\end{array}$ & \\
\hline
\end{tabular}

* SIAS/CIAS actuation due to high containment pressure not affected. 
TABLE 7.3-2

DESIGN BASIS EVENTS REQUIRING ESF SYSTEM ACTION

Event

Feedline Break

LOCA - Large Break

LOCA - Small Break (1)

Steam Generator Tube

Rupture

Steam Line $E$ ?ak

(Inside Cont: nment)

Steam Line Breik

coutside

Containment)

(3)

Excess Heat Removal

Due to Secondary

System Malfunctions

Inadvertent

Pressurization or

Depressurization of RCS

Change in Normal Heat

Transfer Capability

Between Steam and

Reactor Coolant

Systems

Complete Loss of $A C$

Power to Station

Auxiliaries

\section{SYSTEM}

$\begin{array}{cr}\begin{array}{c}\text { Containment } \\ \text { Isolation }\end{array} & \begin{array}{r}\text { Contain } \\ \text { Spray }\end{array} \\ * & \\ * & * \\ * & *\end{array}$

*(2)

Main Steam

Isolation

*

Safety Emergency

Injection

Feedwater

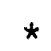

$\star$

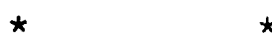

*

$\star$

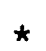

$\star$

*

*

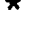

$\star$

$\star$

$\star$

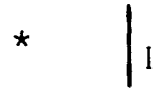

*

NOTES: 1. Includes CEA Ejection and Pressurizer Safety Valve Opening.

2. Manual Actuation.

3. Includes Opening of Secondary Safety Valve. 


\section{CESSAR DESIN DIITATION}

TABLE 7.3-3

MONITORED VARIABLES REQUIRED FOR ESFAS PROTECTIVE SIGNALS

\begin{tabular}{|c|c|c|c|c|c|}
\hline & CIAS & CSAS & MSIS & SIAS & EFAS \\
\hline Pressurizer Pressure & 3 & & & 3 & \\
\hline Containment Pressure & 1 & 2 & 1 & 1 & \\
\hline Steam Generator Pressure & & & 3 & & \\
\hline Steam Generator Water Level & & & 1 & & 1,3 \\
\hline
\end{tabular}

LEGEND: $\quad 1$ - High

2 - High-High

3 - Low 
TABLE 7.3-4

\section{ENGINEERED SAFETY FEATURES ACTUATION SYSTEM SENSORS}

\begin{tabular}{|c|c|c|c|}
\hline $\begin{array}{c}\text { Monitored } \\
\text { Variable } \\
\end{array}$ & Sensor Type & Number of Sensors & Location \\
\hline $\begin{array}{l}\text { Pressurizer } \\
\text { Pressure }\end{array}$ & $\begin{array}{l}\text { Pressure Transducer } \\
\text { (High and Low range) }\end{array}$ & $8 *$ & Pressurizer \\
\hline $\begin{array}{l}\text { Containment } \\
\text { Pressure }\end{array}$ & Pressure Transducer & $4 *$ & $\begin{array}{l}\text { Enclosure } \\
\text { Complex }\end{array}$ \\
\hline $\begin{array}{l}\text { Steam Generator } \\
\text { Pressure }\end{array}$ & Pressure Transducer & 4/Steam Generator* & Steam Generator \\
\hline $\begin{array}{l}\text { Steam Generator } \\
\text { Level }\end{array}$ & $\begin{array}{l}\text { Differential Pressure } \\
\text { Transducer (Wide and } \\
\text { Narrow Range) }\end{array}$ & 8/Steam Generator* & Steam Generator \\
\hline
\end{tabular}

* Shared with the Reactor Protective System 
ENGINEERED SAFETY FEATURES ACTUATION SYSTEM SETPOINTS AND MARGINS TO ACTUATION

\section{Actuation Signal}

\section{SIAS \& CIAS}

Low Pressurizer Pressure

High Containment Pressure

CSAS

High-High Containment Pressure

MSIS

Low Steam Generator Pressure

High Containment Pressure

High Steam Generator Level

EFAS

Low Steam Generator Level ang
High Steam Generator Level

ALTERNATE PROTECTION SYSTEM

Low Steam Generator Level
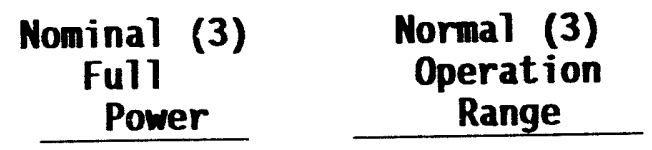

Nominal (3)

Actuation

Setpoint

Margin to (3)

Actuation

2250 psia

0 psig

$1905-2375$ psia

-0.3 to $+0.3 \mathrm{psig}$

1825 psia $^{(1)}$

2.7 psig

425 psia

$2.7 \mathrm{psig}$

0 psig

-0.3 to $+0.3 \mathrm{psig}$

8.5 psig

$8.5 \mathrm{psig}$

$\begin{aligned} 1000 & \text { psia } \\ 0 & \text { psig }\end{aligned}$

$59.1 \%$ NR

$76.8 \%$ WR

$76.8 \%$ WR

$76.8 \%$ WR

$$
\begin{gathered}
1000-1100 \text { psia } \\
-0.3 \text { to }+0.3 \text { psig } \\
0-95 \% \text { NR }
\end{gathered}
$$
843 psia $^{(1)}$
2.7 psig
$90.8 \%$

157 psia

2.7 psig

$31.7 \%$

MOTES: 1 - Setpoint can be manually decreased as pressure is reduced and is automatically increased as pressure increases.

2. Narrow Range Transmitter Signal used to automatically close EFW valves.

3. Values given are typical. Actual values are site dependent based on the equipment procured. Therefore, the site specific SAR shall make appropriate adjustments as necessary. 
TABLE 7.3-6

ENGINEERED SAFETY FEATURES ACTUATION SYSTEM PLANT VARIABLE RANGES

\begin{tabular}{|c|c|c|c|}
\hline Monitored Variable & Minimum & Nominal Full Power (2) & Maximum \\
\hline $\begin{array}{l}\text { Pressurizer Pressure } \\
\text { (Low range) }\end{array}$ & 0 psia & (Note 1) & 1600 psia \\
\hline $\begin{array}{l}\text { Pressurizer Pressure } \\
\text { (High range) }\end{array}$ & 1500 psia & 2250 psia & 2500 psia \\
\hline Containment Pressure & -4 psig & 0 psig & 60 psig \\
\hline Steam Generator Pressure & 0 psia & 1000 psia & 1400 psia \\
\hline $\begin{array}{l}\text { Steam Generator Level } \\
\text { (Wide Range) }\end{array}$ & $0 \%$ & $76.8 \%$ & $100 \%$ \\
\hline $\begin{array}{l}\text { Steam Generator Level } \\
\text { (Narrow Range) }\end{array}$ & $0 \%$ & $59.1 \%$ & $100 \%$ \\
\hline
\end{tabular}

NOTE: (1) The high and low pressurizer pressure sensor ranges are combined electronically within the PPS bistable for wide range applications.

(2) Nominal values given are typical. These values may be adjusted during the final design process. 


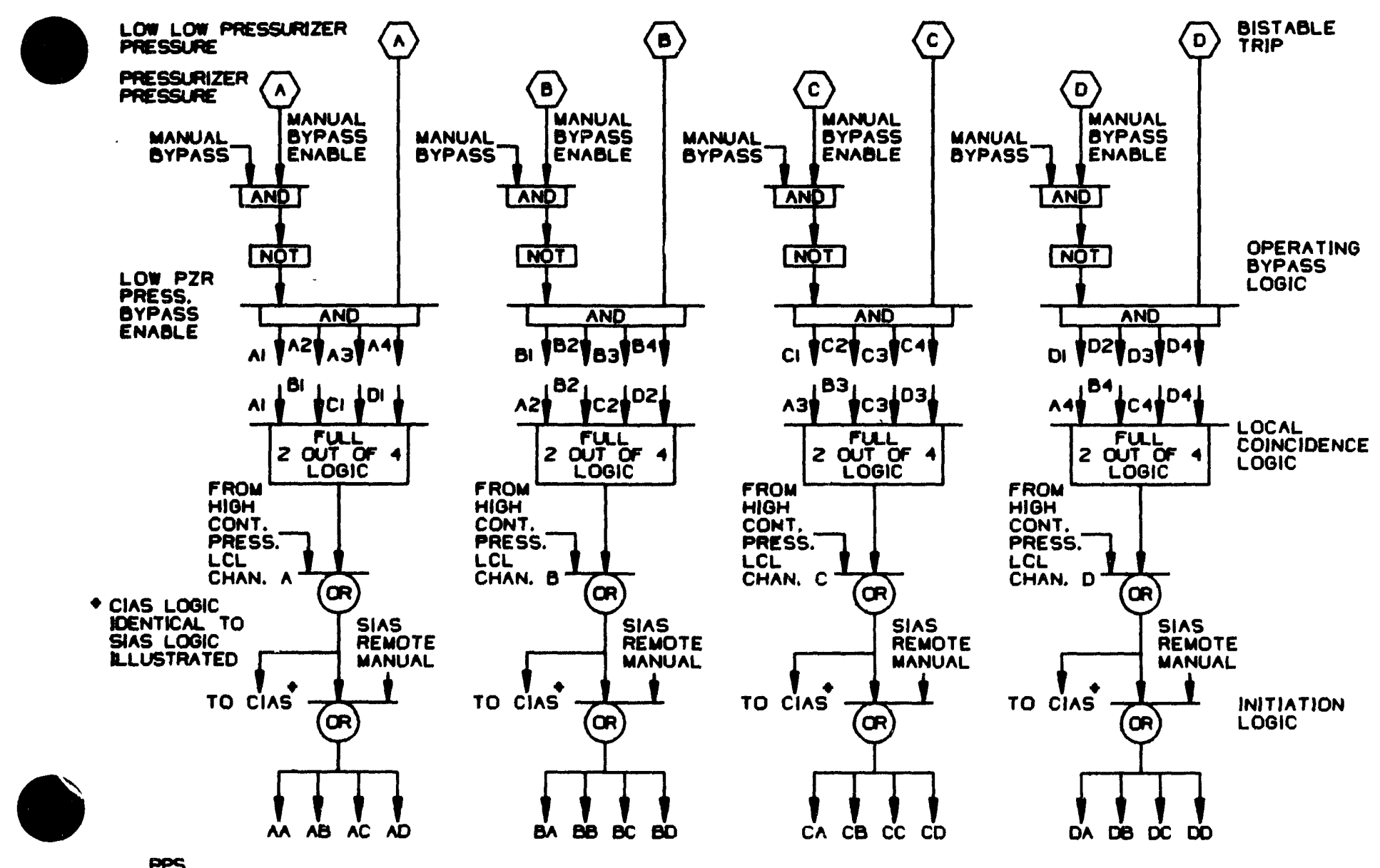

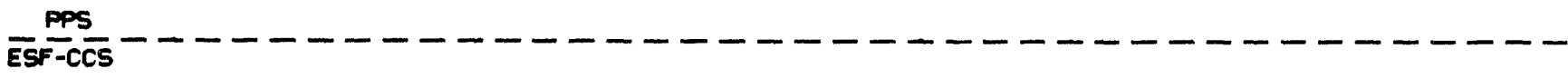

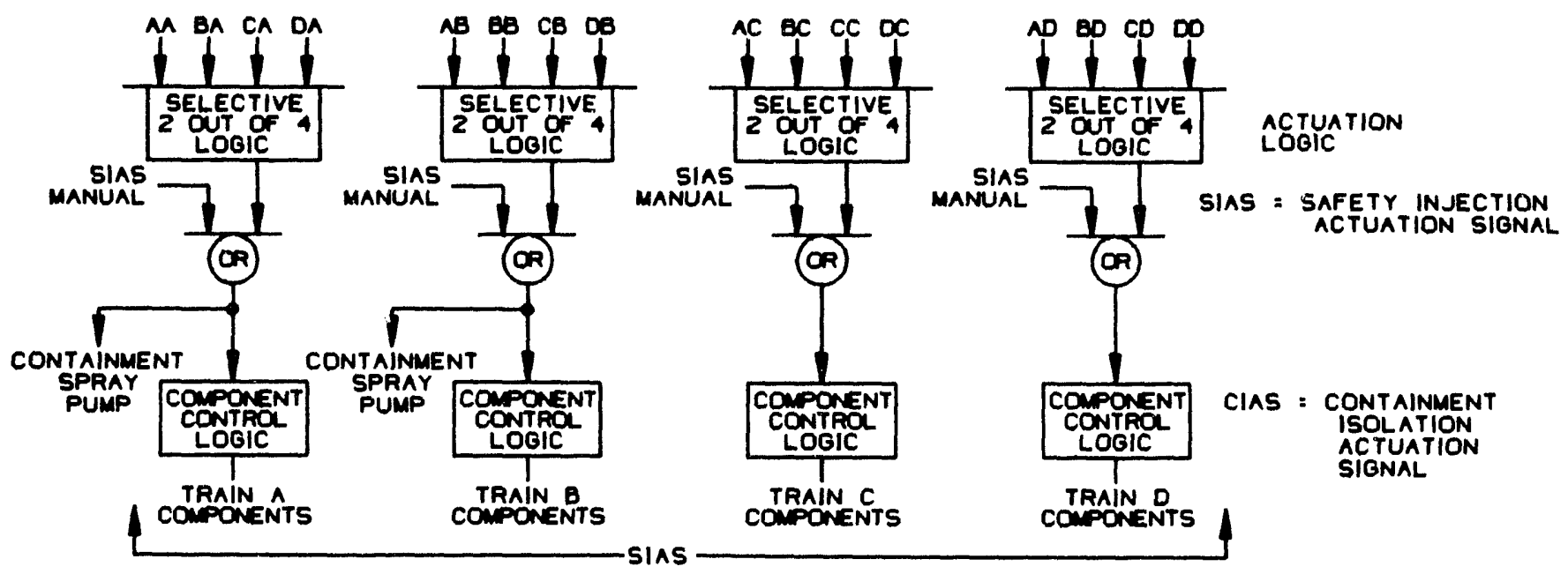

Amendment I

December 21, 1990

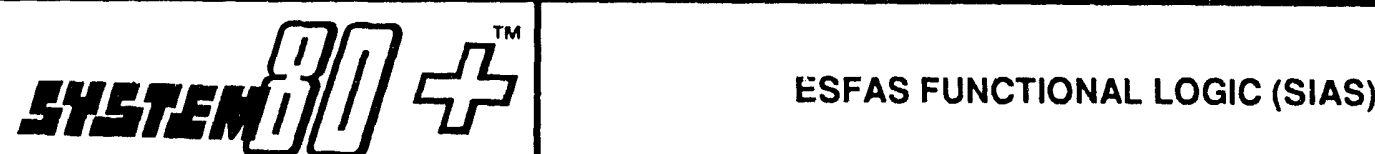


HIGH HIGH CONTAINMENT PRESSURE

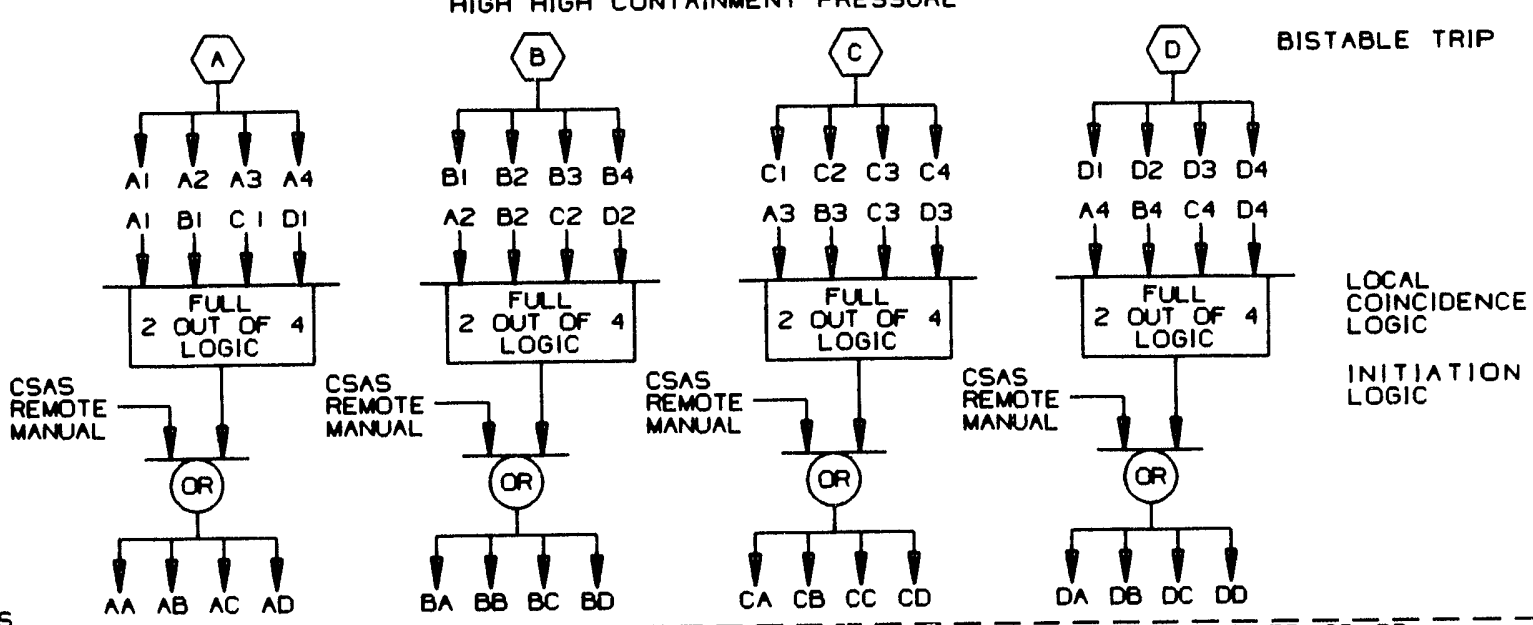

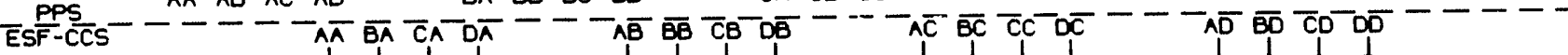

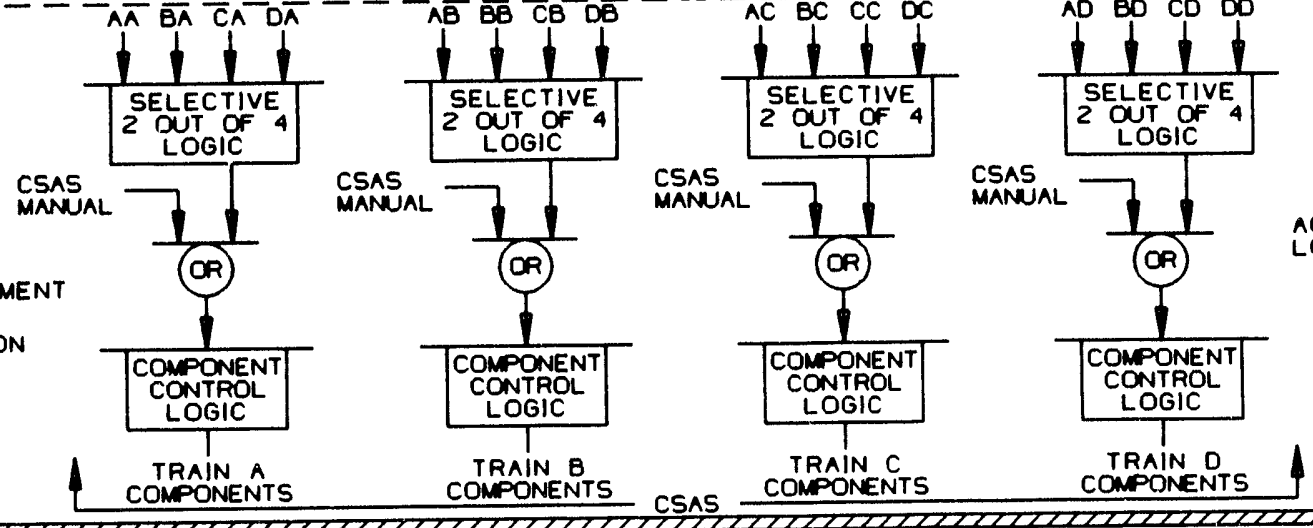

CSAS: CONTAINMENT

SPRAY

ACTUATION

SIGNAL

COMPONENTS

COMPONENTS

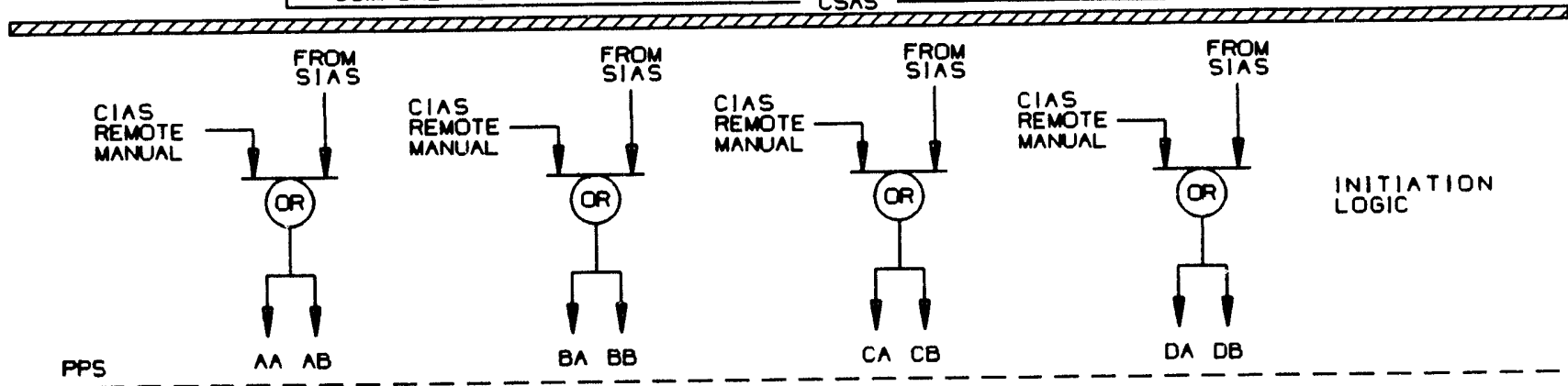

PPS

$A A A B \quad B A B B$

CA CB

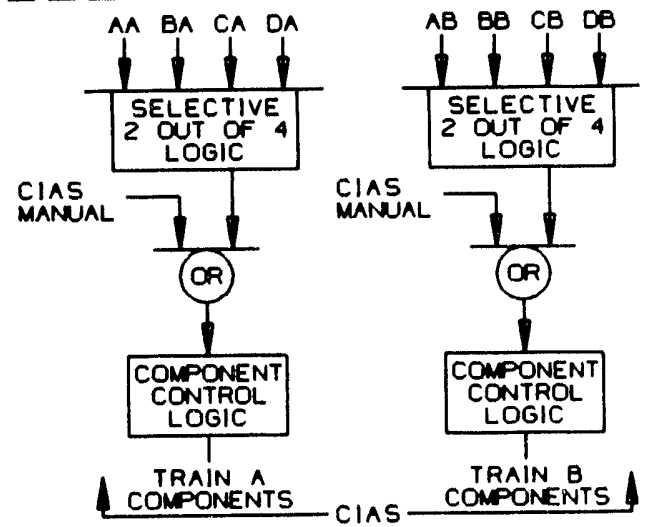

Amendment I

December 21, 1990 
(B) C

A
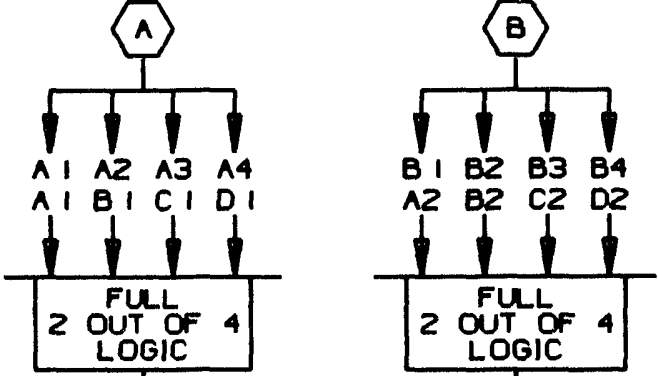
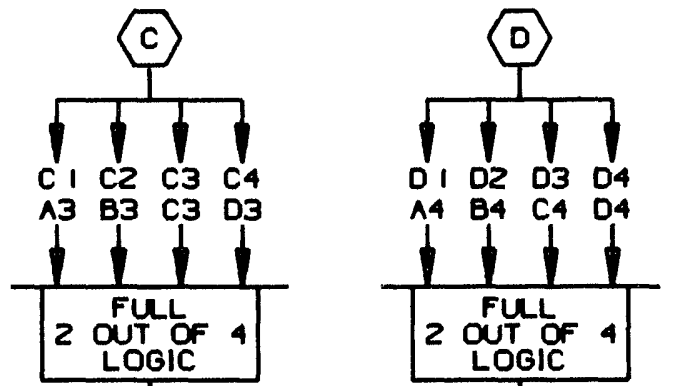

BISTABLE

LOCAL

COINCIDENCE
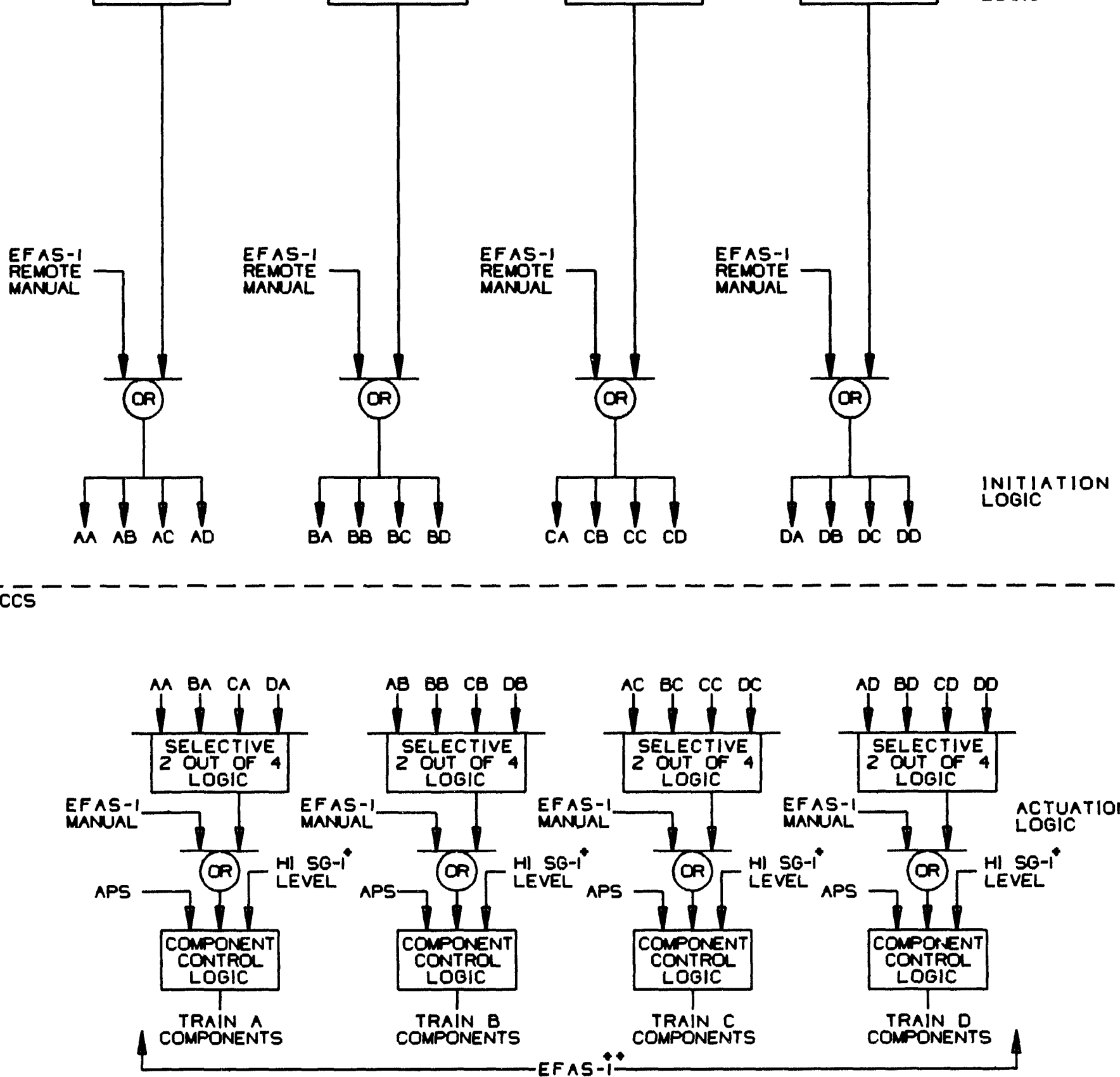

* HISG-I LEVEL

* eFAS-z LOgIC

LLUSTRATED

$B A$ BB BC BD

CA CB CC CD

OA DE DC DO

ACTUATION

EFAS-1 = EMERGENCY FEEDWATER

ACTUATION SIGNAL-I

EFAS-2 = EMERGENCY FEEDWATER

ACTUATION SIGNAL-2

APS = ALTERNATE PROTECTION

Amendment I

SYSTEM

December 21, 1990 
CALMA FILE:

I.CLKOHLIFIG73IC

HIGH CONTAINMENT PRESSURE

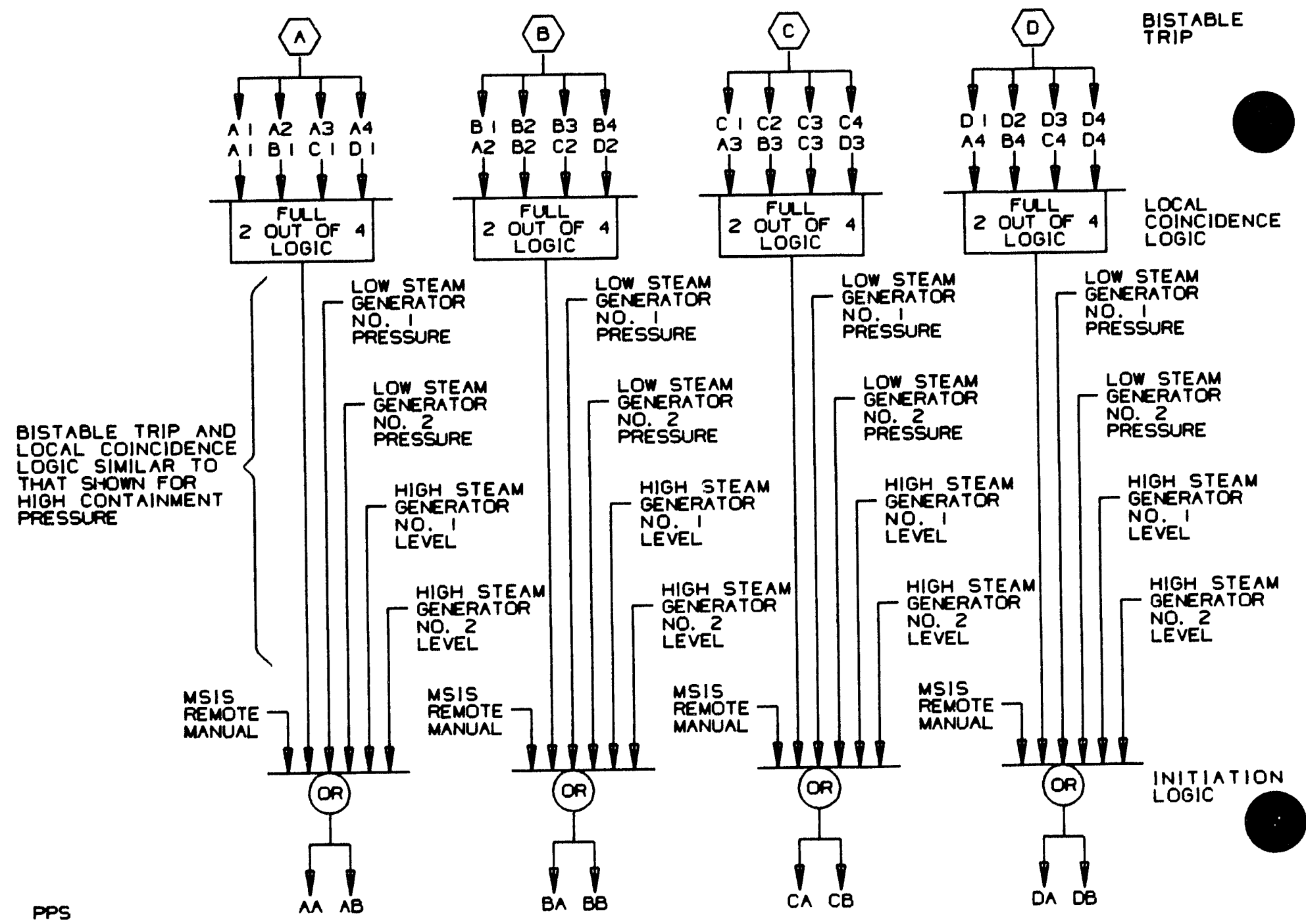

ESF-CCS

MSIS: MAIN STEAM

ISOLATION

SIGNAL

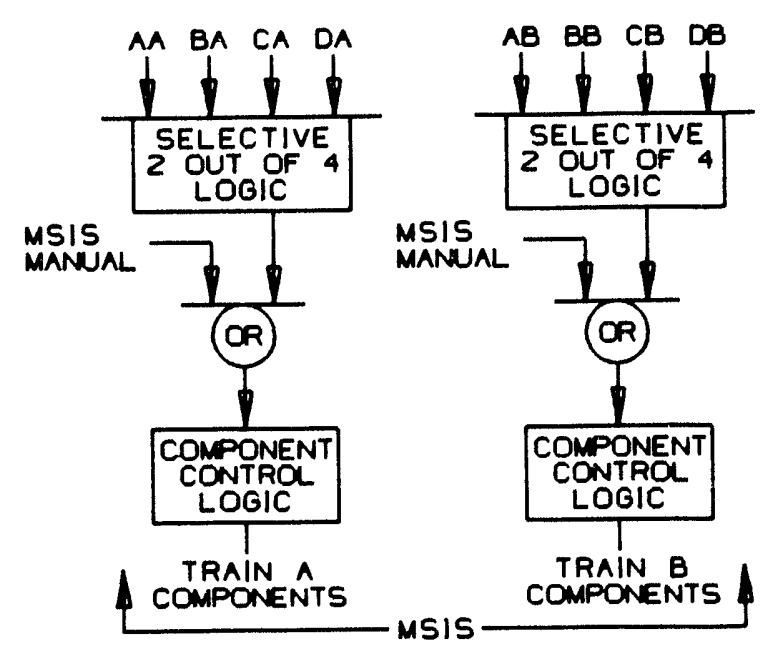

ACTUATION

LOBIC

Amendment I

December 21, 1990

Figure 


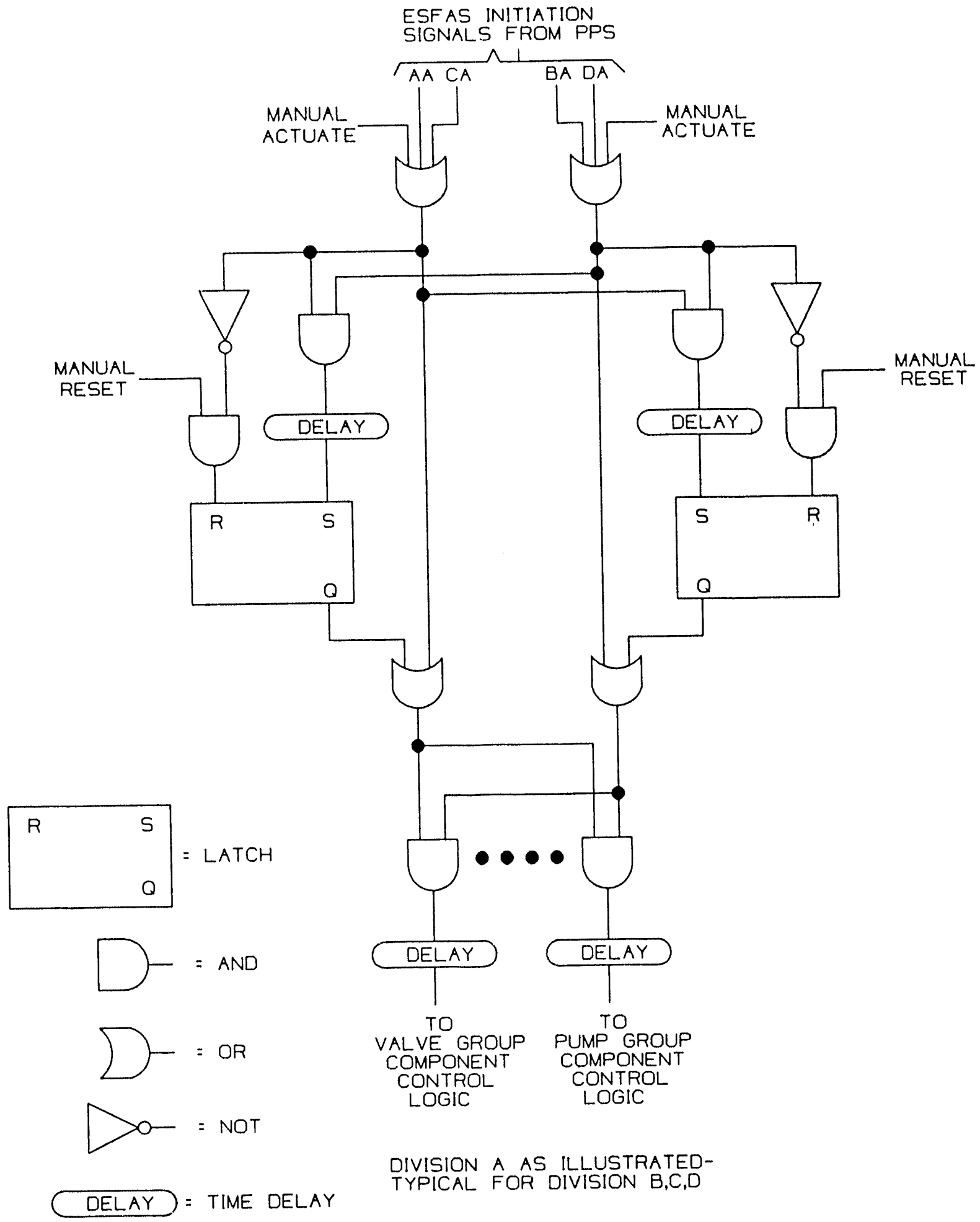

Amendment I

December 21, 1990 


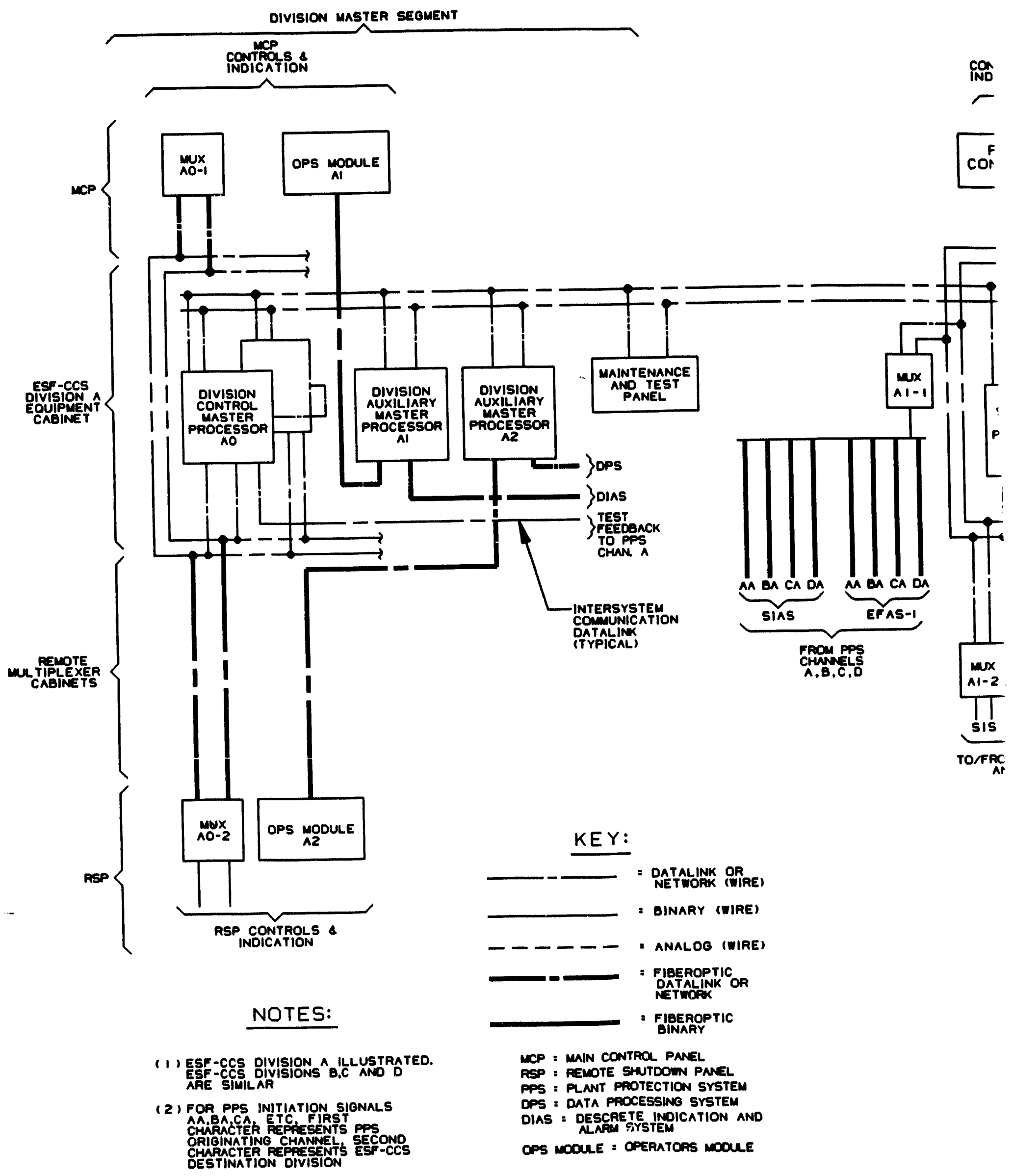




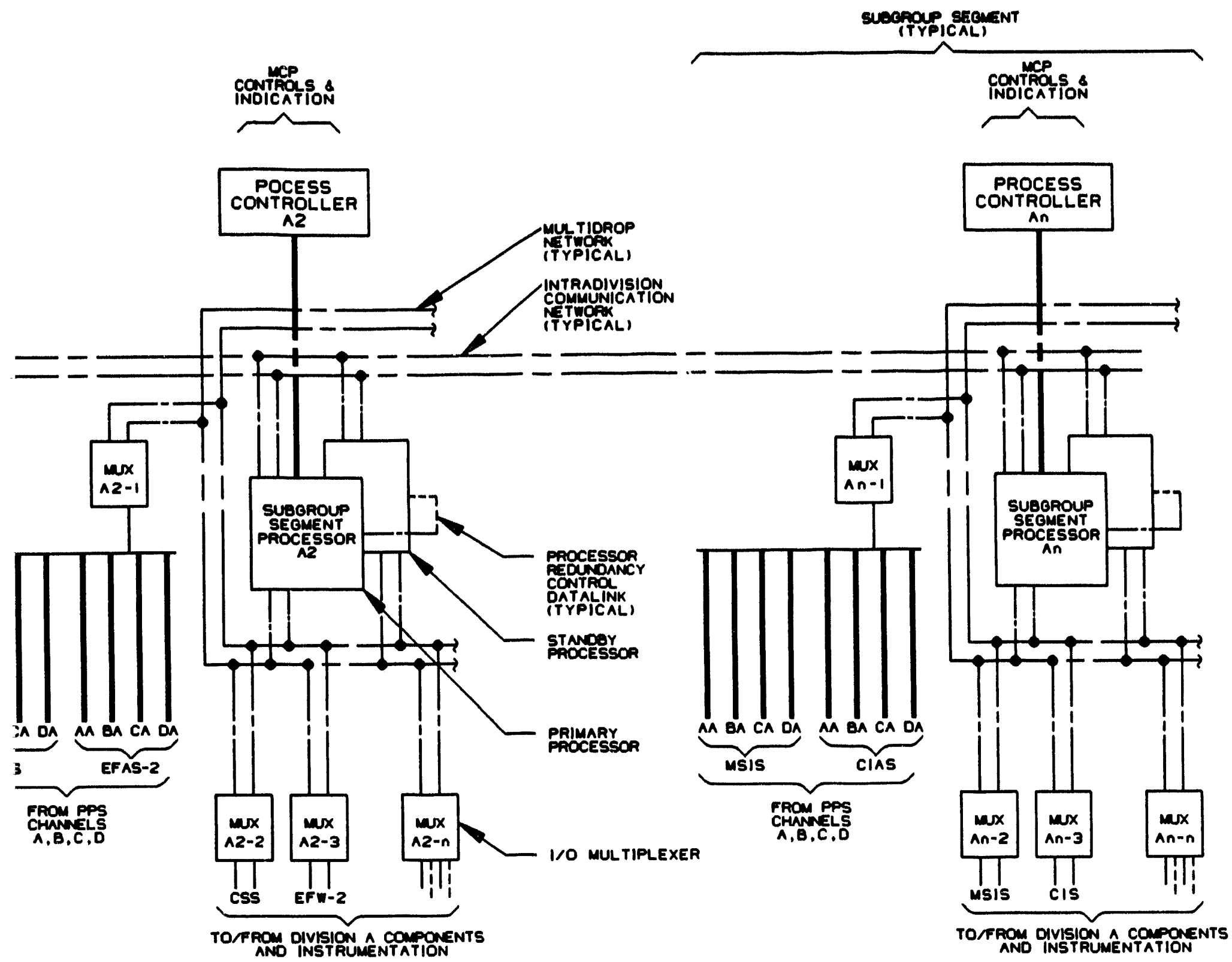

Amendment I

December 21, 1990

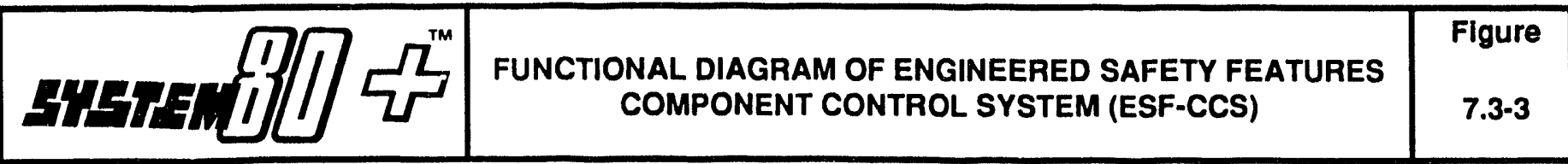




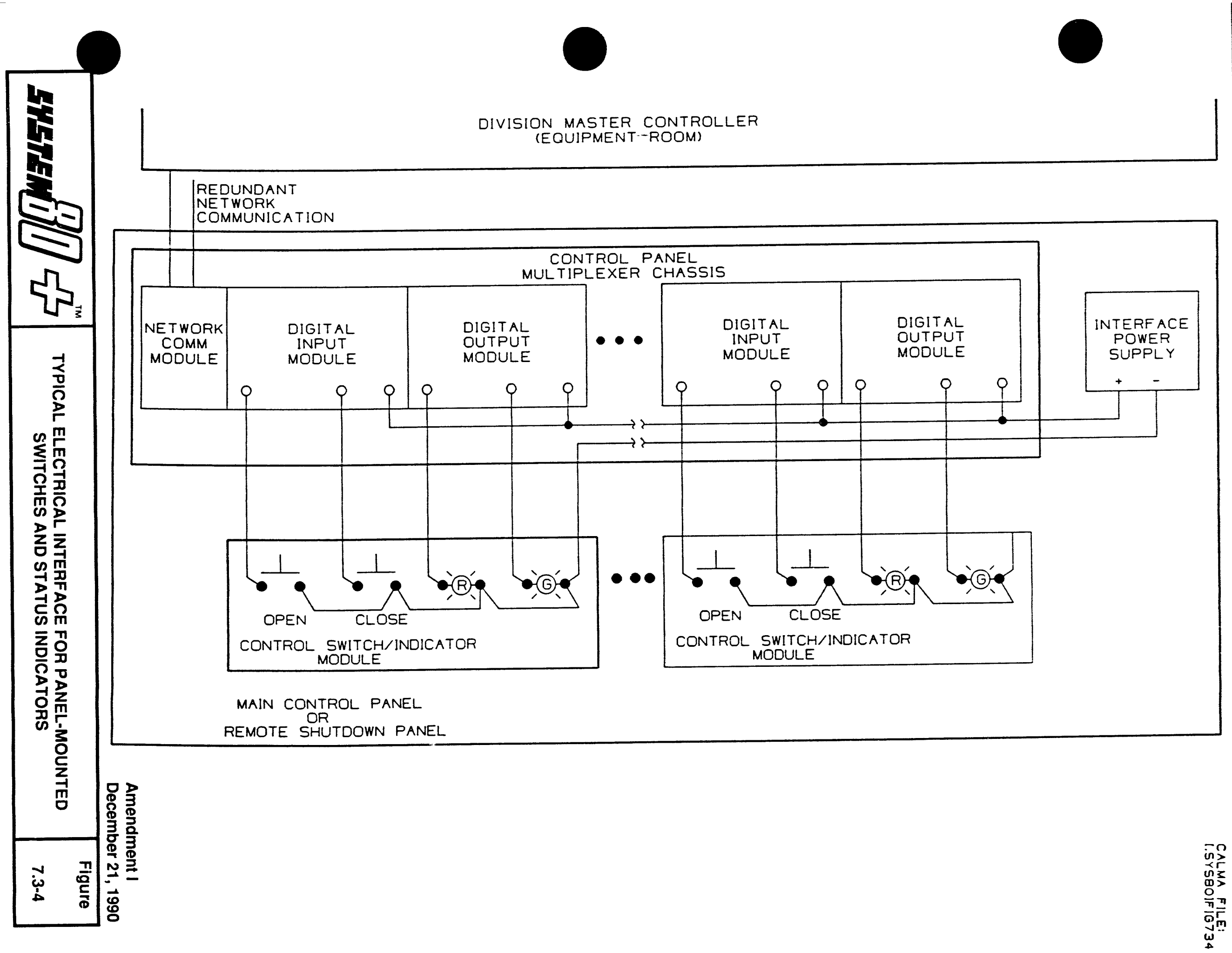




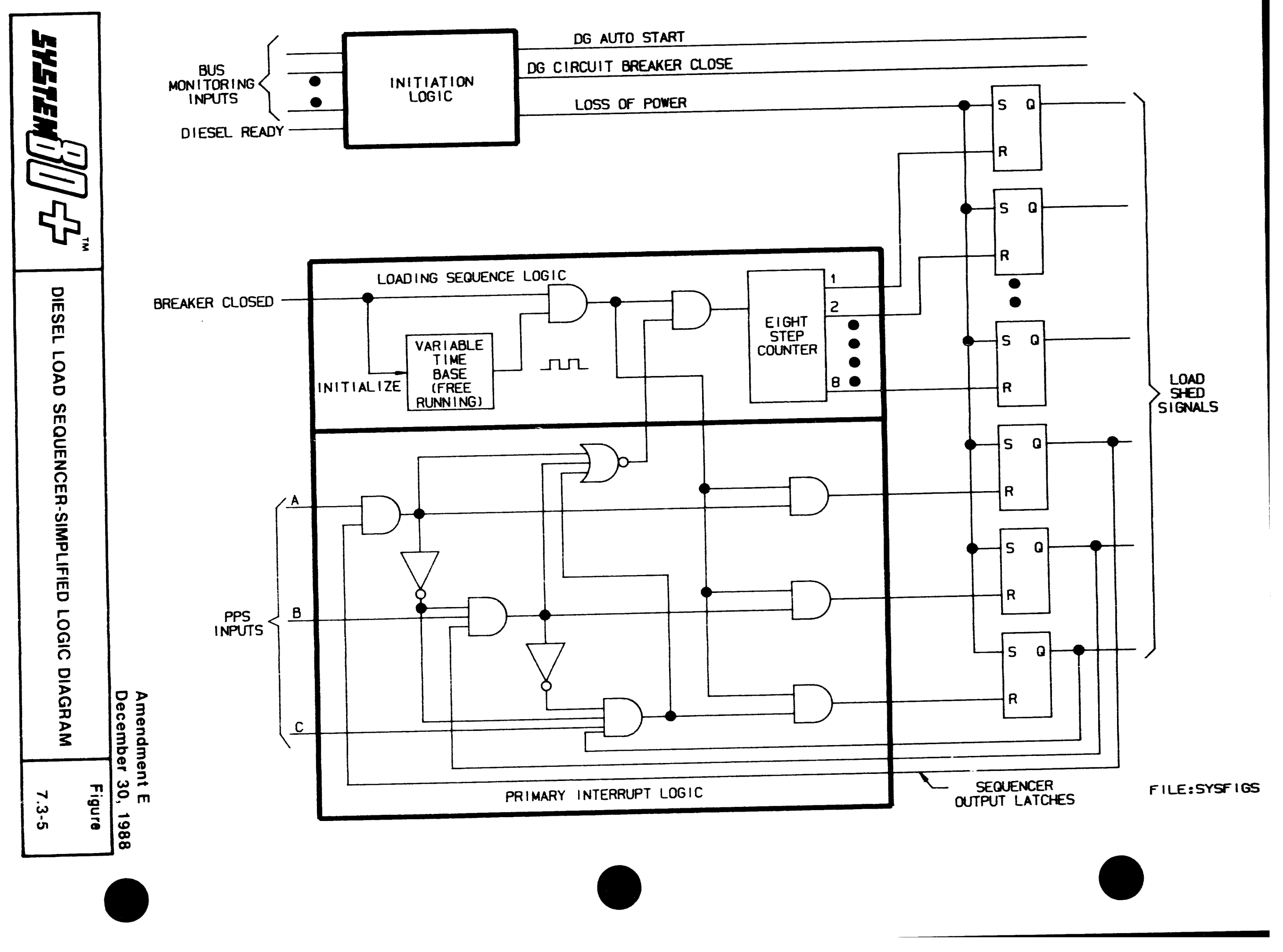




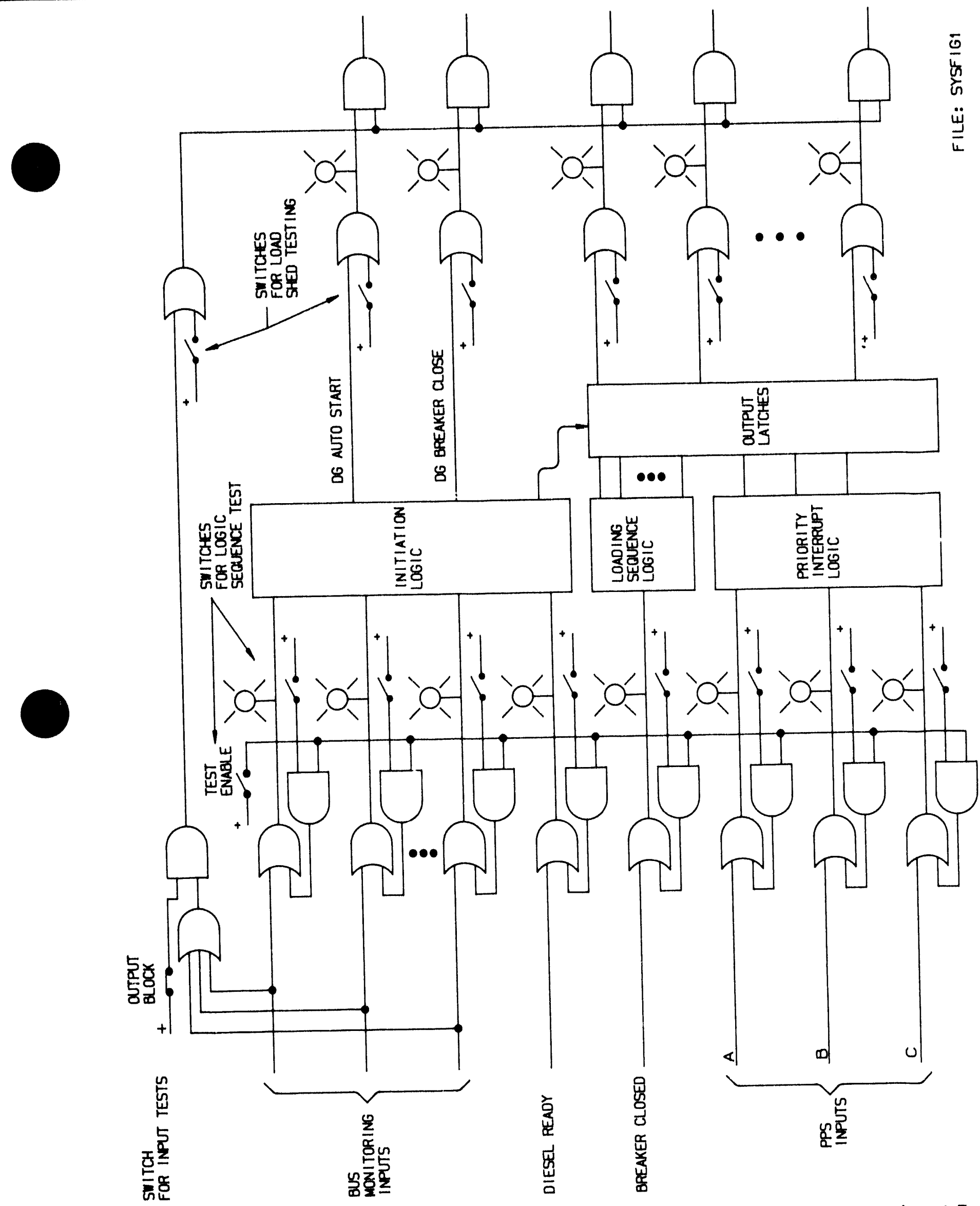

Amendment $\mathrm{E}$

December 30, 1988 


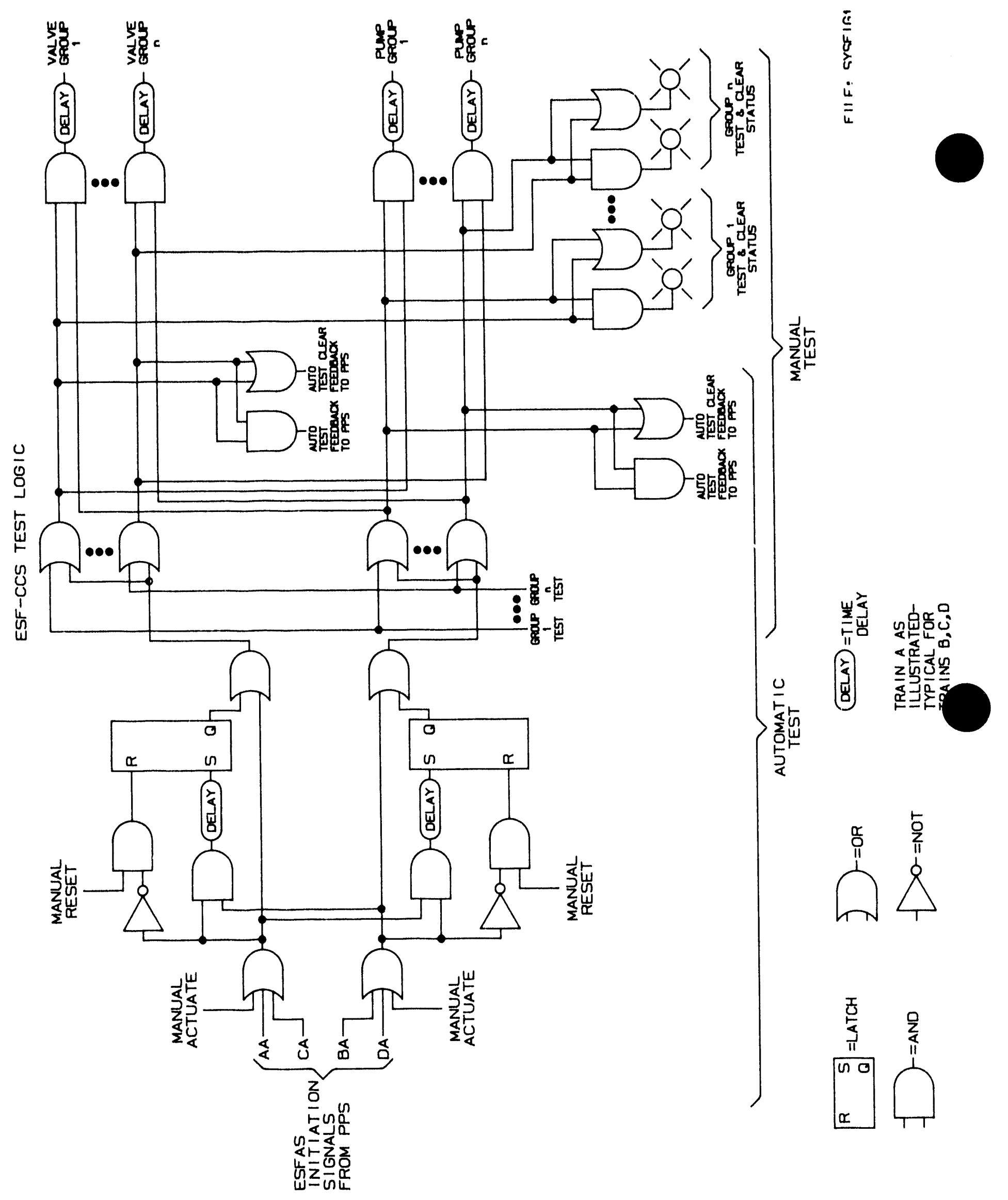

Amendment $\mathrm{E}$

December 30, 1988 


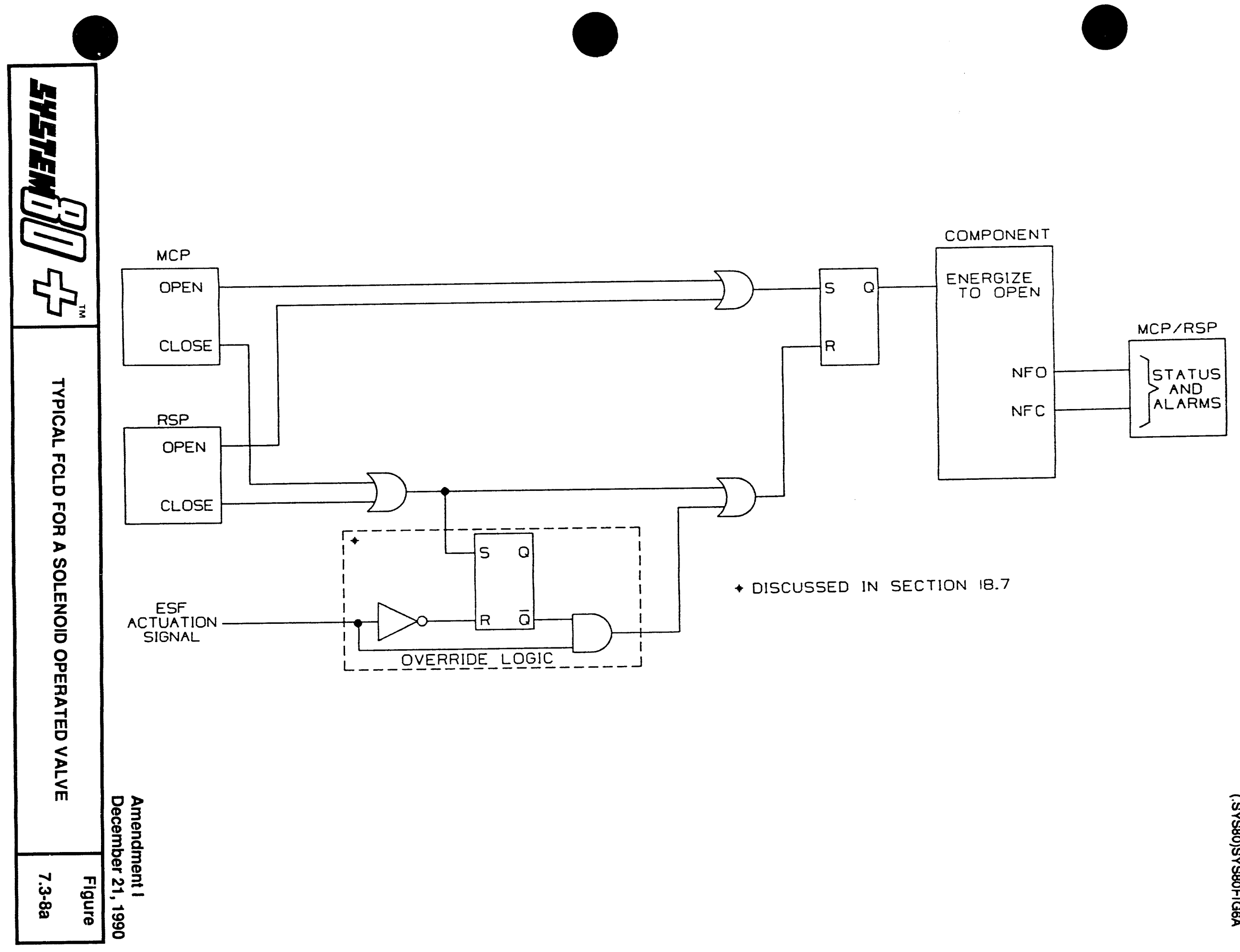




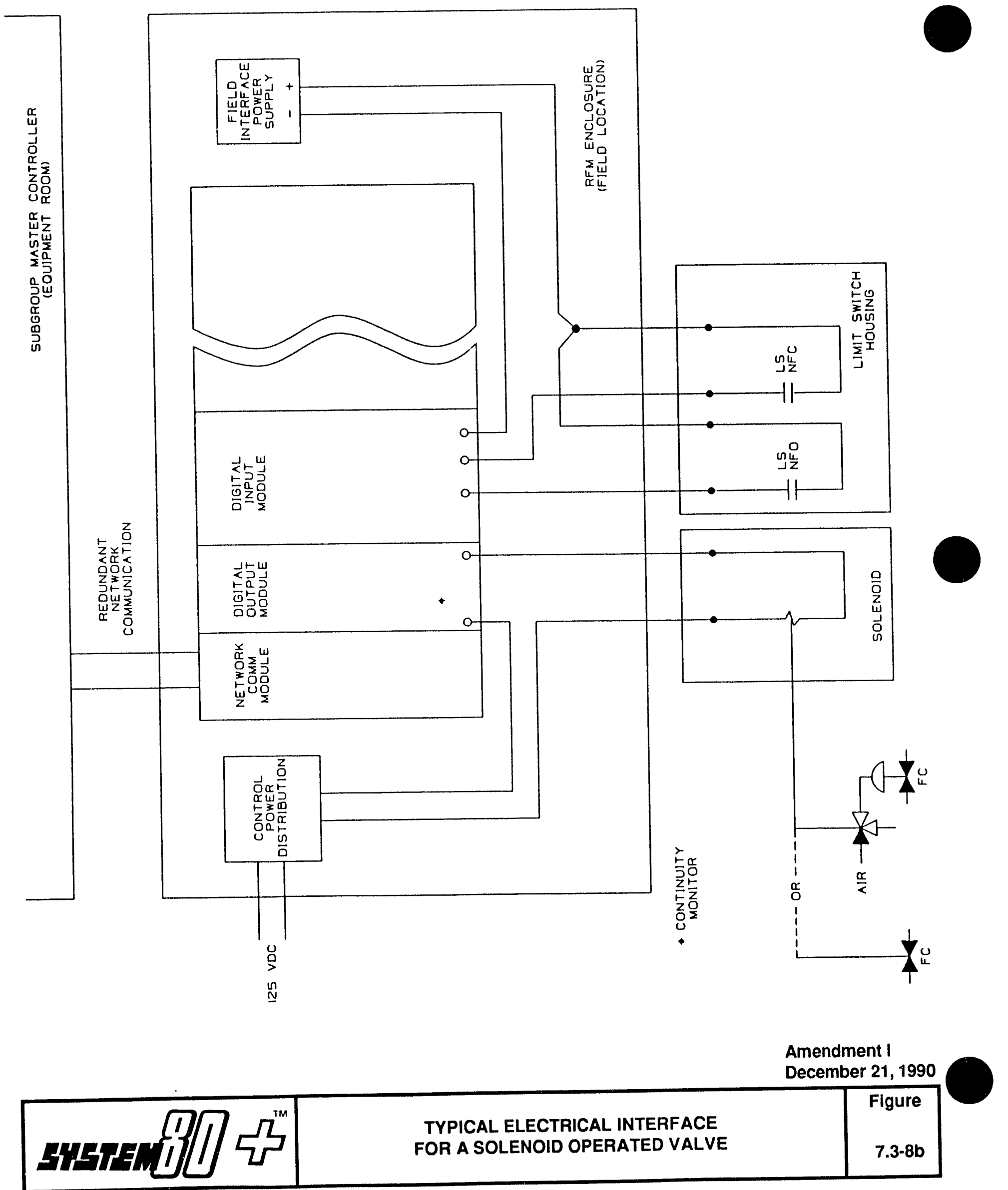




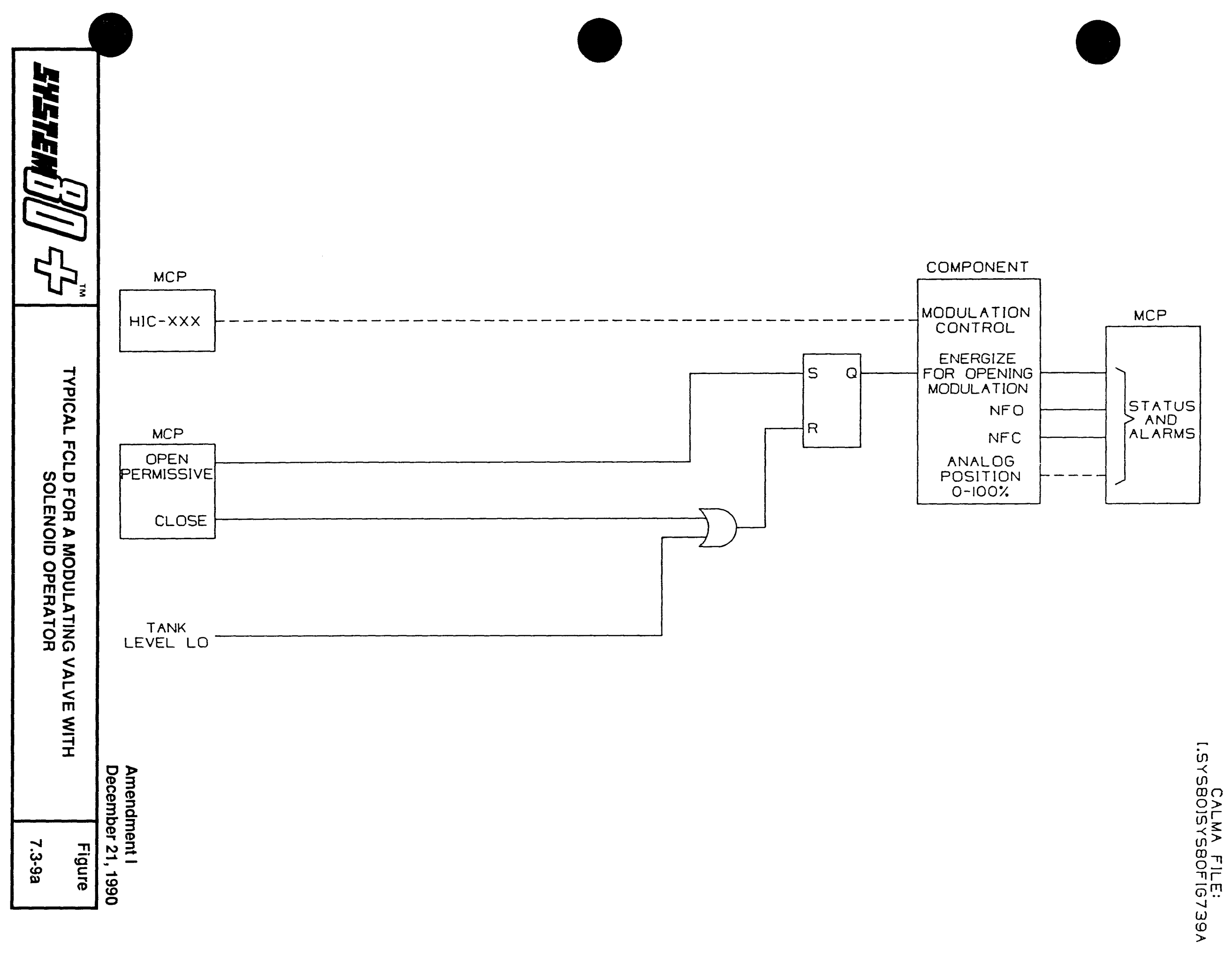




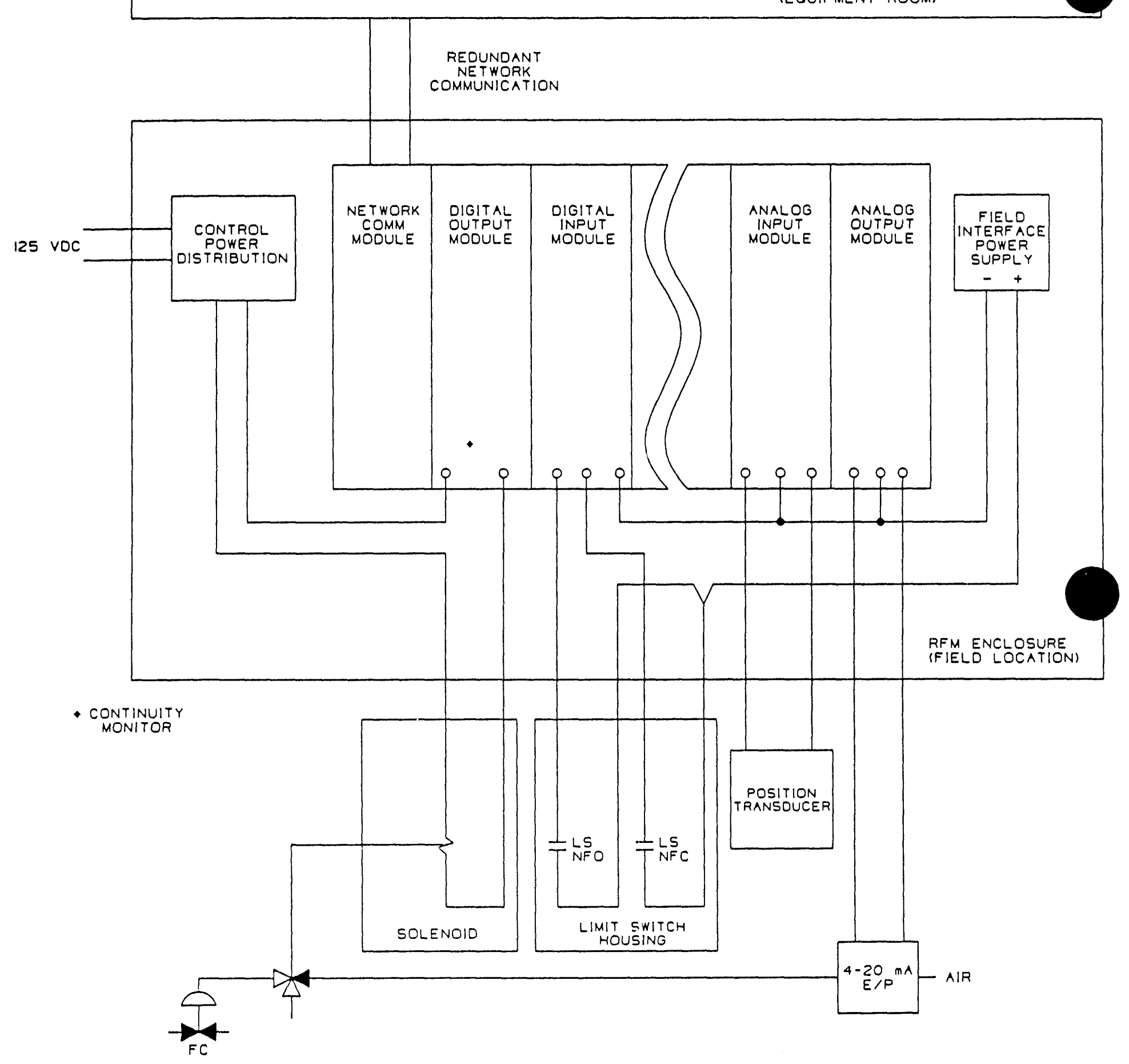

Amendment I

December 21, 199 
CALMA FILE:

[.SYSBO]FIG $7310 A$
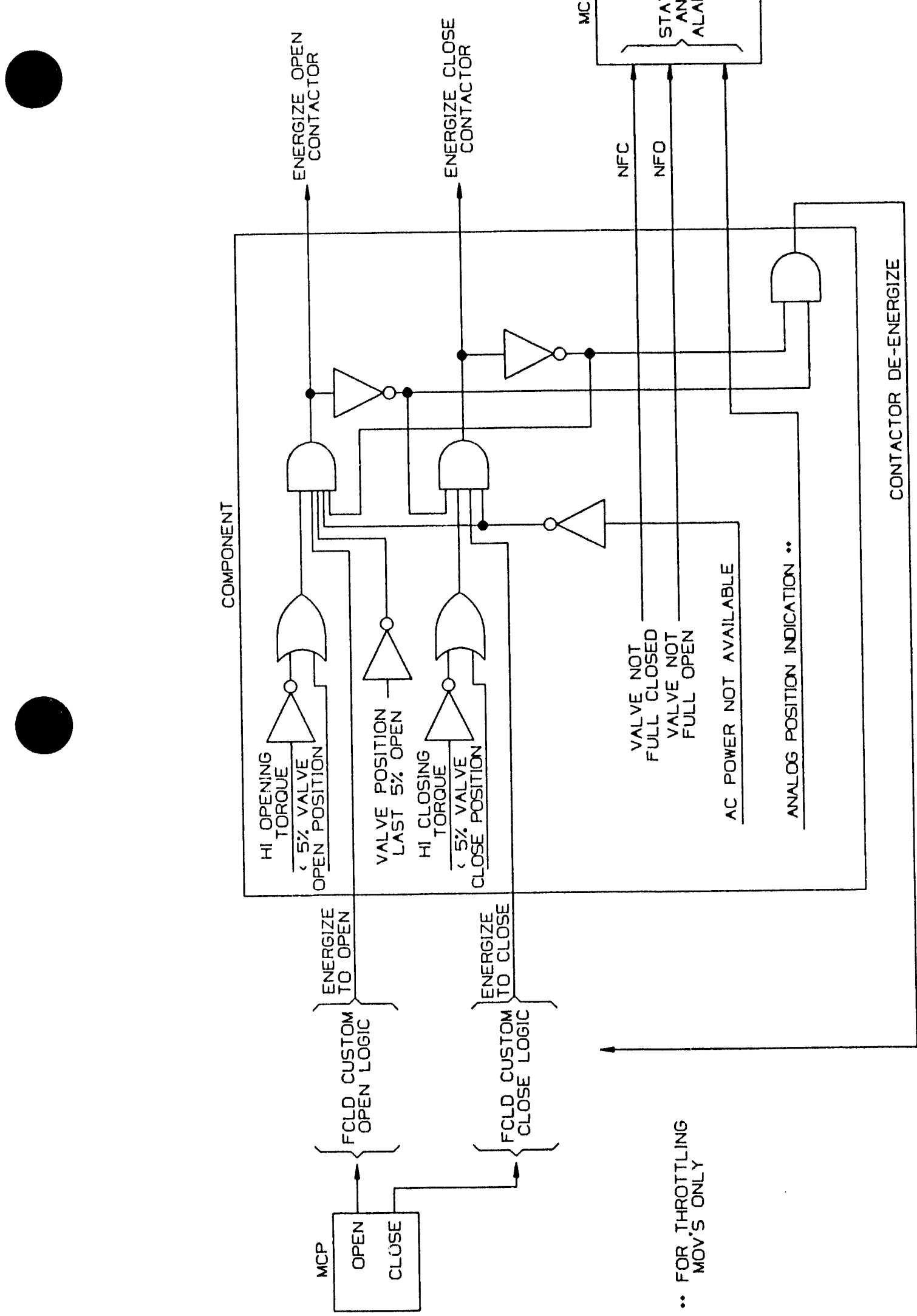

Amendment I

December 21, 1990 


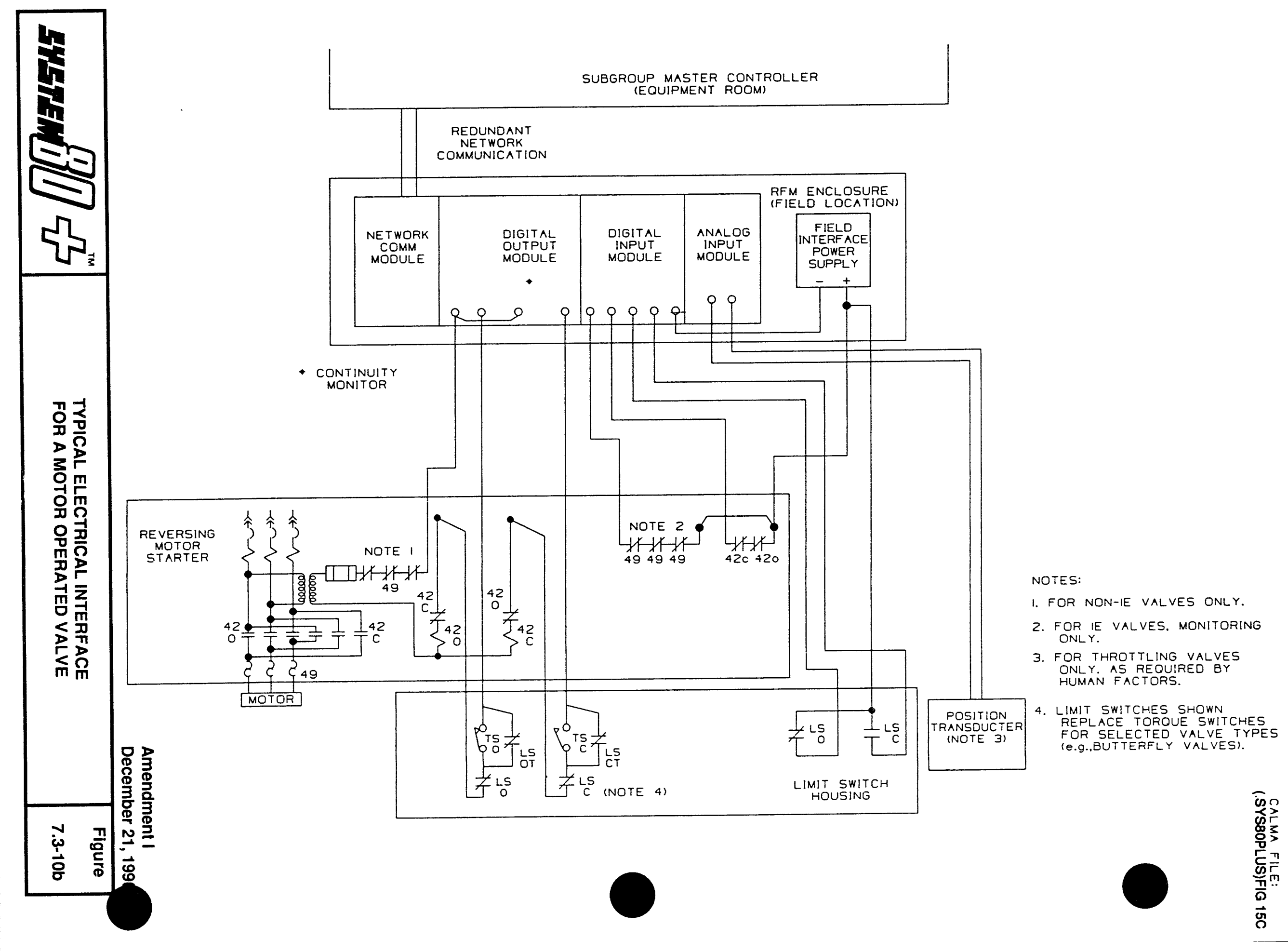




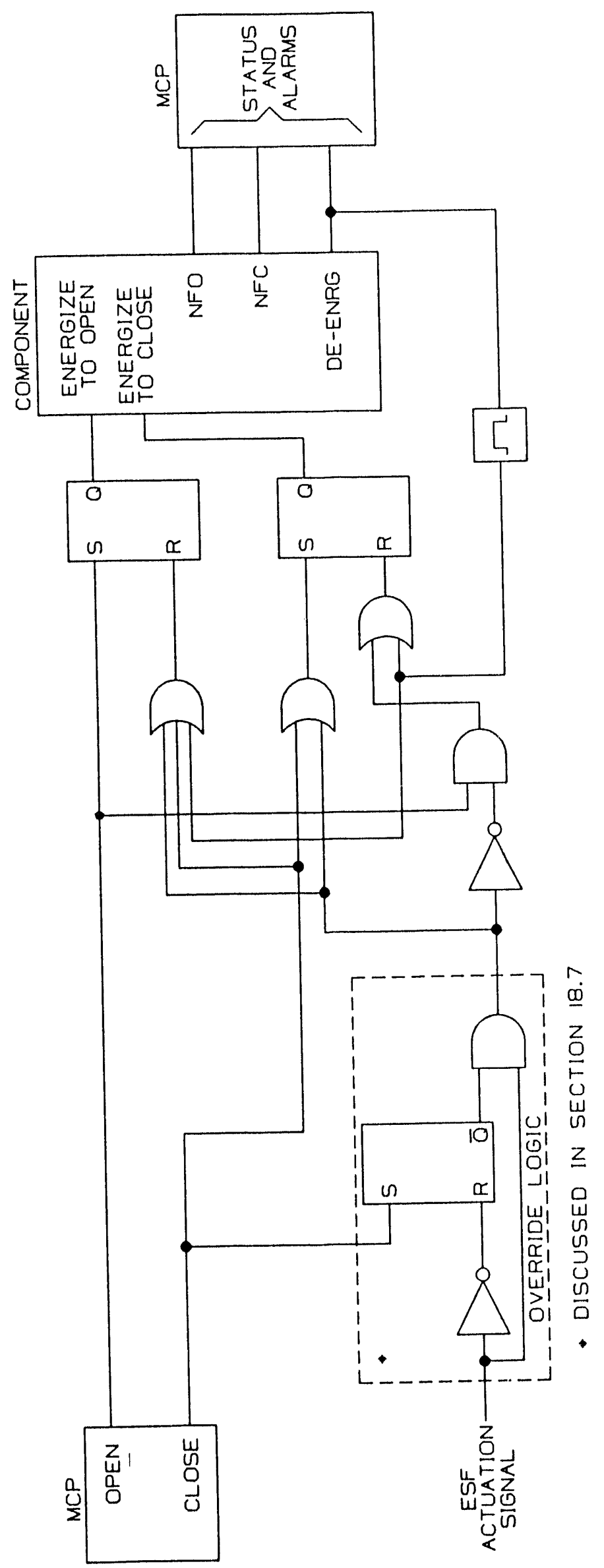




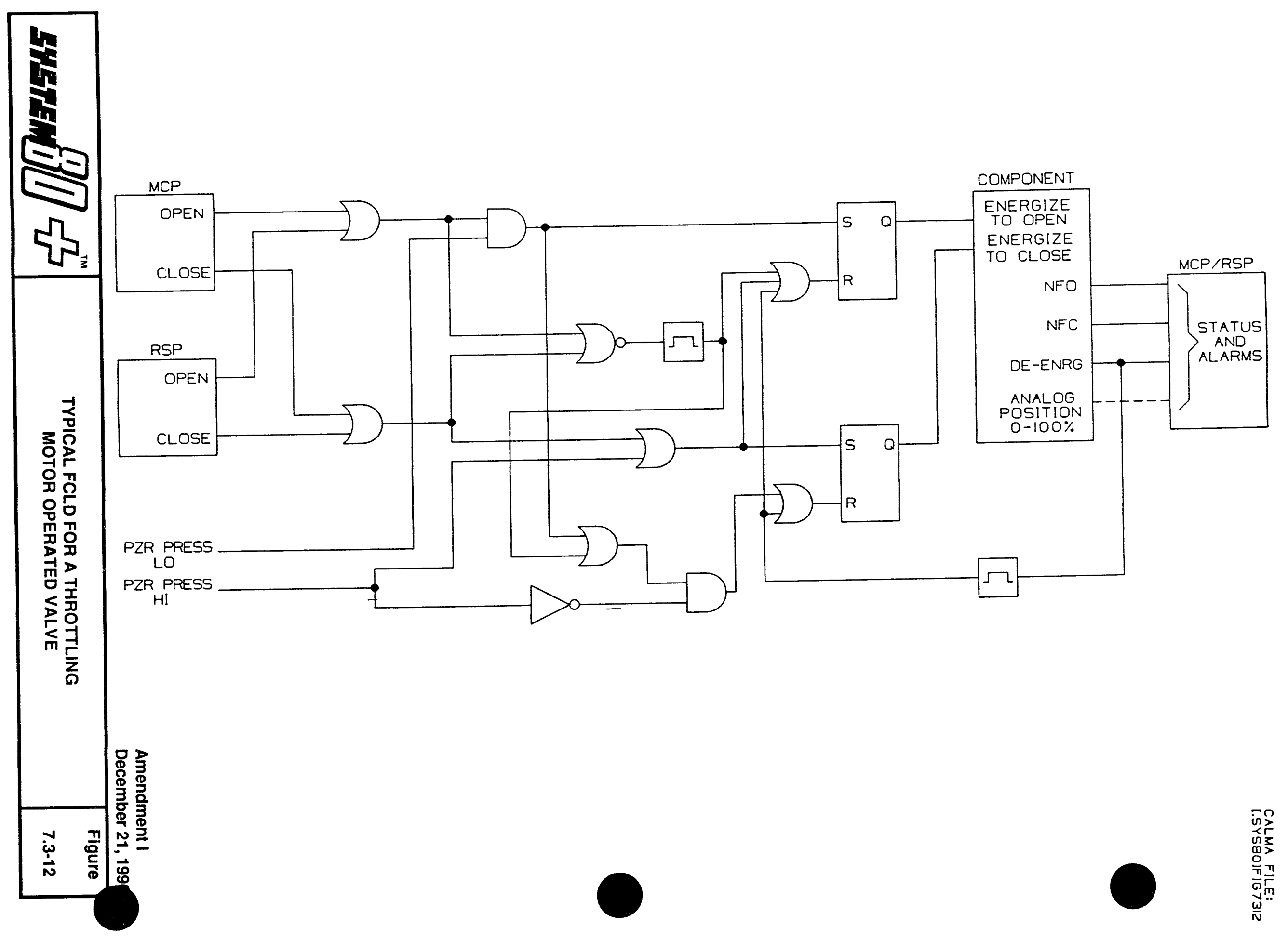




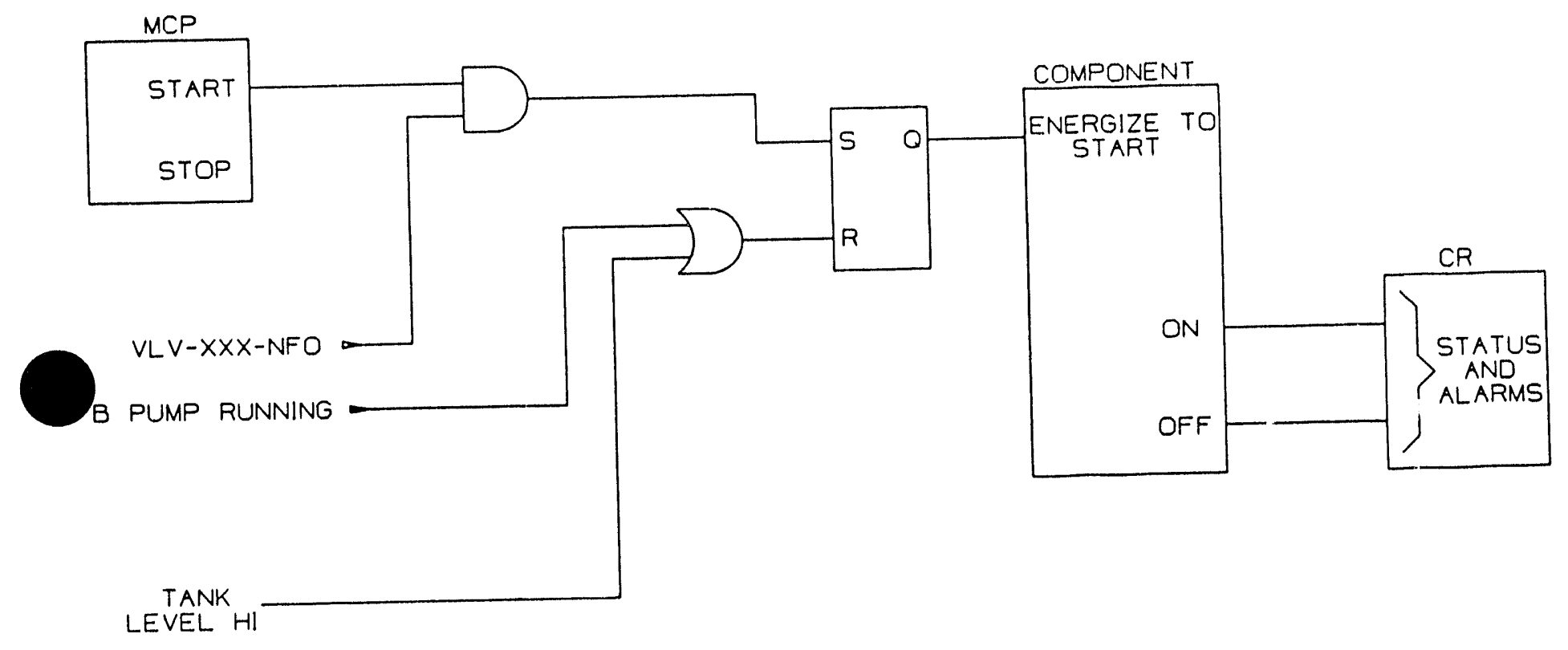




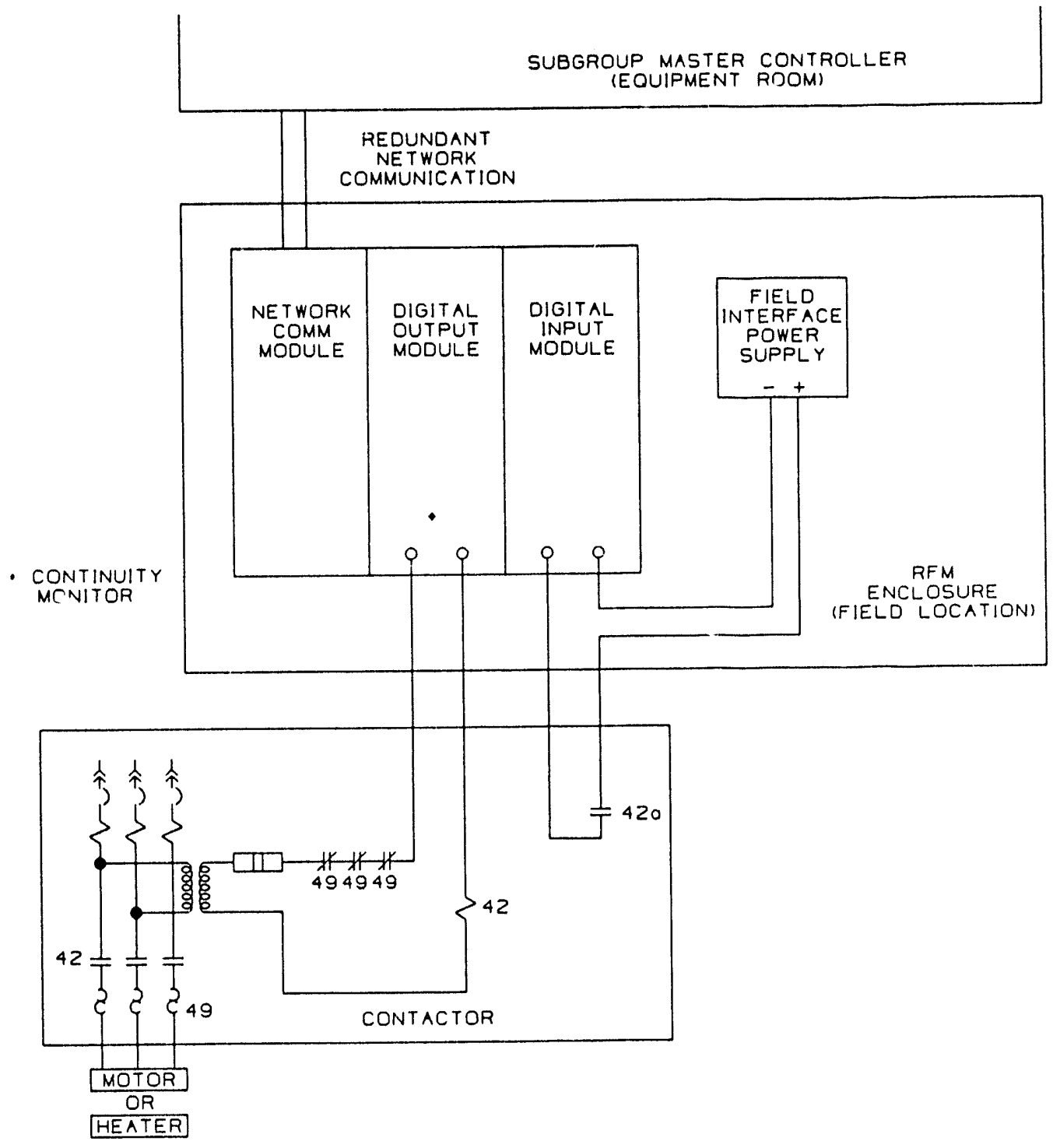

Amendment I

December 21, 199 

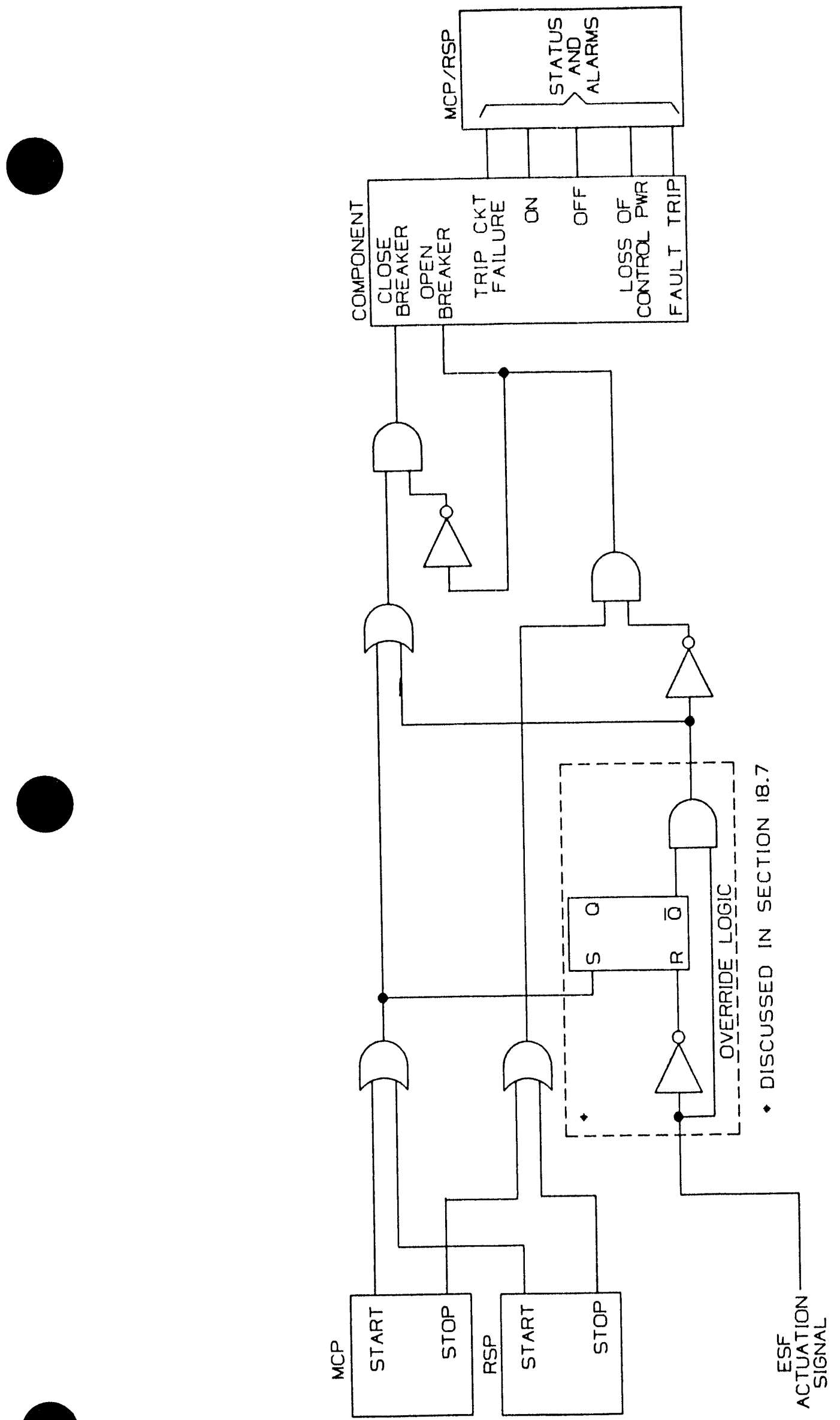

Amendment I

December 21, 1990 


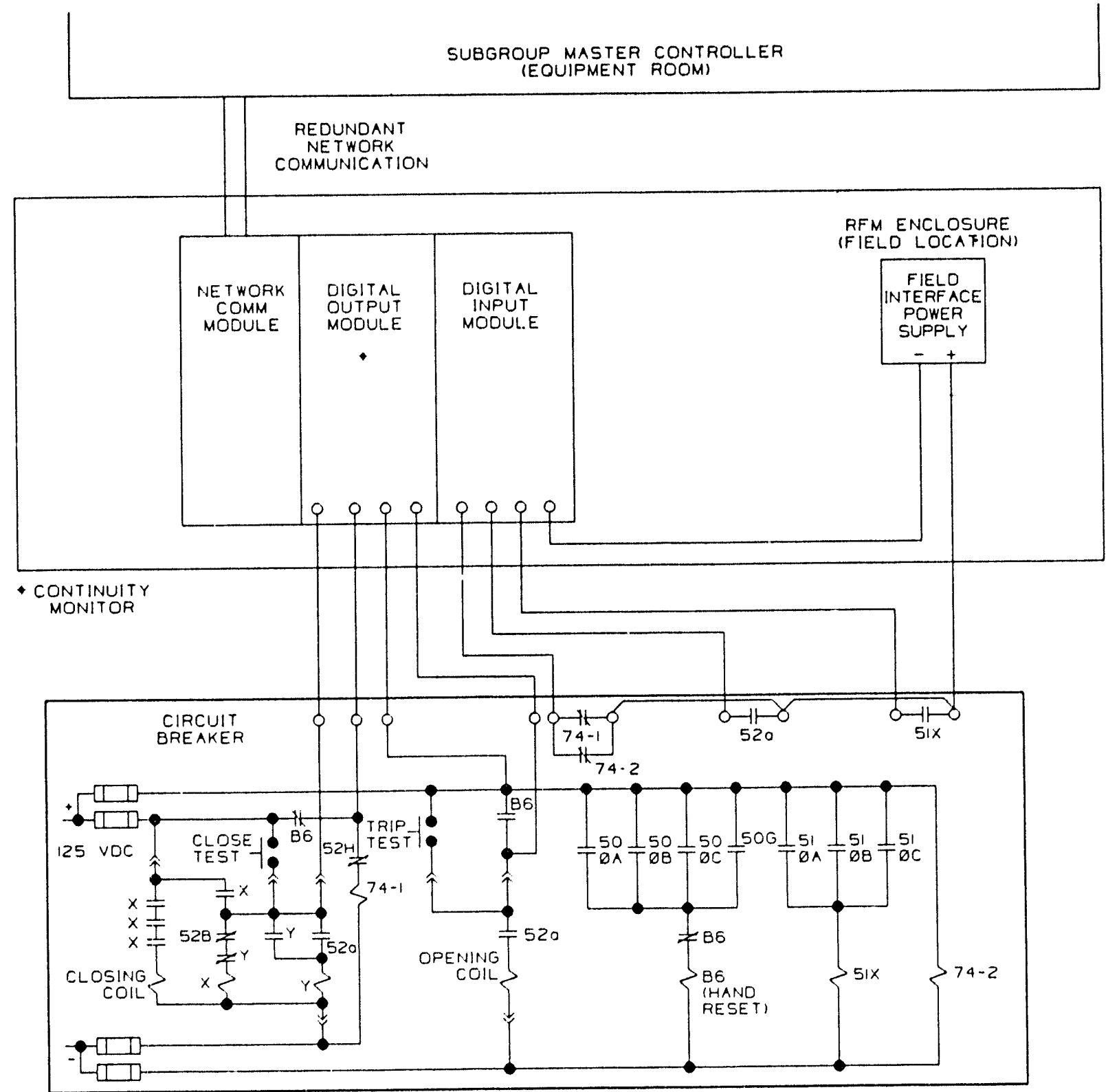

Amendment I

December 21, 1990 
CALMA FILE:

I.SYSBOISYSBOFIGI3A

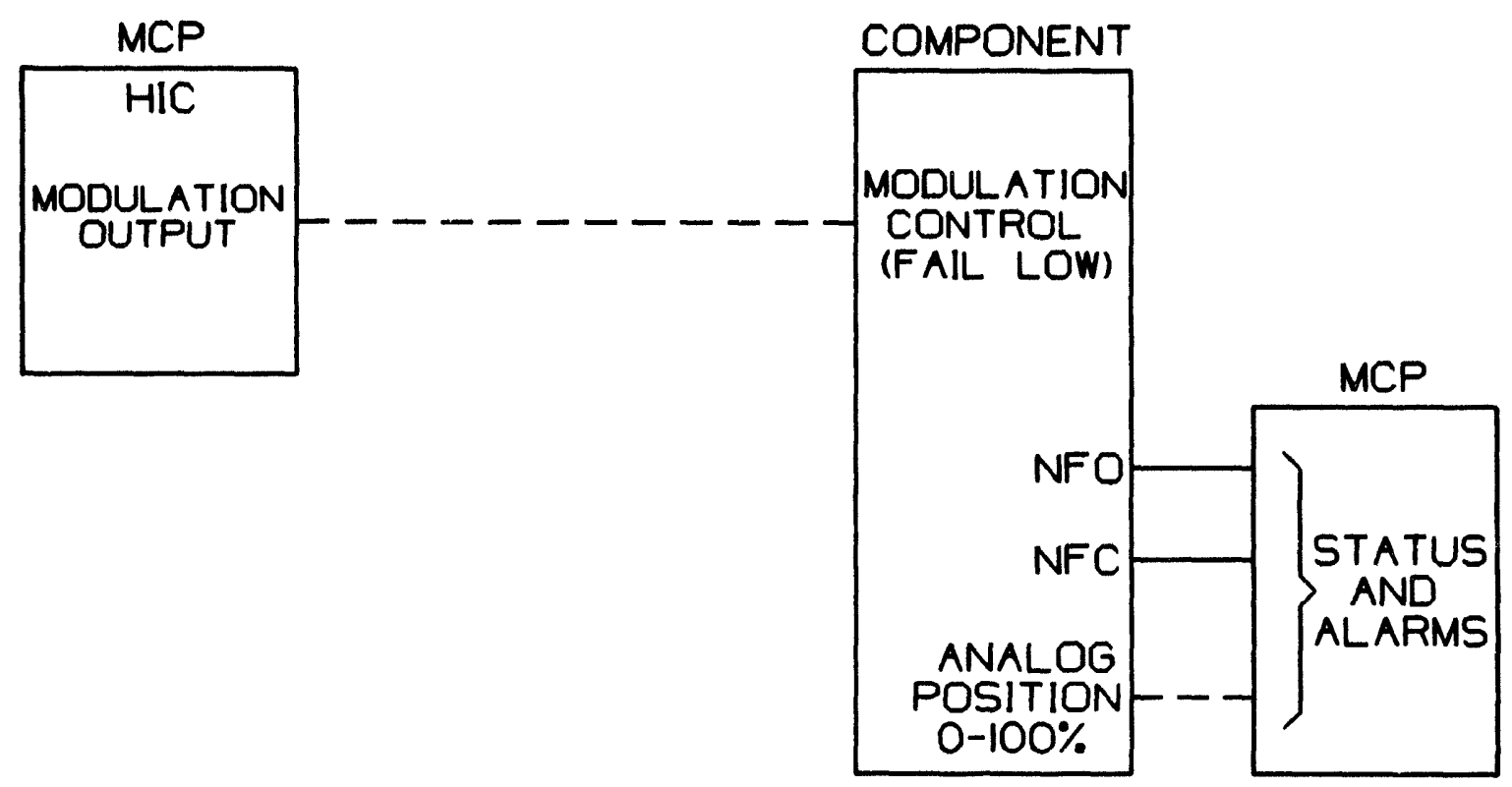

Amendment I

December 21, 1990 


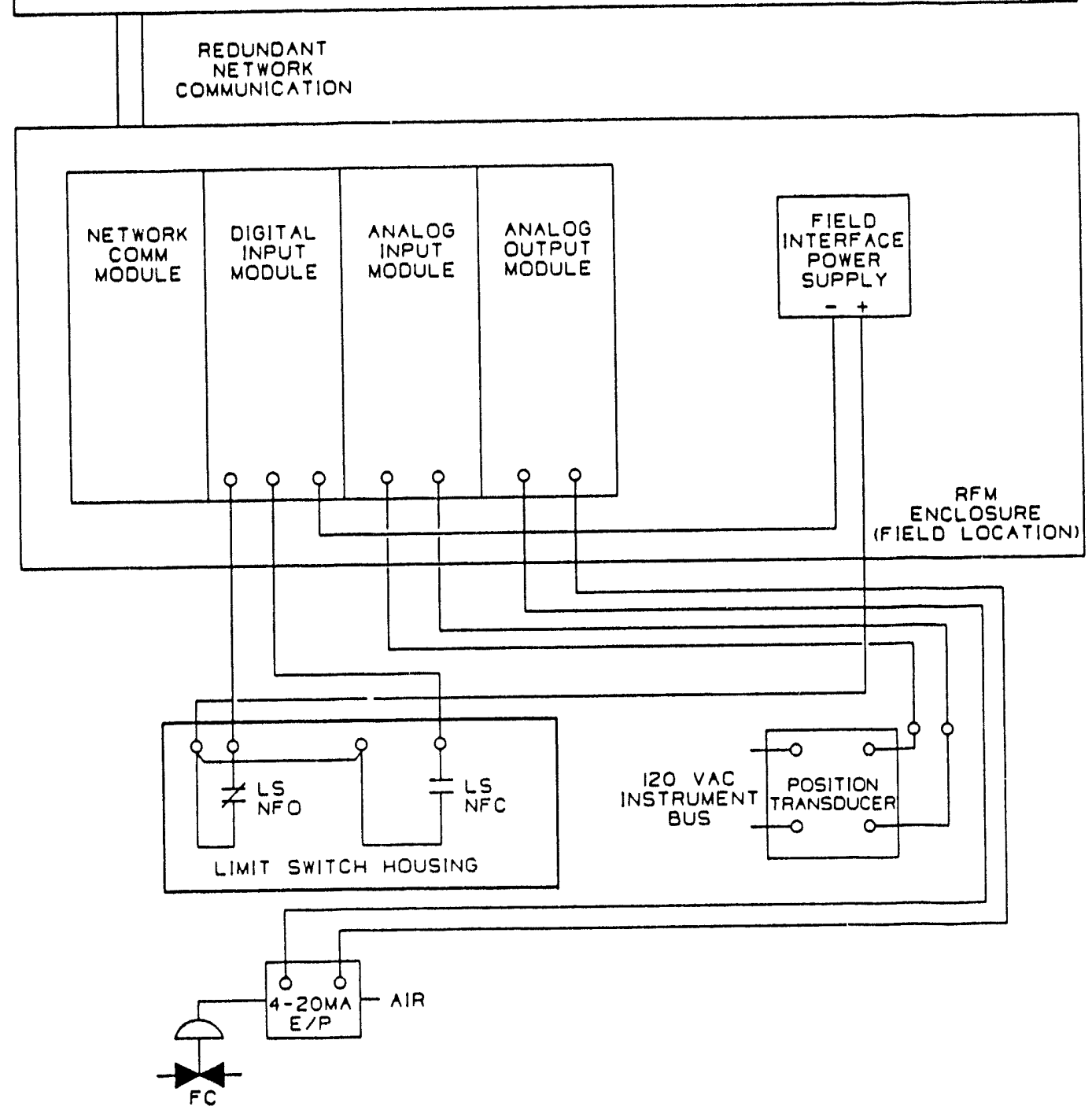

Amendment I

December 21, 1990 


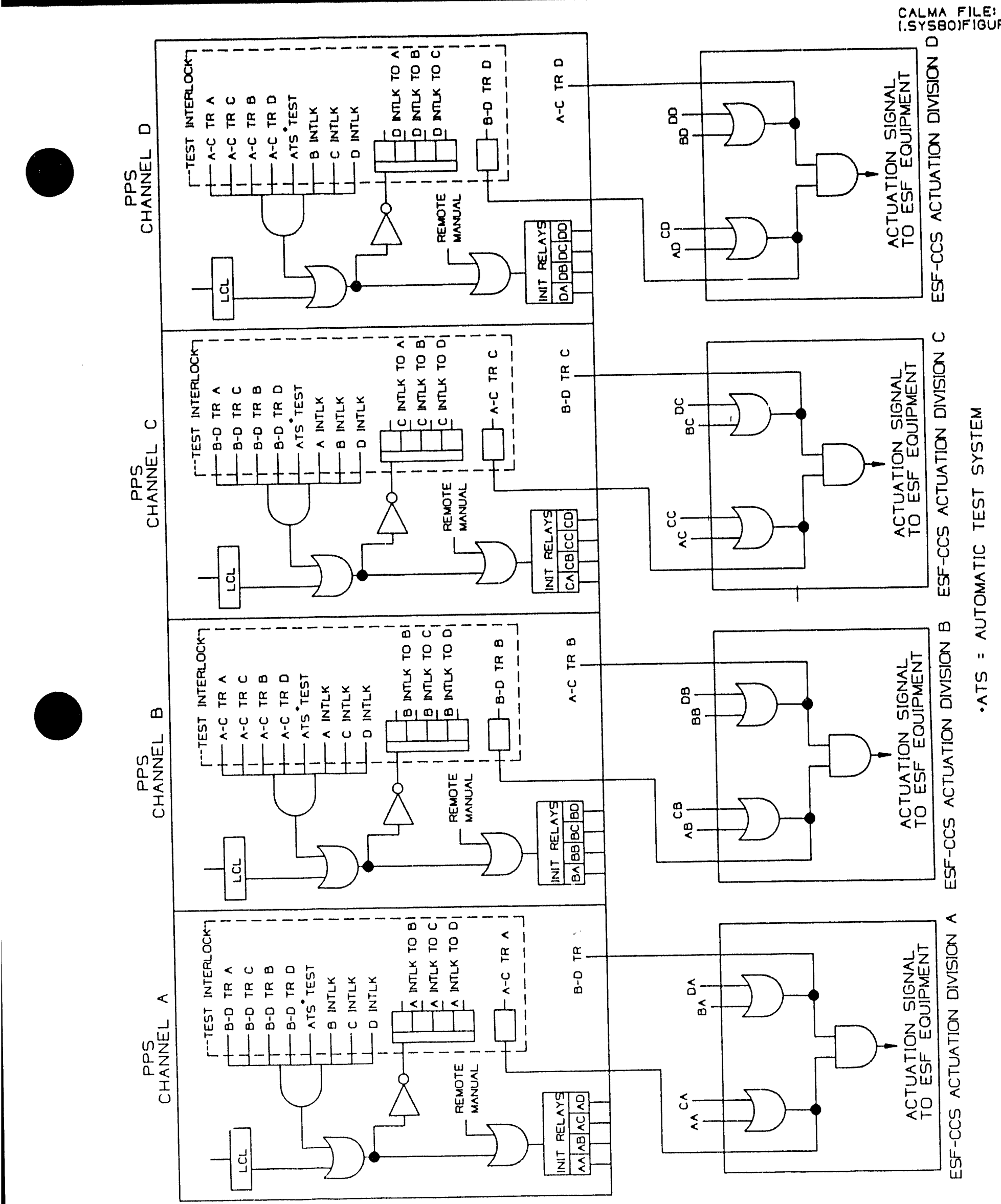

Amendment I

December 21, 1990 


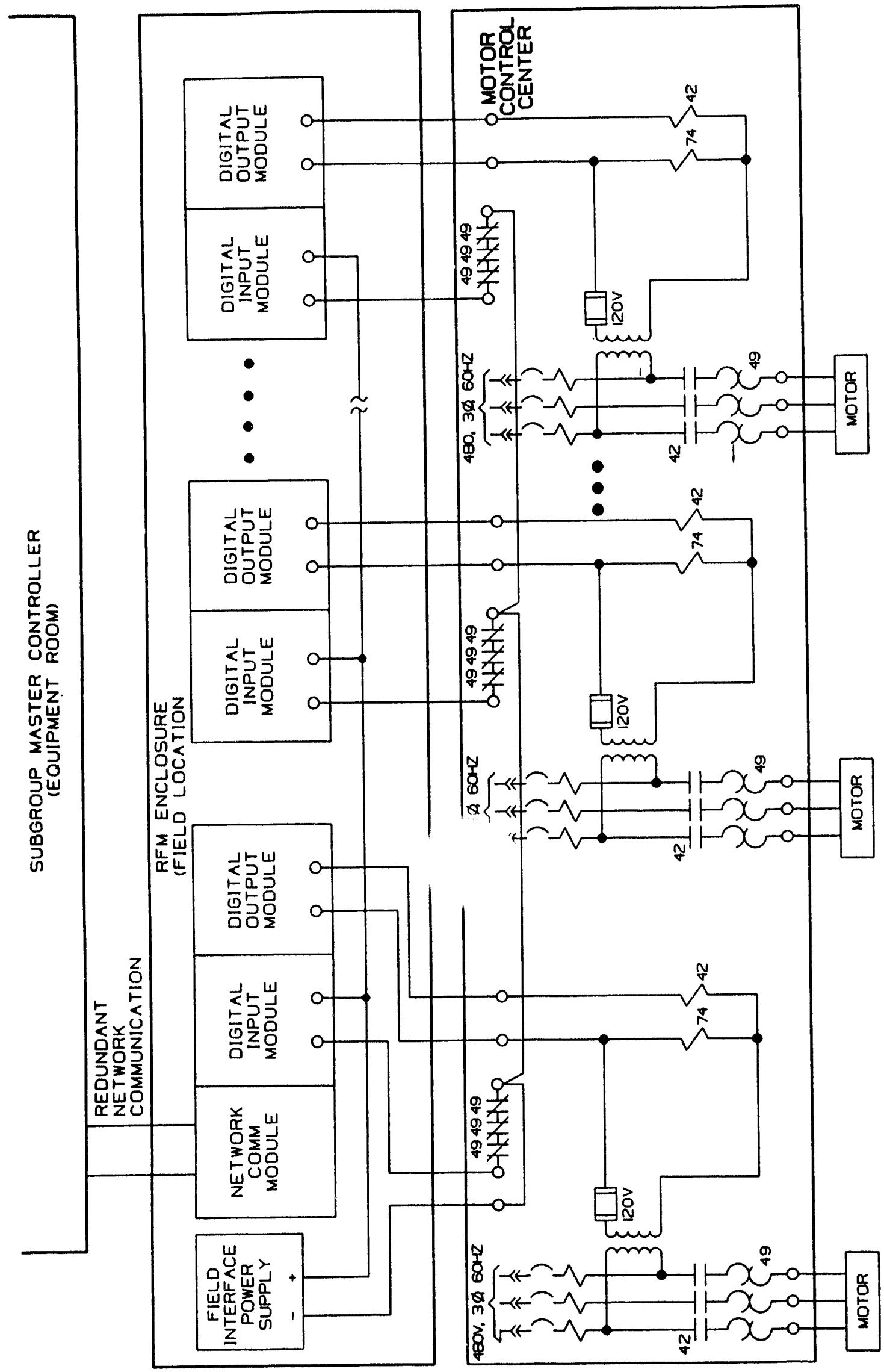




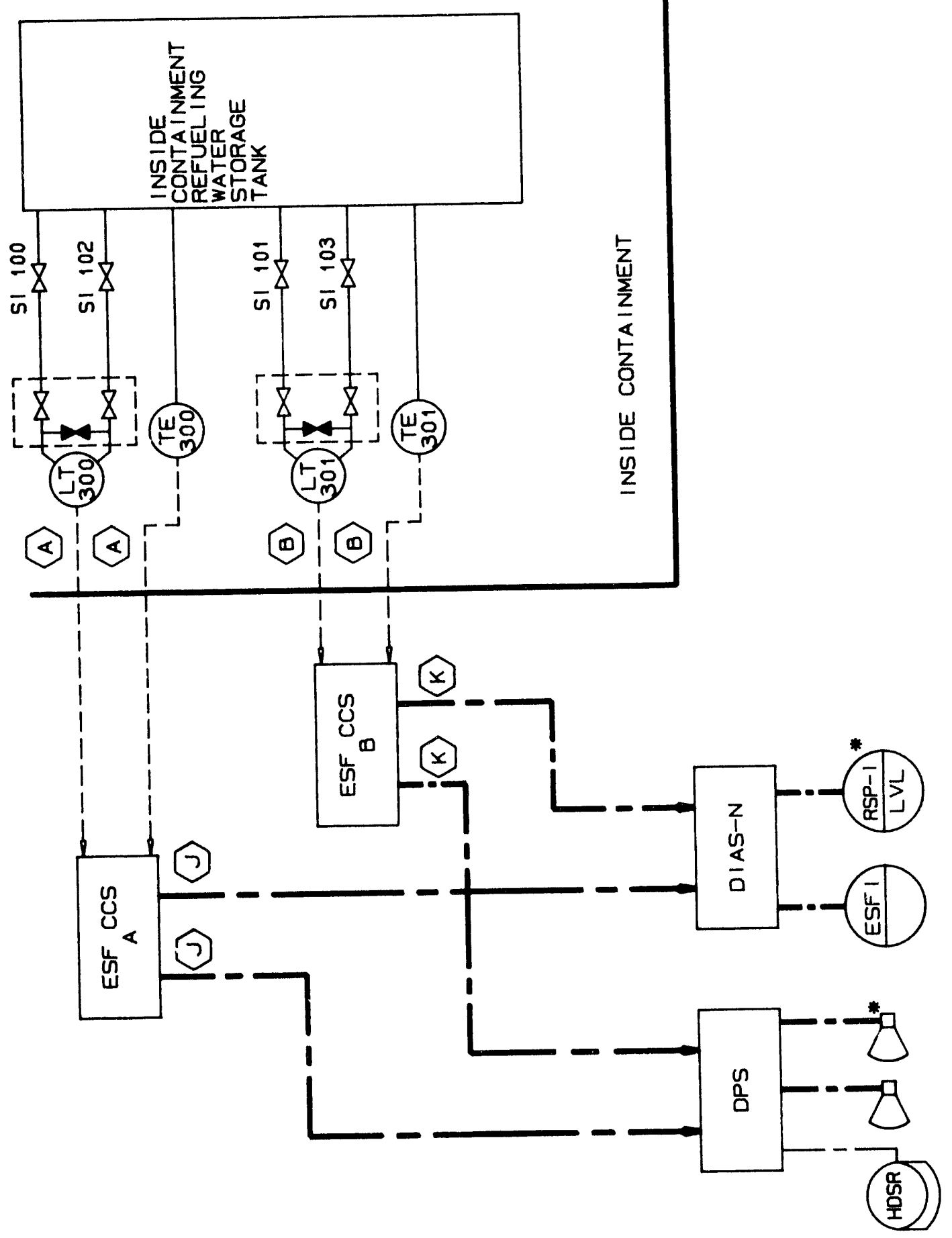

Amendment E December 30, 1988 


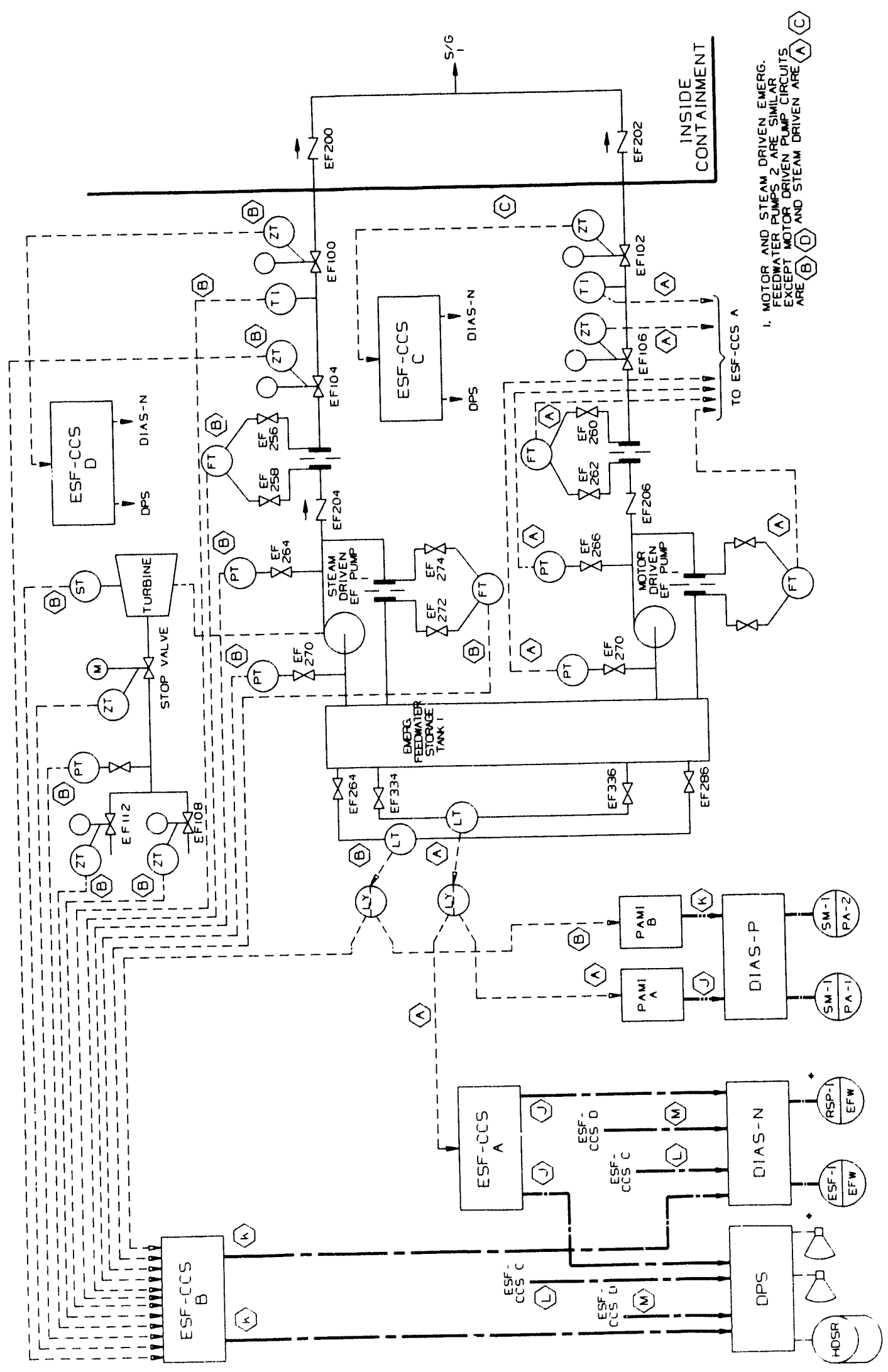

Amendment I

December 21, 1990 


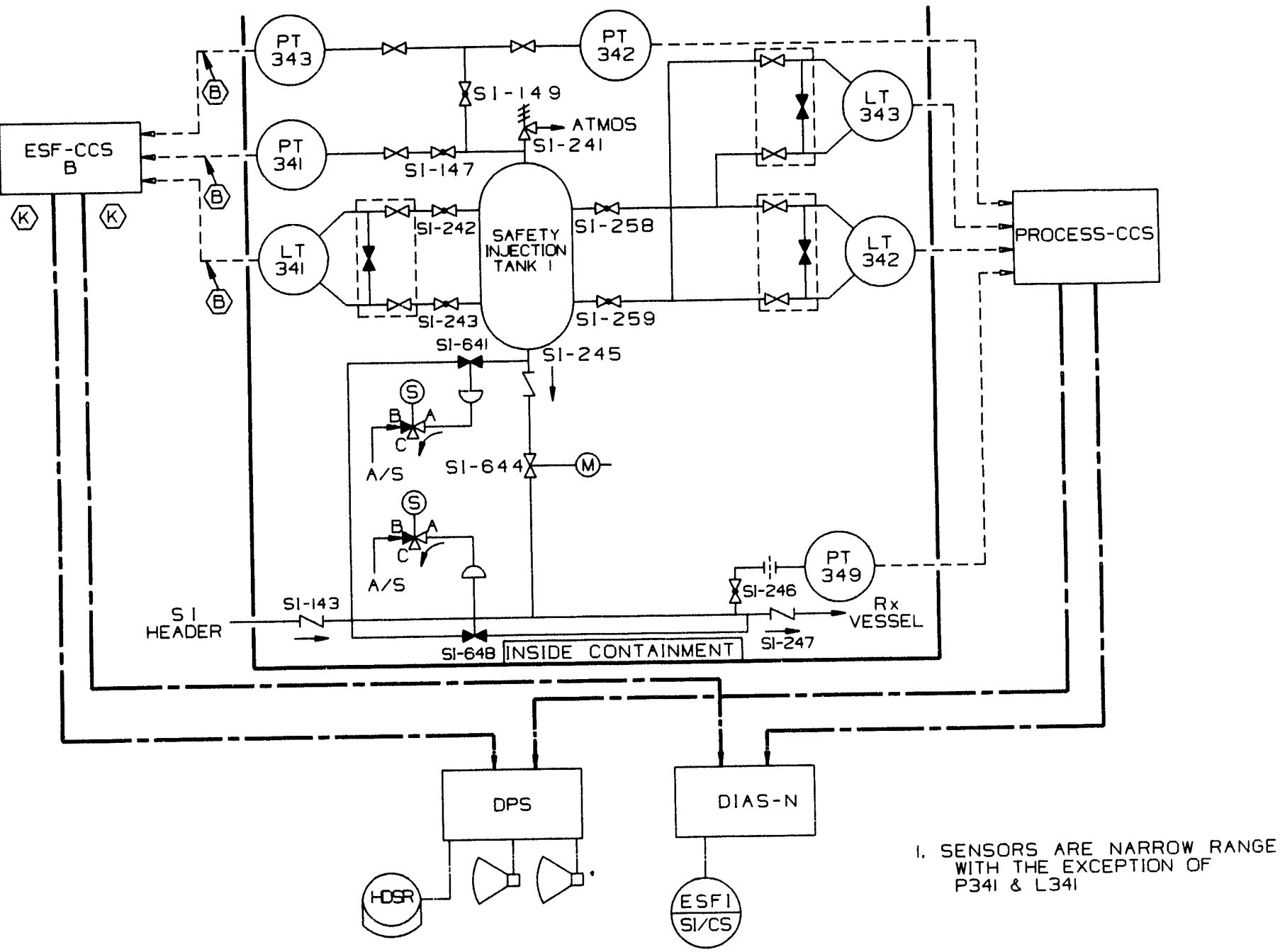

Amendment 1

December 21, 1990 


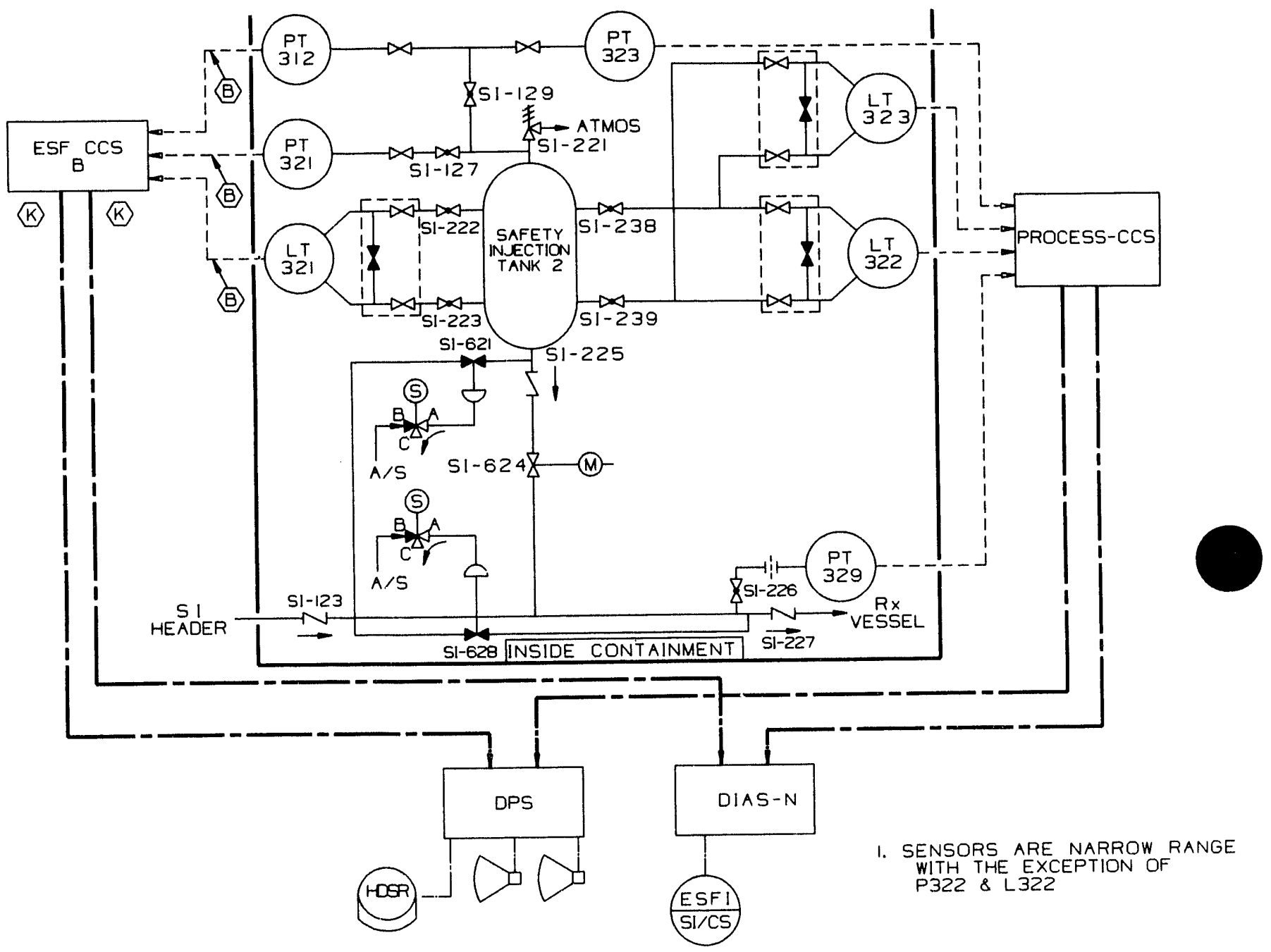

Amendment I

December 21, 1990 


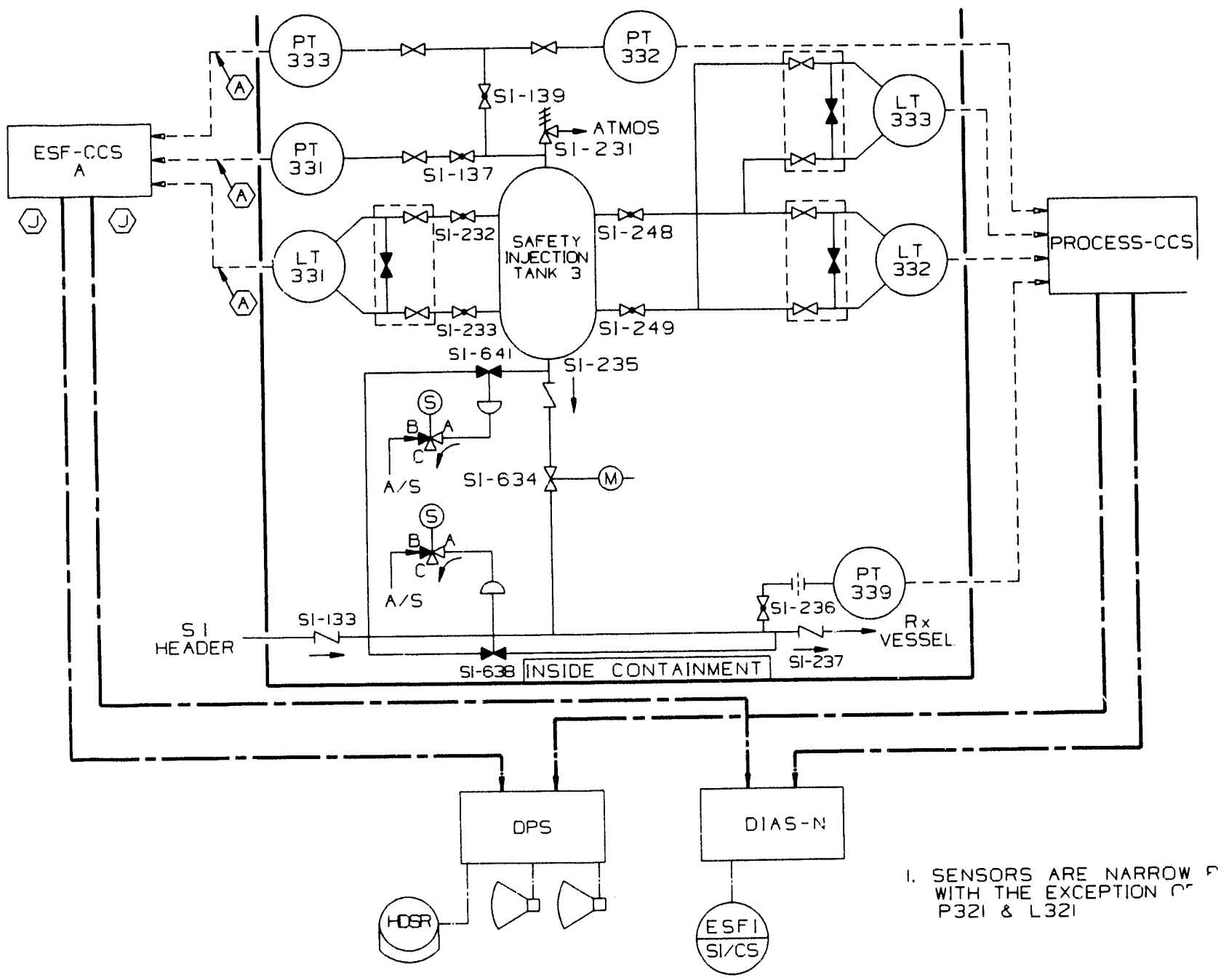

Amendment I

December 21, 1990 


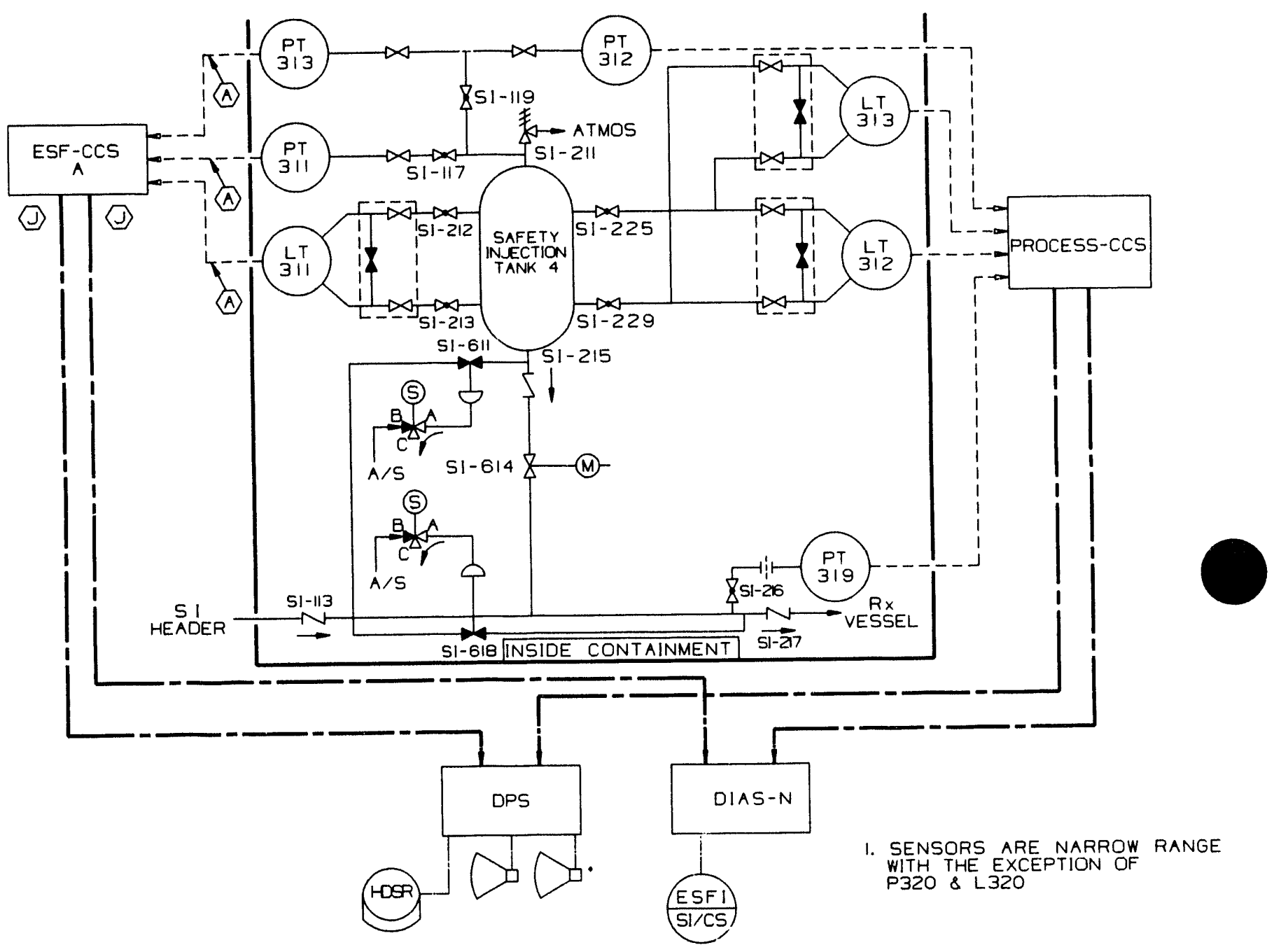

Amendment I

December 21, 1990 


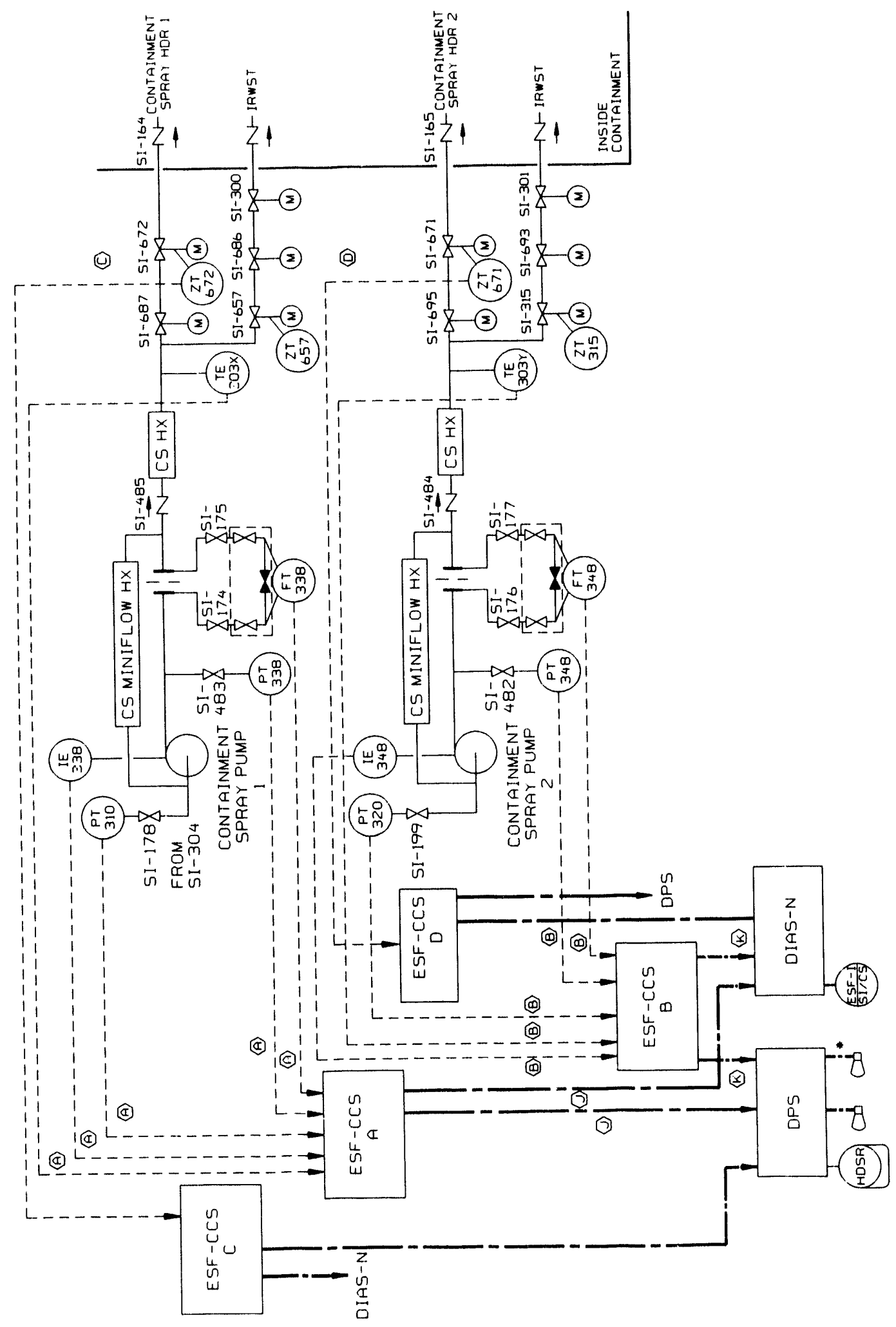

Amendment I

December 21, 1990 


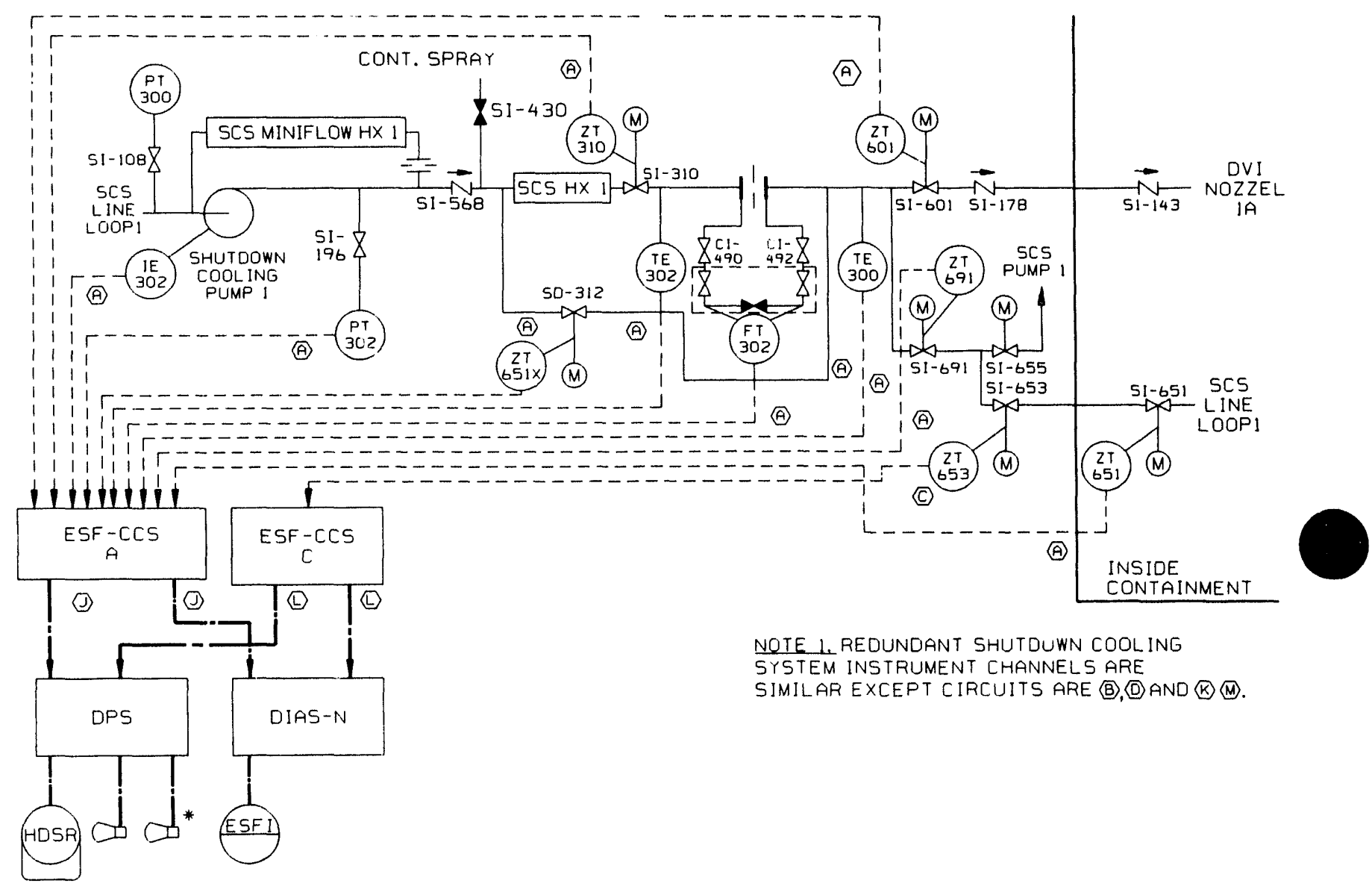

Amendment I

December 21, 1990 


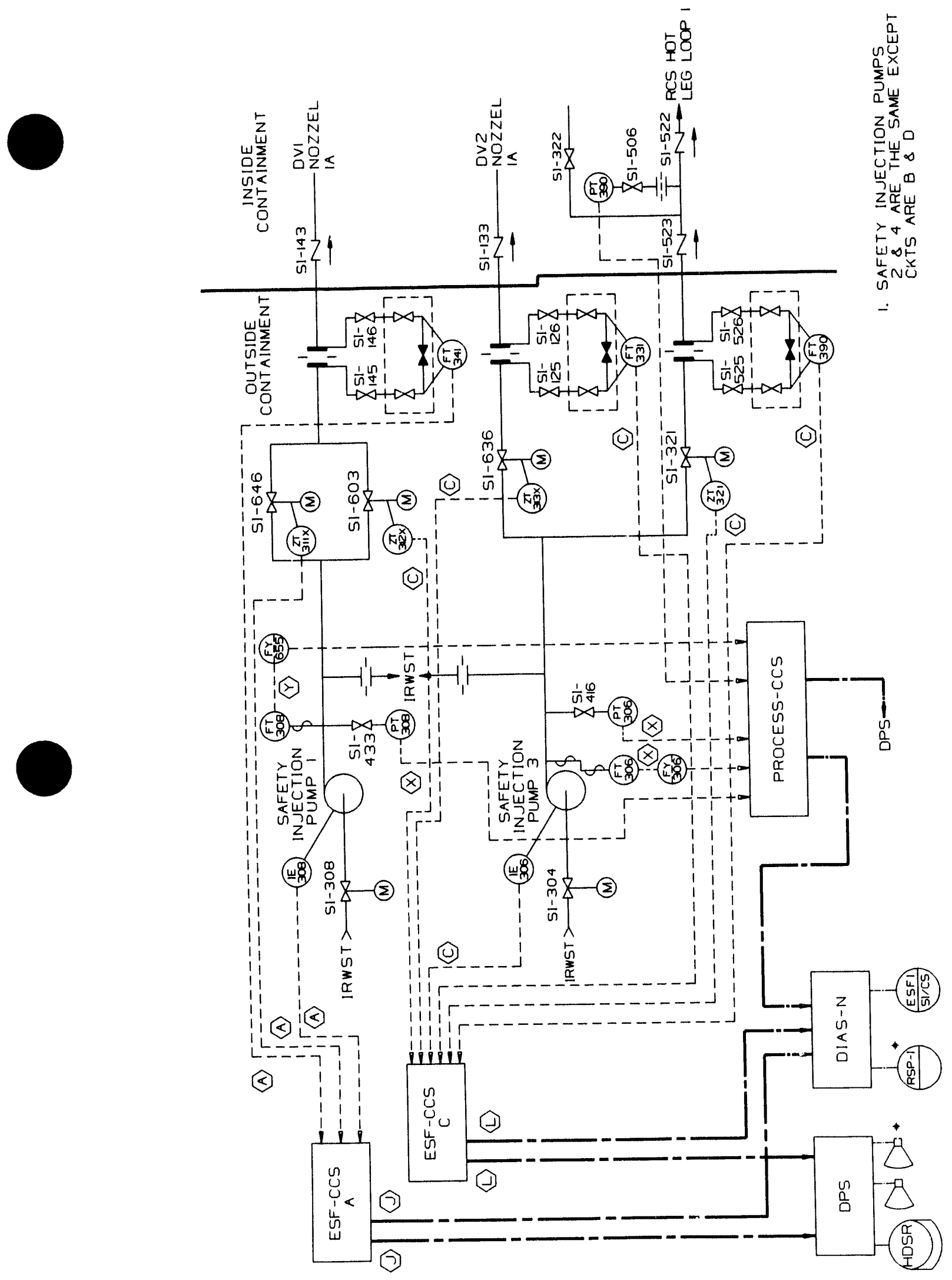

Amendment I

December 21, 1990 


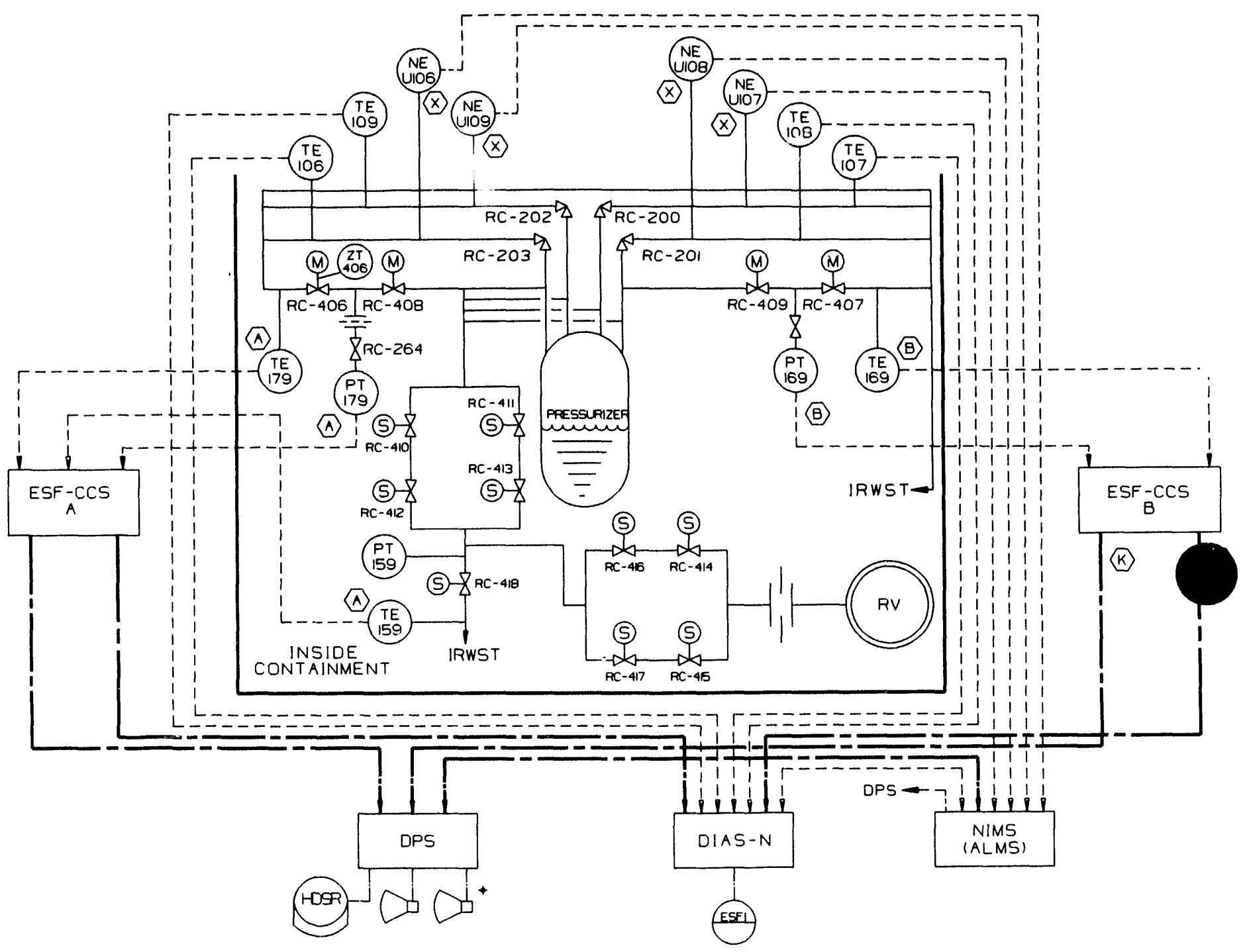

Amendment I

December 21, 1990 


\subsection{SYSTEMS REQUIRED FOR SAFE SHUTDOWN}

This section describes the instrumentation and controls that are required to place and maintain the reactor in a safe shutdown condition. These systems are in many cases utilized in the performance of normal plant operations and, as such, cannot be exclusively identified with the safe shutdown function.

However, prescribed procedures for securing and maintaining the plant in a safe condition can be instituted by appropriate alignment of selected subsystems. The discussion of these systems, together with the applicable codes, criteria and guidelines, is found in other sections. In addition, the alignment of shutdown functions associated with the engineered safety features that are invoked under postulated limiting fault conditions is discussed in chapter 6 and section 7.3.

The instrumentation and control functions required to maintain the reactor in a safe shutdown condition are discussed in this section and represent the minimum number required under non-accident conditions. These functions permit necessary operations that will:

A. Prevent the reactor from achieving criticality in violation of the technical specifications.

B. Provide an adequate heat sink such that design and safety limits are not exceeded.

The specific requirements for achieving safe shutdown that are contained in USNRC Branch Technical Position RSB 5-1 are met as follows:

A. The design of the safe shutdown systems permits the reactor to be taken from normal operating conditions to cold shutdown using only safety-grade systems. These systems satisfy General Design Criteria 1 through 5.

B. The systems all have suitable redundancy in components and features, and suitable interconnections, leak detection, and isolation capabilities to assure that, for onsite electrical power system operation (assuming offsite power is not available) and for offsite electrical power system operation (assuming onsite power is not available), the system function can be accomplished assuming a single failure. 
c. The systems are capable of being operated from the control room with either only onsite or only offsite power available.

D. The systems are capable of bringing the reactor to a cold shutdown condition, with only offsite or onsite power available, within a reasonable period of time following shutdown, assuming the most limiting single failure.

\subsubsection{DESCRIPTION}

The following systems are required to achieve and maintain a safe shutdown of the reactor:
A. Emergency Feedwater System (EFW)
B. Atmospheric Dump System (ADS)
C. Shutdown Cooling system (SCS)
D. Safety Injection system (SIS)
E. Safety Depressurization System (SDS)

The following auxiliary support systems are also required to function:
A. Station Service Water System (SSWS)
B. Component cooling Water system (CCWS)
C. Onsite Power system (OPS), including Diesel Generator Systems (DGS)
D. Heating, Ventilating and Air Conditioning (HVAC) systems

\subsubsection{Systems Required for Safe Shutdown}

The safe shutdown instrumentation and information displays provided on the main control panels are included in section 7.5 Tables 7.5-1, 7.5-2 and 7.5-3, as part of the safety-related display instrumentation. The controls provided in the control room for safe shutdown systems are identified in their respective system description sections. 
The safe shutdown auxiliary support systems instrumentation, information displays and controls are provided on the main control panels and are described in their respective system description sections as well.

Additional information regarding main control panel layouts, including process instrumentation displays, controls and Human Factors Engineering (HFE) task analysis for safe shutdown operations, is contained in Chapter 18.

\subsection{Plant Diesel Generators}

Two independent, $100 \%$ capacity diesel generators provide a dependable onsite power source capable of starting and supplying the essential loads necessary to shut the plant down safely and to maintain it in a safe shutdown condition under loss of offsite power conditions. Load sequences are provided to sequentially load the diesel generators and are a part of the Engineered Safety Features (ESF) Component Control system (CCS), as described in Section 7.3.

The diesel generators are started automatically by undervoltage (loss of offsit? power on the associated $4.16 \mathrm{kV}$ ESF bus), by an Emergency Feedwater Actuation signal (EFAS), or by a safety Injection Actuation Signal (SIAS).

Section 8.3.1 describes the standby power supply (diesel generator) and the diesel generator starting system is described in section 9.5.6. Additional information on diesel generator supporting auxiliaries may be found in sections 9.5.4, 9.5.5, 9.5 .7 , and 9.5 .8 .

\subsection{Plant Diesel Generator Fuel oil storage and Transfer System}

The instrumentation and controls for this system are discussed in Sections 9.5.4.

\section{$7.4 \cdot 1 \cdot 1.3$ \\ Class 1E Power Distribution System}

This system is described in section 8.3 .

\subsection{Station Service Water System}

The controls and instrumentation for this system are discussed in Sections 9.2 .1 . 


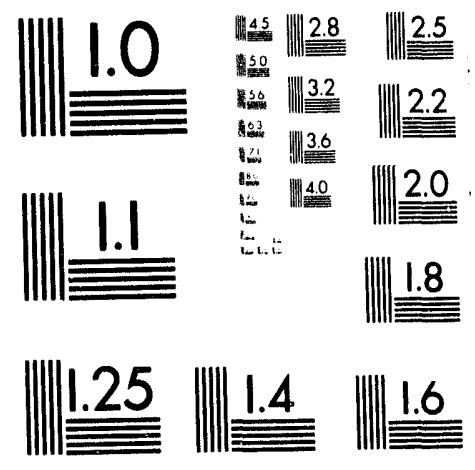



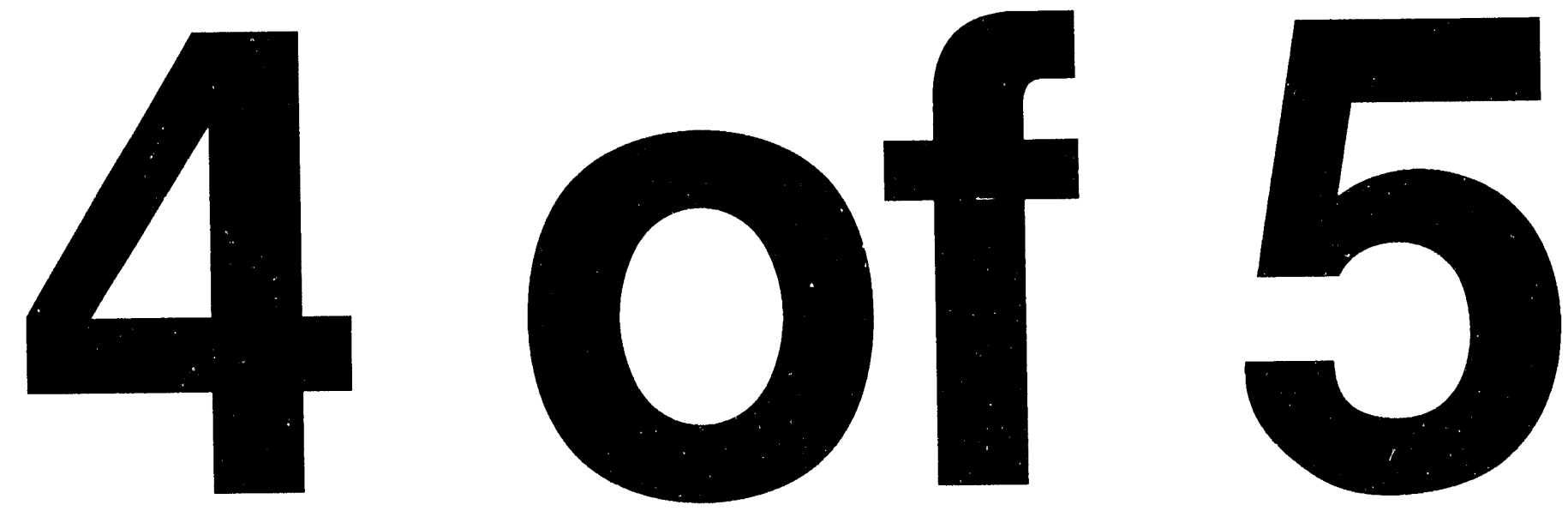


\section{4 .1 .1 .5}

\section{Component Cooling Water System}

The controls and instrumentation for this system are discussed in Sections 9.2 .2 .

7.4 .1 .1 .6

Emergency Feedwater System

The safe shutdown features of these systems are discussed in Section 10.4.9. The controls and instrumentation for the Emergency Feedwater system are discussed in section 7.3 .1 .

7.4 .1 .1 .7

\section{Atmospheric Dump System (ADS)}

The atmospheric dump valves are discussed in section 10.3. The valves are located outside the containment upstream of the main steam isolation valves.

The valves are used to remove decay heat from the steam generator in the event that the main condenser is unavailable for service for any reason including a loss of AC power. The decay heat is dissipated by venting steam to the atmosphere. In this way, the Reactor coolant system (RCS) can either be maintained at hot standby conditions or cooled down.

The ADS valve control circuits are designed such that no single failure shall prevent operation of at least one ADV on each steam generator.

7.4 .1 .1 .8

\section{Shutdown cooling System (SCS)}

The shutdown cooling system (SCS) is discussed in section 5.4.7. The SCS instrumentation and control necessary to achieve and maintain cold shutdown are discussed below. The piping is shown on Figure 5.4.7-3.

7.4.1.1.8.1 Initiating circuits and Logic

The SCS is designed to be manually initiated upon the attainment of the required Reactor coolant system (RCS) conditions. The SCS valve interlocks prevent overpressurization of the low pressure portion of the system, and are discussed in section 7.6. 
Control board process indication and status instrumentation are provided to enable the operator to determine system status, evaluate system performance, and detect malfunctions. Control panel hand switches and valve position limit indication lights are provided for the isolation valves and the heat exchanger inlet, outlet, and bypass valves. Indication is provided for low Shutdown cooling system pump discharge pressure and temperature, heat exchanger outlet temperature, and shutdown cooling system flow and pressure. SCS pump operating status is also indicated on the control board.

\subsection{Interlocks, Sequencing and Bypasses}

The SCS has overpressure protection interlocks as discussed in Section 7.6 .

The system sequencing will be in approved operating procedures provided by the site operator for the manually controlled equipment. There are no bypasses in the sCS instrumentation that would jeopardize the protection afforded by the interlocks.

\subsection{Redundancy and Diversity}

Each of the two SCS trains has sufficient instrumentation to assure adequate monitoring during all modes of operation. Tra isolation valves are discussed in section 7.6 .

\subsection{Supporting Systems}

The sCS trains $A$ and $B$ have independent Class $1 \mathrm{E}$ power sources for their actuated equipment (e.g., pumps, valves). The SCS isolation valve interlocks are implemented via the ESF-CCS using a redundant channel configuration such that a single failure will not cause loss of shutdown cooling nor spuriously actuate it.

\subsection{Safety Injection System (SIS)}

Boron addition via the SIS may be used if the CVCS is not available for the hot and cold shutdown processes. The CVCS is discussed in section 9.3.4. The SIS instrumentation and controls that are utilized to achieve cold shutdown are described below. The SIS logic and piping are provided in section 7.3 and Figures $6 \cdot 3 \cdot 2-1 \mathrm{~A}$ through $6.3 \cdot 2-1 \mathrm{~F}$. 
7.4 .1 .1 .9 .1

Initiating circuits and Logic

To aid in achieving cold shutdown the sIS component actuation steps required are:

A. Coordinated control of the SIS pumps and SIS pump discharge valves to adjust and maintain the correct pressurizer water level.

B. Periodic sampling and adjustment of the boron concentration to compensate for the temperature decrease and other variables until shutdown concentration is reached.

Pressurizer level is automatically controlled during normal operation by the Pressurizer Level Control system (PLCS) as discussed in section 7.7.1.1.2.2. The operation of the SIS for RCS inventory control is further discussed in section 6.3.2. Boric acid is injected to ensure that sufficient shutdown margin is maintained as the RCS is cooled down. Control board process indication and status instrumentation are provided to enable the operator to evaluate system performance and manually control system operation.

\subsection{Interlocks, Sequencing and Bypasses}

The interlocks, sequence of operation, and bypasses of the SIS are discussed in section 6.3.1.

\subsection{Redundancy and Diversity}

The SIS is redundant as discussed in section 6.3 .1 and diverse from the CVCS as described in section 9.3.4.

\subsection{Supporting Systems}

The components of the system are powered from two separate $1 E$ electrical buses. Additional sIs supporting systems are described in section 3.6.1.

\subsection{Emergency Shutdown from Outside the Control Room}

In the unlikely event that the control room should become inaccessible, sufficient instrumentation and controls are provided (per 10 CFR 50, Appendix A, Criterion 19) outside the control room to:

A. Achieve prompt hot standby of the reactor (hot standby, as
used here, means the reactor is subcritical at Mode 3 operating pressure and temperature).


B. Maintain the unit in a safe condition during hot shutdown. ID

C. Achieve cold shutdown of the reactor through the use of
suitable procedures using the Remote shutdown Panel (RSP).

Postulated conditions or events that make the control room uninhabitable are considered in the control complex design. It is assumed these circumstances may be attended by destruction of $D$ equipment due to a fire within the control room.

The main control room panels and the remote shutdown panels are placed in separate physical locations, on separate elevations, with separate ventilation systems, with multiple communication systems and with lighted access routes between the two. The design includes signal isolation and disabling of all main controls and the transfer of all hot standby controls to the Remote Shutdown Panel. Therefore, no single credible event that will cause evacuation of the main control room (and/or fire damage in the main control panels) will also cause the remote shutdown panels to be inoperable.

The Human Factors Engineering (HFE) design approach for the RSP is described in Chapter 18.

\subsection{Hot Standby}

Sufficient instrumentation and controls are provided external to the control room to achieve and maintain hot standby of the reactor should the control room become uninhabitable under the assumption that (1) the operator trips the reactor prior to evacuation from the control room and (2) no other adverse consequences occur in addition to the control room fire and evacuation (i.e., events proceed as expected as a result of a reactor trip).

Hot standby, as used here, means that the reactor is subcritical at normal operating pressure and temperature (Mode 3 per technical specifications).

Table 7.4-1 lists the instrumentation and controls available at the remote shutdown panel.

\subsection{Cold Shutdown}

Cold shutdown can be achieved from outside the control room through the use of suitable procedures with the RSP by virtue of I control of the equipment listed in Tables 7.4-1 and 7.4-2. A Data Processing System Video Display Unit (VDU) is located on the
RSP for operator convenience in monitoring the cold shutdown evolution. 
The SDS may be used to depressurize the RCS if the CVCS auxiliary spray is not available. The system is also designed to remove decay heat via bleed and feed, if necessary, to reach SCS entry conditions. The SDS and its instrumentation and controls that may be used to achieve safe shutdown are described in sections 6.7 and 7.3 .

\subsubsection{System Drawings}

The logic for the operation of the SCS and SDS are shown in Chapters 5 and 6 . Section 1.7 includes a list of functional control logic, electrical and instrumentation drawings and piping and instrumentation diagrams for safe shutdown systems. The final functional control logic, electrical wiring diagrams and layout drawings for the SCS, SDS and the Remote shutdown Panel appear in the site-specific SAR.

\subsubsection{ANALYSIS}

\subsubsection{Conformance to IEEE 279-1971}

IEEE 279-1971, "Criteria For Protection systems For Nuclear Power Generating stations," establishes minimum requirements for protection systems. The instrumentation and controls associated with the safe shutdown systems are not protection systems as defined in IEEE 279-1971. However, many criteria of IEEE 279-1971 have been incorporated in the design of the instrumentation and controls of the safe shutdown systems. Conformance of the instrumentation and controls to section 4 of IEEE 279-1971 is discussed below.

A. General Functional Requirements (Section 4.1):

The instrumentation and controls of the safe shutdown systems enable the operator to:

1. Determine when a condition monitored by display instrumentation reaches a predetermined level requiring action.

2. Manually accomplish the appropriate safety $\operatorname{action}(\mathrm{s})$. 
B. Single Failure Criterion (Section 4.2):

The instrumentation and controls required for safe shutdown are designed and arranged such that no single failure can prevent a safe shuidown. Single failures considered include electrical faults and physical events resulting in mechanical damage. Each system is composed of redundant trains, including instrumentation and controls which are physically separated.

c. Quality Control of Components (Section 4.3):

The instrumentation and controls used for the safe shutdown systems are designated C-E Quality Class 1 and designed in accordance with the quality assurance program described in Chpater 17. Guidance for quality assurance of safe shutdown instrumentation channels used for monitoring and display are as defined by Regulatory Guide 1.97, Categories 1, 2 and 3 (refer to section 7.5).

D. Equipment Qualification (Section 4.4):

The essential instrumentation and controls associated with the safe shutdown systems are designed for the normal ambient conditions of the area in which they are located. Those components located in the control complex, which is air conditioned, are designed to operate with a loss of air conditioning for the time necessary to achieve safe shutdown. Instrumentation channels used for monitoring are qualified in accordance with the intent of Regulatory Guide 1.97, Categories 1,2 and 3 (refer to section 7.5).

E. Channel Integrity (Section 4.5):

Essential instrumentation and controls are Class $1 \mathrm{E}$ powered and designed as seismic category I to ensure their ability to operate during and following a design basis earthquake. The site operator is responsible for conducting preoperational tests and inspections to verify that all automatic and manual controls, and sequences of the integrated systems provided for safe shutdown, accomplish the intended design function. Preoperational test procedures are discussed in section 14.2 .

F. Channel Independence (Section 4.6):

Safe shutdown instrumentation and control channel independence is achieved by electrical and physical separation. This independence precludes a single event causing multiple channel failures. 
G. Control and Protection System Interaction (Section 4.7):

Control and safe shutdown systems that have identical sensor input requirements utilize the same sensors. The control systems use sensor signal validation logic as described in section 7.7.1.1.13 to avoid control/protection system interactions.

No other portion of the safe shutdown systems is used for both protection and control functions. Therefore there are no control functions that can adversely affect operation of safe shutdown systems.

H. Derivation of System Inputs (Section 4.8):

Pressure and temperature are directly measured. Level and flow signals are derived from differential pressure signals. Valve position signals are provided by limit switches or variable resistance devices. The derivations of various other signals are discussed in the sections where the safe shutdown systems are discussed.

I. Capability for Sensor Check (Section 4.9):

Sensor checking is discussed in the sections where the safe shutdown systems are discussed.

J. Capability for Test and Calibration (Section 4.10):

The instrumentation and control components required for safe shutdown that are not normally in operation are capable of being periodically tested. This includes instrumentation and controls for the SCS, SIS and SDS. AII automatic and manual actuation devices are capable of being tested to verify their operability. Periodic testing is further discussed in sections 13.5 and 16.3 .

K. Bypassing (Sections 4.11 through 4.14):

There are PPS bypasses in the instrumentation and controls for the SIAS that apply to the operation of the safe shutdown system (refer to section 7.3.2.3.2).

L. Multiple setpoints (Section 4.15):

There are PPS variable setpoints associated with SIAS that permit a controlled reduction of RCS pressure as discussed in section $7 \cdot 3 \cdot 2 \cdot 3.2$. 
M. Completion of Protective Action once It Is Initiated (Section 4.16):

The ESF-CCS, EFAS and SIAS, as described in section I 7.3.2.3.2, are designed to go to completion should they be automatically actuated during a normal plant shutdown. All other safe shutdown systems are not automatic protection systems and do not take protective action unless manually actuated.

N. Manual Initiation (Section 4.17):

The safe shutdown systems can be manually actuated. No I single failure in the instrumentation and controls for the safe shutdown systems will prevent achieving a safe shutdown.

o. Access to setpoint Adjustments, Calibration and Test Points (Section 4.18$)$ :

A key is required for access to setpoint adjustments, calibration and test points in the PPS and ESF-CCS for the EFAS and SIAS instrumentation as described in sections 7.2 and 7.3. Access is also annunciated. Setpoints are continuously monitored by the DPS.

P. Identification of Protective Action (Section 4.19):

Indication lights are provided for all shutdown cooling interlock protective actions.

Q. Information Readouts (Section 4.20):

All safe shutdown system monitoring and control channels have appropriate indicators to provide the operator with sufficient, accurate information to evaluate system performance and to perform necessary actions. The design of the RSP meets the HFE design criteria and methods of implementation as described in Chapter 18.

R. System Repair (Section 4.21):

For safe shutdown systems actuated manually, replacement or repair of instrumentation and control components can be accomplished, in reasonable time, when the systems are not actuated. outage of system instrumentation and control components for replacement or repair will be limited by the Technical Specifications 16.3.6. 
S. Identification (Section 4.22):

Identification of redundant channels is as described in Sections $7.1 .3(\mathrm{P})$ and 8.3 .1 .

\subsubsection{Conformance to IEEE 308-1980}

The electrical circuitry of the instrumentation and controls conforms to the criteria of IEEE 308-1980, "IEEE standard Criteria for Class $1 \mathrm{E}$ Electric Systems for Nuclear Power Generating stations." The instrumentation and controls associated with other systems and components are discussed in Section 8.3 .

\subsubsection{Conformance to General Design Criterion 19}

Conformance to GDC 19 is discussed in section 3.1.15. Remote instrumentation enables hot standby to be achieved if the control room is not habitable. Hot standby, as used here, means the reactor is subcritical at normal operating pressure and temperature. The reactor can be brought to cold shutdown, outside of the control room, by use of appropriate procedures, the RSP and local controls.

\section{4 .2 .4 \\ Consideration of Selected Plant Contingencies}

\section{$7.4 \cdot 2.4 .1$}

\section{Loss of Instrument Air System}

None of the essential control or monitoring instrumentation rely solely on instrument air. Where necessary, accumulator tanks are provided or the failure mode of pneumatic devices upon loss of air is designed to fail in the safe shutdown mode. Therefore, loss of instrument air will not degrade instrumentation and control associated with systems required for plant shutdown.

\subsection{Loss of Cooling Water to Vital Equipment}

None of the instrumentation and control equipment rely on cooling water for operation.

\section{$7.4 .2 \cdot 4.3$ \\ Plant Load Rejection, Turbine Trip, and Loss of Offsite Power}

In the event of loss of offsite power associated with plant load rejection or turbine trip, power for safe shutdown is provided by the onsite emergency power system. The standby diesel generators will provide power for operation of pumps and valves; the batteries and standby generators via the battery chargers will provide power for operation of instrumentation and control systems required to actuate and control essential components. 


\subsubsection{Emergency Shutdowi from Outside the Control Room}

Equipment and arrangements discussed in section 7.4 .1 are in response to GDC 19 which requires certain functional capabilities outside of the control room as discussed below.

7.4.2.5.1 Design Capability for Prompt Hot standby and to Maintain Hot standby

Should the control room become uninhabitable, the reactor may be manually tripped from the control room, as it is being evacuated, or from the Reactor Trip Switchgear system (RTSS).

Hot standby conditions can be maintained from outside the control room as described ir section 7.4.1.1.10 by control of pressurizer pressure and level, feedwater flow, and atmospheric steam dump. Hot standby, as usied here, means the reactor is subcritical at normal operating pressure and temperature.

\subsection{Cold Shutdown}

cold shutdown of the reactor without access to the control room is possible by use of instrumentation and controls described in section 7.4.1.1.10 and suitable procedures prepared by the site operator. 
TABLE 7.4-1

(Sheet 1 of 2 )

REMOTE SHUTDOWN PANEL INSTRUMENTATION AND CONTROLS FOR HOT STANDBY

\section{NSSS Instrumentation}

Neutron Logarithmic Power

Hot/Cold Leg Temperature

Pressurizer Pressure

Pressurizer Level

Pressurizer RCGV Valve Positions

Steam Generator No. 1 Pressure

Steam Generator No. 1 Level

Steam Generator No. 2 Pressure

Steam Generator No. 2 Level

CVCS Charging Flow

CVCS Charging Pressure

Boric Acid Storage Tank Level

In-containment Refueling Water storage Tank (IRWST) Level

SIS Pump No. 3,4 Discharge Flow

SIS Pump No. 3,4 Discharge Header Pressure

EFW Motor-Driven Pump 1 Discharge Pressure

EFW Motor-Driven Pump 2 Discharge Pressure

EFW Steam-Driven Pump 1 Discharge Pressure

EFW Steam-Driven Pump 2 Discharge Pressure

EFW Motor-Driven Pump 1 Suction Pressure and Low Pressure Alarm

EFW Motor-Driven Pump 2 suction Pressure and Low Pressure Alarm

EFW Steam-Driven Pump 1 Suction Pressure and Low Pressure Alarm

EFW Steam-Driven Pump 2 Suction Pressure and Low Pressure Alarm

EFW Steam-Driven Pump Turbine 1 Inlet Pressure

EFW Steam-Driven Pump Turbine 2 Inlet Pressure

EFW Motor-Driven Pump 1 Flow

EFW Motor-Driven Pump 2 Flow

EFW Steam-Driven Pump 1 Flow

EFW Steam-Driven Pump 2 Flow

EFW Motor-Driven Pump 1 Recirculation Flow

EFW Motor-Driven Pump 2 Recirculation Flow

EFW Steam-Driven Pump 1 Recirculation Flow

EFW Steam-Driven Pump 2 Recirculation Flow

EFW Storage Tank 1 Level and Low Alarm

EFW Storage Tank 2 Level and Low Alarm

EFW Steam-Driven Pump 1 Turbine speed

EFW Steam-Driven Pump 2 Turbine speed

EFW Turbine Trip and Throttle (Stop) Valves 1 \& 2 Open/Close Position and Close Position Alarm 


\section{TABLE 7.4-1 (Cont'd)}

(Sheet 2 of 2 )

\section{REMOTE SHUTDOWN PANEL INSTRUMENTATION AND CONTROLS FOR HOT STANDBY}

\section{BOP Instrumentation}

Ultimate Heat sink status Indication

Emergency Diesel Generator Status Indication

\section{NSSS Controls}

Reactor Coolant Pump Trip Pushbuttons Backup Heater Groups 1 and 2 Controls Atmospheric steam Dump Valve and ADV Block Valves Pressurizer Auxiliary Spray Valve Controls Pressurizer RCGV Valves RC-410, RC-411, RC-412, RC-413 Charsing Pump Controls

Letdown Isolation Valve Controls

Reactor Coolant Pump Seal Bleedoff Valve Controls

SIS Pump No. 3 \& 4 Controls

SIS Header No. 3 \& 4 Valve Controls

MSIS Actuation Switches

EFW Motor Driven Pump 1 Controls

EFW Motor Driven Pump 2 Controls

EFW Steam Driven Pump 1 Controls

EFW Steam Driven Pump 2 Controls

EFW Steam Generator Isolation Valves EF-100, EF-101, EF-102, EF-103

EFW Flow Control Valves EF-104, EF-105, EF-106, EF-107

EFW Steam Supply Bypass Valves EF-112, EF-113

EFW Steam Supply Isolation Valves EF-108, EF-109

EFW Turbine Trip and Throttle (Stop) Valves 1 \& 2 Trip/Reset Control

EFW Turbine 1 \& 2 speed Control

\section{BOP Controls}

Ultimate Heat Sink Controls 
TABLE 7.4-2

\section{REMOTE SHUTDOWN CONTROLLED FUNCTIONS FOR COLD SHUTDOWN}

\section{Instrumentation}

Pressurizer Pressure Variable Setpoints

Steam Generator Pressure Variable Setpoints

Shutdown cooling system suction Line Isolation Valve Interlock status

Safety Injection Tank (SIT) Pressure SCS Pump Flow

Shutdown Cooling Heat Exchanger Differential Temperature Data Processing System VDU*

\section{Controls}

Steam Generator Pressure Setpoint Reset

Pressurizer Pressure Setpoint Reset and operating Bypass

SCS Pumps

SIT Vent Valves

SIT Isolation Valves

Shutdown Cooling Header Valves

Shutdown cooling Heat Exchanger Flow Control Valves

Shutdown Cooling Warm-up Bypass Valves

Shutdown Cooling Suction Line Valves

Shutdown Cooling Heat Exchanger Bypass Flow Control Valves

* VDU monitor provided for convenience as an operator aid. 


\subsection{SAFETY RELATED DISPLAY INSTRUMENTATION}

\section{$7.5 .1 \quad$ DESCRIPTION}

This section includes a description of that safety-related display instrumentation which is available to the operator to allow him to monitor conditions in the reactor, the Reactor coolant system, containment, and safety-related process systems, for all operating conditions of the plant so that he may perform manual actions important to plant safety.

The Nuplex 80+ Control Room uses an integrated information display hierarchy to present both safety-related and non-safetyrelated plant data for monitoring and control by the operator. All information is integrated (inaccordance with Regulatory Guide 1.97) such that the same instrumentation used for accident monitoring is also used for normal plant operation. If an accident scenario develops, this integration allows the operators to diagnose and monitor the event using instruments with which they are most familiar. The Nuplex $80+$ information systems also include automatic signal validation, through cross channel data comparison, prior to data presentation or alarm generation. This ensures that the process information displayed to the operator is correct. Multiple diverse systems are utilized to process and display the data to ensure that information processing errors are detected and alarmed. This integrated information display hierarchy is composed of the following major elements:

\section{A. Integrated Process status Overview (IPSO) Panel}

A simplified large panel mimic is provided to allow a quick assessment of the status of the plant power production process and safety functions.

B. Discrete Indication and Alarm system (DIAS)

Discrete indicators are used to display validated safety and non-safety plant process parameters. Alarms are generated, processed and presented in an integrated manner through the use of alarm indications, message displays and the DPS CRT display pages.

C. Data Processing System (DPS)

The DPS acquires plant data, validates it, and executes monitoring and performance calculations for presentation of information through a hierarchical set of CRT display pages. 
D. Component Control and System Operator Module Displays

other I\&C system operator modules and plant component (pumps, valves, heaters) on/off, open/closed status information provided directly from the controlling I\&C system is integrated into the main control panel design.

The following sections further describe the functional applications of these elements within the context of the ACC safety-related display instrumentation. Descriptions of the DIAS, IPSO, and DPS implementation for Nuplex $80+$ are provided in Sections 7.7.1.4, 7.7.1.5 and 7.7.1.7, respectively. See Chapter 18 for a further discussion of this hierarchical approach, task analysis and other HFE related aspects for these elements.

Display information identified on Tables 7.5-1 through 7.5-3, within the Reactor coolant system, steam generating system and the containment, provides for the remote monitoring of process variables during and following design basis events.

The safety-related display instrumentation is designed to satisfy NUREG-0737 TMI Action Plan requirements I.D.2 as described in the following categories:

A. Safety-Related Plant Process Display Instrumentation

Information available to the operator for monitoring conditions in the reactor and related systems.

B. Reactor Trip System (RTS) Monitoring

Information available to the operator for monitoring the status of the RTS.

C. Engineered Safety Feature (ESF) System Monitoring

Information available to the operator for monitoring the status of each ESF system.

D. CEA Position Indication

Information available to the operator for monitoring the position of the CEAs.

E. Post-Accident Monitoring

Information available to the operator for monitoring the plant conditions during and following an accident. Safety-related post-accident monitoring instrumentation for 
Regulatory Guide 1.97 applicable Category 1, 2, and 3 variables is provided to monitor plant variables and systems during and following an accident, in accordance with the intent of TMI action item II.F.3.

F. Automatic Bypass Indication

Information available to the operator for monitoring the bypassed and inoperable status of the plant safety systems.

G. Inadequate core Cooling Monitoring

Information available to the operator for monitoring core cooling prior to and following an accident.

7.5 .1 .1

\section{System Description}

$7 \cdot 5 \cdot 1.1 .1$

Safety-Related Plant Process Display Instrumentation

Table 7.5-1 lists the significant process instrumentation that is provided to inform the operator of the status of the reactor and plant. This information, which is used for the startup, operation, and shutdown of the plant, is provided in the control Room. The information is provided in a form that is useful to the operator and may be indicated, recorded, or monitored in conjunction with a controlling function. Alternate indication and control instrumentation are provided at the remote shutdown panel and local stations outside the control room to allow reactor shutdown and maintenance of the reactor in a safe hot standby condition should the control room become uninhabitable (refer to section 7.4.1.10).

\subsection{Reactor Trip System Monitoring}

Even though the RTS is automatic and does not require operator action (with the exception of a manual trip capability), sufficient information is provided to the operator in the control room to allow confirmation that a reactor trip has taken place and whether or not a limiting safety system setting (LSSS) has been reached. This information consists of indication of:
A. Process parameters that initiate reactor trip
B. Trip, pre-trip, and bypass lights
C. Audible and visual alarms

D. Control Element Assembly (CEA) "dropped rod" information 


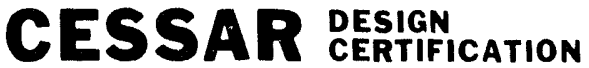

E. Trip switchgear circuit breaker position

Operating bypass indication is provided on the remote modules located in the main control room and is described in section 7.1.2.21. Individual trip channel bypass indication is provided locally at the PPS as well as on the remote modules in the main control room (refer to sections 7.1.2.21, 7.2, 7.5.1.1.1 and $7.5 .1 .1 .6)$.

\section{$7 \cdot 5 \cdot 1 \cdot 1 \cdot 3$}

\section{Engineered safety Features Monitoring}

The Engineered Safety Features Actuation system (ESFAS) continuously monitors the system input parameters and employs an actuation logic to initiate the Engineered Safety Feature (ESF) systems should these inputs reach their trip setpoints.

After automatic actuation, the ESF systems will continue to function properly without operator action for up to 30 minutes. See applicable ESF system descriptions for any required subsequent manual operations. operator action is taken to start other systems such as the shutdown cooling system (SCS).

Information is provided to the operator in the control room to allow him to monitor the operation of the ESF and related systems in the post-accident period. This information consists of valve position indication, pump operating status, tank level indication, flow indication, indication of the process parameters that actuate Engineered Safety Feature systems (refer to Table 7.5-2) and ESF system performance displays via the DPS as discussed in section 7.7.1.1.0. In addition, four remote modules provide indication of the pre-trip, trip, bypass, and operating bypass condition for each of the associated actuation system input signals. Individual trip channel bypass indication is provided at the PPS cabinet as well as on the modules in the main control room.

\section{$7 \cdot 5 \cdot 1 \cdot 1 \cdot 4$}

\section{CEA POsition Indication}

Two diverse, independent CEA position indication systems provide CEA position information to the operator. The systems are the pulse counting CEA position indication system and the reed switch CEA position indication system. The pulse counting system is discussed in section 7.7.1.1.1. The reed switch system is discussed below. CEA position displays are located on the main control board.

The reed switch CEA position indication system utilizes a series of magnetically actuated reed switches (reed switch position transmitters) to provide signals representing CEA position. Two independent reed switch position transmitters (RSPT) are provided 
for each CEA. The RSPT provides an analog position indication signal and three physically separate discrete reed switch position signals. The analog position indication system utilizes a series of magnetically actuated reed switches spaced at 1.5-inch intervals along the RSPT assembly and arranged with precision resistors in a voltage divider network. The RSPT is affixed adjacent to the CEDM pressure housing, which contains the CEA extension shaft and actuating magnet. The analog output signal is proportional to the CEA position within the reactor core. The three discrete reed switch position signals are contact closure signals from three separately located reed switches. These signals are an Upper Electrical Limit (UEL), a Lower Electrical Limit (LEL) and a Drop Rod contact (DRC).

The analog reed switch CEA position signals are input to the Core Protector Calculator system (see section 7.2). CEA position information is provided to the core protection Calculators (CPCS) directly and also to the CEA Calculators. The CEA Calculators display the position of each regulating, shutdown, and part-strength on demand by the operator in a bar chart format on channels B and C CPC operator modules at the main control board. The operator can address any analog position signal for display on the CPC operator's module. In addition to the displays, CEA deviation information is provided by the CEA Calculators to the CPCs and a CEA deviation alarm. A CEA deviation alarm is provided in the event a CEA Calculator indicates that the difference between the highest and lowest CEA positions in a subgroup exceeds a predetermined allowable deviation. The CEA deviation information is used in the CPC determination of power distribution. The power distribution is then factored into the low DNBR and high local power density trip function. pre-trip alarms are initiated if the DNBR or LPD trip limits are approached. A pre-trip alarm indication is provided on the PPS operator's control panel (both local and remote). Also, a pre-trip alarm is provided to the plant annunciator system (DIAS).

The three discrete CEA position reed switches (UEL, LEL, DRC) provide contact closure signals to the Control Element Drive Mechanism Control system (CEDMCS). These signals and the CEA positions based on CEDMCS pulse counting are utilized for CEDMCS CEA control and position indication on the main control panel.

The DPS provides a validated CEA position CRT display based on the RSPT and CEDMCS pulse counting CEA position information. The validation logic identifies and alarms discrepancies between them. 


\subsection{Post-Accident Monitoring}

The Post-Accident Monitoring Instrumentation (PAMI) listed in Table 7.5-3 is provided to allow the operator to assess the state of the plant following Design Basis Events. Most of these indications monitor instruments, equipment, or systems that provide automatic action for the Design Basis Event.

The Main Control Room ( $\left.N_{H} C R\right)$ design utilizes the following three methods to integrate SPDS and PAMI. The design is in accordance with the intent of Regulatory Guide 1.97 as depicted in Figure $7 \cdot 5-1$.

A. Seismically qualified DIAS channel $P$ processors and displays dedicated to continuously monitor and display Regulatory Guide 1.97 Category 1 individual parameters. These displays are located on the MCR Safety Monitoring Panel.

B. Seismically qualified DIAS channel $\mathrm{N}$ displays are integrated into the MCR panels for normal operations as well as for providing Regulatory Guide 1.97 Categories 1,2 , and 3 parameters. These displays provide the ability to select various PAMI channels and are isolated from the DIAS channel $P$ displays.

C. The DPS provides CRT displays for all Regulatory Guide 1.97 variables in a manner that is isolated from DIAS channels $P$ and $\mathrm{N}$. The system provides integrated displays, in accordance with chapter 18 HFE design requirements, for Critical Safety Functions, Inadequate core cooling Monitoring and other safety related plant parameters. The DPS also includes historical data storage, retrieval and trending. The DPS design includes data links to the on-site Technical support Center and Emergency operations Facility to provide the capability for monitoring plant conditions.

\subsection{Automatic Bypass Indication on a System Level}

Automatic bypass indication on a system level as defined in Regulatory Guide 1.47 is described in section 7.1.2.21.

$$
7.5 .1 .1 .7
$$

\section{Inadequate Core Cooling Monitoring Instrumentation}

This section provides a description of the generic Nuplex $80+$ approach to NUREG-0737, Section II.F.2, Inadequate Core cooling (ICC) requirements. 
The instrument sensor package selected to monitor the ICC event progression consists of:
A. Resistance Temperature Detectors (RTDs)
B. Pressurizer Pressure Sensors
C. Reactor Vessel Level Monitors employing the Heated Junction Thermocouples (HJTC) design concept
D. Core Exit Thermocouples

The signals from the RTDs, unheated thermocouples in the HJTC system, and pressure sensors can be combined to indicate the loss of subcooling, occurrence of saturation and achievement of a subcooled condition following core recovery. The reactor vessel level monitors provide information to the operator on the decreasing liquid inventory in the reactor pressure vessel (RPV) regions above the fuel alignment plate (FAP), as well as the increasing RPV liquid inventory above the FAP following core recovery. The core exit thermocouples (CETs) monitor the increasing steam temperatures associated with ICC and the decreasing steam temperatures associated with recovery from ICC.

As shown in Figure 7.5-1, these sensors are inputs to:

A. DIAS channel P processing equipment for continuous display along with other Regulatory Guide 1.97 Category 1 variables located on the Safety Monitoring Panel in the Main Control Room.

B. DIAS channel $\mathrm{N}$ processing equipment for display along with other plant parameters used by the operator for normal monitoring as well as post-accident monitoring.

C. Data Processing system for integration into the CRT plant process display pages. The DPS also processes ICC algorithms for saturation margin, reactor vessel level and critical safety functions for display and alarming.

All of the above display methods provide validated information to the operator as further described in sections 7.7.1.4, 7.7.1.7 and Chapter 18.

\subsection{Sensor Design}

Detailed information on the associated ICC sensors is presented in the following sections. 
Saturation Margin Monitoring (SMM) provides information to the reactor operator on:

(A) The approach to and existence of saturation.

(B) The existence of core uncovery.

The SMM utilizes jnputs from the RCS cold and hot leg temperatures measured by RTDs, the maximum temperature of the top three Unheated Junction Thermocouples (UHJTC), and pressurizer pressure sensors. The UHJTC input comes from the output of the Heated Junction Thermocouple (HJTC) processing units. In summary, the sensor inputs are as follows:

Input

Pressurizer Pressure

Pressurizer Pressure

RCS Pressure

Cold Leg Temperature

Hot Leg Temperature

Maximum UHJTC Temperature of top three sensors (from HJTC processing)

Representative CET Temperature
Range

$0-1600$ psia

1500-2500 psia

$0-4000$ psia

$50-750^{\circ} \mathrm{F}$

$50-750^{\circ} \mathrm{F}$

$32-2300^{\circ} \mathrm{F}$

$32-2300^{\circ} \mathrm{F}$

\section{$1.5 \cdot 1 \cdot 1.7 \cdot 1.2$ \\ Heated Junction Thermocouple (HJTC) Probe Assembly}

The HJTC probe assembly measures reactor coolant liquid inventory above the fuel alignment plate with discrete HJTC sensors located at different levels within a separator tube ranging from the top of the fuel alignment plate to the reactor vessel head. The basic principle of operation is the detection of a temperature difference between adjacent heated and unheated thermocouples.

As pictured in Figure 7.5-2 the HJTC sensor consists of a Chromel-Alumel thermocouple near a heater (or heated junction) and another chromel-Alumel thermocouple positioned away from the 
heater (or unheated junction). In a fluid with relatively good heat transfer properties, the temperature difference between the adjacent thermocouples is small. In a fluid with relatively poor heat transfer properties, the temperature difference between the thermocouples is large.

Two probe assemblies are provided to allow two channels of HJTC instruments. Each HJTC probe assembly includes eight (8) HJTC sensors, a separator tube, a seal plug, and electrical connectors (Figure 7.5-3). The eight (8) HJTC sensors are electrically independent.

Two design features ensure proper operation under all thermal-hydraulic conditions. First, each HJTC is shielded to avoid overcooling due to direct water contact during two phase fluid conditions. The HJTC with the splash shield is referred to as the HJTC sensor (see Figure 7.5-2). Second, a string of HJTC sensors is enclosed in a tube that separates the liquid and gas phases that surround it.

The separator tube (see Figure 7.5-4) creates a collapsed liquid. level that the HJTC sensors measure. This collapsed liquid level is directly related to the average liquid fraction of the fluid in the reactor head volume above the fuel alignment plate. This mode of direct in-vessel sensing reduces spurious effects due to pressure, fluid properties, and heterogeneities of the fluid medium. The string of HJTC sensors and the separator tube are referred to as the probe assembly.

The probe assembly is housed in a stainless steel structure that protects it from flow loads.

\subsection{3 Core Exit Thermocouples (CET)}

The Core Exit Thermocouples provide a measure of core heatup via measurement of core exit fluid temperature.

The design of the neutron flux In-Core Instrumentation (ICI) system includes Type $\mathrm{K}$ (Chromel-Alumel) thermocouples within each of the ICI detector assemblies. These Core Exit Thermocouples (CET) monitor the temperature of the reactor coolant as it exits the fuel assemblies. The core locations of the ICI detector assemblies are shown in Figure 7.5-5.

The CETs have a usable temperature range from $32^{\circ} \mathrm{F}$ to $2300^{\circ} \mathrm{F}$.

\subsection{Description of ICC sensor signal Processing}

The following sections provicle a description of the processing control and display functions associated with each of the ICC

$$
\begin{array}{ll}
7.5-9 & \begin{array}{l}
\text { Amendment } D \\
\text { September } 30,1988
\end{array}
\end{array}
$$


detection instruments. The sensor inputs for the major ICC parameters (reactor vessel inventory/temperature above the core, and core exit temperature) are signal conditioned by the two-channel PAMI processors and transmitted to the DIAS and DPS for primary display and trending.

\subsection{1 Heated Junction Thermocouple}

The signal conditioning equipment performs the following functions for the HJTC:

A. Determine collapsed liquid level above core.

The heated and unheated thermocouples in the HJTC are connected in such a way that absolute and differential temperature signals are available. This is shown in Figure 7.5-6. When liquid water surrounds the thermocouples, their temperature and voltage output are approximately equal. The voltage $\mathrm{V}(\mathrm{A}-\mathrm{C})$ on Figure 7.5-6 is, therefore, approximately zero. In the absence of liquid, the thermocouple temperatures and output voltages become unequal, causing $\mathrm{V}(\mathrm{A}-\mathrm{C})$ to rise. When $\mathrm{V}(\mathrm{A}-\mathrm{C})$ of the individual HJTC rises above a predetermined setpoint, liquid inventory does not exist at this HJTC position.

B. Determine the maximum upper plenum/head fluid temperature of the top three unheated thermocouples for use as an output to the SMM calculation (the temperature processing range is from $32^{\circ} \mathrm{F}$ to $2300^{\circ} \mathrm{F}$ ) in the DIAS channel $\mathrm{N}$ and DPS.

C. Process input signals to alarm and display, via the DIAS and DPS, collapsed liquid level and unheated junction thermocouple temperatures.

D. Provide control of heater power for proper HJTC output signal level. Figure 7.5-7 shows the design for one of the two channels, which includes the heater controller power supplies.

\subsection{2 Core Exit Thermocouple}

The signal conditioning equipment performs the following CET processing functions:

A. Process core exit thermocouple inputs.

B. Calculate a representative core exit temperature. This temperature will be either the maximum valid core exit temperature or a statistically derived value representing 958 of the temperature distribution. 
C. Process CETs for alarm and display of CET temperature and superheat via DIAS and DPS.

$7 \cdot 5 \cdot 1 \cdot 1 \cdot 7 \cdot 3$

$7 \cdot 5 \cdot 1 \cdot 1 \cdot 7 \cdot 3 \cdot 1$
ICC Information Displays

DIAS Channel P

The ICC sensed parameters previously described in section 7.5.1.1.7.1 are continuously displayed on the safety Monitoring section of the main control panels by DIAS channel P.

These displays are seismically qualified and provide dedicated, validated indication of each ICC sensed parameter. If the variable cannot be validated by the DIAS algorithm the condition will be alarmed and any input channel can be selected. However, either a validated or individual channel value is presented at all times.

The DIAS channel $P$ also generates an alarm signal when: (1) any of the HJTCs detects the absence of liquid level or (2) any of the CET temperatures reaches a value indicative of the potential for inadequate core cooling. The alarm signal is transmitted to the DPS for display.

Refer to section 7.7.1.4 and Chapter 18 for a further description of the DIAS system configuration and display reacout technology utilized.

\subsection{2 DIAS Channel $\mathrm{N}$}

\section{A. ICC Sensed Parameters}

The ICC sensed parameters previously described in section 7.5.1.1.7.1 are available on DIAS channel $\mathrm{N}$ displays located on the applicable plant system section of the main control panels. These displays are seismically qualified and provide validated information as described in section 7.7.1.4 and Chapter 18.

\section{B. Saturation Margin}

The DIAS channel $\mathrm{N}$ processing equipment will perform the following saturation margin monitoring functions:

1. Perform signal validation on sensor inputs prior to determination of temperature saturation margin. 
2. Calculate the saturation margin.

The saturation temperature is calculated from the minimum pressure input. The temperature subcooled or superheat margin is the difference between saturation temperature and the sensor temperature input. validated sensor data is used in these margin calculations. Three temperature subcooled or superheat margin presentations will be available. These are as follows:

a. RCS saturation margin - the temperature saturation margin based on the difference between the saturation temperature and the maximum temperature from the RTDs in the hot and cold legs.

b. Upper head saturation margin - temperature saturation margin based on the difference between the saturation temperature and the UHJTC temperature (based on the maximum of the top three UHJTCS.)

c. CET saturation margin - temperature saturation margin based on the difference between the saturation temperature and the representative core exit temperature calculated from the CETs.

3. Provide an alarm output for an annunciator when temperature saturation margin reaches a preselected

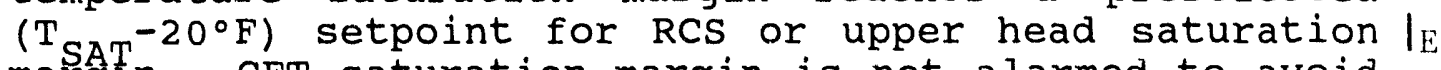
margin. CET saturation margin is not alarmed to avoid spurious indication.

\subsection{3 DPS ICC Displays}

The ICC parameters are incorporated into the Data Processing system (DPS) Critical Function Monitoring (CFM) displays and alarm logic. The CFM is a computer applications program that is a part of the DPS as described in section 7.7.1.10.

The critical safety functions are directly monitored by a set of algorithms which process the measured plant variables to determine the plant's safety status relative to safety function control. If any of the critical functions are violated (by exceeding logic setpoints), a critical Function Alarm (CFA) is initiated. The ICC instrument outputs are incorporated in this critical function alarm logic. 
The DPS ICC detection displays have an ICC summary page as part of the core heat removal control critical function, supported by more detailed display pages for each of the ICC variable categories.

The summary page will include:

A. RCS/Upper Head saturation margin - the maximum of the RCS and Upper Head saturation margin

B. Reactor vessel level above the core

C. Representative core exit temperature

Since the DPS has more display capabilities than the DIAS, such as color graphics, trending and a larger format, additional information is added to enhance the presentation. All DPS displays are consistent with DIAS. These displays are designed to meet the HFE criteria as discussed in Chapter 18.

The DPS receives all channels of ICC input for the CFM displays. The following information is available on lower level display pages:

A. Saturation Margin Displays

1. Temperature and pressure saturation margins for RCS, upper head, and core exit temperature.

2. Temperature and pressure inputs.

B. Heated Junction Thermocouple Displays

1. Representative liquid inventory level above the fuel alignment plate.

2. Discrete HJTC positions indicating liquid inventory above the fuel alignment plate.

3. Inputs from the HJTCs

a. Unheated junction temperature at each position.

b. Heated junction temperature at each position.

c. Differential junction temperature at each position. 
C. Core Exit Thermocouple Displays

1. A spatially oriented core map indicating the temperature at each of the CETs.

2. A selective reading of CET temperatures.

3. The representative core exit temperature.

D. ICC Trend Displays

Although all DPS inputs are accessible for trending and historical recall, the DPS has a dedicated ICC trend page for RCS/upper head saturation margin, reactor vessel level, and representative core exit temperature and core exit saturation margin.

$7 \cdot 5 \cdot 2$

$7 \cdot 5 \cdot 2 \cdot 1$

\section{NNAIYBIB}

\section{Mnalysis of Bafety-Related Plant Process Display} Instrumentation

Plant process information is provided to enable the operator to monitor conditions in the plant and perform operations important to plant safety. In addition, the information allows the operator to perform the cross-checking of Plant Protection System measurement channels to assure operational availability of these channels as discussed in sections 7.2.1.1.9 and 7.3.1.1.8. The following design criteria were used in the selection of plant instrumentation:

A. Provide continuous monitoring of validated process parameters required by the operator.

B. Provide a permanent record via the DPS of those parameters for which trend information is useful from a safety standpoint.

c. Provide display information to the operator that is reliable, comprehensible, and timely.

D. Provide multiple channels of indication for the RPS and ESFAS process parameters to allow cross-checking of channels.

E. Provide instrumentation display that adequately monitors the parameters over the ranges required for various conditions.

The information provided is sufficient to allow the operator to accurately assess the conditions within the reactor systems, and 
perform those appropriate actions in a timely manner to maintain the reactor systems within the conditions assumed by the safety analysis in Chapter 15 and the Human Factors Engineering Task Analyses described in chapter 18. In addition, the information allows the operator to perform the cross-checking of measurement channels to assure operational availability of these channels as discussed in Sections 7.2.1.1.9 and 7.3.1.1.8.

\subsubsection{Mnalysis of Reactor Trip 8ystem Yonitoring}

Sufficient information is provided to the operator to allow confirmation that a trip has occurred and to determine the process parameter that has provided a trip input.

CEA insertion information can be determined by the operator after a trip by CRT bar chart information and CEA limit indication (refer to section 7.5.1.1.4).

Indication of neutron flux levels in the reactor core, as well as other reactor and Reactor coolant system information, is provided for the operator.

The following design criteria were used in the selection of information that is provided to the operator:
A. System conditions requiring operator attention during routine plant operations and at the time of reactor trip are available in the control room.
B. Annunciation in the control room of all operations performed at the RPS cabinet affecting the function of the system.
c. Indication of any selected plant variables that are manually bypassed.
D. Indication of automatic removal of a bypass.

\subsubsection{Analysis of Engineered Bafety Features Yonitoring}

Information is provided to the operator so that he may monitor the status (pre-actuation availability and post-actuation performance) of the Engineered Safety Feature systems. The following design criteria were used in the selection of information that is provided to the operator:

A. System conditions requiring operator attention or action during routine plant operations are displayed and/or controlled in the control room. 
B. Annunciation is provided in the control room of all operations performed at the ESFAS cabinets affecting the availability of the systems.

c. Indication of any selected plant variable that is manually blocked or bypassed is provided.

D. Indication of automatic removal of block or bypass status is provided.

Consistent with the above criteria, the information shown in Table 7.5-2 is provided to aid the operator in determining that manual actuation of an Engineered Safety Feature is required and to confirm proper system operation after automatic initiation. Input parameters used for actuation are indicated in the control room as are positive indications that pumps and valves have actuated and that flows have been established. The DPS ESF fluid system and CFM displays provide an integrated overview of the ESF system performance.

\subsubsection{Mnalysis of CEA Position Indication}

CEA position indication allows the operator to easily determine that the CEAs are in the required position, that a CEA has dropped into the core, or that the CEA positions are as required after a reactor trip.

The following design criteria were used in providing the CEA position indication function:

A. Position readouts of all CEAs may be obtained.

B. Continuous position indication of all CEAs is provided.

C. A means is provided to alert the operator of CEA deviations within a group.

D. A permanent record may be made of the position of any or all CEAS.

E. The "full-in" and "full-out" indications are provided for each CEA.

F. Redundant and diverse means of monitoring and indicating CEA position are provided.

\subsubsection{Analysis of Post-Accident Konitoring Instrumentation}

The Post-Accident Monitoring Instrumentation (PAMI) that is $D$ identified in Table $7.5-3$ is provided for remote monitoring of

$$
\begin{array}{ll} 
& \text { Amendment } D \\
7.5-16 & \text { September } 30,1988
\end{array}
$$


post-accident conditions. Post-accident conditions are defined as those conditions which exist during and following an accident.

The extensive instrumentation and controls identified in Table 7.5-3 provide the plant operator with long-term monitoring and surveillance capabilities of post-accident conditions within the primary containment. Table 7.5-3 identifies Category 1,2 , and 3 variables from Regulatory Guide 1.97, "Instrumentation for Light-Water-Cooled Nuclear Power Plants to Assess Plant and Environs Conditions During and Following an Accident."

PAMI shall function with precision and reliability to display the appropriate monitored variables. Each instrument's performance characteristics, response time and accuracy are compatible with the design goal of providing the operator with reliable information.

The guidance of Regulatory Guide 1.97 is applicable to the design of the PAMI and are applied to the design of this instrumentation by appropriate category for each variable as follows.

$7 \cdot 5 \cdot 2 \cdot 5 \cdot 1$

Category 1:

Category 2:

\section{Bquipment Qualification}

Available displays for Category 1 variables are the DPS and DIAS channels $P$ and $N$. Class $1 E$ qualification includes the entire instrument channel up to the channel isolation device. Class $1 \mathrm{E}$ signals are isolated either prior to transmission to or within qualified I/O sections of the DIAS and DPS. The DIAS displays and processing units are non-Class $1 \mathrm{E}$, but are considered important to safety; therefore, they are seismically qualified to enhance channel availability. The DPS also displays all category 1 variables, though it is designed as a non-safety system with no functional seismic qualification.

Available displays for Category 2 variables are provided by the DIAS channel $\mathrm{N}$ and/or the DPS. All Category 2 variables are available on the DPS. Qualification for Category 2 variables is the same as for Category 1, except that there is no specific seismic qualification of the display devices. 
Category 3:

No specific qualification

requirements apply for sensors or displays. These variables are presented by DIAS channel $N$ and/or the DPS, as appropriate for each variable.

$7 \cdot 5 \cdot 2 \cdot 5 \cdot 2$

Category 1:

Category 2:

Category 3:

\section{Redundancy}

Redundancy with respect to Category 1 variables is provided for both the instrument channels supplying the signal and for the displays in the control room. Instrument channels are electrically independent and physically separated from each other and from non-safety equipment by qualified isolation devices. Credited redundancy for the display of Category 1 variables is provided by the channel $P$ and channel $N$ DIAS displays. These displays are electrically independent and physically separated. To minimize technical specification limitations for conditions when a DIAS channel is out of service, each Category 1 variable is also presented on the DPS. The DPS is physically separated and independent from both DIAS channels. Channel availability is further discussed in Section 7.5.2.5.4.

Although there are no specific provisions recommended by Regulatory Guide 1.97, the implementation of DIAS channel $N$ and the DPS display methods do provide a degree of redundancy such that no single failure will result in a loss of this information displayed to the control room operator.

Although there are no specific provisions required by Regulatory Guide 1.97, the implementation of DIAS channel $\mathrm{N}$ and/or the DPS display methods may provide a degree of redundancy.

To prevent ambiguity in the information presented to the operator (as required by Regulatory Guide 1.97) the information system employs a number of features to ensure that the information presented to the operator is correct. These are displayed in Figures 7.5-1 and 7.7-15.

A. DIAS channel $P$ monitors two redundant PAMI instruments for each Category 1 process parameter. If the signals have an acceptable deviation from each other, an average value is displayed on the ACSC panels. When the signals deviate unacceptably, both channels are displayed to allow the 
operator to select the correct instrument based on his evaluation of data from DIAS channel N, the DPS and/or other related process measurements.

B. DIAS channel $\mathrm{N}$ monitors the same redundant PAMI instruments as DIAS channel $P$ as well as other instruments measuring the same process parameters. All measurements are compared, deviating sensors are eliminated and an average of the good sensors is displayed. [The average is considered validated data.] This process is conducted first with only narrow range sensors to display the most accurate data available to the operator. If valid data cannot be determined based on narrow range sensors (due to failures or out-of-range conditions) the validation and display process is then conducted for wide range sensors. In either case, wide or narrow range validation, all sensors are checked against the valid data and unacceptable deviations are alarmed. In addition, when the valid data shows an acceptable deviation from the PAMI sensors, a PAMI symbol is displayed indicating that the display may be used for post-accident monitoring. This technique ensures that the operator uses the most accurate unambiguous information at all times. It also allows him to use the same instruments during accident conditions as he uses during the normal operation of the plant because DIAS channel $\mathrm{N}$ displays are located on control panels where that parameter is most frequently monitored.

C. The DPS monitors the same measurement channels and processes the data for display in the same manner as DIAS channel $N$. Both systems conduct the validation sequence described in $B$ above. However, the systems employ diverse hardware and software to enhance the reliability of the overall Nuplex $80+$ information display system. The DPS continuously compares its validation results to that of DIAS channel $\mathrm{N}$ and DIAS channel $P$ and alarms unacceptable deviations. The DPS displays normal and accident monitoring information in the context of color graphic plant mimics and function achievement displays selectable at any CRT in the Nuplex $80+$ ACC. As with DIAS channel $N$, the signal validation and cross system comparison technique provides the most accurate unambiguous displays to operating and technical support personnel allowing the same display media to be used for normal and accident monitoring.

\subsection{Power Source}

The PAMI displays are capable of operating independent of offsite power as follows: 
Category 1: Independent Class 1E power busses are provided for each redundant sensor instrument channel up to and including the channel isolation devices. The DIAS channel $P$ processing units and displays are powered from isolated Class $1 \mathrm{E}$ power busses. The DIAS channel $\mathrm{N}$ processors and displays are powered from isolated Class $1 \mathrm{E}$, battery backed, $\mathrm{C}$ and $\mathrm{D} / \mathrm{I}$ instrument busses. The DPS is powered from non-safety, battery backed computer busses.

Category 2: These variables are displayed on DIAS channel $N$ and DPS with power supplies from the non-safety instrument busses and computer bus, respectively. Both are battery backed. Instrument channels are powered from the $\mathrm{X}$ or $\mathrm{Y}$ instrumentation bus.

Category 3: Although no specific provisions are recommended by Regulatory Guide 1.97, these variables may be displayed on DIAS channel $\mathrm{N}$ and/or DPS with power supplies from the non-safety instrument busses and computer bus, respectively. Instrument channels are powered from $X$ or $Y$ instrumentation busses.

\section{$7 \cdot 5 \cdot 2 \cdot 5 \cdot 4$}

\section{Channel Availability}

The system is designed to permit any one channel or method of display to be maintained when required during normal power operation. During such operations the active parts of the system need not continue to meet the single failure criterion. The limitations for maintenance procedures are detailed in the plant technical specifications.

Category 1: Channel availability is assured for the display of Category 1 variables by the use of the seismically qualified channels $P$ and $N$ DIAS displays that are electrically isolated. Additional indication of Category 1 variables is provided by the non-safety DPS. This allows DIAS channels $\mathrm{P}$ or $\mathrm{N}$ to be out of service for maintenance. Channel availability is also assured for the instrument channels leading up to the displays. This is provided by the independence, separation and power supply requirements discussed previously for Category 1 instrument channels. 
Category 2: Channel availability for Category 2 variables is provided by the DIAS and DPS displays for these variables. DIAS and DPS are electrically independent and powered from independent battery backed sources. Both systems are internally redundant and the two designs are diverse from each other.

Category 3: No specific channel availability requirements apply. Therefore, these variables are provided in DIAS and/or the DPS, as appropriate, similar to Category 2 parameters.

$7 \cdot 5 \cdot 2 \cdot 5 \cdot 5$

Category 1:

Category 2:

Category 3:

$7 \cdot 5 \cdot 2 \cdot 5 \cdot 6$

Category 1:

\section{Quality Assurance}

The PAMI channels are subject to a complete $Q A$ program described in chapter 17 according to the requirements for Class $1 E$ equipment. DIAS and DPS processors and displays are designed in accordance with a $Q A$ program for non-class $1 \mathrm{E}$ equipment considered important to safety.

Quality assurance status is the same as described above for Category 1 .

The PAMI channels are high quality commercial grade, selected to withstand the specified environment. The DIAS and DPS quality assurance status is the same as described for Category 1 variables above.

\section{Display and Recording}

All Category 1 variables are continuously displayed in the control room on a DIAS channel $P$ display. This display normally provides a validated indication of each variable calculated from redundant post-accident instrument channels. If the variable cannot be validated by the DIAS algorithm, any input channel indication can be selected. However, either a validated value or individual channel value is available at all times. DIAS channel $\mathrm{N}$ also displays all Category 1 parameters. These may not be displayed continuously but are always available. All Category 1 variables also are available on demand from the DPS. No continuously displayed recorded information is necessary for post-accident operation; therefore, recording will be performed 
Category 2: Category 2 variables are available on the DIAS

Category 3: Same as Category 2. Meteorological data will be

$7 \cdot 5 \cdot 2 \cdot 5 \cdot 7$

Categories 1, 2 and 3 :

\section{$7 \cdot 5 \cdot 2 \cdot 5 \cdot 8$}

Categories 1 and 2: channel $N$ and/or the DPS display pages. These display methods are integrated into the control panel layouts based on Chapter 18 HFE task analyses. Recording of radiation monitors will be performed by DPS. recorded by DPS.

within the DPS and is available on demand. Both $A$ and $B$ channels of Category 1 variables are recorded by DPS.

\section{Range}

The range of the indicators extends over the maximum range of the variable being measured. Where the required range of monitoring instrumentation results in a loss of sensitivity during normal operating conditions, separate instrumentation channel is provided.

The DPS and DIAS channel $N$ provide validated parameter displays with automatic range changes for variables requiring more than one instrument channel to cover the entire range. The DIAS channels $P$ and $N$ and the DPS also allow access to individual sensor channels for each range.

DIAS channel $P$ shows only digital representations of parameter values. However, where multiple ranges exist, the display will indicate if the value is from the narrow or wide range sensor.

DPS and DIAS channels $\mathbf{P}$ and $\mathbf{N}$ will attempt to validate data first using only narrow range sensors. If successful, narrow range scale and demarcation will be displayed. If the parameter is out of the narrow range, wide range sensors will be used for the display with wide range scale and demarcation.

\section{Equiprent Identification}

Displays of Categories 1 and 2 types A, B and C variables provided in the control room have a dedicated designation to indicate they are 
intended for use under accident conditions. This is an integral part of the panel layout criteria.

The DIAS channel $P$ display is identified as post-accident monitoring instrumentation by a red "PAMI" on the display label. Similarly, channel $N$ DIAS indicators which present Categories 1 and 2 post-accident monitoring indications are identified on their labels by a red "PAMI".

DPS and DIAS display validated parameters are based partially on PAMI channels. These displays are programmed to continuously conduct a validity check of the validated parameter against the PAMI channels. If a significant deviation from the post-accident channels exists, a channel deviation alarm is generated. Deviation checking and the auto ranging described in section 7.5.2.5.7 allow narrow range sensors to be used normally and during accidents. When an individual post-accident instrumentation channel is being displayed on one of these DIAS indicators, the display indicates that with a dedicated "PAMI" light.

Post-accident instrumentation is indicated on the DPS displays by the "PAMI" acronym located after the parameter value.

Category 3: No specific provisions are required. Therefore, these parameters are identified on DIAS indicators as appropriate for the variables being displayed.

$7 \cdot 5 \cdot 2 \cdot 5 \cdot 9$

Categories 1 and 2 :

Category 3:

\section{Interfaces}

Instrument channel interfaces for Categories 1 and 2 variables are provided with qualified isolation devices. Instrument channels that input to DIAS or the DPS have channel isolation devices to provide isolation from the display processing system. The transmission of signals for other non-safety related use from safety-related PAMI channels is also provided through isolation devices.

No specific provisions are required. Therefore, these parameters are interfaced without isolation devices. 
$7 \cdot 5 \cdot 2 \cdot 5 \cdot 10$

Categories 1, 2, and 3:

\section{$7 \cdot 5 \cdot 2 \cdot 5 \cdot 11$}

Categories 1 , 2 and 3 :

\section{servicing, Testing and Calibration}

The design permits the administrative control of access to all sensor adjustments, module calibration adjustments, and test points. Periodic checking, testing, calibration, and verification will be done in accordance with intent of Regulatory Guide 1.118 pertaining to testing of sensor channels.

Means are provided for removing DIAS processing units and displays from service. Administrative control of these actions will be developed by the site operator. Changes to constants, alarm setpoints and calibration must be made off-line and will be similarly controlled. Redundant processing units will assure continuous display or availability of Regulatory Guide 1.97 variables during adjustments. Administrative controls will also be required for the DPS. The display systems are designed to allow control of access to constants, alarm setpoints, calibration and test points. The DPS continuously checks the validated DIAS data against its own and alarms any deviations. Isolation devices are located outside containment so that they may be accessed by personnel for maintenance during accident conditions.

\section{Human Factors}

The DIAS allows repair, adjustment or replacement of the display and processing system. The DPS is also designed to facilitate repair, replacement and adjustment of processing modules and CRTs.

Functional task analysis is used to determine the type and location of all displays in the Nuplex $80+$ control room, including the Regulatory Guide 1.97 indications. The DIAS and DPS displays provide Regulatory Guide 1.97 indication through the same method as normal operating information. In addition, the instrument channels used normally are continuously validated against PAMI channels such that the displays used normally are the same displays used during an accident. 
Refer to chapter 18 for further information regarding Human Factors Engineering display criteria utilized for the Nuplex $80+$ control panels.

7.5.2.5.12 Direot Measurament

Categories 1, To the extent practical, the PAMI provides direct 2 and 3: measurement of desired variables.

$7 \cdot 5 \cdot 2 \cdot 6$

Inalyais of Automatio Bypass Indication

The bypass/inoperable status is displayed in the control room for the following systems:

A. Containment spray

B. Containment Isolation

c. Safety Injection

D. Safety Depressurization

E. Emergency Feedwater

F. Shutdown cooling

G. Essential Service Water

H. Component Cooling Water

I. Emergency Diesel Generators

J. ESF Electrical Auxiliary Power Buses

K. Reactor Containment Fan Coolers

L. Control Room HVAC

M. Switchgear Room HVAC

N. Diesel Generator Room HVAC

o. Mechanical and Electrical Penetration Exhaust system

P. Fuel Building Emergency Exhaust System 
Visual indication is provided on a system level. Input to the system is provided by direct measurement at the equipment or control switch or by administrative insertion into the program where direct measurement is not provided.

The automatic bypass indication meets the intent of Regulatory Guide 1.47 paragraph $c$ guidance as described in section 7.1.2.21.

\section{$7 \cdot 5 \cdot 2 \cdot 7$}

\section{Inalysis of Inadequate core cooling yonitors}

The Inadequate core cooling (ICC) monitoring instrumentation provides the operator with indication of the thermal-hydraulic states within the reactor pressure vessel during the progression toward and recovery from ICC.

The following design criteria were used in the selection of ICC monitoring instrumentation:

A. Provide continuous monitoring of parameters associated with ICC.

B. Provide the operator with advance warning of the approach to ICC.

c. Provide instrumentation to cover the full range of ICC from normal operation to core uncovery.

D. Provide multiple channels of instrumentation to ensure high availability.

E. Provide display information to the operator that is reliable, comprehensible, and timely.

$7 \cdot 5 \cdot 2 \cdot 7 \cdot 1$

Description of ICC Progression (Coolant states Related to ICC)

The instrument sensor package for ICC detection provides the reactor operator with continuous indication of the thermal-hydraulic states within the Reactor Pressure Vessel (RPV) during the progression toward and away from ICC. This progression can be divided into conditions based on physical processes occurring within the RPV. These are characterized as follows:

Conditions Associated with the Approach to ICC Condition la Loss of fluid subcooling prior to the first
occurrence of saturation conditions in the coolant. 
Condition 2 a Decreasing coolant inventory within the upper plenum (from the top of the vessel to the top of the active fuel).

Condition 3a Increasing core exit temperature produced by uncovery of the core resulting from the drop in level of the mixture of vapor bubbles and liquid from the top of the active fuel.

\section{Conditions Associated with Recovery from ICC}

Condition $3 b$

Decreasing core exit steam temperature resulting from the increase in level within the core.

Condition $2 \mathrm{~b}$ Vessel fill by the increase in inventory above the fuel.

Condition 1b Establishment of saturation conditions followed by an increase in fluid subcooling.

In order to provide indicators during the entire progression of an event, an ICC instrumentation system consists of instruments which provide at least one appropriate indicator for each of the physical conditions described above.

Applying this description of the "approach to," and "recovery from" ICC to ICC instrument selection:

A. Provides assurance that the selected ICC system detects and indicates the entire progression.

B. Demonstrates the extent of instrument diversity or redundancy which is possible with the available instruments.

Furthermore, by defining the ICC progression on a physical basis the general labels of "approach to," and "recovery from" ICC can now be associated with the following specific physically measurable processes.

\subsection{Approach to ICC}

The ICC instrumentation provides the operator with an advance warning of the approach to ICC by providing indications of:

A. The loss of subcooling and occurrence of saturation (Condition 1a) with a saturation margin display receiving input from primary system RTDs, upper head HJTCs, pressurizer pressure and RCS loop pressure sensors.

B. The loss of inventory in the RPV (Condition 2a) with the Heated Junction Thermocouples (HJTCs). 
c. The increasing core coolant exit temperature (Condition 3a) with CETs.

It should be noted that the HJTCs measure inventory (collapsed liquid level) rather than two-phase level. This measurement provides the operator with an advanced indication of the coolant level should conditions arise to cause the two-phase froth to collapse via system overpressurization or the loss of operating reactor coolant pumps.

\subsection{Recovery From ICC}

Following an event leading to ICC, the ICC instruments will provide information to the reactor operator so that he may:

A. Verify that the core heat removal safety function is being met.

B. Establish the potential for fission product release.

ICC instrumentation indications are used to support the operator in helping to verify that the core heat removal safety function is being met. ICC indications available to the operator are:

A. Increasing inventory level above the fuel alignment plate.

B. Increasing subcooling in the RPV and RCS piping.

c. Decreasing core exit steam superheat.

The operator is informed about the progression of an event by both static and trend displays. The trending of ICC information enables the operator to quickly assess the success of automatically or manually performed mitigating actions.

\subsection{Instrument Range}

In the ICC sensor package, saturation temperature and water inventory are used as indicators for the "approach to" and "recovery from" ICC when there is water inventory above the fuel alignment plate. These measurements characterize Conditions $1 a_{\text {, }}$ $1 b, 2 a$, and $2 b$ of the ICC progression.

When the two-phase level is below the fuel alignment plate, the measurement of core exit fluid temperature represents a direct indication of the "approach to" and "recovery from" ICC (Conditions $3 a$ and $3 b$ ). Therefore, the ICC sensor package is sufficient to provide information to the reactor operator on the entire progression of an event with ICC potential. 


\section{REPERENCES FOR BECTION 7.5}

1. "Description of the C-E Nuclear Steam Supply System Quality Assurance Program," Combustion CENPD-210-A, Revision 4, January 1987.

Engineering, Inc. 
TABLE $7.5-1$

\section{(Sheet 1 of 2)}

\section{SAFETY-RELATED PLANT PROCESS DISPLAY INSTRUMENTATION}

\section{Parameter}

Pressurizer Pressure Pressurizer Pressure RCS Pressure

Steam Generator Differential Pressure (RCS)

Coolant Temperature (Hot)

Coolant Temperature (Cold)

Containment Pressure (Wide Range)

Containment Pressure (Narrow Range)

Steam Generator Pressure

Steam Generator Level (Wide Range)

Steam Generator Leve1

(Narrow Range)

Pressurizer Leve1

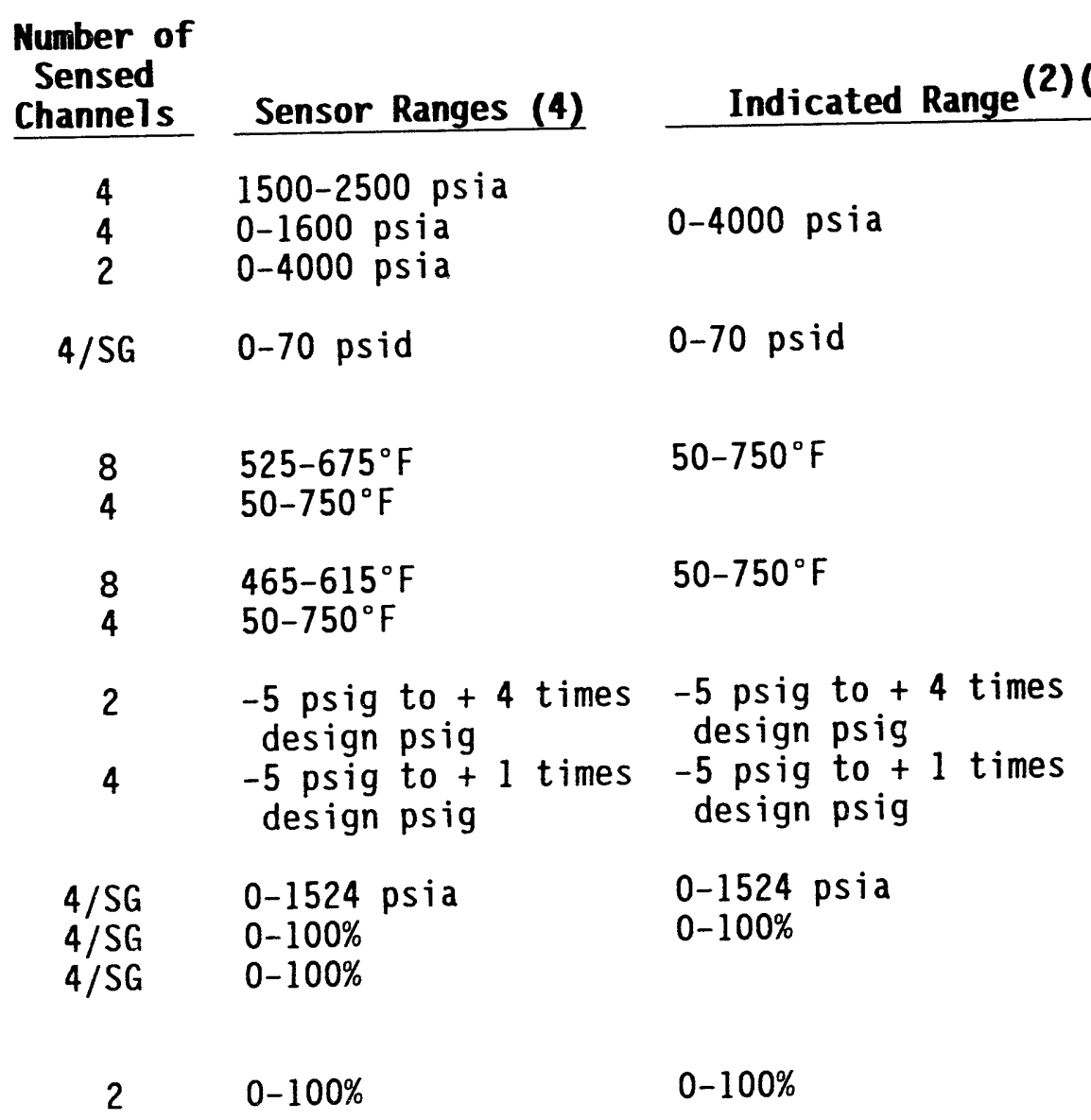

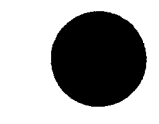


TABLE 7.5-1 (Cont'd)

(Sheet 2 of 2)

\section{SAFETY-RELATED PLANT PROCESS DISPLAY INSTRUMENTATION}

Parameter

\section{Local Power Density}

DNBR Margin

Neutron Flux Level Rate of Change

Neutron Flux Power Level

(Safety Channels)

Neutron Flux Power Level (Safety Channels)

Neutron Flux Power Level (DNBR/LPD Calculators)

\section{Number of \\ Sensed \\ Channels}$$
4
$$$$
4
$$$$
4 \quad-1 \text { to }+7 \text { DPM }
$$$$
4 \quad 1 \times 10^{-7} \text { to } 200 \%
$$$$
\text { power }
$$$$
4 \quad 0-200 \% \text { power }
$$$$
4 \quad 0-200 \% \text { power }
$$

Indicated Range ${ }^{(2)(3)(4)}$

$0-25 \mathrm{~kW} / \mathrm{ft}$

$0-10$

-1 to +7 DPM

$1 \times 10^{-7}$ to $200 \%$

$1 \times 10^{-7}$ to $200 \%$

$1 \times 10^{-7}$ to $200 \%$
Location(1)

Control Room

Control Room

Control Room

Control Room

Control Room

Control Room

NOTES: (1) See Chapter 18 for type of readout.

(2) Display channel inaccuracies negligible due to digital processing and display.

(3) See Sections 7.7.1.4 and 7.7.1.7 for a description of the Discrete Indication and Alarm System and Data Processing System displays.

(4) Ranges given are typical. Actual ranges are site dependent based on the equipment procured. Therefore, the site specific SAR shall make appropriate adjustments as necessary. 
TABLE 7.5-2

(Sheet 1 of 5)

ENGINEERED SAFETY FEATURE SYSTEM MONITORING

Parameter

Containment Isolation System

Containment Isolation Valve Position

Safety Injection System

Safety Injection

Valve Position

\section{Safety Injection}

Tank Level

In-containment Refueling Water Storage Tank Isolation Valve Position

In-containment Refueling Water Storage Tank Level

In-containment Refueling

Water Storage Tank Temperature

Safety Injection Flow

Safety Injection

Hot Leg Flow

\section{Number \\ of $1 E$ \\ Channels}

of

Channels

1 pair/

valve

1 pair/
valve
1/Tank
$2 /$ Tank
1 pair/
valve

4

2
(Note 1)

Open/Close

$0-100 \%$ (34 ft. scale)

$0-100 \%$ ( $4 \mathrm{ft}$. scale)

N/A

$0-100 \%$

$50-250^{\circ} \mathrm{F}$

4

$0-1500 \mathrm{gpm}$

$0-1500 \mathrm{gpm}$
Location(1)

(2) (5)

Control Room

Control Room

Control Room

Control Room

Control Room

Control Room

Control Room

Control Room

Control Room/Local 
TABLE 7.5-2 (Cont'd)

(Sheet 2 of 5 )

\section{ENGINEERED SAFETY FEATURE SYSTEM MONITORING}

\section{Parameter}

Safety Injection

Pump Discharge Pressure

Safety Injection

Tank Pressure

Direct Vessel and Hot

Leg Injection Line

Pressure

Shutdown Cooling System

Shutdown Cooling Inlet and Outlet Temperature

Shutdown Cooling

Pump Header Pressure

Shutdown Cooling Flow

Shutdown Cooling Heat

Exchanger Inlet Pressure

Shutdown Cooling Heat

Exchanger Outlet Temperature

\begin{tabular}{c}
$\begin{array}{c}\text { Number } \\
\text { of } \\
\text { Channels }\end{array}$ \\
\hline
\end{tabular}

4

\section{1/Tank \\ 2/Tank}

6

2

2

2

2

2

\section{Number}

of $1 E$

Channels

$$
--
$$

1/Tank

$1 /$ Tank

$--$

2

$-$

2

$--$

2

\section{Range ${ }^{(2)(5)}$}

0-2500 psig

0-750 psig

450-650 psig

$0-2500$ psig
Location (1) I

Control Room

Control Room/Local

Control Room

Control Room
Control Room/Local

Control Room

Control Room/Local

Control Room

Control Room 
TABLE 7.5-2 (Cont'd)

(Sheet 3 of 5)

ENGINEERED SAFETY FEATURE SYSTEM MONITORING

\section{Parameter}

Shutdown Cooling Valve Positions

Main Steam Isolation System

Main Steam Isolation Valve

Position

Main Steam Isolation Valve

Bypass Valve Position

Main Feedwater Isolation

Valve Position

Steam Generator Blowdown Isolation Valve Position

Emergency Feedwater System

EFW Pump Status

EFW Valve Position

EFW Pump Flow

EFW Pump Discharge Pressure

\begin{tabular}{c} 
Number \\
of \\
Channels \\
\hline
\end{tabular}

$$
1 \text { pair/ }
$$

vaive

1 pair/

valve

1 pair/

valve

$$
1 \text { pair/ }
$$

valve

1 pair/

valve

1 pair/
pump
1 pair/
valve

4

4

\section{Number \\ of $1 E$ \\ Channels}

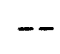

$--$

$-$

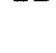

$--$

$-$

$--$

--

4

4

Range (2)(5)

Open/Close

Open/Close

Open/Close

Open/Close

Open/Close

On/Off

Open/Close

$0-800 \mathrm{gpm}$

0-2925 psia $\underset{\text { Location (1) }}{ } \mid$ I

Control Room (Note 4)

Control Room

Control Room

Control Room

Control Room

Control Room (Note 4)

Control Room (Note 4)

Control Room (Note 4)

Control Room (Note 4) 
TABLE 7.5-2 (Cont'd)

(Sheet 4 of 5)

\section{ENGINEERED SAFETY FEATURE SYSTEM MONITORING}

\section{Parameter}

EFW Pump Suction Pressure

EFW Steam Driven Pump Turbine Inlet Steam Pressure

EFW Storage Tank Temperature

EFW Storage Tank Level

EFW Pump Turbine Speed

EFW Line Temperature

EFW Recirculation Flow

Safety Depressurization System

Safety Depressurization System Valve Position

SDS Temperature

SDS Pressure

\section{Number \\ of \\ Channels}

4

2

2

2/Tank

2

4

4

1 pair/

valve

3

2

\section{Number \\ of $1 E$ \\ Channels}

4

2

2

2/Tank

2

4

4

$0-100 \%$

$0-4450 \mathrm{rpm}$

$40-250^{\circ} \mathrm{F}$

0-700 gpm

Open/Close

$0-700^{\circ} \mathrm{F}$

0-2500 psia

(2) (5)

Location (1) $\mid$ I

Control Room (Note 4)

Control Room

(Note 4)

Control Room

Control Room (Note 4)

Control Room (Note 4)

Control Room

Control Room (Note 4)

Control Room

Control Room

Control Room 
TABLE 7.5-2 (Cont'd)

(Sheet 5 of 5 )

\section{ENGINEERED SAFETY FEATURE SYSTEM MONITORING}

Parameter

Containment Spray System

CS Pump Pressure

CS Pump Flow

Spray Header Isolation

Valve Position

CS Pump Status

\begin{tabular}{cc}
$\begin{array}{c}\text { Number } \\
\text { of } \\
\text { Channels }\end{array}$ & $\begin{array}{c}\text { Number } \\
\text { of lE } \\
\text { Channels }\end{array}$ \\
\hline
\end{tabular}

2

2

1 pair/

valve

1 pair/

pump

NOTES: $1 . \quad$ See Chapter 18 for type of readout.

2. Display channel inaccuracies negligible due to digital processing and display.

$0-1000$ psig

$0-6500 \mathrm{gpm}$

Open/Close

On/Off

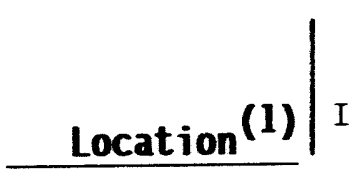

Control Room

Control Room

Control Room

Control Room

3. All indication on electrically actuated valves in the Safety Injection/Shutdown Cooling Systems, with exception of SI-661, receive $1 E$ power.

4. Valves which are required to bring the plant to cold shutdown have open/close position indicated outside the control foom also.

5. Ranges given are typical. Actual ranges are site dependent based on the equipment procurred. Therefore, the site specific SAR shall make appropriate adjustments as necessary. 
TABLE 7.5-3

(Sheet 1 of 7 )

\section{POST-ACCIDENT MONITORING INSTRUMENTATION}

\section{Parameter}

\section{RCS Pressure}

Primary Safety Valve Position (Acoustic Leak Detector)

In-containment RWST Leve1

In-containment RWST Temperature

Coolant Temperature (Hot)

Coolant Temperature (Cold)

Containment Pressure (Wide Range)

Containment Pressure (Narrow Range)

Steam Generator Pressure

Steam Generator Level (Wide Range)

Pressurizer Level

Pressurizer Heater Status

\begin{tabular}{|c|c|}
\hline $\begin{array}{c}\text { Number of } \\
\text { Sensed (5) } \\
\text { Channels }\end{array}$ & Sensor Ranges $(6,3,7)$ \\
\hline 2 & $0-4000$ psig \\
\hline 1/Valve & $N / A$ \\
\hline 2 & $0-100 \%$ \\
\hline 2 & $50-250^{\circ} \mathrm{F}$ \\
\hline 4 & $50-750^{\circ} \mathrm{F}$ \\
\hline 4 & $50-750^{\circ} \mathrm{F}$ \\
\hline 2 & $\begin{array}{l}-5 \text { psig to } 4 \text { times } \\
\text { design psig }\end{array}$ \\
\hline 4 & $\begin{array}{l}-5 \text { psig to } 1 \text { times } \\
\text { design psig }\end{array}$ \\
\hline $2 / S G$ & $0-1524$ psia \\
\hline $2 / S G$ & $0-100 \%$ \\
\hline 2 & $0-100 \%$ \\
\hline $\begin{array}{c}1 \text { pair } / \\
\text { heater bank }\end{array}$ & $N / A$ \\
\hline
\end{tabular}

Indicated Range $(7)$
$0-4000$ psig
Closed/Not Closed
$0-100 \%$
$50-250^{\circ} \mathrm{F}$
$50-750^{\circ} \mathrm{F}$
$50-750^{\circ} \mathrm{F}$
-5 psig to 4 times
design psig
-5 psig to 1 times
design psig
$0-1524$ psia
$0-100 \%$
$0-100 \%$
0 n $/ 0$ ff

Indicated Range ${ }^{(7)}$

Location $(1,2)$

Reg. Guide

Control Room

Control Room

Control Room

Control Room

Control Room

Control Room

Control Room

Control Room

Control Room

Control Room

Control Room

Control Room
1,2

\section{.97 Category}

\begin{tabular}{c|c}
1,2 \\
2 \\
2 \\
2 \\
1 \\
1,3 \\
1 \\
1 \\
1,2 \\
1 \\
1 \\
2
\end{tabular}


TABLE 7.5-3 (Cont'd)

(Sheet 2 of 7)

\section{POST-ACCIDENT MONITORING INSTRUMENTATION}

\section{Paraneter}

Degree of Subcooling

Neutron Flux Power Level

(Safety Channels)

Reactor Cavity Level

Containment Sump Temperature

Containment Area Radiation

Containment Hydrogen Concentration

Containment Spray Flow

Containment Atmosphere Temperature

Containment Isolation Valve Position

Core Exit Temperature

Reactor Vessel Coolant Level

\section{Number of}

Sensed Channels (5)

($$
2
$$$$
\text { Note (4) }
$$

$21 \times 10^{-7}$ to $200 \%$

$(6,3,7)$

$2 \quad 0-100 \%$

$1 \quad 0-250^{\circ} \mathrm{F}$

$2 \quad 1 R / h r-10^{8} R / h r$

$2 \quad 0-15 \%$ by volume

$1 \quad 0-6500 \mathrm{gpm}$

$2 \quad 0-400^{\circ} \mathrm{F}$

1 pair/ N/A

valve

61

2 $32-2300^{\circ} \mathrm{F}$

0-370 inches above core support surface
Indicated Range ${ }^{(7)}$

$200^{\circ} \mathrm{F}$ subcooling

to $35^{\circ} \mathrm{F}$ superheat

$1 \times 10^{-7}$ to $200 \%$

$0-100 \%$

\section{Location $(1,2) \begin{array}{r}\text { Reg- Guide } \\ 1.97 \text { Category }\end{array}$}

Control Room

1

$0-250^{\circ} \mathrm{F}$

$1 \mathrm{R} / \mathrm{hr}-10^{8} \mathrm{R} / \mathrm{hr}$

$0-15 \%$

$0-6500 \mathrm{gpm}$

$0-400^{\circ} \mathrm{F}$

Closed/Not Closed

$32-2300^{\circ} \mathrm{F}$

$0-100 \%$

Control Room
Control Room

Control Room

Control Room

Control Room

Control Room

Control Room

Control Room

Control Room

Control Room

1

1,2

2

1,3

1

$$
2
$$

2

$$
1
$$

$1,\left.3 \quad\right|_{0}$

1


TABLE 7.5-3 (Cont'd)

(Sheet 3 of 7)

\section{POST-ACCIDENT MONITORING INSTRUMENTATION}

\section{Parameter}

Emergency Feedwater Flow

Emergency Feedwater Storage Tank Leve 1

Safety Injection Flow

Safety Injection Tank Level

Safety Injection Tank Pressure

SIT Isolation Valve Position

Shutdown Cooling Flow

Shutdown Cooling HX

Outlet Temperature

SDS Valve Position

SDS Temperature

SDS Pressure

SG Safety Valve and ADV Position

\section{Number of \\ Sensed} Channels (5)

$2 / S G$
$2 /$ Tank

Sensor Ranges $(6,3,7)$

0-715 gpm

$0-100 \%$

$4 \quad 0-1350 \mathrm{gpm}$

$1 /$ Tank $0-34 \mathrm{ft}$

1/Tank 0-750 psig

1 pair/ N/A

tank

$2 \quad 0-6500 \mathrm{gpm}$

$2 \quad 40-400^{\circ} \mathrm{F}$

1 pair/ N/A

valve

$\begin{array}{ll}3 & 40-700^{\circ} \mathrm{F} \\ 2 & 0-2600 \mathrm{psia} \\ \begin{array}{c}\text { pair/ } \\ \text { valve }\end{array} & \text { N } / \mathrm{A}\end{array}$

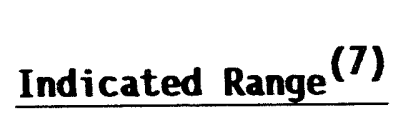

$0-110 \%$

$0-100 \%$

0-1350 gpm

$0-100 \%$

0-750 psig

Open/Close

$0-6500 \mathrm{gpm}$

$40-400^{\circ} \mathrm{F}$

Closed/Not Closed

$40-700^{\circ} \mathrm{F}$

0-2600 psia

Open/Close
Location $(1,2)$

Reg. Guide

Control Room

Control Room

Control Room

Control Room

Control Room

Control Room

Control Room

Control Room

Control Room

Control Room

Control Room

Control Room
2

1.97 Category I

2

1

2

2

2

2

2

2

2

2

2

2 
TABLE 7.5-3 (Cont'd)

(Sheet 4 of 7)

\section{POST-ACCIDENT MONITORING INSTRUMENTATION}

\section{Parameter}

\section{Eifluent Radioactive}

Notle Gas from Identified Release Poin's

Main s,team Line

Unit Vent Monitor:

Particulate

Iodine

Gas

High Gas

Unit Vent Post -

Accident High Gas

Comporient Cooling Water

Temperature to ESF System

Component Cooling Water

Flow to ESF System

Vent Design Flow
Number of

Sensed

Channels $(5)$ Sensor Ranges $(6,3,7)$

Indicated Range (7)

Location $(1,2)$

Reg. Guide 1.97 Category

$0.1-1 \mathrm{E}+7 \mathrm{mR} / \mathrm{hr}$

$0.1-1 \mathrm{E}+7 \mathrm{mR} / \mathrm{hr}$

Control Room

2

2

$1 E-11-1 E-5 \mu \mathrm{Ci} / \mathrm{CC}$

$1 \mathrm{E}-11-1 \mathrm{E}-5 \mu \mathrm{Ci} / \mathrm{cc}$ Control Room

2

1

1

$1 \mathrm{E}-12-1 \mathrm{E}-6 \mu \mathrm{Ci} / \mathrm{CC}$

$1 \mathrm{E}-12-1 \mathrm{E}-6 \mu \mathrm{Ci} / \mathrm{CC}$ Control Room

2

1

1

$1 \mathrm{E}-7-1 \mathrm{E}-1 \mu \mathrm{Ci} / \mathrm{CC}$

$1 \mathrm{E}-7-1 \mathrm{E}-1 \mu \mathrm{Ci} / \mathrm{CC}$ Control Room

$1 \mathrm{E}-3-1 \mathrm{E}+3 \mu \mathrm{Ci} / \mathrm{CC}$

$1 E-3-1 E+3 \mu \mathrm{Ci} / \mathrm{CC}$ Control Room

2

2

$1 \quad 1-1.0 \mathrm{E}+8 \mathrm{R} / \mathrm{hr}$

$1-1.0 \mathrm{E}+8 \mathrm{R} / \mathrm{hr}$

$1 \quad 0-200^{\circ} \mathrm{F}$

$0-200^{\circ} \mathrm{F}$

Control Room

2

Control Room

2

$1 \quad 0-20900 \mathrm{gpm}$

$0-110 \%$

Control Room

1

$0-143500 \mathrm{cfm}$

$0-110 \%$

Control Room

\begin{tabular}{l|l}
2 & I \\
2 &
\end{tabular}




\section{TABLE 7.5-3 (Cont'd)}

(Sheet 5 of 7)

\section{POST-ACCIDENT MONITORING INSTRUMENTATION}

\section{Parameter}

Emergency Ventilation Damper Position

DC Bus Voltage

Diesel Generator Voltage

Diesel Generator Current 4.16-kV Swgr. Voltage

480-V Swgr. Voltage

4.16-kV Swgr. Current 480-V Swgr. Current

Diesel Generator Starting

Air Reservoir Pressure

Reactor Coolant Pump Current

RCS Boron Concentration

Control Rod Position

\section{Number of} Sensed (5)
Channels

1 pair/ damper

2

$2 \quad 0-5250 \mathrm{Vac}$

$2 \quad 0-1200$ Amps

$2 \quad 0-5250 \mathrm{VaC}$

$2 \quad 0-600 \mathrm{Vac}$

$2 \quad 0-1200$ Amps

$2 \quad 0-150$ Amps

1 per DG

$N / A$

1/pump

0-468 Amps

1

0-6000 ppm

$1 / \operatorname{rod}$
Indicated Range ${ }^{(7)}$

Open/Close

$0-150 \mathrm{Vdc}$

$0-5250 \mathrm{Vac}$

0-1200 Amps

$0-5250$ Vac

$0-600 \mathrm{VaC}$

0-1200 Amps

0-150 Amps

$\geq 185$ psig

v-1000 Amps

0-6000 ppm

Full In/Not

Full In
Location $(1,2)$

Reg. Guide

Control Room

2

Control Room

2

Control Room

Control Room

Control Room

Control Room

Control Room

Control Room

Control Room

Control Room

Control Room

Control Room 
TABLE 7.5-3 (Con'c'd)

(Sheet 6 ,f 7 )

\section{POST-ACCIDENT MONITORING INSTRUNENTATION}

\section{Parameter}

RCS Radiation Level

Main Feedwater Flow

High Level Radioactive Liquid

Waste Tank Level (Holdup Tank)

Plant Area Radiation Monitors

Wind Direction

Wind Speed

Atmosphere Stability Temperature Difference
Number of

Sensed (5)

Channels $(5)$ Sensor Ranges $(6,3,7)$

2

$1 / 10$ to 100 times

Tech. Spec. Limit

$1 / S G$

$0-18.8 \times 10^{6} 1 \mathrm{bm} / \mathrm{hr}$

1

$0-435,000$ gal

$10^{-1} \mathrm{R} / \mathrm{hr}$ to $10^{4} \mathrm{R} / \mathrm{hr}$

$10^{-1} \mathrm{R} / \mathrm{hr}$ to

$0-360^{\circ}$

0-50 mph

Exceeds Required

Range

$$
\text { Delta-T }
$$

Reg. Guide Location $(1,2)$ 1.97 Category

Control Room

1

Control Room

Control Room

Control Room

3

Control Room

Control Room

Control Room 


\section{TABLE 7.5-3 (Cont'd)}

(Sheet 7 of 7)

\section{POST-ACCIDENT MONITORING INSTRUMENTATION}

\section{Parameter}

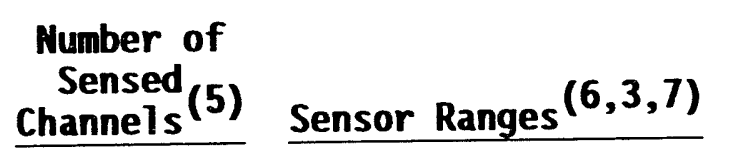

\section{I Indicated Range $(7) \quad$ Location $(1,2) \quad \begin{gathered}\text { Reg. Guide } \\ 1.97 \text { Category }\end{gathered}$}

NOTES: $1 . \quad$ See Chapter 18 for type of readout.

2. A11 Category 1 variables are also recorded via the DPS Historical Data Storage and Retrieval program.

3. Post-accident monitoring instrumentation is qualified for the appropriate environmental conditions (refer to Section 3.11).

4. Degree of subcooling is calculated from RCS pressure, RCS temperature and core exit temperature parameters.

5. MCBDs are provided in appropriate sections of Chapter 7.

6. Post-accident channel accuracy is a time dependent function of post-accident environmental conditions.

7. Ranges given are typical. Actual ranges are site dependent based on the equipment procured. Therefore, the site specific SAR shall make appropriate adjustments as necessary. 


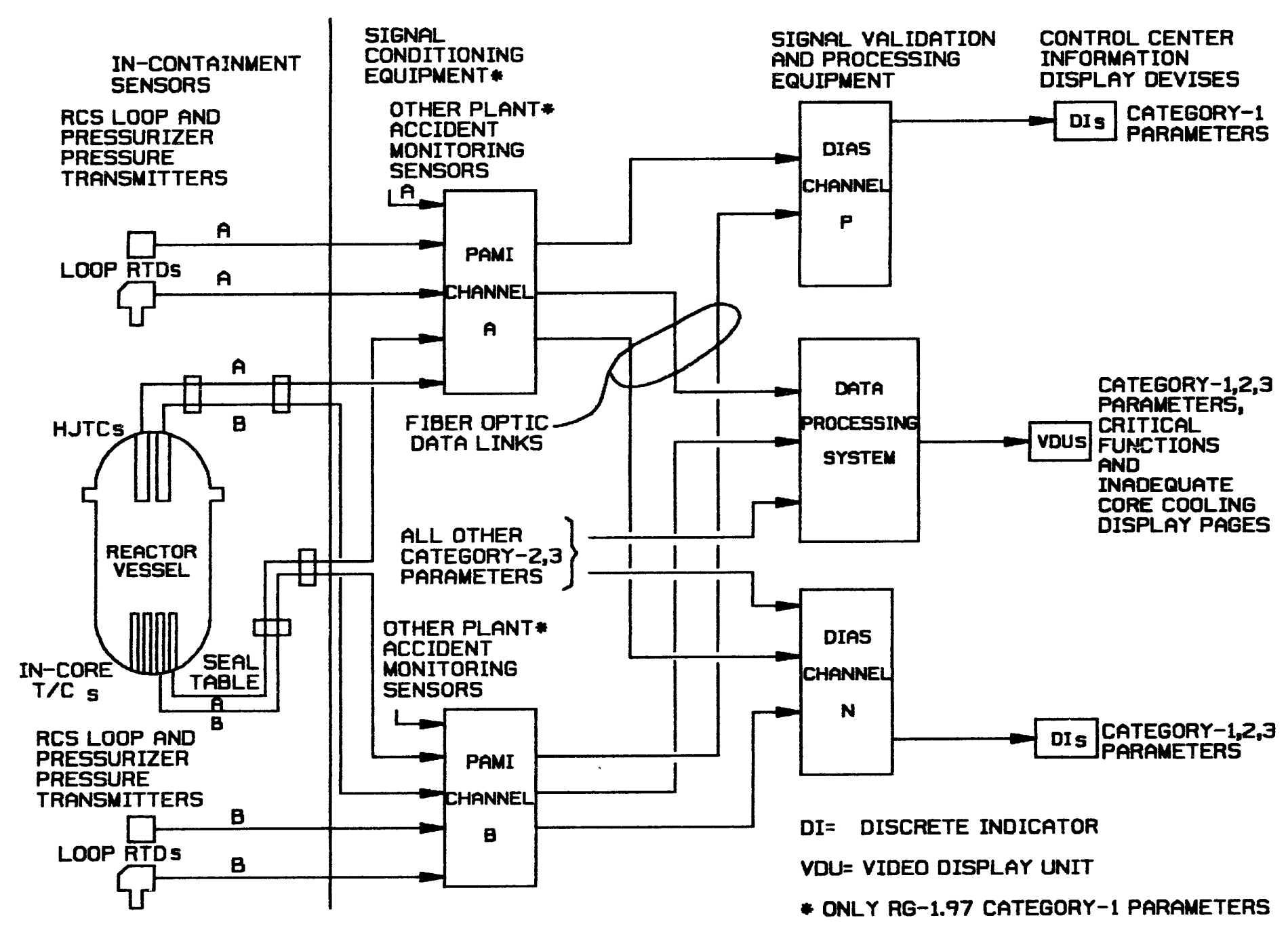




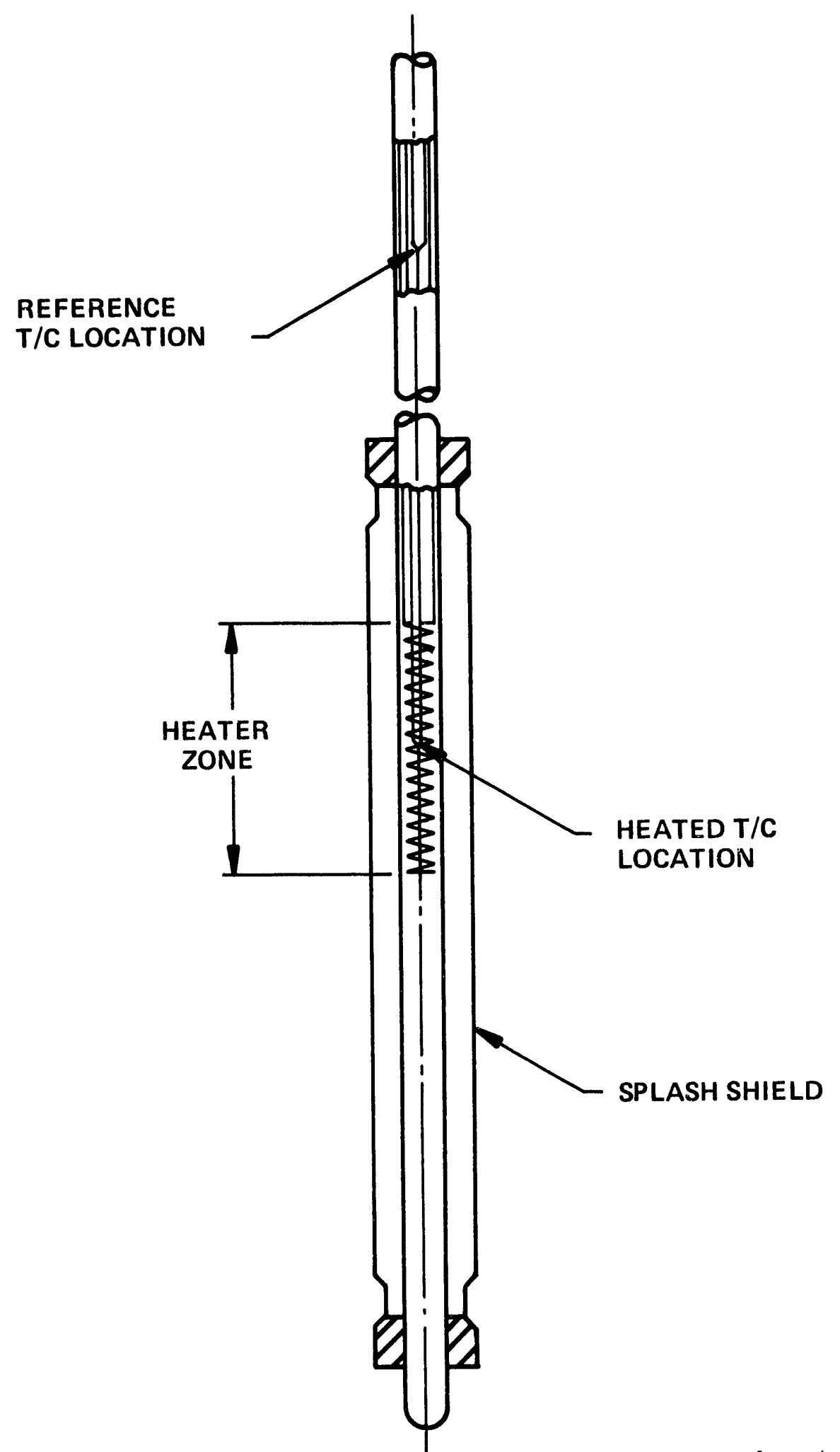

Amendment $D$

September 30, 1988 


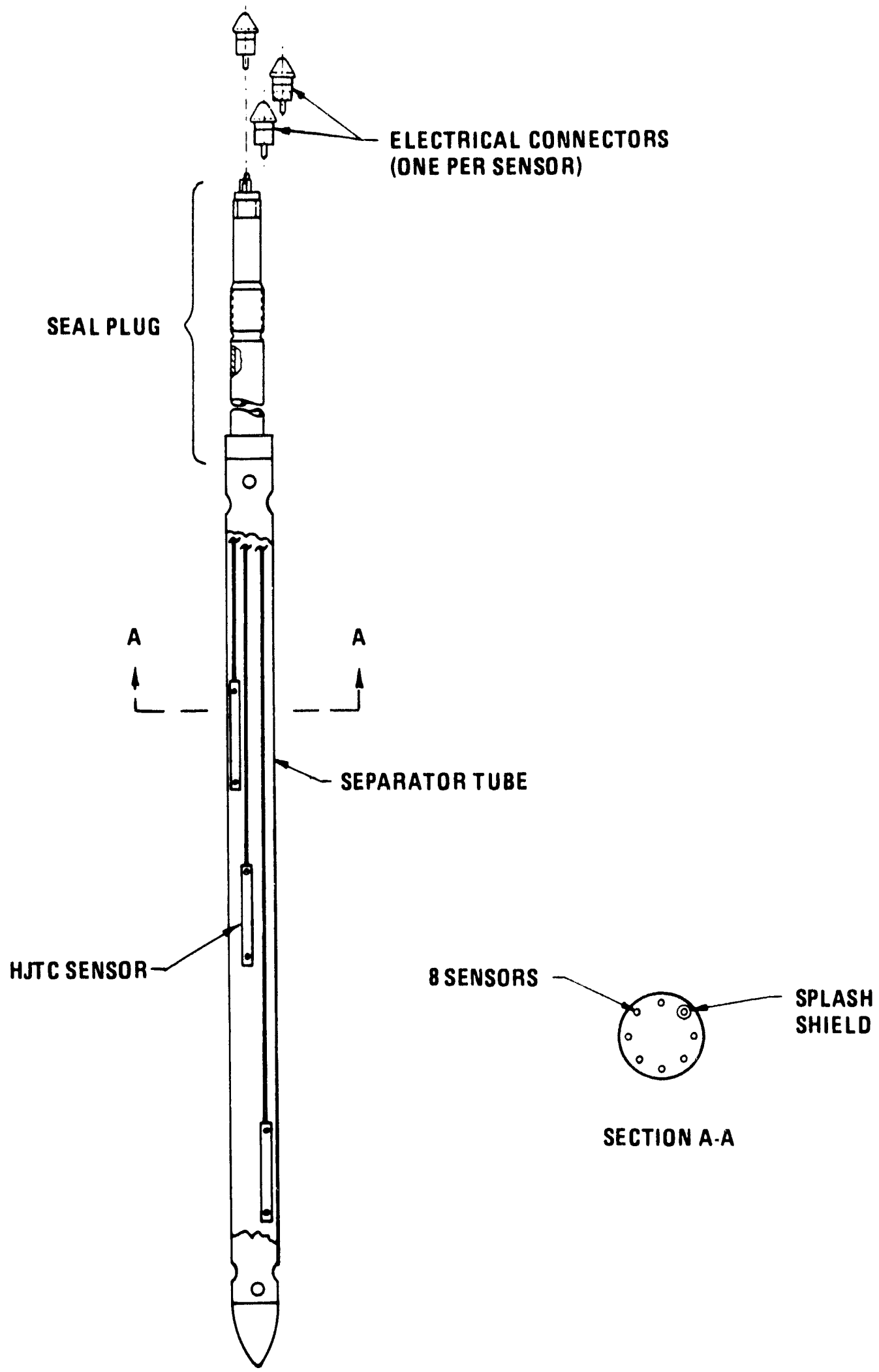

Amendment $D$

September 30, 1988

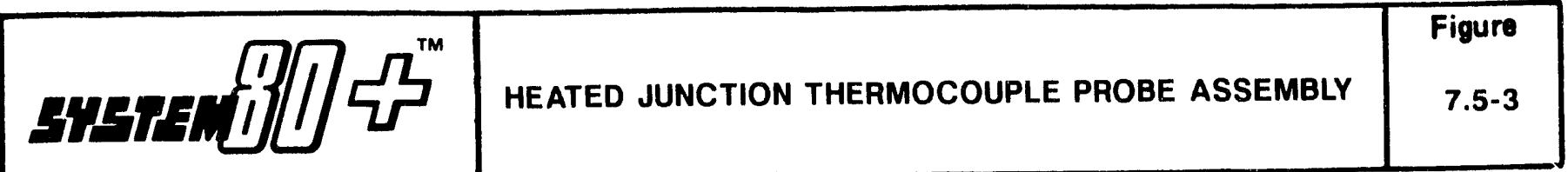




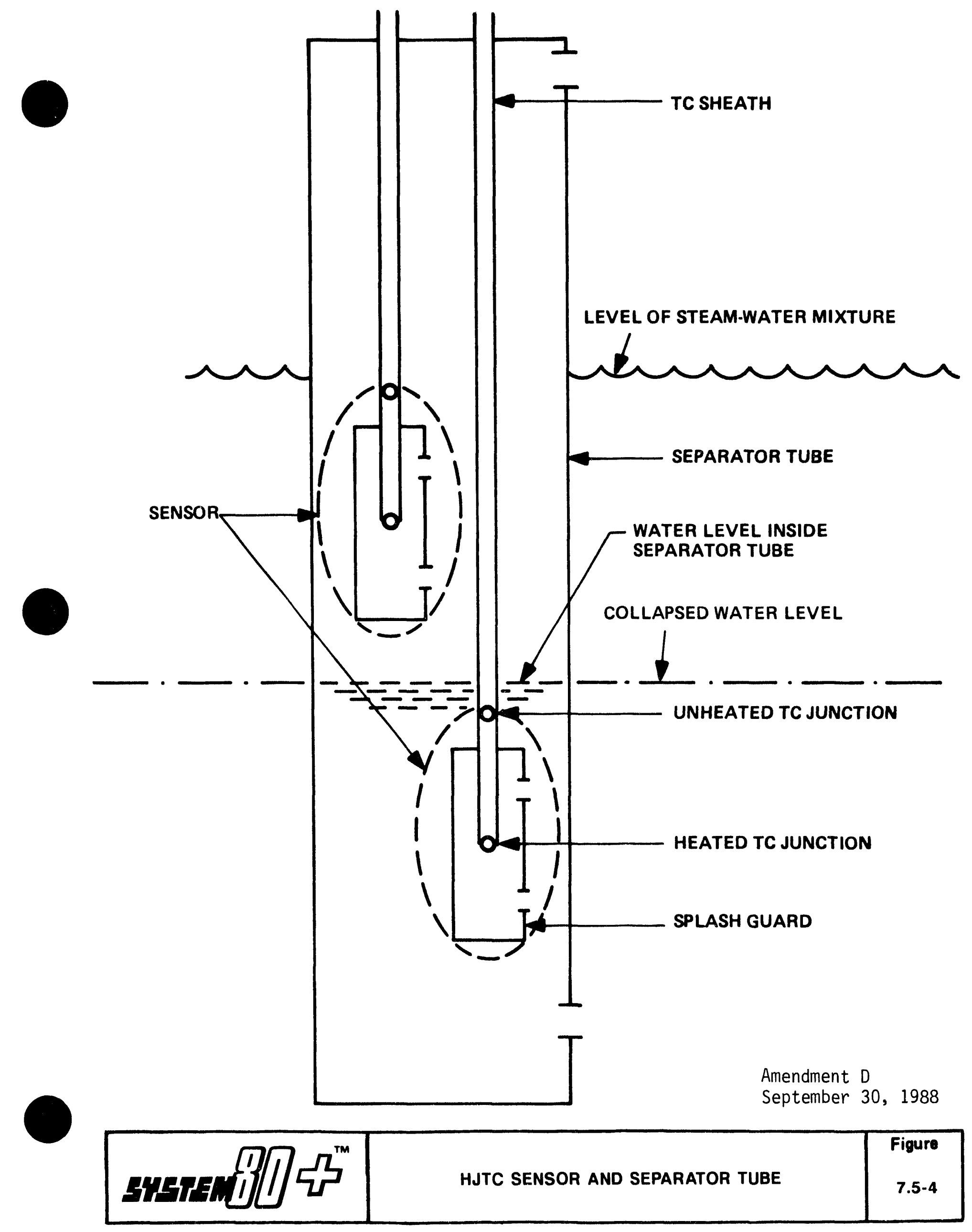




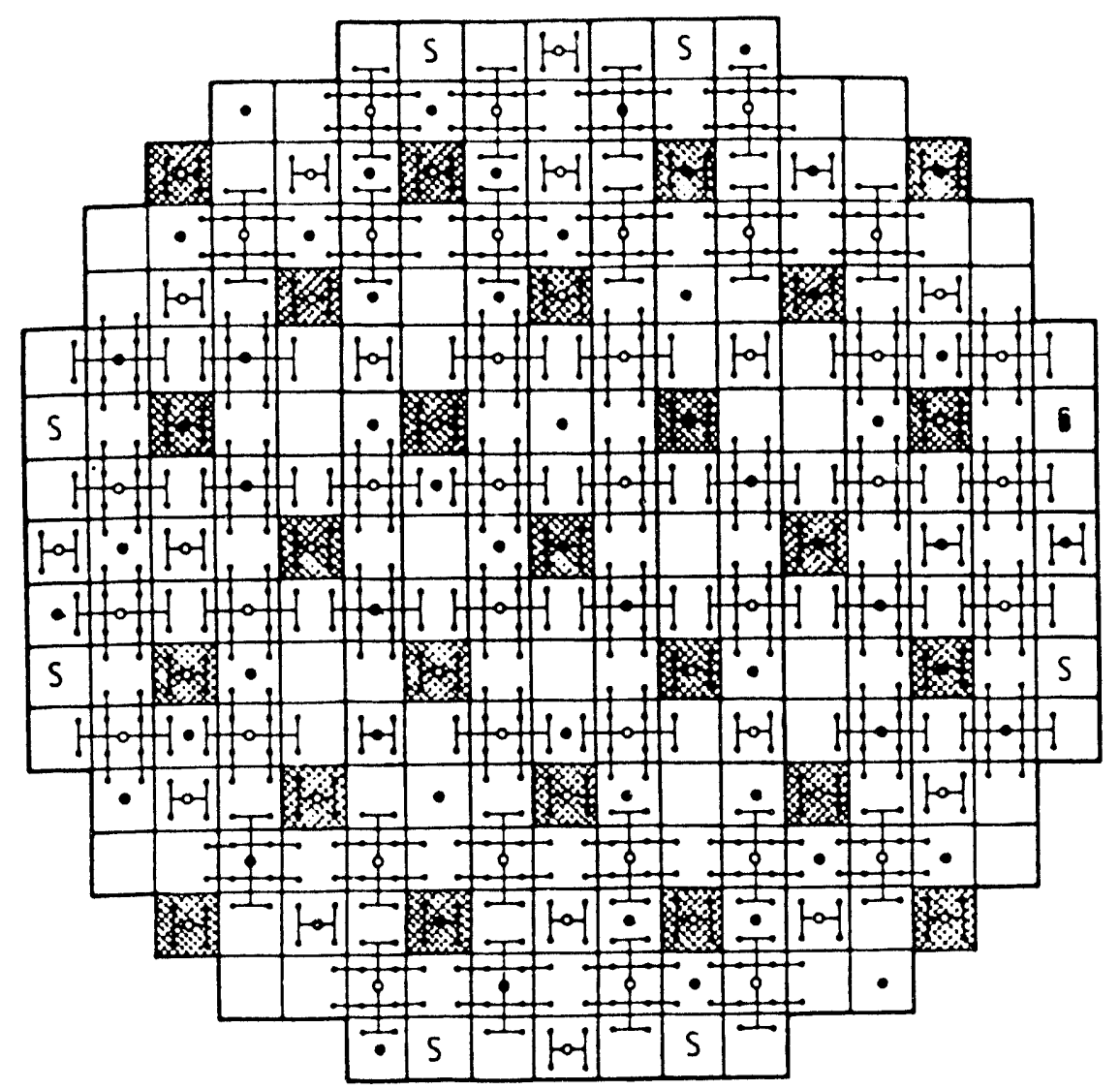

iflement full strength CeA

[-1] a ELEMENT FULL STRENGTH CEA

4 ELEMENT PART STRENGTH CEA

5 DENOTES SPARE CEA locations

FOR OPEN-MARKET PLUTONIUM RECYCLE

- DENOTES LOCATIONS OF FIXED RHODIUM IN-CORE NEUTRON DETECTOR STRINGS

Amendment I

December 21, 1990 


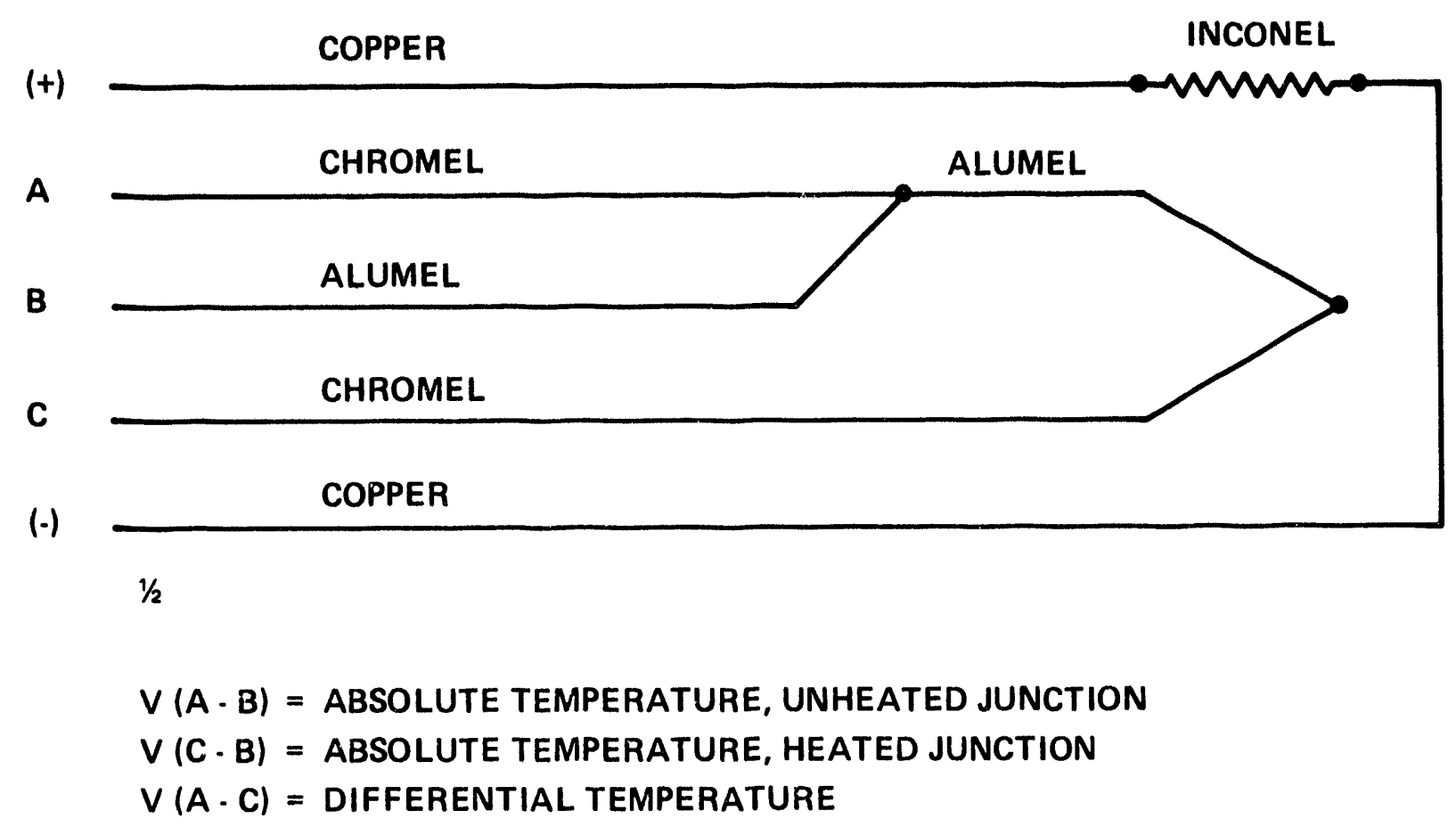

Amendment D

September 30, 1988 


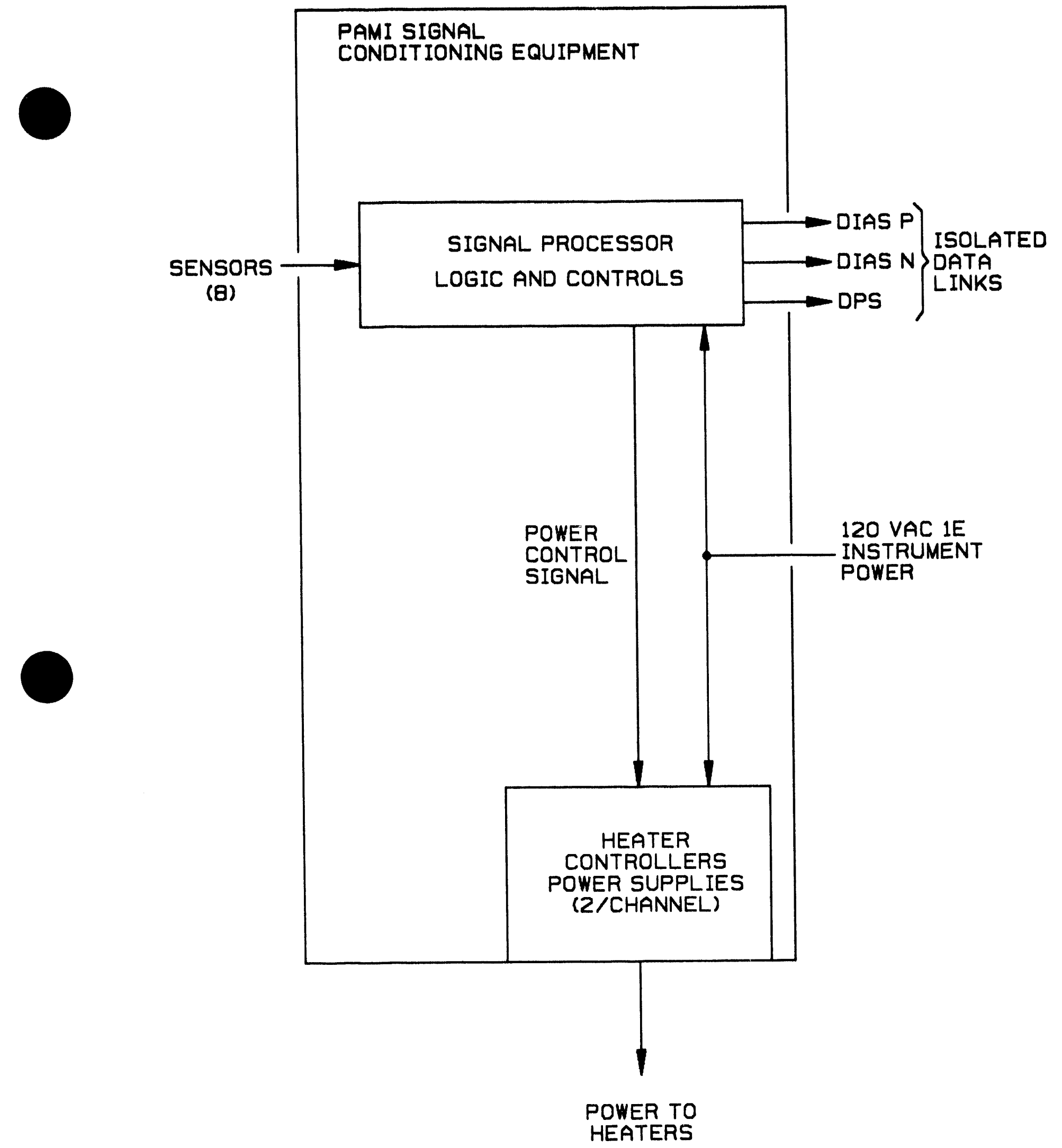

Amendment $D$

September 30, 1988 


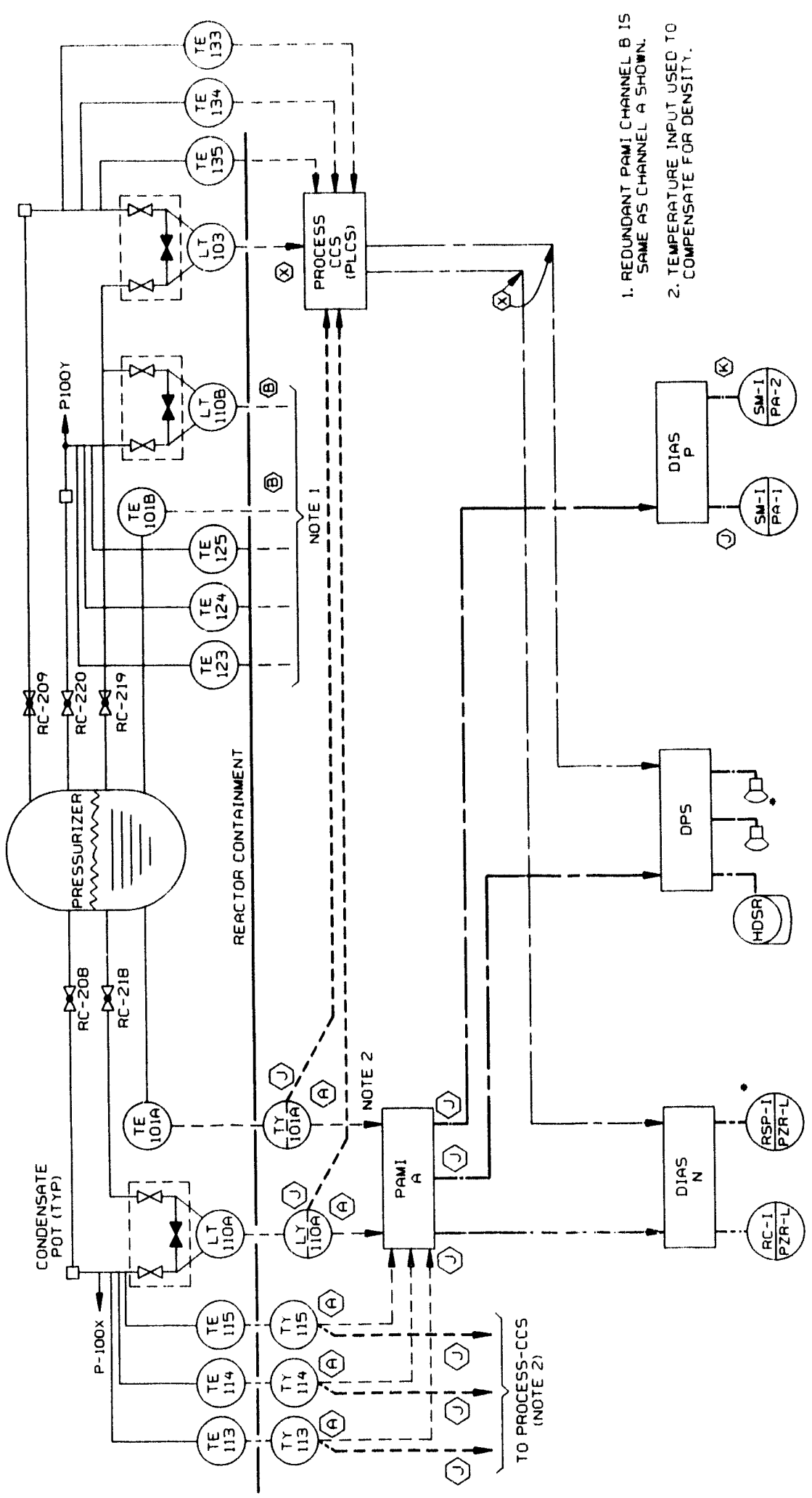




\subsection{ALL OTHER TKBTRUYGNTATIOY BYGTYYS REOUIRED FOR BAFETY \\ 7.6.1 INTRODUCTION}

This section describes the Shutdown cooling system suction line valve interlocks and the safety Injection Tank isolation valve interlocks. The shutdown cooling system (SCS) is discussed in section 5.4.7. The Safety Injection system (SIS) is discussed in Section 6.3 .

The interlocks on the SCS and on the Safety Injection Tanks (SIT) are designed to act as permissives. The SCS suction line valve interlocks permit the isolation valves to be opened below a certain pressure and automatically close them above a certain pressure. The SIT isolation valve interlocks are designed to permit the operator to isolate the SITs at low pressure allowing the SITs to be maintained at a given pressure when the balance of the RCS is depressurized.

Since there are no reactor coolant loop isolation valves, there will always be some flow in an idle loop. There is, therefore, no need for a cold water interlock.

The refueling interlocks are discussed in section 9.1.4. Instrumentation utilized to mitigate the consequences of fuel handling accidents is discussed in sections 9.4 and 15.7.4.

The SCS suction line valve interlocks and the SIT isolation valve interlocks are powered from the emergency busses. This assures that the interlocks and valves will operate under postulated loss of $A C$ power conditions.

7.6 .1 .1

7.6 .1 .1 .1

\section{Bystem Descriptions}

\section{shutdown cooling system suction Line Valve Interlocks}

The SCS is a low temperature, low pressure system used to remove decay heat from the RCS. Cooldown of the RCS is accomplished via the steam generator down to about (LATER) ${ }^{\circ} \mathrm{F}$ and (LATER) psia. Below these values the SCS is used to cool the RCS to refueling temperatures and to maintain these conditions for extended periods of time.

To preclude overpressurization, there are redundant, motor driven, interlocked, isolation valves on each suction line. The interlocks prevent the suction line isolation valves from being opened if RCS pressure has not decreased below the value shown on Table 7.6-1. If the SCS is operating and RCS pressure increases 
above the setpoint shown on Table 7.6-1, the interlock will automatically close the isolation valves. The RCS pressure signals used are provided by pressurizer pressure safety channels. (See Figures 7.6-1a, 7.6-1b and 7.6-1c for this $\log i c)$.

These interlocks are redundant so that any single failure will not cause a suction line and heat exchanger to be subjected to pressures greater than design pressure. The interlock cannot be overridden so that operator action cannot inadvertently subject the SCS to RCS pressure. In addition, no single failure can prevent the operator from aligning the valves, on at least one suction line, for shutdown cooling after RCS pressure requirements are satisfied.

Redundant relief valves are provided on the suction lines to prevent or mitigate overpressurization from pressure transients. These transients can be caused by inadvertent starting of safety injection pumps, charging pumps, inadvertent energization of pressurizer backup heaters, or a combination of these. The relief valves are set at the values shown on Table 7.6-1 to insure the system stays below its design limits.

\section{$7 \cdot 6 \cdot 1 \cdot 1 \cdot 2$ \\ Bafety Injection Tank Isolation Valve Interlocks}

The SIS is designed to inject borated water into the RCS upon receipt of an SIAS (refer to section 7.3) and to provide long term cooling in conjunction with other systems following an accident. The safety Injection Tanks (SITs) inject borated water into the RCS if system pressure drops below their internal pressure. During normal operation, each tank has a motor operated isolation valve that is open with power removed from its motor circuit to eliminate the possibility of spurious actuation. As the RCS pressure is reduced during plant shutdown, the low pressurizer pressure trip setpoint is reduced to avoid inadvertent initiation of safety injection, the sITs are depressurized to a value below the SCS design pressure, and the valves have their power restored and are closed.

The SIT interlocks are used to prevent the SITs from inadvertently pressurizing the SCS while maintaining SIT availability in case of a LOCA. Refer to Figure 7.6-2 for the interlock logic. The isolation valves are manually closed when RCS pressure drops below the value shown on Table 7.6-1 such that the SITs cannot cause overpressurization of the sCs while the SITs are maintained at some pressure above atmospheric. As RCS pressure increases, the valves will automatically reopen at the pressure indicated in Table 7.6-1. This opening of the SIT 
isolation valves insures that the SITs are available for injection during plant startup. If the isolation valves are closed and an SIAS is initiated, the isolation valves will automatically open. The SIAS overrides the interlock or any manual signal.

There is an alarm associated with the SITs. The alarm will sound if the RCS pressure is increased to approximately 700 psig and the SITs have not been repressurized. Refer to Section 6.3.2.2.2 for further information. This insures that the SITs will be available for injection at the RCS pressure specified in the SIS analysis (see section 6.3.3).

\subsection{DIAS Channel $\mathrm{N}$ and DPS Alarms}

The DIAS channel-N and DPS include alarms for a limited number of operational occurrences for which no specific automatic actuation of a safety system is required. Both of these systems provide alarm checking, but DIAS channel $\mathrm{N}$ activates priority-1 alarm tiles for both systems, as described further in section 7.7.1.4 and Chapter 18 .

Alarms are provided for the following conditions to alert the operator to keep the plant operating within technical specification limits and prevent equipment damage.

\subsection{Reactor Coolant Pump Cooling Water Supply Monitoring}

Instrumentation is provided to detect the loss of cooling water to the reactor coolant pumps in order to ensure that the operator will have sufficient time to initiate manual tripping of the pumps to prevent shaft or bearing seizure. The cooling water flow rate to each pump is monitored by a flow transmitter. If the cooling water flow rate is reduced below the minimum required for pump operation, a low flow signal will be initiated for the affected pump. The low flow signals will independently actuate their respective DIAS channel $\mathrm{N}$ and DPS alarms in the control room. The setpoint for alarming is selected with sufficient margin to assure that proper operator action will be taken.

$7.6 \cdot 1 \cdot 1 \cdot 3.2$

Safety Injection Tank Pressure Monitoring

Safety grade instrumentation is provided to alert the operator of the unavailability of the SITs to perform their core flooding function in the event of a LOCA. The pressure in each SIT is independently monitored. Each SIT has three pressure sensors that are processed by the DIAS channel $N$ and DPS to provide validated SIT pressure signals. RCS pressure is monitored by pressurizer pressure sensors that are also validated by DIAS channel $\mathrm{N}$ and DPS. 
If SIT pressure is reduced below that required for core flooding, a low pressure signal will be validated in the DIAS channel $N$ and DPS for the affected tank.

The validated low pressure signal will actuate its respective tank $1,2,3$ or 4 alarm in the control room. The setpoint for alarming low SIT pressure supports the SIT Technical specifications. The alarm system utilizes a one-out-of-one logic for each SIT, with a one-out-of-four logic for each visual alarm window. Each alarm is also included in the system level SIS bypassed/inoperable DIAS alarm logic described in section 7.7 .1 .4 .

\subsection{Fire Protection Instrumentation and Detection System}

The instrumentation utilized to detect, alarm, or mitigate the consequences of fires is discussed in section 9.5.1.

7.6 .1 .2

\section{Design Bases}

7.6 .1 .2 .1

\section{Shutdown Cooling System Suction Line Valve Interlocks}

The scs interlocks conform to the following design criteria:

A. Each suction line shall have at least two valves in series to provide isolation between the RCS and the SCS.

B. The isolation valves shall have interlocks to prevent opening the isolation valves while the RCS pressure is above that which would result in the allowable SCS pressure being exceeded.

c. The interlocks shall meet functional requirements given a single failure.

D. The interlocks shall not prevent achieving cold shutdown from the control room after a single failure.

E. Pressurizer pressure shall be used to control the interlock functions. 
F. Separate, physically independent and diverse sensors, located on separate pressurizer sensing nozzles, shall be provided.

G. The interlocks must not fail so as to preclude opening of at least one SCS path (if RCS pressure permits), or closing of both suction paths after a LOCA.

\subsection{Safety Injection Tank Isolation Valve Interlocks}

The SIT isolation valve interlocks are designed consistent with the balance of the SIS. Because the SIS is an engineered safety feature, the ESF criteria take precedence over any applied to the interlocks. The interlocks conform, generally, to the SIS criteria specified in section 6.3. The SIT interlocks meet the following criteria:

A. The SITs shall not be isolated from the RCS when RCS pressure exceeds a preset value. The interlocks shall function to automatically open the isolation valves when RCS pressure exceeds a preset value.

B. Pressurizer pressure shall control the required function.

C. Separate, physically independent, diverse sensors, located on separate pressurizer sensing nozzles, shall be provided.

D. Operating procedures, administrative controls, and the interlocks, all insure that the isolation valves are open when pressure in the RCS is greater than a preset value.

E. When system pressure exceeds the setpoint the interlock opens the valve. Refer to section 6.3 .2 .2 .2 for additional information.

\subsubsection{System Drawings}

The interlock and isolation valve functional logic is shown in Figures 7.6-1a,7.6-1b,7.6-1c and 7.6-2. Refer to Section 7.3 for detailed Component control system description and Chapter 18 D

for main control panel layouts.

\section{6 .2 \\ ANALYSIS}

7.6 .2 .1

Design Criteria

7.6 .2 .1 .1

\section{Shutdown cooling System Suction Line Valve Interlocks}

A. The isolation valve interlocks are redundant in that there are two trains. Train A has three valves, two receive their 
signal from one pressure sensor and the third valve receives its signal from a diverse sensor. Train $B$ also has three valves which use two different pressure sensors. Each path to each valve will be physically independent and separate from the others. With this degree of redundancy, diversity, and independence, the interlocks can sustain a single failure and can still isolate both heat exchangers or make one available when required.

B. The interlocks and valves can be tested in accordance with General Design Criteria 1 and 21, the intent of Regulatory Guides 1.22 and 1.68 , and the appropriate sections of IEEE standards 279-1971, 336-1985, 338-1977 and 603-1980.

c. The method for identifying power and signal cables and cable trays dedicated to the instrumentation, control, and electrical equipment associated with the isolation valves will be as discussed in section 7.3.2.3.2(V) and will conform to the intent of Regulatory Guide 1.75 as discussed in section 7.1 .2 .10 .

D. The instrumentation, control, and electrical equipment associated with the sCS interlocks are seismically and environmentally qualified to operate under all required design basis events in accordance with the requirements stated in section 3.10 and 3.11 .

7.6 .2 .1 .2

Safety Injection Tank Isolation Valve Interlocks

Because the SIS is an engineered safety feature, the requirements of the General Design Criteria, Regulatory Guides, and IEEE standards appropriate for ESF systems are used for all of the instrumentation and controls. The interlocks are designed to be consistent with the balance of the system and its requirements. Refer to section 6.3 for a discussion of the SIS and section 7.3 for a discussion of the ESFAS.

$7.6 .2 \cdot 1.3$

DIAS Channel $\mathrm{N}$ and DPS Alarms

The DIAS channel $\mathrm{N}$ and DPS alarms utilize validated inputs. There are no operating bypasses for these alarm systems or inputs. The audible alarms for each channel must be acknowledged individually by the operator.

7.6.2.1.3.1 Reactor Coolant Pump Cooling Water Supply Monitoring

Monitoring the cooling water flow rate to the reactor coolant pumps with validated visual status alarms for each pump on low cooling water flow provides sufficient information to the 
operator to determine if cooling water is available to each pump and to take appropriate action in less than 30 minutes to protect the reactor coolant pump affected.

\section{$7 \cdot 6 \cdot 2 \cdot 1 \cdot 3 \cdot 2$ \\ safety Injection Tank Pressure Monitoring}

Monitoring the SIT pressure with validated visual status alarms for each channel on low SIT pressure provides information to the operator to determine the unavailability of the SITs to perform their core flooding function in the event of a LOCA.

$7.6 .2 \cdot 2$

$7 \cdot 6 \cdot 2 \cdot 2 \cdot 1$

\section{Equipment Design Criteria}

\section{shutdown Cooling system suction Line valve \\ Interlocks}

This description is only for the interlocks. The valves and piping are discussed in section 5.4.7. The applicable requirements of IEEE 603-1980 as embodied in section 4 of IEEE 279-1971 are met as described below:

A. General Functional Requirement (Section 4.1):

The interlocks are designed to operate during accident environmental conditions.

B. Single Failure criterion (Section 4.2):

Any single failure leading to loss of one channel will not result in opening of all of the isolation valves installed in series in one SCS suction line. Loss of two selective interlock channels (both part of one SCS suction line) and violation of administrative controls and procedures is required to open all three isolation valves.

c. Quality Control of Components (Section 4.3):

The sensors for these interlocks meet the same quality requirements imposed on the protection system sensors.

D. Equipment Qualification (Section 4.4):

Qualification will be performed as described in section 7.1 .2 .5 on the instrumentation to ensure its operation during expected environmental conditions.

E. Channel Integrity (Section 4.5):

The interlocks are designed to maintain functional capability during accident environments. Failure of an 
interlock will not preclude opening a path or closing both paths of the SCS.

F. Channel Independence (Section 4.6):

The pressure transmitters are located on separate pressurizer nozzles. Separation is maintained between channels.

G. Control and Protection System Interaction (Section 4.7):

Interlocks and control systems that have identical sensor requirements utilize the same sensors. The control systems use sensor signal validation logic, as described in section 7.7.1.1.13, to avoid control/protection system interactions.

No other portions of the interlocks have a non-safety control function.

H. Derivation of System Inputs (Section 4.8):

Pressurizer pressure is the sensed parameter.

I. Capability for Sensor Check (Section 4.9):

The operational availability of the four pressure sensing channels is determined by automatically comparing their outputs once pressurizer pressure has come within the range of the sensors. This is done continuously and independently by DIAS channel $N$ and the DPS as shown on Figure 7.6-3.

J. Capability for Test and Calibration (Section 4.10):

Complete testing capability of the scs isolation valve interlock exists. The tests will be performed in conjunction with periodic in-service testing and inspection of the valves. The test, using the built-in ESF-CCS test logic, will include testing of the interlock logic, valve control circuits, and actuation of the individual valves. This testability will be equivalent to the testability required for ESF circuits. A simplified diagram of the test method is shown on Figure 7.6-3.

Testing may be accomplished sequentially for each series valve by inserting a test signal simulating a decreased pressure condition (while holding the control switch in the open position) to the point where the valve partially opens. It is further lested by manually reclosing the valve, simulating an increased pressure condition and observing that the valve does not open when the hand switch is moved 
to the open position. Finally, the valve can be opened, an increasing pressure signal applied, and the automatic closing of the valve can be observed.

K. Capability for Bypass or Removal from operation (Section 4.11):

Removal of one channel for testing does not compromise system reliability. Failure of one of the remaining channels during a test outage would not create an unacceptable situation, since valve position indication monitoring, with alarms and administrative controls, effectively precludes inadvertent opening of the valves by the operator.

In addition, valve openings during power modes of operation are included in the DIAS and DPS LTOP alarm logic.

L. Bypassing (Sections 4.12 through 4.14):

There are no bypasses.

M. Multiple setpoints (Section 4.15):

This requirement is not applicable.

N. Completion of Protective Action once it is Initiated (Section 4.16$)$ :

This requirement is not applicable.

0. Manual Initiation (Section 4.17):

This requirement is not applicable.

P. Access to Setpoint Adjustments, Calibration and Test Points (Section 4.18 ):

Access is controlled by the administrative procedures.

Q. Identification of the Protective Action (Section 4.19):

Indication of isolation is provided by redundant valve position indication.

R. Information Readout (Section 4.20):

The readout consists of individual and validated cross channel pressure indications on DIAS channel $\mathrm{N}$ and DPS. Analog position indication for four of the six valves and full limit travel position for all six valves are provided. 
S. System Repair (Section 4.21):

Components are accessible for repair such that one channel can be placed out of service for maintenance without jeopardizing the isolation of the SCS.

T. Identification (Section 4.22):

The instrumentation and cables associated with the ScS interlocks will not be uniquely identified as such. The channels will be identified to distinguish between redundant channels of safety-related equipment (see section $7 \cdot 3 \cdot 2 \cdot 3 \cdot 2(V))$.

\subsection{Safety Injection Tank Isolation Valve Interlocks}

The SIS and its design requirements are discussed in section 6.3. The applicable requirements of IEEE 603-1980 as embodied in section 4 of IEEE 279-1971 are met as described below:

A. General Functional Requirement (Section 4.1):

The interlocks are designed to operate during accident environmental conditions.

$\therefore \quad$ Single Failure Criterion (Section 4.2):

loss of an interlock channel, at operating pressure, will not cause a valve to close since the valve motor circuit breaker is racked out. At low pressure, if the interlock should fail and a SIT starts to pressurize the RCS, the SCS is protected since the SITs are depressurized to an acceptable value prior to initiation of shutdown cooling to prevent an interlock failure from causing such a problem.

C. Quality control of Components (Section 4.3):

The sensors for these interlocks meet the same quality requirements imposed on the protection system sensors.

D. Equipment Qualification (Section 4.4):

Type tests will be performed on the instrumentation to ensure its operation during expected environmental conditions. 
E. Channel Integrity (Section 4.5):

The interlocks have been designed to maintain functional capability when exposed to accident environments. They will not preclude safety injection during accident conditions.

F. Channel Independence (Section 4.6):

The pressure transmitters are located on separate pressurizer nozzles. Separation is maintained between channels.

G. Control and Protection System Interaction (Section 4.7):

Interlock and control systems that have identical sensor requirements utilize the same sensors. The control systems use sensor signal validation logic, as described in section 7.7.1.1.13, to avoid control/protection system interactions.

No other portions of the interlocks have a non-safety control function.

The interlocks automatically open the valves when RCS pressure reaches the fixed setpoint shown in Table 7.6-1.

H. Derivation of System Inputs (Section 4.8):

Pressurizer pressure is the sensed parameter.

I. Capability for Sensor Checks (Section 4.9):

The operational availability of the two pressure sensing channels is determined by automatically comparing their outputs via DIAS channel $\mathrm{N}$ and DPS. This may also be done manually at any time by the operator.

J. Capability for Test and Calibration (Section 4.10):

Complete testing capability of the SIT isolation valve interlocks exists. The tests will be performed in conjunction with periodic in-service testing and inspection of the valves. The tests, using the built-in ESF-CCS test logic, will include testing of the interlock logic, valve control circuits, and actuation of the individual valves. A simplified diagram of the test method is shown on Figure 7.6-3.

Testing may be accomplished sequentially for each valve by inserting a test signal simulating a decreased pressure condition (while holding the control switch in the close 
position) to the point where the valve partially closes, and then simulating an increased pressure condition to the point where the interlock circuit causes the valve to return to the fully open position. This procedure will then be repeated to allow testing of the SIAS signal to the valve.

K. Capability for Bypass or Removal from operation (section 4.11):

Removal of one channel for testing does not compromise system reliability. Failure of one of the remaining channels during a test outage would not create an unacceptable situation, since valve position monitoring with alarms, administrative controls and racked out breakers preclude inadvertent closing of the valves by the operator.

L. Bypassing (Sections 4.12 through 4.14):

There are no bypasses.

M. Multiple Set Points (Section 4.15):

This requirement is not applicable.

N. Completion of Protective Action once It Is Initiated (Section 4.16$)$ :

This requirement is not applicable.

0. Manual Initiation (Section 4.17):

This requirement is not applicable.

P. Access to Setpoint Adjustments, Calibration and Test Points (Section 4.18):

Access is controlled by administrative procedures.

Q. Identification of the Protective Action (Section 4.19):

Identification of isolation is provided by redundant valve position indication.

R. Information Readout (Section 4.20):

The readout consists of individual and validated pressure indication for each SIT via DIAS channel $N$ and DPS. Redundant position indication is provided for each valve. This provides the operator with clear, concise information. 
S. System Repair (Section 4.21):

The components are accessible for repair. One channel can be placed out of service without jeopardizing the availability of the SITs.

T. Identification (Section 4.22):

The instrumentation and cables associated with the SIT isolation valve interlocks will not be uniquely identified as such. The channels will be identified to distinguish between channels of safety related equipment (see section $7 \cdot 3 \cdot 2 \cdot 3 \cdot 2(\mathrm{~V}))$.

7.6 .2 .3

Fire Protection Instrumentation and Detection

System

An analysis of the fire protection system is discussed in section 9.5.1. 
TABLE 7.6-1

SHUTDOWN COOLING SYSTEM AND SAFETY INJECTION TANK INTERLOCKS

SYSTEM

Shutdown Cooling System

Suction Line Valves

(SI-654, SI-653, SI-652, SI-651)

Safety Injection Tank

Isolation Valves

Shutdown Cooling Relief Valves
SETPOINT ${ }^{(4)}$

FUNCTION
Permits valves to be opened by operator.

$\geq 500$ psig (2) Valves are automatically opened.

$\leq 415$ psig (2) Permits values to be closed by operator.

SIAS

(3)
Automatically opens the valves, if the valves are closed. Sends an open signal if valves are open that overrides a closing signal.

Prevents or mitigates overpressurization of the SCS.

NOTES: (1) The interlock setpoint is established such that the set pressure of the SCS relief valves (SI-179 and SI-189) will not be exceeded upon opening of the valves. Refer to Section 5.4.7.2.

(2) Refer to Section 6.3.2.2.2.

(3) Refer to Section 5.2.2.10.

(4) Values given are typical. Actual values are site dependent based on the equipment procured. Therefore, the site specific SAR shall make appropriate adjustments as necessary. 


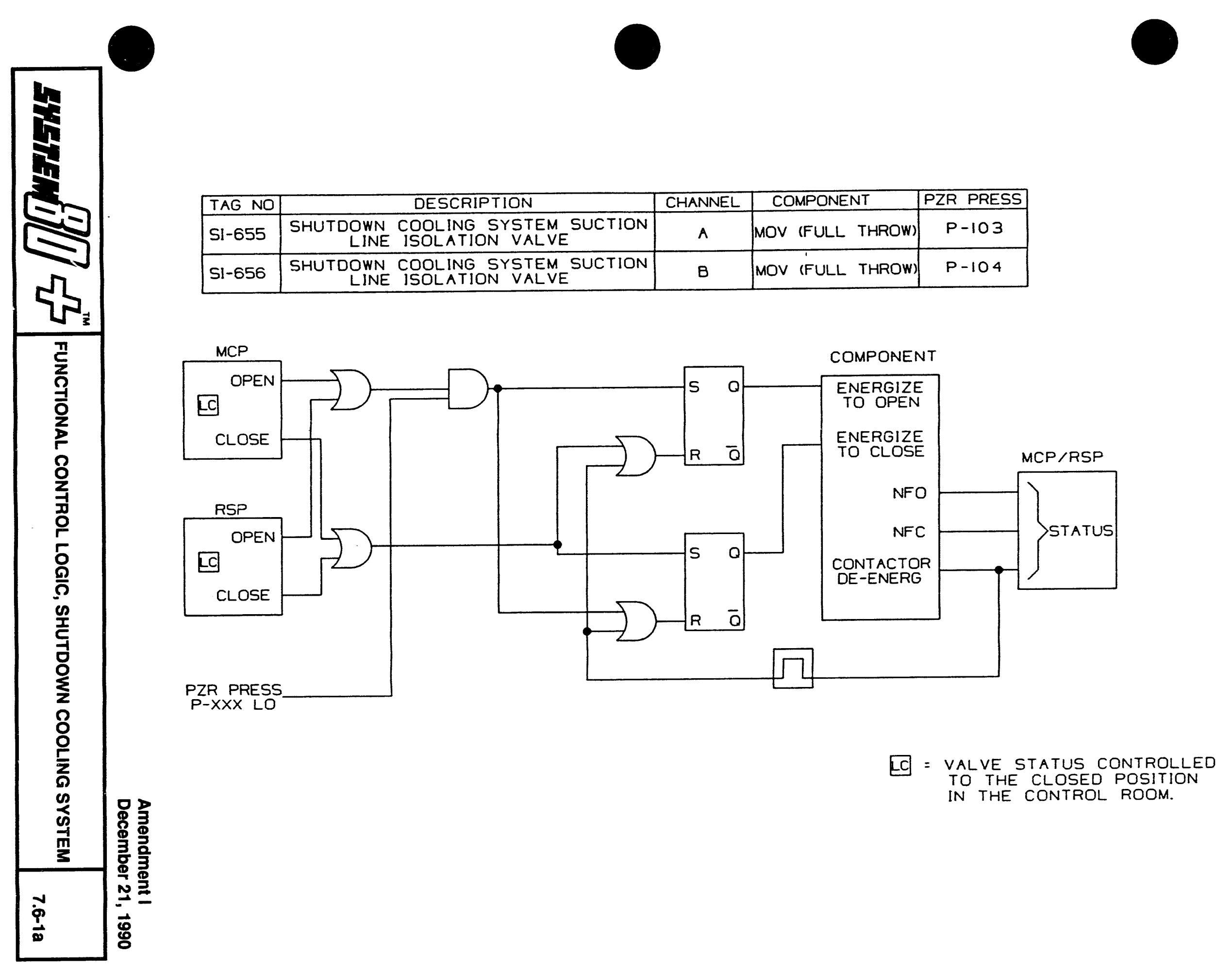




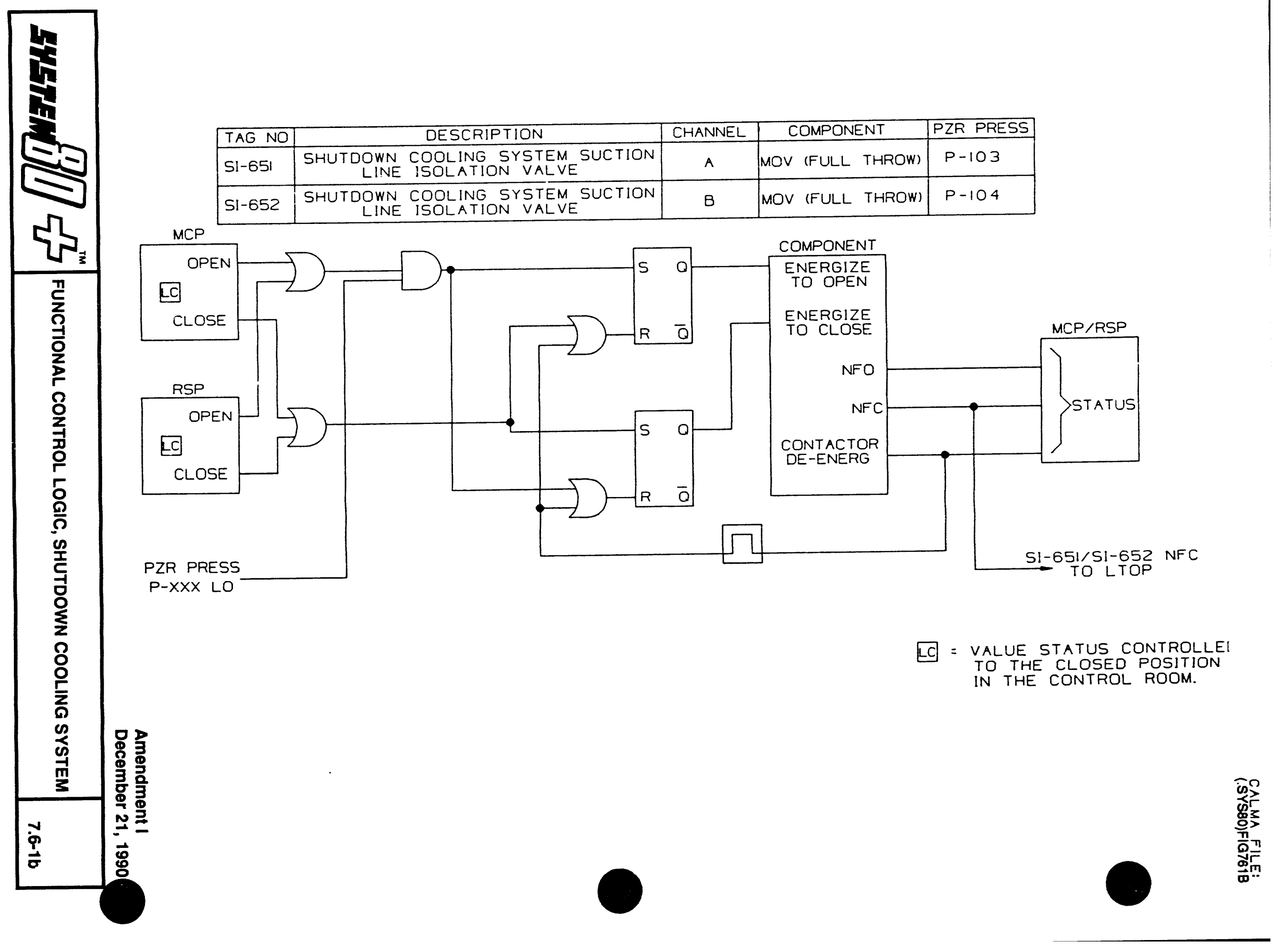




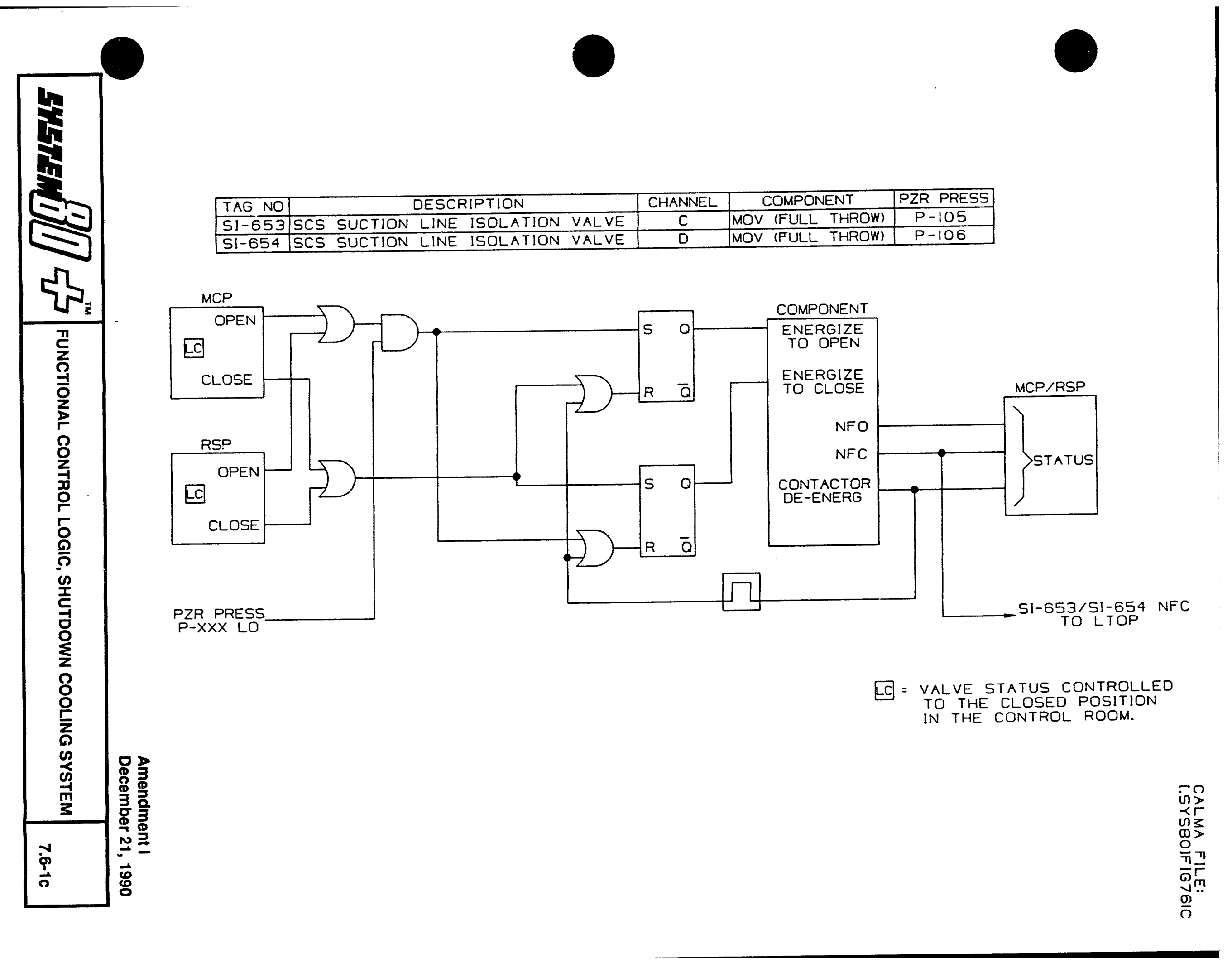




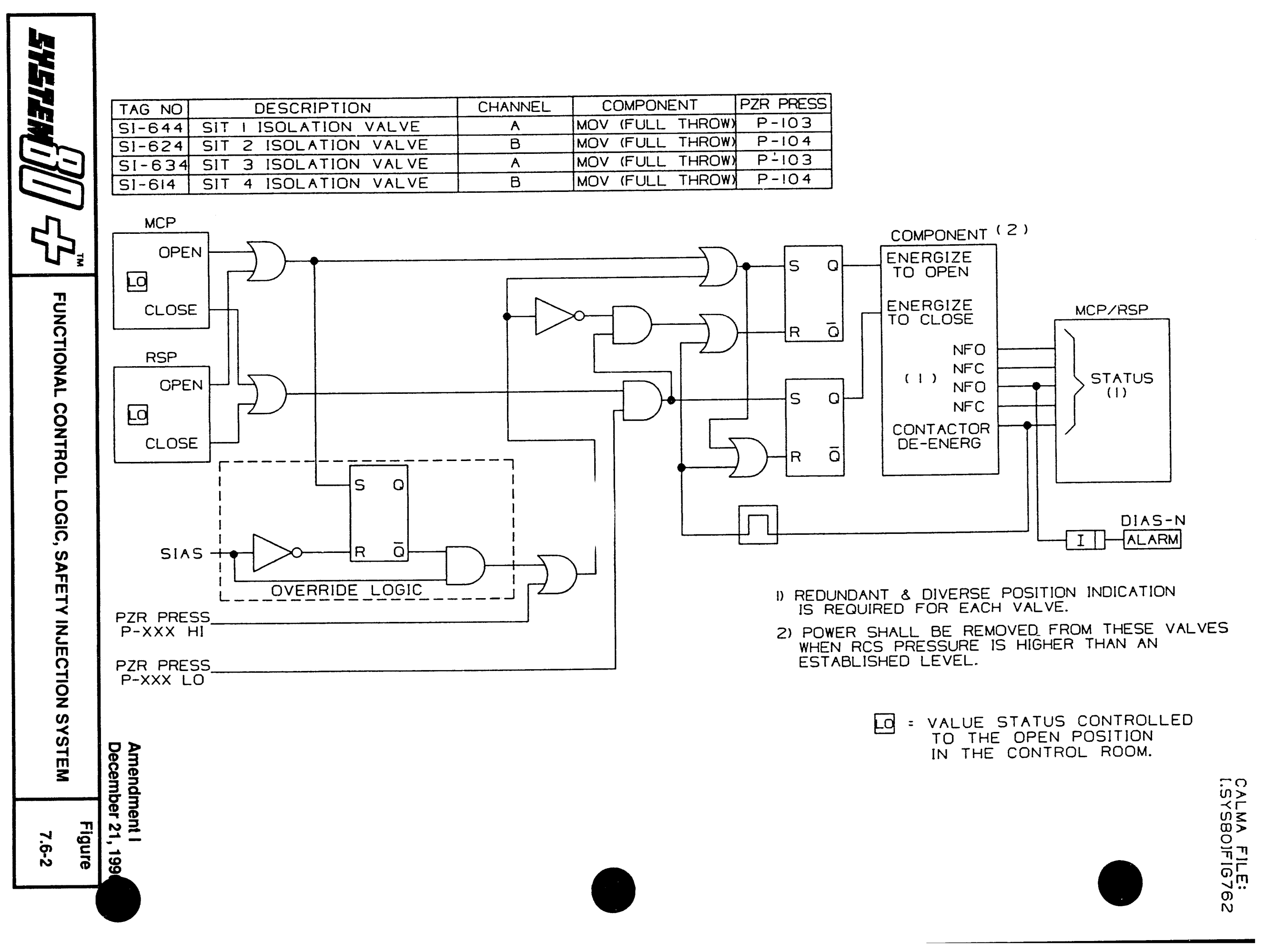



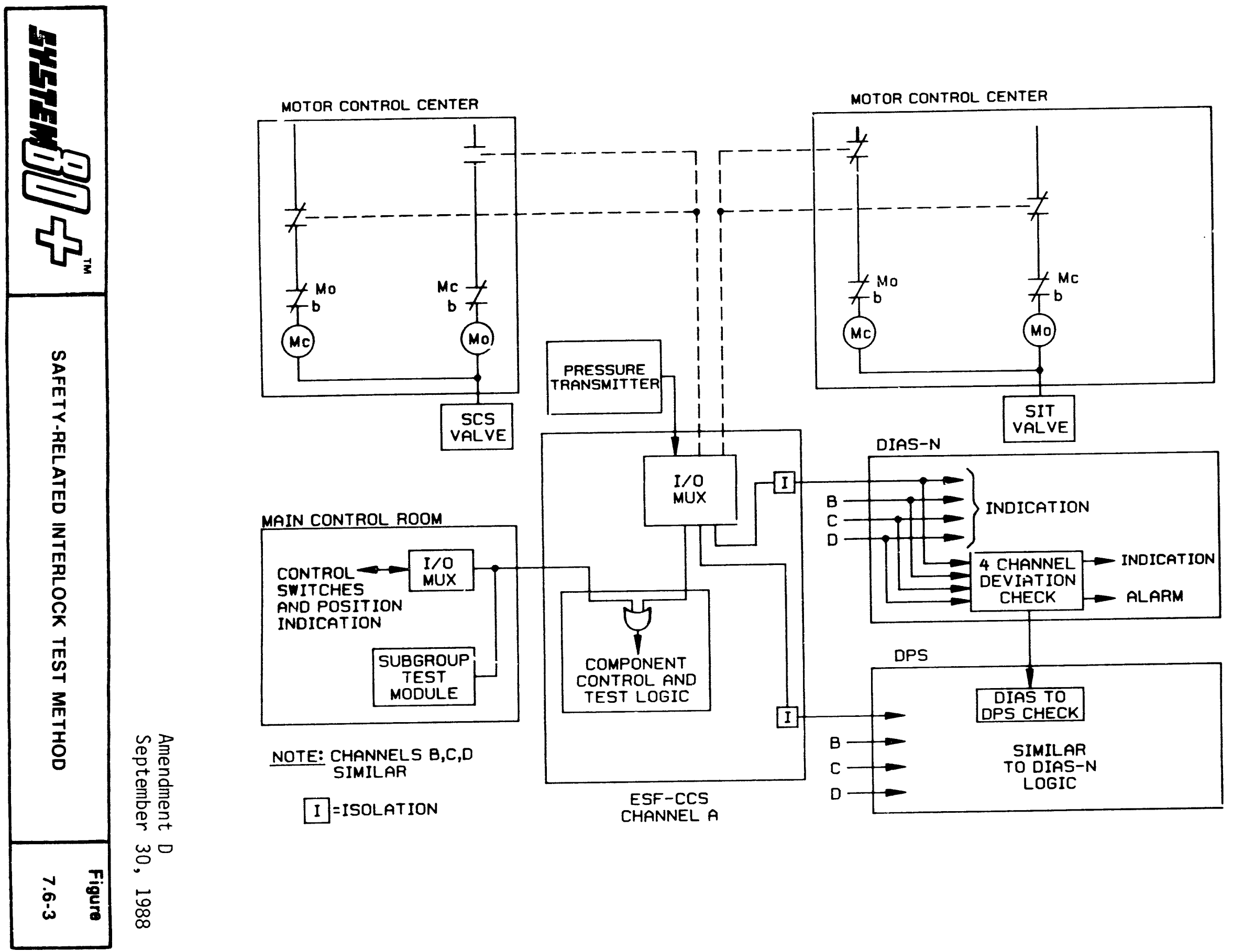


\subsection{CONTROL SYSTEMS NOT REQUIRED FOR SAFETY}

\subsubsection{DESCRIPTION}

The control, instrumentation and monitoring systems whose functions are not essential for the safety of the plant include instrumentation and control equipment not addressed in sections 7.2 through 7.6 .

These systems are provided as an integral part of the Nuplex $80+$ Advanced Control Complex (ACC). As such, they, provide the operating staff the ability to monitor the plant's operating status, change its operating mode and take those actions necessary to maintain the plant within its design basis for all normal modes of plant operation. The ACC systems and equipment described below include the control systems, main control panels and monitoring systems.

\subsubsection{Control Systems}

The general description given below permits an understanding of the reactor and important subsystem control methodology.

The design reactivity feedback properties of the NSSS will inherently cause reactor power to match the total NSSS load. The resulting reactor coolant temperature at which this occurs is a controlled parameter and is adjusted by changes in total reactivity as implemented through CEA position changes or through boric acid concentration changes in the primary coolant.

The ability of the NSSS to follow turbine load changes is dependent on the ability of the control systems or operator to adjust reactivity, feedwater flow, bypass steam flow, reactor coolant inventory, and energy content of the pressurizer such that NSSS conditions remain within normal operating limits.

Except as limited by Xenon conditions, the major control systems described below provide the capability to automatically follow design load changes. Additionally, these automatic systems provide the capability to accommodate load rejections of any magnitude or the loss of one of two operating feedwater pumps.

\subsection{Reactivity Control Systems}

The reactor's reactivity is controiled by adjustments of CEAs for rapid reactivity changes or by adjustment of boric acid concentration for slow reactivity changes. The boric acid is used to compensate for such long term effects as fuel burnup and changes in fission product concentration. The boric acid concentration can be used to do some load following. Since these long term changes occur slowly, operator action is suitable for 
boric acid concentration control. The CEAs can either be controlled manually by the operator or automatically to maintain the programmed reactor coolant temperature and power level during boric acid concentration changes, within the limits of CEA travel.

The Reactor Regulating system (RRS) is used to automatically adjust reactor power and reactor coolant temperature to follow turbine load transients within established limits. The RRS receives a turbine load index signal (linear indication of load) and reactor coolant temperature signals (see Figure 7.7-1). The turbine load index is supplied to a reference temperature $\left(\mathrm{T}_{\mathrm{RFF}}\right)$ program that establishes the desired average temperature. RFFe hot leg and cold leg temperature signals are averaged $\left(\mathrm{T}_{\mathrm{AVG}}\right)$ in the RRS. The $\mathrm{T}_{\mathrm{REF}}$ signal is then subtracted from the $\mathrm{T}_{\mathrm{AVG}}$ AVG $\mathrm{sinal}$ to provide a temperature error signal. Power range neutron flux is subtracted from the turbine load index to provide compensation to the $T_{A V G}-T_{R E F}$ error signal generated.

This resulting error signal is fed to a CEA rate program, to determine whether the CEAs are to be moved at a high or low rate, and to a CEA motion demand program that determines if the CEAs are to be withdrawn, inserted or held. The outputs of the rate and motion demand programs are used by the control Element Drive Mechanism Control system (CEDMCS).

If the temperature error signal is very high, that is, $T_{A V G}$ is much higher than $T_{R E F}$, an Automatic Withdrawal Prohibit AV(AWP) signal is generated. REF ince the withdrawal of CEAs causes $M$ to increase, prohibiting a withdrawal prevents an increase ing the error signal.

CEDMCS uses automatic CEA motion demand signals from the RRS or manual motion signals from the CEDMCS Operator's Module and converts these signals to direct current pulses that are transmitted to the CEDM coils to cause CEA motion.

A reactor trip initiated by either the Reactor protective system (RPS) or the Alternate Protection system (APS) causes the input motive power to be removed from the CEDMCS by the trip switchgear, which in turn causes all CEAs to be inserted by gravity. CEDMCS is thus not required for safety (see Figure $7 \cdot 7-2)$.

There are four different modes of control: sequential group movement in manual and automatic control; manual group movement; and, manual individual CEA movement. Sequential group movement functions such that, when the moving group reaches a programmed low (or high) position, the next group begins inserting (or withdrawing), thus providing for overlapping motion of the regulating groups. The initial group stops upon reaching its 
lower (or upper) limit. Applied successively to all regulating groups, the procedure allows a smooth continuous rate of change of reactivity. The CEDMCS group sequencing logic necessitates that the preceding group reach a specified limit before the next group is permitted to move. The CEDMCS and DPS monitor for proper sequential motion and alarm out of sequence conditions.

The CEDMCS also includes normal CEA control limits for all CEAs and PSCEAs (Part-strength CEAs). These limits include both the upper and lower group stops for full-strength CEAs and the upper (and lower) group stops for the PSCEAs. Control limits are provided to automatically terminate CEA motion upon reaching the CEA limits of travel.

The shutdown CEAs are moved in the manual control mode only, with either individual or group movement. The CEDMCS operator Module permits withdrawal of no more than one shutdown group at any time.

The PSCEAs may be moved manually, with either individual or group movement.

During plant startup and shutdown, and all cases where power is below a preset value, manual control is used. Automatic control of the regulating CEAs by the RRS may be selected by the operator only when power exceeds the preset value. Manual control may be used to override automatic control at any time. The RRS is implemented as part of the CEDMCS.

The CISDMCS includes pulse counting to infer each CEA position by electronically monitoring the mechanical actions within each CEDM to determine when a CEDM has raised or lowered the CEA. This differs from previous designs which inferred each CEA position by counting the "raise" and "lower" control pulses sent to each magnetic jack control element drive mechanism (CEDM). In both designs, the pulse counting CEA position signal associated with each CEA is reset to zero whenever the rod drop contact (located within the reed switch position transmitter housing) is closed. This permits the pulse counting system to automatically reset the position to zero, whenever a reactor trip occurs or whenever a CEA is dropped into the core. This CEA position information is used to feed control board digital displays. Digital displays provide CEA group information and individual CEA position information.

The CEDMCS also provides the DPS with each CEA position from the pulse counting system for use in the DPS CEA monitoring displays and alarms and the core operating Limit supervisory system (COLSS) as described in section 7.7.1.8. 
The CEDMCS receives a CEA withdrawal prohibit (CWP) interlock from the Plant Protection system (PPS). This signal stops withdrawal motion of all CEAs. It can be overridden by the operator at the CEDMCS operator's Module located on the Main control Panel. The CWP interlock is initiated by the PPS based on high pressurizer pressure or CPC pre-trip.

The CEDMCS receives four CEA Motion Inhibit (CMI) interlocks, one from each of the core protection calculators. The interlocks utilize a two-out-of-four configuration to stop CEA motion in both directions. The interlocks can be overridden individually by the operator at the CEDMCS Operator's Module. All four CMI interlocks are initiated any time a CEA deviation is detected by either of the two CEA Calculators. The redundant CMI interlock is part of a defense in depth approach to allow reclassification of a CEA withdrawal deviation from an Anticipated operational occurrence (AOO) to an Accident. This is discussed further in Sections 7.2 and Chapter 15.

CWP and CMI interlocks are interfaced to the protection systems via optical isolation to ensure separation and independence.

Reactor Regulating system (RRS) and Control Element Drive Mechanism Control System (CEDMCS) functions are implemented as part of the Power control system (PCS).

\subsection{Pressurizer Pressure and Level Control Systems}

\subsection{Pressurizer Pressure Control System}

The Pressurizer Pressure Control system (PPCS) maintains the RCS pressure within specified limits by the use of pressurizer heaters and spray valves. The pressurizer provides a water/steam surge volume to minimize pressure variations due to density changes in the coolant. The pressurizer is described in section 5.4 .10 .

A pressurizer pressure signal is used in a proportional controller to control the proportional heaters (see Figure 7.7-3). The heaters will be operated to maintain the pressurizer pressure as required. The operator can take manual control to regulate the pressure.

The pressurizer pressure signal is also sent to a spray valve controller. This provides a signal to the spray valves to control their opening. Since reactor coolant is somewhat cooler than the water/steam mixture, reactor coolant sprayed in will cause some steam to condense and thereby reduce the system pressure. The operator can take manual control of the spray valves to control the pressure. 
If the proportional heaters are being used and system pressure is still decreasing, the backup heaters would be automatically energized. The operator can also manually energize these backup heaters.

The control system has a low level interlock and a high pressure interlock. The low level interlock shuts off the heaters when the level falls below a setpoint.

If the pressurizer pressure reaches a high setpoint, all heaters will be deenergized; this is to ensure that the heaters will not cause the pressure to increase further.

\subsection{Pressurizer Level Control System}

The Pressurizer Level Control system (PLCS) minimizes changes in RCS coolant inventory by using the charging pumps, charging flow control valves and letdown control valves in the chemical and volume control system (CVCS) discussed in section 9.3.4. It also maintains a vapor volume in the pressurizer to accommodate surges during transients. Figure $7.7-4$ shows the PLCS diagram.

During normal operations the level is programmed as a function of RCS average temperature ( $\left.T_{A V G}\right)$ in order to minimize charging and letdown flow requirements. The $T_{A V G}$ goes through a level setpoint program and the setpoint program signal is compared to the actual level signal. The level error signal is sent to a Proportional plus Integral plus Derivative (PID) controller which is used to control the charging and letdown flow control valves.

If the level error program shows that the level is very high it will throttle back the selected charging pump flow control valve to its minimum preset position. If the level is very low, the level error program will cause the charging pump flow control valve(s) to open while the letdown flow control valve is throttled to its preselected minimum flow setpoint.

The auto-manual control allows the operator to control level manually by controlling the charging and letdown valves. The charging and letdown valve selector switches allow the operator to select which valve will be operated by the PLCS.

Pressurizer pressure and level control functions are implemented as part of the Process Component Control system (Process-CCS).

$7 \cdot 7 \cdot 1 \cdot 1 \cdot 3$

Megawatt Demand Setter

The Megawatt Demand setter (MDS) automatically coordinates turbine generator control with specific plant parameters to prevent exceeding NSSS limits affected by load transients. This 
supervisory function can be performed by the unit operator through the Turbine control system (TCS) or, if load is set remotely, manually or automatically through the MDS.

The MDS provides the capability of accepting increase or decrease power load commands from either an Automatic Dispatch System (ADS) remote station or the local MDS panel as shown in Figure 7.7-5. The MDS is functionally similar to systems provided for Arkansas Nuclear one Unit 2 and Waterford Unit 3 . Power denand is compared with various operating limits including those available from the plant protection system (PPS) and the COLSS algorithms in the Data Processing System (DPS). If the demanded load rate of change is greater than that allowed by unit operating limits, an override rate will be generated that will bring turbine loading to a level consistent with the limits (see Figure $7 \cdot 7-6$ ).

The MDS controller calculates overrides based on NSSS trip, BOP and colss limits. As a limit is approached, a maximum rate of load increase is generated. This maximum rate is reduced to zero as the operating condition approaches the limit, thereby allowing unit output to smoothly attain the power allowed by the current unit limiting condition. Similarly, if an operating limit is exceeded, the MDS will generate a minimum negative rate, forcing a load decrease.

Turbine limiting conditions are monitored and used to initiate MDS actions to assure consistency with TCS operation. These actions include taking the MDS completely out of service for major upsets, such as turbine trip, since fast turbine control actions are required to maintain grid stability during grid frequency disturbances.

Megawatt Demand setter (MDS) functions are implemented as part of the Power Control System (PCS).

\section{MDS Modes of Operation}

The MDS has four operational modes: OUT, READY, OPERATOR SET, and ADS. In the latter two modes the loading of the turbine is controlled by the MDS. In the former two modes the loading of the turbine is controlled manually from the Turbine control system Panel, and without MDS supervision.

A. OUT Mode

MDS load control actions are prohibited while in the OUT mode. The TCS is also prohibited from being placed in REMOTE AUTO by an interlock. When the MDS is in OUT, turbine loading must be controlled manually from the TCS 
Panel. For this reason the OUT mode serves as the testing and maintenance mode of the MDS. The MDS can be removed from service at any time by selecting the OUT mode at the MDS Panel. The MDS will automatically assume the oUT mode when a failure is detecter that precludes proper MDS operation.

\section{B. READY Mode}

The READY mode serves as the standby mode for the MDS, and is the preferred mode of operation when plant power is below 15 percent. Placing the MDS in this mode initiates program logic that readies the MDS for the OPERATOR SET mode of control. In this mode the MDS is monitoring and tracking the operation of the plant, and provides limit status information to the operator.

\section{OPERATOR SET MOde}

The OPERATOR SET mode is the preferred mode above 15 percent power when the operator is controlling load. The desired load and loading rate are selected by the operator at the MDS Panel. Manual load limits are selected by the operator at the TCS panel to restrict load transients. The MDS will cause the plant to assume the desired load at the selected rate within the constraints of the manual and NSSS limits.

The OPERATOR SET mode is selected at the TCS Panel when in the READY mode. If the MDS is in READY, it will automatically go to OPERATOR SET when the TCS is placed in the REMOTE AUTO mode. If the MDS is in the ADS mode, the OPERATOR SET mode is selected at the MDS Panel.

D. ADS Mode

In the ADS mode, the plant is loaded in response to signals from the remote Automatic Dispatch System as shown on Figure 7.7-6. The ADS can increase or decrease the generator output of the plant within the manual and unit limits of the MDS. The ADS mode is selected by the operator at the MDS panel when in the OPERATOR SET mode.

With no MDS or plant restrictions on load level or loading rate, the MDS responds directly to ADS or operator loading requests. These requests are limited to 5 percent per minute and are then sent by the MDS to the TCS Load Reference. The NSSS responds by following the turbine load. 
The Feedwater control system (FWCS) is designed to automatically control the steam generator downcomer water level during power operations between $5 \%$ and 100\%. Steam generator level will be controlled during the following conditions (assuming that all other control systems are operating in automatic):
A. Steady state operations.
B. $1 \%$ per minute turbine load ramps between $5 \%$ and $15 \%$ NSSS power and $5 \%$ per minute turbine load ramps between $15 \%$ and $100 \%$ NSSS power.
C. $10 \%$ turbine load steps between $15 \%$ and $100 \%$ NSSS power.
D. Loss of one of two operating feedwater pumps.
E. Load rejection of any magnitude.

The discussion of the FWCS will refer to only one steam generator. Each FWCS controls the level in its corresponding steam generator. Refer to Figure 7.7-7 for the FWCS block diagram and Section 10.4.7 for condensate and feedwater system descriptions.

Below 15\% NSSS power, the FWCS performs dynamic compensation of the steam generator level signal to generate a flow demand signal that is sent to a downcomer valve program where a downcomer valve demand signal is generated. The programmed signal, or a manual control signal from the operator is passed to the valve. The signal will control the valve position. When the FWCS is in this control mode, the economizer control valve will be closed and the pump speed setpoint will be near its minimum value.

As NSSS power increases above 15\%, the downcomer valve closes, allowing the economizer valve to regulate the feedwater flow rate and the steam generator level signal is compensated by the difference between the total feedwater flow and total steam generator flow signals. The resulting signal is subtracted from the level setpoint signal and sent through a proportional plus integral (PI) controller. The resulting total feedwater demand signal goes to an economizer valve program which produces a valve demand signal which controls the economizer valve. This signal can also be manipulated manually using a process controller. Process controller operation is described in section 18.7.1.7.

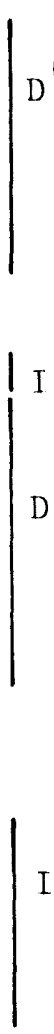


The signal also goes to a high select function that selects the higher of the total feedwater demand signals from both feedwater systems and passes it to the pump program. The pump program generates a pump speed setpoint signal which is directed to one of the feedwater pumps. This signal can also be manipulated manually using a Process cont,oller.

The FWCS has two variable speed motor-driven main feedwater pumps normally operating and one variable speed motor-driven pump which will be started manually in the event of loss of one of the two operating pumps. Selector switches are provided on the main control board for this purpose. An interlock is provided to preclude selection of more than two main feedwater pumps. The selector switches also permit operation of any combination of two main feedwater pumps from one Process Controller in the event of a FWCS channel failure.

Feedwater control functions are implemented in the Process-CCs.

\section{$7 \cdot 7 \cdot 1 \cdot 1 \cdot 5$} Steam Bypass Control system

The Turbine Bypass system consists primarily of the turbine bypass valves and the steam Bypass control system (SBCS). The SBCS controls the positioning of the turbine bypass valves through which steam is bypassed around the turbine into the unit condenser.

The system is designed to increase plant availability by making full utilization of turbine bypass capacity to remove excess NSSS thermal energy following turbine load rejections. This is achieved by the selective use of turbine bypass valves and the controlled release of steam. This avoids unnecessary reactor trips and prevents the opening of pressurizer or secondary safety valves.

Refer to Figure 7.7-8 for the SBCS block diagram. The Reactor Power Cutback System (RPCS), discussed in section 7.7.1.1.6, is used in conjunction with the SBCS to reduce the required turbine bypass valve capacity. Additionally, the SBCS is used during turbine loading to provide an even load on the reactor as the turbine is brought up to load. The system is also used during reactor heatup and cooldown to remove excess NSSS energy, and control the rate of temperature change.

The following three types of valve signals are generated for each turbine bypass valve: a modulation signal which controls the flow rate through the valve; a quick opening signal which causes the valve to fully open in a short time; and, a valve permissive signal which is required for the preceding two signals to operate the bypass valve. 
In the modulation mode, a steam flow signal is sent to a program which develops a main steam header pressure program signal. At the same time, the pressurizer pressure is used to generate a pressurizer pressure bias program. The two program signals and the measured main steam header pressure are compared to provide an error signal that goes to the controller. The controller demand, or a manual signal provided by the operator, is passed to an electro-pneumatic converter on each turbine bypass valve. This converts the electrical signal to an air signal that is passed through the first solenoid valve to the air actuated turbine bypass valve as shown on Figure 7.7-8.

In the quick opening mode, the steam flow signal is biased based on pressurizer pressure and is sent to a steam flow rate change detector. The change detector output is compared to a threshold value so that, if the change signal exceeds the threshold, a quick opening signal is produced. The quick opening signal energizes the solenoid which then blocks the modulated air signal and applies the full air system pressure to quickly open the valve.

A permissive signal is also produced by the SBCS. This signal is provided by control logic identical to that described above except that the output of the permissive controller is converted to a binary signal and fed into an OR function with the permissive quick opening signal. If a permissive signal is present it will open the second solenoid valve and allow either the modulated or the quick open air signal to be applied to the pneumatically operated bypass valves. When the permissive signal is removed the control air is vented to the atmosphere and the valve quickly closes. When turbine condenser pressure exceeds a preset value, the turbine bypass valves are prevented from opening.

Reactor Power Cutback demand signals are generated at a higher threshold by the same functions that produce the valve quick opening signals. These redundant signals are sent to the RPCS.

Steam bypass control functions are implemented as part of the Process-cCs.

\section{7 .1 .1 .6 \\ Reactor Power Cutback System}

The NSSS normally operates with minor perturbations in power and flow. These can be handled by the control systems discussed above. Certain large plant imbalances can occur however, such as a large turbine load rejection, turbine trip or loss of one of two on-line main feedwater pumps. Under these conditions, maintaining the NSSS within the control band ranges can be accomplished by rapid reduction of NSSS power at a rate which is 
greater than that provided by the normal high speed CEA insertion. In addition, rapid NSSS power reduction is effective in gaining sufficient thermal margin to accommodate inward CEA deviations (including spurious rod drops) without a reactor trip, (refer to section 7.2 regarding the Core protection Calculators). Refer to Figure 7.7-9 for functional block diagram of the RPCS.

The RPCS is a control system designed to accommodate certain types of imbalances by providing a "step" reduction in reactor power. The step reduction in reactor power is accomplished by the simultaneous dropping of one or more preselected groups of full strength regulating CEAs into the core. The CEA groups are dropped in their normal sequence of insertion. The RPCS also provides control signals to the turbine to rebalance turbine and reactor power following the initial reduction in reactor power as well as to restore steam generator water level and pressure to their normal controlled values. The system is designed to accommodate large load rejections, the loss of one feedwater pump or inward deviations of CEAs (including spurious rod drops).

The RPCS receives each of the following signals: loss of any II operating feedwater pump (two signals per pump); two cutback demand signals from the SBCS; and, four cutback demand signals from the core protection calculators (one signal from each calculator). A two-out-of-two logic is required to actuate the system for load rejections or loss of a feedwater pump. A two-out-of-four logic is required to actuate the system for CEA deviations to ve consistent with the two-out-of-four trip initiation from the CPCs and Plant protection system. The CEDMCS two-out-of-four logics for the CPC cutback demand may be converted to two-out-of-three during CPC maintenance. The operator has the capability to manually actuate the system.

The predetermined pattern of appropriate CEA groups for use in the reactor power cutback is accomplished via CEA selection logic in the Data Processing system (DPS). This logic utilizes NSSS power, CEA positions, and coolant temperatures, and provides the RPCS with the CEA groups selected for dropping during reactor power cutback. If the DPS CEA selection logic is inoperable, the RPCS control logic switches to the manual select mode. In the manual select mode, the operator inputs the CEA group drop selection through the RPCS operator's console. This feature increases the availability of the system.

RPCS actuation initiates the dropping of the preselected pattern of CEAs. There are inhibits in the control Element Drive Mechanisms Control system (CEDMCS) to prevent the possibility of the RPCS dropping CEA groups that are not intended to drop for a reactor power cutback (e.g., part-strength groups, shutdown groups). Subsequent insertion of other groups either 
automatically by the Reactor Regulating System (RRS) or manually by the operator occurs as necessary. The actuation logic also temporarily changes plant control to a turbine follow mode by first initiating a rapid turbine power reduction to $60 \%$ power followed by a further reduction if necessary to balance turbine power with reactor power. The RPCS is implemented as part of the Power Control system (PCS).

\subsection{Boron Control System}

Information is supplied to the operator to allow regulation and monitoring of the boron concentration in the reactor coolant. The means by which RCS boron control is accomplished is by dilution and boron addition using the process-Component control System described in section 7.7.1.1.12. Refer to Section 9.3.4 for a discussion of the Chemical and Volume control system (CVCS). To allow the operator to maintain the required boron concentration in the reactor coolant, the volume control Tank contents may be maintained at a prescribed boron concentration either manually or automatically. To assist the operator in maintaining the proper boric acid concentration in the RCS, indications of boron concentration, in parts per million (ppm), are available on a DIAS discrete indicator, the DPS CRT displays and trends described in Sections 7.7.1.4, 7.7.1.7 and Chapter 18 . These signals are supplied by the Boronometer. Additional discrete indicators and CRT displays indicate reactor makeup water flow and boric acid makeup flow which can be used to determine whether boron addition or dilution is occurring.

The Boronometer detects the boron concentration by passing reactor coolant around a neutron source. Refer to Figure 7.7-10 for the Boronometer block diagram. Around the source are $\mathrm{BF}_{3}$ neutron detectors. As the boron concentration decreases the neutron flux detected will increase. The circuitry converts this flux signal, corrected for sample temperature, to a ppm boron signal in the signal processing drawer. These processed signals are sent to the DPS and Discrete Indication and Alarm system (DIAS) for display in the control room.

The information supplied by the Boronometer system is used in addition to regular sampling of the reactor coolant to determine boron concentration.

At power, the boron coricentration and the CEA position determine reactor coolant temperature. Because of the long time required to change the boron concentration, the boron is used for long term effects such as fuel burnup and fission product build up. Boron concentration control can also be used for load following. By adjusting the boron concentration, the CEAs can be withdrawn to provide an adequate shutdown margin. Boron control is provided via the Process-CCS. 


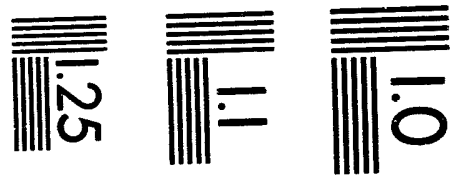

$$
\begin{aligned}
& \overline{\overline{\overline{|l|}}}
\end{aligned}
$$

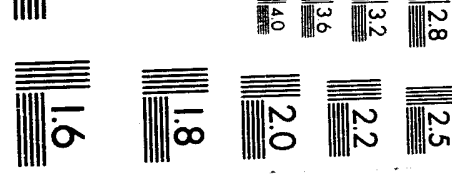



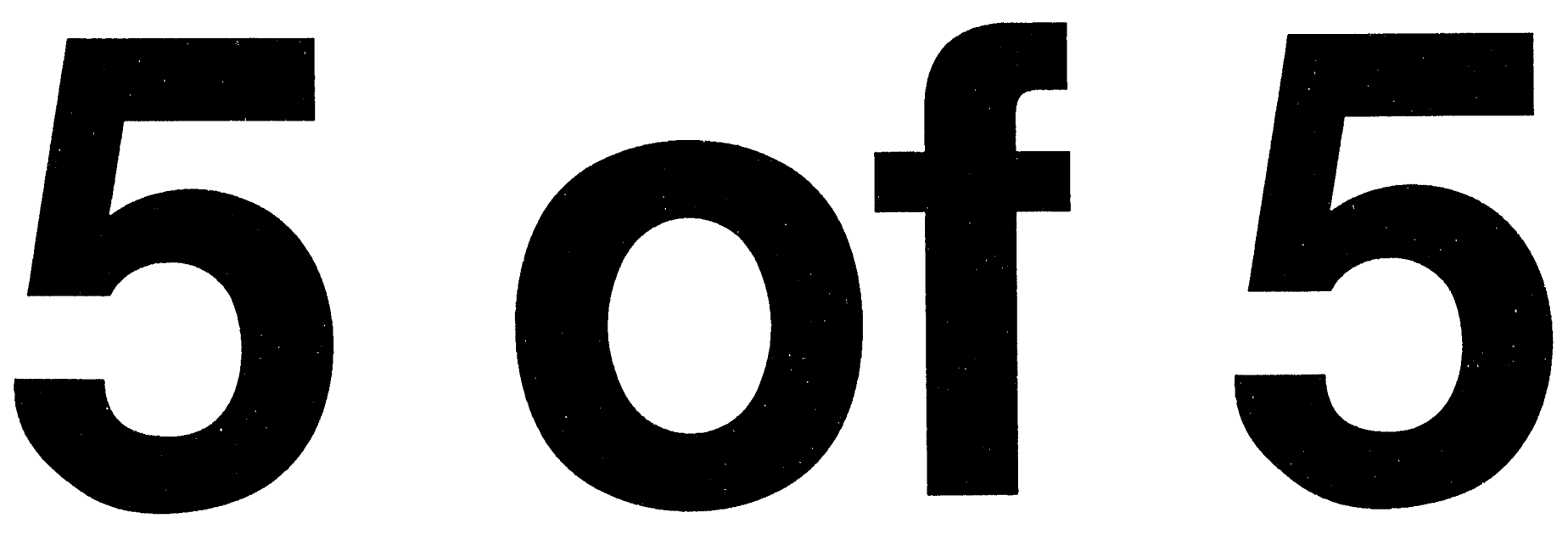
The in-core neutron flux instrumentation is used to monitor the core power distribution and are fixed in place at all times during operation.

There are 61 fixed in-core monitoring assemblies with-five self-powered Rhodium detectors in each location. The 61 assemblies are strategically distributed about the reactor core and the five detectors are axially distributed along the length of the core at $10,30,50,70$ and $90 \%$ of core height. This permits representative three dimensional flux mapping of the core. The Rhodium detectors produce a delayed beta current proportional to the neutron activation of the detectors which is proportional to the neutron flux in the detector region.

The signals from the in-core detectors are sent to the DPS for monitoring and display. The DPS performs the background, beta decay delay and Rhodium depletion compensation using digital signal processing routines.

The fixed in-core instrumentation system is designed to perform the following functions:

A. To determine the gross power distribution in the core during different operating conditions from $20 \%$ to $100 \%$ power.

B. To provide data to estimate fuel burn-up in each fuel assembly.

C. To provide data for the evaluation of thermal margins in the core.

The fixed in-core detectors can be used to assist in the calibration of the ex-core detectors by providing azimuthal and axial power distribution information. The safety-related ex-core neutron flux monitoring system is used to provide indication of the flux power and axial distribution for the Reactor Protective system.

\section{7 .1 .1 .9}

\section{Ex-Core Neutron Flux Monitoring system}

The ex-core neutron flux monitoring system includes neutron detectors located around the reactor core and signal conditioning equipment located in the control room area.

Ex-core detector channels provide source level neutron flux information to the reactor operator for use during extended shutdown periods, initial reactor startup, startups after 
extended shutdown periods, and following reactor refueling operations. Each channel consists of a dual section proportional counter assembly, with each section having multiple $\mathrm{BF}_{3}$ proportional counters, one preamplifier located outside the reactor shield, and a signal processing drawer containing power supplies, a logarithmic amplifier, and test circuitry. High voltage power to the proportional counters is terminated several decades of neutron flux above the source level to extend detector life. These channels provide readout and audio count rate information but have no direct control or protective functions.

Ex-core detector channels also provide neutron flux information, |D in the power operating range of 18 to $125 \%$, to the Reactor Regulating system fo: use during automatic turbine load-following operation (see section 7.7.1.1.1). Each channel consists of detectors and signal conditioning equipment including power supplies, a linear amplifier, and test circuitry.

$7 \cdot 7 \cdot 1 \cdot 1 \cdot 10$

Boron Dilution Alarm system

Reactivity control in the reactor core is affected, in part, by soluble boron in the RCS. The Boron Dilution Alarm Logic (BDAL) (see Figure 7.7-11) utilizes the ex-core detector instrumentation signals to detect a possible inadvertent boron dilution event while in Modes 3-6. The BDAL is implemented separately in the DIAS and DPS to ensure detection and alarming of the event.

The BDAL detects a possible inadvertent boron dilution event by monitoring the neutron flux indications. When these neutron flux signals increase (during shutdown) to equal or greater than the calculated alarm setpoint, alarm signals are generated by the DIAS and DPS. The alarm setpoint is periodically, automatically lowered to be a fixed amount above the current neutron flux signal. The alarm setpoint will only follow decreasing or steady flux levels, not an increasing signal. The current neutron flux indication and alarm setpoint are available via the DIAS and DPS CRT displays. There is also a reset capability to allow the operator to acknowledge the alarm and initialize the system.

\subsection{Alternate Protection system}

The Alternate Protection system (APS) augments the Reactor Protective System to address 10 CFR 50.62 requirements for the reduction in risk of Anticipated Transients without Scram (ATWS) and the use of ATWS Mitigating Systems Actuation circuitry (AMSAC) . 
The APS design includes an Alternate Reactor Trip signal (ARTS) and Alternate Feedwater Actuation signal (AFAS) that are separate and diverse from the Plant protection system (PPS) as described in section 7.1.19. The ARTS equipment provides a simple, yet diverse mechanism to significantly decrease the possibility of an ATWS and the AFAS provides added assurance that an ATWS event could be mitigated if it were to occur.

The ARTS will initiate a reactor trip when pressurizer pressure exceeds a predetermined value (see Table 7.7-1). Turbine tripped signals can also initiate ARTS if the Reactor Power cutback System is out of service. The ARTS turbine trip input is manually enabled from the main control panel. The ARTs circuitry is diverse from that of the RPS. The ARTS design uses a two-out-of-two logic to open the CEDM motor generator output contactors, thus removing motive power to the Reactor Trip Switchgear system (RTSS). (See Figure 7.7-12).

The AFAS will initiate emergency feedwater when the level in $D$ either steam generator decreases below a predetermined value (see Table 7.7-1). Its circuitry is diverse from that of the PPS Reactor Protection system as described in section 7.1.1.9. Actuation of the EFW components (pumps and valves) is achieved by sending isolated AFAS signals to the ESF-Component Control system described in section 7.3.

The following data is supplied to the DIAS: ARTS and AFAS trip status; pressurizer pressure; and, steam generator 1 and 2 level parameters for display. The DPS receives the same data for display as supplied to the DIAS. APS functions are implemented as part of the Process-CCS.

\subsection{Process Component Control System}

The Process Component Control system (Process-CCS) is designed to control non-safety related components such as pumps, valves, heaters and fans. It also provides process variables and CCS status information to the DPS and DIAS for plant monitoring.

The system is designed, as shown in Figure 7.7-13, to permit component assignments to independent non-class 1E subgroup segments to minimize the plant impact due to component or system level failures. Standardized component control logic and I/O interfaces are provided for the various types of components to be controlled as described in section 7.3. The design includes Subgroup Control Logic to perform complex supervisory control of subgroups of components and to generate system status information for use by the DPS and DIAS. The design also includes master transfer capability with isolation to disable all Main control Room controls and enable component controls for the Remote Shutdown Panel as described in section 7.3. 
The Process-CSS Division Master Processors include a sequencer to $\left.\right|_{1}$ automatically siart and load the Alternate AC source with Essential Non-safety loads during LOOP events coincident with a loss of non-safety on-site power. When an Emergency Diesel Generator is out of service this sequencer is blocked permitting automatic loading of selected Class $1 \mathrm{E}$ Division loads by the ESF-CCS sequencer as described in sections 8.3.1.1.4 and 8.3 .1 .1 .5 .

The Process-cCs configuration is designed to accommodate both local and remote distribution of input/output (I/O) multiplexers.

The system architecture uses multiple redundant component control logic processors with redundant internal data communications similar to that described in section 7.3 .

The ESF-CCS described in Section 7.3 and the Process-CCS utilize diverse electronics. They are both microprocessor based systems with programmable software providing their unique component control applications. Diversity is incorporated between the two designs to offer a defense in depth approach to ensuring maximum availability of normal and emergency systems.

\subsection{Control and Monitoring Systems Sensed Parameters}

Where control and protection systems have identical sensor input requirements, redundant class $1 \mathrm{E}$ sensors that are used independently by each channel of the protection system may, in selected cases, also be used by the control system. For each sensed parameter, the control system monitors all four redundant instrument channels via fiber-optic interfaces to ensure electrical independence. Within the control and monitoring systems, signal validation logic is used to detect bypassed or failed sensors, thereby ensuring that they cause no erroneous control actions and to select the sensed value to be used in the control system. The control system signal validation logic is described further below.

The validation logic design ensures that with a PPS sensor or channel in bypass, another sensor can fail with no resulting control system action. Therefore with one channel in bypass the protection system remains in an effective two-out-of-three configuration, meeting the required single failure criteria.

\section{Signal Validation Description}

The signal validation logic functions as follows:

A. All "good" sensors are averaged ("good" is explained below). 
B. Each sensor is then deviation-checked against the average to verify that the average was calculated using only sensors that have not drifted or failed.

Sensors that show acceptable deviations from the average are considered "good"; deviating sensors are considered "bad". If the average was calculated with "bad" sensors, the most deviating sensor is eliminated, then steps $A$ and $B$ are repeated. 


\section{THIS PAGE INTENTIONALLY BLANK}


C. An average calculated with only "good" sensors is considered valid and is then used as the controlling signal within the control system(s). "Bad" sensors are automatically declared "good" when they show an acceptable deviation from the previously determined valid signal.

The algorithm will eliminate bad sensor values under all fa-ilure conditions. However, the validation algorithm will be unable to determine a valid signal to be used for control under two conditions:

A. If successive failures have occurred leaving less than two "good" sensors available.

B. If two sensors are declared "bad" within the same execution cycle of the algorithm. If this occurs, it is assumed that two sensors have failed simultaneously (even though this is an unlikely event). With two simultaneous failures a valid signal cannot be determined.

In either case above, the control system will be automatically switched to the manual mode, with all control outputs remaining unchanged and an alarm will be generated. The operator can select a sensor to be used and can then return the system to the automatic mode. Administrative procedures will ensure that if a protection channel is in bypass, the only sensor selected is within the bypassed or tripped channel if that sensor is operable. If the sensor from the bypassed or tripped channel is not operable, the control system must be left in manual. This will avoid adverse control/protection interaction if a subsequent failure should occur in the selested channel. It is noted that once a sensor is selected by the operator, that sensor is used by the validation algorithm to automatically return "bad" sensors to "good". A "good" sensor is declared when its deviation check against the selected sensor is acceptable.

\section{Signal Validation Classification}

To ensure correct performance of the validation logic, it will be designed using the same quality assurance program as for class $1 \mathrm{E}$ systems. The logic will be implemented within the respective control systems. The following two design features ensure that plant safety is not diminished as a result of placing the validation logic in the control systems.

A. The fiber-optic interfaces used to transmit the class $1 \mathrm{E}$ protection channels to the control systems ensure that there are no electrical failures that can adversely propagate from 
the control systems to the protection system. In addition, this isolation ensures that an electrical fault on any single sensor will not cause failures in the signal validation logic.

B. The sensors are qualified to operate through adverse seismic and environmental conditions. Since the sensors are not affected by such conditions, the protection system will not be adversely affected.

To ensure that no undetected failures exist within the signal validation logic, three levels of testing are provided:

A. The hardware in which the logic is implemented is continuously tested to detect electronic component failures.

B. The result of the validation logic (i.e., the controlling signal) is continuously transmitted to the DPS from the control system while the raw sensor data is transmitted to the DPS from the protection system. The DPS calculates its own valid signal and continuously compares it to the valid signal from the control system. Unacceptable deviations are alarmed.

c. On a periodic basis, sensor inputs to the control system are manually disturbed to verify that the logic correctly discriminates the bad data.

\section{Signal Validation Failure Analysis}

The design described above provides a highly reliable system that will discriminate bad sensor inputs to prevent erroneous control system actions. Not withstanding this high reliability, the following section describes the effects of failures in the signal validation logic.

A. All protection sensors and channels operable, followed by a control system failure - Failure of the signal validation logic can cause erroneous control systems action similar to any other failure postulated within the control systems. In this case failure of the control system, including the signal validation logic, is considered the initiating event. The fiber optic isolation between the control system and protection channels ensures that this event does not result in any common cause failures within the protection system. with all four protection sensors operable, an unrelated 
random protection sensor or channel failure can occur while leaving the protection system with three operable channels to protect the plant (two are required for protective action).

B. All protection sensors and channels initially operable, followed by a single sensor failure - In this scenario the sensor failure is considered the initiating event. Since the signal validation logic is isolated from the sensor (as discussed above) and it is periodically tested to ensure correct operability, the signal validation logic can be expected to function correctly. It, therefore, discriminates the bad sensors, avoiding erroneous control systems action. A failure of the control system, including the signal validation logic, would be considered an independent single failure. Under the assumption that all sensors and protection channels were initially available, three protection channels remain operable to protect the plant (two are required for protective action).

c. One protection sensor or channel bypassed or inoperable, followed by a control system failure - Failure of the signal validation logic can cause erroneous control systems action, as described above. Again, this is considered the initiating event. As in case $A$. above, the fiber optic interface ensures that the failure does not propagate to the protection system. With one protection sensor or channel inoperable, an unrelated random failure can occur in another protection sensor or channel, still leaving the protection system with the required two channels to protect the plant.

D. One protection sensor or channel bypassed or inoperable, followed by a single sensor failure - The sensor failure is considered the initiating event. As explained previously in case B., due to its independence and periodic testing, the signal validation logic can be expected to discriminate the bad sensor. A failure of the control system, including the signal validation logic, would be considered an independent random single failure. Under the assumption that one protection channel was initially inoperable, the required two channeis would still be available to protect the plant.

In summary, for all potential failure scenarios it has been demonstrated that subsequent to the initiating event, the worst possible single random failure can occur with the required two channels of the plant protection system always remaining available. 
7.7 .1 .1 .14

The following systems are provided to address severe accident conditions:

\section{Severe Accident Systems}

A. Cavity flooding system (CFS)

B. Hydrogen Mitigation System (HMS)

\subsection{Cavity Flooding System (CFS)}

The Cavity flooding system (CFS) provides a means of directing flow from the In-containment Refueling Water storage Tank (IRWST) to flood the reactor cavity in the event of a severe accident. The CFS is controlled manually from the control room. CFS controls and instrumentation are discussed below and shown in Figures 7.7-27 through 7.7-29. Electrical power distribution is defined in section 8.3 .

IRWST instrumentation includes two level transmitters which provide independent level readout in the main control room. Level indication allows the operator to monitor the effect of any actions taken to flood the Holdup Volume and Reactor Cavity.

Four isolation valves are provided in the spillway pipes between the IRWST and the Holdup Volume. Each valve is provided with limit switches to indicate valve position in the control room via backlit component control switches. Two valves are powered from vital A power and two are powered from vital B power.

The Holdup Volume includes a level switch in each of the two sumps to alert the operator of the presence of water. Two level transmitters are also provided to indicate Holdup volume level in the control room.

Two isolation valves are provided to transfer water from the Holdup Volume to the Reactor Cavity. Each valve is provided with limit switches to indicate valve position in the control room. One valve is powered from vital $A$ power and one is powered from vital B power.

Reactor Cavity instrumentation consists of two level transmitters which provide indication of Reactor Cavity level in the control room. A level switch is also provided in the sump which provides an alarm in the control room to alert the operator of the presence of water in this area. 
7.7.1.1.14.2 Hydrogen Mitigation System (HMS)

The Hydrogen Mitigation system (HMS) allows adiabatic, controlled burning of hydrogen at low concentrations during degraded core accident conditions. Channelized HMS ignitors are manually actuated from the control room. HMS controls and instrumentation are discussed in section 6.2.5. Electrical power distribution is defined in section 8.3 . 


\subsubsection{Design Comparison}

The design differences between the control systems previously discussed and those provided for the referenced plant (Palo Verde Nuclear Generating station (PVNGS) - Unit 1) are discussed in this section.

\subsection{Reactivity Control systems}

The RRS is functionally identical to that of the reference plant. The CEDMCS is functionally identical to that of the reference plant with the following changes:

A. The determination of CEA positions based on pulse counting and CEA group sequencing logic previously performed by the Plant Monitoring system computer have been transferred to the CEDMCS. The Nuplex $80+$ DPS will continue to monitor these runctions as described in section 7.7.1.8.2.

B. The maximum number of CEA subgroups to move simultaneously is four ( 17 CEAs maximum) as opposed to six (25 CEAs maximum) in the reference design. This simplifies the CEDMCS design, thereby improving system reliability, and reducing CEDM power requirements.

c. A CEA Motion Inhibit has been added to reduce the probability of withdrawal deviations.

With the exception of item $C$ above (CEA Motion Inhibit), other design differences in the RRS or CEDMCS have not been credited in the safety analysis since they have no safety significance.

\subsection{Pressurizer Pressure and Level Control systems}

The PPCS is functionally identical to that used in the reference plant. The PLCS design, however, differs from that of the reference plant for charging flow control. Charging flow control valves are used in lieu of charging pump control.

\subsection{Megawatt Demand setter}

The MDS is a standard feature of the Nuplex $80+$ design. It is an improved version of the system provided for Waterford Unit 3 and ANO-2.

The improved design monitors the status of the Plant Protection system RPS trip functions to assess available margins to trip. The MDS uses this data to inhibit plant load changes that could otherwise result in a reactor trip. Since the RPS design 
utilizes a two-out-of-four trip coincidence logic, the MDS uses the two most conservative of the four channels of RPS data to assess the available margin to trip. This logic ensures that a non-conservative RPS channel failure, with another channel in bypass, will not result in erroneous margin calculations by the MDS. Therefore, unacceptable plant maneuvering is precluded.

The MDS interfaces to the PPS are provided via fiber-optic cables to ensure electrical independence.

This system did not exist in the reference plant. It has not been credited in the safety analyses.

\subsection{Feedwater Control system}

The FWCS is functionally identical to that of the reference plant.

$7 \cdot 7 \cdot 1 \cdot 2 \cdot 5$

steam Bypass Control system

The SBCS is functionally identical to that of the reference plant.

\subsection{Reactor Power Cutback 8ystem}

The RPCS is functionally identical to that of the reference plant for loss of feedwater pump and large load rejection events. For the System $80+$ standard Design, the RPCS has been expanded to accommodate inward CEA deviations.

\subsection{Boron Control system}

The BCS is functionally idertical to that used in the reference plant.

\subsection{In-Core Instrumentation 8ystem}

The in-core neutron flux instrumentation system is functionally identical to that of the reference plant; however, the moveable in-core system is eliminated.

This design difference has not been credited in the safety analysis since this system has no safety significance.

\section{$7 \cdot 7 \cdot 1.2 \cdot 9$ \\ Ex-Core Neutron Flux Monitoring system}

The ex-core monitoring system is functionally identical to that of the reference plant. 


\subsection{Boron Dilution Alarm 8ystem}

The Boron Dilution Alarm Logic is functionally identical to that of the reference plant.

\subsection{Alternate Protection 8ystem}

The APS includes the following functional changes:

A. The alternate reactor trip function is accomplished based on a two-out-of-two coincidence logic to open the CEDM motor generator output contactors.

B. An alternate emergency feedwater actuation signal based on low level in either steam generator has been added to address ATWS mitigation requirements.

c. The design includes the ability to manually enable turbine tripped signals to initiate a control grade reactor trip for conditions when the RPCS is not available.

\subsection{Process Component Control system}

In the reference plant, component controls were implemented through the interconnection of relays and switch contacts distributed throughout the plant to establish the appropriate control logic.

The Process Component Control system (Process-CCS) implements these same functions through programmable solid state logic. The Process-CCS is also used for implementation of the PLCS, PPCS, SBCS and FWCS. In the reference plant, these systems employed hardwired solid state implementation methods.

The process-cCs has not been credited in the safety analysis since it has no safety significance.

\section{$7 \cdot 7 \cdot 1 \cdot 2 \cdot 13$ \\ Control and Monitoring systems sensed Parameters}

Control and protection systems that have identical sensor input requirements may utilize the same sensors. The control systems include signal validation logic as described in section 7.7.1.1.13 to avoid control/protection system irteractions. 


\subsubsection{Advanced Control Complex}

The Nuplex 80+ Advanced Control Complex (ACC) design integrates instrumentation and controls for both NSSS and Balance of Plant (BOP) systems. The ACC is comprised of the following major functional units:

A. The Main Control Room (MCR), which includes the Main Control Panels and adjacent offices for shift personnel (supervisor, senior reactor operator, reactor operator, nuclear equipment operator) who support the control room operator. Refer to sections 7.7.1.3.1 and 7.7.1.3.2.

B. The Computer Room, which contains the Data Processing system (plant computer) that monitors plant performance, drives various control panel visual display units and logs plant data. I:efer to section 7.7.1.7.

c. The Remote shutdown control Room, which is designed to achieve an orderly plant shutdown, external and isolated from the Main Control Room. Refer to section 7.4.1.1.10.

D. The Technical Support Center/Visitors Gallery. Refer to Chapter 13 .

E. Instrumentation and Control Equipment Rooms, CEDMCS \& Non-1E |I
Power/Equipment Rooms and $1 \mathrm{E}$ Power/Equipment Rooms.

The ACC is designed to accommodate NRC Branch Technical Position CMEB 9.5-1 which requires consideration of exposure to fires that cause damage or require personnel evacuation. Redundant channels of Class $1 \mathrm{E}$ equipment are designed to accommodate separation by locating them in different unmanned I\&C equipment rooms. Master transfer and isolation of controls and indications are provided for equipment in the MCR and RSCR. The ACC design prevents faults from either location from propagating to plant systems outside the MCR or RSCR.

The ACC Class $1 \mathrm{E}$ equipment seismic categories are defined in section 3.10. The equipment is qualified to meet the requirements of IEE $344-1987$ as further described in sections 7.7.1.3.1 through 7.7.1.10.

Refer to section 3.11 for the definition of environmental design requirements (temperature, humidity, radiation, pressure) relevant to the $A C C$ equipment. 
The main control and remote shutdown panel arrangements, layouts, information displays and controls on these panels are designed, verified and validated in accordance with the human factors design criteria and analyses provided in Chapter 18. Refer to that chapter for panel layouts and information displays utilized.

\subsection{Main Control Room and Panels}

Conformance to the GDC 19, "Control Room," is achieved by the implementation of the Nuplex $80+$ Advanced Control Complex. The controlling workspace of the main control room is designed to continuously accommodate from one to three persons during normal plant operations and up to five people during emergencies. The main control room, which includes offices adjacent to the controlling workspace, can accommodate a staff of up to seven people.

The main control panels are designed as compact workstations segmented as shown on Figure 7.7-14. Each workstation integrates in a human engineered fashion miniaturized back lighted component control switches, process controllers, discrete indicators, alarm tiles, message windows and video display units (CRTs, plasma and electro-luminescent displays) such that both safety and non-safety display devices are routinely used by the operator. Descriptions of the DIAS, IPSO and DPS which drive these information display devices are contained in sections 7.7.1.4, $7.7 .1 .5,7.7 .1 .7$ and Chapter 18.

The main control panels are designed to maintain structural integrity, such that no control room missile hazards result as a consequence of a seismic event. Any safety-related class $1 \mathrm{E}$ components mounted in the panels are seismically qualified to perform their safety functions. Modular equipment is used and the panels are designed for rear access to accommodate routine maintenance activities.

All NSSS and BOP instrumentation, controls and alarms interface with the DIAS, DPS or CCS for routing to the control panels; except for operator's modules dedicated to specific plant components (e.g., Plant Protection system, Turbine control System, CEDMCS).

The Nuplex $80+$ main control panels are designed to optimize the man-machine interface while meeting requirements for independence of redundant circuits. This is accomplished through a defense in depth approach that takes advantage of the intrinsic reliability of low energy circuits and the independence of the Main control Panels and Remote Shutdown Panels. To minimize the potential for multiple channel damage within the Main Control Panels or Remote Shutdown Panels the following design features are employed: 
A. Low energy circuits (less than 50 volts) are used to the maximum extent practical. This includes, for example, switch sense, lamps, indicators and alarm tiles.

B. Fire retardant materials are used throughout the panel enclosures, and the enclosures are equipped with smoke detectors.

c. Electrical independence of channelized circuits is maintained throughout the panel enclosures.

D. Physical separation or barriers are used to enhance the independence of all circuits greater than 50 volts.

Although the design features above minimize the potential for multiple redundant channel damage, the following design features accommodate such a catastrophic event:

A. All main control room circuits are fault isolated from the electronics to which they interface. Similarly, all remote shutdown panel circuits are fault isolated from the electronics. Therefore, the main control room and remote shutdown panel circuits are inherently isolated from each other and share no common failure modes.

B. All Main Control Panel and Remote shutdown Panel circuits are passive. Momentary contacts are used for all switches with the memory of control panel commands retained only in electronics located in the I\&C equipment rooms. This passive design is used for discrete state component controls as well as setpoint change commands and position change commands from process controllers for analog components. This passive design ensures that transfer of control from the main control room to the remote shutdown panel (or vice versa) is bumpless (i.e., no setpoints or component states will be affected). This design also ensures that all open circuit failures have no impact on control setpoints, modes or component states.

C. The main control room, remote shutdown panel and the I\&C equipment rooms are each located in separate fire zones. Therefore, the plant can be safely shut down with a catastrophic fire in either the main control room, the remote shutdown panel or any one of the I\&C equipment rooms.

Transfer of control to the remote shutdown panel is accomplished in two steps. If a fire is detected within a main control room panel section (as would be indicated by a early warning smoke detectors), power is removed from the affected panel section by activating channelized disconnect switches located within the main control room. This removes power to the affected panel 
components, preventing the transfer of erroneous operator commands to the system electronics (located in the I\&C equipment rooms). Control is then transferred to the remote shutdown panel by activating channelized control transfer switches located on the same elevation as the remote shutdown panel but in different fire zones.

The defense in depth design described above ensures the independence of redundant control panel circuits while accommodating catastrophic events. The design facilitates control panel designs that adhere to sound human factors engineering principles and that minimize the potential for failure of multiple redundant channels.

\section{$7 \cdot 7 \cdot 1 \cdot 3 \cdot 2$ \\ Technical Support Center and Emergency Operations Facility Interfaces}

The specific guidance for the Safety Parameters Display system (SPDS) and the emergency response facilities are defined in NUREG-0696, "Functional criteria for Emergency Response Facilities." This document provides basic design and qualification criteria for the SPDS, the onsite Technical support Center (TSC), the nearsite Emergency Operations Facility (EOF), and the Nuclear Data Link (NDL). Guidance specified in NUREG-0696 have evolved from numerous industry actions pertaining to earlier NRC documents such as NUREG-0585, "TMI-2 Lessons Learned Task Force Final Report."

Regulatory Guide 1.97, "Instrumentation for Light-Water-Cooled Nuclear Power Plants to Assess Plant and Environs Conditions During and Following an Accident," specifies parameters and associated design criteria for monitoring accident situations. The ACC provides the capability for integrated human factors presentation and recall of post-accident monitoring information.

The ACC Data Processing System provides the necessary interfaces with the TSC, EOF and NDL to make the same information that is available to the operating staff available to other interested personnel. The DPS equipment includes CRT work stations and line printers installed as shown on Figure 7.7-15 and described further in section 7.7.1.7. See Chapter 13 for a description of the TSC and EOF.

\subsubsection{Discrete Indication and Alarm System (DIAS)}

The DIAS is designed to provide displays and alarms that utilize signal validation, automatic ranging, alarm filtering, alarm prioritization, pattern recognition and other features designed to improve the man-machine interface in accordance with the 
Nuplex 80+ Human Factors Engineering criteria established in Chapter 18. Refer to that chapter for the definition of the display and alarm format conventions that ensure consistency and compatibility with the DPS displays.

The DIAS receives analog and digital signals from both safety and non-safety systems, analyzes the data and presents the information to the operator via discrete indicators, alarm tiles and message windows located on the main control panels. The system interfaces with the DPS to integrate alarm and process status information into its displays. DIAS is designed to support continuous plant operation should the DPS be unavailable.

\subsection{DIAS System Architecture}

The DIAS is a segmented, distributed architecture. The system consists of a DIAS channel $P$ segment for display of post-accident monitoring Regulatory Guide 1.97 Category-1 variables and DIAS channels $\mathrm{N} 1$ through $\mathrm{N} 5$ for the remaining segments as listed in Table 7.7-2. Each segment is configured to consist of:

A. Input/Output (I/O) data links and multiplexors

B. Central Processing Units (CPUs)

C. Display and alarm devices

The DIAS uses a segmented design to provide a degree of hardware independence and fault resistance between the various segments. The DIAS channel $\mathrm{P}$ segment is designed to be physically and electrically independent from the remaining DIAS channel $N$ segments and the DPS such that a single failure will not cause a loss of more than one of the three display methods (DIAS-P or DIAS-N or DPS).

As shown on Figures 7.7-16 and 7.7-17, each segment utilizes redundant I/O data links and CPUs such that fail-over to the back-up CPU may be accomplished without interrupting the information being displayed on the control panel devices.

Fiber-optic cables are used to provide isolation between the redundant safety related channel I/O and DIAS CPU processors.

Fiber-optic cables are also used to provide isolation between the DIAS CPU processors, the main control room panel I/O multiplexors and the remote shutdown panel I/O multiplexors.

The DIAS receives analog and digital signals from both safety and non-safety channels. These signals are continuously scanned and transmitted at rates consistent with the requirements for alarm checking, signal conversion and signal validation. 
Input signals are transmitted to DIAS from the following equipment and systems:
A. Boronometer
B. Radiation Monitoring
C. Process Component Control system, which includes:
1. Pressurizer Pressure and Level Control System
2. Steam Bypass Control System
3. Feedwater Control System
4. Alternate Protection System
D. Power Control system, which includes:

1. Control Element Drive Mechanism Control System

2. Reactor Regulating System

3. Reactor Power Cutback System

4. Megawatt Demand Setter

E. Reactor Trip Switchgear System

F. Ex-core and In-core Nuclear Instrumentation

G. Core Protection Calculator system

1. Trip Logic Calculators

2. Control Element Assembly Calculators

H. NSSS Integrity Monitoring System

I. Plant Protection system

$\mathrm{J}$. Process Instrumentation

K. Diesel Generator Uninterruptible Power Supplies

L. Electrical Distribution System

M. Reactor Coolant Pump Speed Sensing System

N. In-Core Instrumentation (HJTC and CET)

o. Motor Generator Sets

Input data, calculated values or parameters associated with another DIAS segment are available through a data network that interconnects each of the DIAS-N segments. This permits the sharing of all available plant data needed for the signal validation and individual alarm logic algorithms. The DIAS-P segments remain independent.

Redundant CPUs and data links are provided to permit on-line maintenance, testing and repair with minimum impact on the amount and quality of information displayed to the operator. If the segments' redundant CPUs and data links fail, the DPS will utilize its own data to drive its alarms and displays.

The DIAS CPUs utilize dynamic CMOS random access memory such that all tasks are memory resident. Battery backup is provided to prevent loss of memory due to power interruptions and achieve automatic restart without operator intervention. 
Power distribution to each segment is assigned, as shown in Figures 7.7-16 and 7.7-17, such that the loss of a single vital instrument power bus will not result in the loss of more than one I/O multiplexor or a set of control panel display devices.

\subsection{Discrete Indicators}

The DIAS processors for each segment drive discrete indicators located on the main and remote shutdown control panels. They provide continuous display of all frequently monitored plant information. Data reduction and increased accuracy of this information are provided by validation algorithms and automatic scaling of displays. Both these techniques reduce the amount of information processing required of the operator by using the DIAS processor to perform these functions. The discrete indicator is a flat panel display device with touch screen controls. A typical discrete indicator display is shown on Figure 7.7-18. Discrete indicators also provide the operator touch screen access to a variety of parameters related to a given system or component. The most important parameter is displayed normally with menu access to other parameters or channels.

The discrete indicators are driven by the DIAS processors for a given segment. Input signals are received from safety and non-safety instrumentation channels and a validation and range selection process is performed by the DIAS processor. Comparison to the post-accident monitoring channel(s) is also performed as part of the validation. output is then provided to the appropriate discrete indicator display device. Selected parameters are displayed continuously with alternate parameters available for display if selected at the discrete indicator.

Each discrete indicator has a CRT access selector to call up appropriate menus for related detailed data on CRT displays. This is communicated to the DPS through the DIAS-DPS data link. This link also provides all validated parameter values from DIAS to the DPS for display on the CRTs. The DPS independently performs the validation algorithm and periodically checks its results against the DIAS results. If a discrepancy in the validated parameter exists, a discrepancy alarm is actuated.

The failure of an individual discrete indicator has no adverse impact on the DIAS CPU. Validation continues and validated data are still sent to the DPS and IPSO for display.

Each digital display provides a means to determine when a failure has occurred in the DIAS. A slowly pulsating decimal point (heartbeat) is used for an immediate check of system availability. A discrete display page or alarm is used to access more detailed diagnostic information. 
If the DIAS logic cannot validate a parameter, it is identified to the operator via the discrete indicator so that the parameter of choice can be selected and displayed.

The DIAS-P segment contains the algorithms for Inadequate core cooling Monitoring as described in section 7.5.1.1.7.3. These same algorithms are also duplicated in various DIAS-N segments. The DIAS-P indicators will continuously display alphanumeric values for all Regulatory Guide 1.97 Category-1 parameters.

Refer to chapter 18 for more information regarding all the various types of displays utilized, signal validation techniques, automatic ranging, trending rates, other display dynamic features and other Human Factors Engineering design aspects.

\subsection{Alarm Indication and Message Display}

Alarm status is provided in the DIAS by:

A. Three audible tones.

B. Alarm indications.

C. Alarm message displays.

The alarm indication provides a means for the operator to acknowledge alarms, request additional data on the alarms, and to reset cleared alarms. Alarm indication and message displays are flat panel display devices with touchscreen controls. These display devices are similar to those used for discrete indicators described above, however the alarm indication section of the display is designed to mimic the function of alarm tiles. The message display is also designed as part of the display screen. The alarm tiles are backlighted and represent groups of related alarm conditions. The touchscreen feature provides the operator a means to request additional information about the alarm. The message display is an alphanumeric display that presents the requested alarm information. For an incoming alarm, the alarm tile flashes and an audible tone is generated for a short fixed duration ( $\sim 1$ second). By touching the alarm tile the operator acknowledges the alarm and a detailed description of the specific alarm condition is provided in the message display. Since each alarm tile may represent more than one alarm, there is a message for each possible alarm. These are predefined, stored messages.

The alarm logic processed by the CPU utilizes validated process variables, alarm filtering via plant mode and equipment mode dependency to reduce nuisance alarms. 


\section{CESSAR DESIEN

The DIAS-N3 segment receives safety system status information and DPS data to activate the various safety system Bypassed/Inoperable alarm tiles. The design includes the ability of the operator to manually activate each of these alarms individually from the main control panel via a dedicated discrete indicator. 


$$
\begin{aligned}
& \text { 코 } \\
& \text { 모 } \\
& \text { 而 } \\
& \text { 恶 } \\
& \text { 罯 }
\end{aligned}
$$


The discrete alarm tiles are grouped by control panel section to indicate relative priorities of 1,2 and 3 as follows:

A. Priority 1 alarms require operator action within 10 minutes to prevent a reactor trip, major equipment damage, critical function violations, personnel radiation exposure or to take an immediate Technical specification action.

B. Priority 2 alarms are actuated by conditions that may cause a reactor trip in greater than 10 minutes, result in equipment damage or require Technical specification actions not included in Priority 1 alarms.

c. Priority 3 alarms, for less important conditions, are displayed only through the CRTs with a single discrete alarm window to indicate their actuation.

Refer to Chapter 18 for more information regarding the alarm logic algorithms, prioritization, mode dependencies, first out alarms, other dynamic features and HFE design aspects.

Individual DIAS segments are designed such that a failure of one segment's processor or a communications link will not affect any segment's alarms. Additional failures may result in the degradation of one (or more) segment's displays. If this occurs, alarms and alarm discrepancies are still provided independently by the DPS CRT displays and printer logs.

Since message displays are driven by the DIAS segments as previously described, their failure modes are the same as described above for the alarms. If they should fail, descriptive alarm information will be available independently via the DPS CRT displays and printer logs.

The failure of an individual alarm indication and message display has no adverse impact on that segment's CPU. The CPU still functions to generate alarms that are transmitted to the DPS for display and acknowledgement.

\subsection{DIAS Environmental Qualification}

Class $1 \mathrm{E}$ instrument channels are seismically and environmentally qualified up to and including the channel isolation device (fiber optic modems) such that the instrument channel is not degraded.

The DIAS displays and central processing units are non-class $1 E$ designed to meet control room and electronic equipment room ambient temperature, pressure and humidity requirements. 
All DIAS displays and CPUs are seismically qualified for physical. and functional integrity to enhance control room information availability.

\subsection{DIAS Quality Classification}

The DIAS performs no direct plant safety function since it strictly monitors and displays data. However, due to its importance, DIAS is designed in accordance with a quality program to assure product quality commensurate with the intended use of the equipment.

Although the DIAS is a non-safety system, it receives both Class $1 \mathrm{E}$ and non-class $1 \mathrm{E}$ input signals. All DIAS input/output equipment is qualified to not generate faults that would degrade the channel A, B, C and D Class $1 E$ inputs. As shown in Figures 7.7-15 and 7.7-17, the Class 1E signal interface equipment uses qualified fiber-optic data links to maintain isolation.

\subsubsection{Integrated Process Status Overview (IPSO)}

The IPSO provides a single location to allow quick assessment of key information indicative of critical plant power production and safety functions. The IPSO displays information that both the operators and supervisory personnel require for quickly assessing overall plant status. It indicates existence of Priority 1 alarms, deviations from control setpoints, key parameter values, and system operational status and non-operational availability in a schematic representation. The IPSO is implemented as a big board mimic display located above the Master control console (MCC) in the Nuplex 80+ control room (see Chapter 18) and as a top level DPS CRT display page.

The plant systems represented on the IPSO will be the major heat transport path systems and systems that are required to support the major heat transport process, either power or safety related. These systems include those that require availability monitoring per Regulatory Guide 1.47 .

The following systems have dynamic representations on IPSO:

\begin{tabular}{|c|c|c|}
\hline $\mathrm{CCW}$ & - & Component Cooling Water \\
\hline$C D$ & - & Condensate \\
\hline CI & - & Containment Isolation \\
\hline CS & - & Containment Spray \\
\hline CW & - & Circulating water \\
\hline EF & - & Emergency Feedwater \\
\hline FW & - & Feedwater \\
\hline IA & - & Instrument Air \\
\hline SC & - & Shutdown cooling. \\
\hline
\end{tabular}




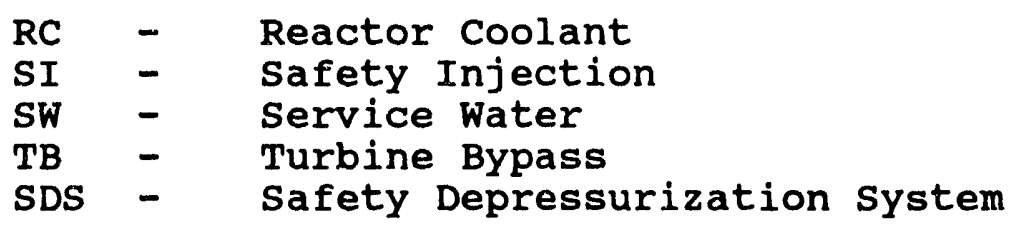

The IPSO design basis is to present high level process overview information by which the plant staff can quickly: determine the plant's operating status, identify major operational concern and establish priorities for operator actions. This is accomplished by selecting key plant parameters and data for presentation in accordance with Human Factors Engineering design criteria identified in Chapter 18.

Also refer to Chapter 18 for the bases used to select the parameters and other indications that are used on IPSO.

\subsection{IP8O Configuration}

The high availability of IPSO data presented to the operator is achieved by using two different display methods and systems (big board and DPS CRTs) as depicted on Figure 7.7-19. The loss of either display system will not significantly reduce the operator's ability to assess the plant's status since the big board is visible throughout the controlling work space and the IPSO page is accessible on all CRTs. In addition, both systems include redundancy and are powered by redundant battery backed non-vital instrument power busses.

\subsection{IP8O Big Board Panel}

The large panel IPSO display, as described in chapter 18, is driven by a display processor which receives data from both the DPS and DIAS-N. Data are provided to the IPSO processor by independent data links from the DPS and DIAS as shown on Figure 7.7-19. The total complement of DIAS data is sent from one processor after being collected via a data bus from the others.

Component and system status and availability and deviations from control setpoints are calculated by the DPS and transmitted to the large panel IPSO. Individual validated key parameters, Priority 1 alarm actuations and parameter trends are based on calculations by the appropriate DIAS segments for display on the large panel IPSO. This allows key data to remain on the large panel IPSO with either the loss of DPS or DIAS information.

IPSO normally uses the DIAS data for process instrumentation alarms, digital values and trends. If DIAS inputs are not available, the IPSO uses data supplied from the DPS. If the DPS 
should fail, the operator can monitor existing DIAS displays to assess operational availability and performance of the plant systems.

High reliability of the IPSO data presented is achieved by each system using validated parameter values. In addition, DIAS results are verified independently by the DPS calculations.

The IPSO big board is designed to maintain physical integrity during seismic events.

\subsection{DP8 IP8O Display}

The IPSO will also be the top level display page in the DPS CRT display page hierarchy. This allows access to the IPSO from any control room panel or from remote locations such as the Technical Support Center and Emergency Operations Facility.

\subsubsection{N888 Integrity Monitoring 8ystem}

The NSSS integrity monitoring system detects selected conditions which indicate a deterioration or which could lead to a deterioration of the RCS pressure boundary. The system consists of the following three subsystems:

A. Internals vibration Monitoring system,

B. Acoustic Leak Monitoring System, and

C. Loose Parts Monitoring System.

\subsection{Internals vibration Konitoring system (IVMs)}

\section{Function}

The primary function of the Internals Vibration Monitoring system (IVMS) is to provide data from which changes in the motion of the reactor internals can be detected.

The secondary function of the IVMS is to provide data that can be used to diagnose the reason for these changes.

\section{Theory of Operation}

Internals vibration monitoring utilizes the linear summed detector signals from each of the ex-core channels. The system detects the time variations in the neutron flux produced by changes in the neutron absorption path lengths caused by motion of the reactor internals, specifically the fuel assemblies and the core support barrel. 
The change in the motion of these components is generally reflected in a change in either or both the frequency and amplitude of the peaks in the spectra related to their motion. These changes are related to changes in the structural conditions of these components.

The joint ASME/ANSI OM5 standard on the use of ex-core neutron detector signals for the monitoring of core support barrel pre-load contains non-mandatory recommendations for the times during a fuel cycle at which monitoring should be done, and the analysis of the data acquired during these monitoring periods. The IVMS has the capability to perform all the analyses recommended by this standard.

\section{System Description}

The operator can select from the available ex-core neutron flux detector signals for simultaneous evaluation. Each selected signal is scaled and band pass filtered prior to analog-to-digital conversion. The digitized signals are input to a computer which performs the following functions:

A. Detection of internals motion change - based on amplitude classification of signals - by computing:

1. amplitude probability distribution (APD)

2. cumulative probability density (integral of the APD)

3. statistical moments (mean, variance, skewness, and kurtosis)

B. Diagnosis of cause of motion change - Based on amplitude, frequency, and phase classification of signals - by computing:

1. auto-power spectral density (APSD)

2. cross-power spectral density (CPSD)

3. coherence

4. relative phase

Root-mean-square (RMS) values can be computed from the APSD and/or CPSDs over the complete frequency range of the analysis (typically 0 to $50 \mathrm{~Hz}$ ) or in selected ranges of frequency.

\subsection{Acoustic Leak Monitoring System (ALMS)}

\section{Functions}

The function of the ALMS is to detect a leak at specific locations or within specific components in the primary system. The ALMS is designed to meet, in part, the guidance of Regulatory Guide 1.45, "Reactor Coolant Pressure Boundary Leakage Detection 
Systems," May 1973. The ALMS provides one method of determining the position (closed or not closed) of the pressurizer safety valves as required by NUREG-0718, Item II.D.3. The ALMS provides indication of the pressurizer safety valves position as defined by Regulatory Guide 1.97, Rev. 3, "Instrumentation of Light-Water-Cooled Nuclear Power Plants to Assess Plant and Environs Conditions During and Following an Accident."

\section{Theory of Operation}

Leakage of a fluid produces turbulent fluctuations in pressure which result in transmission of stress waves through the medium. This results in motion of the boundary surface which can be detected by a piezoelectric accelerometer. The accelerometers are mounted on, or close to, the component for which the leak is to be detected. The presence of a leak can be detected as a change in the amplitude of the accelerometer signal above a local background level. The RMS value of the signal amplitude, being proportional to the energy of the motion caused by the leak, is proportional to the leak rate. The proportionality constant is, however, dependent upon the geometry of the leak and distance between the leak and accelerometer.

System Description

Sensors are installed at the locations given in Table 7.7-3. Signals from the sensor area are routed via high temperature, low noise cable to in-containment charge amplifiers. The charge amplifier output is transmitted to alarm units located within the control room. At the alarm units the RMS value of the signal within a selected frequency range is computed and compared against alarm limits. The monitored frequency range is based on considerations of sensitivity (leak size and distance) vs. background noise rejection. Alarm levels are determined during startup testing. Alarms are provided to the control room and plant computer annunciator systems. Provisions are included to check the calibration of the electronics during plant operation.

After passing through the alarm unit the amplified accelerometer signals are multiplexed, filtered, digitized and transmitted to a computer for further analysis. The computer performs the following functions on a periodic basis:

1) data storage and comparison

2) trending, and

3) analyses to better define the signal characteristics. 
$7 \cdot 7 \cdot 1 \cdot 6 \cdot 3$

Loose Parts Monitoring syaten (LPMB)

\section{Function}

The primary function of an LPMS is to detect the presence of a loose part within the primary pressure boundary.

The secondary function of an LPMS is to provide diagnostic information that will assist in determining: (a) the nature of the loose parts (e.g., fixed or free): (b) the location of the loose part; and, (c) the characteristics of the loose part (e.g., size, mass, and velocity).

The system is designed so that the guidance of Regulatory Guide 1.133, Revision 1, "Loose Part Detection Program for the Primary System of Light-Water-Cooled Reactors," can be met.

\section{Theory of Operation}

The impact of a loose part on the boundary surface of a system is transmitted as a series of waves through this boundary. The passage of these waves causes motion of the boundary surface. This motion is detected by accelerometers mounted on the surface.

Loose parts produce random impulsive impacts whose amplitude, repetition rate, frequency, and time delay between sensors can be related to the size, mass, velocity, and location of the part.

\section{System Description}

LPMS sensors are installed at the locations given in Table 7.7-4. These locations correspond to natural collection regions for loose parts in the primary system and secondary side of the steam generator. Sensors, cabling, and amplifier associated with the two sensors at each natural collection region are physically separated.

Signals from the sensors are routed via high-temperature, low-noise cable to in-containment charge amplifiers. The charge amplifier output is transmitted to alarm units located within the control room. The alarm unit compares the peak value of the accelerometer output to a predetermined threshold and provides an alarm to the control room annunciator and plant computer systems.

\section{$7 \cdot 7 \cdot 1 \cdot 7$}

Data Processing system (DPB)

The Nuplex $80+$ DPS is a computer based system that serves to provide plant data and status information to the operator as depicted in Figure 7.7-20. The information is derived from plant sensors, other I\&C systems and self-contained algorithms called 
application programs. The DPS makes the information available to the plant operations staff both on a real-time and historical basis.

The DPS is designed to enhance overall power plant operation, availability and efficiency. This is accomplished through the use of integrated plant information displays and early warning of conditions that could lead to shutdown. Through analysis of data it assists the plant staff in operating the plant within specified limits while evaluating the performance of the reactor core, primary and secondary plant systems and components.

The DPS performs in a supervisory monitoring capacity for the NSSS and BOP steam and electrical production processes. It allows the plant operations staff to obtain detailed plant data via its man-machine interfaces. These man-machine interface devices are integrated into the ACC main control panels such that they complement the other instrumentation and controls (DIAS, IPSO and CCS) in a manner that meets the Human Factors Engineering desig^ criteria discussed in Chapter 18.

The major functions performed by the DPS include plant wide data acquisition, validation of sensed parameters, the execution of NSSS application programs and BOP performance calculations, the monitoring of plant safety and general status, the presentation of status and calculation results for CRT display, the provision of logs, and the determination of alarm conditions. It includes the capability of direct interaction with plant control systems to provide permissive or control inputs to these systems based upon calculational determinations of plant conditions.

\subsection{DP8 Functions}

The DPS performs complex algorithmic processing of input data. output results from this processing are transmitted externally to other systems, as required, and is made available to the plant operator via workstation CRTs.

The DPS consists of host processors, intelligent display generators, CRTs and other support devices. The host processors perform applications processing of the received data and transmits computed results to the intelligent display system. In turn, the intelligent display system processes these data for output to the CRTs and also serves as the man-machine interface for operator requests made via the CRT touch screens.

The major functions performed by the DPS include:

A. Acquires plant $I / O$ data from the other plant systems via data links. 
B. Performs applications processing on the acquired data via NSSS, BOP and general plant monitoring program tasks.

C. Provides detailed plant process data to the operating staff via a CRT display system.

D. Provides for data archive and retrieval.

E. Provides safety parameter displays to assist the operations staff during abnormal or accident conditions and provides these data to the control room, technical support center and emergency operations facility.

F. Generates alarm reports and integrates alarm processing with the DIAS system.

G. Generates $\log$ reports.

H. Provides the man-machine interface to the DPS.

I. Provides plant status and alarm data to the Integrated Process status Overview (IPSO) system.

J. Provides on-line diagnostics for continuous self health monitoring.

K. Performs signal validation on input signals such that a single value is determined that best represents a given parameter being sensed by multiple sensors.

L. Performs a cross-check of validated parameters independently calculated by the DIAS and DPS.

M. Accommodates the failure of any single hardware element so that no single failure within the DPS will disable any of the aforementioned functions. Hardware redundancy coupled with continuous on-line diagnostics provides high availability.

The following types of DPS displays are provided at each CRT workstation:

$\begin{array}{ll}0 & \text { Plant system mimics } \\ 0 & \text { Directories } \\ 0 & \text { Alpha-numeric text } \\ 0 & \text { Video trends } \\ 0 & \text { Bar charts }\end{array}$


These displays are accessed via touch screen menu selections from within the display page hierarchy illustrated on Figure 7.7-21 and further described in Chapter 18.

Intelligent alarm processing is built into the DPS so that the total number of alarms presented to the operator is minimized and spurious alarm (nuisance alarm) generation is minimized. Alarm priority categories are established to inform the operator of the relative importance of any alarm.

Behavior attributes such as blink, color change, and inverse video are utilized to convey the appropriate alarm state information to the operating staff.

The DPS alarm system works in conjunction with the DIAS so that alarms acknowledged via DIAS are also automatically acknowledged on the DPS and, similarly, alarms acknowledged on DPS are automatically acknowledged on DIAS. (The DIAS/DPS alarm coordination is further discussed in Chapter 18).

The DPS is designed with sufficient alarm buffer capacity in place so that no alarms are "lost" during high DPS loading conditions and/or during conditions of a high influx of alarms.

$7 \cdot 7 \cdot 1 \cdot 7 \cdot 2$

DP8 Configuration

Figure 7.7-22 provides a high level overview of the interrelationships between the DPS components. The Data Processing system architecture is redundant and based on a distributed design. DPS data links acquire plant process data from other plant systems and transmit it to the host processors.

The system configuration is based upon high speed redundant host processors and redundant peripherals. The hosts communicate information to and from a number of plant instrumentation and control systems, process the received data, and supply information to the operations staff via CRTs and line printers. Communications between the hosts and safety related plant instrumentation and control systems are accomplished via fiberoptic data links to maintain isolation. All others are via standard electronic data communication links.

Each host processor independently receives all requisite plant data and information from the plant systems shown on Figure 7.7-22 and actively processes the received data. However, only one host processor outputs data to the plant systems, the CRTs and the line printers. The other processor is in a "hot standby" state and assumes the active output role only when a failure is detected in the primary processor. 
Three dual-ported magnetic disks are assigned among the primary and backup host processors. Each processor has one disk assigned to itself which it may read from or write to. These two assigned disks are used to: boot-up the assigned processor, load the operating system, application programs and data base, store historical data from the assigned processor, store time dependent variable data from the assigned processor, temporarily store data while formatting output logs and store other programs, data and files as required.

The third magnetic disk is used primarily as a dedicated software maintenance disk. This disk contains source and object images of all application programs as well as a complete data base.

Two optical disks are used for permanent archive of historic data. In addition, each of the primary and backup host processors has one assigned tape drive, that is used in conjunction with the data collection snapshot function and general software support.

Each host processor is supplied with a system console which is the primary system communication device for the programmer. The host processor is composed of a dual CPU. One CPU is dedicated to $I / O$ and demand tasks while the other CPU is dedicated to periodic tasks. In this manner variable loading, caused by asynchronous system demands, is handled by the first processor without impact to the periodic application executions.

High speed line printers are provided for the programmer, control room operating staff, Technical support Center and Emergency Operations Facility.

The DPS control room operator man-machine interface is primarily achieved via touch screen color CRT workstations and other touch panel devices (e.g., DIAS annunciator tiles, as described in Sections 7.7.1.4 and Chapter 18. Switches are provided to transfer display processor workstations between the primary and backup host processors. CRT workstations are also provided for the control room offices, Technical support Center, Remote Shutdown Panel and Emergency operations Facility.

All applications are programmed using structured programming rules and techniques. The developed code is commented consistently throughout the source listings.

The software is composed of modular, structured programs. DPS on-line operation minimizes reliance on any electromechanical peripherials. All major applications (as appropriate) are memory resident and are structured to allow continued execution in the event of a disk, printer, or magnetic tape failure. 
An application executive program is implemented to control the scheduling of the DPS host programs. The application executive also handles (as appropriate) diagnostic scheduling messages generated on-line by the constituent programs.

\subsection{DPS Environmental Qualification}

The DPS is not a safety-related system, performs no safety related function, and is not required to operate during or after a seismic event. However, the DPS is designed so that no control room missile hazards result as a consequence of a seismic event. Qualification is performed by test and/or analysis. The DPS is designed to operate over the environmental range specified for the Advanced Control Complex equipment per sections 3.10 and 3.11 .

\subsection{DPS Verification and Validation Requirements}

The DPS is subject to a thorough and systematic verification and validation program to assure that the system is correctly implemented and satisfies all its functional requirements. The program is implemented in accordance with Reference 3 .

\subsubsection{DPS NSSS Applications Programs}

The NSSS applications programs, listed in Table 7.7-5, are implemented in the DPS to provide information to assist the operator in maintaining the plant within specified limits and evaluating the performance of the reactor core.

7.7 .1 .8 .1

Core Operating Limit Supervisory System (coLss)

7.7 .1 .8 .1 .1

General

The core operating Limit supervisory system (COLSS) consists of process instrumentation and algorithms used to continually monitor the following Limiting Conditions for Operation (LCO):

A. Linear Heat Rate Margin

B. DNB Margin

C. Total Core Power

D. Azimuthal Tilt

E. Axial Shape Index

The colss continually calculates these parameters and compares the calculated values to the appropriate LCO. If an LCO is 
exceeded for any of these parameters, colss alarms are initiated and operator action is taken as required by the technical specifications.

The Limiting safety system settings (LSSS), core power operating limits, the axial shape index and azimuthal tilt operating limits are specified such that the following criteria are met:

A. No safety 1 imit will be exceeded as a result of anticipated operational occurrences (AOO).

B. The consequences of postulated accidents will be acceptable.

The Reactor Protective system functions to initiate a reactor trip at the specified LSSS. The COLSS is not required for plant safety since it does not initiate any direct safety-related function during AOOs or postulated accidents. The technical specifications define the LCOs required to ensure that reactor core conditions during operation are no more severe than the initial conditions assumed in the safety analyses and in the design of the low DNBR and high local power density trips. The colss serves to monitor reactor core conditions in an efficient manner, to supply data to the Megawatt Demand Setter and provides indication and alarm functions to aid the operator in maintenance of core conditions within the LCOs.

The colss algorithms are executed in the DPS. The calculational speed and capacity of the DPS enables numerous separate plant operating parameters to be integrated into three easily monitored parameters: (1) margin to a core power limit (based upon DNBR limits, colss linear heat rate and licensed power limits); (2) azimuthal tilt; and, (3) axial shape index. This information is provided to MDS which can limit plant load changes such that NSSS operating limits are not exceeded. If colss were not provided, maintenance of reactor core parameters within the LCOs would be accomplished by monitoring and alarming on the separate non-safety-related process parameters used in the colss calculations. Therefore, the essential difference in using colss in lieu of previous monitoring concepts is the integration of many separate process parameters into a few easily monitored parameters. The conciseness of the colss displays has distinct operational advantages when MDS is not available since the number of parameters that must be monitored by the operator is reduced.

Detailed process testing of colss is conducted to ensure proper system performance and to ensure that algorithms yield proper results for all expected conditions. 
Sensor validity checks are performed by colss on those measured input parameters used in the colss calculations. The validity checks consist of checking sensor inputs for the following conditions:

A. Sensor out of range.

B. Excessive deviation between like sensors.

One of the following actions is taken for out-of-range sensors:

A. Automatic replacement of the failed sensor by an equivalent sensor (when available).

B. Automatic function termination when adequate process information is not available.

c. Substitution of constants for selected colss inputs (performed under administrative control).

If an out-of-range sensor is detected, an alarm is actuated and corrective action is automatically initiated. A more detailed discussion of sensor validity checks is included in CEN-312, "Overview Description of the core operating Limit supervisory system", (Reference 2).

The core power distribution is continually monitored by coIss, and a core average axial shape index is computed. Operation of the reactor at or below this power operating limit assures that the peak linear heat rate is never more adverse than that postulated in the LOCA analysis.

core parameters affecting the DNBR margin are continually monitored by colss, and a core power operating limit based on DNBR is computed. Operation of the reactor at or below this power operating limit ensures that the most rapid DNBR transient that can result from an $A O O$ does not result in a reduction of DNBR to a value less than the specified Acceptable Fuel Design Limit (SAFDL).

A core power operating limit based on licensed power level is also monitored by colss. Operation of the reactor at or below this operating limit ensures that the total core power is never greater than that assumed as an initial condition in the safety analyses.

The core power and the core power operating limits based on peak linear heat rate, DNBR limits and axial shape index are continually indicated on the control board. The margin between 
the core power and the nearest core power operating limit is also provided as part of the DPS CRT displays. A DIAS alarm is initiated in the event that the CoLSs calculated core power level exceeds a colss calculated core power operating limit.

In addition to the above calculations, the azimuthal flux tilt is calculated in colss. The azimuthal flux is not directly monitored by the plant protection system; rather, an azimuthal flux tilt allowance, based on the maximum tilt anticipated to exist during normal operation, is provided as an addressable constant in the protection system. This tilt allowance is used in the low DNBR and high local power density trip function. The azimuthal flux is continually monitored by coLSS and a DIAS alarm initiated in the event that the azimuthal flux tilt exceeds the azimuthal flux tilt allowance setting in the plant protection system.

The following are calculated by colss:

A. Reactor coolant volumetric flow rate

B. Core power as determined by:

1. reactor coolant $\Delta \mathrm{T}$

2. secondary system calorimetric

3. turbine first stage pressure

4. axial shape index azimuthal tilt

c. Linear heat rate core power operating limit

D. DNBR core power operating limit

E. Margin to each core power operating limit

Control board indication of the following colss parameters is continually available to the operator via a dedicated flat panel display.

A. Linear heat rate

B. DNBR core power operating limit

c. Total core power

D. Margin between core power and nearest core power operating limit

E. Axial shape index

The algorithms are executed in the DPS. Technical specifications (Chapter 16) for the reactor core provide an alternate means of 
monitoring the LCOs in the event that the DPS is out of service. colss alarms are initiated if:

A. Core power exceeds a core power operating limit

B. Axial shape index exceeds its limits

c. Azimuthal flux tilt exceeds the azimuthal flux tilt limit

A description of colss algorithms and a discussion of the treatment of colss input information are included in Reference 2 . Table 7.7-6 provides a listing of the types, quantities, and ranges of sensors that provide input information for the colss algorithms. A functional diagram of the colss is provided in Figure 7 7-23.

$7 \cdot 7 \cdot 1 \cdot 8 \cdot 1.3$

$7 \cdot 7 \cdot 1 \cdot 8 \cdot 1 \cdot 3 \cdot 1$

\section{Description of colss Algorithms}

\section{Reactor Coolant Volumetric Flow Rate}

The DNB margin is a function of the reactor coolant volumetric flow rate. The four reactor coolant pump rotational speed signals and four RCP differential pressure instruments are monitored by coLss and used to calculate the volumetric flow rate. The pump characteristics are determined from testing conducted at the pump vendor's test facility and correlations between the pump rotational speed, pump differential pressure, and the volumetric flow rate are developed. Measurement uncertainties in the pump testing and coLSs measurement channel uncertainties are factored into the calculation of the margin to a power operating limit.

The four pump volumetric flow rates are summed to obtain the reactor vessel volumetric flow rate. Necessary allowances for core bypass flow, flow factors, reactor coolant temperature, and other considerations are factored into the value of flow used in the DNBR calculation.

\subsection{2 Core Power Calculation}

The reactor coolant $\Delta T$ power, turbine power and the secondary calorimetric power are computed in colss. The reactor coolant $\Delta T$ power and turbine power are less complex algorithms than the secondary calorimetric power and are performed at a more frequent interval. The secondary calorimetric power is used as a standard against which reactor coolant $\Delta \mathrm{T}$ power and turbine power are continually calibrated. This arrangement provides the benefits of the secondary calorimetric accuracy and the reactor coolant $\Delta T$ power and turbine power speed of computation. 
The reactor coolant $\Delta \mathrm{T}$ power is calculated based on the reactor coolant volumetric flow rate, the reactor coolant cold leg temperature, and the reactor coolant hot leg temperature. The turbine power is calculated based on turbine first stage pressure. Turbine power provides a leading indication of core power changes in response to load changes.

The secondary calorimetric power is based on measurements of feedwater flow rate, feedwater temperature, steam flow, and steam pressure. A detailed energy balance is performed for each steam generator. The energy output of the two steam generators is summed and allowances made for reactor coolant pump heat, pressurizer heaters, and primary and secondary system energy losses.

\section{$7 \cdot 7 \cdot 1 \cdot 8 \cdot 1 \cdot 3 \cdot 3$}

\section{CoLs8 Determination of Power Distribution}

The determination of the 3-D peaking factor, the integrated radial peaking factor, the power shape in the hottest channel, and the azimuthal tilt magnitude is performed based on in-core measurements of the flux distribution processed by pre-programmed algorithms and stored as constants. A brief description is given here of the data processing approach employed by colss to yield the desired power distribution information. This analysis is repeated at least once per minute and thus represents continual on-line ronitoring.

The core is regarded as being divided into several radial regions in the $X-Y$ plane. The regions are selected taking into account the locations of the part-strength and regulating CEA groups, and the locations of the various batches of reload fuel.

The dynamic response characteristic of the self-powered rhodium in-core detectors is a function of both prompt and delayed components of electrical current generated in the detector and cabling. The delayed portion of the current signal is governed by the decay of isotopes of Rhodium having half-lives of 0.7 minutes and 4.4 minutes. This provides the capability to compensate for the delayed portion of the signal. The colss power distribution determination includes a compensation algorithm for the in-core signals used as input to colss. The algorithm approximately represents the inverse of the in-core detector dynamic response, such that the combination of detector response and dynamic compensation produces a signal closely representative of the actual neutron flux response. The basis for the dynamic compensation is described in Reference 1.

The capability for signal filtering is provided through selection of algorithm constants. With the capability for dynamic compensation and filtering of the in-core signals, changes in 
local flux level during operational load follow transients are adequately represented by the colss power distribution determination.

Following correction of the fixed detector signals for background and burnup, the five axially distinct region-average power integrals corresponding to the five $\mathrm{Rh}$ detector segments are constructed. These take into account the signal-to-power conversion factors which are a function of burnup in the surrounding fuel. The five power integrals are expanded into a forty node core average axial power distribution using a Fourier synthesis technique. Employing tables of factors relating power in the hot pin to the core average, the axial power profile in the hot pin is computed.

Malpositioning of a CEA or CEA group, the uncontrolled insertion or withdrawal of a CEA or CEA group, or a dropped CEA, will be detected by colss with inputs received from the CEA position indicating systems. Should these deviations occur, adjustments to the planar radial peaking factors are performed to ensure that the COLSS DNBR and peak linear heat rate calculations remain conservative. It is noted that with the MDS out of service, colss only provides a monitoring function. The protective action for the CEA related events is provided by the RPS.

Flux tilts are detected by comparison of signals from symmetrically located sets of fixed in-core detectors at various levels in the core. The flux tilts are included in the computation of margin to the power operating limit. In this way, postulated nonseparable asymmetric Xenon shifts are identified and reflected in the power distribution assessment. Alarms are provided by colss when the tilt exceeds the allowances for these effects carried in the core protection calculators as penalties. An alarm will also occur when the tilt exceeds an absolute limit (imposed by technical specifications) indicating possible power distribution abnormalities.

The possibility of inoperable fixed in-core detectors is allowed for by provision of redundant detector strings within each region of the core. If an inoperable fixed in-core detector is identified during internal consistency checks of the data, that detector is dropped from colss calculations prior to replacement (e.g., at a subsequent refueling).

Once in operation periodic confirmation of the colss assessment of the power distribution, including the suitability of any updated stored constants, is obtained by comparison with a more detailed, off-line processing of an extensive in-core flux map produced by the fixed in-core instrument system. One means of analyzing the detailed flux map is to compare it with detailed 
calculations of the power distribution which include computations of the flux at the instrument location. Folding this together with other analyses of the ability of the detailed calculation to estimate the local pin-by-pin power distribution enables an overall assessment of the colss power distribution error. This is factored into the margin assessment as noted in section $7.7 .1 .8 \cdot 1.4$.

$7 \cdot 7 \cdot 1 \cdot 8 \cdot 1 \cdot 3 \cdot 4$

Core Power Operating Iinit Based on Peak Inear Heat Rate

The core power operating limit based on peak linear heat rate is calculated as a function of the core power distribution ( $F_{\text {f }}$ ). The power level that results from this calculation corresponds to the $\mathrm{LCO}$ on linear heat rate margin. 7.7.1.8.1.3.5 Core Power Operating Limit Based on Margin to

The core power operating limit based on margin to DNB is calculated as a function of the reactor coolant volumetric flowrate, the core power distribution, the maximum value of the four reactor coolant cold leg temperatures, and the Reactor coolant system pressure. The CE-1 correlation is used in conjunction with an iterative scheme to compute the operating power limit. (See section 4.4 for a detailed discussion of the CE-1 correlation). The power level that results from this calculation corresponds to the LCO on DNB margin.

\subsection{Calculation and Measurement Oncertainties}

The uncertainties in coLss algorithms can be categorized as:

A. Uncertainties associated with the computation methods used to correlate the monitored variables to the calculated parameters.

B. The measurement uncertainties associated with the colss process instrumentation.

The colss is designed to accurately calculate power operating limits for normal core operating conditions. A large number of cases spanning the expected core operating conditions (1200 cases each at $B O C$, MOC, and EOC) are run using the COLSS FORTRAN simulation code and on FLAIR, a 3-D reactor simulator code. These runs establish the modeling error between COLSS and the reactor simulator. This information, along with other appropriate data, such as CECOR errors and instrument errors, is used to determine coLss power operating limit uncertainty factors which are then installed in the data base. The reactor simulator 
and error analysis codes are certified under the quality assurance program described in Chapter 17 (since they are also used for CPC analysis) while the colss uncertainty factors are reviewed independently. The uncertainty analysis methodology is documented in CENPD-169 (Reference 1).

\section{$7 \cdot 7 \cdot 1 \cdot 8 \cdot 2$}

N888 Monitoring Programs

The DPS application programs, exclusive of colss, that provide either a reactor monitoring or plant protection system monitoring function are described below:

\section{A. CEA Position Monitoring Program}

The DPS receives CEA positions from 2 sources, the CEACs ( 2 channels) and the CEDMCS ( 1 Channel). CEA position determination by these 2 separate sources is diverse. The CEAC utilizes reed switch position transmitters to sense CEA position while the CEDMCS counts the "Raise" and "Lower" control signals (pulses) to each control element drive mechanism to determine CEA position.

The CEA position, as obtained from the CEDMCS, is used directly as input to NSSS application programs. CEA positions determined by CEAC and CEDMCS are compared and validated to derive a validated CEA position for each rod. Differences in position, as determined by the diverse CEA position systems (CEDMCS and CEAC), are alarmed via DIAS. The validated CEA position information is used for display and data logging purposes.

B. CEA Trip Report Program

Upon detection of a reactor trip, a CEA trip processing program is activated within the CEDMCS which determines the rod drop time. This information is then sent to the DPS which compares them to the maximum allowable drop time and generates a report of the CEA trip behavior.

C. CEA Reassignment Program

Provisions to reassign individual CEAs to various CEA groups are provided to allow reconfiguration as would occur during a refueling outage.

D. CEA Exposure Accumulation Program

The CEA exposure accumulation program determines the approximate thermal megawatt hours of exposure for each CEA element based on average core power. 
E. CEA Related Alarm Programs

The following alarms are included in the system design to provide information to the operator to assist in maintaining proper CEA control and to aid in the monitoring of CEA limits:

1. Power-Dependent Insertion Limits (PDILs) Alarms

An alarm is provided in the event CEA insertion exceeds predetermined limits required to maintain adequate shutdown margin, to ensure CEA insertion consistent with the CEA ejection analysis and to maintain fuel integrity. The PDILs use reactor power and CEA position signals.

2. Pre-Power-Dependent Insertion Limits (PPDILs) Alarm

This alarm is provided to advise the operator of an impending approach to PDILs.

3. out or Sequence Alarm

An alarm is provided to alert the operator in the event the CEA groups are inserted in a sequence other than the predetermined acceptable sequence as described in section 7.7.1.1.1. The actual sequencing logic is located within the CEDMCS. The DPS performs an independent check to detect any abnormal sequence condition.

4. CEA Deviation Alarm

An alarm is provided to alert the operator in the event the deviation in position between the highest and lowest CEA in any group exceeds a predetermined allowable deviation.

5. Core operating Limit supervisory system Alarms

CEA position data is provided as input to coLSS. These data are used in the colss power distribution calculations and alarms are initiated in the event the colss limits are reached. The basis for the colss alarms is discussed in Section 7.7.1.8.1.

\section{F. In-core Detector Signal Processing Program}

This program processes electrical signals from the Rhodium fixed in-core neutron detectors to calculate neutron flux levels. For each detector the program stores information on 
initial calibrated sensitivity and cumulative electrical charge to track the detector sensitivity and depletion with time over multiple fuel cycles.

G. Xenon Reactivity Prediction Program

This program calculates the core reactivity worth of Xenon by solving the governing equations and using, as input, core-specific constants and reactor power history.

H. Reactivity Balance Program

This program calculates critical boron concentration for power operation at any point in the fuel cycle including power level changes accounting for CEA group positions.

I. Deviation and set Point Monitoring Program

The DPS performs deviation and setpoint monitoring for 3 separate systems, each of which is multichannel. Data received from these systems consists of sensor inputs, setpoints and calculated values.

There are three major programs associated with this function. The first program monitors core protection Calculator (CPC) data, received over data links, and performs a four channel cross comparison of the received data. The data includes calibrated ex-core neutron flux power and margin to DNB and local power density trip setpoints. Parameters which differ by a predetermined amount are alarmed. The second program monitors the data from the plant Protection system (PPS), performs a four channel cross comparison and alarms when any setpoint exceeds a predefined reference value. The third program monitors CEAC data received over data links and performs a 2-channel cross comparison of the received data. Parameters which differ by a predetermined amount are alarmed.

J. Data Snapshot Collection Program

The application program collects and records selected plant operating data sufficient to support off-line fuel management applications.

The output files, identified by data and time of data collection, are stored on magnetic tape for subsequent off-line analysis. This off-line analysis is accomplished on computer facilities other than the DPS. 


\section{K. Historical Data storage and Retrieval Program}

The Historical Data Storage and Retrieval (HDSR) application program records, stores, recalls, and displays historical information as it is needed by plant personnel. This program provides a means of monitoring events before and after a plant trip. Important pre-selected process parameters may be periodically stored on a dedicated optical disk. Two optical disk systems are provided for redundancy. In addition, the dual disks allow uninterrupted data recording when one disk becomes full by automatically continuing the data recording via the second disk.

The HDSR displays data in two forms:

1. A CRT representation made available through CRT trend displays.

2. A CRT listing or hard cryy printout of individual data points in a log format.

L. Sequence of Events Program

The sequence-of-events program monitors pPS bistable trip status and other RPS and ESF equipment status. The program records changes (channel trips) with a resolution of several milliseconds to monitor events before and after plant trip.

M. ESF Computer Aided Test Program

The Computer Aided Test (COMAT) program monitors Engineered Safety Feature system pre-test plant line-ups for correct initial conditions, monitors and records test results, and monitors post-test plant line-ups. COMAT, a program in the Data Processing system, receives input from the ESF-CCS operator modules and feedback signals from each ESF actuated component.

Each of the above DPS functions is intended to assist the plant operator in supervision or analysis of plant conditions. None of these functions are required to ensure plant safety or permit plant operation. 
The DPS application programs that provide input to plant control systems are described below:

A. Reactor Power Cutback CEA Selection

The CEA selection algorithm communicates to the CEDMCS which CEA groups are to be released in the event a reactor power cutback is initiated. The selection algorithm is based on CEA group reactivity worth and the effect of the CEA group on core power distribution.

B. Megawatt Demand Setter Data

The COLSS algorithms described in section 7.7.1.8.1 provide data which the MDS requires in order to supervise and/or limit the loading of the main turbine based on NSSS core operating conditions.

Each of these functions is intended to enhance flexibility of plant operation.

All other functions presently implemented in the DPS are solely for operator and administrative convenience and involve neither the Plant Protection system nor plant control. None of the DPS functions are required to ensure plant safety or permit plant operation.

\section{7 .1 .9}

Balance of Plant Application Programs

The BOP application programs listed in Table 7.7-7 are implemented within the DPS and provide performance evaluation information for the secondary plant systems.

The following BOP performance calculations are performed by the DPS. All computer inputs that are required by or generated from the BOP performance calculations are provided.

A. Feedwater Heater Performance Calculations

The feedwater heater performance calculations include the terminal temperature difference, drains cooler approach temperature and feedwater heater temperature rise.

B. Condensate Pump Performance Calculations

Condensate pump performance is determined by calculating the output from measurements of flow and total head developed by the pump. 
C. Steam Generator Performance Calculations

Steam generator output is calculated by engineering specifications for colss software for each steam generator. These will be based on secondary parameters such as the mass flow rates and enthalpies of the steam, feedwater, and blowdown fluids.

D. Unit Generation Calculations

The unit generation calculations provide summed, averaged, and instantaneous values of critical plant parameters. The summed calculations provide 10-minute, hourly, and daily values of certain plant parameters and are expressed in units of energy. The average calculations provide 10-minute, hourly, and daily values of certain plant parameters and are expressed in units of power. Instantaneous calculations are based on directly measured analog inputs.

E. Turbine Performance Calculations

The performance of the turbine is determined by calculating the turbine cycle net heat rate.

F. Moisture Separator Reheater Performance Calculations

Moisture separator reheater performance is determined by calculating the amount of superheat in the output steam to the low-pressure turbine, the pressure drop across the moisture separator and reheater and the terminal temperature difference.

\subsubsection{DPS Critical Functions Monitoring Program}

The Critical Functions Monitoring (CFM) application program includes critical plant power production and safety functions. The DPS implementation integrates crucial power production monitoring with TMI Action Plan requirements for Inadequate Core cooling Monitoring and Safety parameter Display systems in a human engineered manner. The algorithm also includes success path monitoring for safety system critical functions. 
A. Critical Functions Monitoring

The CFM application program provides the capability to display the status of the following critical functions:

1. core reactivity control

2. core heat removal control

3. reactor coolant system inventory control

4. reactor coolant system pressure control

5. reactor coolant system heat removal control

6. containment environment control

7. containment isolation control

8. radiological emission control

9. steam/feed systems control

10. vital auxiliary systems control

11. lectric generation control

12. Itimate heat rejection control

B. Success Path Monitoring

The Suc ess Path Monitoring (SPM) program continuously monitors the status and performance of the plant systems and components to determine their ability to satisfy the critical safety functions (items A.1 thru A.8 above).

The SPM program provides the capability to display the success path status for each critical safety function and initiates alarms when they become bypassed or inoperable.

C. CFM Man-Machine Interface

The CFM operator interface consists of DPS human-engineered graphic and alphanumeric displays, alarms, and user input capability as described in section 7.7.1.7.1.

The CFM provides the user with concise, understandable, integrated information to assist in assessing plant status during all modes of plant operation. The CFM displays meet the human-engineering principles discussed in Chapter 18.

Movement through the display hierarchy is provided by using the DPS touch screen CRT menus.

\subsubsection{ANALYSIS}

The plant control systems and equipment are designed to provide high reliability during steady state operation and anticipated 
transient conditions. The RPS analysis of section 7.2 .2 encompasses the failure modes of these control systems and demonstrates that these systems are not required for safety.

The safety analyses of Chapter 15 do not require these syctems to remain functional.

The man-machine interface for the control complex are designed in accordance with the Human Factors Engineering criteria described in Chapter 18 which meet applicable TMI Action Plan guidance. 


\section{REFERENCES FOR SECTION 7.7}

(1) "Assessinent of the Accuracy of PWR operating Limits as Determined by the Core operating Limit supervisory System," Combustion Engineering, Inc., CENPD-169, July 1975.

(2) "Overview of the core operating Limit supervisor system," Combustion Engineering, Inc., CEN-312, Revision 01-P, November 1986.

(3) "Verification and Validation for safety Parameter Display Systems," NSAC-39, December 1981. 
TABLE 7.7-1

\section{ALTERNATE PROTECTION SYSTEA SENSED PARAMETERS}

\begin{tabular}{|c|c|c|c|c|}
\hline $\begin{array}{l}\text { Monitored } \\
\text { Variable }\end{array}$ & Type & $\begin{array}{c}\text { Number of } \\
\text { Sensors }\end{array}$ & $\begin{array}{c}\text { Sensor } \\
\text { Range }\end{array}$ & $\begin{array}{l}\text { Nominal (1) } \\
\text { Setpoint }\end{array}$ \\
\hline $\begin{array}{l}\text { Pressurizer } \\
\text { Pressure }\end{array}$ & $\begin{array}{l}\text { Pressure } \\
\text { Transducer }\end{array}$ & 2 & $1500-2500$ psia & 2420 psia \\
\hline $\begin{array}{l}\text { Steam } \\
\text { Generator } \\
\text { Level } \\
\text { (Wide } \\
\text { Range) }\end{array}$ & $\begin{array}{l}\text { Differential } \\
\text { Pressure } \\
\text { Transducer }\end{array}$ & $\begin{array}{l}2 \text { / steam } \\
\text { Generator }\end{array}$ & $\begin{array}{c}0-100 \% \\
0-400 \text { inches }\end{array}$ & 22.28 \\
\hline $\begin{array}{l}\text { Turbine } \\
\text { Tripped }\end{array}$ & $\begin{array}{l}\text { Electro-Hydraulic } \\
\text { Control Header } \\
\text { Pressure Switch }\end{array}$ & 2 & contact & contact \\
\hline
\end{tabular}

NOTE:
(1) Values given are typical. Actual values are site dependent based on the equipment procured. Therefore, the site specific SAR shall make I appropriate adjustments as necessary.


TABLE 7.7-2

DIA 8 8EGYEHTS

Designation

$\mathbf{P}$

N1

N2

N3

N4

N5
Yain control panel/8egment (1)

Safety Status Monitoring - consisting of Regulatory Guide 1.97 Category 1 signals.

Reactor Coolant System (RCS) - consisting of reactor coolant system, chemical and volume control system, control element assembly control, primary system monitoring and IPSO.

Secondary system - consisting of steam generator, feedwater, condenser, and turbine monitoring.

Safe Shutdown - consisting of Enc ineered Safety Feature (ESF) train A, ESF train B, and safety monitoring.

Secondary controls - consisting of turbine generator, condenser, feedwater, electrical power distribution, and diesel generator controls.

General - consisting of cooling water, radiation monitoring, and heating, ventilating, and air conditioning.

Note: (1) The Remote Shutdown Panel indicators are driven from at least two segments. 
TABLE 7.7-3

\section{SENSOR LOCATIONS FOR ACOUSTIC LEAR MONITORING SYSTEM}

\begin{tabular}{|c|c|c|c|}
\hline Component & $\begin{array}{c}\text { Number } \\
\text { of Sensors }\end{array}$ & $\begin{array}{l}\text { Sensor } \\
\text { No. } \\
\end{array}$ & Location \\
\hline Reactor Coolant Pump & (1 per pump) & $\begin{array}{l}\text { U118 } \\
\text { U128 } \\
\text { U138 } \\
\text { U148 }\end{array}$ & Seal \\
\hline Steam Generators & (1 ${ }^{2}$ per $\left.S G\right)$ & $\begin{array}{l}\text { U105 } \\
\text { U106 }\end{array}$ & $\begin{array}{l}\text { Primary side, } \\
\text { manway }\end{array}$ \\
\hline Hot legs & (1 per Leg) & $\begin{array}{l}\mathrm{U} 110 \\
\mathrm{U} 111\end{array}$ & $\begin{array}{l}\text { Reactor vessel } \\
\text { outlet nozzle }\end{array}$ \\
\hline Cold legs & (1 per leg) & $\begin{array}{l}\mathrm{U} 112 \\
\mathrm{U} 113 \\
\mathrm{U} 114 \\
\mathrm{U} 115\end{array}$ & $\begin{array}{l}\text { Reactor vessel } \\
\text { inlet nozzle }\end{array}$ \\
\hline Reactor vessel & 3 & $\begin{array}{l}\mathrm{U} 101 \\
\mathrm{U} 102 \\
\mathrm{U} 103\end{array}$ & $\begin{array}{l}\text { Upper head, } \\
\text { CEDM nozzles }\end{array}$ \\
\hline Reactor vessel & 1 & U104 & $\begin{array}{l}\text { Lower head, } \\
\text { instrument nozzle }\end{array}$ \\
\hline $\begin{array}{l}\text { Pressurizer safety } \\
\text { valves }\end{array}$ & (1 per valve) & $\begin{array}{l}\text { U106 } \\
\text { U107 } \\
\text { U108 } \\
\text { U109 }\end{array}$ & Discharge line \\
\hline Pressurizer & 1 & $\mathrm{U} 116$ & Heater region \\
\hline Total per plant & 21 & & \\
\hline
\end{tabular}


TABLE 7.7-4

LOCATION OF LOOSE PARTS MONITORING SYSTEM ACCELEROMETERS

\begin{tabular}{|c|c|c|c|}
\hline Component & $\begin{array}{c}\text { Number } \\
\text { of Sensors }\end{array}$ & $\begin{array}{c}\text { Sensor } \\
\text { No. } \\
\end{array}$ & Location \\
\hline Reactor Vessel & 6 & $\begin{array}{l}\text { V101 } \\
\text { V102 } \\
\text { V103 }\end{array}$ & Lower head \\
\hline & & $\begin{array}{l}V 104 \\
V 105 \\
V 106\end{array}$ & Upper head \\
\hline steam generator 1 & 4 & $\begin{array}{l}\text { V109 } \\
\text { V110 } \\
\text { V108 } \\
\text { V107 }\end{array}$ & $\begin{array}{l}\text { Primary (inlet plenum) } \\
\text { Primary (outlet plenum) } \\
\text { Secondary (economizer } \\
\text { region) } \\
\text { Secondary (can deck } \\
\text { region) }\end{array}$ \\
\hline steam generator 2 & 4 & $\begin{array}{l}\text { V113 } \\
\text { V114 } \\
\text { V112 } \\
\text { V111 }\end{array}$ & $\begin{array}{l}\text { Primary (inlet plenum) } \\
\text { Primary (outlet plenum) } \\
\text { Secondary (economizer } \\
\text { region) } \\
\text { Secondary (can deck } \\
\text { region) }\end{array}$ \\
\hline Total per plant & 14 & & \\
\hline
\end{tabular}


TABLE 7.7-5

DPE NOCLEAR BTEAY 8OPPLY 8Y8TEY

APPI ICATIOA PROCRAYS

Function

CoLss Algorithm

CEA Position Monitoring

CEA PDIL/PPDIL Monitoring

CEA Out-of-Sequence Monitoring

CEA Deviation Monitoring

CEA Trip Program

CEA Reassignment

CEA Exposure Accumulation

In-Core Detector Processing

Xenon Reactivity Prediction

Reactivity Balance

CPC Deviation Monitoring

CEAC Deviation Monitoring

PPS Deviation Monitoring

Critical Function Monitoring

Time Dependent Variables Processing

Reactor Power Cutback CEA Selection

Data Snapshot Collection Program

Historical Data Storage and Retrieval

Sequence of Events

ESF Computer Aided Test Program
Execution Category (see notes)

Real Time-(Periodic)

Real Time

Real Time-(Periodic)

Real Time

Real Time

Real Time-(Event)

Demand Program-(Background)

Real Time-(Periodic)

Real Time-(Periodic)

Demand Program-(Background)

Demand Program-(Background)

Real Time-(Periodic)

Real Time-(Periodic)

Real Time-(Periodic)

Real Time-(Periodic)

Real Time-(Periodic)

Real Time-(Periodic)

Demand Program

Real Time-(Periodic)

Real Time-(Event)

Demand Program-(Background)

NOTES: 1) Real Time-(Periodic) is defined as a real time program which is executed on a periodic scheduled basis.

2) Real Time-(Event) is defined as a real time program which is executed automatically in response to some event (it is asynchronous in nature as opposed to periodic).

3) Demand Program is defined as a real time program which is only activated upon operator request.

4) Background Program is defined as a program which is activated by operator request but which functions in a background processing mode (as opposed to a real time mode).

5) CEA position is detected and transmitted to DPS from CEDMCS and from the CEACs.

6) Upon detection of a trip condition, via undervoltage relays, the DPS requests the trip report from CEDMCS. 
TABLE 7.7-6

\section{COLSS MONITORED PLANT VARTABLES}

\section{Monitored \\ Parameters}

Core volumetric flow

Core power

Primary calorimetric

Secondary calorimetric

Core power distribution

In-core monitoring system

\section{CEA position}

Reactor coolant pressure Pressurizer pressure

Turbine power

Turbine first

stage pressure
Number of Sensors

\section{2 per pump}

2 per pump

1 per cold leg

1 per hot leg

1 per generator

1 per generator

1 per generator

1 per generator

61 in-core assemblies each containing 5

axial stacked

detectors

1 per CEA group

2 (on pressurizer)

2 (on turbine)
(2) $\left.\right|_{I}$

$0-1,320 \mathrm{rpm}$

$0-150$ psid

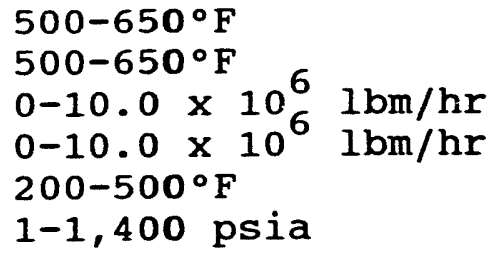

$\mathrm{NA}(1)$

0-150 inches

$1,500-2,500$ psia

$0-1,000$ psia

Notes:

(1) Core power distribution is provided in a graphic format.

(2) Ranges given are typical. Actual ranges are site dependent based on the equipment procured. Therefore, the site specific SAR shall make appropriate adjustments as necessary. 


\section{TABLE 7.7-7}

BATANCE OF PLANT

\section{APPLICATION PROGRAMS}

\section{Function}

Feedwater Heater Performance

Condenser Performance

Turbine Performance

Moisture Separator Reheater Performance

Condensate Pump Performance

Unit Generation

Steam Generator Performance
Execution Category ${ }^{(1)}$

Real Time - (Periodic)

Real Time - (Periodic)

Real Time - (Periodic)

Real Time - (Periodic)

Real Time - (Periodic)

Real Time - (Periodic)

Real Time - (Periodic)

\section{Note:}

(1) Real Time-(Periodic) program which is (scheduled) basis.

is defined as a real time executed on a periodic 


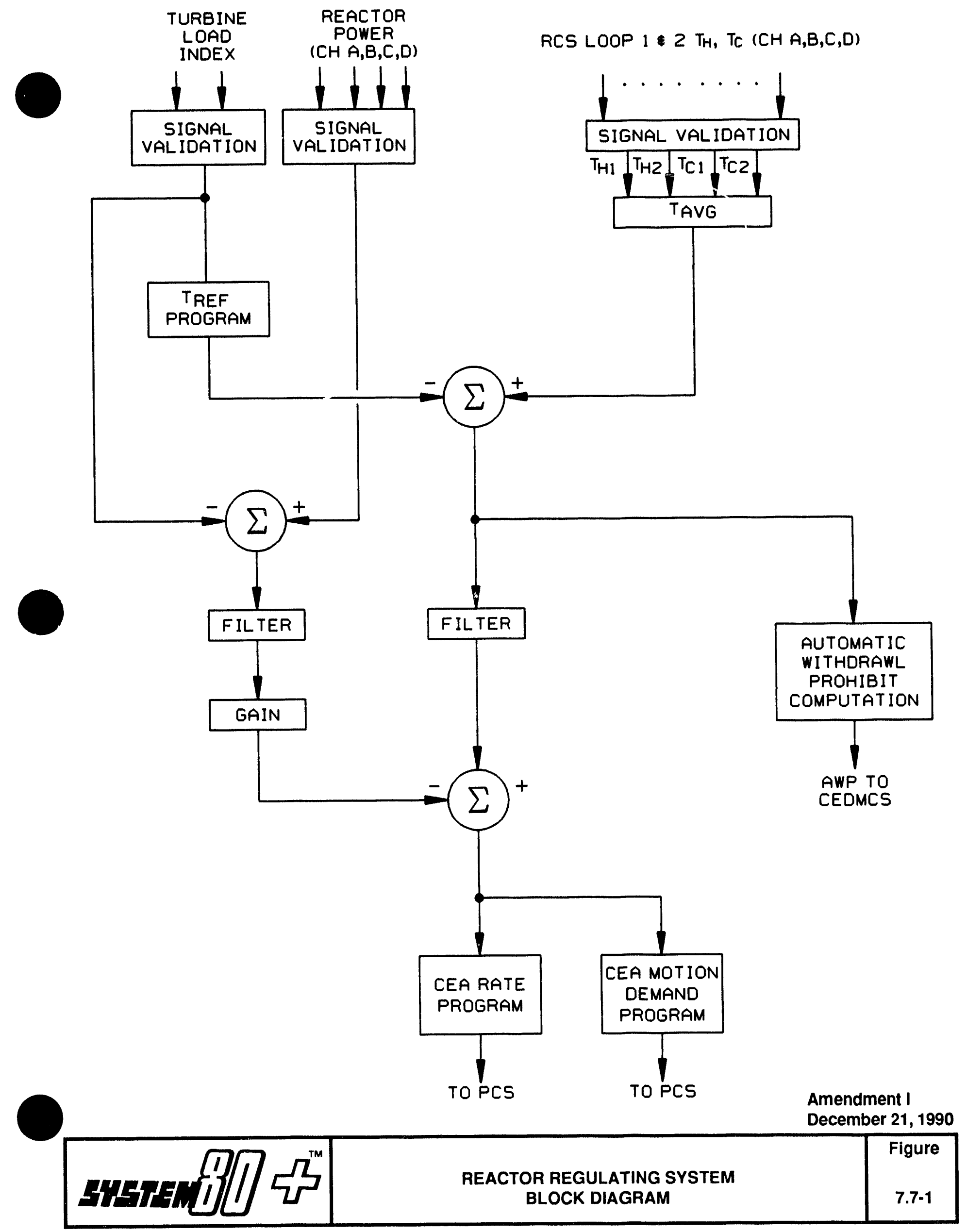




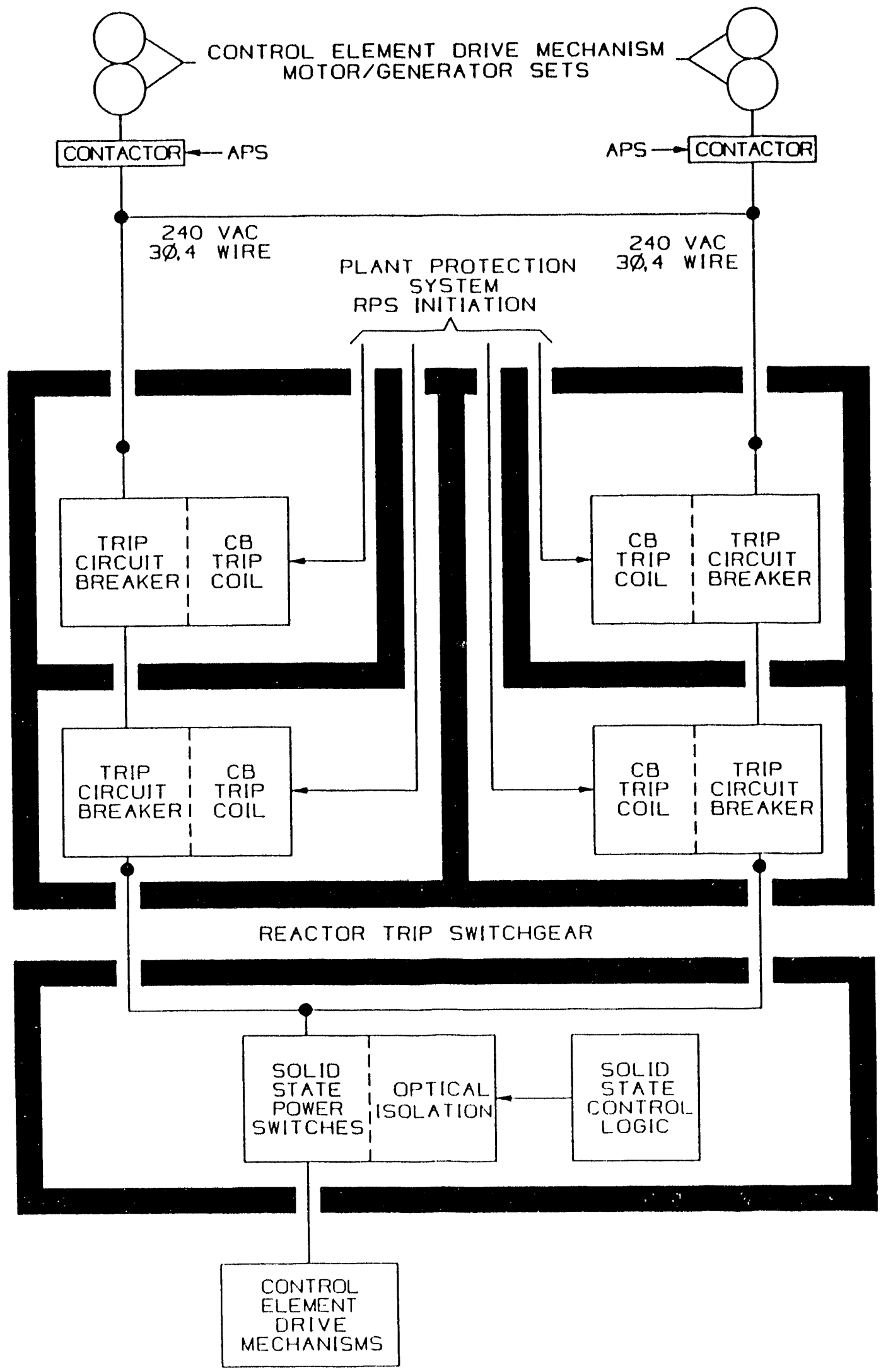

Amendment I

December 21, 1990 
PRESSURIZER

PRESSURE

(CH $A, B, C, D)$
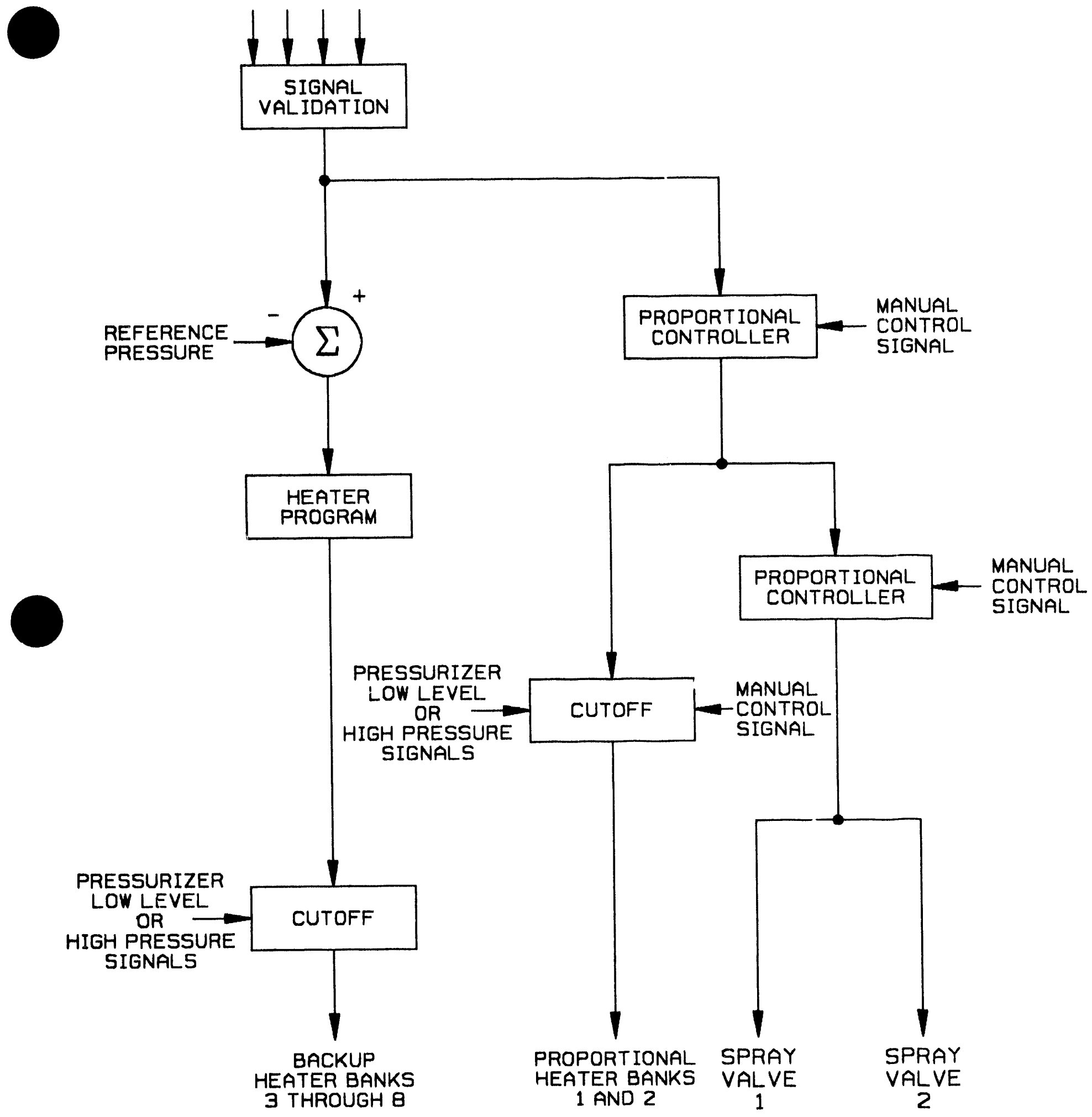

Amendment $\mathrm{E}$

December 30, 1988 


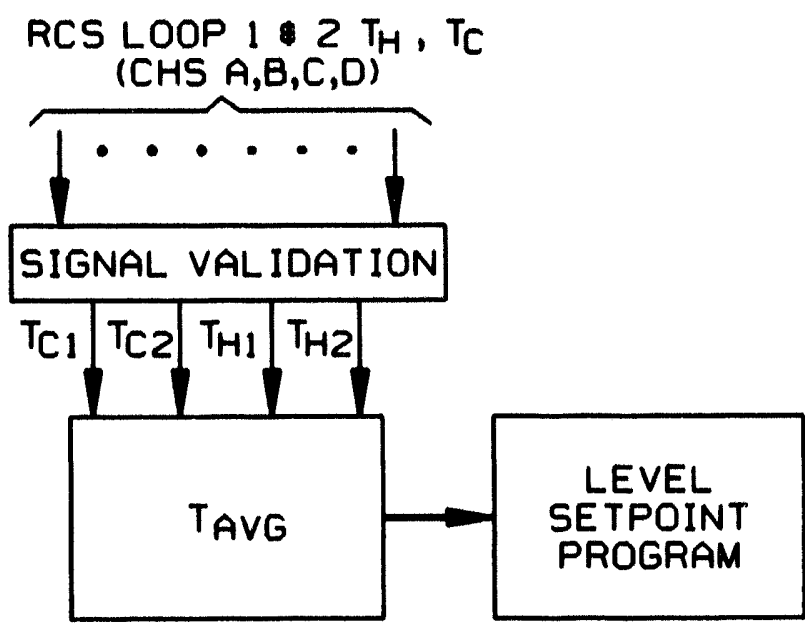

PRESSURIZER

LEVEL

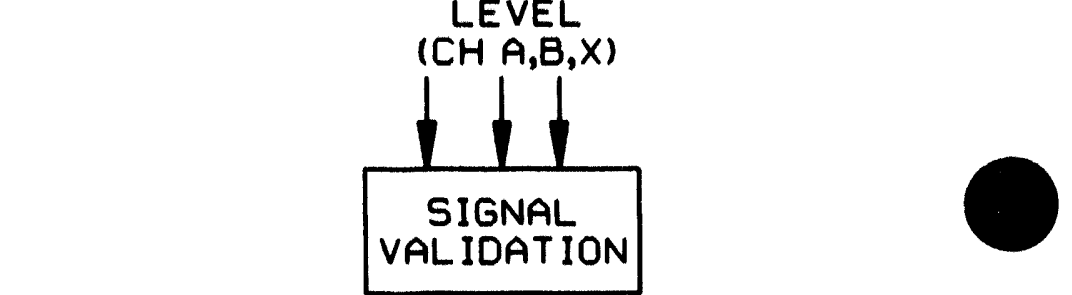

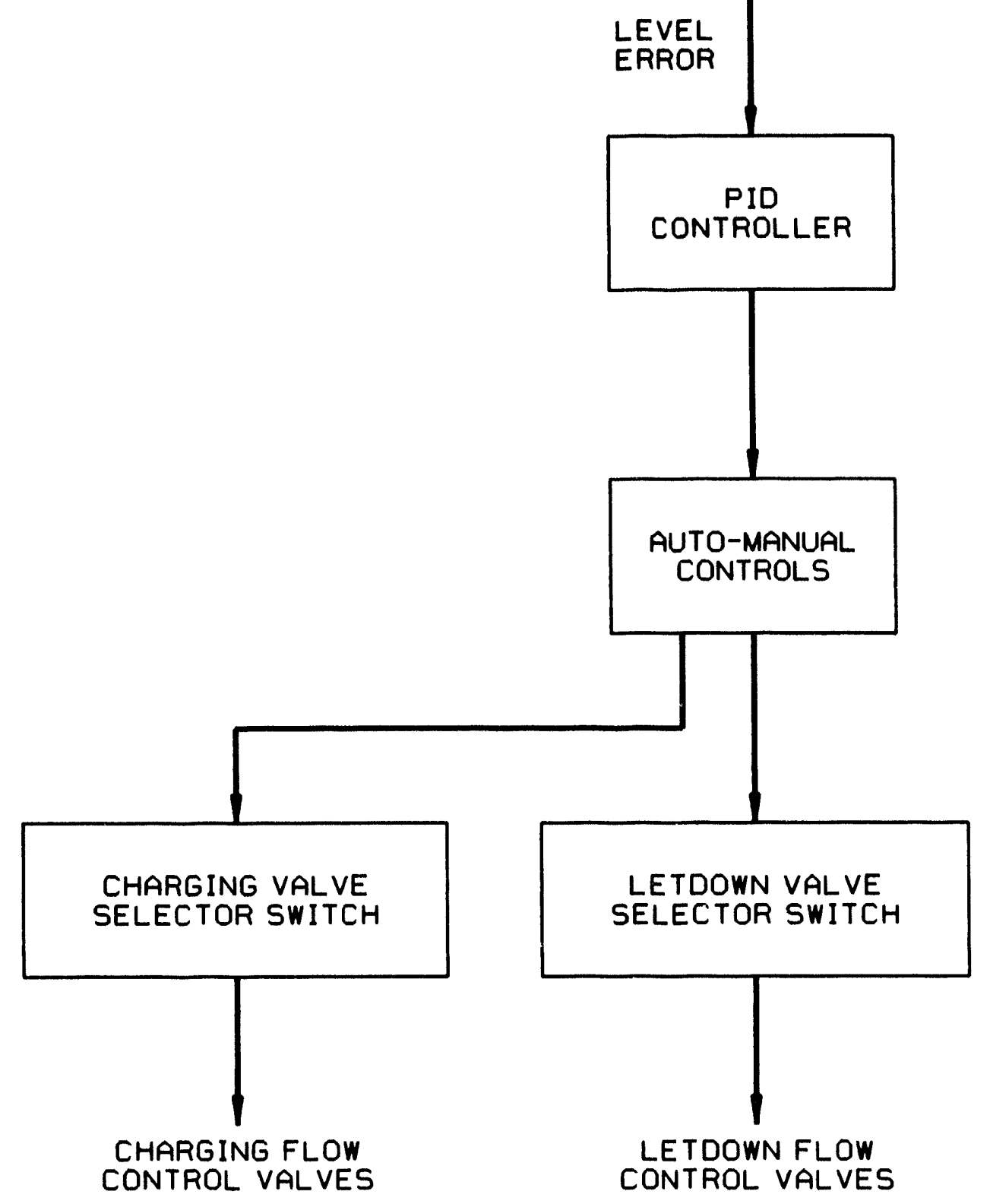

Amendment I

December 21, 1990 

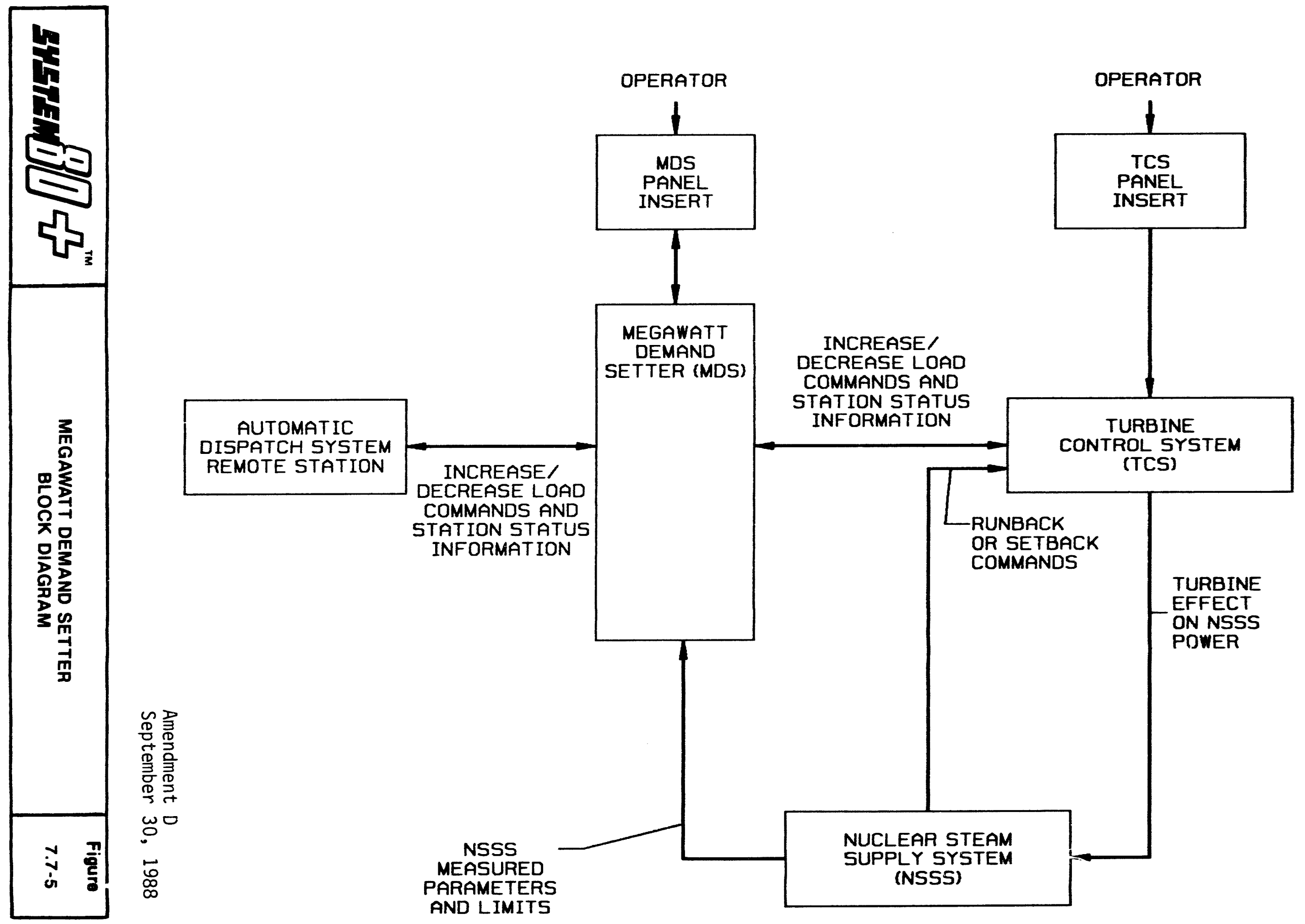


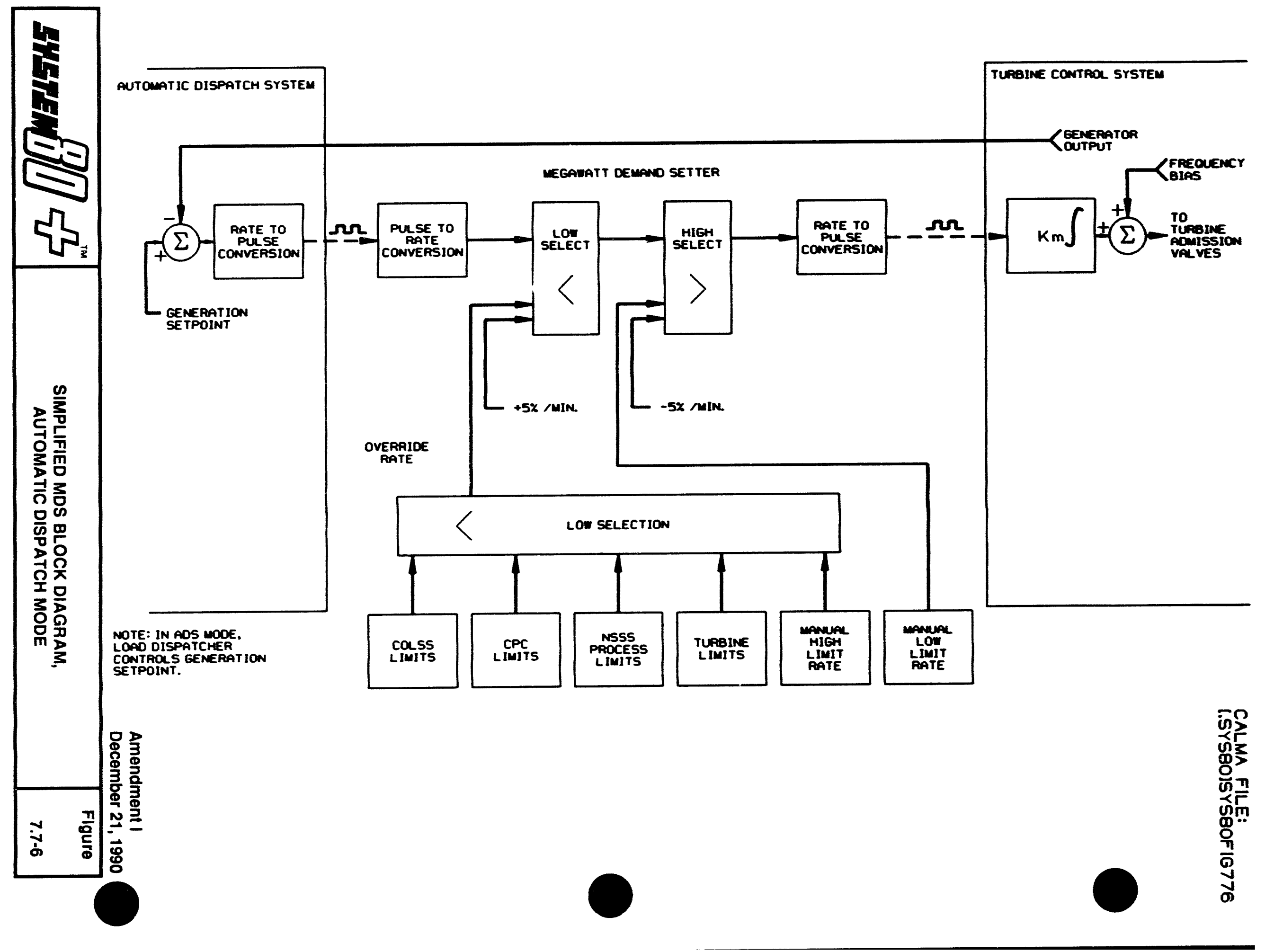




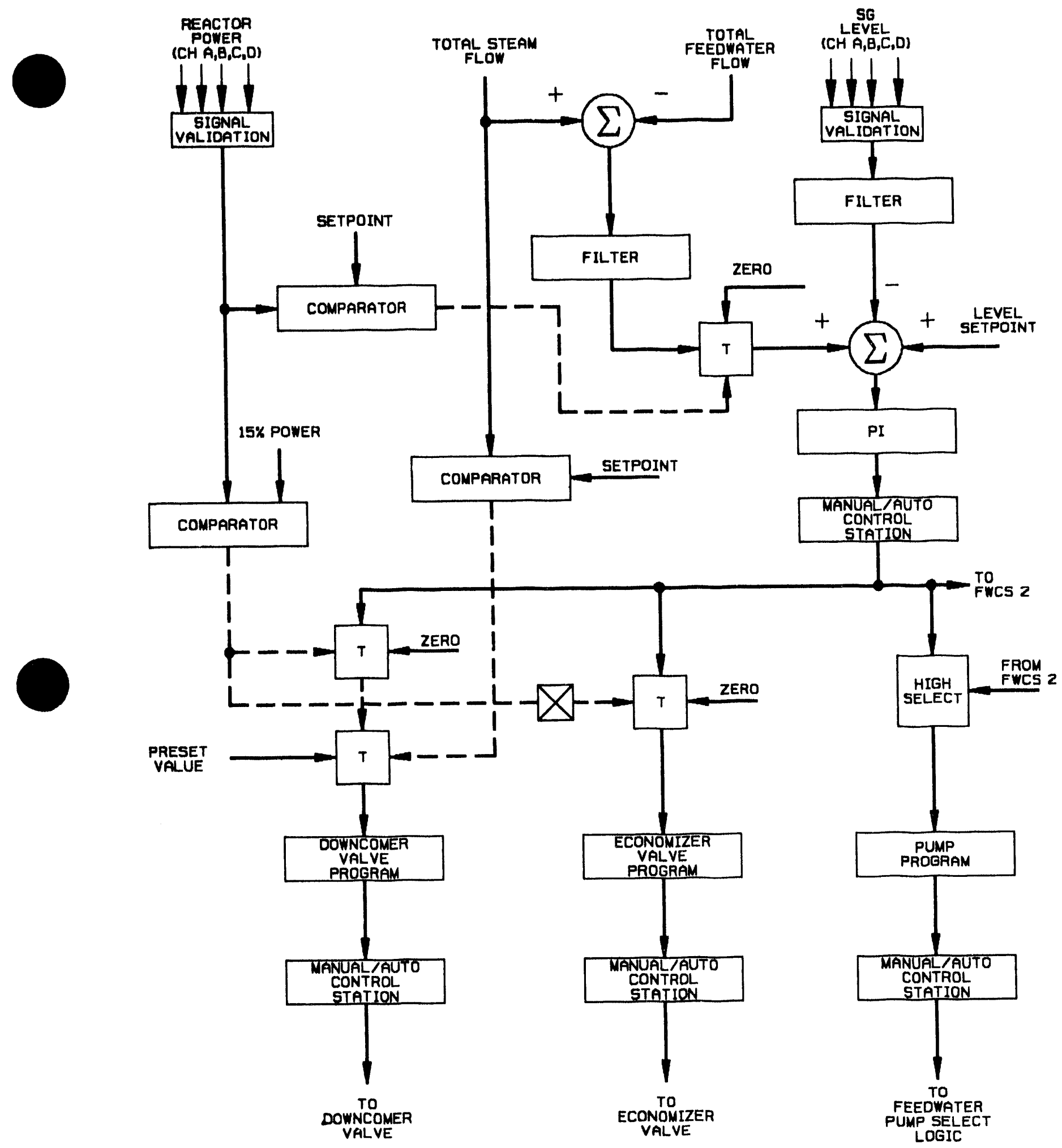

Amendment $\mathrm{E}$ December 30, 1988 


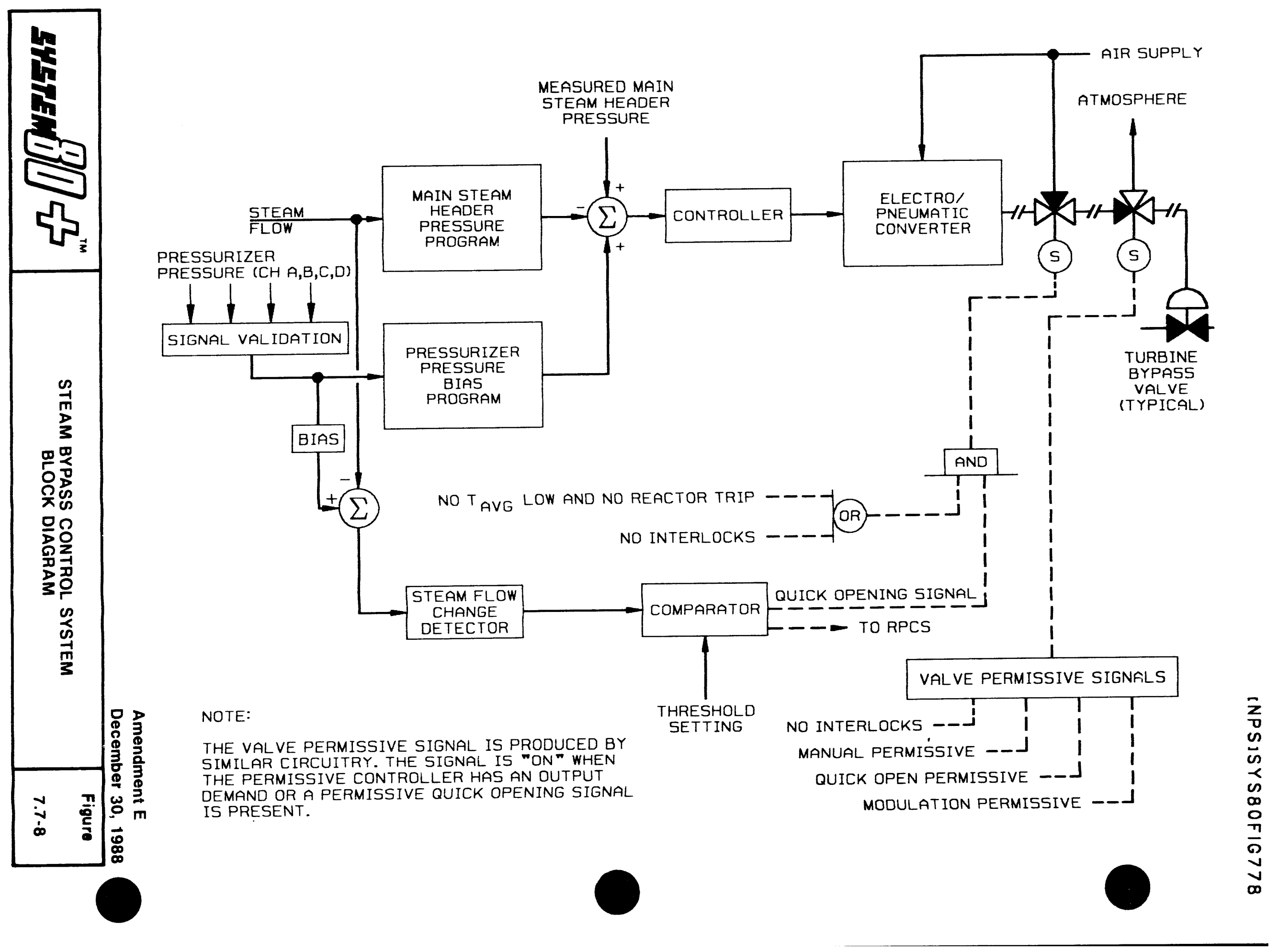




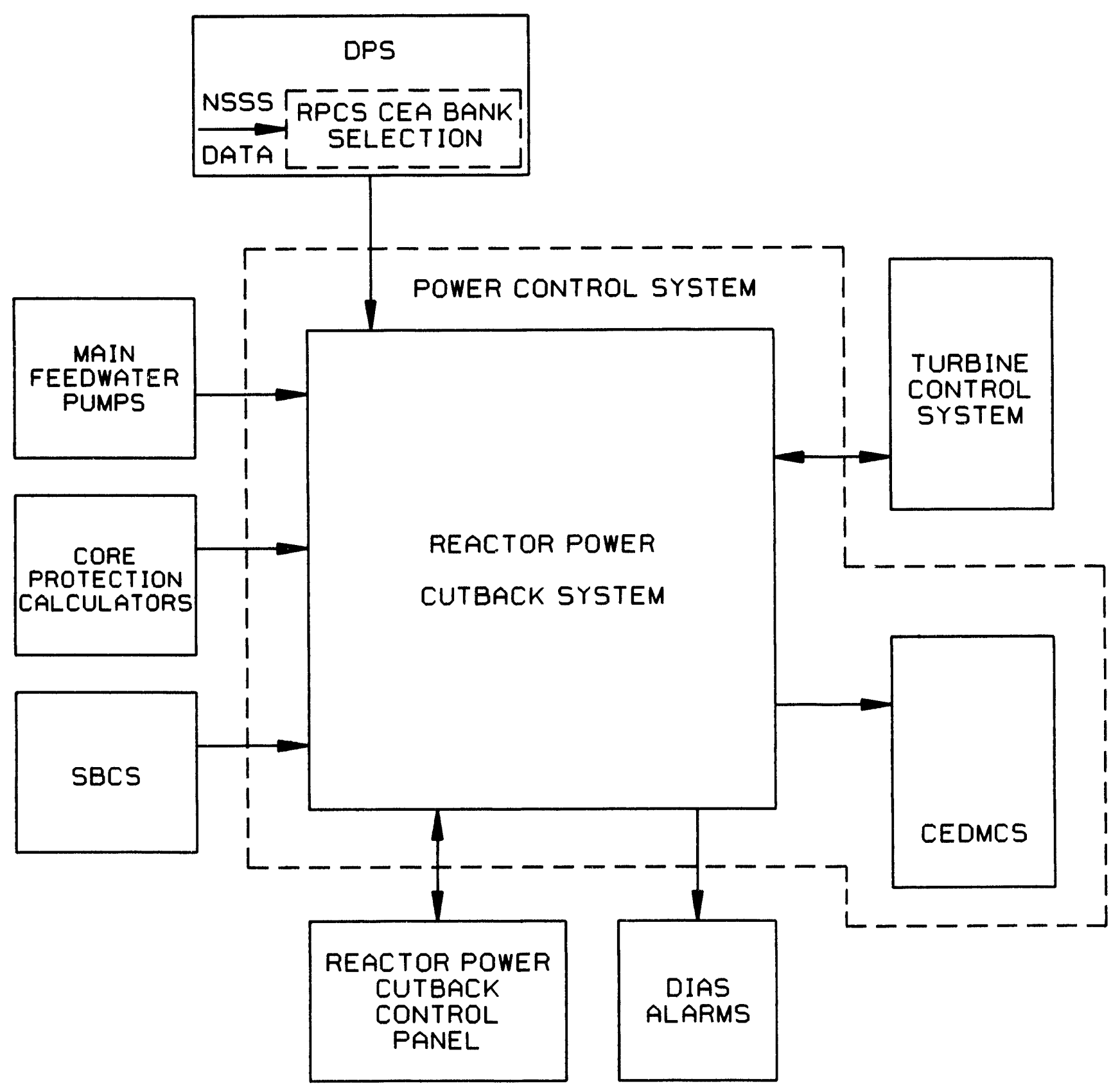




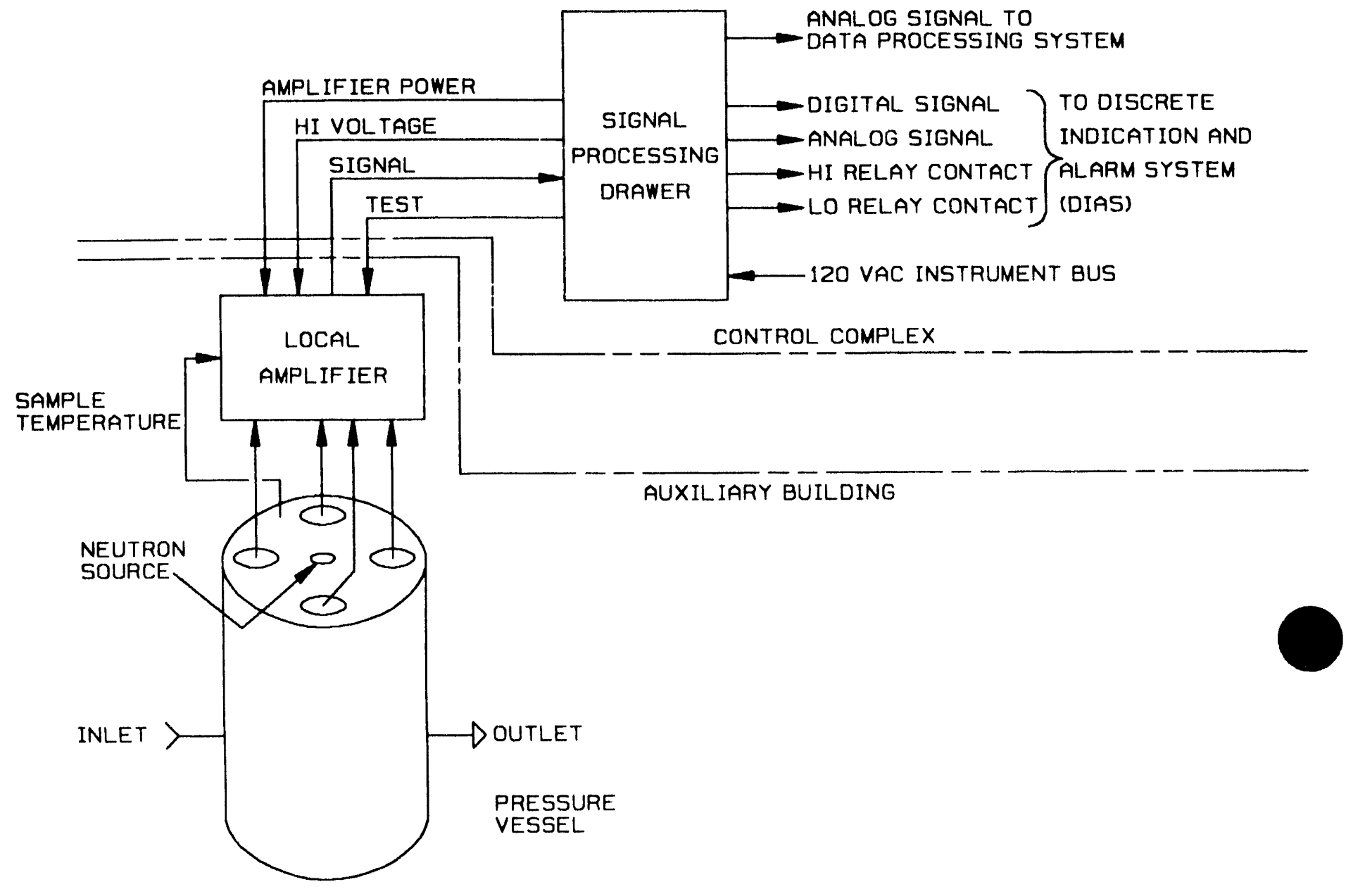

Amendment $D$

September 30, 1988 


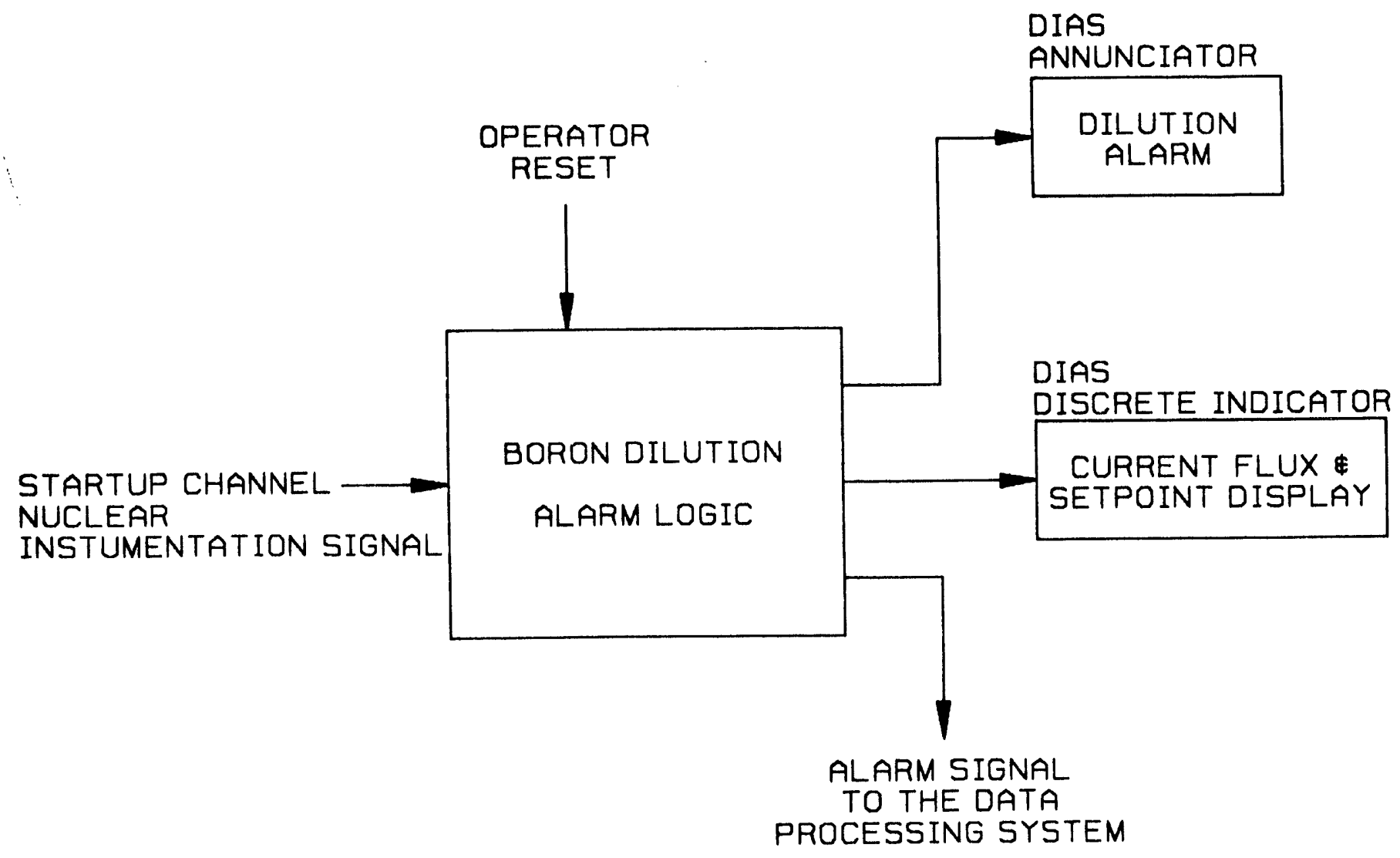

NOTE: DIAS IMPLEMENTATION SHOWN. DPS ALARM AND DISPLAY LOGIC SIMILAR. 


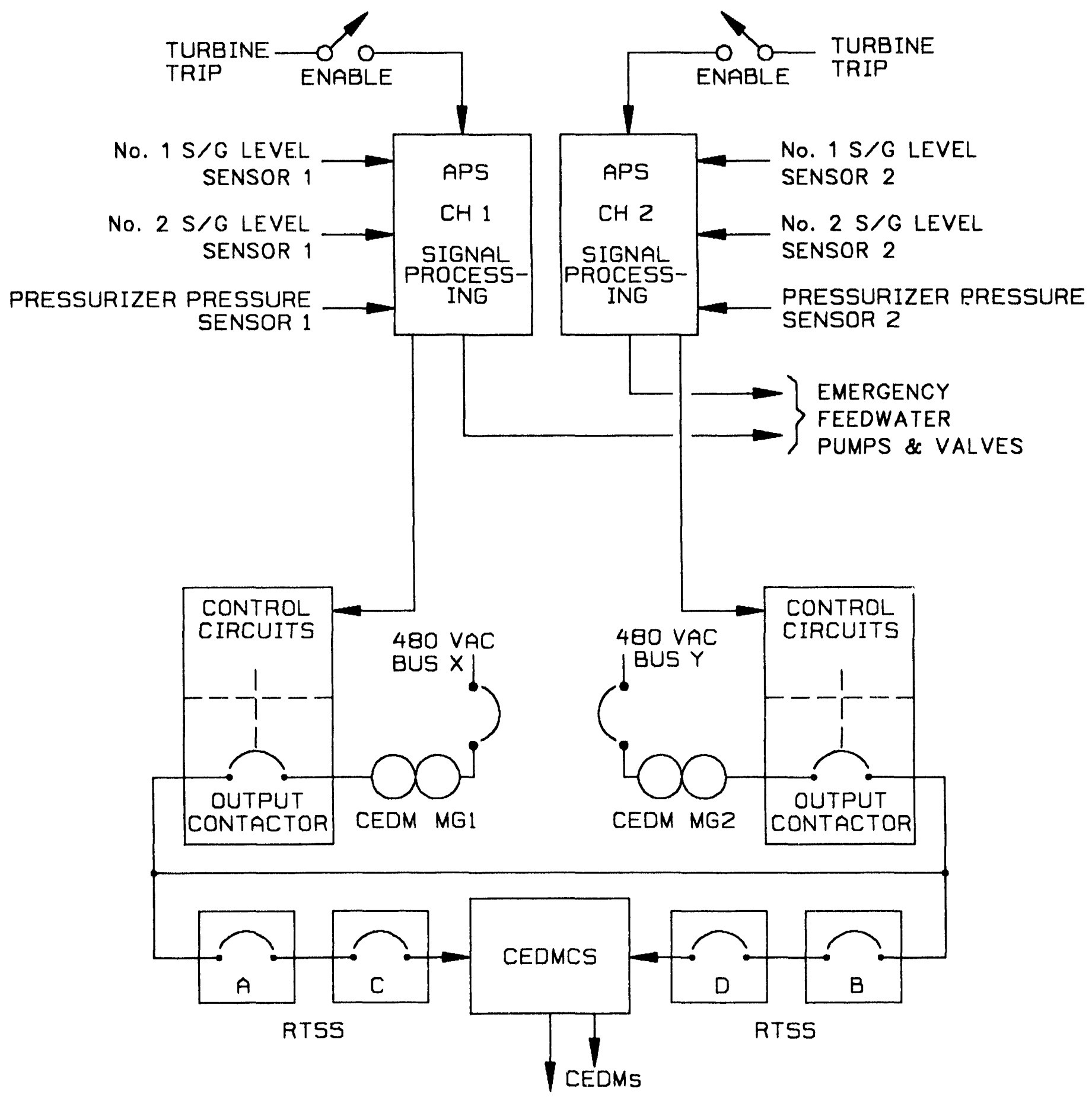

TURBINE TRIP 


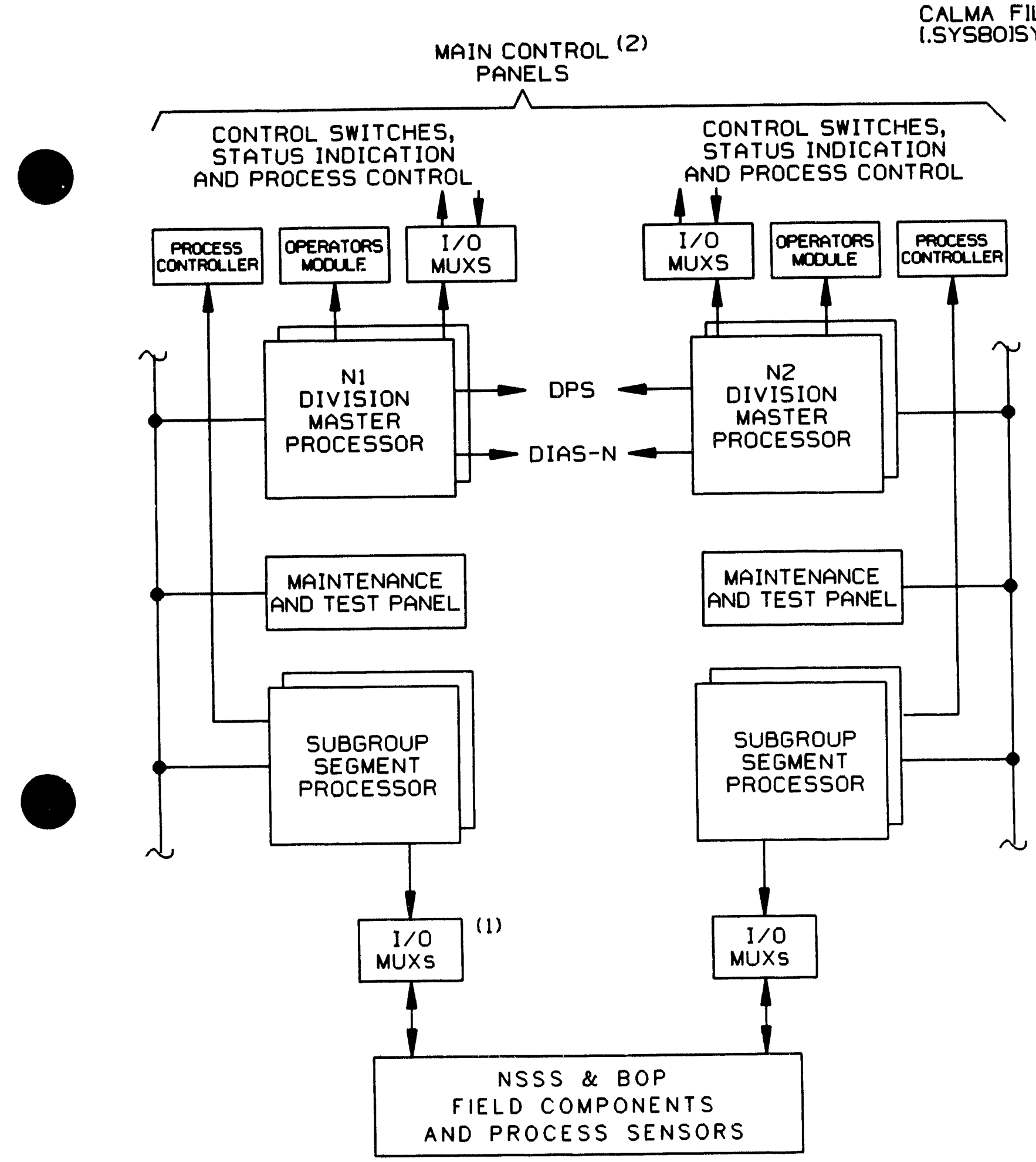

NOTES: (1) MAY BE LOCATED AT PROCESS-CCS ASSEMBLY OR DISTRIBUTED REMOTELY. (2) A DUPLICATE SUBSET OF THE MAIN CONTROL. PANEL DEVICES SHOWN AFIE ALSO LOCATED ON REMOTE SHUTDOWN PANELS.

(3) DATA COMMUNICATIONS ARE REDUNDANT BETWEEN ALL I/O MUX $\mathbf{S}_{5}$ AND PROCESSORS.

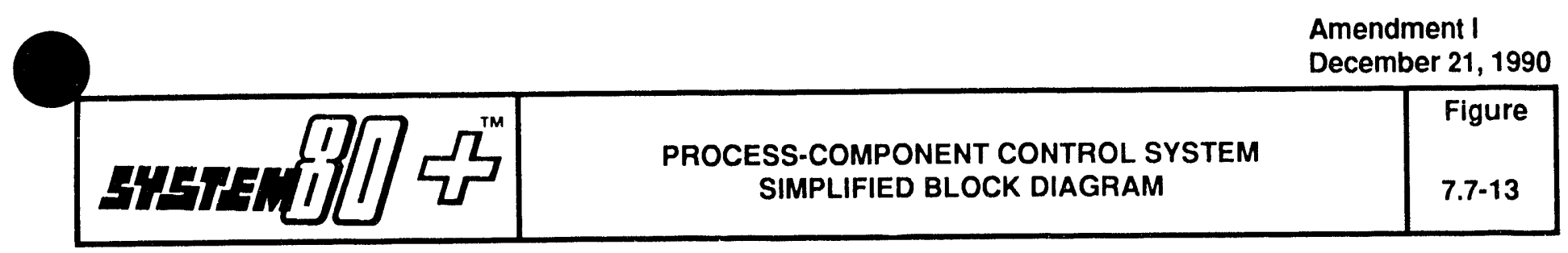


CALMA FILE

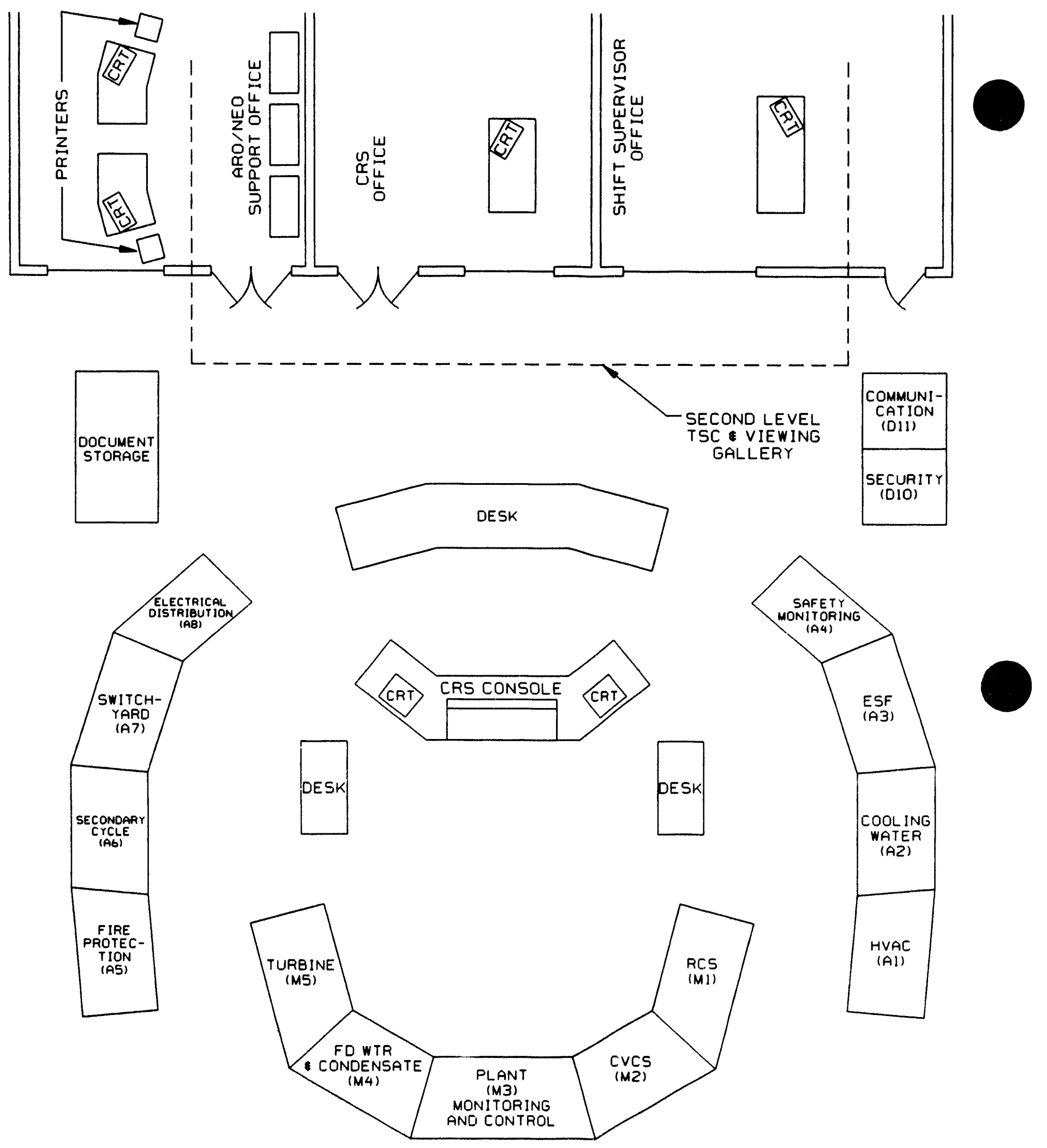




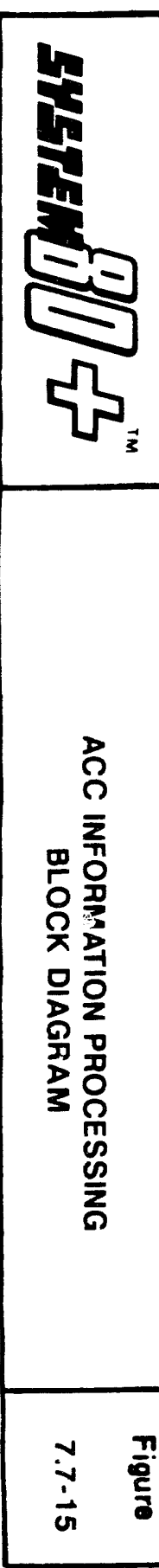

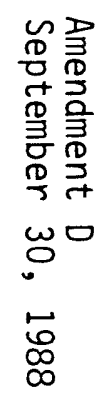

\section{LEGEND}

CET - CORE EXIT THERMOCOUPLES

CFM - CRITICAL FUNCTION MONITORING

DL - DATA LINK

HDSR - HISTORICAL DATA STORAGE \& RETRIEVAL

KB - KEYBOARD

NPM - NUCLEAR POWER MODULE

PL - PHONE LINE

QDU - QUALIFIED DISPLAY UNIT

RVLMS - REACTOR VESSEL LEVEL MONITORING SYSTEM

SCM - SUBCOOLED MARGIN MONITOR

SPD - SAFETY PARAMETER DISPLAY

VDU - VIDEO DISPLAY UNIT 


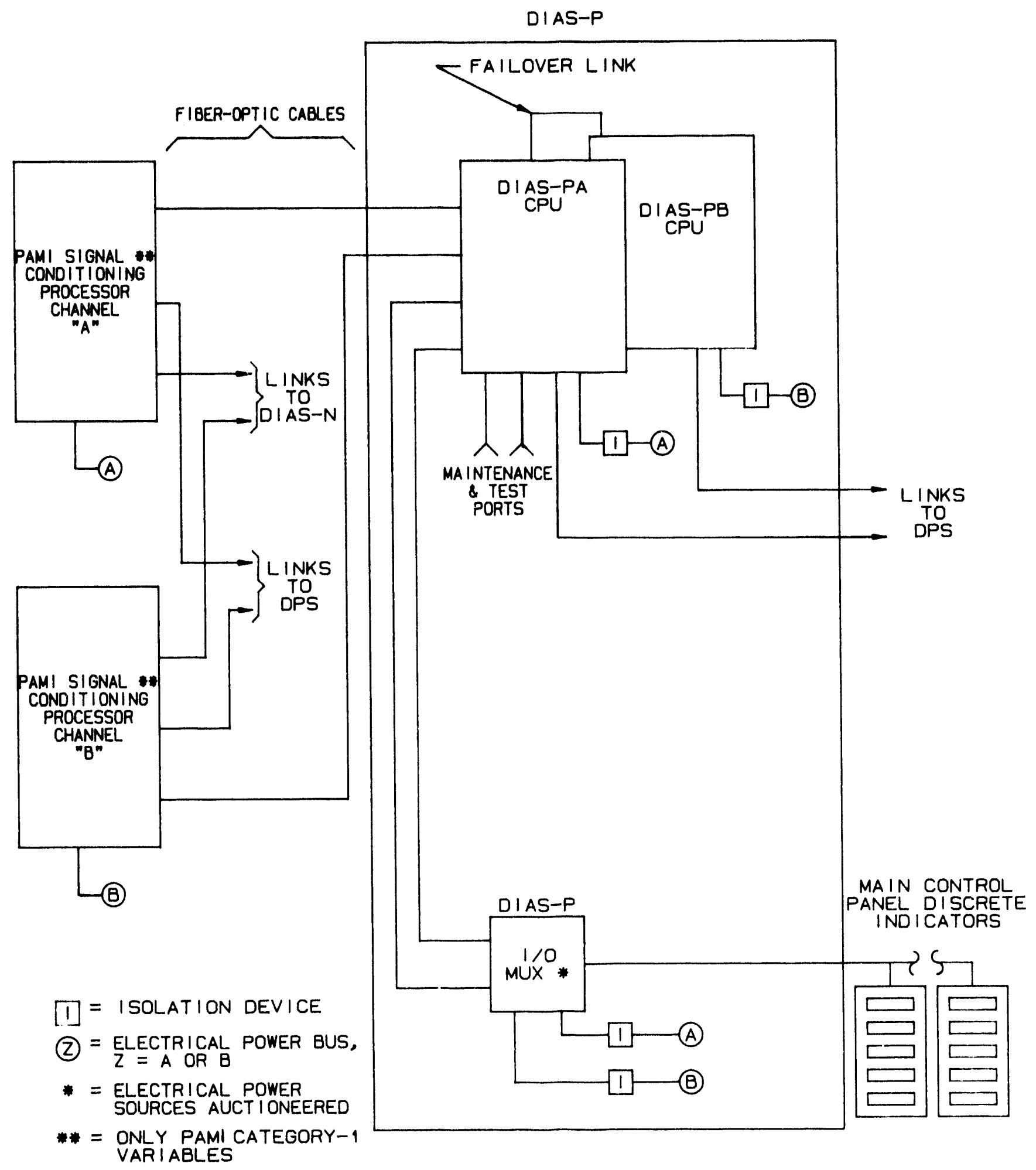

Amendment $D$

September 30, 1988 


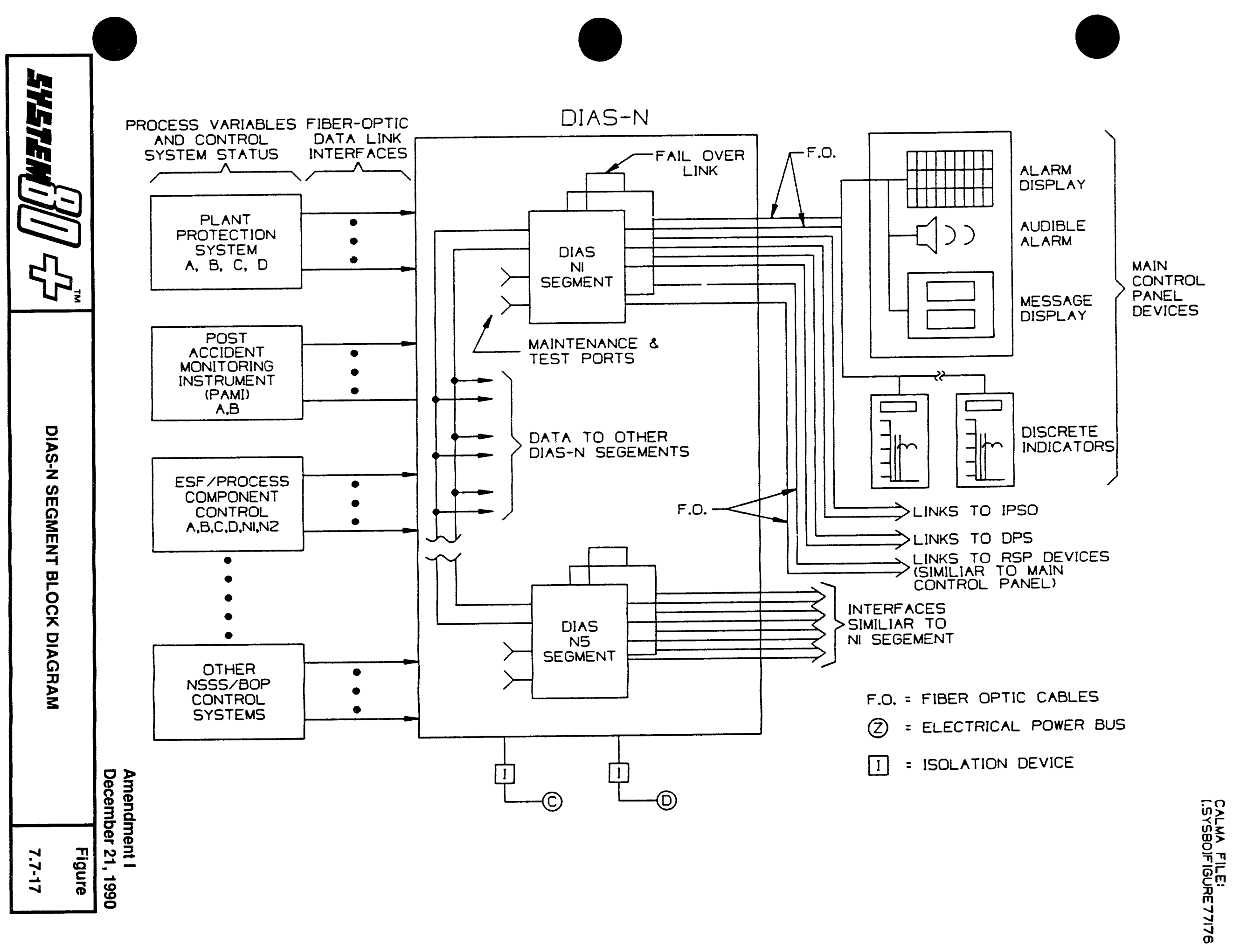




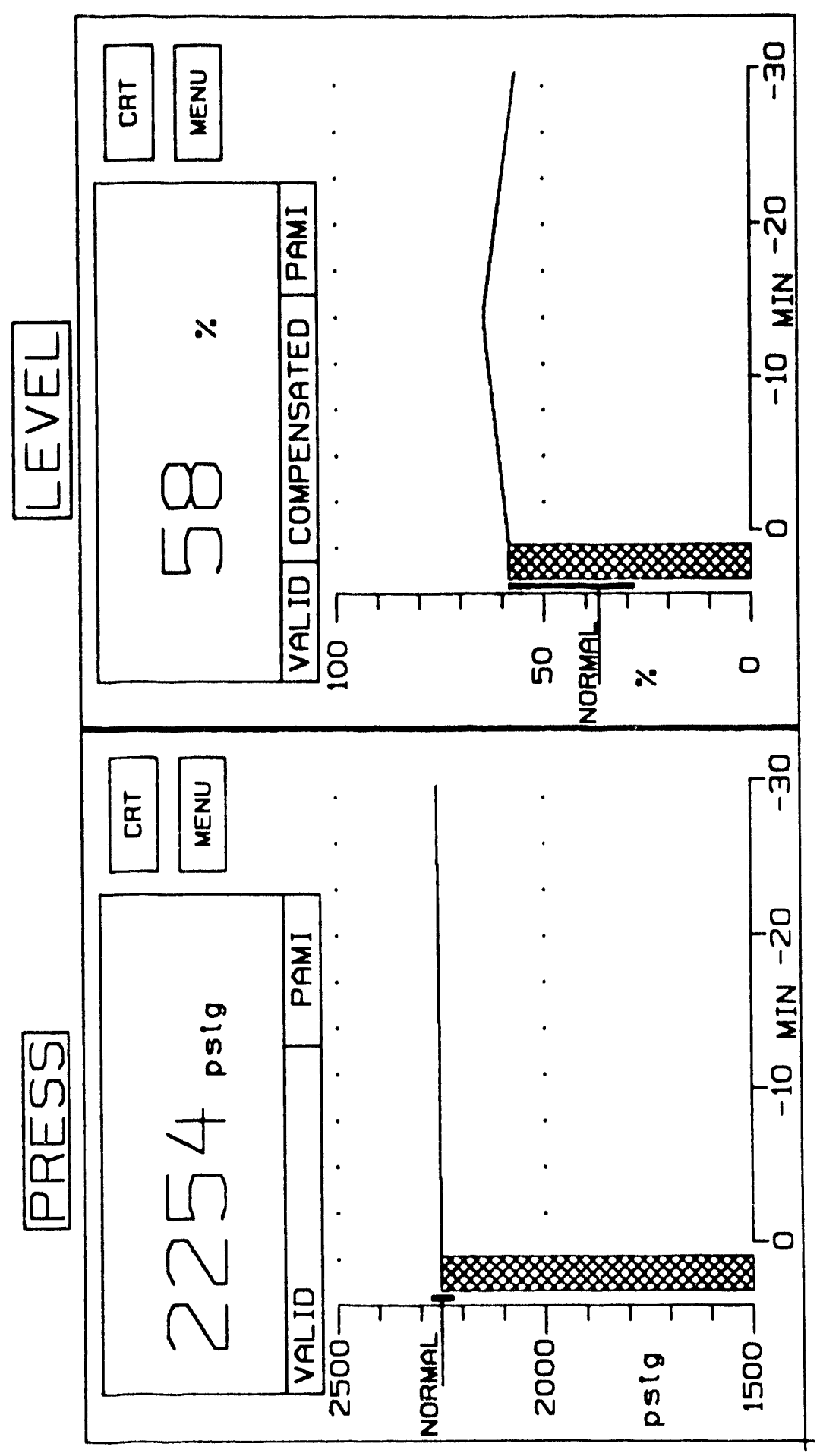

Amendment I

December 21, 1990 


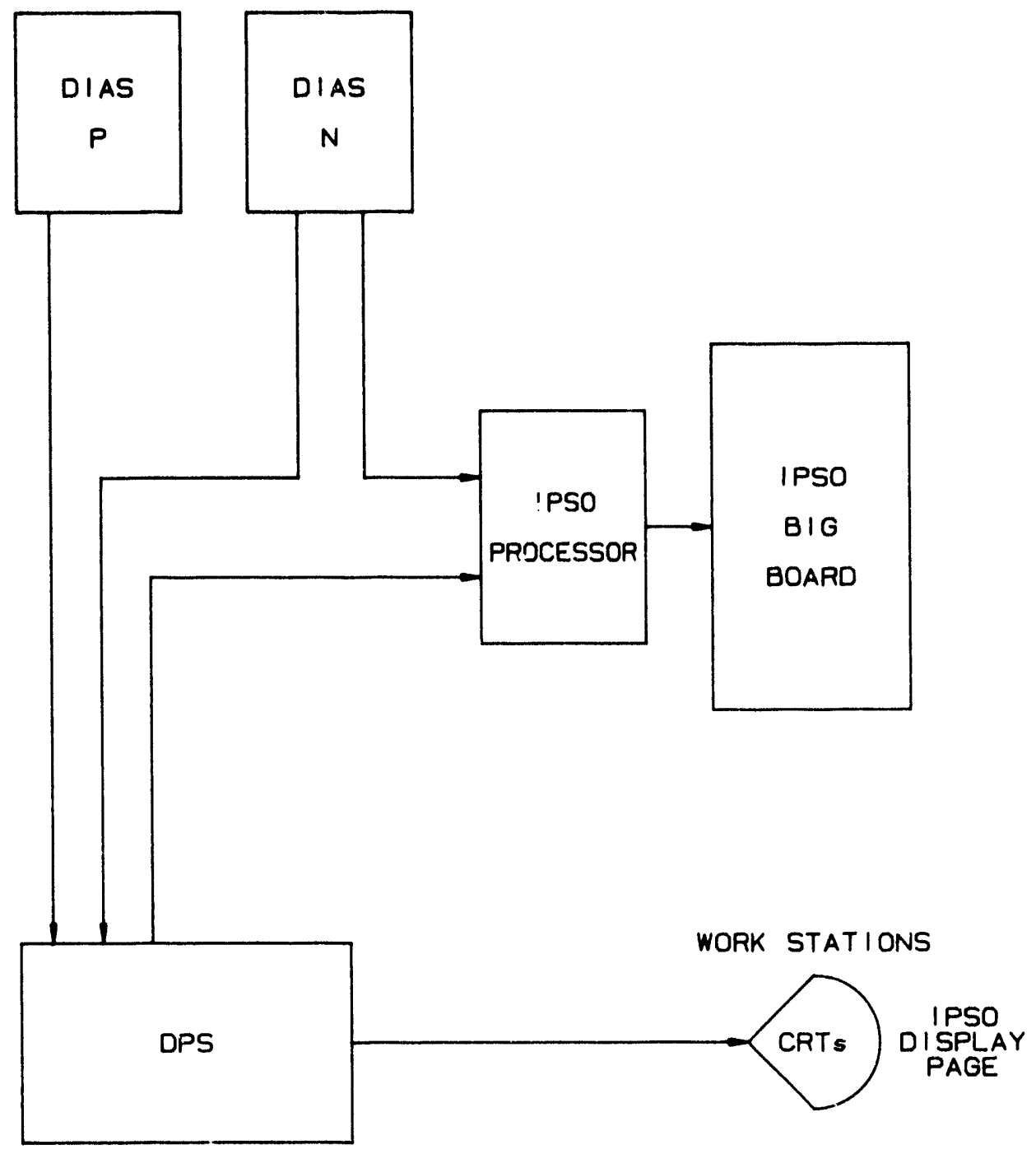

NOTE: REDUNDANT DATA COMMUNICATION LINKS USED BETWEEN DIAS, DPS AND IPSO PROCESSOR.

Amendment $D$

September 30,1988 

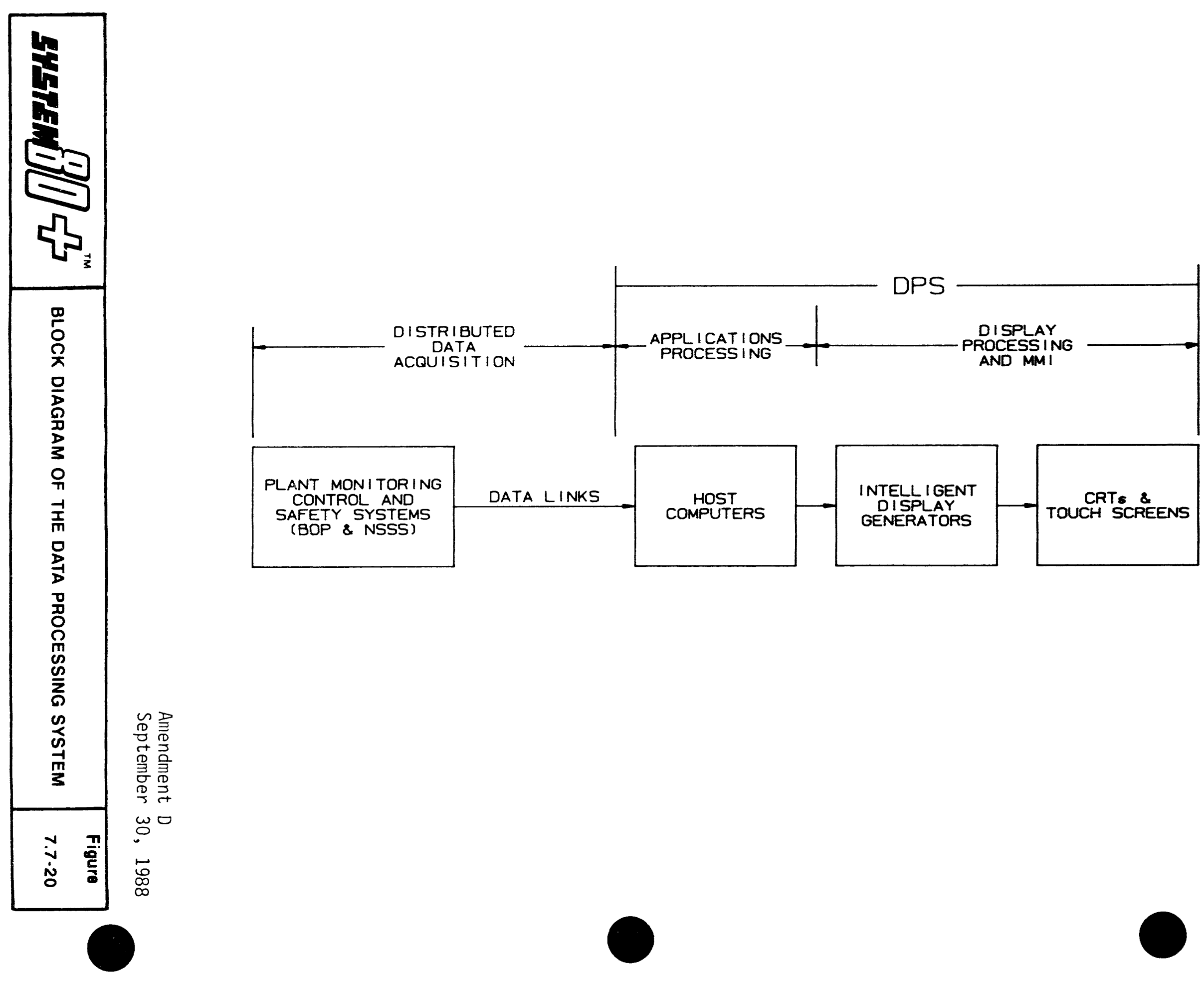


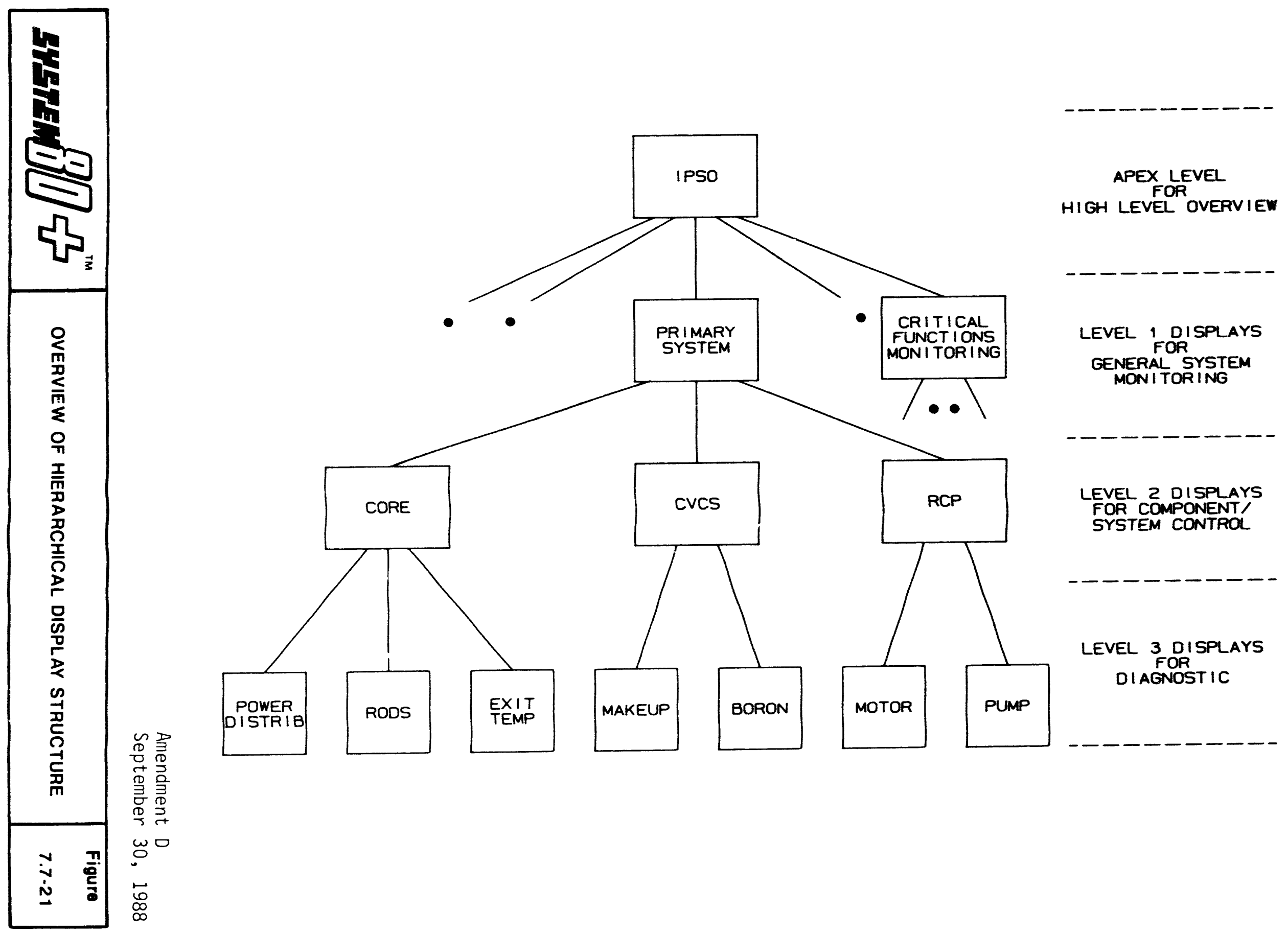




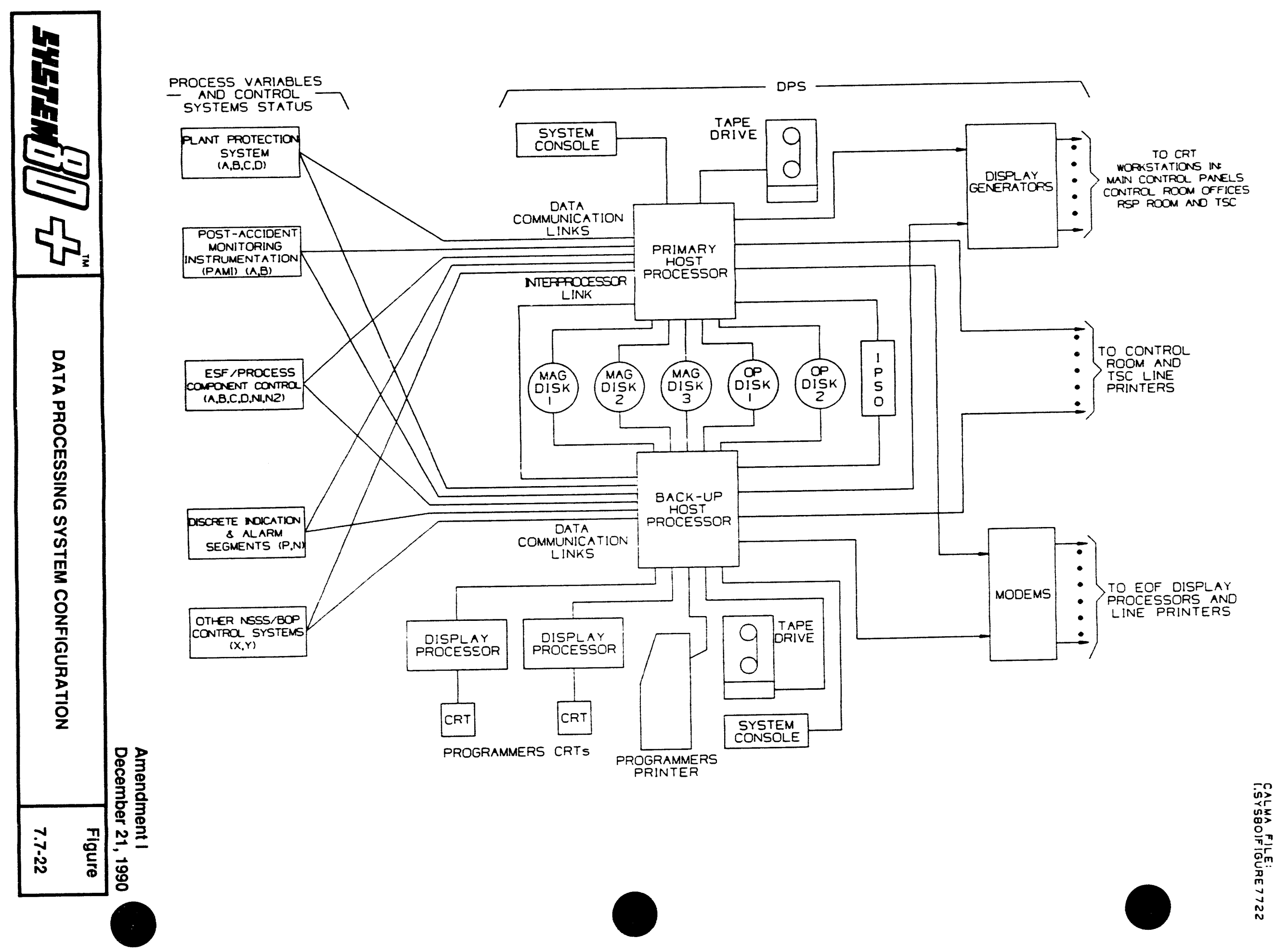




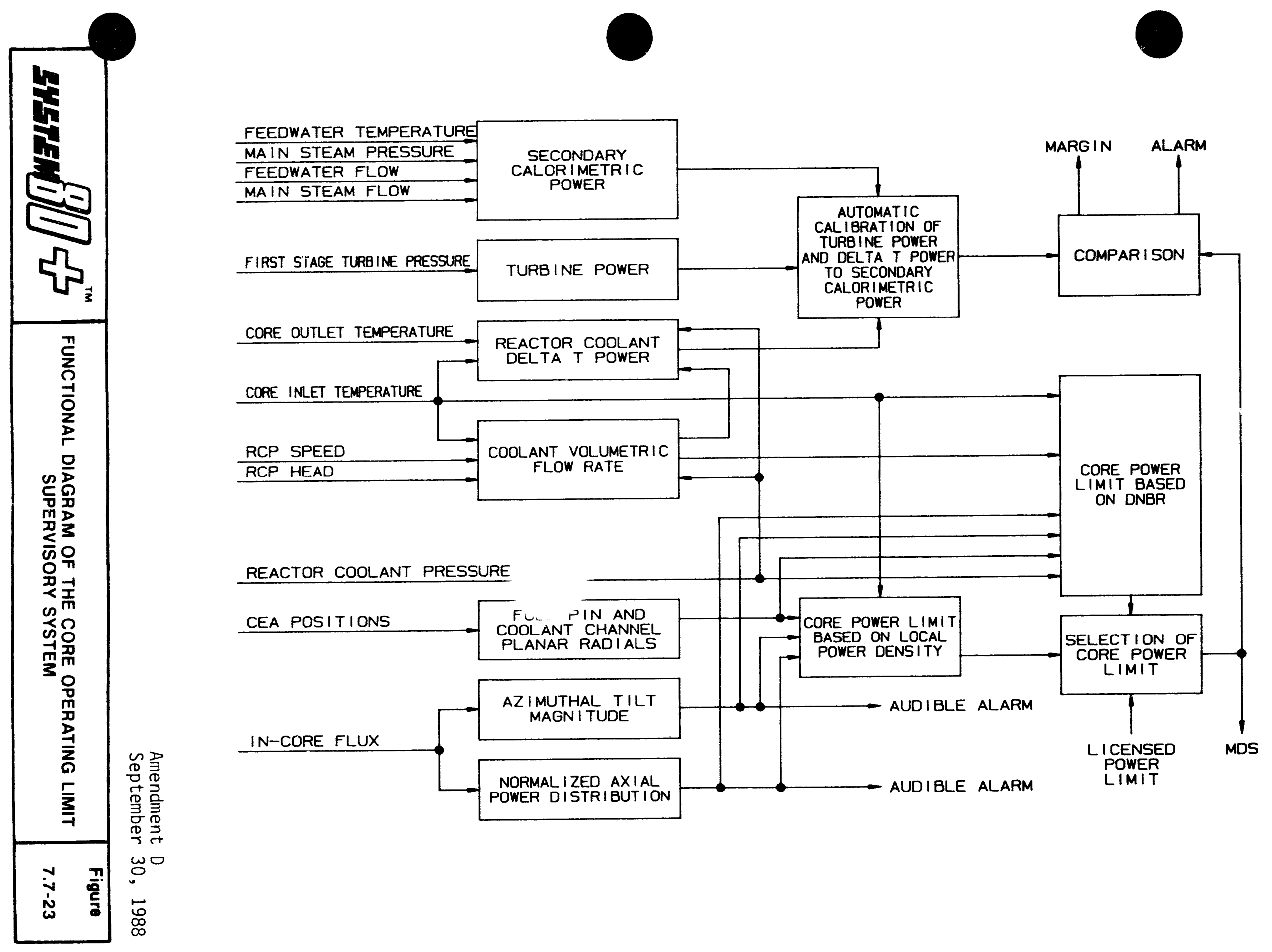




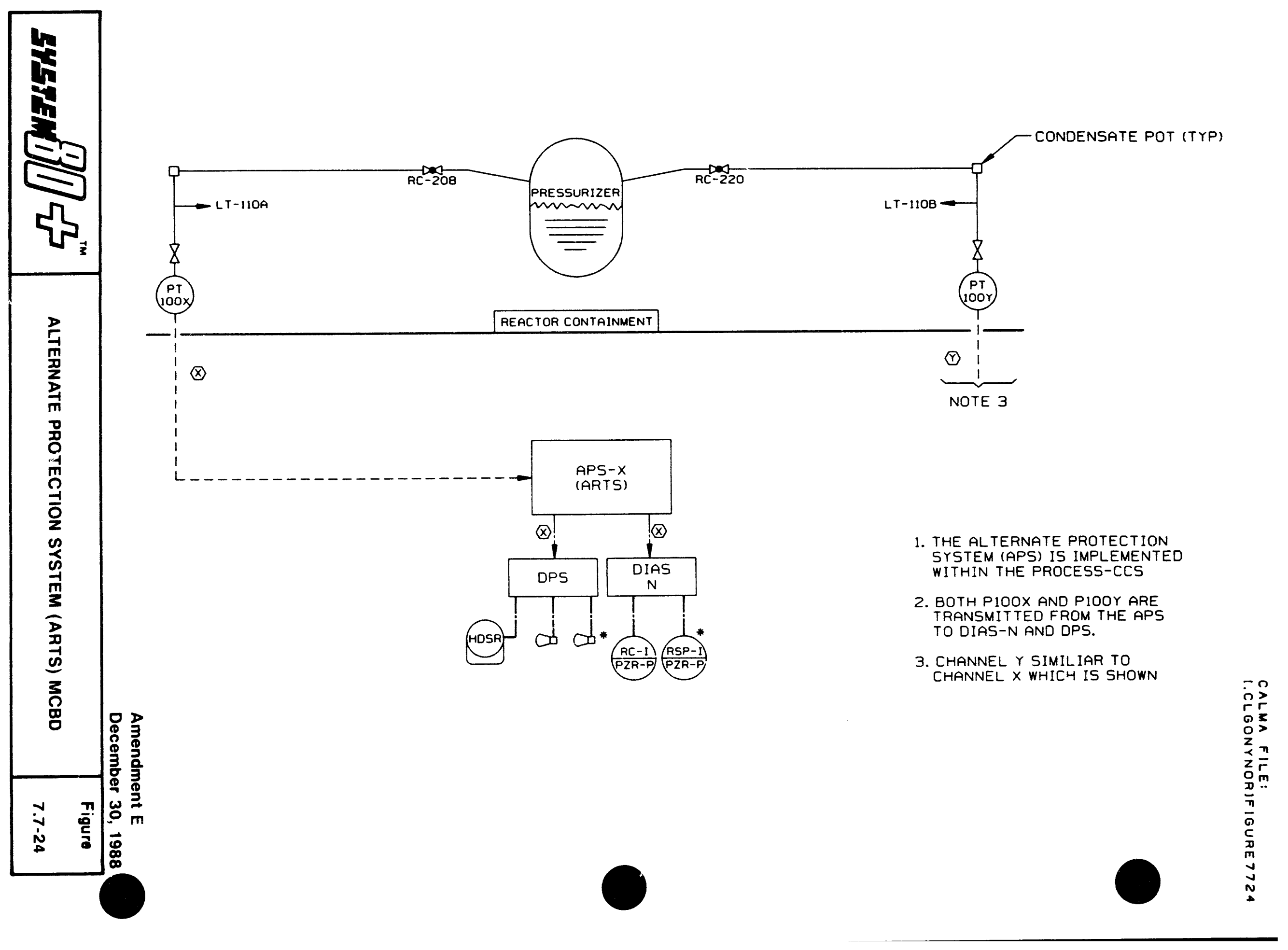




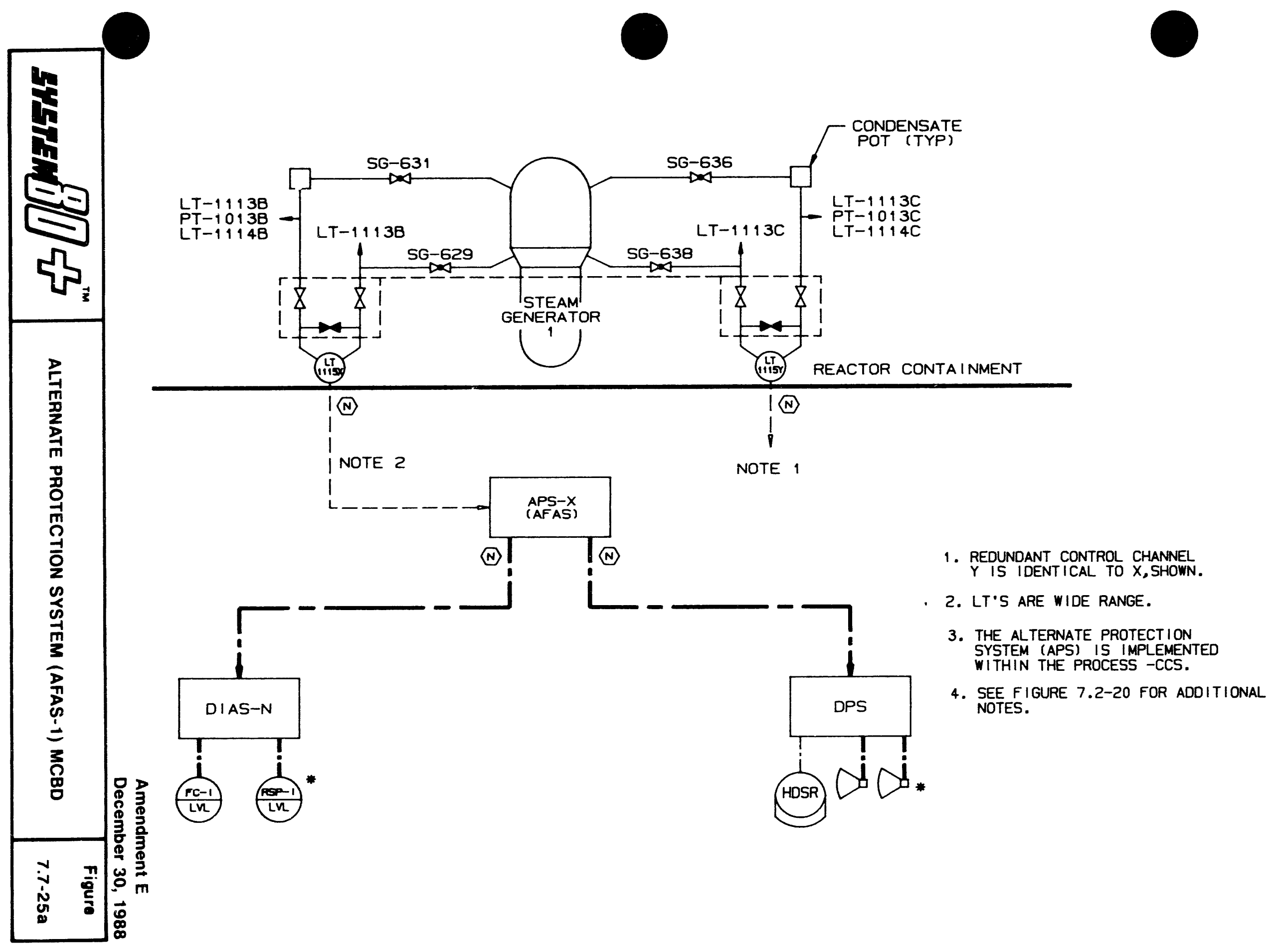




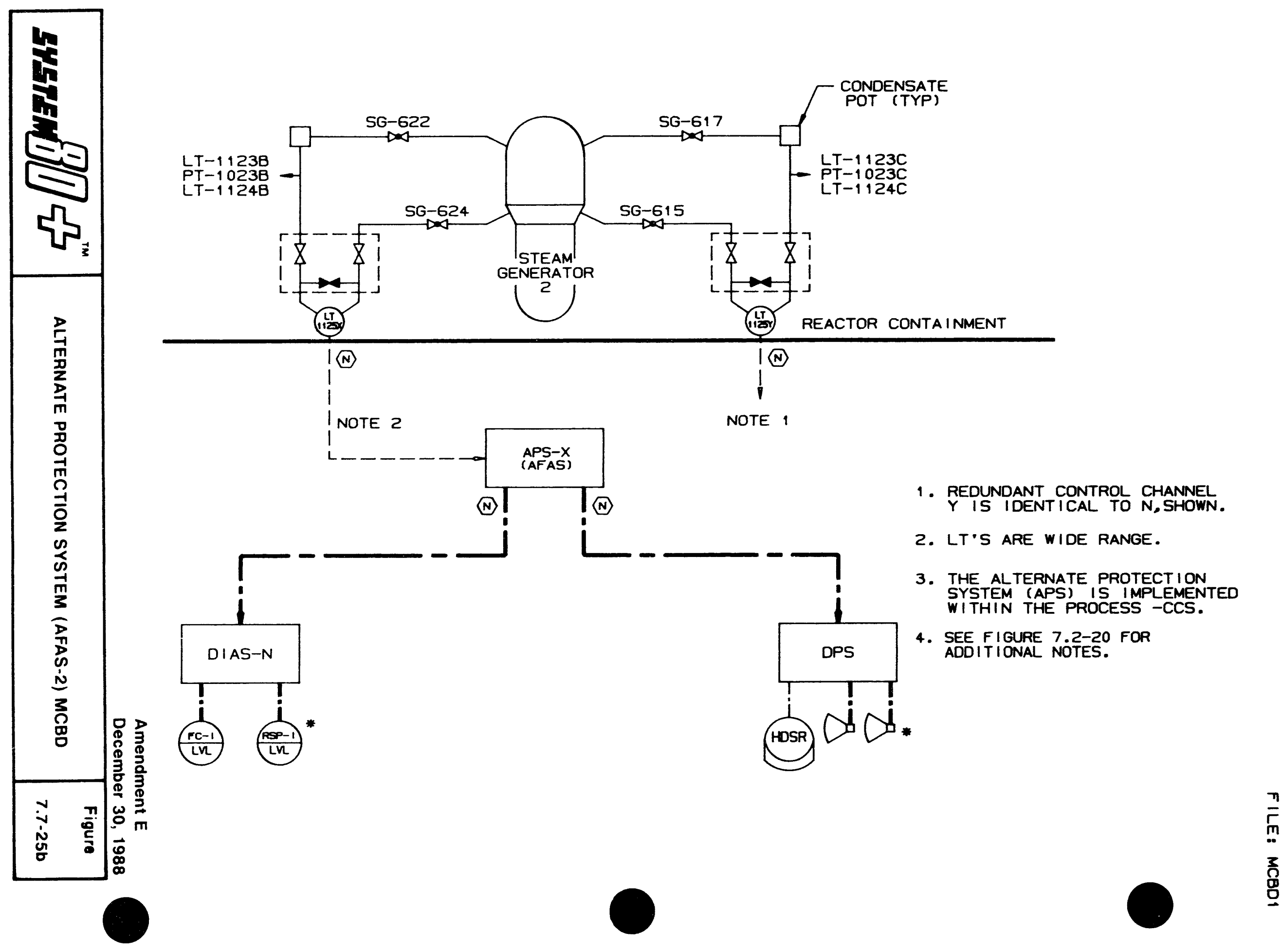




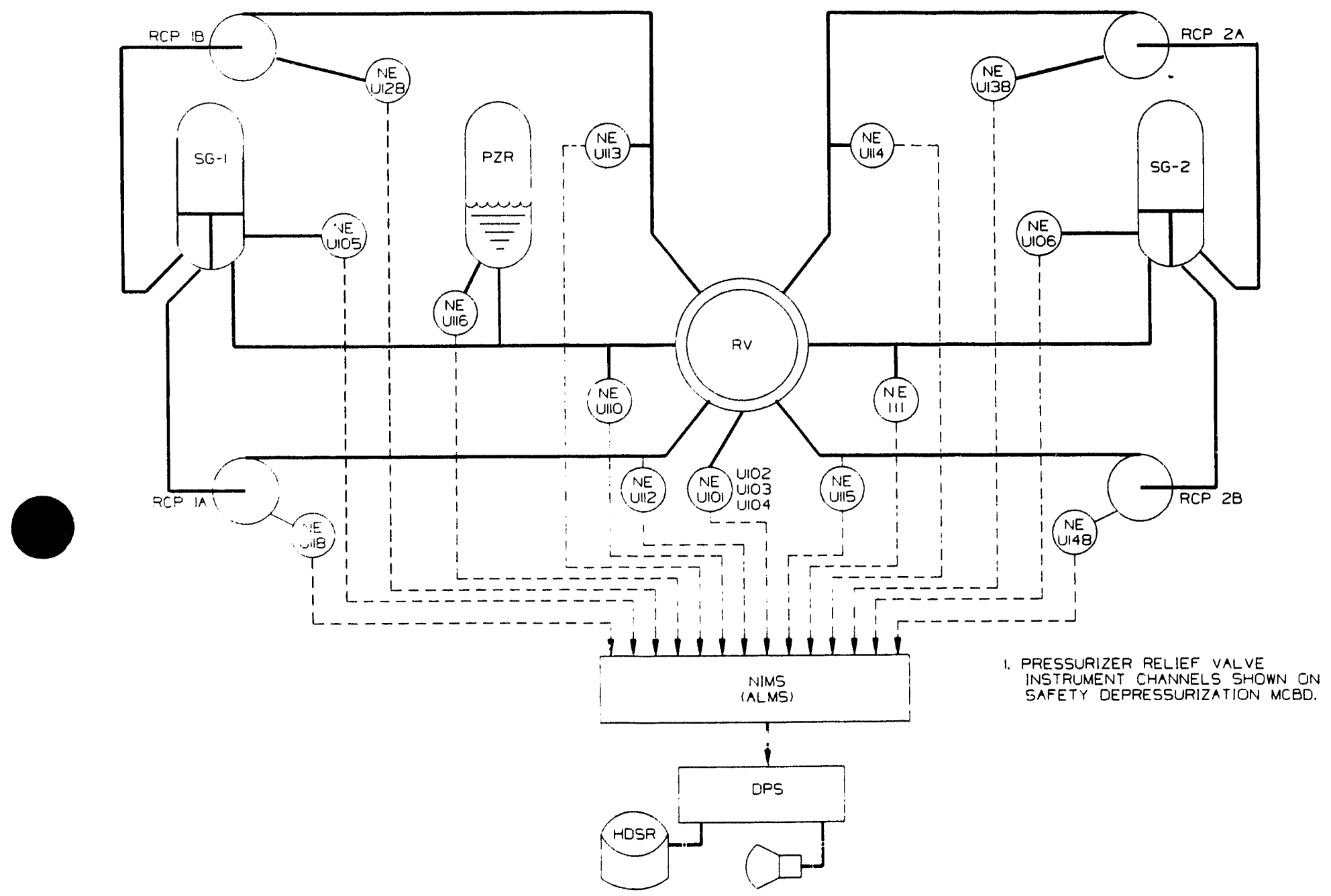




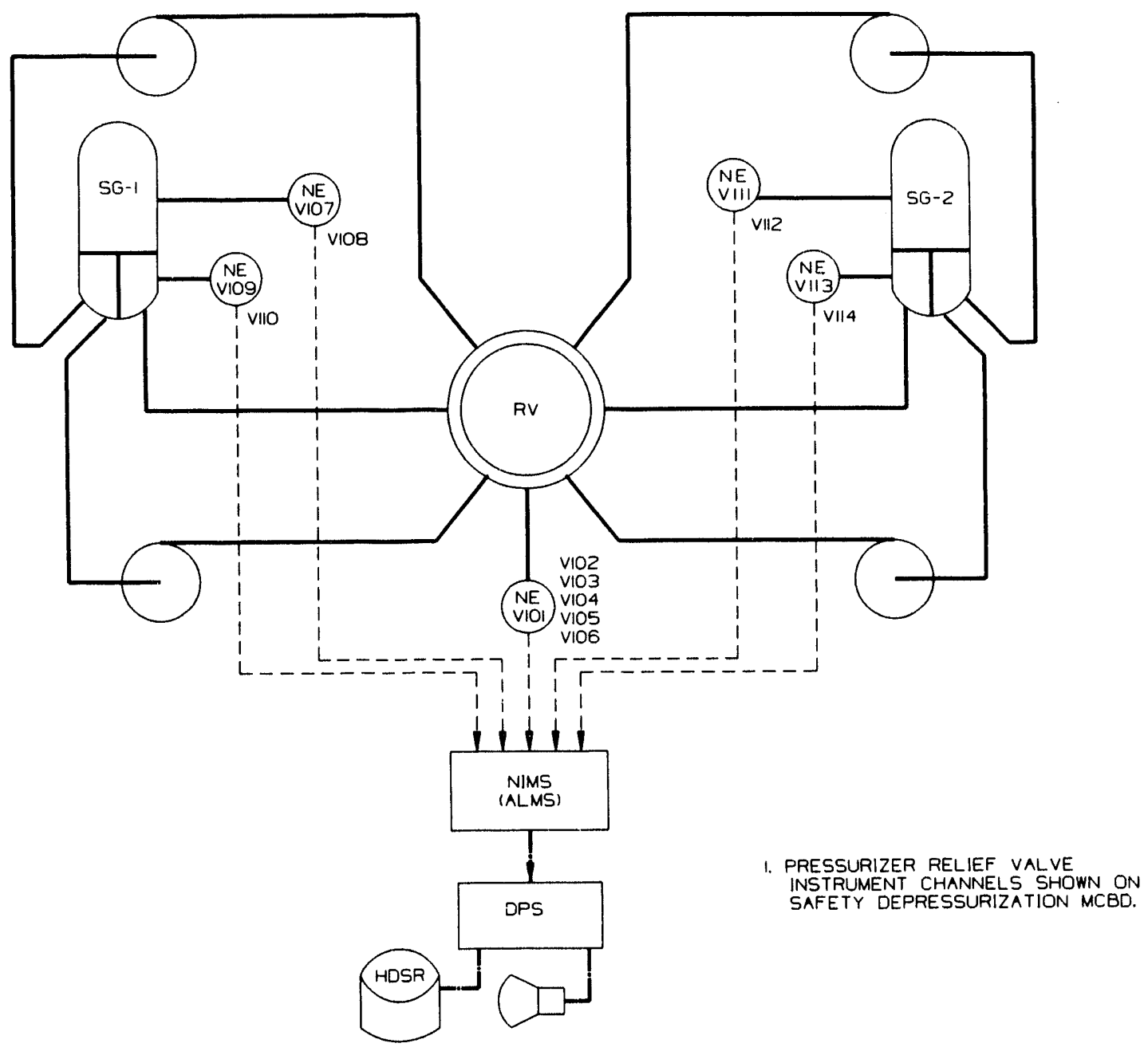

Amendment I

December 21, 1990 


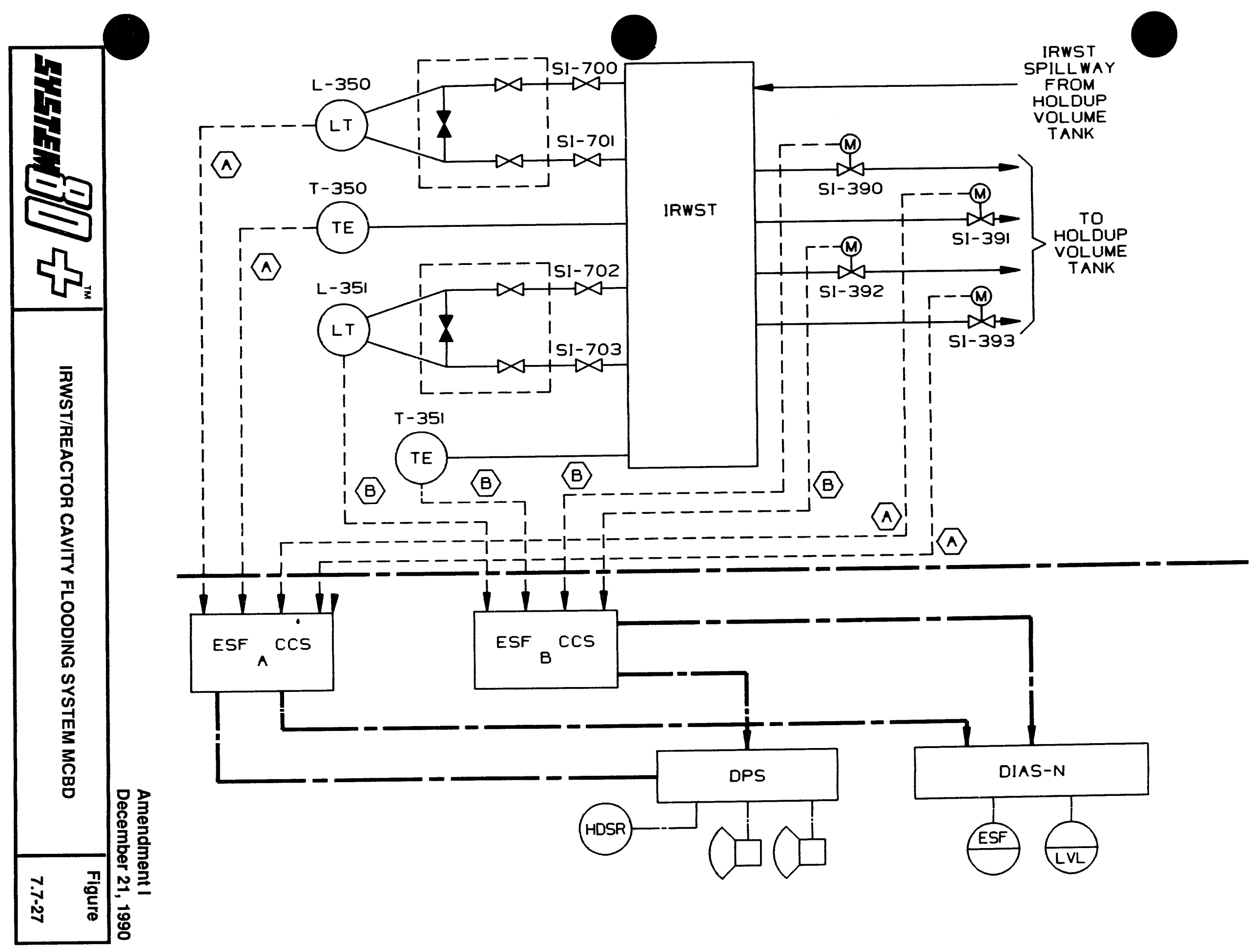




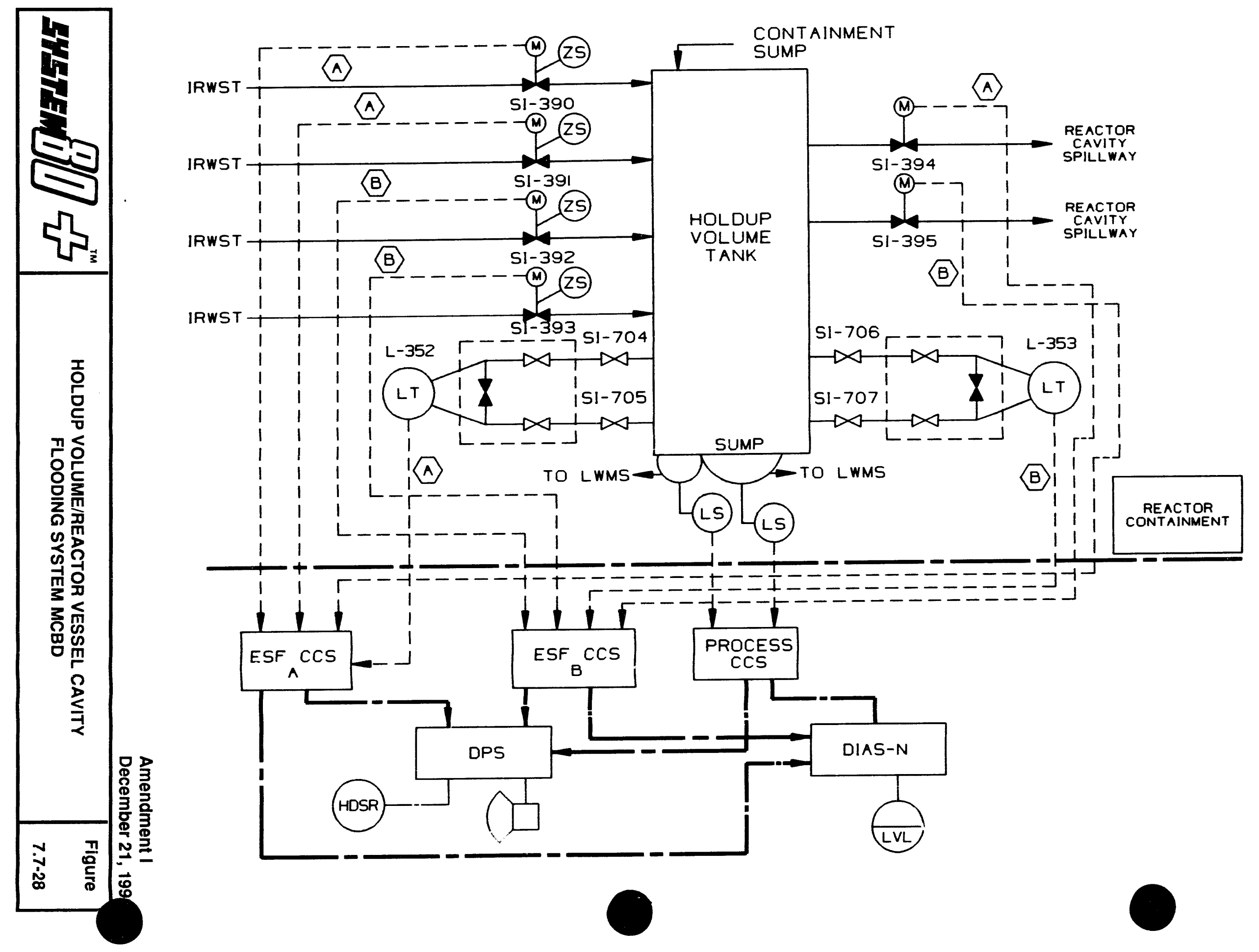




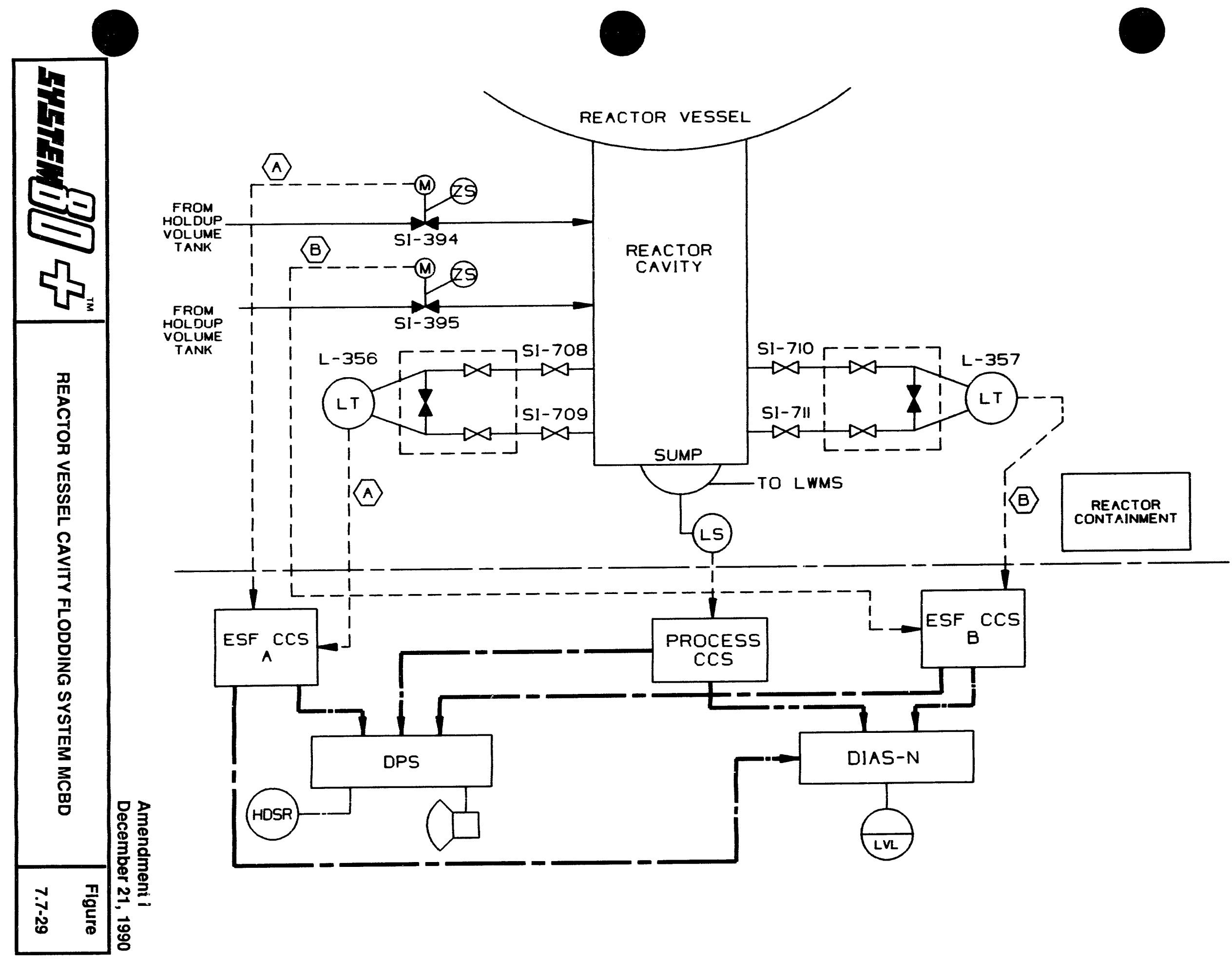



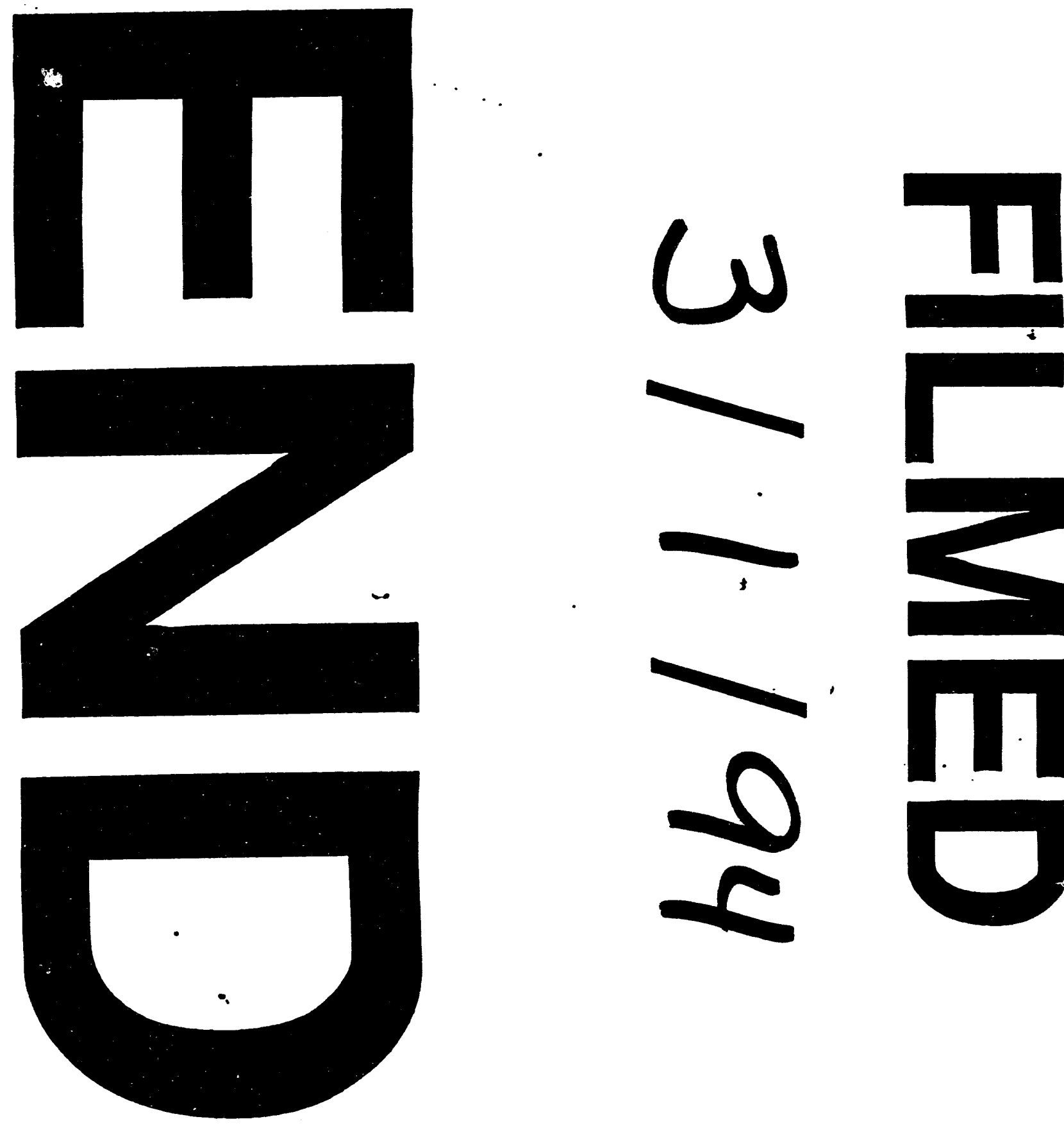

0
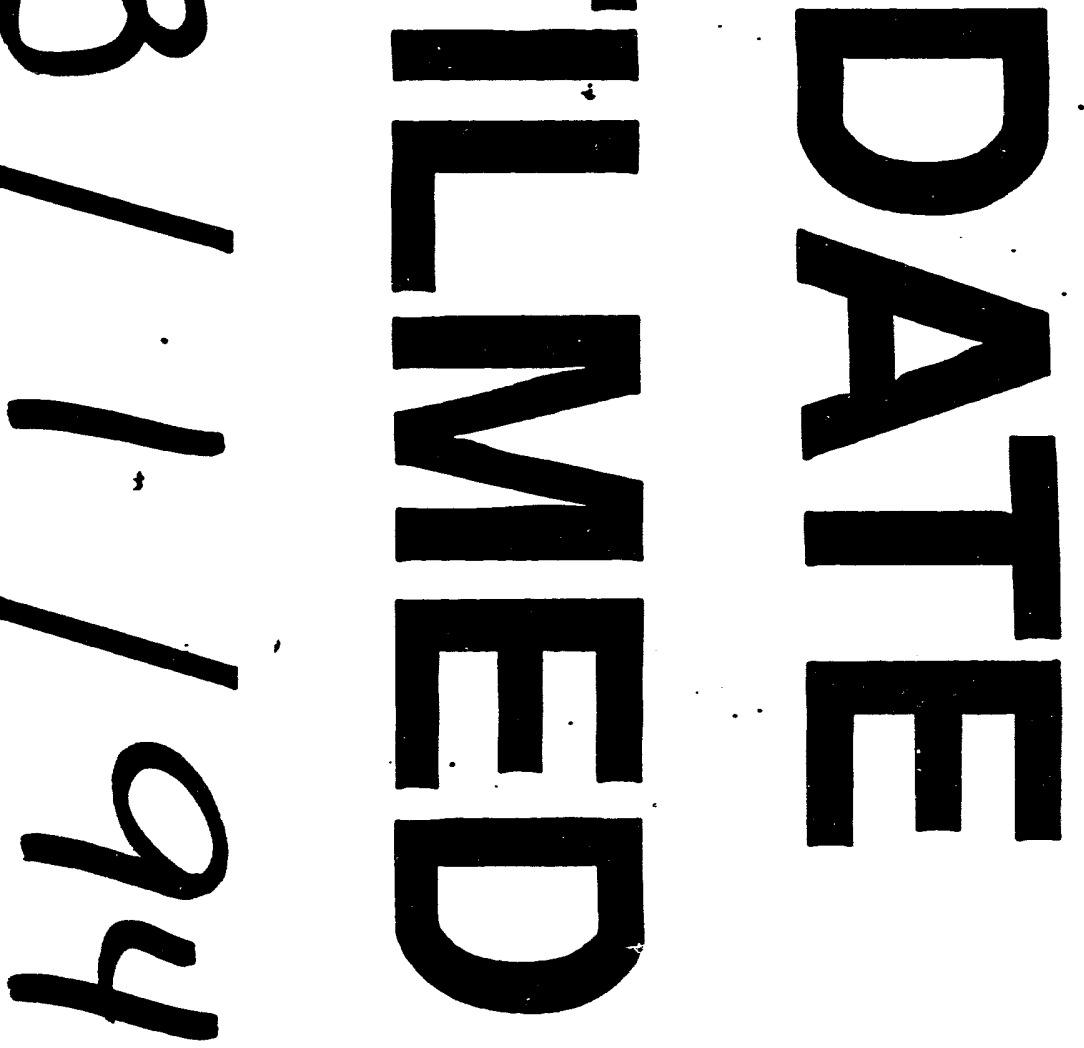


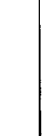

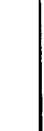

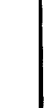

$$
\overline{1}
$$

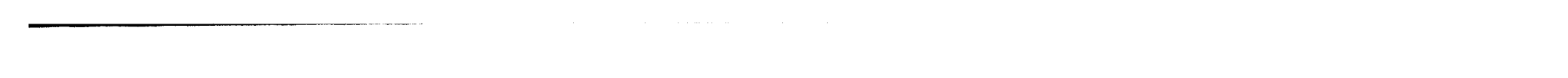

